NIST NCSTAR 1-2

Federal Building and Fire Safety Investigation of the World Trade Center Disaster

\title{
Baseline Structural Performance and Aircraft Impact Damage Analysis of the World Trade Center Towers
}

Fahim Sadek

NST National Instifute of Standards and Technology - Technology Administration - U.S. Deportment of Commerce 

NIST NCSTAR 1-2

Federal Building and Fire Safety Investigation of the World Trade Center Disaster

\section{Baseline Structural Performance and Aircraft Impact Damage Analysis of the World Trade Center Towers}

Fahim Sadek

Building and Fire Research Laboratory

National Institute of Standards and Technology

September 2005

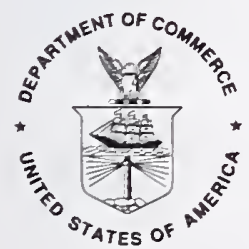

U.S. Department of Commerce Carlos M. Gutierrez, Secretary

Technology Administration

Michelle O'Neill, Acting Under Secretary for Technology

National Institute of Standards and Technology

William Jeffrey, Director 


\title{
Disclaimer No. 1
}

Certain commercial entities, equipment, products, or materials are identified in this document in order to describe a procedure or concept adequately or to trace the history of the procedures and practices used. Such identification is not intended to imply recommendation, endorsement, or implication that the entities, products, materials, or equipment are necessarily the best available for the purpose. Nor does such identification imply a finding of fault or negligence by the National Institute of Standards and Technology.

\section{Disclaimer No. 2}

The policy of NIST is to use the International System of Units (metric units) in all publications. In this document, however, units are presented in metric units or the inch-pound system, whichever is prevalent in the discipline.

\section{Disclaimer No. 3}

Pursuant to section 7 of the National Construction Safety Team Act, the NIST Director has determined that certain evidence received by NIST in the course of this Investigation is "voluntarily provided safety-related information" that is "not directly related to the building failure being investigated" and that "disclosure of that information would inhibit the voluntary provision of that type of information" (15 USC 7306c).

In addition, a substantial portion of the evidence collected by NIST in the course of the Investigation has been provided to NIST under nondisclosure agreements.

\section{Disclaimer No. 4}

NIST takes no position as to whether the design or construction of a WTC building was compliant with any code since, due to the destruction of the WTC buildings, NIST could not verify the actual (or as-built) construction, the properties and condition of the materials used, or changes to the original construction made over the life of the buildings. In addition, NIST could not verify the interpretations of codes used by applicable authorities in determining compliance when implementing building codes. Where an Investigation report states whether a system was designed or installed as required by a code provision, NIST has documentary or anecdotal evidence indicating whether the requirement was met, or NIST has independently conducted tests or analyses indicating whether the requirement was met.

\section{Use in Legal Proceedings}

No part of any report resulting from a NIST investigation into a structural failure or from an investigation under the National Construction Safety Team Act may be used in any suit or action for damages arising out of any matter mentioned in such report (15 USC 281a; as amended by P.L. 107-231).

National Institute of Standards and Technology National Construction Safety Team Act Report 1-2 Natl. Inst. Stand. Technol. Natl. Constr. Sfty. Tm. Act Rpt. 1-2, 458 pages (September 2005) CODEN: NSPUE2

\author{
U.S. GOVERNMENT PRINTING OFFICE \\ WASHINGTON: 2005
}

For sale by the Superintendent of Documents, U.S. Government Printing Office Internet: bookstore.gpo.gov - Phone: (202) 512-1800 — Fax: (202) 512-2250 Mail: Stop SSOP, Washington, DC 20402-0001 


\section{ABSTRACT}

The baseline structural performance and aircraft impact damage analysis of the National Institute of Standards and Technology (NIST) Investigation of the World Trade Center (WTC) disaster had two primary tasks: (1) to develop reference structural models of the WTC towers and use these models to establish the baseline performance of each of the towers under gravity and wind loads, and (2) to estimate the damage to the towers due to aircraft impacts and establish the initial conditions for the fire dynamics modeling and the thermal-structural response and collapse initiation analysis. This report provides the technical approach, methodology, and results related to both tasks.

For the first task, the baseline performance of the WTC towers under gravity and wind loads was established in order to assess the towers" ability to withstand those loads safely and to evaluate the reserve capacity of the towers to withstand unanticipatcd events. The baseline performance study provides a measure of the behavior of the towers under design loading conditions, specifically: (1) total and interstory drift (the sway of the building under design wind loads), (2) floor deflections under gravity loads, (3) the stress demand-to-capacity ratio for primary structural components of the towers such as exterior walls, core columns, and floor framing, (4) performance of exterior walls under wind loading, including distribution of axial stresses and presence of tensile forces, (5) performance of connections between exterior columns, and (6) resistance of the towers to shear sliding and overturning at the foundation level.

Wind loads were a governing factor in the design of the structural components that made up the frametube steel framing system. Wind load capacity was also a key factor in determining the overall strength of the towers and was important in determining not only the ability of the towers to withstand winds but also the reserve capacity of the towers to withstand unanticipated events such as major fire or impact damage. Accurate estimation of the wind load on tall buildings is a challenging task, given that wind engineering is still an evolving technology. For example, estimates of the wind-induced response presented in two recent independent studies of the WTC towers differed from each other by about 40 percent. In this study, NIST developed refined estimates of wind effects by critically assessing information obtaincd from the Cermak Peterka Peterson, Inc. (CPP) and Rowan Williams Davis and Irwin, Inc. (RWDI) reports and by bringing to bear state-of-the-art considerations. Furthermore, the available prescriptive codes specify wind loads on tall buildings that are significantly lower than wind tunnel-based loads. This case study provided an opportunity to assess effectively current design practices and various code provisions on wind loads.

For the purpose of establishing the baseline performance of the towers, various wind loads were considered in this study, including wind loads used in the original WTC design, wind loads based on two recent wind tunnel studies conducted in 2002 by CPP and RWDI for insurance litigation concerning the towers, and refined wind load estimates developed by NIST.

In order to develop the reference models and conduct the baseline performance analyses, the following steps were undertaken:

- Develop structural databases for the primary structural components of the WTC 1 and WTC 2 towers from the original computer printouts of the structural design documents. 
- Develop reference structural analysis models that captured the intended behavior of each of the two towers using the generated databases. These reference models were used to establish the baseline performance of the towers and also served as a reference for more detailed models for aircraft impact damage analysis and thermal-structural response and collapse initiation analysis. The models included: (1) two global models (one for each tower) of the major structural components and systems of the towers, and (2) floor models of a typical truss-framed floor and a typical beam-framed floor.

- Develop estimates of design gravity (dead and live loads) and wind loads on each of the two towers for implementation into the reference structural models. The following three loading cases were considered:

- Original WTC design loads case. Loads included dead and live loads as in original WTC design, in conjunction with original WTC design wind loads.

- State-of-the-practice case. Loads included dead loads; current New York City Building Code (NYCBC 2001) live loads; and wind loads from the RWDI wind tunnel study, scaled in accordance with NYCBC 2001 wind speed.

- Refined NIST estimate case. Loads included dead loads; live loads from the American Society of Civil Engineers (ASCE) 7-02 Standard (a national standard); and refined wind loads developed by NIST.

- Perform structural analyses to establish the baseline performance of each of the two towers under design gravity and wind loads.

For the second task related to aircraft impact, the aircraft impact damage to the exterior of the WTC towers could be visibly identified from the video and photographic records. However, no visible information could be obtained for the extent of damage to the interior of the towers, including the structural system (floors and core columns), partition walls, and interior building contents. Such information was needed for the subsequent fire dynamics simulations and post-impact structural analyses. In addition, for the fire dynamics modeling, the dispersion of the jet fuel and the location of combustible aircraft debris were required. The estimate of the extent of damage to the fireproofing on the structural steel in the towers due to impact was essential for the thermal and structural analyses. The aircraft impact damage analyses were the primary tool by which most of the information on the tower damage could be estimated.

The focus of the analysis was to analyze the aircraft impacts into each of the WTC towers to provide the following: (1) estimates of probable damage to structural systems, including exterior walls, floor systems, and interior core columns; (2) estimates of the aircraft fuel dispersion during the impact; and (3) estimates of debris damage to the building nonstructural contents, including partitions and workstations. The results were to be used to estimate the damage to fireproofing based on the predicted path of the debris field inside the towers. This analysis thus estimated the condition of the two WTC towers immediately following the aircraft impacts and established the initial conditions for the fire dynamics modeling and the thermal-structural response and collapse initiation analysis. The impact analyses were conducted at various levels of complexity including: (1) the component level, (2) the subassembly level, and (3) the global level to estimate the probable damage to the towers due to aircraft impact. 
In order to estimate the aircraft impact damage to the WTC towers, the following steps were undertaken:

- Constitutive relationships were developed to describe the behavior and failure of the materials under the dynamic impact conditions of the aircraft. These materials included the various grades of steels used in the exterior walls, core columns, and floor trusses of the towers, weldment metal, bolts, reinforced concrete, aircraft materials, and nonstructural contents.

- Global impact models were developed for the towers and aircraft. The tower models included the primary structural components of the towers in the impact zone, including exterior walls, floor systems, core columns, and connections, along with nonstructural building contents. A refined finite element mesh was used for the areas in the path of the aircraft, and a coarser mesh was used elsewhere. The aircraft model included the aircraft engines, wings, fuselage, the empennage, and landing gear, as well as nonstructural components of the aircraft. The aircraft model also included a representation of the fuel, using the smooth particle hydrodynamics approach.

- Component and subassembly impact analyses were conducted to support the development of the global impact models. The primary objectives of these analyses were to (1) develop an understanding of the interactive failure phenomenon of the aircraft and tower components, and (2) develop the simulation techniques required for the global analysis of the aircraft impacts into the WTC towers, including variations in mesh density and numerical tools for modeling fluid-structure interaction for fuel impact and dispersion. The component and subassembly analyses were used to determine model simplifications for reducing the overall model size while maintaining fidelity in the global analyses.

- Initial conditions were estimated for the impact of the aircraft into the WTC towers. These included the aircraft speed at impact, aircraft orientation and trajectory, and impact location of the aircraft nose. The estimates also included the uncertainties associated with these parameters. This step utilized the videos and photographs that captured the impact event and subsequent damage to the exterior of the towers.

- Sensitivity analyses were conducted at the component and subassembly levels to assess the effect of uncertainties on the level of damage to the towers due to impact and to determine the most influential parameters that affect the damage estimates. The analyses were used to reduce the number of parameters that would be varied in the global impact simulations.

- Analyses of aircraft impact into WTC 1 and WTC 2 were conducted using the global tower and aircraft models. The analysis results included the estimation of the structural damage that degraded their strength and the condition and position of nonstructural contents such as partitions, workstations, aircraft fuel, and other debris that influenced the behavior of the subsequent fires in the towers. The global analyses included, for each tower, a "base case" based on reasonable initial estimates of all input parameters. They also provided a range of damage estimates based on variations of the most influential parameters. This range included more severe and less severe damage cases. 
- Approximate analyses were conducted to provide guidance to the global finite element impact analyscs. These included: (1) analysis of the overall aircraft impact forces and assessment of the relative importance of the airframe strength and weight distribution, (2) evaluation of the potential effects of the cnergy in the rotating engine components on the calculated engine impact response, (3) influence of the static preloads in the towers on the calculated impact damage and residual strength predictions, and (4) analysis of the load characteristics required to damage core columns compared to the potential loading from impact of aircraft components.

Keywords: Aircraft impact, finite element analysis, floor system, load, model, structural, truss, wind loads, World Trade Center. 


\section{TABLE OF CONTENTS}

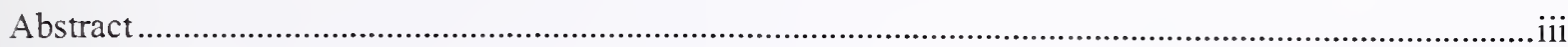

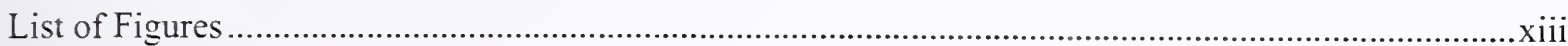

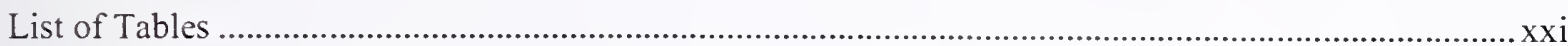

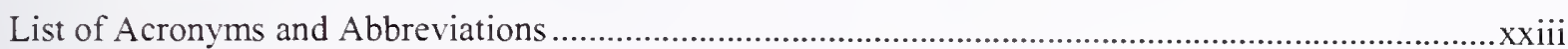

Preface

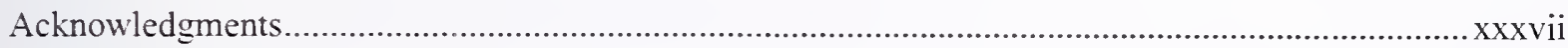

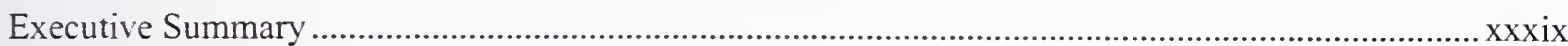

\section{Chapter 1}

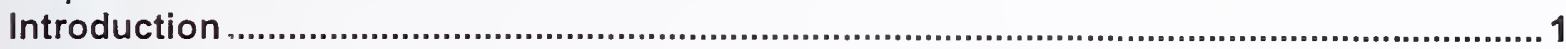

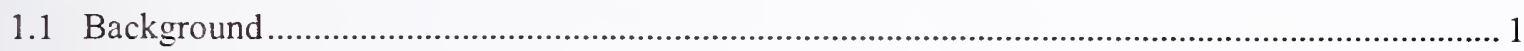

1.2 Reference Models and Baseline Performance Analysis......................................................... 1

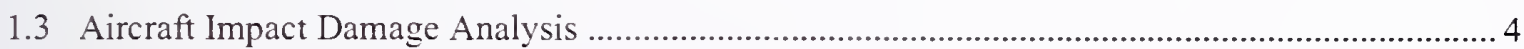

\section{Chapter 2}

Development of Reference Structural Models ...................................................................9

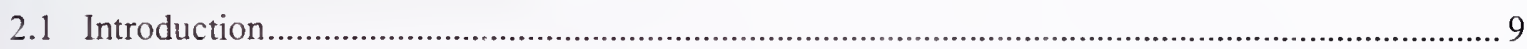

2.2 Development of Structural Databases .................................................................................. 10

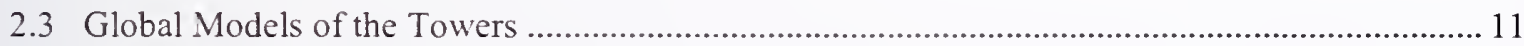

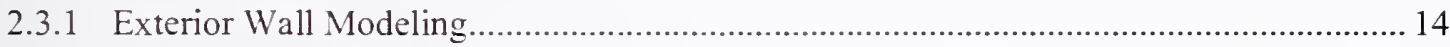

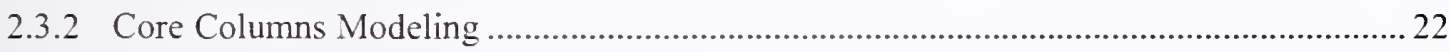

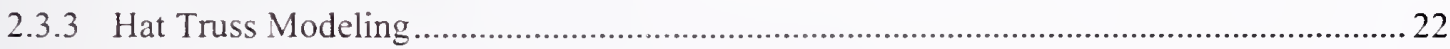

2.3.4 Flexible and Rigid Floor Diaphragm Modeling .................................................... 24

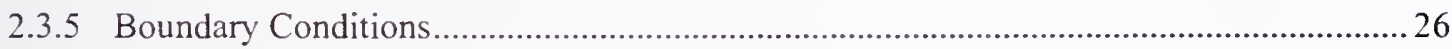

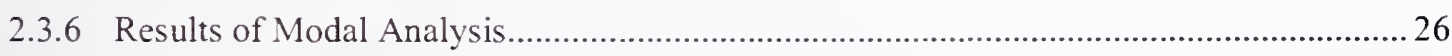

2.4 Typical Truss-Framed Floor Model-Floor 96 of WTC 1 ....................................................29

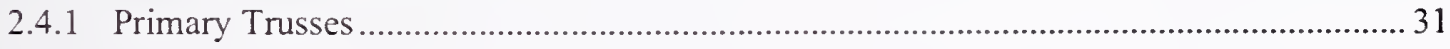

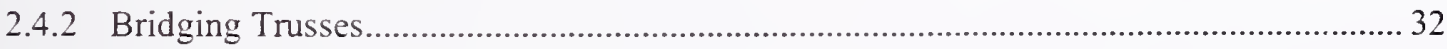

2.4.3 Concrete Slab and Metal Deck ..................................................................................... 33

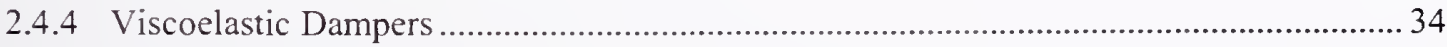

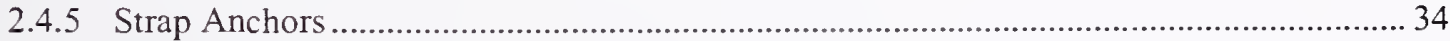

2.5 Typical Beam-Framed Floor Model-Floor 75 of WTC 2 ….............................................. 34

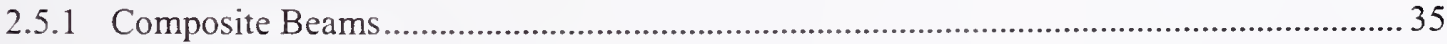




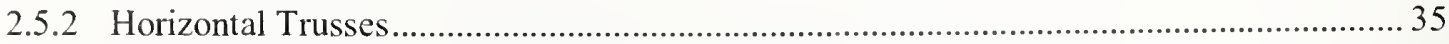

2.5.3 Concrete Slab and Metal Deck ................................................................................. 36

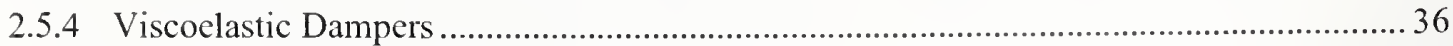

2.6 Review of the Structural Databases and Reference Models of the Towers ................................ 37

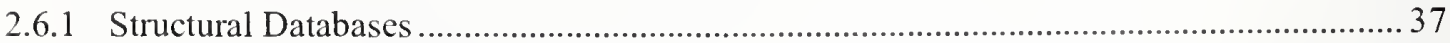

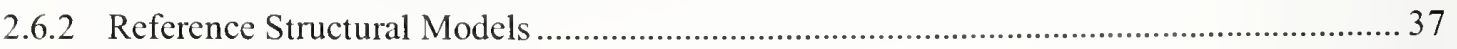

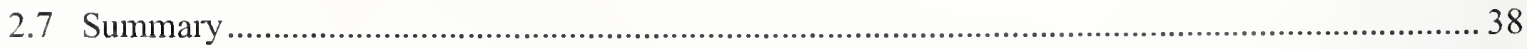

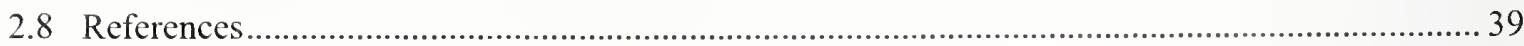

\section{Chapter 3}

Wind Loads on the WTC Towers ....................................................................................... 41

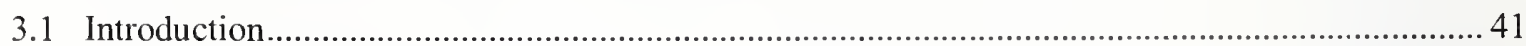

3.2 Original WTC Design Wind Loads .......................................................................... 43

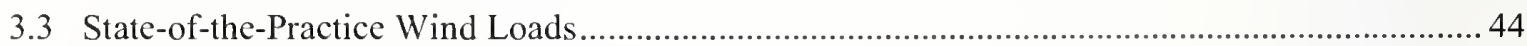

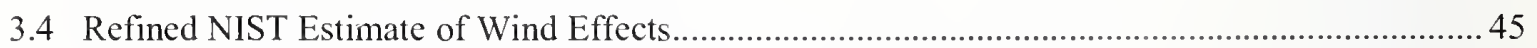

3.4.1 Summary Comparison by Weidlinger Associates, Inc., of CPP and RWDI Estimates..... 46

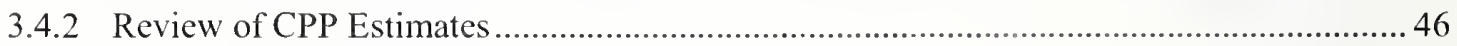

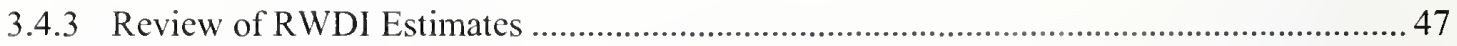

3.4.4 Comments by Third Party Reviewer (Skidmore, Owings \& Merrill LLP - SOM) -

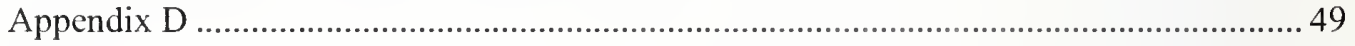

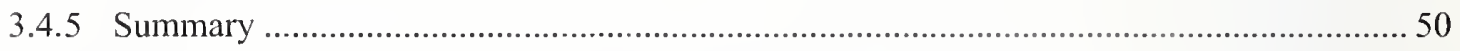

3.5 Comparisons of Wind Loads, Wind Speeds, and Practices ................................................... 50

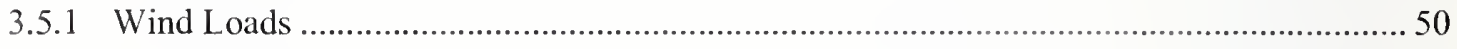

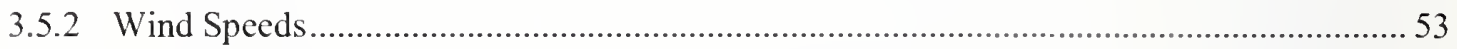

3.5.3 Wind Engineering Practices Pertaining to Tall Buildings ................................................ 55

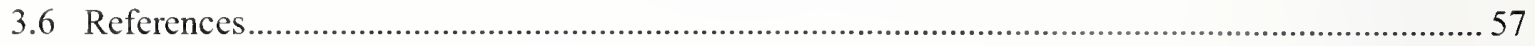

\section{Chapter 4}

Baseline Performance of the WTC Towers ..............................................................59

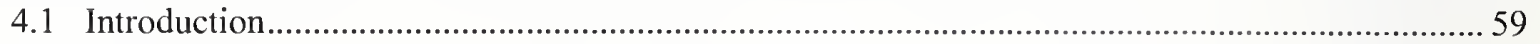

4.2 Baseline Performance of the Global Models ............................................................................. 59

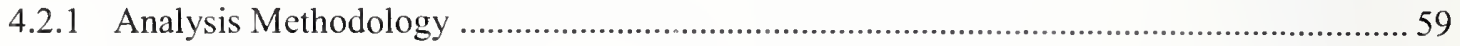

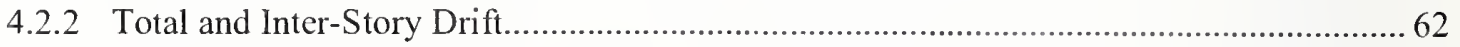

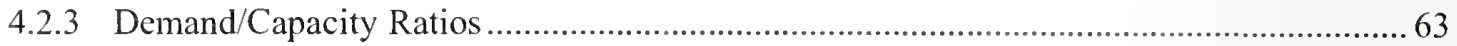

4.2.4 Exterior Columns Axial Loads and Stresses ............................................................. 77

4.2.5 Exterior Columns Splice Connection ............................................................................. 84 
4.2.6 Resistance of the Towers to Shear Sliding and Overturning Moment .............................. 84

4.3 Baseline Performance of the Typical Floor Models ............................................................ 85

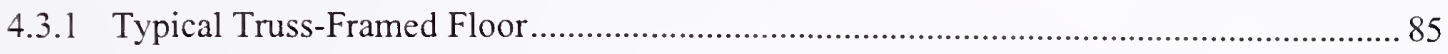

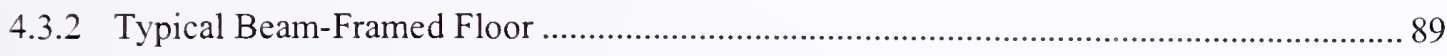

4.4 Review of Baseline Performance Analyses ....................................................................... 90

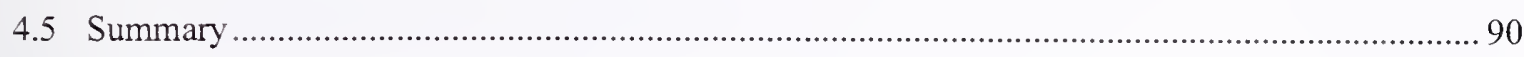

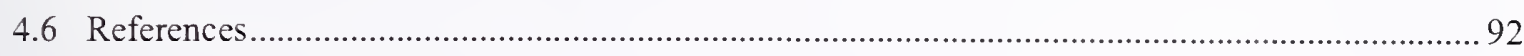

\section{Chapter 5}

Development of Tower and Aircraft Impact Models ..................................................... 93

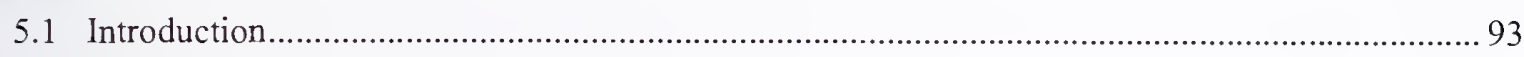

5.2 Development of Tower Impact Models ............................................................................ 94

5.2.1 Exterior Wall Model Development ........................................................................ 95

5.2.2 Core Columns and Floors Model Development ....................................................... 99

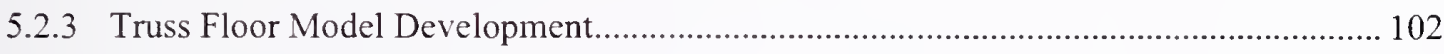

5.2.4 Interior Contents Model Development ....................................................................... 105

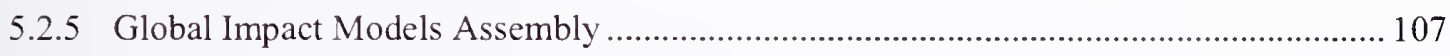

5.2.6 Tower Material Constitutive Models..................................................................... 110

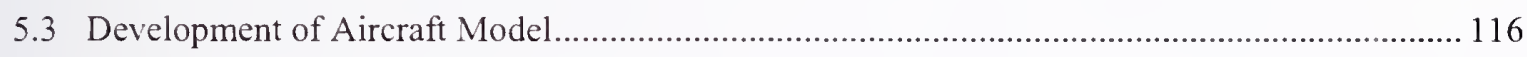

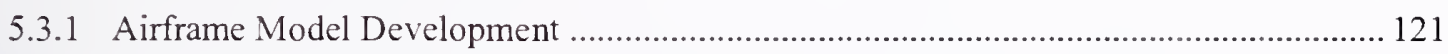

5.3.2 Wing Section Component Model Development.................................................. 125

5.3 .3 Engine Model Development.......................................................................... 126

5.3.4 Aircraft Material Constitutive Models ................................................................. 130

5.4 Component and Subassembly Level Analyses ............................................................. 131

5.4.1 Exterior Column Impacted with an Empty Wing ....................................................... 132

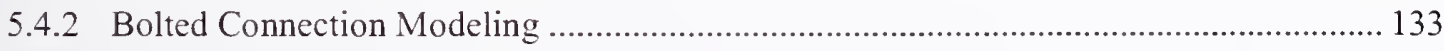

5.4.3 Floor Assembly Component Analysis ............................................................................ 134

5.4.4 Modeling of Aircraft Wing Section Impact with Fuel ................................................... 138

5.4.5 Engine Impacts Subassembly Analyses .................................................................. 145

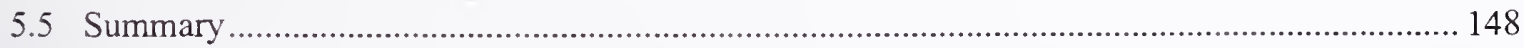

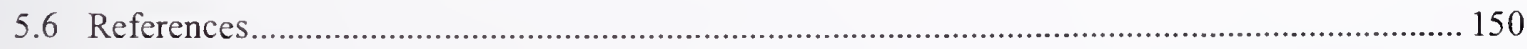

\section{Chapter 6}

Aircraft Impact Initial Conditions ........................................................................ 151

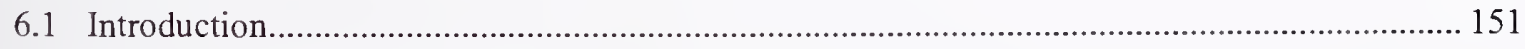

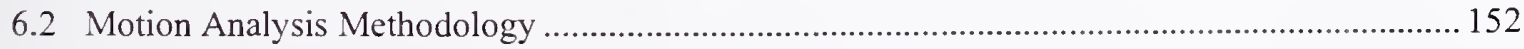


6.2.I Videos Used in the Analysis.................................................................................. 152

6.2.2 Complex Motion Analysis........................................................................................ 153

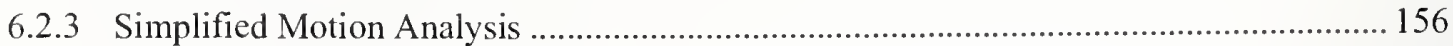

6.3 Refinement of Aircraft Impact Conditions ...................................................................... 158

6.4 Comparison with Previous Estimates of Aircraft Impact Initial Conditions ............................ 164

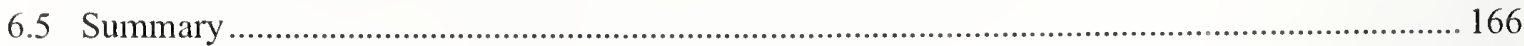

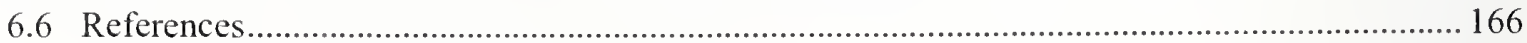

\section{Chapter 7}

Aircraft Impact Damage Results ....................................................................... 167

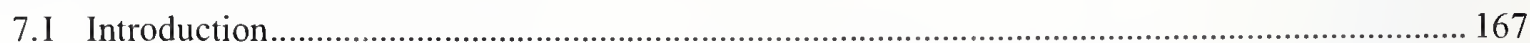

7.2 Analysis Methodology, Assumptions, and Limitations ..................................................... 167

7.3 WTC I Base Case Impact Analysis - CASE A …........................................................... 171

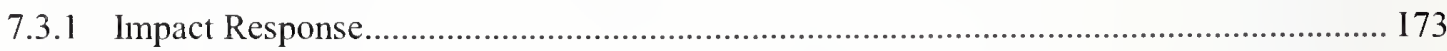

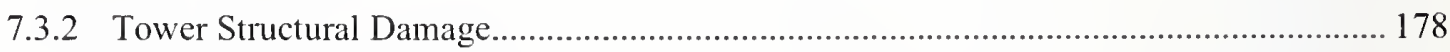

7.3.3 Fuel and Debris Distributions ......................................................................... 190

7.4 WTC 1 More Severe Impact Analysis - CASE B ......................................................... 196

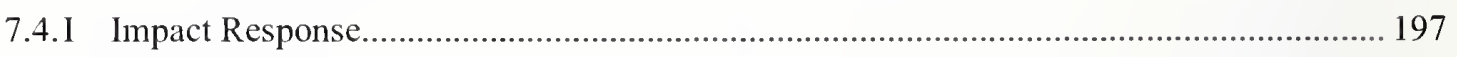

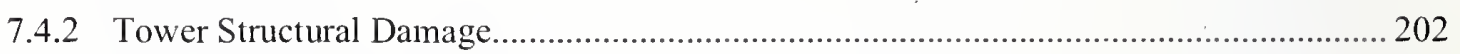

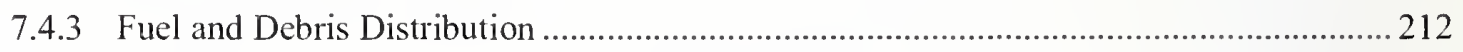

7.5 WTC I Less Severe Impact Analysis - Brief Description...................................................... 217

7.6 WTC 2 Base Case Impact Analysis - CASE C .................................................................. 217

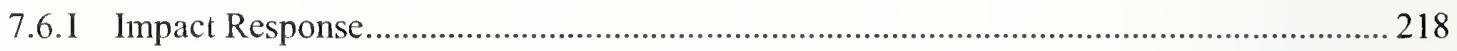

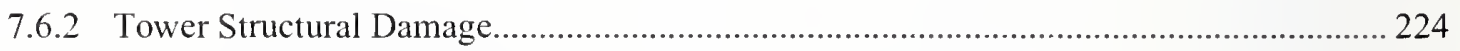

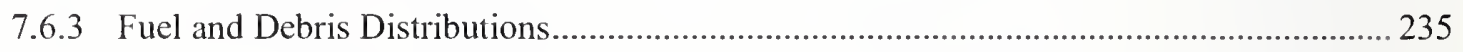

7.7 WTC 2 More Severe Impact Analysis - CASE D ............................................................. 241

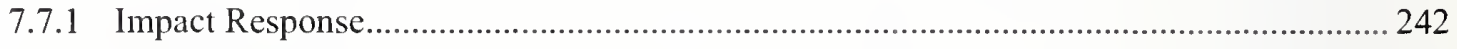

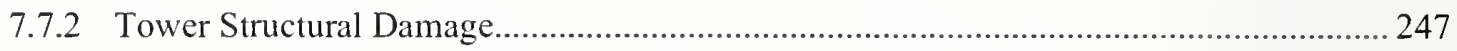

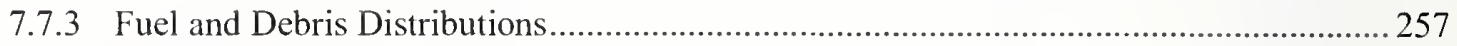

7.8 WTC 2 Less Severe Impact Analysis - Brief Description..................................................... 263

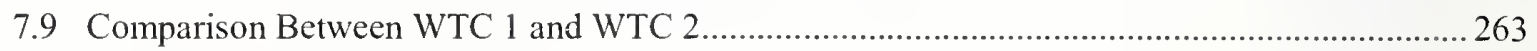

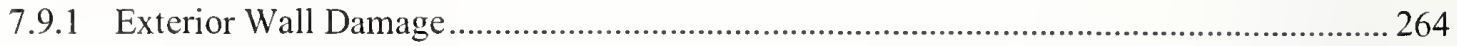

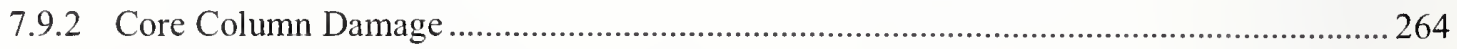

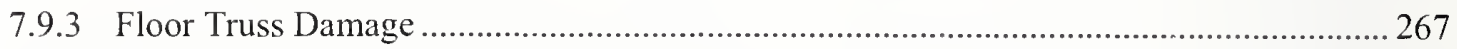

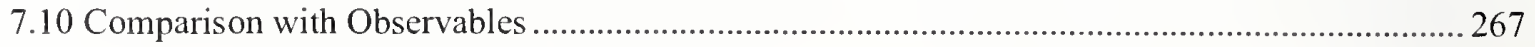




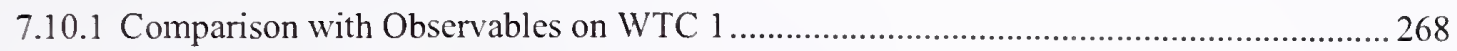

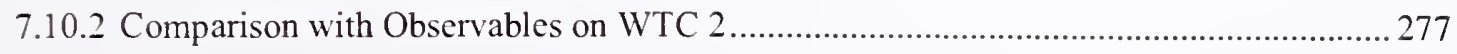

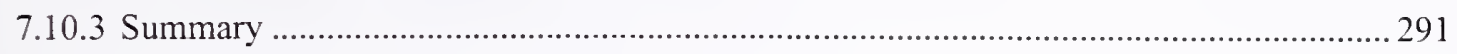

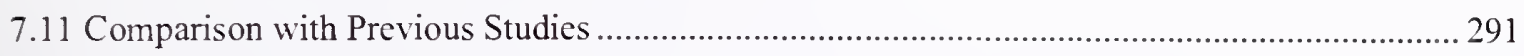

7.11.1 Comparison of Exterior Wall Damage ...................................................................... 291

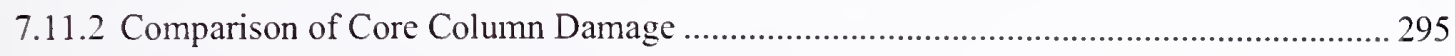

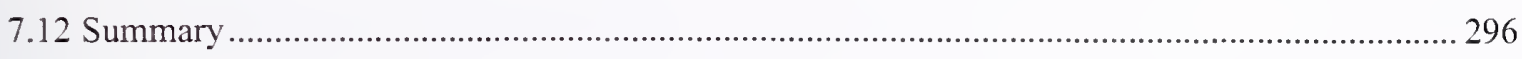

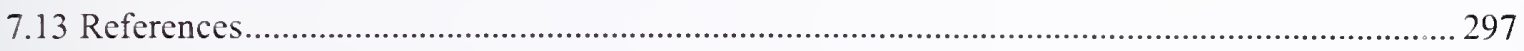

Chapter 8

Findings. 299

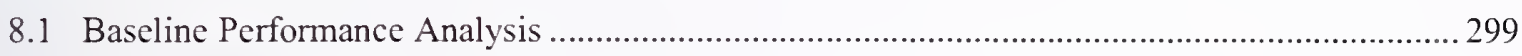

8.1.1 Wind Loads on the World Trade Center Towers ....................................................... 299

8.1.2 Baseline Performance of the Global Tower Models .................................................... 300

8.1.3 Baseline Performance of the Typical Floor Models ................................................... 301

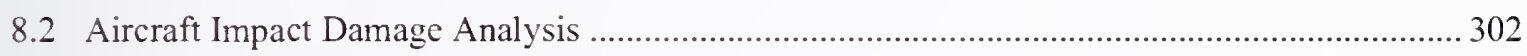

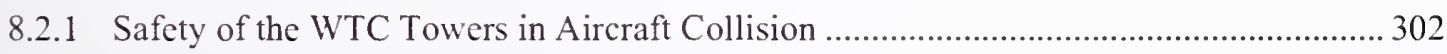

8.2.2 Preliminary Impact Analyses (Component and Subassembly Levels)........................... 302

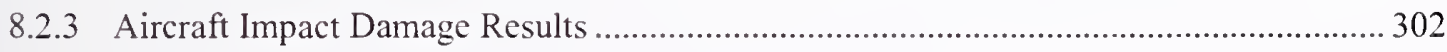

\section{Appendix A}

Salient Points with Regard to the Structural Design of the World Trade Center Tower ..305

Appendix B

Estimation of Sectorial Extreme Wind Speeds

Appendix C

Wind Tunnel Testing and the Sector-by-Sector Approach to Wind

Directionality Effects

Appendix D

SOM Project 2, Progress Report No. 3, WTC Wind Load Estimates

Appendix $E$

Still Images of the Video Records Used in Chapter 6. 
This page intentionally left blank. 


\section{LIST OF FIGURES}

Figure $\mathrm{P}-1$. The eight projects in the federal building and fire safety investigation of the WTC disaster. xxix

Figure 2-1. Rendered isometric views of the WTC 1 global model. 12

Figure 2-2. Frame view of the WTC 2 model: (a) exterior wall elevation, and (b) interior section. ........ 13

Figure 2-3. Frame view and rendered view of the WTC 1 model (foundation to floor 9)...................... 15

Figure 2-4. Exterior wall tree panel (taken from Drawing Book 2, page 2-AB2-2) ........................... 16

Figure 2-5. Frame and rendered view of an exterior wall tree ...................................................... 17

Figure 2-6. Typical WTC tower exterior wall panel. .................................................................... 18

Figure 2-7. (a), (b) Shell element, and (c) frame element models of a typical exterior wall panel.......... 19

Figure 2-8. Selection of column and spandrel rigidity of typical exterior wall panel.............................20

Figure 2-9. Shell element and frame models of typical exterior wall corner panel. .............................. 21

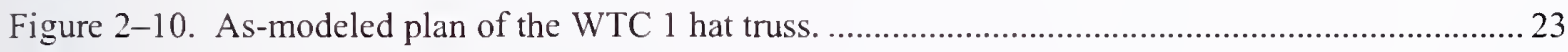

Figure 2-11. Rendered 3-D model of the WTC 1 hat truss............................................................... 23

Figure 2-12. Deflection of typical beam-framed floor model due to lateral loading (exaggerated

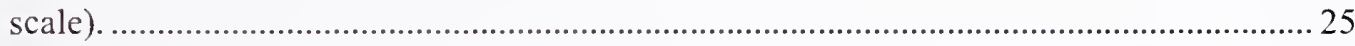

Figure 2-13. Deflection of equivalent floor model due to lateral loading (exaggerated scale)............... 25

Figure 2-14. Deflections of the north and south faces of the floor for the detailed and equivalent floor models. 26

Figure 2-15. Displacement of floor 70 of WTC 2 after impact based on video analysis (NIST

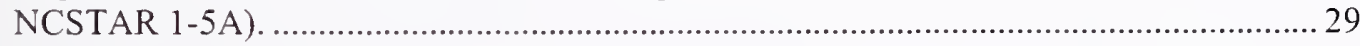

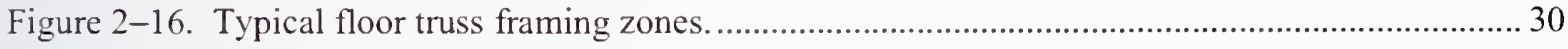

Figure 2-17. Typical truss-framed floor model (floor 96 of WTC 1), slab not shown............................31

Figure 2-18. Typical primary truss cross-section, as-designed and as-modeled. .................................. 32

Figure 2-19. Typical bridging truss cross-section, as-designed and as-modeled. .............................. 33

Figure 2-20. Strap anchors modeling, slab not shown. ................................................................... 34

Figure 2-21. Typical beam-framed floor model (floor 75 of WTC 2).............................................. 35

Figure 2-22. Horizontal truss modeling, slab not shown................................................................ 36

Figure 4-1. Cumulative drift diagrams for WTC 1 under the three wind loading cases. ........................6 64

Figure 4-2. Inter-story drift diagrams for WTC 1 under the three wind loading cases...........................65

Figure 4-3. DCRs for the exterior walls of WTC 1 under original design case, (a) north elevation, (b) east elevation, (c) south elevation, and (d) west elevation. 
Figure 4-4. RCRs for WTC 1 under original design loads below floor 9, (a) north elevation.

Figure 4-5. DCRs for WTC 1 core columns under original design loads, (a) 500 line, and (b) 600 line.

Figure 4-6. Distribution of normal stresses in the exterior walls of WTC 1 due to original WTC wind loads only at (a) floor B6, and (b) floor 39.

Figure 4-7. Three-dimensional distribution of normal stresses in the exterior walls of WTC 1 due to original WTC wind loads only at floors B6 and 39.

Figure 4-8. Tension force distribution (kip) in the exterior wall columns of WTC 1 under original design dcad and wind loads (no live loads included), (a) 100 face (north), and (b) 200 face (east).

Figure 4-9. DCRs for the typical beam-framed floor under original WTC design criteria loading......... 89

Figure 4-10. Beam-framed floor member groups.

Figure 5-1. User interface for exterior panel generator. 95

Figure 5-2. Impact facc of the WTC 1 global model, floors 91-101. 96

Figure 5-3. Impact face of the WTC 2 global model, floors 75-86. 97

Figure 5-4. Model of the spandrel splice plate connection. 98

Figure 5-5. Placement of spandrel splice plates in the exterior wall model.. 98

Figure 5-6. Model of the WTC 1 core columns and connections, floors 95-97. 99

Figure 5-7. Detail of wide flange core columns splices. 100

Figure 5-8. Detail of box column-to-wide flange core columns connection. 100

Figure 5-9. Model of the core of floor 96 of WTC 1 (with and without floor slab). 101

Figure 5-10. Model detail of core column and beam connections. 102

Figure 5-11. Model of the WTC 1 core, floors 94-98. 102

Figure 5-12. Model of a truss floor segment. 103

Figure 5-13. Simplified far field truss floor model. 104

Figure 5-14. Truss floor connection detail at exterior wall. 104

Figure 5-15. Truss floor connection detail at core perimeter. 105

Figure 5-16. Detailed model of floor 96 of WTC 1. 105

Figure 5-17. Model of floor 96 of WTC 1, including interior contents. 106

Figure 5-18. Global impact model of the WTC 1 tower. 107

Figure 5-19. Interior structures and contents of the WTC 1 global impact model. 108

Figure 5-20. Nonstructural building contents in the WTC 1 global impact model. 108

Figure 5-21. Global impact model of the WTC 2 tower. 109

Figure 5-22. Interior structures and contents of the WTC 2 global impact model. 110

Figure 5-23. Nonstructural building contents in the WTC 2 global impact model. 110 
Figure 5-24. Finite element models of the ASTM 370 rectangular tensile specimen.

Figure 5-25. Tabular true stress-strain constitutive model curves for the tower steels.

Figure 5-26. Comparison of rate effects model and test data.

Figure 5-27. Finite element analysis of the unconfined compression test.

Figure 5-28. Comparison of the calculated unconfined compression behavior with concrete compression test data.

Figure 5-29. Tabular concrete strain rate effects curve. 116

Figure 5-30. Finite element model of the Boeing 767-200ER.

Figure 5-31. Boeing 767-200ER with fuel load at time of impact.

Figure 5-32. Boeing 767-200ER model wing deflections

Figure 5-33. Empennage model of the 767-200ER aircraft.

Figure 5-34. Retracted landing gear components for the 767-200ER aircraft model.

Figure 5-35. Underside of the 767 airframe model (skin removed) showing retracted landing gear, engine, and ULDs.

Figure 5-36. Complete wing structures for the 767 aircraft model.

Figure 5-37. Model of fuselage interior frame and stringer construction.

Figure 5-38. Integration of the fuselage and wing structures.

Figure 5-39. Wing section model for component level and subassembly analyses.

Figure 5-40. Pratt \& Whitney PW4000 turbofan engine.

Figure 5-41. PW4000 engine cross-sectional geometry and simplification.........

Figure 5-42. Pratt \& Whitney PW4000 turbofan engine model.

Figure 5-43. True stress-strain curves developed for various aircraft aluminum alloys.

Figure 5-44. Tabular stress-strain curves developed for various aircraft aluminum alloys.

Figure 5-45. Exterior column response comparison, showing contours of the displacement magnitude (in.).

Figure 5-46. Modeling of exterior column bolted connection.

Figure 5-47. Failure comparison of exterior column bolted connection treatments.

Figure 5-48. Detailed model of the truss floor system.

Figure 5-49. Simplified model of the truss floor system.

Figure 5-50. Constitutive behavior for the combined concrete and metal decking.

Figure 5-51. Floor assembly impact response with brick element concrete slab.

Figure 5-52. Floor assembly impact response with shell element concrete slab.

Figure 5-53. SPH and ALE fuel models in the small wing segment.

Figure 5-54. Wing segment, fuel, and exterior panel configuration.

Figure 5-55. Impact response of a wing section laden with fuel modeled using ALE approach.

Figure 5-56. Impact response of a wing section laden with fuel modeled using SPH approach. 
Figure 5-57. Exterior panels aftcr impact with a wing segment with fuel. .......................................... 142

Figure 5-58. Top view of structural damage and fuel dispersion at $0.04 \mathrm{~s}$........................................ 143

Figure 5-59. Side view of structural damage and fuel dispersion at 0.04 s....................................... 144

Figure 5-60. Tower subassembly model. ................................................................................... 145

Figure 5-61. Response of the subasscmbly model to engine impact.................................................. 146

Figure 5-62. Subasscmbly-engine impact and breakup response (side view).................................... 147

Figure 5-63. Speed history for the engine subassembly impact analysis....................................... 148

Figure 6-1. Definition of the aircraft impact parameters........................................................ 152

Figurc 6-2. Complex motion analysis to measure object motions using multiple cameras. .................. 154

Figure 6-3. Simplified motion analysis procedure to determine aircraft speed.................................. 156

Figure 6-4. Estimated impact locations of aircraft components superimposed on the damaged face

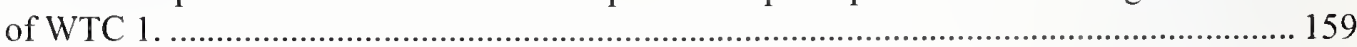

Figure 6-5. Orientation and trajectory of AA 11 that matched the impact pattern (vertical

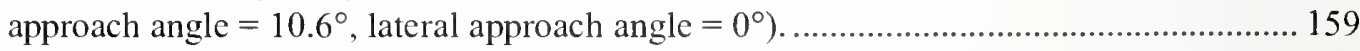

Figure 6-6. Estimated impact locations of aircraft components superimposed on the damaged face

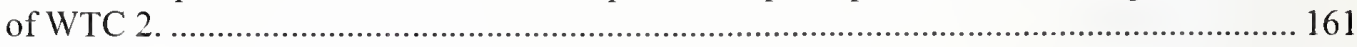

Figure 6-7. Orientation and Trajectory of UAL 175 from Video Analysis....................................... 161

Figure 6-8. Orientation and trajectory of UAL 175 that matches the impact pattern (vertical

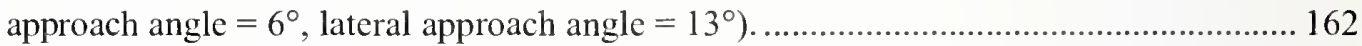

Figure 6-9. Orientation and trajectory of UAL 175 that matches the impact pattern (vertical approach angle $=6^{\circ}$, lateral approach angle $=17^{\circ}$ ).

Figure 6-10. Projected trajectory of the starboard engine of UAL 175 with an initial lateral approach angle of $13^{\circ}$.

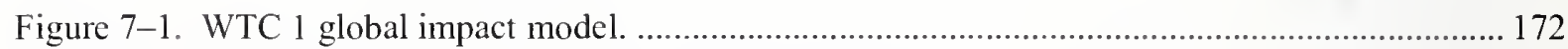

Figure 7-2. WTC 1 base case global impact analysis (side view) ............................................... 174

Figure 7-3. WTC 1 base case global impact analysis (plan view) ............................................... 176

Figure 7-4. Normalized aircraft momentum for the WTC 1 base case impact. .................................. 178

Figure 7-5. Base case impact damage to the WTC 1 exterior wall .................................................... 181

Figure 7-6. Base case impact damage to the WTC 1 core columns.................................................. 182

Figure 7-7. Classification of damage levels in core columns...................................................... 183

Figure 7-8. Base case impact damage to the core beams of floors 95 and 96 of WTC 1................... 184

Figure 7-9. Base case impact damage to the WTC 1 floor trusses (front view).................................. 185

Figure 7-10. Base case impact damage to the trusses on floors 95 and 96 of WTC 1 (plan view)........ 186

Figure 7-11. Base Case impact damage to the slabs on floors 95 and 96 of WTC 1 (plan view).......... 187 
Figure 7-12. Summary of the floor-by-floor structural damage to the floors and columns of WTC 1 (base case).

Figure 7-13. Cumulative structural damage to the floors and columns of WTC 1 (base case).

Figure 7-14. Calculated fuel distribution in the base case WTC 1 analysis.

Figure 7-15. Plan view of calculated WTC 1 building, fuel, and aircraft debris distribution for the base case

Figure 7-16. Calculated floor 95 contents and fuel distribution (base case). 194

Figure 7-17. Calculated floor 96 contents and fuel distribution (base case). 195

Figure 7-18. WTC 1 more severe global impact analysis (side view). 198

Figure 7-19. WTC 1 more severe global impact analysis (plan view). 200

Figure 7-20. More severe impact damage to the WTC 1 exterior wall. 203

Figure 7-21. More severe impact response of the WTC 1 core columns. 204

Figure 7-22. More severe impact damage to the core beams of floors 95 and 96 of WTC 1. 205

Figure 7-23. More severe impact damage to the WTC 1 floor trusses (front view). 207

Figure 7-24. More severe impact damage to the trusses on floors 95 and 96 of WTC 1 (plan view).... 208

Figure 7-25. More severe impact damage to the slabs on floors 95 and 96 of WTC 1 (plan view).......209

Figure 7-26. Summary of the floor-by-floor structural damage to the floors and columns of WTC 1 (more severe case).

Figure 7-27. Cumulative structural damage to the floors and columns of WTC 1 (more severe case).

Figure 7-28. Calculated fuel distribution in the more severe WTC 1 analysis.

Figure 7-29. Plan view of calculated WTC 1 building, fuel, and aircraft debris distribution for the more severe case.

Figure 7-30. Calculated more severe WTC 1 impact response of floor 95 contents. 215

Figure 7-31. Calculated more severe WTC 1 impact response of floor 96 contents......... 216

Figure 7-32. WTC 2 global impact model. 218

Figure 7-33. WTC 2 base case global impact analysis (side view). 220

Figure 7-34. WTC 2 base case global impact analysis (plan view). 222

Figure 7-35. Normalized aircraft momentum for the WTC 2 base case impact. 224

Figure 7-36. Base case impact damage to the WTC 2 exterior wall. 226

Figure 7-37. Base case impact damage to the WTC 2 core columns. 227

Figure 7-38. Base case impact damage to the core beams of floors 80 and 81 of WTC 2 . 228

Figure 7-39. Base case impact damage to the WTC 2 floor trusses (front view)....... 229

Figure 7-40. Base case impact damage to the trusses on floors 80 and 81 of WTC 2 (plan view)........230

Figure 7-41. Base case impact damage to the slabs on floors 80 and 81 of WTC 2 (plan view). 231 
Figure 7-42. Summary of the floor-by-floor structural damage to the floors and columns of WTC 2 (base case).

Figure 7-43. Cumulative structural damage to the floors and columns of WTC 2 (base case)......

Figure 7-44. Calculated fuel distribution in the base case WTC 2 analysis.

Figure 7-45. Plan view of calculated WTC 2 building, fuel, and aircraft debris distribution for the base case.

Figure 7-46. Calculated floor 80 contents, and fuel distribution (base case). 239

Figure 7-47. Calculated floor 81 contents and fuel distribution (base case). 240

Figure 7-48. WTC 2 more severe global impact analysis (side view). 243

Figure 7-49. WTC 2 more severe global impact analysis (plan view). 245

Figure 7-50. More severe impact damage to the WTC 2 exterior wall. 248

Figure 7-51. More severe impact damage to the WTC 2 core columns. 249

Figure 7-52. More sevcre impact damage to the core beams of floors 80 and 81 of WTC 2............... 250

Figure 7-53. More sevcre impact damage to the WTC 2 floor trusses (front view). ........................... 252

Figure 7-54. More severe impact damage to the trusses on floors 80 and 81 of WTC 2 (plan view).... 253

Figure 7-55. More severe impact damage to the WTC 2 floor slab (plan view)................................254

Figure 7-56. Summary of the floor-by-floor structural damage to the floors and columns of WTC 2 (more severe case).

Figure 7-57. Cumulative structural damage to the floors and columns of WTC 2 (more severe case).

Figure 7-58. Calculated fuel distribution in the more severe WTC 2 analysis.

Figure 7-59. Plan view of calculated more WTC 2 building, fuel, and aircraft debris distribution for the more severe case. 260

Figure 7-60. Calculated floor 80 contents and fuel distribution (more severe case). 261

Figure 7-61. Calculated floor 81 contents and fuel distribution (more severe case). 262

Figure 7-62. Comparison of base case impact damage to the exterior walls of WTC 1 and WTC 2..... 265

Figure 7-63. Comparison of base case impact damage to the core columns of WTC 1 and WTC $2 \ldots . .266$

Figure 7-64. Comparison of base case impact damage to floor trusses of WTC 1 and WTC 2. 267

Figure 7-65. Comparison of observable and calculated base case impact damage to the north wall of WTC 1 . 269

Figure 7-66. Base case aircraft debris distribution in WTC 1 ...............................................2 270

Figure 7-67. More severe damage aircraft debris distribution in WTC 1. .........................................2 271

Figure 7-68. Damage to the south face of WTC 1 from the more severe damage global analysis. ........ 272

Figure 7-69. Landing gear found at the corner of West and Rector Streets....................................... 273

Figure 7-70. Landing gear found embedded in exterior panel knocked free from WTC 1.................. 274

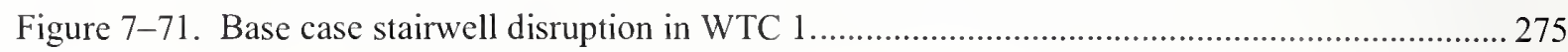


Figure 7-72. Observed and calculated WTC 1 damage (front view) 276

Figure 7-73. Comparison of observable and calculated base case impact damage to the south wall of WTC 2.

Figure 7-74. Impact damage to the northeast corner of the exterior wall of WTC 2 278

Figure 7-75. Documented damage to the northeast corner of floor 81 of WTC 2. 279

Figure 7-76. Base case response on the northeast corner of floor 81 of WTC 2. 280

Figure 7-77. Base case stairwell disruption on floor 78 in WTC 2. 281

Figure 7-78. Base case damage aircraft debris distribution in WTC 2 ...........................................2 282

Figure 7-79. Aircraft debris distribution in the more severe WTC 2 impact. .....................................2283

Figure 7-80. Starboard engine fragment trajectory in the base case global analysis of WTC 2...........285

Figure 7-81. Speed of the aft portion of the starboard engine ............................................................228

Figure 7-82. Calculated and observed engine damage...................................................................28

Figure 7-83. Starboard engine impact with the south face of WTC 2 in the base case global

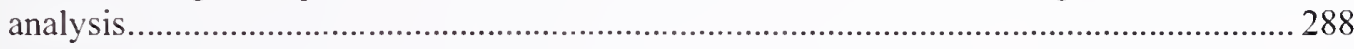

Figure 7-84. Projected debris path for the WTC 2 north face cold spot ............................................ 290

Figure 7-85. Base case WTC 2 impact orientation and trajectory (vertical approach angle $=$

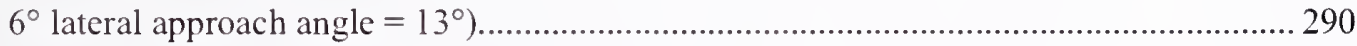

Figure 7-86. Comparison of impact damage to the north wall of WTC 1 ............................................293

Figure 7-87. Comparison of impact damage to the south wall of WTC 2. .....................................2 294 
This page intentionally left blank. 


\section{LIST OF TABLES}

Table P-1. Federal building and fire safety investigation of the WTC disaster...............................xxviii

Table P-2. Public meetings and briefings of the WTC Investigation. ..............................................xxi

Table 2-1. Approximate size of the reference structural models (rounded).................................... 14

Table 2-2. Lateral displacement (in.) for the shell and frame models of typical exterior wall panel with varied column and spandrel rigidities. ...................................................... 21

Table 2-3. Calculated first six periods and frequencies without P- $\Delta$ effects.....................................2 27

Table 2-4. Calculated first six periods and frequencies with P- $\Delta$ effects.........................................2 27

Table 2-5. Comparison of measured and calculated natural frequencies and periods for WTC 1 ....... 28

Table 3-1. Approximate maximum base moments for WTC 2 induced by ASCE 7-98 standard

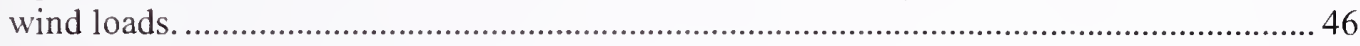

Table 3-2. Comparison of wind load estimates for WTC 1 based on various sources....................... 52

Table 3-3. Comparison of wind load estimates for WTC 2 based on various sources........................ 53

Table 3-4. Base shears and base moments due to wind loads based on various building codes...........53

Table 3-5. Comparison between various design wind speeds. ........................................................ 55

Table 3-6. Comparison between the various wind studies............................................................5

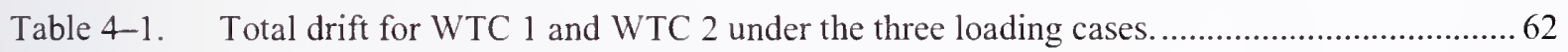

Table 4-2. Statistics of DCRs for WTC 1 under original design load case....................................... 68

Table 4-3. Statistics of DCRs for WTC 1 under the lower estimate, state-of-the practice case............ 69

Table 4-4. Statistics of DCRs for WTC 1 under the refined NIST estimate case. ............................. 70

Table 4-5. Statistics of DCRs for WTC 1 under the refined NIST estimate case using LRFD and

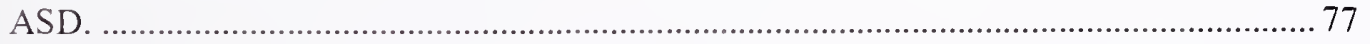

Table 4-6. Maximum calculated DCRs for exterior wall column splices for WTC 1 under original design dead and wind load case.

Table 4-7. Summary of maximum deflections for typical truss-framed floor under dead and live loads for areas outside of core..... 86

Table 4-8. DCR statistics for the typical truss-framed floor under the original design load case........ 87

Table 4-9. DCR statistics for floor the typical truss-framed floor under the ASCE 7-02 loading case.

Table 4-10. DCR statistics for the typical beam-framed floor under the original design loading case. 90 
Table 5-1. Summary of the size of the global impact tower models. ................................................ 95

Table 5-2. Bocing 767-200ER aircraft model parameters.............................................................. 118

Table 5-3. Density scale factors and weights for aircraft components............................................ 125

Table 5-4. Boeing 767 Engine Comparison. .................................................................................. 126

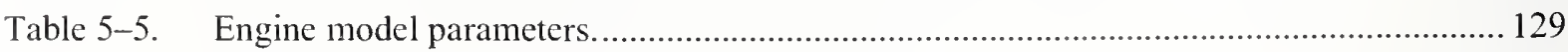

Table 5-6. Exterior column component analyses comparison.................................................... 133

Table 5-7. Truss floor assembly component analyses comparison. ............................................... 134

Table 6-1. Videos used for the analysis of aircraft impact initial conditions. ................................... 153

Table 6-2. Measured UAL 175 impact speeds using the simplified analysis methodology.............. 157

Table 6-3. Summary of measured aircraft impact conditions from video analysis.......................... 158

Table 6-4. Aircraft impact locations on the WTC towers. ......................................................... 162

Table 6-5. Summary of refined aircraft impact conditions. .......................................................... 162

Table 6-6. AA 11 (WTC 1) aircraft impact analysis comparison. .................................................. 165

Table 6-7. UAL 175 (WTC 2) aircraft impact analysis comparison............................................... 165

Table 7-1. Summary of core column damage for the base case WTC 1 impact. ............................ 183

Table 7-2. Fuel and aircraft debris distribution for the base case WTC 1 impact........................... 196

Table 7-3. Input parameters for the more and less severe WTC 1 impact analysis. ......................... 197

Table 7-4. Summary of core column damage for the more severe WTC 1 impact.......................... 205

Table 7-5. Fuel and aircraft debris distribution for the more severe WTC 1 impact. ....................... 212

Table 7-6. Summary of core column damage for the base case WTC 2 impact. .............................228

Table 7-7. Fuel and aircraft debris distribution for the base case WTC 2 impact........................... 241

Table 7-8. Input parameters for the more severe WTC 2 impact analysis. ...................................... 242

Table 7-9. Summary of core column damage for the more severe WTC 2 impact.......................... 251

Table 7-10. Fuel and aircraft debris distribution for the more severe WTC 2 impact. .....................258

Table 7-11. Comparison of damage to core columns from various studies ......................................296 


\section{LIST OF ACRONYMS AND ABBREVIATIONS}

\section{Acronyms}

AA

AISC

ALE

ARA

ASCE

ASD

ASTM

$\mathrm{CDL}$

C.O.V.

CPP

CPU

CSU

DCR

DL

E-W

FBI

FEMA

HAZ

HFFB

LERA

LL

LRFD

MIT

NIST

$\mathrm{N}-\mathrm{S}$

NOAA

NTSC

NYCBC
American Airlines

American Institute of Steel Construction

Arbitrary-Lagrangian-Eulerian

Applied Research Associates, Incorporated

American Society of Civil Engineers

Allowable Stress Design

American Society for Testing and Materials

Construction dead load

coefficient of variation

Cermak Peterka Peterson, Inc.

central processing unit

Colorado State University

demand/capacity ratio

dead load

East-West direction

Federal Bureau of Investigation

Federal Emergency Management Agency

heat affected zone

heat-frequency force-balance

Leslic E. Robertson Associates, RLLP

live load

Load and Resistance Factor Design

Massachusetts Institute of Technology

National Institute of Standards and Technology

North-South direction

National Oceanic Atmospheric Administration

National Television System Committee

New York City Building Code 
PAL Phase Alternating Line

PANYNJ Port Authority of New York and New Jersey

RWDI Rowan Williams Davies and Irwin, Inc.

SDL superimposed dead load

SOM Skidmore, Owings, and Merrill

SPH Smoothed Particle Hydrodynamics

UAL United Airlines

ULD unit load device

WAI Weidlinger Associates, Inc.

WSHJ Worthington, Skilling, Helle \& Jackson

WTC World Trade Center

WTC $1 \quad$ World Trade Center 1 (North Tower)

WTC 2 World Trade Center 2 (South Tower)

WTC $7 \quad$ World Trade Center 7

\section{Abbreviations}

$\pm \quad$ plus or minus

2D two dimensional

3D three dimensional

fps foot per second

$\mathrm{ft} \quad$ foot

$\mathrm{ft}^{2} \quad$ square foot

$\mathrm{GHz} \quad$ gigahertz

h hour

in. inch

kip a stress equal to 1,000 pounds

ksi $\quad 1,000$ pounds per square inch

lb pound

m meter

$\min \quad$ minute

mph miles per hour

pef pounds per cubic foot 


$\begin{array}{ll}\text { psf } & \text { pounds per square foot } \\ \text { psi } & \text { pounds per square inch } \\ \mathrm{s} & \text { second } \\ \mathrm{ms} & \text { millisecond }\end{array}$


This page intentionally left blank. 


\section{PREFACE}

Immediately following the terrorist attack on the World Trade Center (WTC) on September 11, 2001, the Federal Emergency Management Agency (FEMA) and the American Society of Civil Engineers began planning a building performance study of the disaster. The week of October 7 , as soon as the rescue and search efforts ceased, the Building Performance Study Team went to the site and began its assessment. This was to be a brief effort, as the study team consisted of experts who largely volunteered their time away from their other professional commitments. The Building Performance Study Team issued its report in May 2002, fulfilling its goal "to determine probable failure mechanisms and to identify areas of future investigation that could lead to practical measures for improving the damage resistance of buildings against such unforeseen events."

On August 21, 2002, with funding from the U.S. Congress through FEMA, the National Institute of Standards and Technology (NIST) announced its building and fire safety investigation of the WTC disaster. On October 1, 2002, the National Construction Safety Team Act (Public Law 107-231), was signed into law. The NIST WTC Investigation was conducted under the authority of the National Construction Safety Team Act.

The goals of the investigation of the WTC disaster were:

- To investigate the building construction, the materials used, and the technical conditions that contributed to the outcome of the WTC disaster.

- To serve as the basis for:

- Improvements in the way buildings are designed, constructed, maintained, and used;

- Improved tools and guidance for industry and safety officials;

- Recommended revisions to current codes, standards, and practices; and

- Improved public safety.

The specific objectives were:

1. Determine why and how WTC 1 and WTC 2 collapsed following the initial impacts of the aircraft and why and how WTC 7 collapsed;

2. Determine why the injuries and fatalities were so high or low depending on location, including all technical aspects of fire protection, occupant behavior, evacuation, and emergency response;

3. Determine what procedures and practices were used in the design, construction, operation, and maintenance of WTC 1, 2, and 7; and

4. Identify, as specifically as possible, areas in current building and fire codes, standards, and practices that warrant revision. 
NIST is a nonregulatory agency of the U.S. Department of Commerce's Technology Administration. The purpose of NIST investigations is to improve the safety and structural integrity of buildings in the United States, and the focus is on fact finding. NIST investigative teams are authorized to assess building performance and emergency response and evacuation procedures in the wake of any building failure that has resulted in substantial loss of life or that posed significant potential of substantial loss of life. NIST does not have the statutory authority to make findings of fault nor negligence by individuals or organizations. Further, no part of any report resulting from a NIST investigation into a building failure or from an investigation under the National Construction Safety Team Act may be used in any suit or action for damages arising out of any matter mentioned in such report (15 USC 281a, as amended by Public Law 107-231).

\section{Organization of the Investigation}

The National Construction Safety Team for this Investigation, appointed by the then NIST Director, Dr. Arden L. Bement, Jr., was led by Dr. S. Shyam Sunder. Dr. William L. Grosshandler served as Associate Lead Investigator, Mr. Stephen A. Cauffman served as Program Manager for Administration, and $\mathrm{Mr}$. Harold E. Nelson served on the team as a private sector expert. The Investigation included eight interdependent projects whose leaders comprised the remainder of the team. A detailed description of each of these eight projects is available at http://wtc.nist.gov. The purpose of each project is summarized in Table $\mathrm{P}-1$, and the key interdependencies among the projects are illustrated in Fig. $\mathrm{P}-1$.

Table P-1. Federal building and fire safety investigation of the WTC disaster.

Technical Area and Project Leader

Analysis of Building and Fire Codes and Practices; Project Leaders: Dr. H. S. Lew and Mr. Richard W. Bukowski

Baseline Structural Performance and Aircraft Impact Damage Analysis; Project Leader: Dr. Fahim H. Sadek

Mechanical and Metallurgical Analysis of Structural Steel; Project Leader: Dr. Frank W. Gayle

Investigation of Active Fire Protection Systems; Project Leader: Dr. David D. Evans; Dr. William Grosshandler

Reconstruction of Thermal and Tenability Environment; Project Leader: Dr. Richard G. Gann

Structural Fire Response and Collapse Analysis; Project Leaders: Dr. John L. Gross and Dr. Therese P. McAllister

Occupant Behavior, Egress, and Emergency Communications; Project Leader: Mr. Jason D. Averill

Emergency Response Technologies and Guidelines; Project Leader: Mr. J. Randall Lawson

Project Purpose

Document and analyze the code provisions, procedures, and practices used in the design, construction, operation, and maintenance of the structural, passive fire protection, and emergency access and evacuation systems of WTC 1,2, and 7 .

Analyze the baseline performance of WTC 1 and WTC 2 under design, service, and abnormal loads, and aircraft impact damage on the structural, fire protection, and egress systems.

Determine and analyze the mechanical and metallurgical properties and quality of steel, weldments, and connections from steel recovered from WTC 1,2 , and 7 .

Investigate the performance of the active fire protection systems in WTC 1, 2, and 7 and their role in fire control, emergency response, and fate of occupants and responders.

Reconstruct the time-evolving temperature, thermal environment, and smoke movement in WTC 1, 2, and 7 for use in evaluating the structural performance of the buildings and behavior and fate of occupants and responders.

Analyze the response of the WTC towers to fires with and without aircraft damage, the response of WTC 7 in fires, the performance of composite steel-trussed floor systems, and determine the most probable structural collapse sequence for WTC 1,2, and 7.

Analyze the behavior and fate of occupants and responders, both those who survived and those who did not, and the performance of the evacuation system.

Document the activities of the emergency responders from the time of the terrorist attacks on WTC 1 and WTC 2 until the collapse of WTC 7, including practices followed and technologies used. 


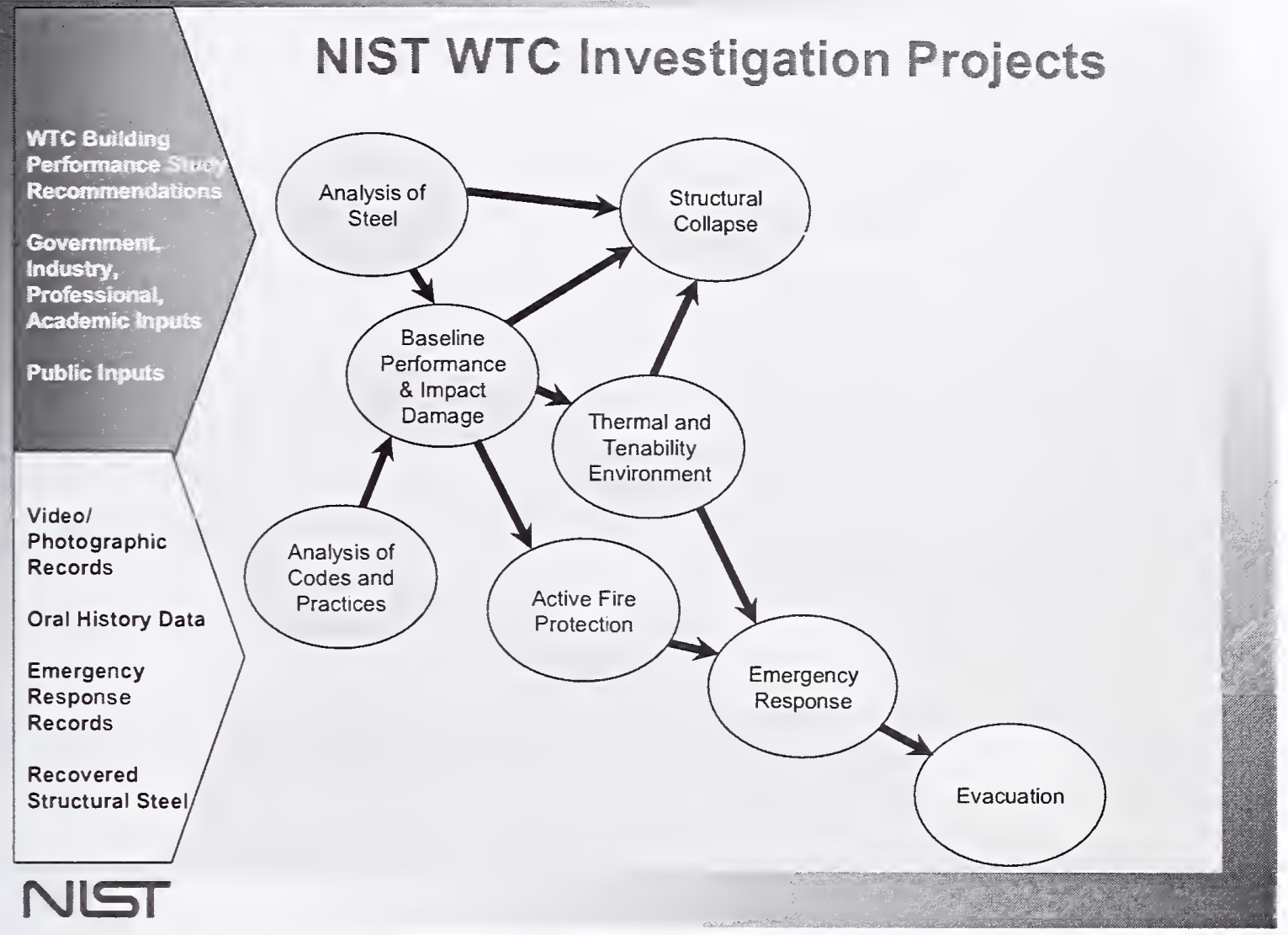

Figure $P-1$. The eight projects in the federal building and fire safety investigation of the WTC disaster.

\section{National Construction Safety Team Advisory Committee}

The NIST Director also established an advisory committee as mandated under the National Construction Safety Team Act. The initial members of the committee were appointed following a public solicitation. These were:

- Paul Fitzgerald. Executive Vice President (retired) FM Global, National Construction Safety Team Advisory Committee Chair

- John Barsom, President, Barsom Consulting, Ltd.

- John Bryan, Professor Emeritus, University of Maryland

- David Collins, President, The Preview Group, Inc.

- Glenn Corbett, Professor, John Jay College of Criminal Justice

- Philip DiNenno, President, Hughes Associates, Inc. 
- Robert Hanson, Professor Emeritus, University of Michigan

- Charles Thornton, Co-Chairman and Managing Principal, The Thornton-Tomasetti Group, Inc.

- Kathleen Tierney, Director, Natural Hazards Research and Applications Information Center, University of Colorado at Boulder

- Forman Williams, Director, Center for Energy Research, University of California at San Diego

This National Construction Safety Team Advisory Committee provided technical advice during the Investigation and commentary on drafts of the Investigation reports prior to their public release. NIST has benefited from the work of many people in the preparation of these reports, including the National Construction Safety Team Advisory Committee. The content of the reports and recommendations, however, are solely the responsibility of NIST.

\section{Public Outreach}

During the course of this Investigation, NIST held public briefings and meetings (listed in Table P-2) to solicit input from the public, present preliminary findings, and obtain comments on the direction and progress of the Investigation from the public and the Advisory Committee.

NIST maintained a publicly accessible Web site during this Investigation at http://wtc.nist.gov. The site contained extensive information on the background and progress of the Investigation.

\section{NIST's WTC Public-Private Response Plan}

The collapse of the WTC buildings has led to broad reexamination of how tall buildings are designed, constructed, maintained, and used, especially with regard to major events such as fires, natural disasters, and terrorist attacks. Reflecting the enhanced interest in effecting necessary change, NIST, with support from Congress and the Administration, has put in place a program, the goal of which is to develop and implement the standards, technology, and practices needed for cost-effective improvements to the safety and security of buildings and building occupants, including evacuation, emergency response procedures, and threat mitigation.

The strategy to meet this goal is a three-part NIST-led public-private response program that includes:

- A federal building and fire safety investigation to study the most probable factors that contributed to post-aircraft impact collapse of the WTC towers and the 47-story WTC 7 building, and the associated evacuation and emergency response experience.

- A research and development $(R \& D)$ program to (a) facilitate the implementation of recommendations resulting from the WTC Investigation, and (b) provide the technical basis for cost-effective improvements to national building and fire codes, standards, and practices that enhance the safety of buildings, their occupants, and emergency responders. 
Table P-2. Public meetings and briefings of the WTC Investigation.

\begin{tabular}{|c|c|c|}
\hline Date & Location & Principal Agenda \\
\hline June 24,2002 & New York City, NY & $\begin{array}{l}\text { Public meeting: Public comments on the Draft Plan for the } \\
\text { pending WTC Investigation. }\end{array}$ \\
\hline August 21, 2002 & Gaithersburg, MD & Media briefing announcing the formal start of the Investigation. \\
\hline December 9, 2002 & Washington, DC & $\begin{array}{l}\text { Media briefing on release of the Public Update and NIST request } \\
\text { for photographs and videos. }\end{array}$ \\
\hline April 8, 2003 & New York City, NY & $\begin{array}{l}\text { Joint public forum with Columbia University on first-person } \\
\text { interviews. }\end{array}$ \\
\hline April 29-30.2003 & Gaithersburg, MD & $\begin{array}{l}\text { NCST Advisory Committee meeting on plan for and progress on } \\
\text { WTC Investigation with a public comment session. }\end{array}$ \\
\hline May 7,2003 & New York City, NY & Media briefing on release of May 2003 Progress Report. \\
\hline August 26-27, 2003 & Gaithersburg, MD & $\begin{array}{l}\text { NCST Advisory Committee meeting on status of the WTC } \\
\text { investigation with a public comment session. }\end{array}$ \\
\hline September 17,2003 & New York City, NY & $\begin{array}{l}\text { Media and public briefing on initiation of first-person data } \\
\text { collection projects. }\end{array}$ \\
\hline December 2-3, 2003 & Gaithersburg, MD & $\begin{array}{l}\text { NCST Advisory Committee meeting on status and initial results } \\
\text { and release of the Public Update with a public comment session. }\end{array}$ \\
\hline February 12,2004 & New York City, NY & $\begin{array}{l}\text { Public meeting on progress and preliminary findings with public } \\
\text { comments on issues to be considered in formulating final } \\
\text { recommendations. }\end{array}$ \\
\hline June 18,2004 & New York City, NY & Media/public briefing on release of Jume 2004 Progress Report. \\
\hline June $22-23,2004$ & Gaithersburg, MD & $\begin{array}{l}\text { NCST Advisory Committee meeting on the status of and } \\
\text { preliminary findings from the WTC Investigation with a public } \\
\text { comment session. }\end{array}$ \\
\hline August 24, 2004 & Northbrook, IL & $\begin{array}{l}\text { Public viewing of standard fire resistance test of WTC floor } \\
\text { system at Underwriters Laboratories, Inc. }\end{array}$ \\
\hline October $19-20,2004$ & Gaithersburg, MD & $\begin{array}{l}\text { NCST Advisory Committee meeting on status and near complete } \\
\text { set of preliminary findings with a public comment session. }\end{array}$ \\
\hline November 22,2004 & Gaithersburg, MD & $\begin{array}{l}\text { NCST Advisory Committee discussion on draft annual report to } \\
\text { Congress, a public comment session, and a closed session to } \\
\text { discuss pre-draft recommendations for WTC Investigation. }\end{array}$ \\
\hline April 5, 2005 & New York City, NY & $\begin{array}{l}\text { Media and public briefing on release of the probable collapse } \\
\text { sequence for the WTC towers and draft reports for the projects on } \\
\text { codes and practices, evacuation, and emergency response. }\end{array}$ \\
\hline June 23,2005 & New York City, NY & $\begin{array}{l}\text { Media and public briefing on release of all draft reports for the } \\
\text { WTC towers and draft recommendations for public comment. }\end{array}$ \\
\hline $\begin{array}{l}\text { September 12-13, } \\
2005\end{array}$ & Gaithersburg, MD & $\begin{array}{l}\text { NCST Advisory Committee meeting on disposition of public } \\
\text { comments and update to draft reports for the WTC towers. }\end{array}$ \\
\hline $\begin{array}{l}\text { September 13-15, } \\
2005\end{array}$ & Gaithersburg, MD & $\begin{array}{l}\text { WTC Technical Conference for stakeholders and technical } \\
\text { community for dissemination of findings and recommendations } \\
\text { and opportunity for public to make technical comments. }\end{array}$ \\
\hline
\end{tabular}

- A dissemination and technical assistance program (DTAP) to (a) engage leaders of the construction and building community in ensuring timely adoption and widespread use of proposed changes to practices, standards, and codes resulting from the WTC Investigation and the R\&D program, and (b) provide practical guidance and tools to better prepare facility owners, contractors, architects, engineers, emergency responders, and regulatory authorities to respond to future disasters.

The desired outcomes are to make buildings, occupants, and first responders safer in future disaster events. 


\section{National Construction Safety Team Reports on the WTC Investigation}

A final report on the collapse of the WTC towers is being issued as NIST NCSTAR 1. A companion report on the collapse of WTC 7 is being issued as NIST NCSTAR 1A. The present report is one of a set that provides more detailed documentation of the Investigation findings and the means by which these technical results were achieved. As such, it is part of the archival record of this Investigation. The titles of the full set of Investigation publications are:

NIST (National Institute of Standards and Technology). 2005. Federal Building and Fire Safety Investigation of the World Trade Center Disaster: Final Report on the Collapse of the World Trade Center Towers. NIST NCSTAR 1. Gaithersburg, MD, September.

NIST (National Institute of Standards and Technology). 2006. Federal Building and Fire Safety Investigation of the World Trade Center Disaster: Final Report on the Collapse of World Trade Center 7. NIST NCSTAR 1A. Gaithersburg, MD.

Lew, H. S., R. W. Bukowski, and N. J. Carino. 2005. Federal Building and Fire Safety Investigation of the World Trade Center Disaster: Design, Construction, and Maintenance of Structural and Life Safety Systems. NIST NCSTAR 1-1. National Institute of Standards and Technology. Gaithersburg, MD, September.

Fanella, D. A., A. T. Derecho, and S. K. Ghosh. 2005. Federal Building and Fire Safety Investigation of the World Trade Center Disaster: Design and Construction of Structural Systems. NIST NCSTAR 1-1A. National Institute of Standards and Technology. Gaithersburg, MD, September.

Ghosh, S. K., and X. Liang. 2005. Federal Building and Fire Safety Investigation of the World Trade Center Disaster: Comparison of Building Code Structural Requirements. NIST NCSTAR 1-1B. National Institute of Standards and Technology. Gaithersburg, MD, September.

Fanella, D. A., A. T. Derecho, and S. K. Ghosh. 2005. Federal Building and Fire Safety Investigation of the World Trade Center Disaster: Maintenance and Modifications to Structural Systems. NIST NCSTAR 1-1C. National Institute of Standards and Technology. Gaithersburg, MD, September.

Grill, R. A., and D. A. Johnson. 2005. Federal Building and Fire Safety Investigation of the World Trade Center Disaster: Fire Protection and Life Safety Provisions Applied to the Design and Construction of World Trade Center 1, 2, and 7 and Post-Construction Provisions Applied after Occupancy. NIST NCSTAR 1-1D. National Institute of Standards and Technology. Gaithersburg, MD, September.

Razza, J. C., and R. A. Grill. 2005. Federal Building and Fire Safety Investigation of the World Trade Center Disaster: Comparison of Codes, Standards, and Practices in Use at the Time of the Design and Construction of World Trade Center 1, 2, and 7. NIST NCSTAR 1-1E. National Institute of Standards and Technology. Gaithersburg, MD, September.

Grill, R. A., D. A. Johnson, and D. A. Fanella. 2005. Federal Building and Fire Safety Investigation of the World Trade Center Disaster: Comparison of the 1968 and Current (2003) New 
York City Building Code Provisions. NIST NCSTAR 1-1F. National Institute of Standards and Technology. Gaithersburg, MD, September.

Grill, R. A., and D. A. Johnson. 2005. Federal Building and Fire Safety Investigation of the World Trade Center Disaster: Ainendments to the Fire Protection and Life Safety Provisions of the New York City Building Code by Local Laws Adopted While World Trade Center 1, 2, and 7 Were in Use. NIST NCSTAR 1-1G. National Institute of Standards and Technology. Gaithersburg, MD, September.

Grill, R. A., and D. A. Johnson. 2005. Federal Building and Fire Safety Investigation of the World Trade Center Disaster: Post-Construction Modifications to Fire Protection and Life Safety Systems of World Trade Center 1 and 2. NIST NCSTAR 1-1H. National Institute of Standards and Technology. Gaithersburg, MD, September.

Grill, R. A., D. A. Johnson, and D. A. Fanella. 2005. Federal Building and Fire Safety Investigation of the World Trade Center Disaster: Post-Construction Modifications to Fire Protection, Life Safety, and Structural Systems of World Trade Center 7. NIST NCSTAR 1-1I. National Institute of Standards and Technology. Gaithersburg, MD, September.

Grill, R. A., and D. A. Johnson. 2005. Federal Building and Fire Safety Investigation of the World Trade Center Disaster: Design, Installation, and Operation of Fuel System for Emergency Power in World Trade Center 7. NIST NCSTAR 1-1J. National Institute of Standards and Technology. Gaithersburg, MD, September.

Sadek, F. 2005. Federal Building and Fire Safety Investigation of the World Trade Center Disaster: Baseline Structural Performance and Aircraft Impact Damage Analysis of the World Trade Center Towers. NIST NCSTAR 1-2. National Institute of Standards and Technology. Gaithersburg, MD, September.

Faschan, W. J., and R. B. Garlock. 2005. Federal Building and Fire Safety Investigation of the World Trade Center Disaster: Reference Structural Models and Baseline Performance Analysis of the World Trade Center Towers. NIST NCSTAR 1-2A. National Institute of Standards and Technology. Gaithersburg, MD, September.

Kirkpatrick, S. W., R. T. Bocchieri, F. Sadek, R. A. MacNeill, S. Holmes, B. D. Peterson, R. W. Cilke, C. Navarro. 2005. Federal Building and Fire Safety Investigation of the World Trade Center Disaster: Analysis of Aircraft Impacts into the World Trade Center Towers, NIST NCSTAR 1-2B. National Institute of Standards and Technology. Gaithersburg, MD, September.

Gayle, F. W., R. J. Fields, W. E. Luecke, S. W. Banovic, T. Foecke, C. N. McCowan, T. A. Siewert, and J. D. McColskey. 2005. Federal Building and Fire Safety Investigation of the World Trade Center Disaster: Mechanical and Metallurgical Analysis of Structural Steel. NIST NCSTAR 1-3. National Institute of Standards and Technology. Gaithersburg, MD, September.

Luecke, W. E., T. A. Siewert, and F. W. Gayle. 2005. Federal Building and Fire Safety Investigation of the World Trade Center Disaster: Contemporaneous Structural Steel Specifications. NIST Special Publication 1-3A. National Institute of Standards and Technology. Gaithersburg, MD, September. 
Banovic, S. W. 2005. Federal Building and Fire Safety Investigation of the World Trade Center Disaster: Steel Inventory and Identification. NIST NCSTAR 1-3B. National Institute of Standards and Technology. Gaithersburg, MD, September.

Banovic, S. W., and T. Foecke. 2005. Federal Building and Fire Safety Investigation of the World Trade Center Disaster: Damage and Failure Modes of Structural Steel Conponents. NIST NCSTAR 1-3C. National Institute of Standards and Technology. Gaithersburg, MD, September.

Luecke, W. E., J. D. McColskey, C. N. McCowan, S. W. Banovic, R. J. Fields, T. Foecke, T. A. Siewert, and F. W. Gayle. 2005. Federal Building and Fire Safety Investigation of the World Trade Center Disaster: Mechanical Properties of Strnctural Steels. NIST NCSTAR 1-3D. National Institutc of Standards and Technology. Gaithersburg, MD, September.

Banovic, S. W., C. N. McCowan, and W. E. Luecke. 2005. Federal Building and Fire Safety Investigation of the World Trade Center Disaster: Physical Properties of Structural Steels. NIST NCSTAR 1-3E. National Institute of Standards and Technology. Gaithersburg, MD, September.

Evans, D. D., R. D. Peacock, E. D. Kuligowski, W. S. Dols, and W. L. Grosshandler. 2005. Federal Building and Fire Safety Investigation of the World Trade Center Disaster: Active Fire Protection Systems. NIST NCSTAR 1-4. National Institute of Standards and Technology. Gaithersburg, MD, September.

Kuligowski, E. D., D. D. Evans, and R. D. Peacock. 2005. Federal Building and Fire Safety Investigation of the World Trade Center Disaster: Post-Construction Fires Prior to September I1, 2001. NIST NCSTAR 1-4A. National Institute of Standards and Technology. Gaithersburg, MD, September.

Hopkins, M., J. Schoenrock, and E. Budnick. 2005. Federal Building and Fire Safety Investigation of the World Trade Center Disaster: Fire Suppression Systems. NIST NCSTAR 1-4B. National Institute of Standards and Technology. Gaithersburg, MD, September.

Keough, R. J., and R. A. Grill. 2005. Federal Building and Fire Safety Investigation of the World Trade Center Disaster: Fire Alarm Systems. NIST NCSTAR 1-4C. National Institute of Standards and Technology. Gaithersburg, MD, September.

Ferreira, M. J., and S. M. Strege. 2005. Federal Building and Fire Safety Investigation of the World Trade Center Disaster: Smoke Management Systems. NIST NCSTAR 1-4D. National Institute of Standards and Technology. Gaithersburg, MD, September.

Gann, R. G., A. Hamins, K. B. McGrattan, G. W. Mulholland, H. E. Nelson, T. J. Ohlemiller, W. M. Pitts, and K. R. Prasad. 2005. Federal Building and Fire Safety Investigation of the World Trade Center Disaster: Reconstruction of the Fires in the World Trade Center Towers. NIST NCSTAR 1-5. National Institute of Standards and Technology. Gaithersburg, MD, September.

Pitts, W. M., K. M. Butler, and V. Junker. 2005. Federal Building and Fire Safety Investigation of the World Trade Center Disaster: Visual Evidence, Damage Estimates, and Timeline Analysis. NIST NCSTAR 1-5A. National Institute of Standards and Technology. Gaithersburg, MD, September. 
Hamins. A., A. Maranghides, K. B. McGrattan, E. Johnsson, T. J. Ohlemiller, M. Donnelly, J. Yang, G. Mulholland, K. R. Prasad, S. Kukuck, R. Anleitner and T. McAllister. 2005. Federal Building and Fire Safety Investigation of the World Trade Center Disaster: Experiments and Modeling of Structural Steel Elements Exposed to Fire. NIST NCSTAR 1-5B. National Institute of Standards and Technology. Gaithersburg, MD, September.

Ohlemiller, T. J., G. W. Mulholland, A. Maranghides, J. J. Filliben, and R. G. Gann. 2005. Federal Building and Fire Safety Investigation of the World Trade Center Disaster: Fire Tests of Single Office Workstations. NIST NCSTAR I-5C. National Institute of Standards and Technology. Gaithersburg, MD, September.

Gann, R. G., M. A. Riley, J. M. Repp, A. S. Whittaker, A. M. Reinhorn, and P. A. Hough. 2005. Federal Building and Fire Safety Investigation of the World Trade Center Disaster: Reaction of Ceiling Tile Systems to Shocks. NIST NCSTAR 1-5D. National Institute of Standards and Technology. Gaithersburg, MD, September.

Hamins, A., A. Maranghides, K. B. McGrattan, T. J. Ohlemiller, and R. Anleitner. 2005. Federal Building and Fire Safety Investigation of the World Trade Center Disaster: Experiments and Modeling of Multiple Workstations Burning in a Compartment. NIST NCSTAR 1-5E. National Institute of Standards and Technology. Gaithersburg, MD, September.

McGrattan, K. B., C. Bouldin, and G. Forney. 2005. Federal Building and Fire Safety Investigation of the World Trade Center Disaster: Computer Simulation of the Fires in the World Trade Center Towers. NIST NCSTAR 1-5F. National Institute of Standards and Technology. Gaithersburg, MD, September.

Prasad, K. R., and H. R. Baum. 2005. Federal Building and Fire Safety Investigation of the World Trade Center Disaster: Fire Structure Interface and Thermal Response of the World Trade Center Towers. NIST NCSTAR 1-5G. National Institute of Standards and Technology. Gaithersburg, MD, September.

Gross, J. L., and T. McAllister. 2005. Federal Building and Fire Safety Investigation of the World Trade Center Disaster: Structural Fire Response and Probable Collapse Sequence of the World Trade Center Towers. NIST NCSTAR 1-6. National Institute of Standards and Technology. Gaithersburg, MD, September.

Carino, N. J., M. A. Starnes, J. L. Gross, J. C. Yang, S. Kukuck, K. R. Prasad, and R. W. Bukowski. 2005. Federal Building and Fire Safety Investigation of the World Trade Center Disaster: Passive Fire Protection. NIST NCSTAR 1-6A. National Institute of Standards and Technology. Gaithersburg, MD, September.

Gross, J., F. Hervey, M. Izydorek, J. Mammoser, and J. Treadway. 2005. Federal Building and Fire Safety Investigation of the World Trade Center Disaster: Fire Resistance Tests of Floor Truss Systems. NIST NCSTAR 1-6B. National Institute of Standards and Technology. Gaithersburg, $\mathrm{MD}$, September.

Zarghamee, M. S., S. Bolourchi, D. W. Eggers, Ö. O. Erbay, F. W. Kan, Y. Kitane, A. A. Liepins, M. Mudlock, W. I. Naguib, R. P. Ojdrovic, A. T. Sarawit, P. R Barrett, J. L. Gross, and 
T. P. McAllister. 2005. Federal Building and Fire Safety Investigation of the World Trade Center Disaster: Component, Connection, and Subsystem Structural Analysis. NIST NCSTAR 1-6C. National Institute of Standards and Technology. Gaithersburg, MD, September.

Zarghamee, M. S., Y. Kitane, Ö. O. Erbay, T. P. McAllister, and J. L. Gross. 2005. Federal Building and Fire Safety Investigation of the World Trade Center Disaster: Global Structural Analysis of the Response of the World Trade Center Towers to Impact Damage and Fire. NIST NCSTAR 1-6D. National Institute of Standards and Technology. Gaithersburg, MD, September.

McAllister, T., R. W. Bukowski, R. G. Gann, J. L. Gross, K. B. McGrattan, H. E. Nelson, L. Phan, W. M. Pitts, K. R. Prasad, F. Sadek. 2006. Federal Building and Fire Safety Investigation of the World Trade Center Disaster: Structural Fire Response and Probable Collapse Sequence of World Trade Center 7. (Provisional). NIST NCSTAR 1-6E. National Institute of Standards and Technology. Gaithersburg, MD.

Gilsanz, R., V. Arbitrio, C. Anders, D. Chlebus, K. Ezzeldin, W. Guo, P. Moloney, A. Montalva, J. Oh, K. Rubenacker. 2006. Federal Building and Fire Safety Investigation of the World Trade Center Disaster: Structural Analysis of the Response of World Trade Center 7 to Debris Damage and Fire. (Provisional). NIST NCSTAR 1-6F. National Institute of Standards and Technology. Gaithersburg, MD.

Kim, W. 2006. Federal Building and Fire Safety Investigation of the World Trade Center Disaster: Analysis of September 11, 2001, Seismogram Data. (Provisional). NIST NCSTAR 1-6G. National Institute of Standards and Technology. Gaithersburg, MD.

Nelson, K. 2006. Federal Building and Fire Safety Investigation of the World Trade Center Disaster: The Con Ed Substation in World Trade Center 7. (Provisional). NIST NCSTAR 1-6H. National Institute of Standards and Technology. Gaithersburg, MD.

Averill, J. D., D. S. Mileti, R. D. Peacock, E. D. Kuligowski, N. Groner, G. Proulx, P. A. Reneke, and H. E. Nelson. 2005. Federal Building and Fire Safety Investigation of the World Trade Center Disaster: Occupant Behavior, Egress, and Emergency Communication. NIST NCSTAR 1-7. National Institute of Standards and Technology. Gaithersburg, MD, September.

Fahy, R., and G. Proulx. 2005. Federal Building and Fire Safety Investigation of the World Trade Center Disaster: Analysis of Published Accounts of the World Trade Center Evacuation. NIST NCSTAR 1-7A. National Institute of Standards and Technology. Gaithersburg, MD, September.

Zmud, J. 2005. Federal Building and Fire Safety Investigation of the World Trade Center Disaster: Technical Documentation for Survey Administration. NIST NCSTAR 1-7B. National Institute of Standards and Technology. Gaithersburg, MD, September.

Lawson, J. R., and R. L. Vettori. 2005. Federal Building and Fire Safety Investigation of the World Trade Center Disaster: The Emergency Response Operations. NIST NCSTAR 1-8. National Institute of Standards and Technology. Gaithersburg, MD, September. 


\section{ACKNOWLEDGMENTS}

The analyses presented in this report were conducted in collaboration with four contractors:

- A team of experts from Leslie E. Robertson Associates, whose work included the development of the structural databases, the reference structural models, and the baseline performance analysis of the World Trade Center (WTC) towers. The team was led by Mr. William J. Faschan and Mr. Richard B. Garlock.

- A team of experts from Skidmore, Owings, and Merrill, who provided the third-party review of the structural databases, the reference structural models, the baseline performance analysis, and the refined NIST estimate of the wind loads on the towers. The team included Mr. William F. Baker, Mr. John J. Zils, and Mr. Robert C. Sinn.

- A team of experts from Applied Research Associates, whose work included the analysis of aircraft impacts into the WTC towers. The team was led by Dr. Steven W. Kirkpatrick with major contributions from Dr. Robert T. Bocchieri.

- Dr. David M. Parks, who provided expertise in the area of computational mechanics for the aircraft impact analysis.

In addition, Dr. Shankar Nair of Teng \& Associates provided help with the baseline analysis study, Professor Daniele Veneziano of MIT provided help with the uncertainty analyses, and Professor Kaspar Willam of the University of Colorado provided help with the constitutive modeling for aircraft impact.

The following individuals from the National Institute of Standards and Technology (NIST) made contributions to this report:

- Dr. Emil Simiu provided the wind engineering expertise required for the development of Chapter 3 "Wind Loads on the WTC Towers" of this report, of which he was the primary author. He was also co-author of Appendix B "Estimation of Sectorial Extreme Wind Speeds."

- Dr. Michael A. Riley and Dr. William P. Fritz assisted with preliminary stability analyses of the towers that were reported in the Interim Report of June 2004. In addition, Dr. Fritz participated in the wind study and was the primary author of Appendix B.

- The mechanical and metallurgical analysis of structural steel team (Dr. Frank W. Gayle, Dr. Richard J. Fields, Dr. William E. Luecke, Mr. J. David McColskey, Dr. Tim J. Foecke, Dr. Stephen W. Banovic, and Dr. Thomas A. Siewert) provided the mechanical characteristics of the tower steels that were used in the constitutive models for the aircraft impact simulations. In addition, Dr. Foecke conducted the comparison of the calculated and observed damage to the exterior walls of the towers and provided the images presented in Figures $7-65$ and 7-73. 
- Dr. Therese P. McAllister and Dr. John L. Gross contributed to the interpretation of the impact simulation results and provided the link between the impact analysis and the subsequent fire-structural analyses. They also helped with the review of certain parts of this report.

- Dr. William M. Pitts provided assistance in the identification of videos and photographs relevant to this project, and in the interpretation of the video and photographic data collected by NIST.

- Dr. James Filliben provided guidance in the performance of the uncertainty analyses. He contributed to the methodologies that allowed a large reduction in the total number of analyses required.

NIST acknowledges the parties to an insurance litigation concerning the WTC towers for voluntarily making available to NIST the Cermak Peterka Peterson, Inc. report and the Rowan Williams Davis and Irwin, Inc. (RWDI) reports containing their estimates of wind loads on the towers. NIST also acknowledges Dr. Najib Abboud of Weidlinger and Associates, Inc. and Dr. Peter Irwin of RWDI for their cooperation in providing answers to NIST questions concerning the RWDI reports.

The author also acknowledges Dr. Raymond Daddazio and Mr. David K. Vaughan of Weidlinger and Associates, Inc., and Professor Tomasz Wierzbicki of Massachusetts Institute of Technology for early discussions on aircraft impact analysis. 


\section{EXECUTIVE SUMMARY}

\section{E.1 INTRODUCTION}

The National Institute of Standards and Technology (NIST) investigation into the collapse of the World Trade Center (WTC) towers included eight interdependent projects. The Baseline Structural Performance and Aircraft Impact Damage Analysis project had two primary tasks. These were:

1. To develop reference structural models of the towers and use these models to establish the baseline performance of the two towers under gravity and wind loads.

2 To estimate the damage to the towers due to aircraft impacts and establish the initial conditions for the fire dynamics modeling and thermal-structural response and collapse initiation analysis.

For the first task, the baseline performance of the WTC towers under gravity and wind loads was established in order to assess the towers' ability to withstand those loads safely and to evaluate the reserve capacity of the towers to withstand unanticipated events. The baseline performance study provided a measure of the behavior of the towers under design loading conditions, specifically: (1) total and interstory drift (the sway of the building under design wind loads), (2) floor deflections under gravity loads, (3) the stress demand-to-capacity ratio for primary structural components of the towers such as exterior walls, core columns, and floor framing, (4) performance of exterior walls under wind loading, including distribution of axial stresses and presence of tensile forces, (5) performance of connections between exterior columns, and (6) resistance of the towers to shear sliding and overturning at the foundation level.

This task included the development of reference structural models that captured the intended behavior of the towers under design loading conditions. These reference models were used to establish the baseline performance of the towers and also served as a reference for more detailed models for aircraft impact damage analysis and the thermal-structural response and collapse initiation analysis. The models included: (1) two global models (one for each tower) of the major structural components and systems of the towers, and (2) floor models of a typical truss-framed floor and a typical beam-framed floor. In the towers, tenant floors were typical truss-framed floors, while the mechanical floors (floors 7, 41, 75, and 108 ) and near mechanical floors (floors $9,43,77,107,110$, and roof) of both towers were typical beamframed floors.

For the second task, the aircraft impact damage to the exterior of the WTC towers could be visibly identified from the video and photographic records collected. However, no visible information could be obtained for the extent of damage to the interior of the towers, including the structural system (floors and core columns), partition walls, and interior building contents. Such information was needed for the subsequent fire dynamics simulations and post-impact structural analyses. In addition, for the fire dynamics modeling, the dispersion of the jet fuel and the location of combustible aircraft debris were required. The estimate of the extent of damage to the fireproofing on the structural steel in the towers due to impact was essential for the thermal and structural analyses. The aircraft impact damage analyses were the primary tool by which most of the information about the tower damage could be estimated. 
The focus of this task was to analyze the aircraft impacts into each of the WTC towers to provide the following: (1) estimates of probable damage to structural systems, including exterior walls, floor systems, and interior core columns; (2) estimates of the aircraft fuel dispersion during the impact; and (3) estimates of debris damage to the building nonstructural contents, including partitions and workstations. The analysis results were used to estimate the damage to fireproofing based on the estimated path of the debris field inside the towers. This analysis thus estimated the condition of the two WTC towers immediately following the aircraft impacts and established the initial conditions for the fire dynamics modeling and the thermal-structural response and collapse initiation analysis.

\section{E.2 DEVELOPMENT OF REFERENCE STRUCTURAL MODELS}

The reference structural models were developed to capture the intended behavior of the WTC towers under design loading conditions. The models were used: (1) to establish the baseline performance of the towers under design gravity and wind loads and (2) as a reference for more detailed models used in other phases of the NIST investigation, including aircraft impact analysis and thermal-structural response and collapse initiation analysis. The reference models included the following:

- Two global models of the primary structural components and systems for each of the two towers.

- Two models, one of a typical truss-framed floor (tenant floor) and one of a typical beamframed floor (mechanical level), within the impact and fire regions.

All reference models were linearly elastic and three-dimensional, and were developed using the Computers and Structures, Inc. SAP2000 software. SAP2000 is a commercial finite element software package that is customarily used for the analysis and design of structures. A summary of the size of the global and floor models of the towers is presented in Table E-1.

Table E-1. Approximate size of the reference structural models (rounded).

\begin{tabular}{|l|c|c|c|c|c|}
\hline \multicolumn{1}{|c|}{ Model } & $\begin{array}{c}\text { Number of } \\
\text { Joints }\end{array}$ & $\begin{array}{c}\text { Degrees of } \\
\text { Freedom }\end{array}$ & $\begin{array}{c}\text { Number of } \\
\text { Frame Elements }\end{array}$ & $\begin{array}{c}\text { Number of } \\
\text { Shell Elements }\end{array}$ & $\begin{array}{c}\text { Total Number } \\
\text { of Elements }\end{array}$ \\
\hline WTC 1 global model $^{\mathrm{a}}$ & 53,700 & 218,700 & 73,900 & 10,000 & 83,900 \\
\hline WTC 2 global model $^{\mathrm{a}}$ & 51,200 & 200,000 & 73,700 & 4,800 & 78,500 \\
\hline Typical truss-framed model & 28,100 & 166,000 & 27,700 & 14,800 & 42,500 \\
\hline Typical beam-framed model & 6,500 & 35,700 & 7,500 & 4,600 & 12,100 \\
\hline
\end{tabular}

a. Model does not include floors except for flexible diaphragms at 17 floors as explained later.

The models were developed by Leslie E. Robertson Associates (LERA), the firm responsible for the original structural engineering of the WTC towers, under contract to NIST. The models were reviewed by independent parties to ensure objectivity. The review process included a third-party review by the firm of Skidmore, Owings, and Merrill (SOM), under contract to NIST, and an in-house review by NIST.

For the global models of the towers, the large amount of data required to construct the models dictated that a database of the primary structural components of the towers be developed from the original 
computer printouts of the structural design documents. The various databases, developed in Microsoft Excel format, were linked together using the relational database technique. The relational databases, developed using Microsoft Access, were generated in a format suitable for the development of the global finite element models of the towers.

\section{E.2.1 Global Models of the Towers}

Three-dimensional models of the 110-story above-grade structure and 6-story below-grade structure within the footprint of each of the two towers were developed. The global models for the towers consisted of all primary structural elements in the towers, including exterior walls (exterior columns, spandrel beams, and bracings in the basement floors), core columns, hat trusses, and rigid and flexible diaphragms representing the floor systems.

For the development of the global models, each tower was divided into several sub-models that included:

- Exterior walls, which in turn was divided into

- Exterior wall, foundation to floor 4

- Exterior wall trees (floors 4 to 9)

- Exterior wall, floors 9 to 106

- Exterior wall, floors 107 to 110

- Core columns

- Hat truss

After these sub-models were assembled into a unified model, rigid and flexible diaphragms representing the floor systems, boundary conditions, gravity and wind loads, and masses were added to the unified model. Isometric views of the complete WTC 1 model showing exterior walls, core columns, bracings, hat trusses, and flexible floor diaphragms are shown in Figure E-1.

The global models were developed primarily using prismatic and non-prismatic frame (beam) elements. Shell elements were used only to represent the flexible floor diaphragms. For the development of beam element representations of the exterior wall panels, detailed shell element models of the panels were developed and used to calibrate the behavior of the beam element model under gravity and lateral loads (Figure E-2). Similarly, the detailed floor models were used to calibrate the response of a simplified shell element representation of the floor systems for use as flexible diaphragms in the global models. 



Figure E-1. Rendered isometric views of the WTC 1 global model. 
To validate the global models, the natural periods of WTC 1 calculated from the model were compared with those measured on the tower based on analyzing acceleration records obtained from accelerometers installed atop WTC 1. Table E-2 presents a comparison of the calculated first three natural frequencies and periods against measured frequencies and periods for WTC 1. The measurements were taken during the period from 1978 through 1994 for wind speeds ranging from $11.5 \mathrm{mph}$ to $41 \mathrm{mph}$. The table indicates longer periods measured at larger wind speeds. The natural periods and frequencies predicted in the original design are also presented in the table. The table shows a good agreement between the calculated and measured periods. Thus, Table E-2 indicates that the reference global model provided a reasonable representation of the actual structure.
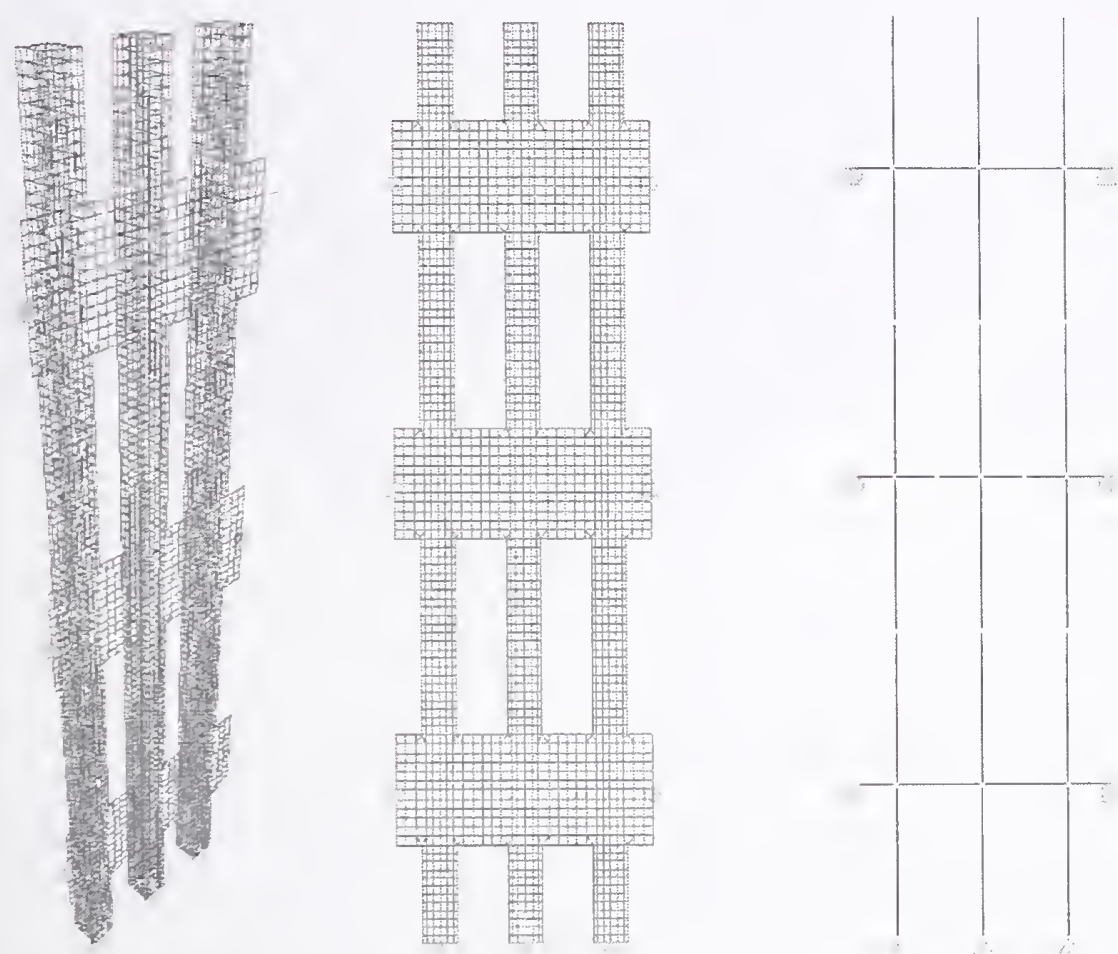

Figure E-2. Shell element and frame element models of an exterior wall panel. 
Table E-2. Comparison of measured and calculated natural periods for WTC 1.

\begin{tabular}{|c|c|c|c|c|c|c|c|}
\hline \multirow{3}{*}{$\begin{array}{l}\text { Data Sourcel } \\
\text { Event Date }\end{array}$} & \multirow{3}{*}{$\begin{array}{l}\text { Wind Speed \& } \\
\text { Direction }\end{array}$} & \multicolumn{3}{|c|}{ Frequency (HZ) } & \multicolumn{3}{|c|}{ Period (s) } \\
\hline & & \multicolumn{3}{|c|}{ Direction of Motion } & \multicolumn{3}{|c|}{ Direction of Motion } \\
\hline & & N-S & E-W & Torsion & N-S & $E-W$ & Torsion \\
\hline \multicolumn{8}{|c|}{ Historical Data } \\
\hline October 11,1978 & $11.5 \mathrm{mph}, \mathrm{E} / \mathrm{SE}$ & 0.098 & 0.105 & 0.211 & 10.2 & 9.5 & 4.7 \\
\hline January 24,1979 & $33 \mathrm{mph}, \mathrm{E} / \mathrm{SE}$ & 0.089 & 0.093 & 0.203 & 11.2 & 10.8 & 4.9 \\
\hline March 21, 1980 & $41 \mathrm{mph}, \mathrm{E} / \mathrm{SE}$ & 0.085 & 0.092 & 0.201 & 11.8 & 10.9 & 5.0 \\
\hline December 11, 1992 & - & 0.087 & 0.092 & - & 11.5 & 10.9 & - \\
\hline February $2,1993^{1}$ & $20 \mathrm{mph}, \mathrm{NW}$ & 0.085 & 0.093 & 0.204 & 11.8 & 10.8 & 4.9 \\
\hline March 13, $1993^{1}$ & $32 \mathrm{mph}, \mathrm{NW}$ & 0.085 & 0.094 & 0.199 & 11.8 & 10.6 & 5.0 \\
\hline March $10,1994^{1}$ & $14 \mathrm{mph}, \mathrm{W}$ & 0.094 & 0.094 & 0.196 & 10.6 & 10.6 & 5.1 \\
\hline December $25,1994^{2}$ & $N$ & 0.081 & 0.091 & - & 12.3 & 11.0 & - \\
\hline \multicolumn{8}{|c|}{ Average of Measured Data } \\
\hline Average & - & 0.088 & 0.094 & 0.202 & 11.4 & 10.6 & 4.9 \\
\hline \multicolumn{8}{|c|}{ Orginal Design - Predicted Values } \\
\hline Theoretical Value & - & 0.084 & 0.096 & - & 11.9 & 10.4 & - \\
\hline \multicolumn{8}{|c|}{ Reference Global Model } \\
\hline $\begin{array}{l}\text { LERA/NIST - WTC } 1 \\
\text { without P-Delta }\end{array}$ & & 0.088 & 0.093 & 0.192 & 11.4 & 10.7 & 5.2 \\
\hline $\begin{array}{c}\text { LERA/NIST - WTC 1 } \\
\text { with P-Delta }\end{array}$ & & 0.083 & 0.088 & 0.189 & 12.1 & 11.3 & 5.3 \\
\hline
\end{tabular}

Notes:

${ }^{1}$ Reported frequency value is the average of the SW corner, NE corner, and center core frequency measurements.

${ }^{2}$ Reported frequency is based on center core data only.

\section{E.2.2 Typical Truss-Framed Floor Model - Floor 96 of WTC 1}

The model of the typical truss-framed floor contained all primary structural members of the floor system, including the primary trusses, bridging trusses, spandrel beams, columns above and below the floor level, concrete slabs, dampers, strap anchors, and beams in the core. The model was developed primarily using frame elements with the exception of the floor slabs, which were modeled using shell elements with typical element sizes of 20 in. An isometric view of the model is shown in Figure E-3. 


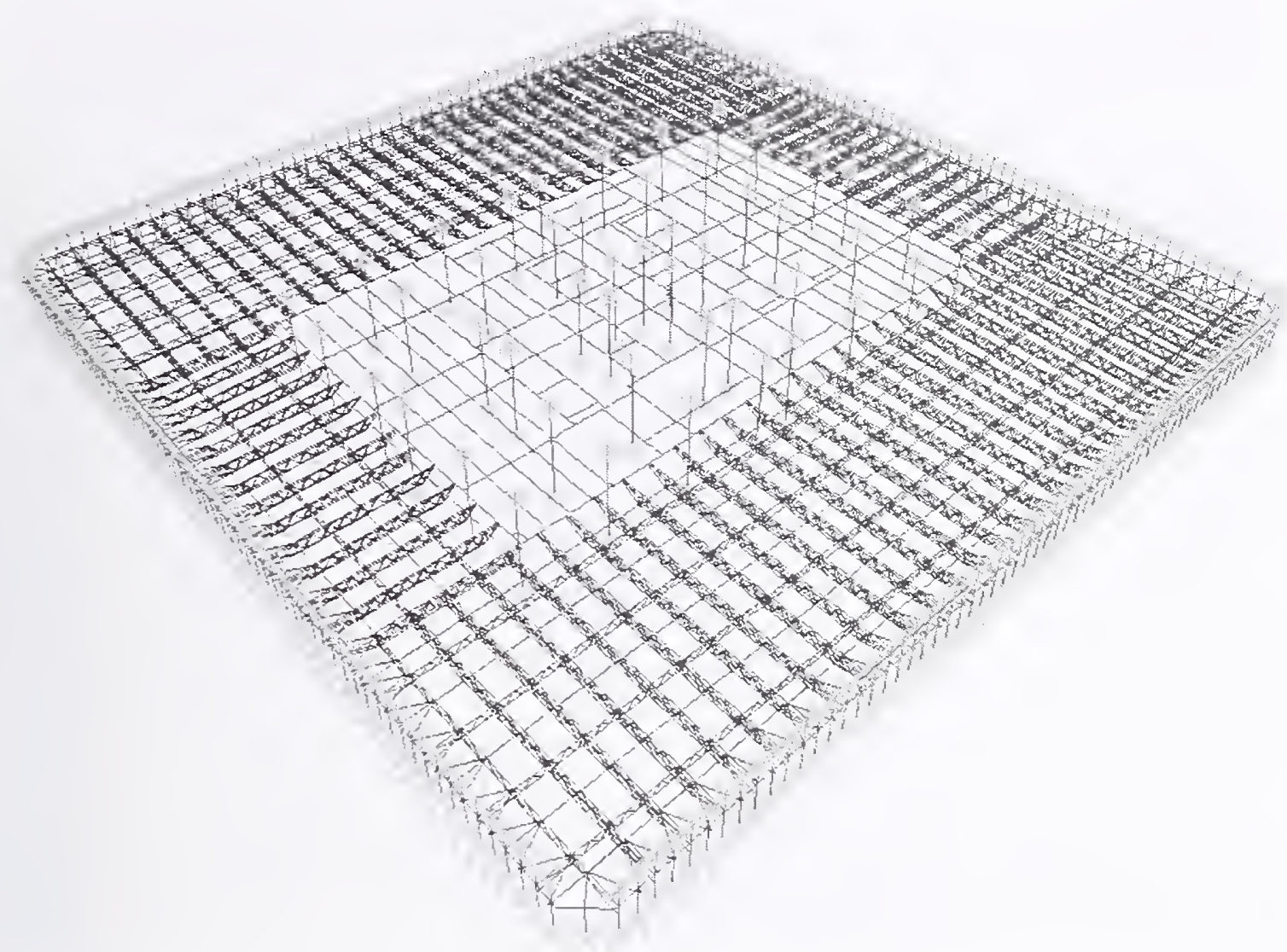

Figure E-3. Typical truss-framed floor model (floor 96 of WTC 1), slab not shown.

\section{E.2.3 Typical Beam-Framed Floor Model - Floor 75 of WTC 2}

The model of the typical beam-framed floor contained all primary structural members of the floor system, including the primary composite beams, horizontal trusses, spandrel beams, columns above and below the floor level, concrete slab, dampers, and beams in the core. Similar to the typical trussed-frame model, this model was developed primarily using frame elements with the exception of the floor slabs, which were modeled using shell elements with typical element sizes of $40 \mathrm{in}$. An isometric view of the modcl is shown in Figure E-4. 


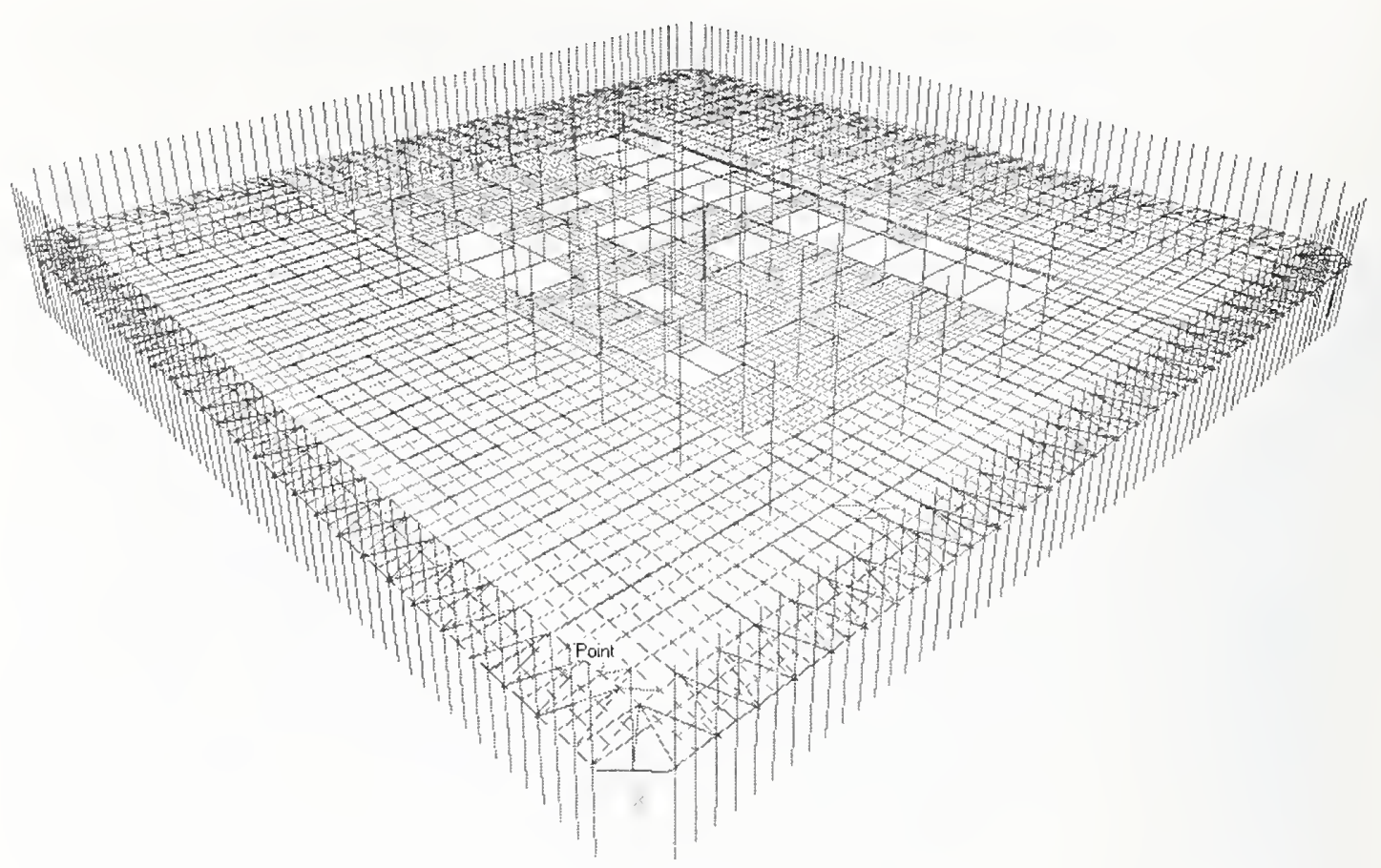

Figure E-4. Typical beam-framed floor model (floor 75 of WTC 2).

\section{E.3 WIND LOADS ON THE WTC TOWERS}

Wind loads were a governing factor in the design of the components of the WTC towers' perimeter frame-tube system. Their study was required for evaluating: (1) the baseline performance of the towers under design loading conditions, (2) the towers' reserve capacity to withstand unanticipated events such as a major fire or impact damage, and (3) design practices, procedures, and codes. Accurate estimation of the wind loads on tall buildings is challenging, since wind engineering is still an evolving technology.

Wind estimates for the WTC towers considered in this study included: (1) wind loads used in the original WTC design, (2) wind loads based on two recent wind tunnel studies conducted in 2002 by Cermak Peterka Peterson, Inc. (CPP) and Rowan Williams Davis and Irwin, Inc. (RWDI), and (3) refined wind loads estimated by NIST by critically assessing information obtained from the CPP and RWDI reports and using state-of-the-art knowledge. These estimates are summarized below.

\section{E.3.1 Original WTC Wind Design Loads}

Wind loads were determined for the original design of the WTC towers through the development and implementation of a boundary-layer wind-tunnel study, which simulated the mean and fluctuating (turbulence) properties of the wind from ground to gradient height by using the knowledge and techniques available in the 1960s. The wind tunnel tests were conducted at Colorado State University (CSU) and the National Physical Laboratory (NPL), United Kingdom. Aeroelastic tests at CSU were conducted at a scale of 1:500, while the aeroelastic models at NPL were conducted with a scale of 1:400. Results from the tests conducted at NPL were in good qualitative and quantitative agreement with those obtained from the CSU tests. Wind tunnel data were collected for each tower for wind approaching from 24 wind 
directions in 15 degree increments. The wind effects were estimated as the summation of static and dynamic components based on results obtained from the wind tunnel tests. The most severe wind effects were determined from diagrams of wind-induced shear forces and overturning moments.

\section{E.3.2 State-of-the-Practice Wind Loads}

For the WTC towers, two wind tunnel tests and wind engineering studies based thereon were conducted in 2002 by independent laboratories as part of insurance litigation unrelated to the NIST investigation. The tests and studies were conducted by CPP and RWDI. The results of both studies were made available to NIST.

The CPP wind tunnel tests modeled the terrain surrounding the WTC towers over an area with a radius of about $2.300 \mathrm{ft}$. The tests used a high-frequency force-balance (HFFB) model and an aeroelastic model of the south tower only. The test scale was 1:400, and testing was conducted for 36 wind directions at 10 degree intervals. The wind-induced loads and responses were determined by combining the wind tunnel test data with recorded directional wind speeds and unspecified hurricane wind speed data. The recorded wind speeds were obtained at the three major airports in the New York area over about 25 years. The directional wind tunnel and wind speed data were combined by using the sector-by-sector approach. Wind effects corresponding to a damping ratio of 2.5 percent were provided for WTC 2 only for nominal 50 year and 720 year mean recurrence intervals. The wind-induced effects were provided as peak shear forces and bending moments for two orthogonal directions and peak torsional moments. The peak components w'ere not applied to the structural model of the tower simultaneously, but were combined by using the full peak load in one direction and "companion point-in-time" loads in the other direction and in torsion.

The RWDI wind tunnel tests modeled the terrain surrounding the WTC towers over an area with a radius of about 4,000 ft. The tests used an HFFB model for both towers and an aeroelastic model for the north tower only. The test scale was 1:500, and testing was conducted for 36 wind directions at 10 degree intervals. Corrections were made to account for the effects on the flow of the presence of the building model (i.e., of wind tunnel blockage). Predictions of the full-scale wind effects and responses were obtained by combining the wind tunnel test data with a statistical model of winds for New York City, based on surface wind measurements taken at three airports between 1948 and 1995 and proprietary simulated hurricane winds. The directional wind tunnel and wind speed data were combined by using an out-crossing approach developed by RWDI. Two sets of wind effects on the towers were developed by scaling the wind loads to the design wind speeds provided in the New York City Building Code (NYCBC) 2001 and the American Society of Civil Engineers (ASCE) 7-98 Standard. The wind effects were provided for a damping ratio of 2.5 percent. The wind-induced effects were provided as peak shear forces and bending moments for two orthogonal directions and pcak torsional moments. These peak components were combined using the "principle of companion loads," entailing combination factors based on engineering judgment and in-house experience.

\section{E.3.3 Refined NIST Estimates of Wind Effects}

NIST completed an independent analysis to estimate the wind loads that would be appropriate for use in designing the towers. The analysis was based on results provided by CPP and RWDI, with refinements that drew on the state of the art in wind engineering. The objective of this analysis was not to assess the 
adequacy of the original design wind loads, but rather to better understand and assess the effects of successive changes in standards, codes, and practices. The analysis yielded refined estimates of wind effects for the north and south WTC towers. These estimates made use of independent extreme wind climatological estimates developed by NIST, based on airport wind speed data obtained from the National Climatic Data Center and on the NIST hurricane wind speed database. The estimates of wind effects relied primarily on RWDI results, since no results for WTC 1 were available from CPP. However, the estimates took into account a comparative assessment of the RWDI and CPP results for WTC 2.

A summary comparison between CPP and RWDI estimates of maximum base moments and shear forces on WTC 2 indicated that the CPP estimates were larger by about 40 percent. The critical base moments from both studies occurred for a wind direction of about 210 degrees. This agreement suggested that a comparison between those results was warranted in some detail for that wind direction. An independent estimate by NIST of the $720 \mathrm{yr}, 3 \mathrm{~s}$ peak gust speed for that direction was $99.8 \mathrm{mph}$, while the CPP estimate was about $117.5 \mathrm{mph}$. The CPP results were therefore multiplied by a factor of approximately $(99.8 / 117.5)^{2}=1 / 1.386$.

In addition, the CPP results were modified to account for the use by CPP of the sector-by-sector approach to integrating aerodynamic data and extreme-wind climatological data. The sector-by-sector approach is not valid from a physical point of view. A study by NIST concluded that the sector-by-sector approach underestimated the wind effects corresponding to a specified mean recurrence interval. According to preliminary estimates, it was assumed that the underestimation was approximately 15 percent. Therefore, the CPP results, modified via multiplication by the factor $1 / 1.386$, were further modified via multiplication by the factor 1.15. The reduction factor applied to the estimated CPP effects was therefore about $1 / 1.205$. To within the limitations inherent in the information available for this investigation, and to within the approximations noted, these reduced values are reasonable estimates of the actual responses of interest.

According to the conclusion concerning the modified CPP results, the RWDI results underestimated the towers' response. This conclusion was consistent with the fact that RWDI assumed wind profiles in hurricanes to be flatter than wind profiles in non-hurricane winds. According to state-of-the-art information on wind profiles at high elevations, hurricane profiles do not differ substantially from nonhurricane wind profiles, and an unconventional model such as the relatively flat hurricane profile model used by RWDI is not supported by measurements in the atmosphere. Based on the assumption that hurricane wind profiles are relatively flat, RWDI used a ratio of approximately 1.1 between tower responses to $88 \mathrm{mph}$ and $80 \mathrm{mph}$ wind speeds. However, in view of the current state of the art, according to which hurricane and non-hurricane profiles are substantially similar, a ratio of about $(88 / 80)^{2}=1.21$ is more appropriate than the ratios of approximately 1.1 used by RWDI.

In addition, the weighting of hurricane wind speeds in proportion to their squares, as used by RWDI in the out-crossing method to integrate aerodynamic and climatological data, did not appear to be warranted. In the standard Peaks-Over-Threshold approach applied to extreme wind speeds, all data above a threshold are affected by the weighting factor 1, while all the data below the threshold are weighted by the factor zero. No justification was provided in the RWDI report for the weighting procedure based on squares of speeds, nor did RWDI list any pertinent reference.

Based on this analysis, the refined NIST estimates, consistent with the design wind speed in the ASCE 7-98 and ASCE 7-02 Standards, were estimated by using the RWDI results multiplied by a factor 
equal to the ratio of the modified CPP estimates to the corresponding RWDI estimates. This factor was found to be about 1.15. The factor 1.15 was recommended for baseline analysis. However, the actual factor could be anywhere between, say; 1.10 and 1.20. It would have been desirable to perform more elaborate calculations providing more comprehensive and precise results than those presented in this document. However, in the absence of sufficiently transparent and detailed information in the CPP and RWDI reports, this was not practicable.

\section{E.3.4 Comparison of Wind Loads}

Table E-3 provides a summary of the wind-induced base shears and base moments for WTC 2, while Table E-4 presents a summary of design base shears and base moments based on the prescriptive provisions in various building codes at the time of the design. The tables indicate the following:

- The original design wind load estimates exceeded in all cases those established by NYCBC (a prescriptive code) prior to 1968, when the WTC towers were designed, and up to and including 2001. The design values were also higher than those required by other prescriptive building codes of the time (the 1964 New York State Code, the 1965 BOCA Basic Building Code, and the 1967 Chicago Municipal Code). However, the prescriptive approach in these codes is oversimplified. These codes are therefore not appropriate for super-tall building design. This was confirmed by the fact that wind effects obtained from three separate windtunnel-based studies were in all cases higher than those based on the prescriptive codes.

- The two orthogonal base shear and base moment components used in the original design were in the majority of cases smaller than the CPP, RWDI, and N1ST estimates. However, the most unfavorable combined peaks from the original design were larger than, or smaller by at most 15 percent than estimates based on the CPP, RWD1, and N1ST estimates. This is due to the conservative procedure used to combine the loads in the original design. (For example, NIST estimates were higher by about 15 percent than the most unfavorable original design wind loads for WTC 1 and lower by about 5 percent than the most unfavorable original design loads for WTC 2.)

- The estimated wind-induced loads on the towers varied by as much as 40 percent between the wind tunnel/climatological studies conducted in 2002 by CPP and RWDI. The primary reasons for these differences appear to lie in the different approaches used in those studies to estimate extreme wind speeds, to estimate wind profiles, to integrate aerodynamic, dynamic, and extreme wind climatological information, and to combine wind effects in two orthogonal directions and in torsion. Such differences highlight the limitations associated with the state of the practice in wind engineering for tall buildings and the need for the development of consensus standards in the field of wind tunnel testing and wind effects estimation. Among the issues that need to be considered are: estimation methods for combining directional wind loads, integrating climatological (wind) and aerodynamic (wind tunnel) data; protocols for conducting the wind tunnel tests; and profiles of hurricane and non-hurricane winds. 
Table E-3. Comparison of wind load estimates for WTC 2 based on various sources.

\begin{tabular}{|c|c|c|c|c|c|c|c|}
\hline \multirow[b]{2}{*}{ Source } & \multirow[b]{2}{*}{ Year } & \multicolumn{3}{|c|}{ Base Shear $10^{3}$ kip } & \multicolumn{3}{|c|}{ Base Moment $10^{6} \mathrm{kip} \cdot \mathrm{ft}$} \\
\hline & & N-S & $E-W$ & $\begin{array}{c}\text { Most } \\
\text { unfavorable } \\
\text { combined } \\
\text { peak }\end{array}$ & $\begin{array}{l}\text { About } \\
\text { N-S }\end{array}$ & $\begin{array}{l}\text { About } \\
\text { E-W }\end{array}$ & $\begin{array}{c}\text { Most } \\
\text { unfavorable } \\
\text { combined } \\
\text { peak }\end{array}$ \\
\hline NYC Building Code & 1938 & 5.3 & 5.3 & & 4.2 & 4.2 & \\
\hline NYC Building Code & $\begin{array}{l}1968 \text { to } \\
\text { date }\end{array}$ & 9.3 & 9.3 & & 7.6 & 7.6 & \\
\hline $\begin{array}{l}\text { RWDI / NYC Building } \\
\text { Code }\end{array}$ & 2002 & 9.7 & 11.1 & 12.3 & 10.1 & 9.2 & 11.3 \\
\hline RWDI / ASCE 7-98 & 2002 & 10.6 & 12.2 & 13.5 & 11.1 & 10.1 & 12.4 \\
\hline $\begin{array}{l}\text { CPP / NYC Building } \\
\text { Code }\end{array}$ & 2002 & None & None & None & None & None & None \\
\hline $\mathrm{CPP} / \mathrm{ASCE} 7-98^{\mathrm{a}}$ & 2002 & 15.1 & 15.3 & 17.1 & 15.5 & 14.0 & 17.0 \\
\hline $\begin{array}{l}\text { NIST / third-party SOM } \\
\text { review }\end{array}$ & 2004 & 12.2 & 14.0 & 15.5 & 12.8 & 11.6 & 14.3 \\
\hline Original WTC Design & $1960 \mathrm{~s}$ & 13.1 & 10.1 & 16.5 & 8.8 & 12.6 & 15.4 \\
\hline
\end{tabular}

a. Using ASCE 7-98 sections 6.5.4.1 and 6.6.

Table E-4. Base shears and base moments due to wind loads based on various building codes.

\begin{tabular}{|l|c|c|c|c|c|}
\hline Building Code & $\begin{array}{c}1938 \\
\text { NYC Code }\end{array}$ & $\begin{array}{c}1968 \text { to date } \\
\text { NYC Code }\end{array}$ & $\begin{array}{c}1964 \\
\text { NY State Code }\end{array}$ & $\begin{array}{c}1965 \\
\text { BOCA/BBC }\end{array}$ & $\begin{array}{c}1967 \\
\text { Chicago } \\
\text { Municipal Code }\end{array}$ \\
\hline $\begin{array}{l}\text { Base Shear } \\
\left(10^{3} \text { kip }\right)\end{array}$ & 5.3 & 9.3 & 9.5 & 9.8 & 8.7 \\
\hline $\begin{array}{l}\text { Base Moment } \\
\left(10^{6} \mathrm{kip} \cdot \mathrm{ft}\right)\end{array}$ & 4.2 & 7.7 & 7.6 & 8.5 & 7.5 \\
\hline
\end{tabular}

\section{E.4 BASELINE PERFORMANCE OF THE WTC TOWERS}

\section{E.4.1 Baseline Performance of the Global Models}

The reference global models were analyzed under gravity and wind loads to establish the baseline performance of the towers. Three loading cases were considered for this analysis. They included:

- Original WTC design loads case. Loads were as follows: dead and live loads as in original WTC design, used in conjunction with original WTC design wind loads (Section E.3.1). 
- State-of-the-practice case. Loads were as follows: dead loads as in original design;

NYCBC 2001 live loads; and wind loads from RWDI wind tunnel study (Section E.3.2), scaled in accordance with NYCBC 2001 wind speed. This wind load was considered to be a lower estimate state-of-the-practice case, as the CPP wind tunnel study produced larger wind loads.

- Refined NIST estimate case. Loads were as follows: dead loads as in original design; live loads from ASCE 7-02; and refined wind loads developed by NIST (Section E.3.3).

The following is a summary of the results.

\section{Total and Inter-Story Drift}

The calculated total drift of both WTC 1 and WTC 2 induced by the three loading cases is presented in Table E-5. The table lists calculated total drift values at the top of the tower, in absolute terms and as a fraction of the building height, $\mathrm{H}$, from the foundation level to the roof (referred to in the table as the drift ratio). According to LERA, limiting total building drift under wind loads was not part of the original WTC design criteria. Instead, inter-story drifts were deterinined and compared to the capability of the architectural building systems, such as the partitions and the exterior cladding, to accommodate these inter-story drifts. Accordingly, there are no historical project-specific data available to which the total drifts may be compared.

Table E-5. Total drift for WTC 1 and WTC 2 under the three loading cases.

\begin{tabular}{|c|c|c|c|c|c|c|c|c|}
\hline \multirow{3}{*}{$\begin{array}{l}\text { Loading } \\
\text { Case }\end{array}$} & \multicolumn{4}{|c|}{ WTC 1} & \multicolumn{4}{|c|}{ WTC 2} \\
\hline & \multicolumn{2}{|c|}{$E-W$} & \multicolumn{2}{|c|}{$\mathrm{N}-\mathrm{S}$} & \multicolumn{2}{|c|}{$E-W$} & \multicolumn{2}{|c|}{$\mathrm{N}-\mathrm{S}$} \\
\hline & $\begin{array}{c}\text { Total } \\
\text { Drift (in.) }\end{array}$ & $\begin{array}{l}\text { Drift } \\
\text { Ratio }\end{array}$ & $\begin{array}{c}\text { Total } \\
\text { Drift (in.) }\end{array}$ & $\begin{array}{l}\text { Drift } \\
\text { Ratio }\end{array}$ & $\begin{array}{c}\text { Total } \\
\text { Drift (in.) }\end{array}$ & $\begin{array}{l}\text { Drift } \\
\text { Ratio }\end{array}$ & $\begin{array}{c}\text { Total } \\
\text { Drift (in.) }\end{array}$ & $\begin{array}{l}\text { Drift } \\
\text { Ratio }\end{array}$ \\
\hline $\begin{array}{l}\text { Original } \\
\text { design case }\end{array}$ & 56.6 & $\mathrm{H} / 304$ & 55.7 & $\mathrm{H} / 309$ & 51.2 & $\mathrm{H} / 335$ & 65.3 & $\mathrm{H} / 263$ \\
\hline SOP case & 56.8 & $H / 303$ & 68.1 & $\mathrm{H} / 253$ & 59.7 & $\mathrm{H} / 287$ & 56.1 & $\mathrm{H} / 306$ \\
\hline $\begin{array}{l}\text { Refined } \\
\text { NiST case }\end{array}$ & 70.6 & $\mathrm{H} / 244$ & 83.9 & $\mathrm{H} / 205$ & 75.6 & $\mathrm{H} / 227$ & 71.0 & $\mathrm{H} / 242$ \\
\hline
\end{tabular}

Under the original WTC design loads, the cumulative drifts at the top of the WTC towers ranged from $\mathrm{H} / 263$ to $\mathrm{H} / 335$. For the lower estimate state-of-the-practice case, those drifts ranged from $\mathrm{H} / 253$ to $\mathrm{H} / 306$. The drifts obtained from the refined NIST estimate case were about 25 percent larger than those from the state-of-the practice case. Under design loading conditions, the maximum inter-story drift was as high as h/230 and h/200 for WTC 1 and WTC 2, respectively, where $h$ is the story height. Maximum inter-story drifts under the state-of-the practice case were about $h / 184$ and $h / 200$ for WTC 1 and WTC 2, respectively. For the refined NIST estimate case, these inter-story drifts were about 25 percent larger than those from the state-of-the practice case. 
Currently no building codes specify a drift limit for wind design. The commentary to Section B.1.2 of the ASCE 7-02 Standard indicates that drift limits in common usage for building design are on the order of $1 / 400$ to $1 / 600$ of the building (for total drift) or story (for inter-story drift) height to minimize damage to cladding and nonstructural walls and partitions. Structural engineers often use in their practice the criterion that total drift ratios should not exceed $\mathrm{H} / 400$ to $\mathrm{H} / 500$ for serviceability considerations and to enhance overall safety and stability (including second order, nonlinear P- $\Delta$ effects). Reducing the drift of the WTC towers to the range of $\mathrm{H} / 400$ to $\mathrm{H} / 500$ would entail enhancing the stiffness and/or damping characteristics of the towers. For inter-story drifts, structural engineers often use in their practice an interstory drift limit in the range of $\mathrm{h} / 300$ to $\mathrm{h} / 400$. This is primarily done for serviceability considerations. Similar to total drift, inter-story drifts of the towers were larger than what is generally used in practice.

\section{Demand/Capacity Ratios (DCRs)}

DCRs were based on the allowable stress design procedure and were estimated using the American Institute of Steel Construction (AISC) Specifications (1989). Figure E-5 shows the distribution of DCRs for the four exterior walls of WTC 1 under the original design load case, while Figure E-6 shows DCRs for the WTC 1 core columns on lines 600 and 900 . The results of the baseline analyses indicated that, for both towers, the DCRs estimated from the original WTC design load case were in general close to those obtained from the lower estimate state-of-the practice case. For both cases, a fraction of structural components had DCRs larger than 1.0. These were mainly observed in both towers at (1) the exterior walls at the columns around the corners, where the hat truss connected to the exterior walls, and below floor 9; and (2) the core columns on the 600 line between floors 80 and 106 and at core perimeter columns 901 and 908 for much of their height.

While it is a normal design practice to achieve a DCR less than unity, the safety of the WTC towers on September 11, 2001, was most likely not affected by the fraction of members for which the demand exceeded capacity due to the following: (1) the inherent factor of safety in the allowable stress design method, (2) the load redistribution capability of ductile steel structures, and (3) on the day of the attack, the towers were subjected to in-service live loads (a fraction of the design live loads) and minimal wind loads.

The DCRs obtained for the refined NIST estimate case were higher than those from the original WTC design and the lower-estimate state-of-the-practice load cases, owing to the following reasons:

(1) the NIST estimated wind loads were higher than those used in the state-of-the-practice case by about 25 percent, and (2) the original WTC design and the state-of-the-practice cases used NYCBC load combinations, which result in lower DCRs than the ASCE 7-02 load combinations used for the refined NIST case. 

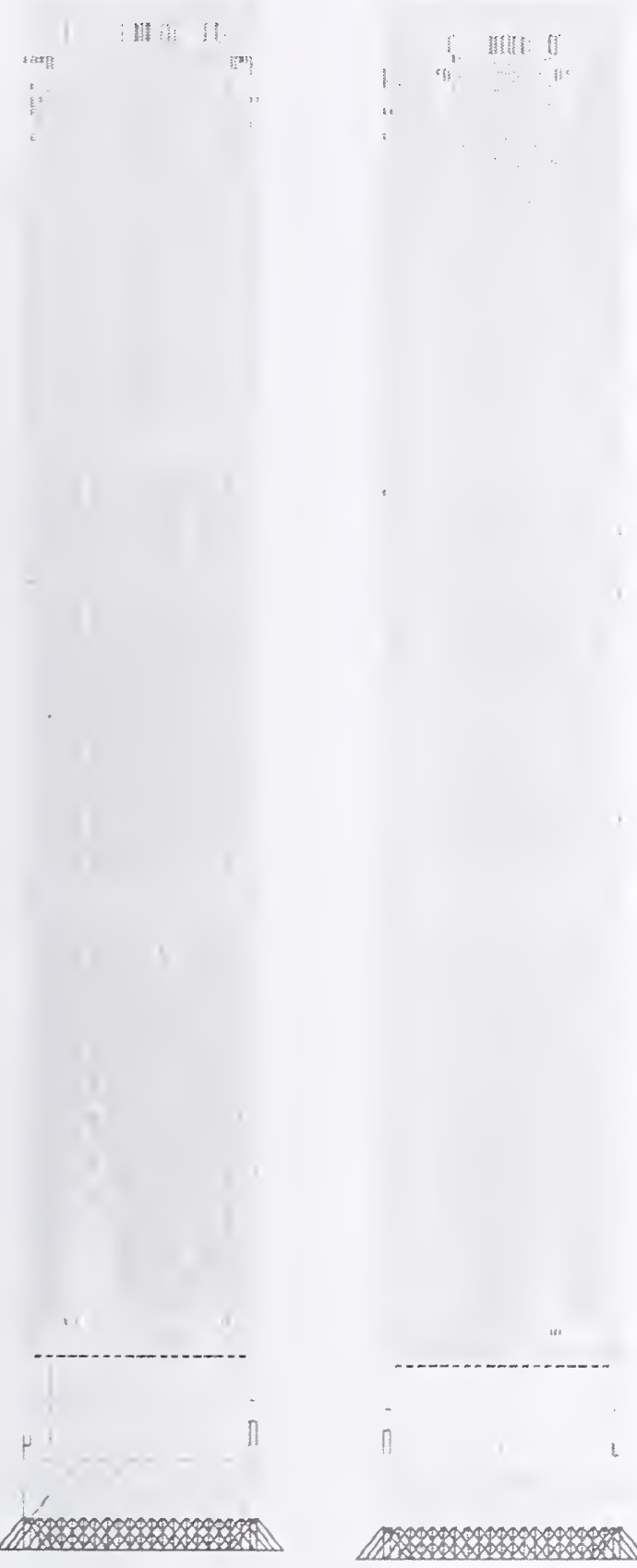

II Mum| /1

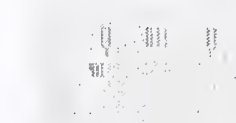

(a)

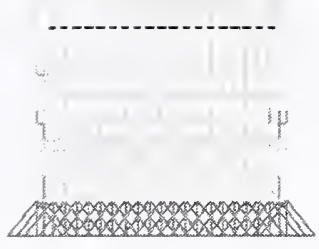

(b)

(c)

(d)

\begin{tabular}{|l|l|l|l|l|l|l|}
\hline & 0.00 & 0.50 & 0.75 & 1.00 & 1.08 & \\
\hline
\end{tabular}

Figure E-5. DCRs for the exterior walls of WTC 1 under original design case, (a) north elevation, (b) east elevation, (c) south elevation, and (d) west elevation. 


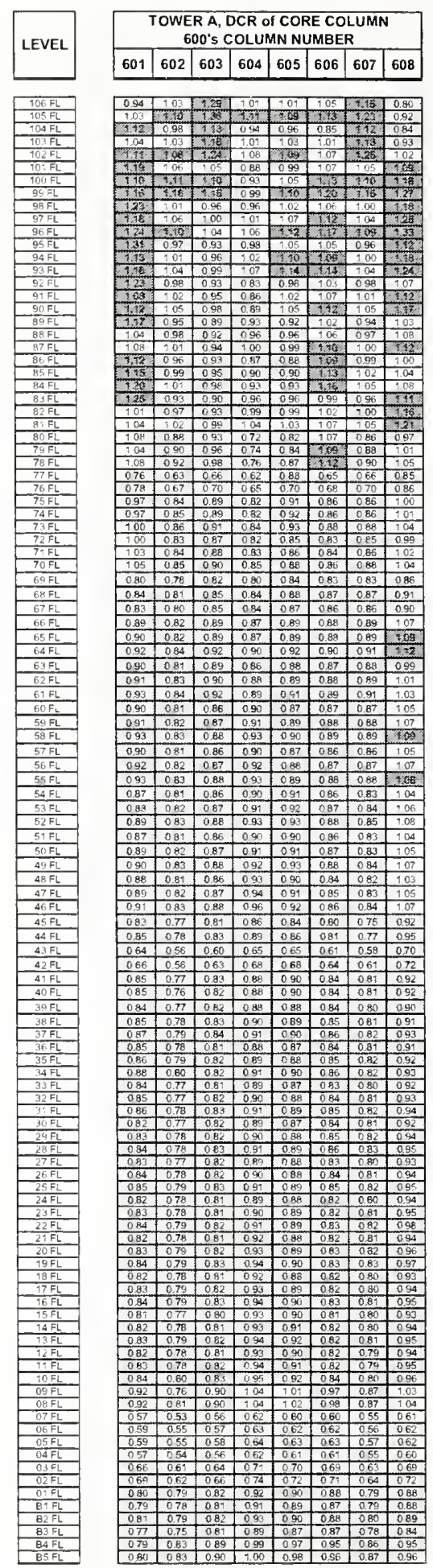

(a)

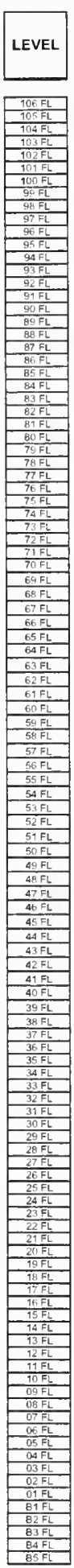

\begin{tabular}{|l|l|l|l|l|l|l|l|}
\hline \multicolumn{5}{|c|}{ TOWER A, DCR Of CORE COLUMMN } \\
\hline 900 's COLUMN NUMBE \\
\hline 901 & 902 & 903 & 904 & 905 & 906 & 907 & 908 \\
\hline
\end{tabular}

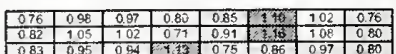

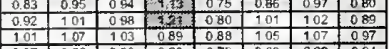

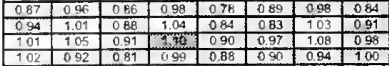

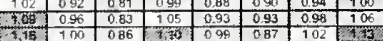

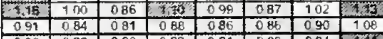

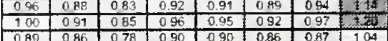

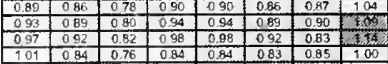

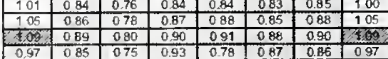

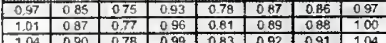

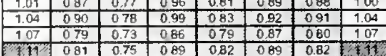

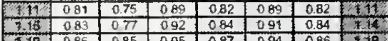

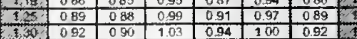

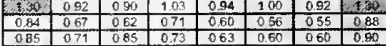

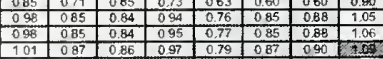

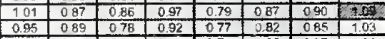

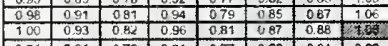

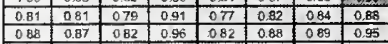

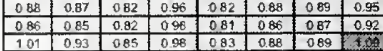

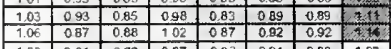
\begin{tabular}{lllllllll}
\hline 1.00 & 0.91 & 0.83 & 0.97 & 0.82 & 0.94 & 0.88 & 107 \\
\hline
\end{tabular}

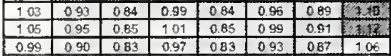

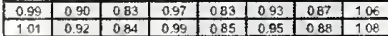

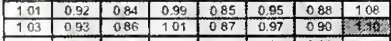
\begin{tabular}{|l|l|l|l|l|l|l|l|}
\hline 106 & 0.88 & 084 & 1.01 & 085 & 093 & 084 & 104 \\
\hline 1.00 & 0.90 & 0.85 & 1.02 & 0.86 & 0.94 & 0.85 & 106 \\
\hline
\end{tabular}

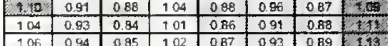

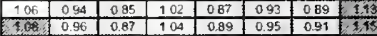

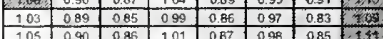

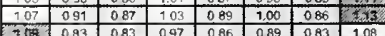

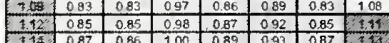
\begin{tabular}{|l|lllllll}
\hline 0.05 & 0.78 & 0.7 & 0.76 & 0.83 & 0.84 & 0.79 & 0.88 \\
\hline 0.03
\end{tabular}

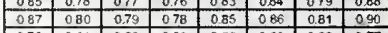

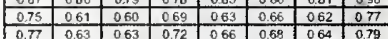

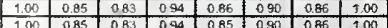

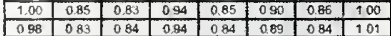

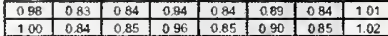

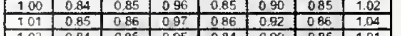

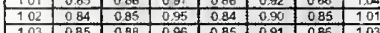

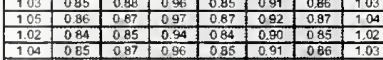

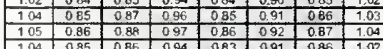

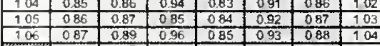

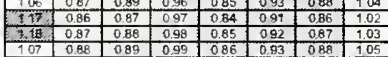

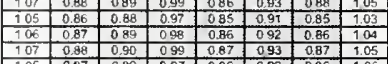

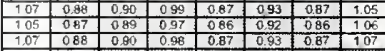

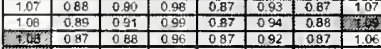

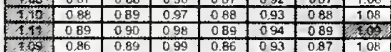

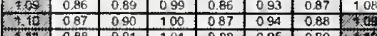

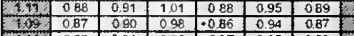

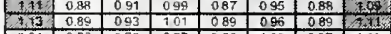

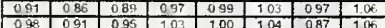

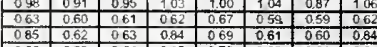

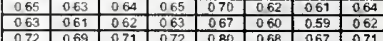

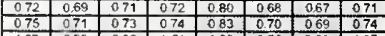

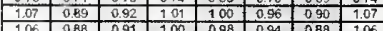

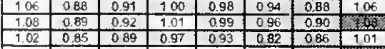

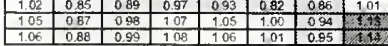
(b)

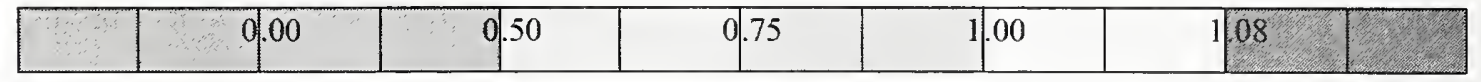

Figure E-6. DCRs for WTC 1 core columns under original design loads, (a) 600 line, and (b) 900 line. 


\section{Exterior Columns Behavior}

Analysis of the axial stress distribution in the columns under lateral wind loads indicated that the behavior of the lower portion of the towers at the basement floors was that of a braced frame, while the behavior of the super-structure was that of a framed tube system. Under a combination of the original WTC design dead and wind loads, tension forces were developed in the exterior walls of both towers. The forces were largest at the base of the building and at the corners. These tensile column loads were transferred from one panel to another through the column splices. The DCRs for the exterior wall splice connections under these tensile forces for both towers were shown to be less than 1.0.

\section{Resistance of the Towers to Shear Sliding and Overturning Moment}

The resistance of the towers to shear sliding and overturning due to wind was provided by the dead loads that acted on the exterior walls of the towers. Considering the resistance to shear sliding under wind load, the factor of safety was calculated to be between 10 and 11.5 , while the factor of safety against overturning ranged from 1.9 to 2.7 for both towers.

\section{E.4.2 Baseline Performance of the Typical Floor Models}

The reference floor models were analyzed under gravity loads to establish their baseline performance. The following presents a summary of the results:

- For the typical truss-framed floor (floor 96 of WTC 1), the DCRs for all floor trusses were less than 1.14 for the original WTC design loads and less than 0.86 for the ASCE 7-02 loading. Under the original WTC design loads, the DCR was less than 1.00 for 99.4 percent of the floor truss components. Inside the core, the DCRs for all floor beams were less than 1.08, and more than 99 percent of the floor beams had a DCR of less than 1.0. The maximum mid-span deflections of the long span and short span zones under the original design loads were approximately 1.79 in. $(\approx \mathrm{L} / 400)$ and 0.57 in. $(\approx \mathrm{L} / 750)$, respectively, where $\mathrm{L}$ is the floor span.

- For the typical beam-framed floor under the original WTC design loads, the DCRs for all floor beams were less than 1.0, except for two core beams where the DCRs in shear were 1.125 and 1.09. The maximum mid-span deflections of the long span and short span zones under the original design loads were approximately $1.55 \mathrm{in} .(\approx \mathrm{L} / 450)$ and 0.70 in. $(\approx \mathrm{L} / 600)$, respectively.

\section{E.5 DEVELOPMENT OF TOWER AND AIRCRAFT IMPACT MODELS}

The WTC tower models for the impact analysis required considerably greater sophistication and detail than was required for the reference models. The reference models provided the basis for the more detailed models required for the impact simulations. The impact models of the towers, which utilized the structural databases described earlier, included the following refinements:

- The material properties used in the impact models accounted for the highly nonlinear behavior of the tower and aircraft materials, including softening and failure of components, and strain rate sensitivity. 
- The impact simulations required a much higher level of detail than that in the reference global models. For instance, the impact analyses necessitated that the floors inside and outside the core in the impact region, as well as connections, be modeled in detail. In addition, structural components in the exterior walls and core of the towers were modeled using shell elements (instead of beam elements in the reference models) to properly capture the impact-induced damage to these components.

- The size of the impact models required a very large mesh (more than ten million degrees of freedom). The SAP2000 program cannot accommodate this model size.

- Contact and erosion algorithms were required for the impact analyses. That necessitated the use of appropriate software, specifically LS-DYNA, for the development of the impact models.

As a result, three separate models were developed for the impact analyses. The first two were detailed models of the impact regions of the WTC 1 and WTC 2 towers. The third was a comprehensive model of the Boeing 767 aircraft. All models were developed using the LS-DYNA finite element code, which is a commercially available nonlinear explicit finite element code for the dynamic analysis of structures. The code has been used for a wide variety of crash, blast, and impact applications.

One of the significant challenges in developing the tower and aircraft models for the global impact analyses was to minimize the model size while keeping sufficient fidelity in the impact zone to capture the deformations and damage distributions. The limitation was that for each analysis the combined aircraft and tower models should not exceed approximately 2.3 million nodes. These were distributed between the global WTC tower model and the aircraft so that the tower model would be about 1.5 million nodes and the aircraft about 0.8 million nodes.

\section{E.5.1 Development of Tower Impact Models}

The approach used to meet this model size limitation was to develop models for the various tower components at different levels of refinement. Components in the path of the impact and debris field were meshed with a higher resolution to capture the local impact damage and failure, while components outside the impact zone were meshed more coarsely to primarily capture their structural stiffness and inertial propcrties. A summary of the size of the global impact models of both towers is presented in Table E-6. As the table indicates, the towers were modeled primarily with shell elements, with the exception of the exterior wall bolted connections (beam and brick elements) and the floor truss diagonals (beam elements). The WTC 1 model extended between floors 92 and 100, while the WTC 2 model extended between floors 77 and 85. 
Table E-6. Summary of the global impact models for the WTC towers.

\begin{tabular}{|l|c|c|}
\hline & WTC 1 Tower Model & WTC 2 Tower Model \\
\hline Number of Nodes & $1,300,537$ & $1,312,092$ \\
\hline Hughes-Liu Beam Elements & 47,952 & 53,488 \\
\hline Belytschko-Tsay Shell Elements & $1,156,947$ & $1,155,815$ \\
\hline Constant Stress Solid Elements & 2,805 & 2,498 \\
\hline
\end{tabular}

The global impact models of the WTC towers included the following components:

- Exterior walls: The exterior columns and spandrels were modeled using shell elements with two mesh densities, a refined density in the immediate impact zone (typical element sizes were 4 in.) and a coarser far field density elsewhere (typical element sizes were $14 \mathrm{in}$.). For the bolted connections between exterior panels in the refined mesh areas, brick elements were used to model the butt plates, and beam elements were used for the bolts. The model of the impact face of WTC 1 is shown in Figure E-7.

- Core columns and floors: Core columns were modeled using shell elements with two mesh densities, a refined density in the direct impact area and a coarser far field density elsewhere. Typical element sizes were 2 in. and 8 in. for the impact zone and far field, respectively. The spliced column connections were included in the model with proper failure criteria. The floors within the core were modeled using shell elements representing the floor slabs and beams. A generated model for the core of WTC 1 between floors 94 and 98 is shown in Figure E-8.

- Truss floors: In the direct impact area, the floor model included shell elements for the combined floor slab and metal decking and for the upper and lower chords of the trusses. Beam elements were used for the truss diagonals. In the far field floor segments, simplified shell element representations were used for the floor slab and trusses, with typical element sizes of $30 \mathrm{in}$. A model assembled for the entire 96th floor of WTC 1 is shown in Figure E-9.

- Interior building contents: The interior nonstructural contents of the towers were modeled explicitly. These included the partitions and workstations, which were modeled with shell elements in the path of the aircraft debris. The live load mass was distributed between the partitions and cubicle workstations. The resulting model of a floor with interior contents is shown in Figure E-10.

Figure E-11 show's the assembled global impact model of WTC 1. 


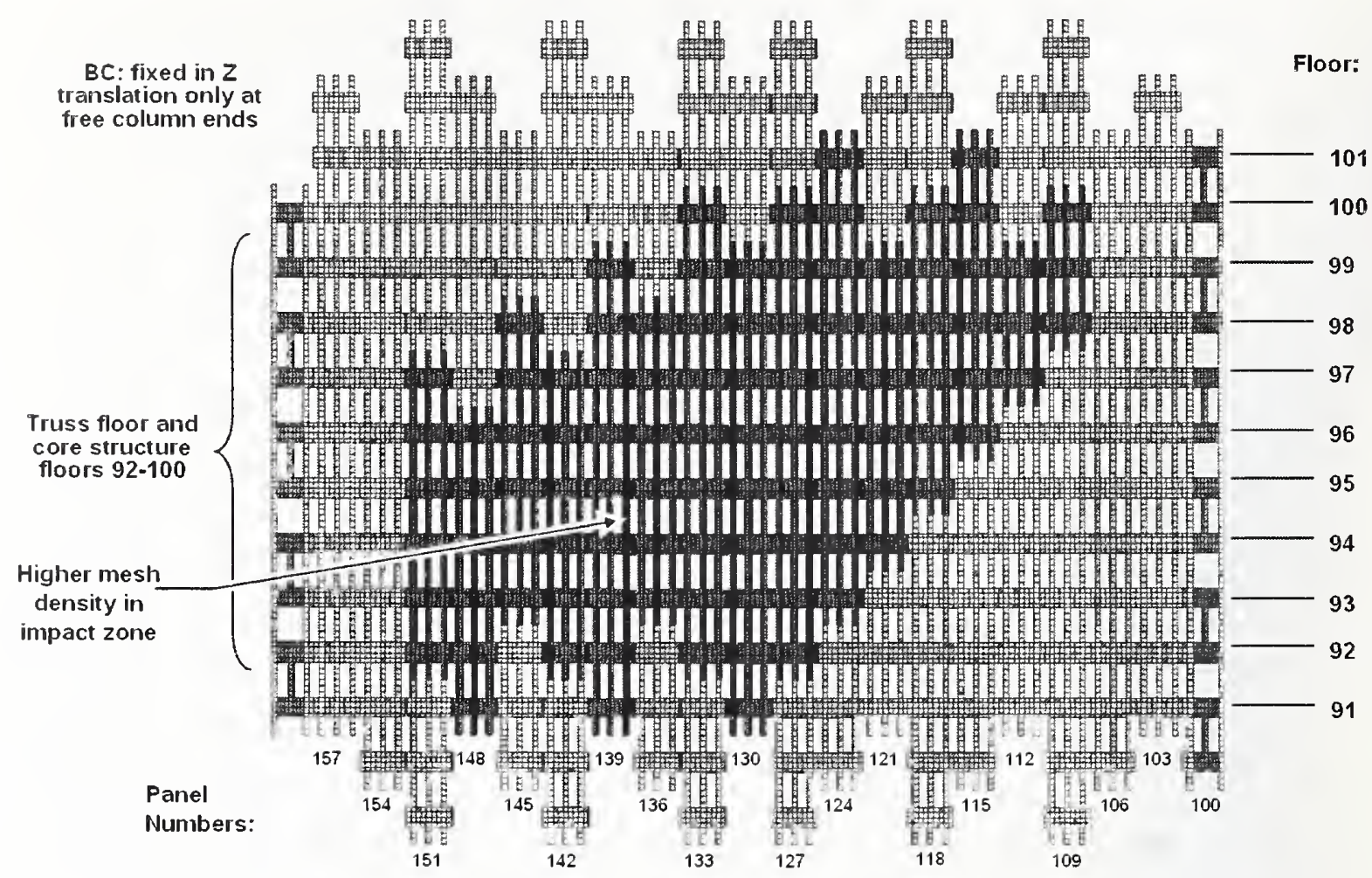

Figure E-7. Impact face of the WTC 1 model, floors 91-101.

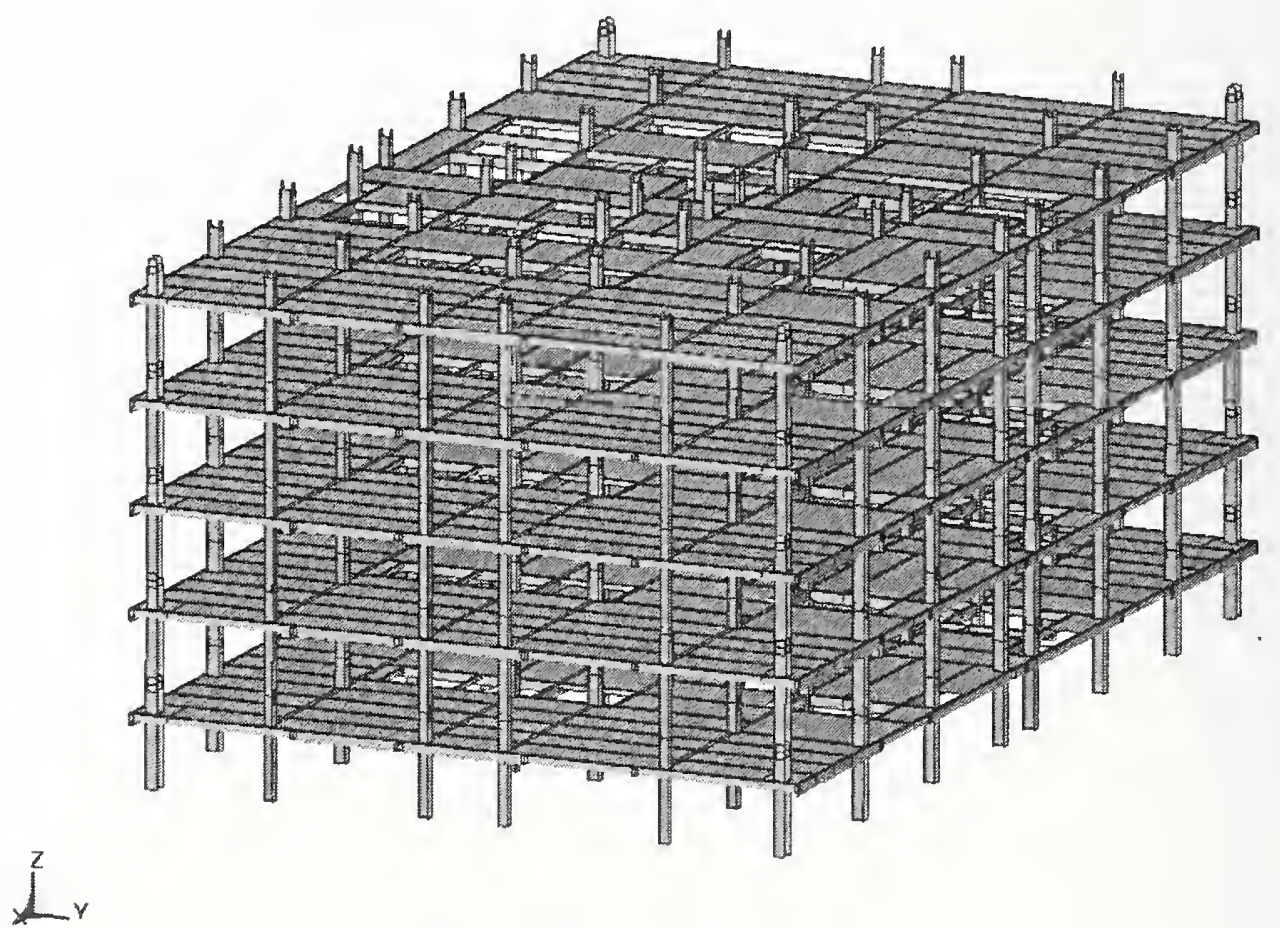

Figure E-8. Model of the WTC 1 core, floors 94-98. 


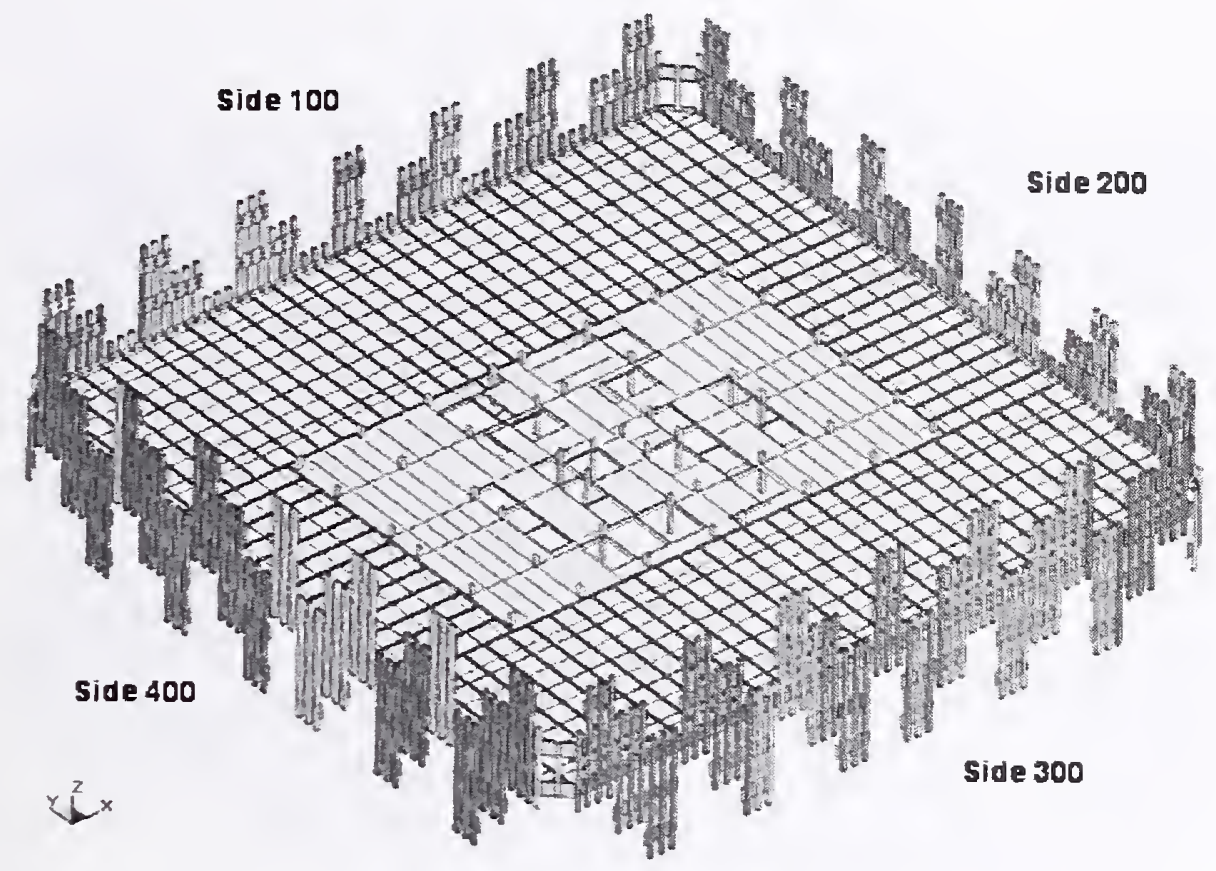

Figure E-9. Model of the 96th floor of WTC 1.

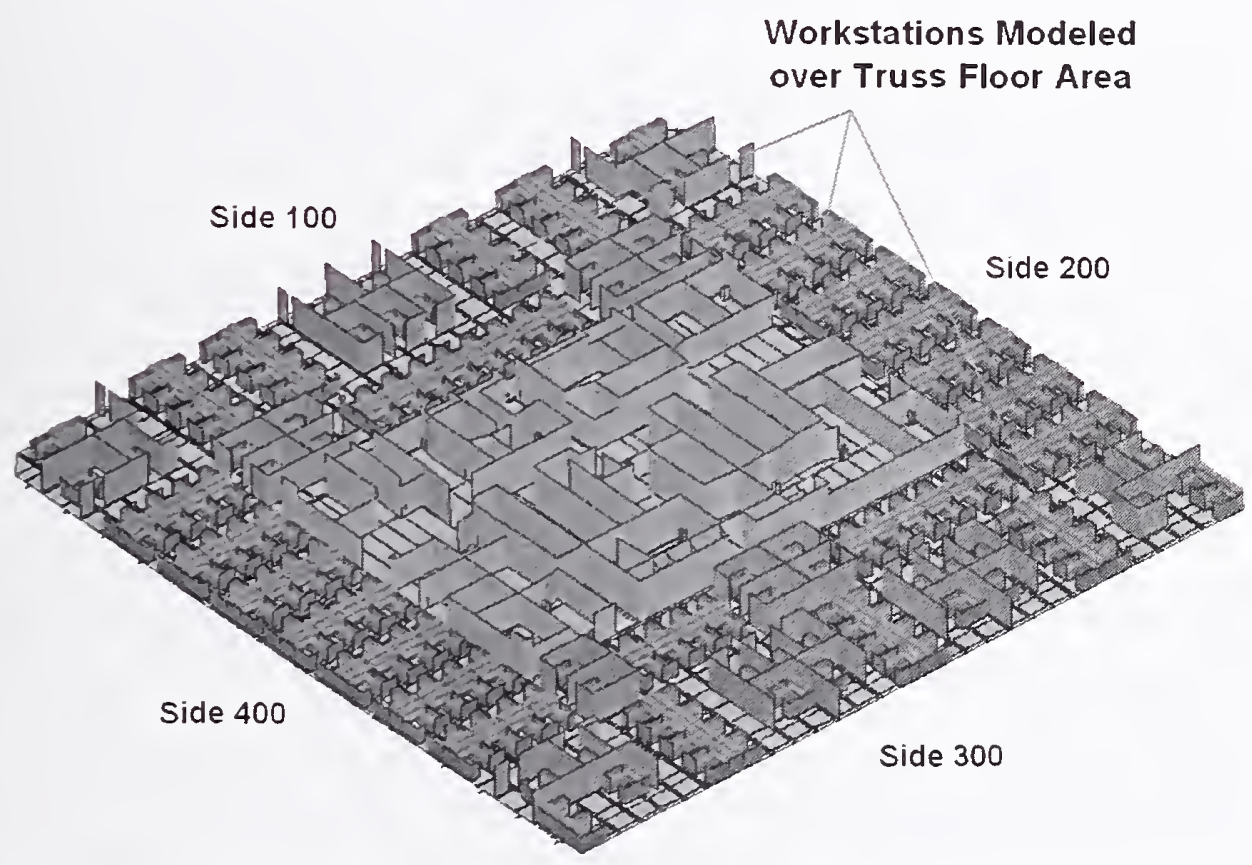

Figure E-10. Model of the 96th floor of WTC 1 including interior contents. 




Figure E-11. Multi-floor global impact model of the WTC 1 tower.

\section{Tower Material Constitutive Models}

The materials that were considered for the tower modeling included: (1) the several grades of steel used in the columns, spandrels, and floor trusses and beams of the WTC towers, (2) the concrete floor slabs, and (3) the nonstructural contents of the towers. These materials exhibit significant nonlinear rate-dependent deformation and failure behavior that need to be represented in the constitutive relationship. The following is a brief summary of the constitutive models used for these materials.

WTC Tower Steel Constitutive Models - The primary constitutive model that was used for the tower steels was the Piecewise Linear Plasticity model in LS-DYNA. This model is sufficient to model the nonlinear rate-dependent deformation and failure of the steel structures. A tabular effective stress versus effective strain curve was used in this model with various definitions of strain rate dependency. The constitutive model parameters for each grade of steel were based on engineering stress-strain data developed by the mechanical and metallurgical analysis of structural steels part of the NIST Investigation. Finite element analyses of the test specimens were conducted with a fine and a medium mesh (similar to that used in the component level analysis) to capture the nonlinear material behavior up to failure (Figure E-12). The finite element analysis provided a validation that the constitutive model parameters were defined accurately and that the model could reproduce the measured response for the test conditions. 


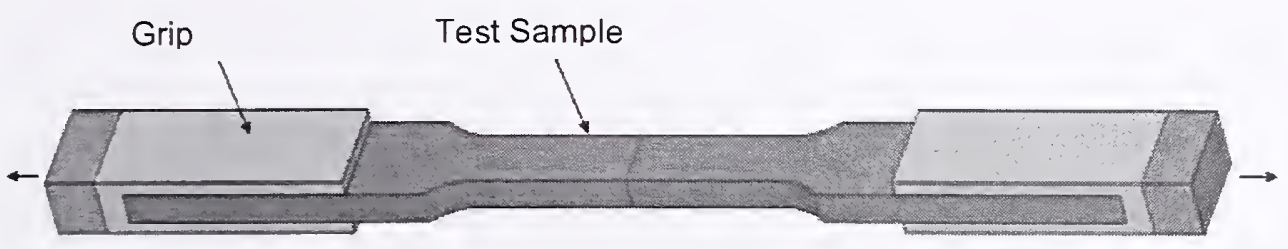

Fine Mesh

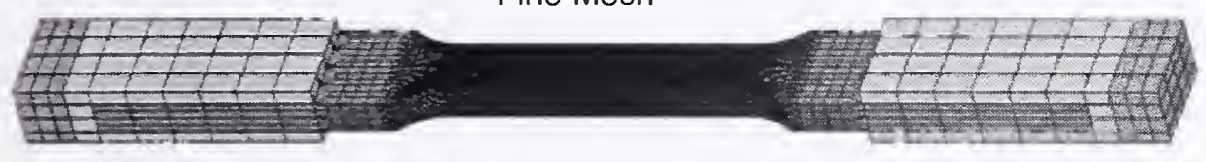

Medium Mesh

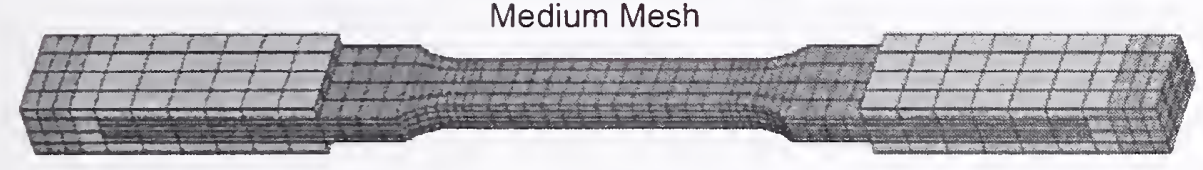

Figure E-12. Finite element models of the ASTM 370 rectangular tensile specimen.

The first step in the constitutive model development process was to obtain a true stress-true strain curve. The typical approach was to select a representative test for each grade of steel and convert the engineering stress-strain curve to true stress-strain. The true stress-strain curve was extrapolated beyond the point of necking onset. This curve was the input used to specify the mechanical behavior in the simulation of the tensile test (Figure E-12). If necessary, the extrapolation of the true stress-strain behavior was adjusted until the simulation matched the measured engineering stress-strain response, including necking and failure. A summary of the true stress-strain curves used in the constitutive models for the various WTC tower steels are summarized in Figure E-13. 


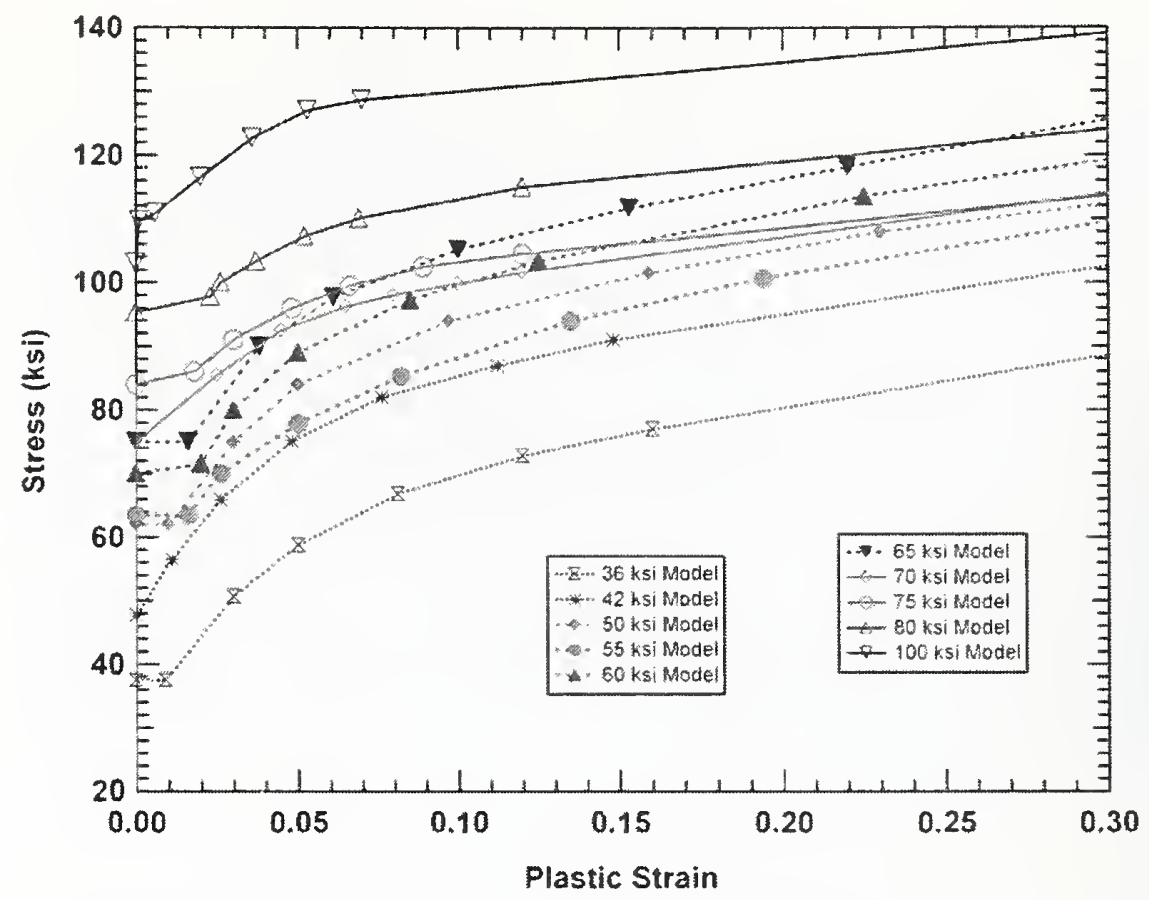

Figure E-13. Tabular true stress-strain constitutive model curves for the tower steels.

Strain-rate effects on the steel yield strength were included in the constitutive model for tower steels with the Cowper and Symonds rate effect model. The resulting rate effects used in the constitutive modeling of tower steels based on this model were compared to the measured high rate test data for the $50 \mathrm{ksi}$, $75 \mathrm{ksi}$, and $100 \mathrm{ksi}$ tower steels in Figure E-14. The comparison showed that the Cowper and Symonds model was capable of reproducing the rate effects for the range of data available.

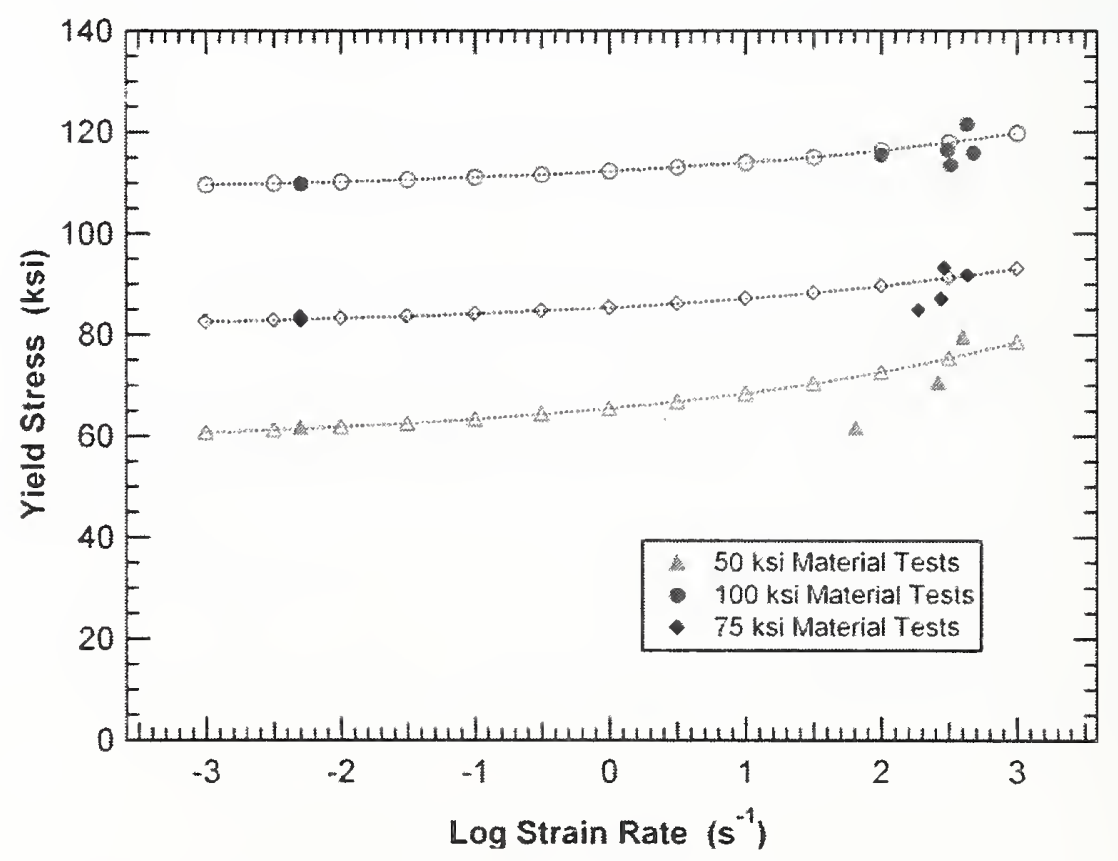

Figure E-14. Comparison of rate effects model and test data. 
Concrete Constitutive Models-The LS-DYNA material Type 16 (pseudo-tensor concrete model) was selected for modeling the concrete floor slabs due to its ability to accurately model the damage and softening of concrete, associated with low confinement. The model uses two pressure-dependent yield functions and a damage-dependent function to migrate between curves. This allows for implementation of tensile failure and damage scaling, which are more dominant material behaviors at low confinement. The pseudo-tensor model also accounts for the sensitivity of concrete to high strain rates. Material constitutive parameters for the pseudo-tensor model were developed. A simulation was performed of a standard unconfined concrete compression test to check the constitutive model behavior. The calculated compressive stress-strain response for the $3 \mathrm{ksi}$ concrete was compared to measured compression data for $2.3 \mathrm{ksi}$ and $3.8 \mathrm{ksi}$ strength concretes in Figure E-15.

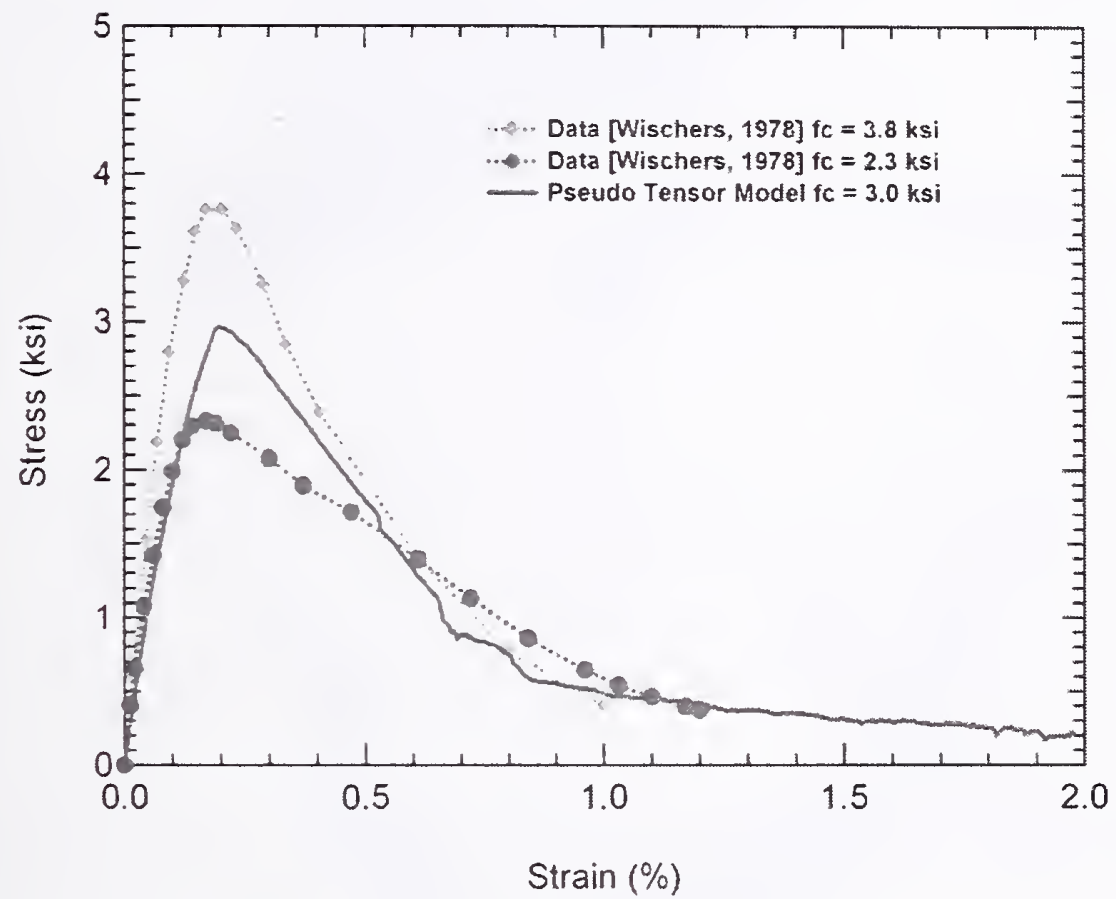

\section{Figure E-15. Comparison of the calculated unconfined compression behavior with concrete compression test data.}

Nonstructural Materials Constitutive Models-The primary influence of the nonstructural components on the impact behavior was their inertial contribution. The effects of their strength were small. As a result, relatively simple approximations of their constitutive behavior were used. Typically, a bilinear elastic-plastic constitutive model was applied for these materials to allow for efficient modeling of deformation and subsequent erosion from the calculations as their distortions became large. The ability to include material failure and erosion of these soft materials was important for the stability of the impact analyses.

\section{E.5.2 Development of Aircraft Impact Model}

The finite element model for the Boeing 767-200ER aircraft was constructed through a three-step process: (1) data collection, (2) data interpretation and engineering analysis, and (3) meshing of the structure. The 
focus of this effort was on gathering sufficient structural data and including adequate detail in the aircraft model so that the mass and strength distribution of the aircraft and contents were properly captured for implementation in the impact analyses. Structural data were collected for the Boeing 767-200ER aircraft from (1) documentary aircraft structural information, and (2) data from measurements on Boeing 767 aircraft.

A summary of the aircraft model size and parameters is presented in Table E-7. The complete model of the Boeing 767-200ER is shown in Figure E-16. The airframe model contained most of the significant structural components in the aircraft. The models of the fuselage, empennage, and wing structures were developed completely using shell elements. Models for the landing gear and engines were developed primarily using shell elements, but contained some brick elements as well. The typical element dimensions were between one and two in. for small components, such as spar or rib flanges, and three to four in. for large parts, such as the wing or fuselage skin.

Table E-7. Boeing 767-200ER aircraft model parameters.

\begin{tabular}{|c|c|c|}
\hline & American Airlines 11 & United Airlines 175 \\
\hline No. Brick Elements & 70,000 & 70,000 \\
\hline No. Shell Elements & 562,000 & 562,000 \\
\hline No. SPH Fuel Particles & 60,672 & 60,672 \\
\hline Total Nodes & 740,000 & 740,000 \\
\hline Total Weight (Empty) & $183,500 \mathrm{lb}$ & $183,500 \mathrm{lb}$ \\
\hline ULD/Cargo Weight & $12,420 \mathrm{lb}$ & $21,660 \mathrm{lb}$ \\
\hline Cabin Contents Weight & $21,580 \mathrm{lb}$ & $10,420 \mathrm{lb}$ \\
\hline Fuel Weight & $66,100 \mathrm{lb}$ & $62,000 \mathrm{lb}$ \\
\hline Total Weight (Loaded) & $\mathbf{2 8 3 , 6 0 0 ~ l b}$ & $\mathbf{2 7 7 , 5 8 0 ~ l b}$ \\
\hline
\end{tabular}

Special emphasis was placed on modeling the aircraft engines due to their potential to produce significant damage to the tower components. The engine model was developed primarily with shell elements. The objective was to develop a mesh with typical element dimensions between one and $2 \mathrm{in}$. However, smaller element dimensions were required at many locations to capture details of the engine geometry. Brick elements were used for some of the thicker hubs and the roots of the compressor blades. The various components of the resulting engine model are shown in Figure E-17. Fuel was distributed in the wing, as shown in Figure E-18, based on a detailed analysis of the likely fuel distribution at the time of impact. 


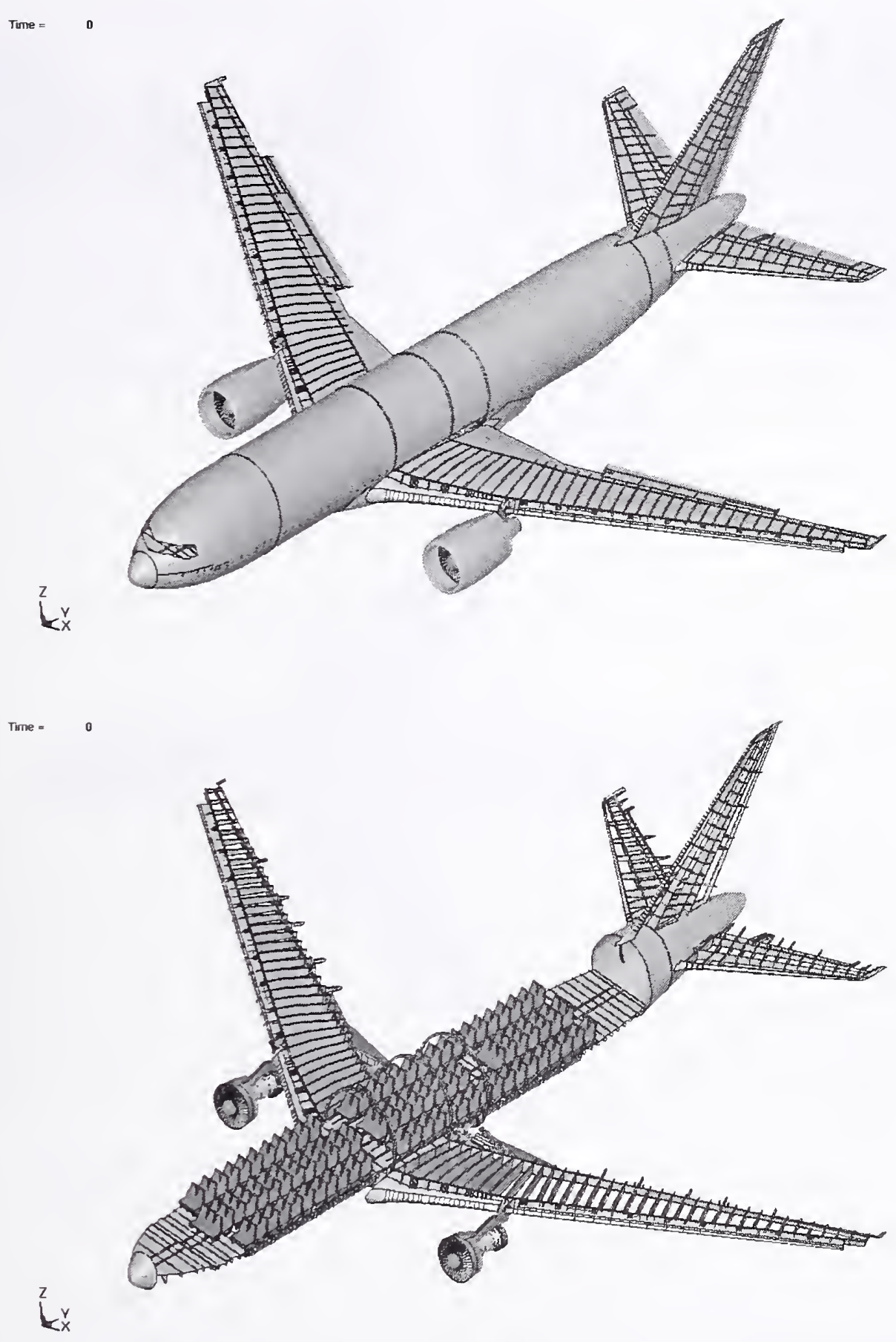

Figure E-16. Finite element model of the Boeing 767-200ER. 

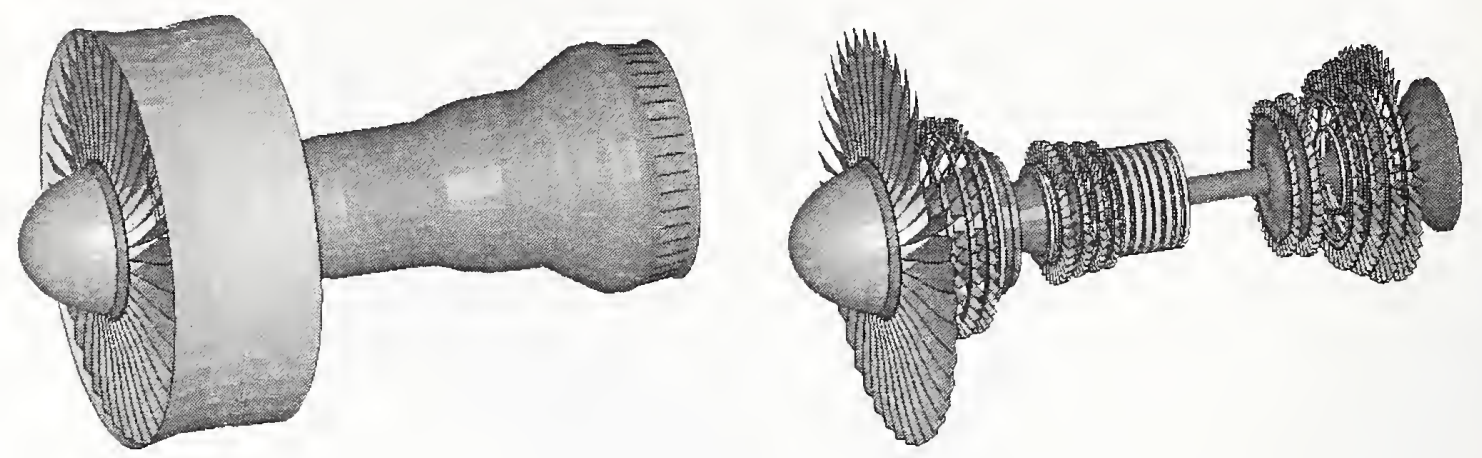

Figure E-17. Pratt \& Whitney PW4000 turbofan engine model.

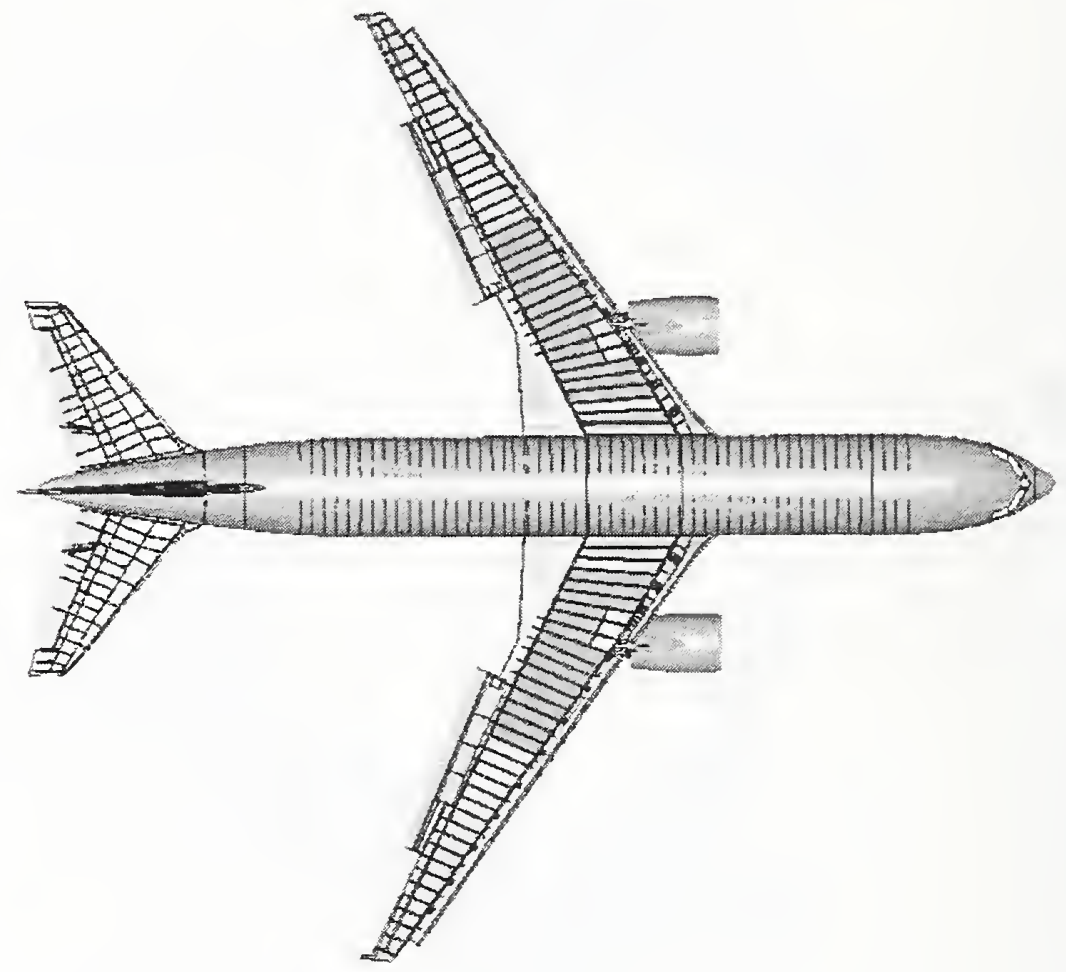

Figure E-18. Boeing 767-200ER with fuel load at time of impact.

\section{Aircraft Materials Constitutive Models}

The constitutive and failure properties for the aircraft materials were developed from data available in the open literature. Complete engineering stress-strain curves were obtained for various 2024 and 7075 aluminum alloys that are commonly used in the construction of the Boeing 767 airframe structures. These curves were digitized for the various aluminum alloys. Representative stress-strain curves were then converted into true stress and true strain and used to develop tabular curves for constitutive models. The tabular constitutive model fits are shown in Figure E-19. No rate sensitivity of the aircraft materials was considered. 


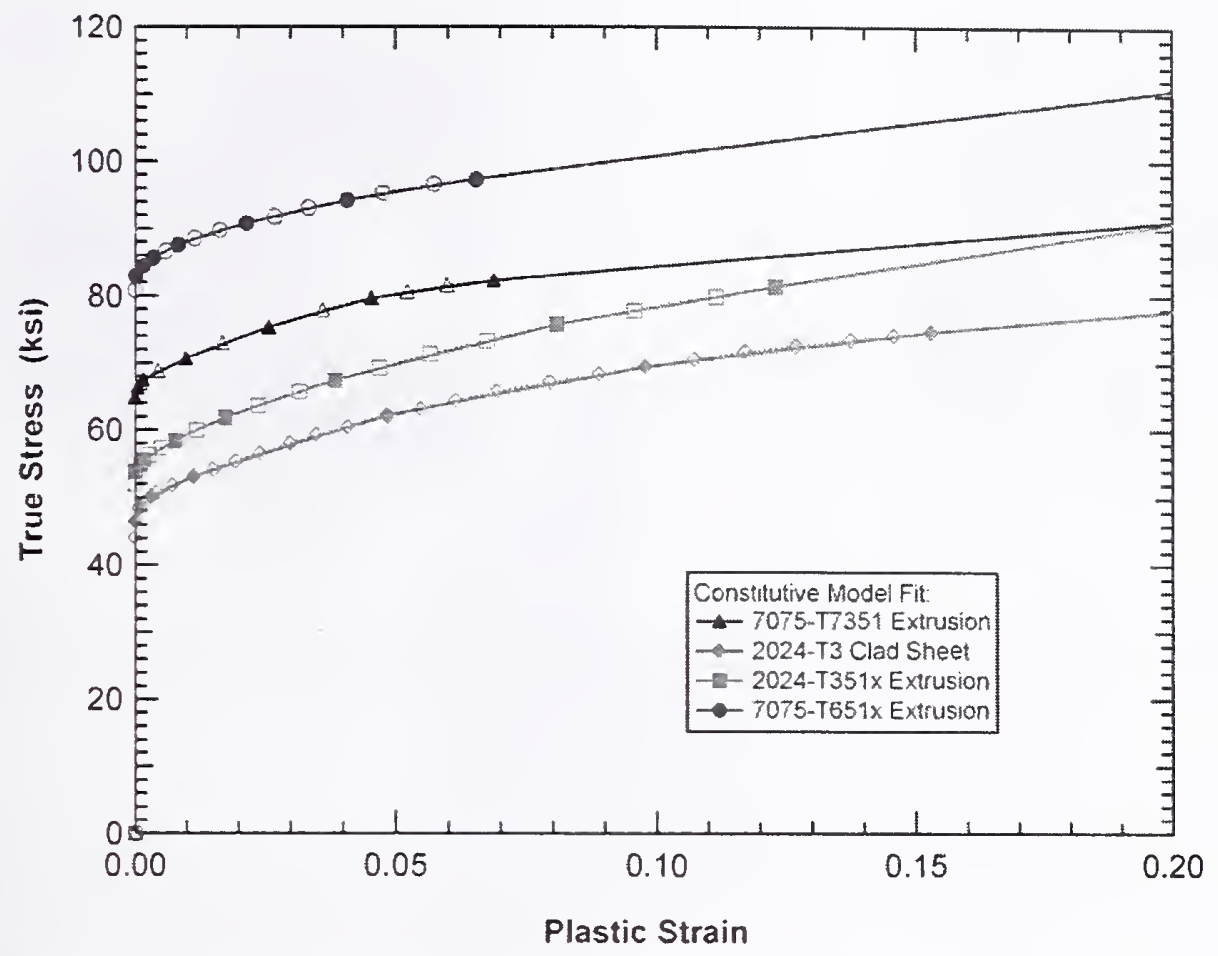

Figure E-19. True stress-strain curves developed for various aircraft aluminum alloys.

\section{E.5.3 Component and Subassembly level analyses}

A large array of component and subassembly models were developed and used in the impact simulations. The primary objectives of the component modeling were to (1) develop understanding of the interactive failure phenomenon of the aircraft and tower components, and (2) develop the simulation techniques required for the global analysis of the aircraft impacts into the WTC towers. The approach taken for component modeling was to start with finely meshed, brick and shell element models of key components of the tower structure and progress to relatively coarsely meshed beam and shell element representations that were used for the global models. Other key technical areas were addressed in the componcnt modeling, including material constitutive modeling, treatment of connections, and modeling of aircraft fuel.

Examples of the component impact analyses conducted include:

- Impact of a segment of an aircraft wing with an exterior column.

- Detailed and simplified modeling of exterior panel bolted connection undcr impact loading.

- Impact of a simplified plow type impactor with truss floor assembly.

- Impact of fuel-filled wing segment with exterior wall panels (Figure E-20). 

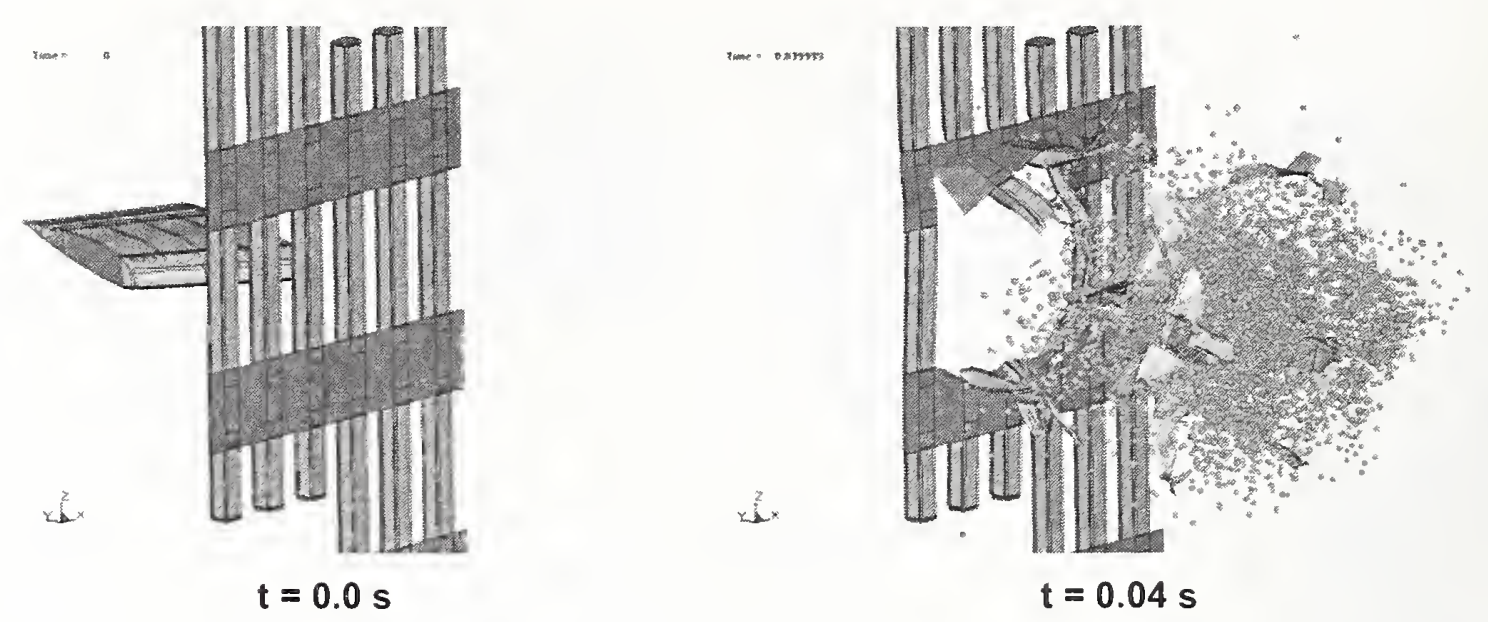

Figure E-20. Calculated impact of a coarse mesh wing section laden with fuel modeled using SPH particles.

The following results were obtained from the component impact analyses:

- A 500 mph engine impact against an exterior wall panel resulted in a penetration of the exterior wall and failure of impacted exterior columns. If the engine did not impact a floor slab, the majority of the engine core would remain intact through the exterior wall penetration, with a reduction in speed between 10 percent and 20 percent. The residual velocity and mass of the engine after penetration of the exterior wall was sufficient to fail a core column in a direct impact condition. Interaction with additional interior building contents prior to impact or a misaligned impact against the core column could change this result.

- A normal impact of the exterior wall by an empty wing segment from approximately midspan of the wing produced significant damage to the exterior columns but not complete failure. Impact of the same wing section, but filled with fuel, resulted in extensive damage to the external panels of the tower, including complete failure of the exterior columns. The resulting debris propagating into the building maintained the majority of its initial momentum prior to impact.

- Three different numerical techniques were investigated for modeling impact effects and dispersion of fuel: (1) standard Lagrangian finite element analysis with erosion, (2) Smoothed Particle Hydrodynamics (SPH) analysis, and (3) Arbitrary-Lagrangian-Eulerian analysis. Of these approaches, use of the SPH offered the best viable option due to its computational efficiency.

The subassembly analyses were used as a transition between the component level analyses and the global impact analyses. With the subassembly analyses, more complex structural behavior not captured in the component analyses could be investigated with significantly shorter run times than required for the global analyses. The subassembly analyses were primarily used to investigate different modeling techniques and associated model size, run times, numerical stability, and impact response. The subassembly model used structural components from the impact zone on the north face of WTC 1. The structural components in 
the subassembly model included the exterior panels, core framing, truss floor structures, and interior contents (workstations), Figure E-21.

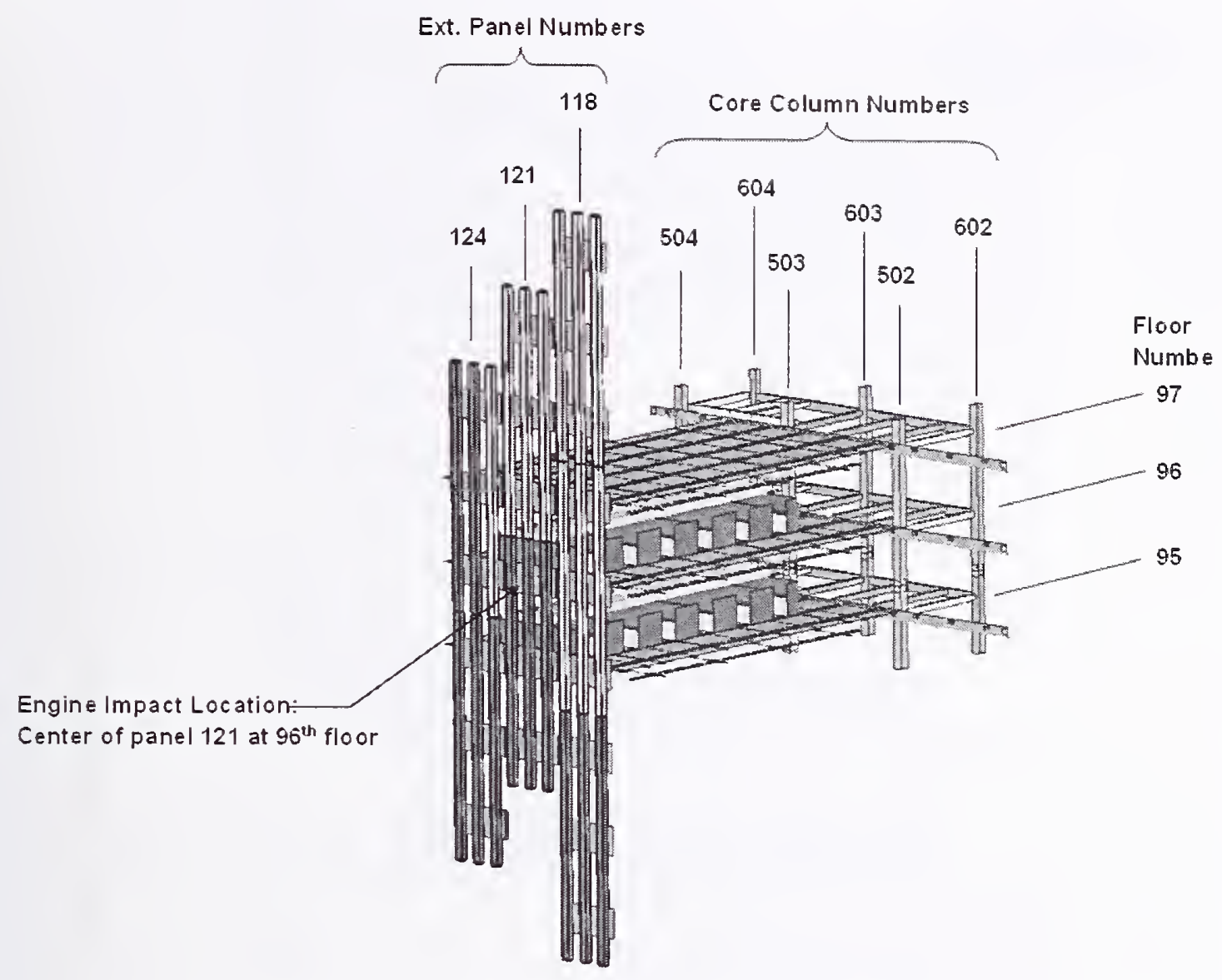

Figure E-21. Final WTC tower subassembly model.

The subassembly model was impacted by an aircraft engine and by a segment of a fuel-filled wing. The response of the structure to the engine impact is shown in Figure E-22. The following results were obtained from the subassembly impact analyses:

- The deceleration profile of the impacting engine indicated that the response of the nonstructural building contents was dominated by the mass of the workstations, rather than by their strength.

- Varying the strength of the floor concrete slab from $3 \mathrm{ksi}$ to $4 \mathrm{ksi}$ did not result in significant change in the impact response. It appears that the mass of the concrete slab had a greater effect on the engine deceleration and damage to the floor than did the concrete strength.

- Varying the ductility of the weld zone in the exterior columns from 8 percent to 1 percent did not result in any noticeable difference in the damage pattern or the energy absorbed by the exterior panels, indicating that the weld ductility had a negligible effect on the impact response. 


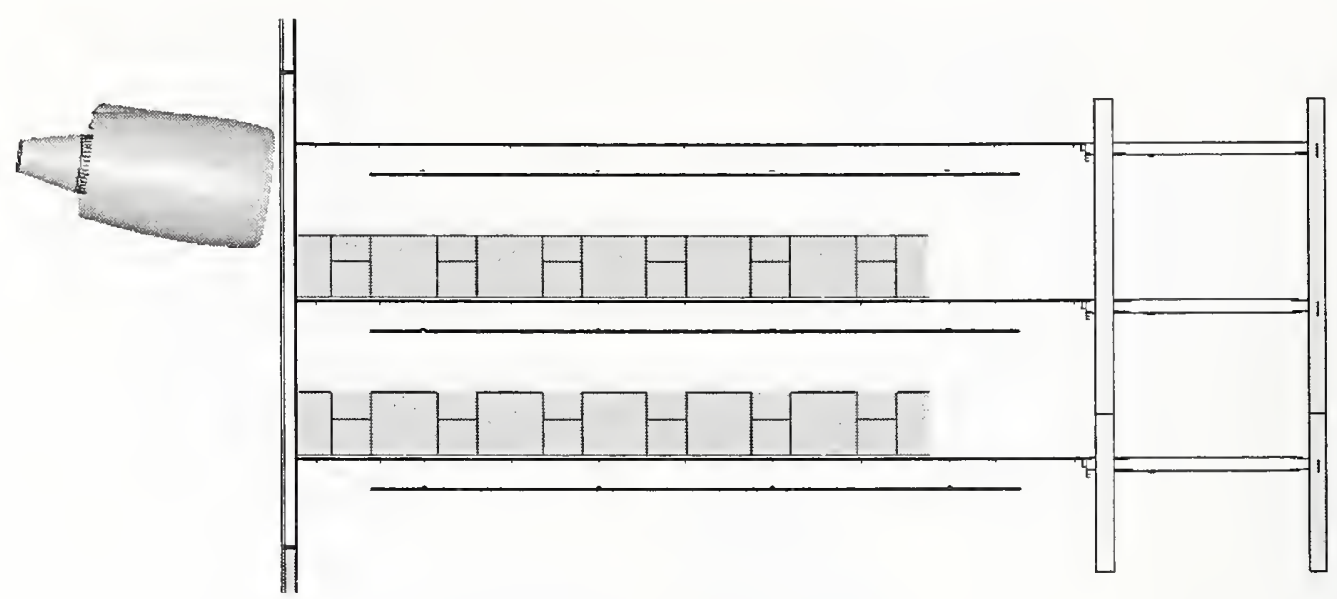

(a) $\operatorname{Time}=0.00 \mathrm{~s}$

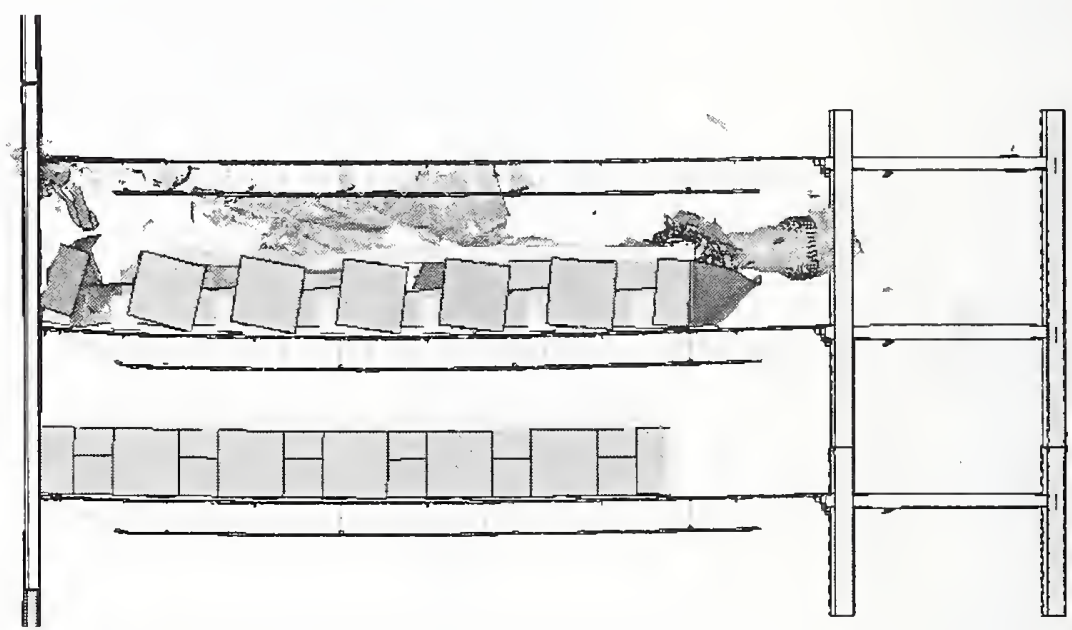

(b) Time $=0.25 \mathrm{~s}$

Figure E-22. Engine impact and breakup behavior (side view).

\section{E.6 AIRCRAFT IMPACT INITIAL CONDITIONS}

Three methods were used to determine the initial conditions for the two aircraft that impacted the towers. The first method used a comparison of videos from different positions to calculate the three-dimensional trajectory of the aircraft. The second method used the relative frame-by-frame motion in a single video scaled to the length of the aircraft in the video to calculate the impact speed. Finally, analysis of the impact damage on the face of each tower was used to refine the relative impact orientation and trajectory.

The aircraft impact conditions matching the observed exterior wall damage are shown in Figure E-23 and Figure E-24 for WTC 1 and WTC 2, respectively. The aircraft and exterior wall models were used to visualize the impact scenario in the figures and the view shown was aligned with the aircraft trajectory. Matching the projected impact points of the wings, fuselage, engines, and vertical stabilizer onto the exterior wall of each tower to the observed damage pattern was an important constraint in the determination of impact conditions. The final set of impact conditions from the analyses are summarized in Table E-8. 


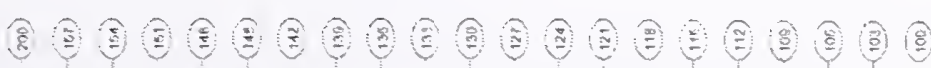

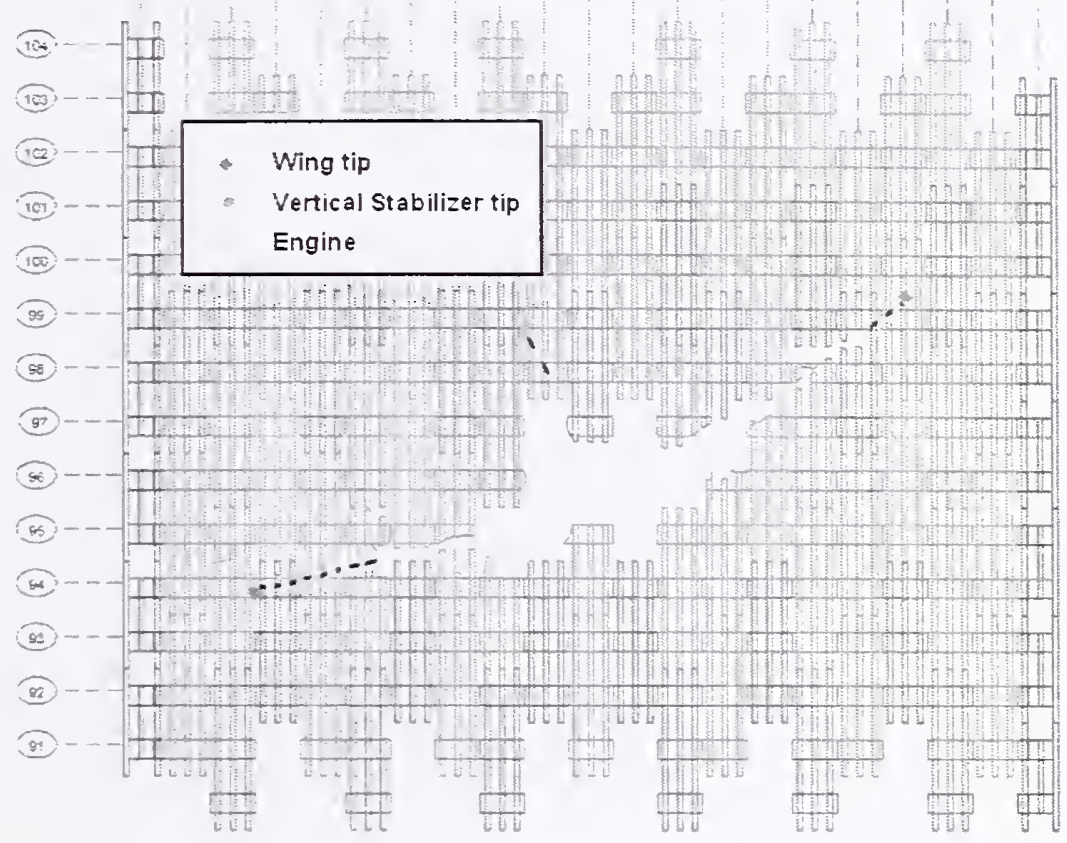

(a) Impact damage

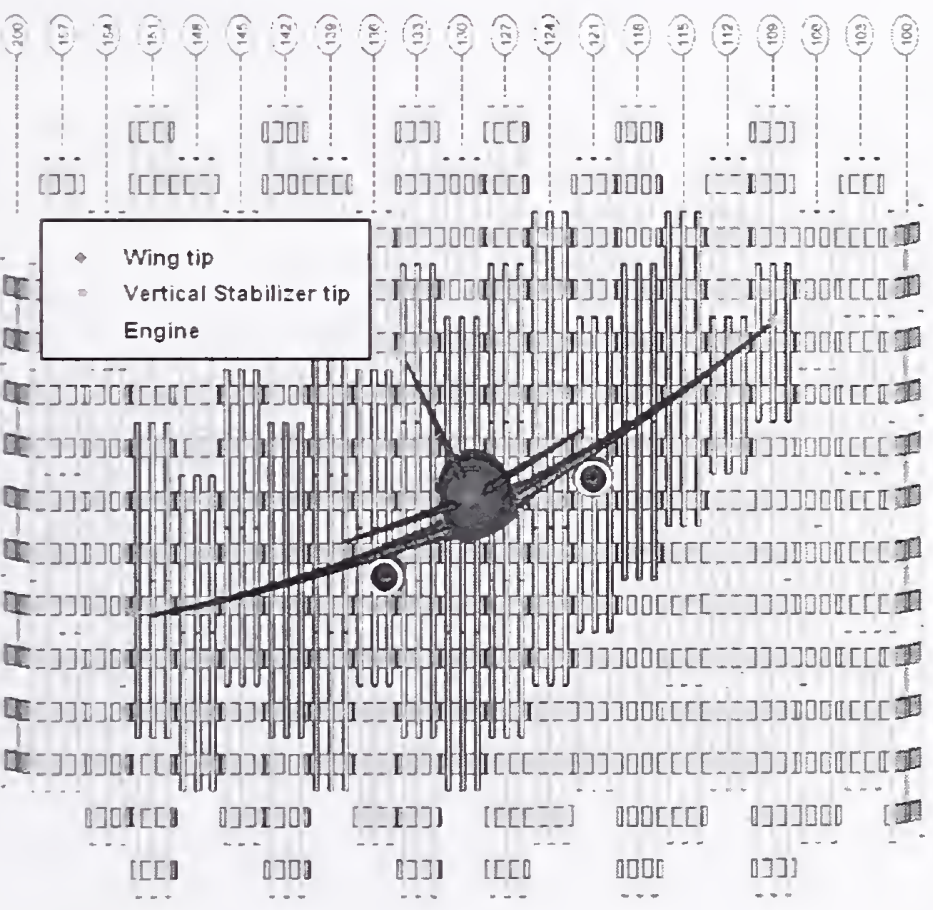

(b) Impact conditions (vertical angle $=10.6^{\circ}$, lateral angle $=0^{\circ}$ )

Figure E-23. WTC1 impact conditions and the impact pattern. 


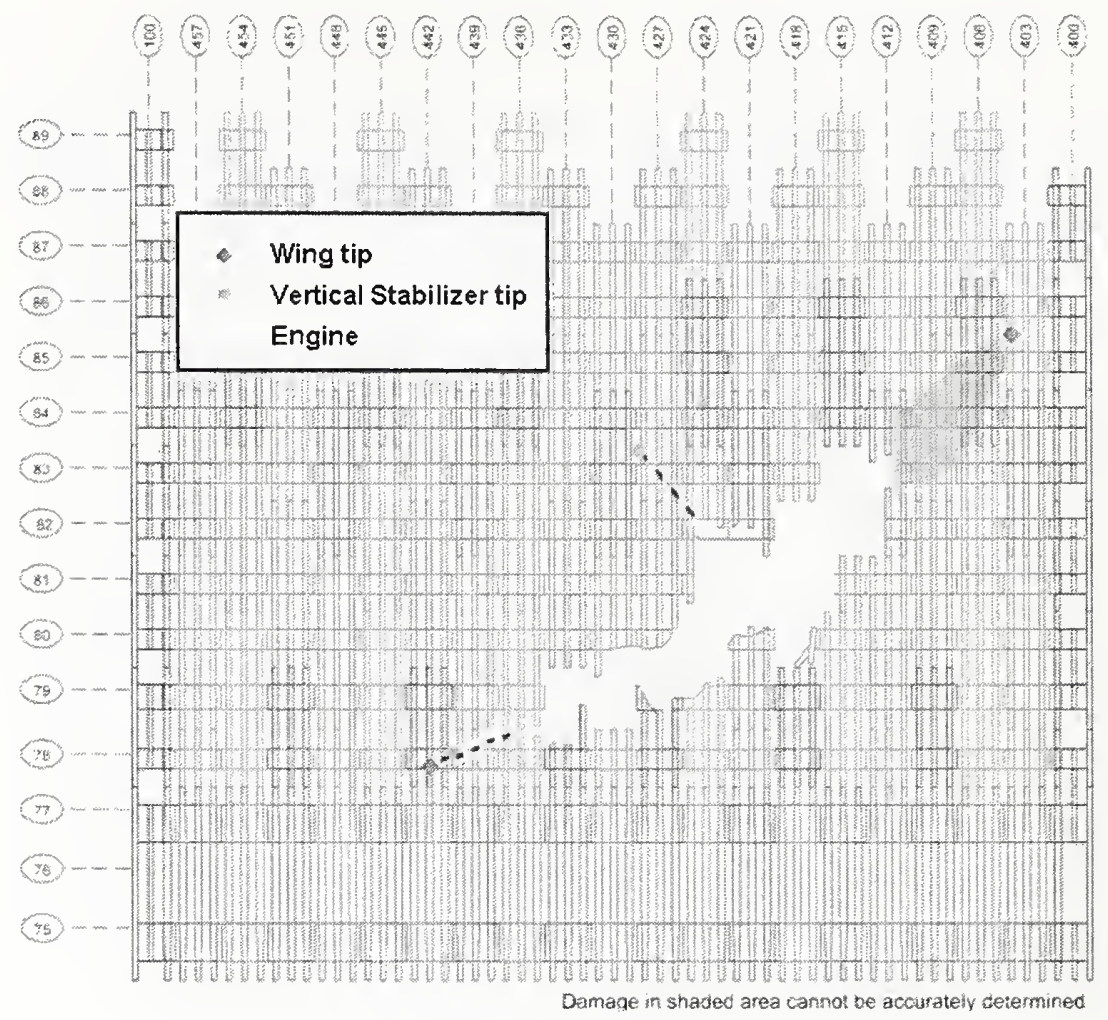

(a) Impact damage

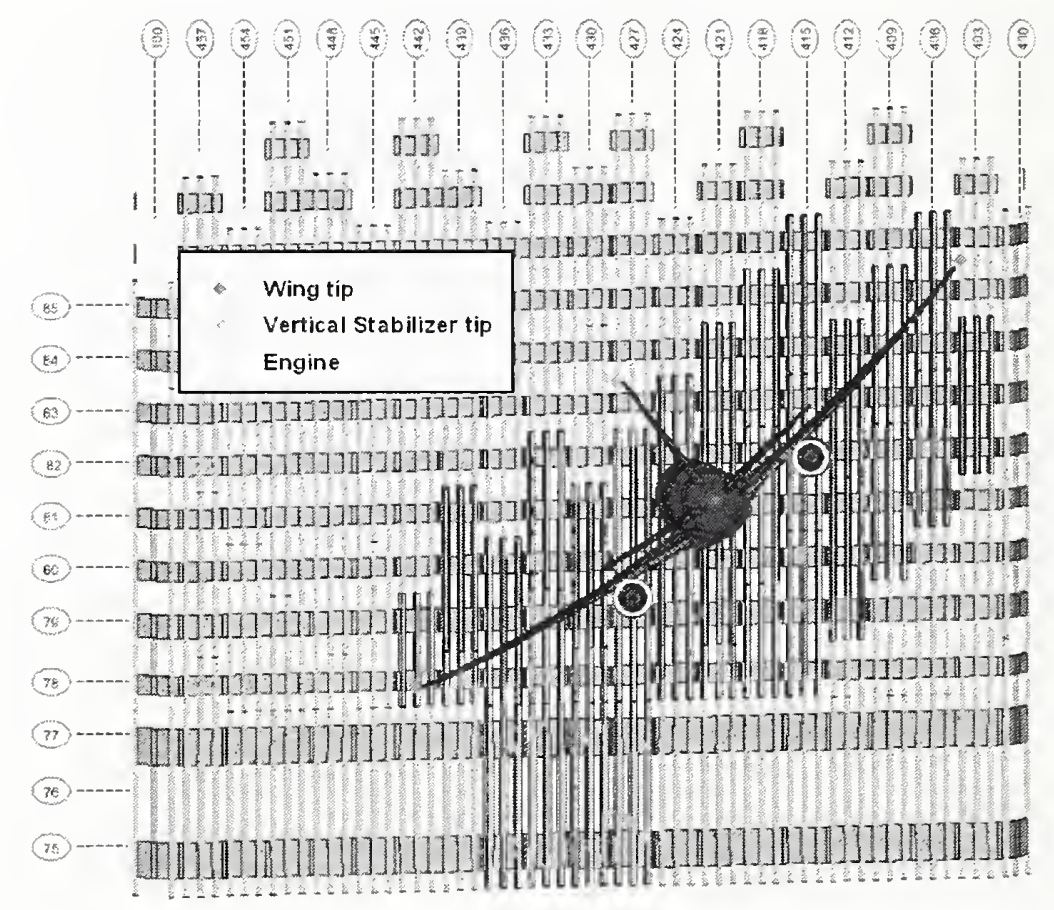

(b) Impact conditions (vertical angle $=6^{\circ}$, lateral angle $=13^{\circ}$ )

Figure E-24. WTC 2 impact conditions and the impact pattern. 
Table E-8. Summary of refined aircraft impact conditions.

\begin{tabular}{|l|c|c|}
\hline & AA 11 (WTC 1) & UAL 175 (WTC 2) \\
\hline Impact Speed (mph) & $443 \pm 30$ & $542 \pm 24$ \\
\hline $\begin{array}{l}\text { Vertical Approach Angle } \\
\text { (Velocity vector) }\end{array}$ & $\begin{array}{c}10.6^{\circ} \pm 3^{\circ} \text { below horizontal } \\
\text { (heading downward) }\end{array}$ & $\begin{array}{c}6^{\circ} \pm 2^{\circ} \text { below horizontal } \\
\text { (heading downward) }\end{array}$ \\
\hline $\begin{array}{l}\text { Lateral Approach Angle } \\
\text { (Velocity vector) }\end{array}$ & $\begin{array}{c}180.3^{\circ} \pm 4^{\circ} \text { clockwise from } \\
\text { Structure North }\end{array}$ & $\begin{array}{c}15^{\circ} \pm 2^{\circ} \text { clockwise from } \\
\text { Structure North }\end{array}$ \\
\hline $\begin{array}{l}\text { Vertical Fuselage Orientation } \\
\text { Relative to Trajectory }\end{array}$ & $\begin{array}{c}2^{\circ} \text { nose-up from the vertical } \\
\text { approach angle }\end{array}$ & $\begin{array}{c}1^{\circ} \text { nose-up from the vertical } \\
\text { approach angle }\end{array}$ \\
\hline $\begin{array}{l}\text { Lateral Fuselage Orientation } \\
\text { Relative to Trajectory }\end{array}$ & $\begin{array}{c}0^{\circ} \text { clockwise from lateral } \\
\text { approach angle }\end{array}$ & $\begin{array}{c}-3^{\circ} \text { clockwise from lateral } \\
\text { approach angle }\end{array}$ \\
\hline Roll Angle (left wing downward) & $25^{\circ} \pm 2^{\circ}$ & $38^{\circ} \pm 2^{\circ}$ \\
\hline
\end{tabular}

\section{E.7 GLOBAL IMPACT ANALYSES}

The objective of these analyses was to estimate the condition of the two WTC towers immediately following the aircraft impacts. This assessment included the estimation of the structural damage that degraded their strength and the condition and position of nonstructural contents such as partitions, workstations, aircraft fuel, and other debris that influenced the behavior of the subsequent fires in the towers. The global impact analyses were the primary method by which the damage to the towers was estimated. The global impact simulations provided, for each tower, a range of damage estimates. These included a base case based on reasonable initial estimates of all input parameters, along with a less severe and a more severe damage scenario. The less severe damage case did not meet two key observables:

(1) no aircraft debris was calculated to exit the side opposite to impact and most of the debris was stopped prior to reaching that side, in contradiction to what was observed in photographs and videos of the impact event and (2) The subsequent structural response analyses of the damaged towers indicated that the towers would not have collapsed had the less severe damage results been used. As a result, this report provides detailed description of the results of the analyses pertaining to the base and the more severe cases, which were used as the initial conditions for the subsequent fire dynamics simulations, thermal analyses, and fire-structural response and collapse initiation analyses. Only a brief description is provided for the less severe damage results for comparison purposes.

\section{E.7.1 WTC 1 Base Case Impact Analysis}

The combined aircraft and tower model for the base case WTC 1 global impact analysis is shown in Figure $\mathrm{E}-25$. The base case impact analysis was performed for a $0.715 \mathrm{~s}$ duration following initial impact of the aircraft nose with the north exterior wall. The analysis was performed on a computer cluster using twelve $2.8 \mathrm{GHz}$ Intel Xeon processors, each on a separate node of the cluster. The run time for this analysis was approximately two weeks. The calculations were terminated when the damage to the towers reached a steady state and the motion of the debris was reduced to a level that was not expected to produce any significant increase in the impact damage. The residual kinetic energy of the airframe components at the termination of a global impact simulation was typically less than one percent of the initial kinetic energy at impact. 


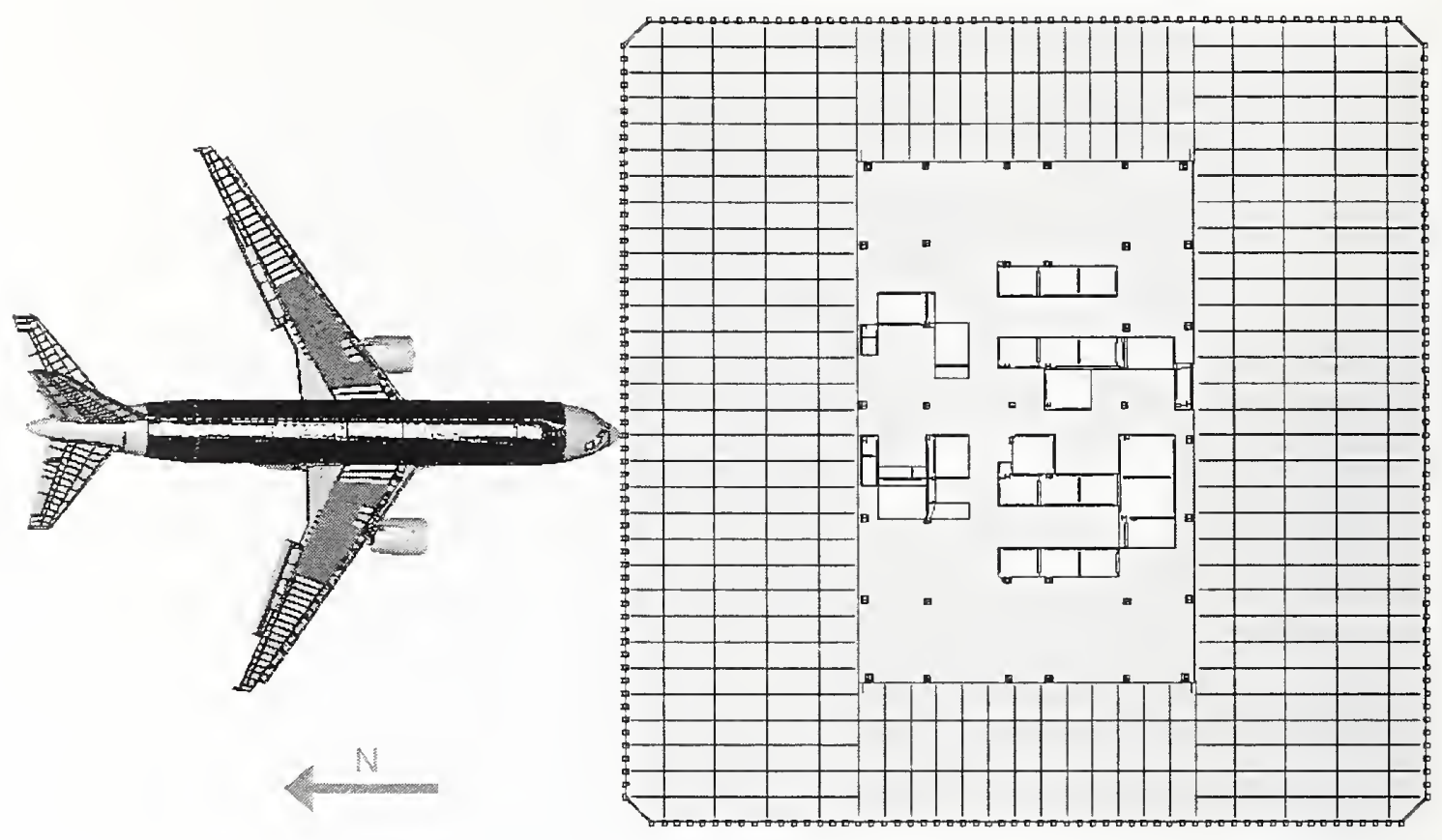

(a) Top view

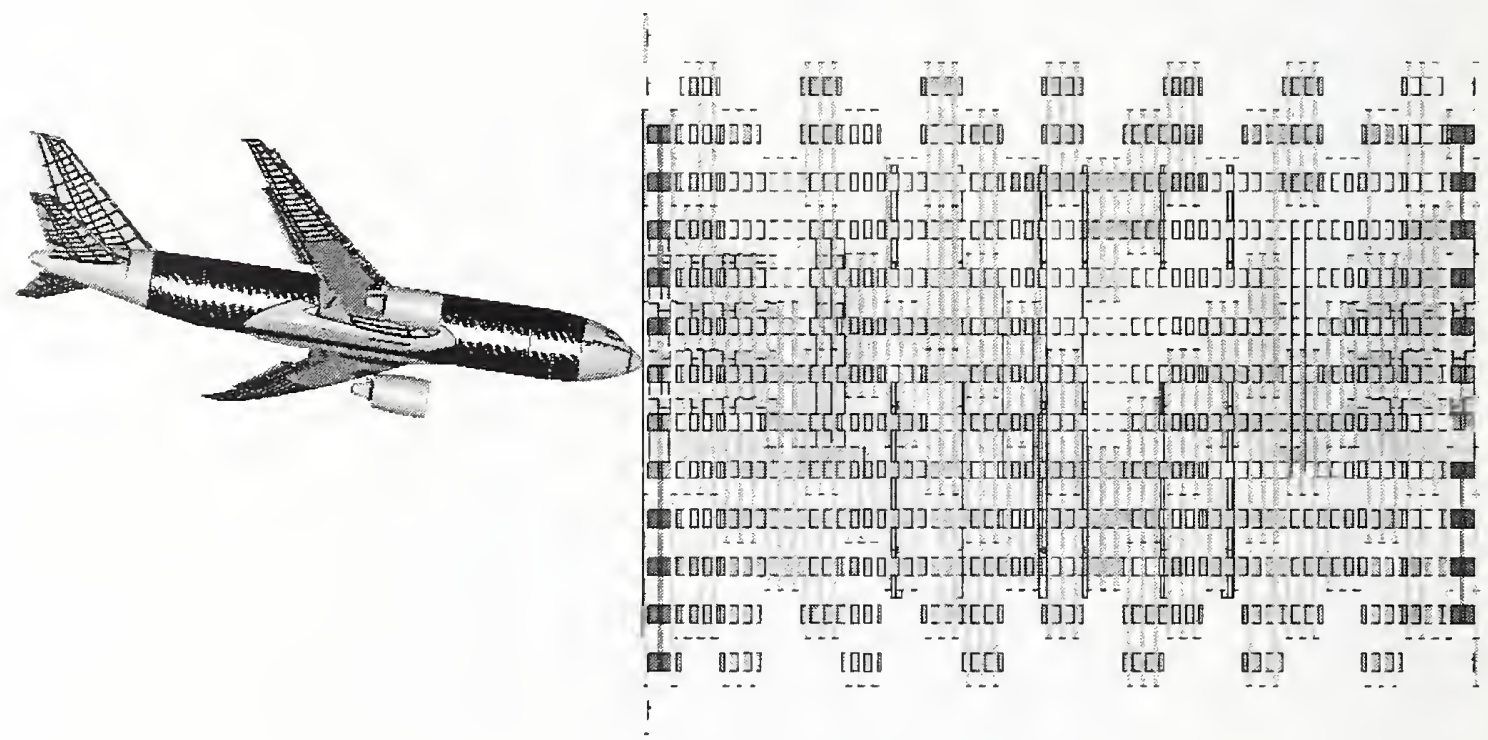

(b) Side view

Figure E-25. WTC 1 global impact model.

A side view of the base case WTC 1 global impact response is shown in Figure E-26. A corresponding top view of the impact response is shown in Figure E-27. The aircraft impact response was dominated by the impact, penetration, and fragmentation of the airframe structures. The entire aircraft fully penetrated the tower at approximately $0.25 \mathrm{~s}$. The fuselage structures were severely damaged both from the penetration through the exterior columns and the penetration of the 96 th floor slab that sliced the fuselage 
structures in half. The downward trajectory of the aircraft structures caused the airframe to collapse against the floor, and the subsequent debris motion was redirected inward along a more horizontal trajectory parallel to the floor. The downward trajectory of the aircraft structures transferred sufficient vertical load such that the truss floor structures on the 95th and 96th floors collapsed in the impact zone.

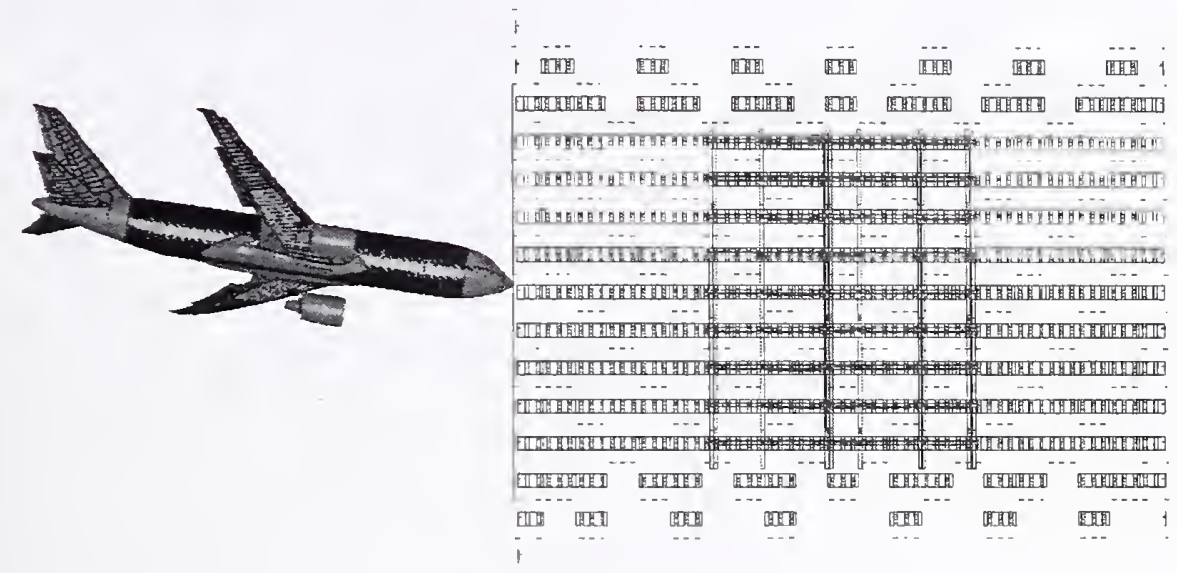

\section{(a) Time $=0.00 \mathrm{~s}$}

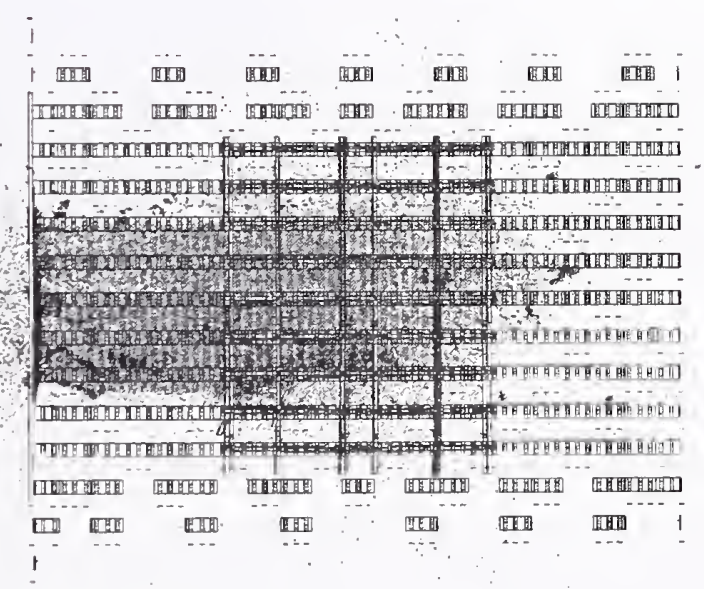

\section{(b) Time $=0.50 \mathrm{~s}$}

Figure E-26. WTC 1 base case global impact analysis - side view. 


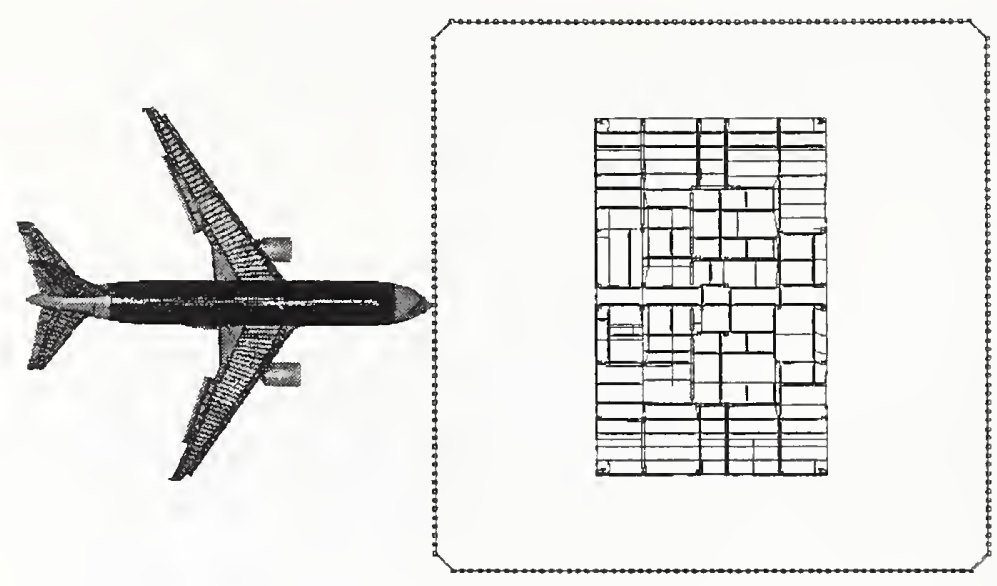

(a) Time $=0.00 \mathrm{~s}$

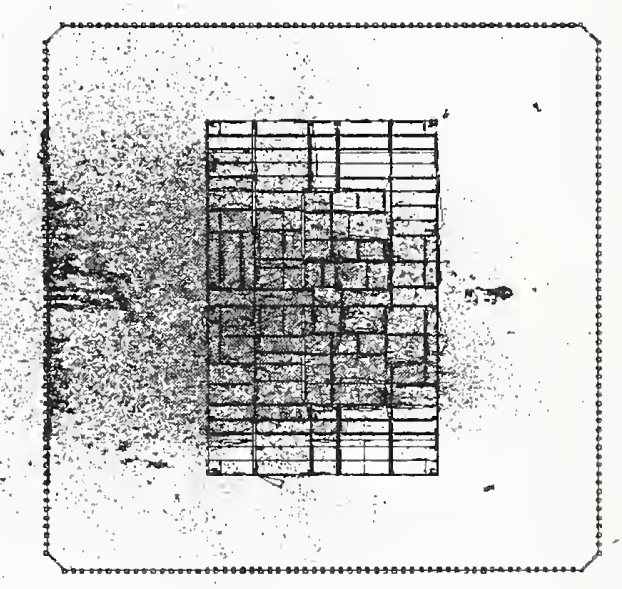

(b) Time $=0.50 \mathrm{~s}$

Figure E-27. WTC 1 base case global impact analysis - top view.

The wing structures were completely fragmented by the exterior wall. The aircraft fuel cloud began to spread out after impact but remained relatively dense until the leading edge of the fuel reached the tower core. The aircraft fuel and debris cloud eventually penetrated most of the distance through the core before their motion was halted.

The aircraft was severely broken into debris as a result of the impact with the tower. At the end of the impact analysis, the aircraft was broken into thousands of debris fragments of various sizes and masses. Larger fragments still existed for specific components, such as the engines. At the end of the simulation, the port engine was still inside the core, and the starboard engine was roughly one third of the distance from the core to the south exterior wall. Each had a speed of less than $50 \mathrm{mph}$.

\section{Exterior Wall Damage}

The exterior wall was the one structural system for which direct visual evidence of the impact damage was available. Therefore, the comparison of the calculated and observed exterior wall damage provided a 
partial validation of the analysis methodologies used in the global impact analyses. A comparison of the north exterior wall observed and calculated damage from the base case WTC 1 global impact analysis is shown in Figure E-28. The comparison of the calculated and observed damage indicated that the geometry and location of the impact damage zone were in good agreement. This agreement in the position and shape of the impact damage served to validate the geometry of the aircraft model, including the aircraft orientation, trajectory, and flight distortions of the wings.

The comparison also indicated a good agreement in the magnitude and mode of impact damage on the exterior wall. The exterior wall completely failed in the regions of the fuselage, engine, and fuel-filled wing section impacts. Damage to the exterior wall was observed all the way out to the wing tips, but the exterior columns were not completely failed in the outer wing and vertical stabilizer impact regions. Failure of the exterior columns occurred both at the bolted connections between column ends and at various locations in the column depending on the local severity of the impact load and the proximity of the bolted connection to the impact. The agreement of both the mode and magnitude of the impact damage served to partially validate the constitutive and damage modeling of the aircraft and exterior wall of the tower.

\section{Core Structural Damage}

The estimation of the damage to the core columns and core beams was important in determining the residual strength for the subsequent analyses of structural stability and collapse. The core had significant damage in the region close to the impact point. The columns in line with the aircraft fuselage failed on the impact side, and several of the core beams were also severely damaged or failed in the impact zone.

The calculated damage to the core columns by row is shown in Figure E-29. A total of three columns were severed, and four columns were heavily damaged. The damage to the core floor framing for floors 95 and 96 is shown in Figure E-30. 


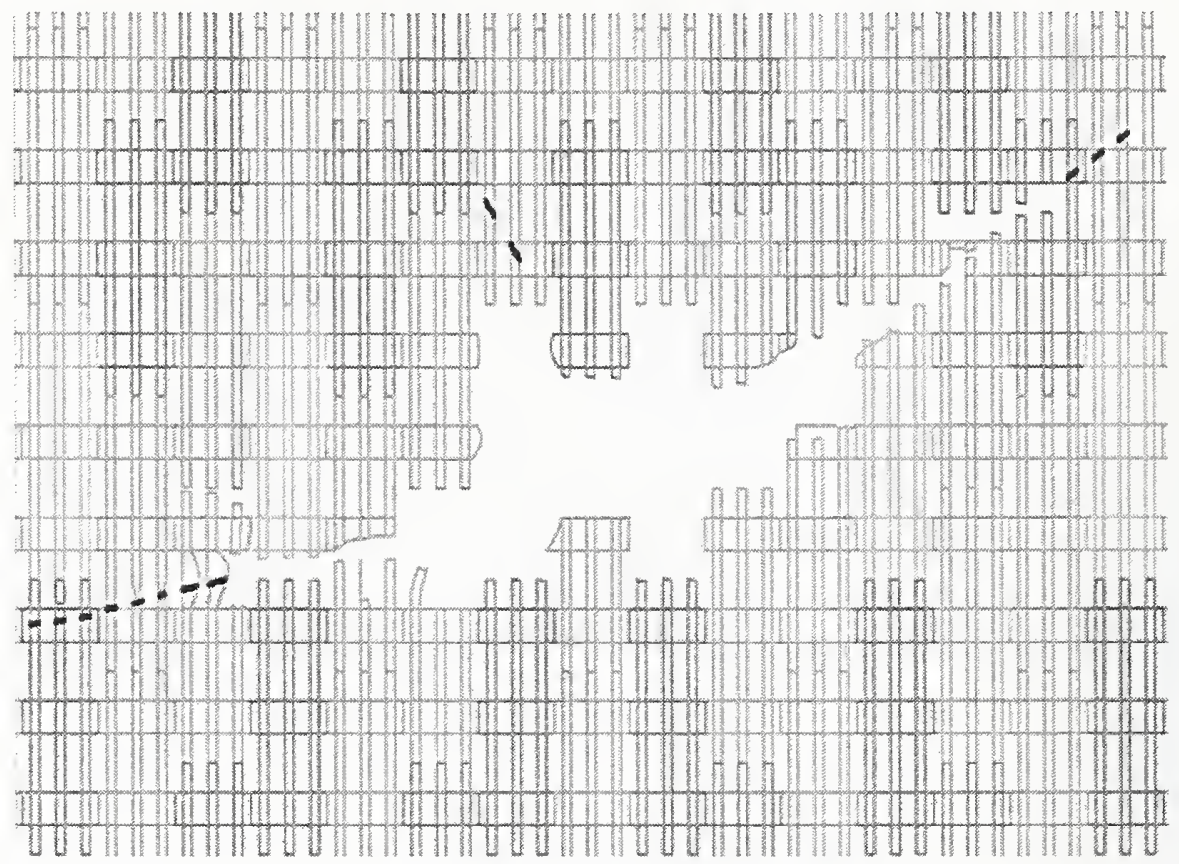

(a) Schematic of observed damage

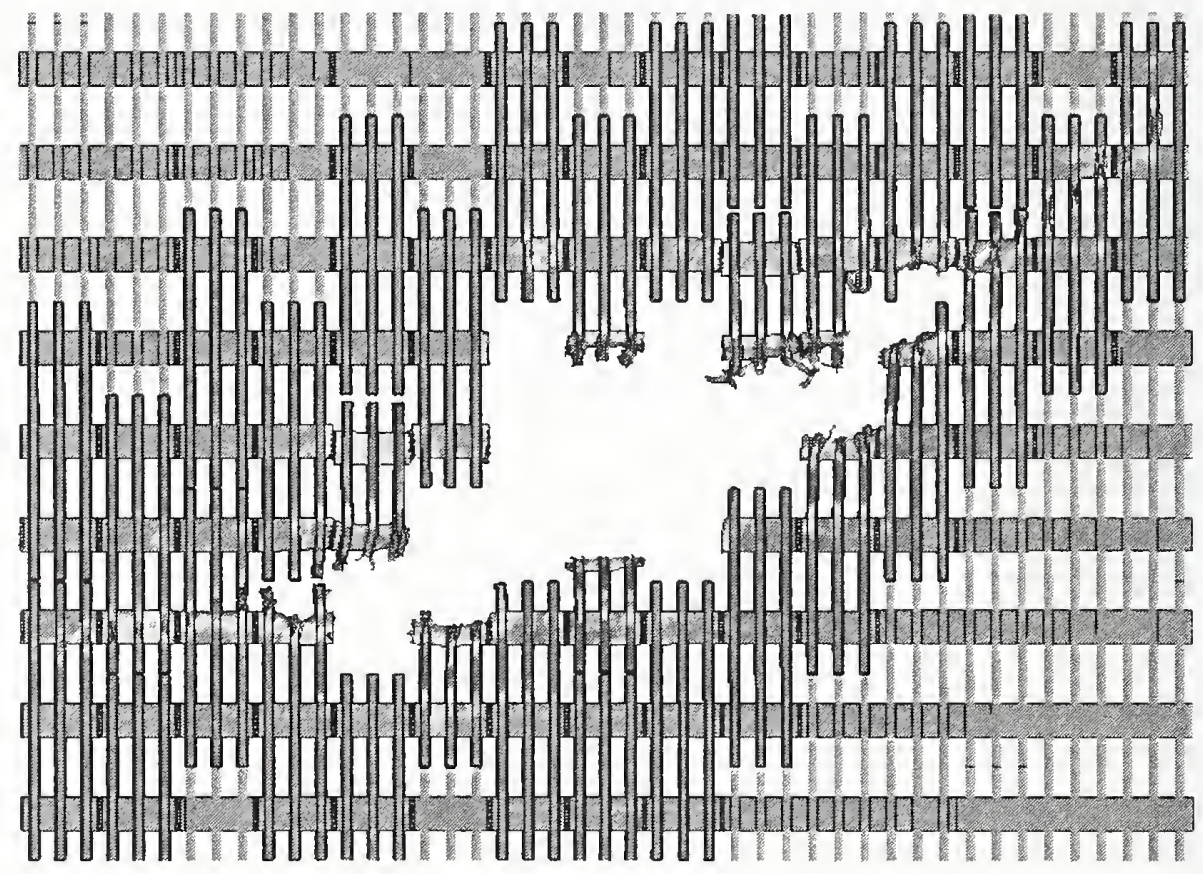

(b) Calculated damage

Figure E-28. Base case impact damage to the WTC 1 exterior wall. 


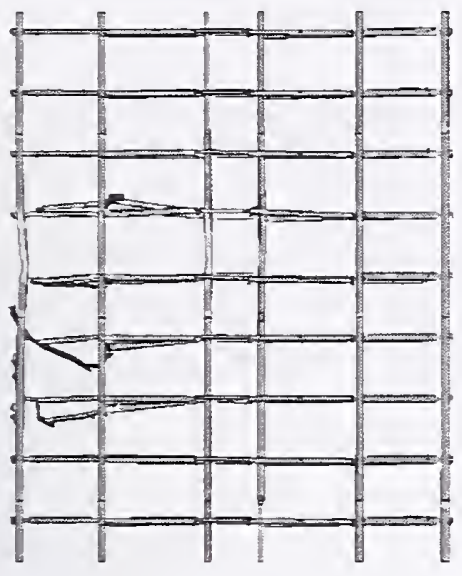

(a) Columns 503-1003

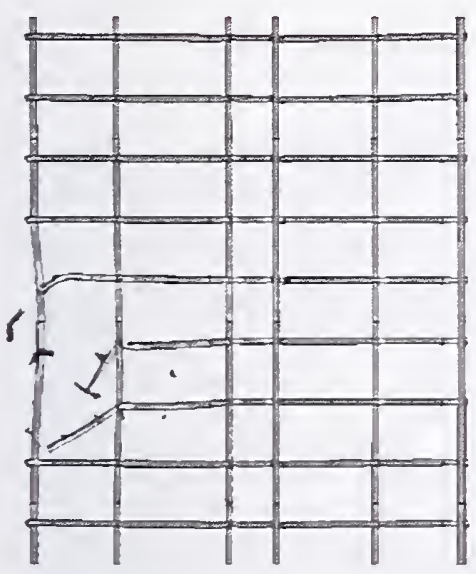

(c) Columns 505-1005

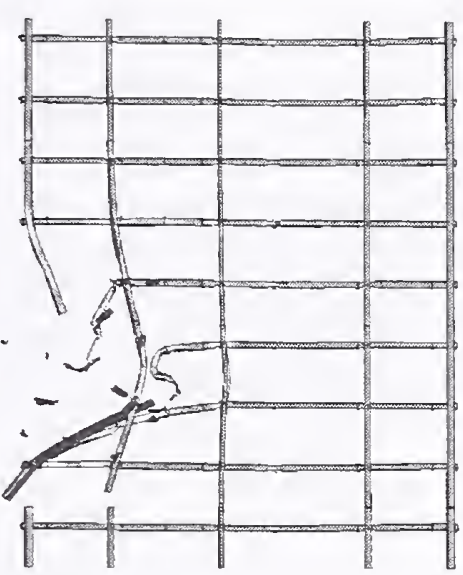

(b) Columns 504-1004

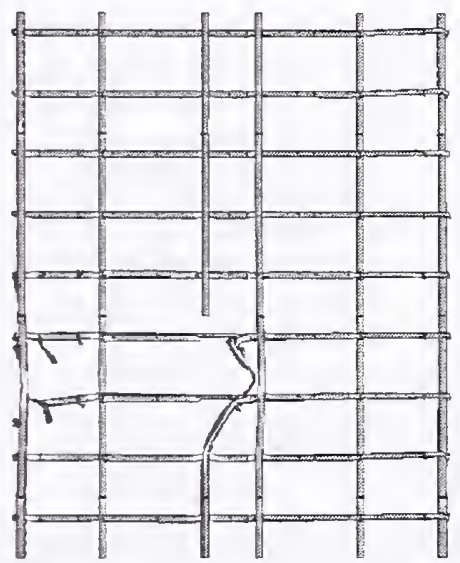

(d) Columns 506-1006

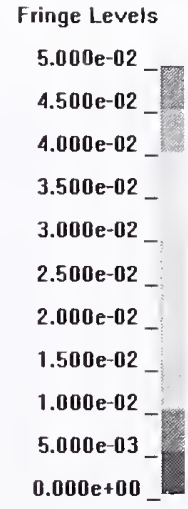

(e) Reference scale

Figure E-29. Base case impact damage to the WTC 1 core columns.

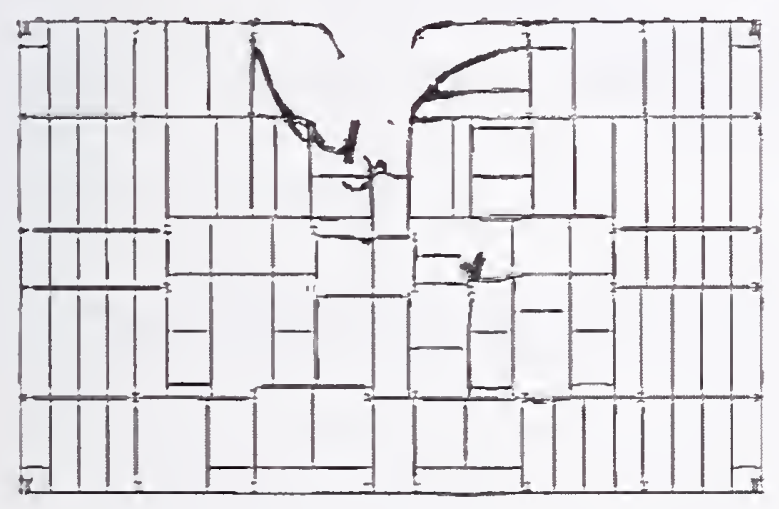

(a) Floor 95 core framing damage

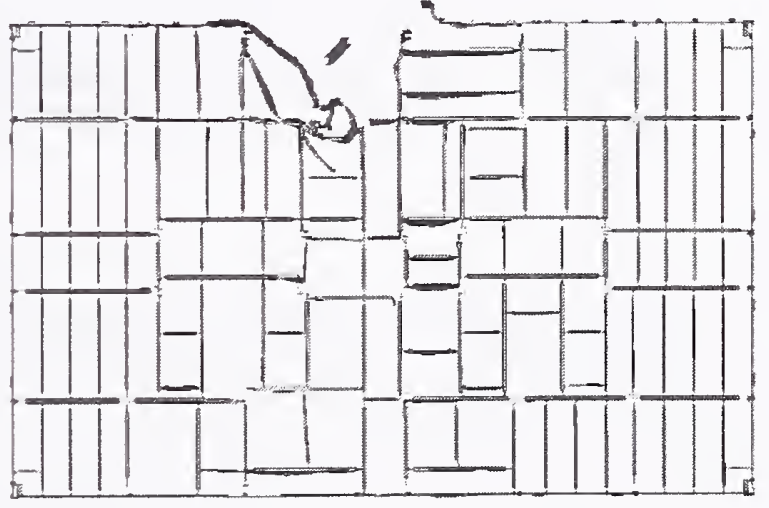

(b) Floor 96 core framing damage

Figure E-30. Base case impact damage to the core beams of floors 95 and 96 of WTC 1. 


\section{Floor Truss and Slab Damage}

An overall frontal view of the floor trusses in the impact zone, along with the calculated impact damage to the floor trusses, is shown in Figure E-31. The figure shows that the trusses experienced significant damagc and sagging in the impact zone. A plan view of the calculated damage to the trusses on floors 95 and 96 is shown in Figure E-32. The calculated impact response produced severe damage to the truss structures in the primary impact path of the fuselage from the exterior wall to the core. The truss floor system on floors 94 through 96 were damaged and sagged downward as a result of the impact loading. The calculated damage to the WTC 1 floor slab for floors 95 and 96 are shown in Figure E-33, where a similar pattern of response to that observed in the trusses can be seen for the floor slabs.
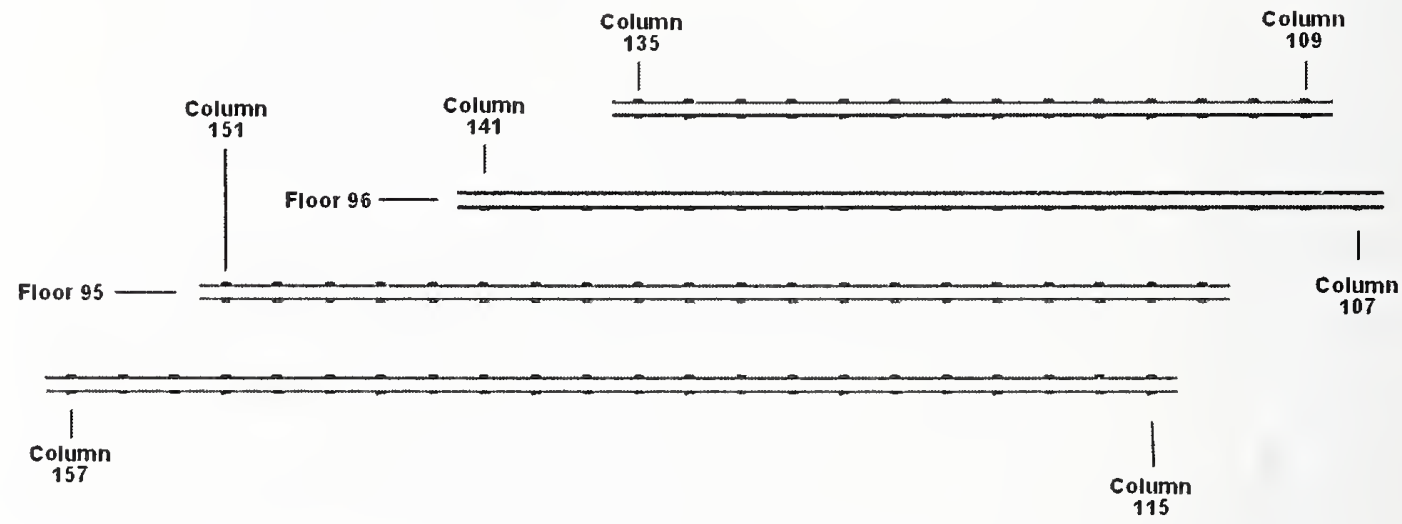

(a) Initial detailed truss structures

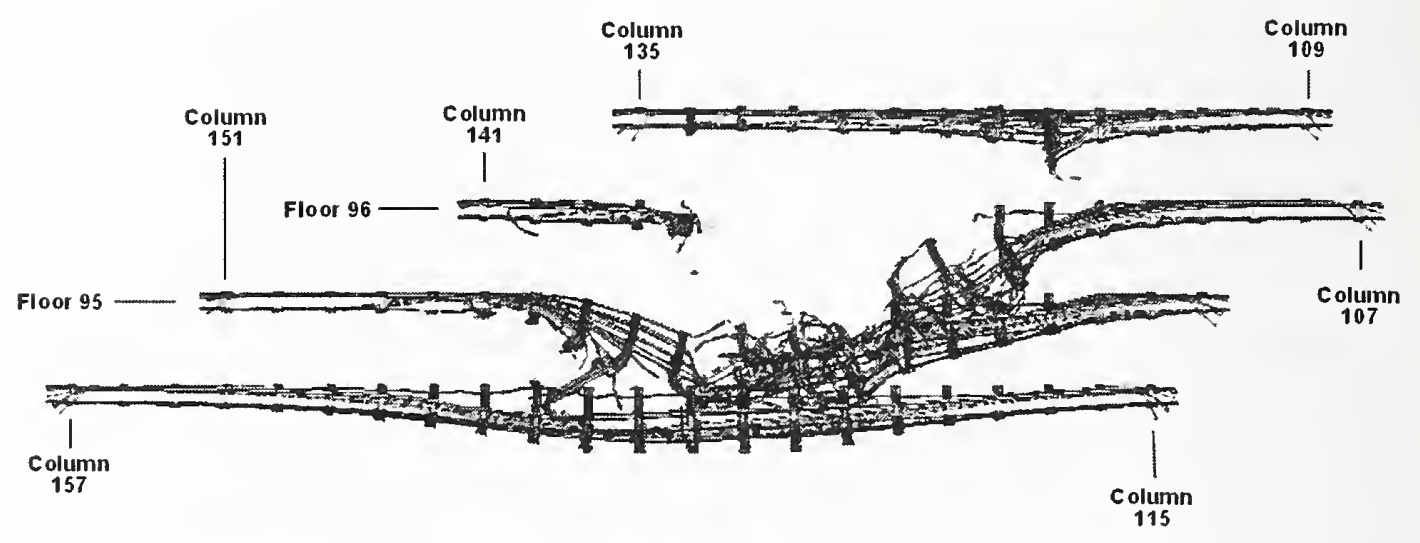

(b) Calculated damage

Figure E-31. Base case impact damage to the WTC 1 floor trusses (front view). 


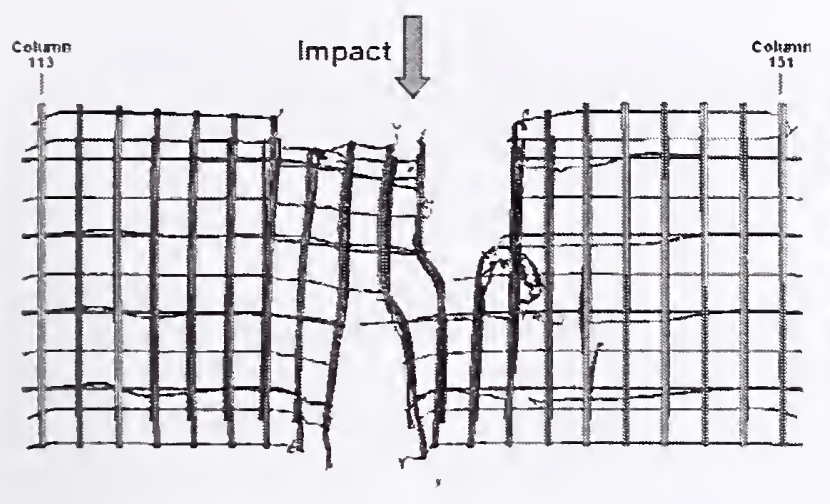

(a) Floor 95 truss damage

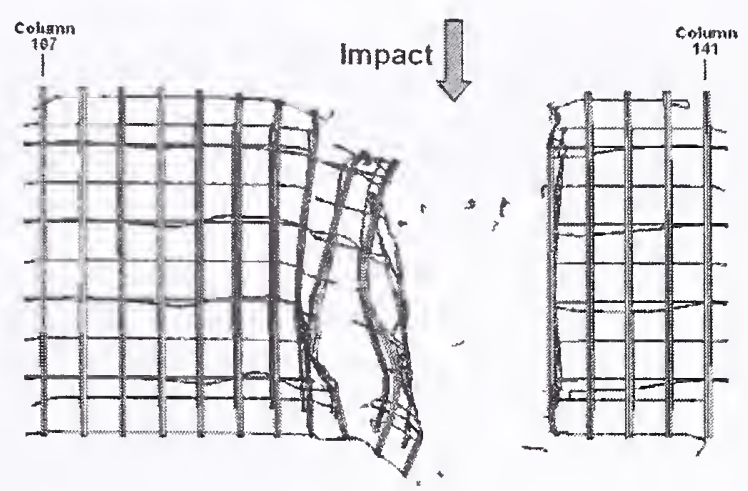

(b) Floor 96 truss damage

Figure E-32. Base case impact damage to the trusses on floors 95 and 96 of WTC 1 (plan view).

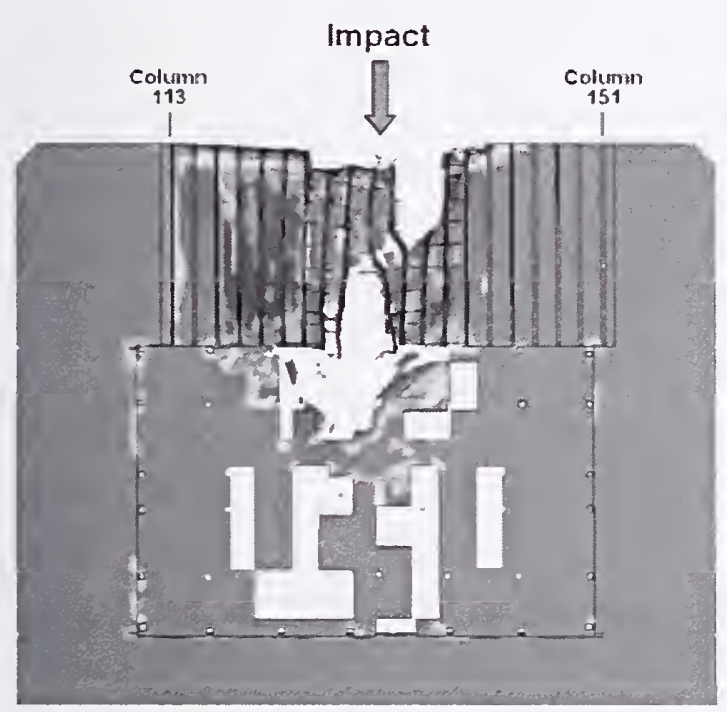

(a) Floor 95 slab damage

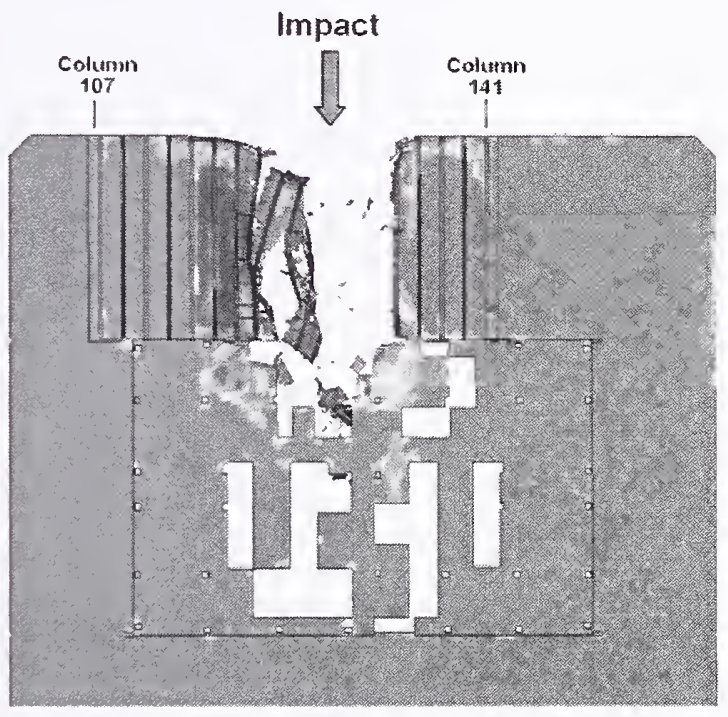

(b) Floor 96 slab damage

Figure E-33. Base Case impact damage to the slabs on floors 95 and 96 of WTC 1 (plan view).

\section{Summary of Structural Damage}

The impact-induced structural damage described above was used as the initial conditions for the postimpact fire-structural analyses. Figure E-34 presents the cumulative damage on all affected floors and columns. The damage to the columns at the various levels is identified by the color of the circles, where red, blue, green, and yellow signify severed, heavily damaged, moderately damaged, and lightly damaged columns, respectively. The dotted boxes on the figures indicate areas where the impact created an opening in the floor. These were used to identify slab openings in the fire dynamics simulations. The solid boxes indicate areas in the floor system that had severe structural damage. These areas were removed from the subsequent structural analyses. Figure E-34 shows the damage to the exterior walls due to impact, based on the photographs of the north wall. Note the panel that was severed in the south 
wall of the tower. While the analysis did not capture the failure of the connections at the ends of this panel due to the coarse mesh of the south wall, photographic evidence showed that this panel was knocked down by the impact. As a result, this panel was removed from the subsequent structural analyses.

Severe Floor Damage

Floor system structural damage

Floor system removed

Column Damage

Severed

Heavy Damage

Moderate Damage

Light Damage

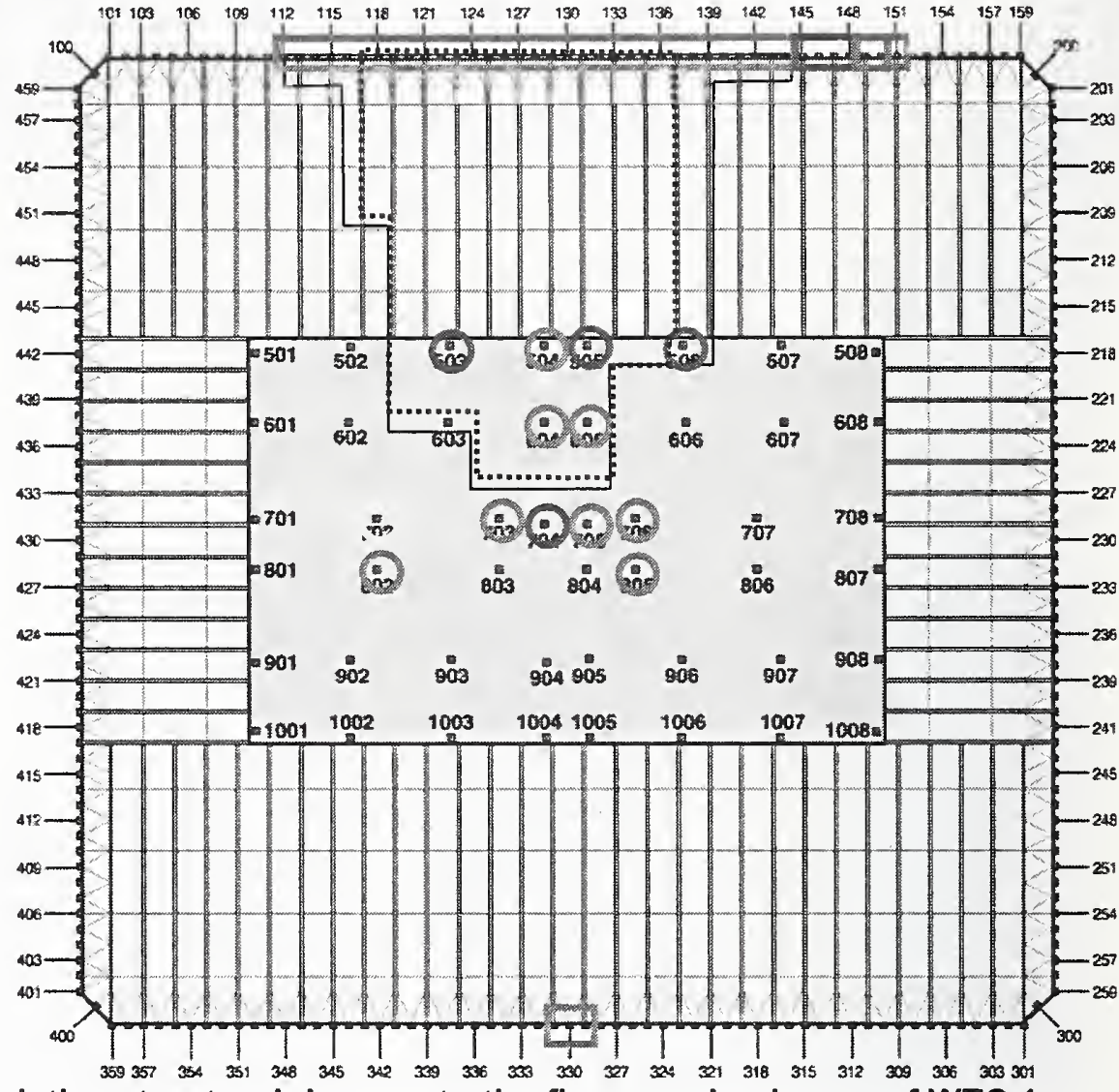

Figure E-34. Cumulative structural damage to the floors and columns of WTC 1 (base case).

\section{Fuel and Debris Distribution}

Another primary objective of the global impact analyses was to determine the initial conditions that influenced the initiation and propagation of the fires in the towers. These initial conditions included the distribution of the jet fuel in the towers, the distribution of tower contents and aircraft debris that provided flammable materials for the fires, and the condition of the partitions and walls that provided barriers to air flow and spreading of the fires. For the base case WTC 1 global impact analysis, the calculated distribution of the fuel in the tower and shape of the fuel cloud in a plan view and side view were shown previously in Figure E-26 and Figure E-27, respectively. Figure E-35 shows the distribution of the fuel and damage to the building contents due to impact.

The bulk of the fuel and aircraft debris was deposited on floors 93 through 97, with the greatest concentration on floor 94 . The calculated debris cloud included 17,400 lbs of debris and 6,700 lbs of aircraft fuel outside of the tower at the end of the impact analysis, either rebounding from the impact face 
(north wall) or passing through the tower (south wall). This amount might have been larger in the calculation since the exterior walls were not modeled with windows that would contain the fuel cloud and other small debris inside the towers. In addition, the impact behavior of the aircraft fuel cloud did not include the ability to stick to, or wet, interior components. Rather, the aircraft fuel SPH particles tended to bounce off of internal structures.

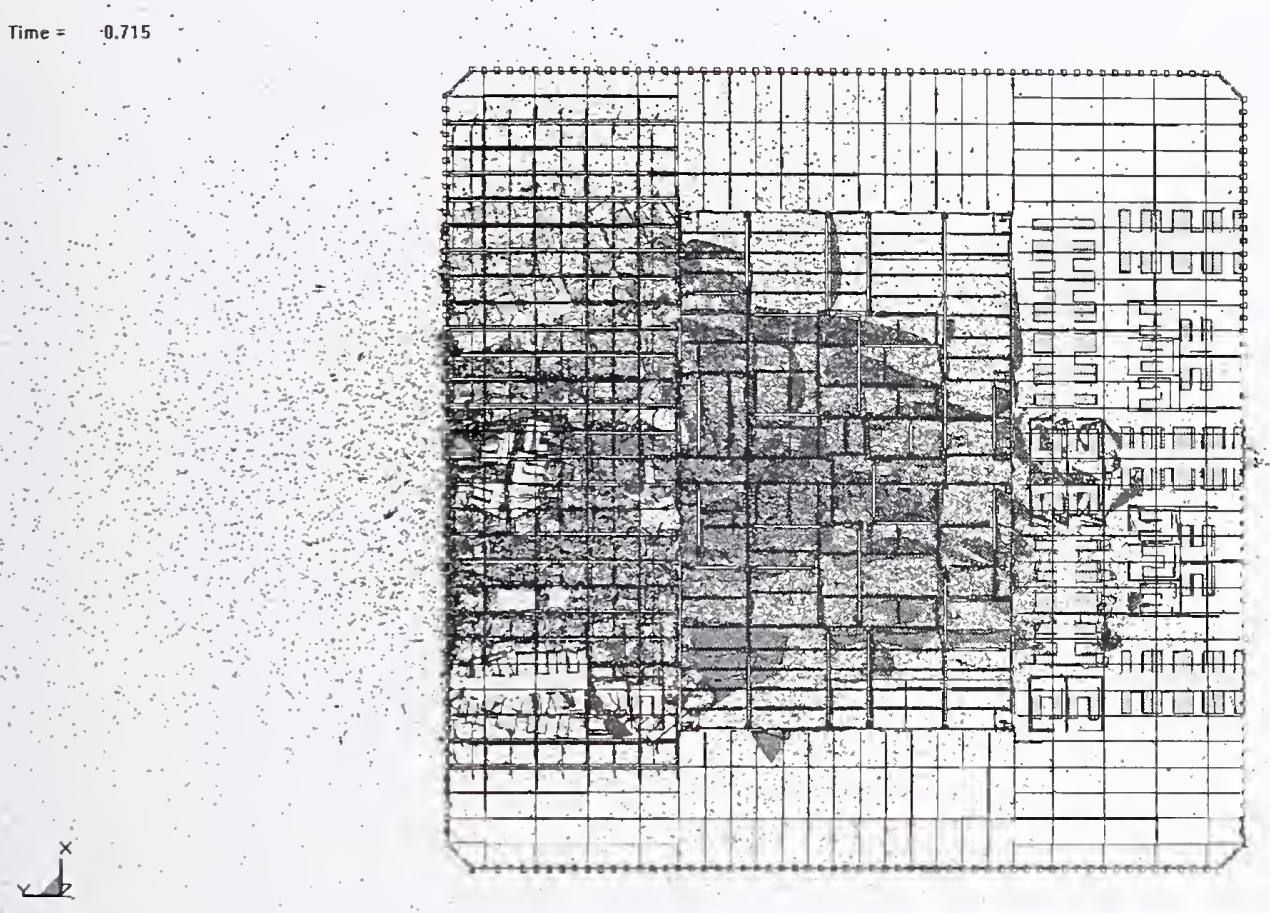

Figure E-35. Calculated fuel distribution and debris damage in the base case WTC 1 analysis.

\section{E.7.2 WTC 1 More Severe Impact Analysis}

The analysis of aircraft impacts into the WTC towers was subject to uncertainties in the input parameters such as:

- Aircraft impact parameters: aircraft speed, horizontal and vertical angles of incidence, orientation, and location of impact.

- Material properties: high strain rate material constitutive behavior and failure criteria for the towers and the aircraft.

- Aircraft mass and stiffness properties, and the jet fuel distribution in the aircraft.

- Tower parameters: structural strength and mass distribution, connection and joint positions relative to impact and joint failure behavior.

- Nonstructural building contents that may share in absorbing energy imparted by the aircraft impact. 
Another important source of uncertainty is the inaccuracy associated with mathematical or numerical models. The inaccuracies of models, also known as modeling errors, are deterministic in nature, but are often treated as random variables to characterize the effects of the analysis methodologics on the calculated response. All of these variables did not necessarily have a significant effect on the estimated impact damage to the WTC towers.

Because of the complexity of the problem and the limited number of parameters that could be varied in the global analyses, it was necessary to down-select a refined list of uncertainty parameters from all of the possible parameters. Thercfore, variable screening was conducted using design of experiments methodology. Screening was first conducted at component and subassembly levels using orthogonal factorial design techniques in order to identify the most influential paramcters and reduce the number of parameters to a more manageable number for the global impact analyses. The sensitivity analyses included engine impacts against core columns, wing section impacts against exterior panels, and engineimpact subassembly analyses.

In addition to the base case impact analysis described in Section E.7.1, two more impact analyses were performed for each tower to provide a range of calculated impact-induced damage. These analyses included a more severe and a less severe case. Based on the three sensitivity analyses, the set of influential modeling parameters was reduced. The following parameters were selected for variation in the more severe and less severe global impact analyses:

- Impact speed.

- Vertical approach angle of the aircraft.

- Lateral approach angle of the aircraft.

- Total aircraft weight.

- Aircraft materials failure strain.

- Tower materials failure strain.

- $\quad$ Building contents weight.

For the more severe case, the impact speed was increased to the upper bound obtained from the analysis of aircraft impact conditions, while the aircraft vertical trajectory angle was reduced to impart more impact energy inward toward the core. A 5 percent increase in the total aircraft weight was considered for the more severe case, while the failure strain was varied to be 125 percent of the baseline value to inflict more damage on the towcrs. For the tower model, the failure strains of the tower steels were reduced to 80 percent of the baseline value, and the mass of the building contents was reduced. These variations contributed to more severe damage to the tower structure, by making the tower structure weaker and the aircraft structure stronger. The opposite was done for the less severe case. This section provides some details of the WTC 1 more severe case, while Section E.7.3 provides a brief description of the WTC 1 less severe case.

\section{Exterior Wall Damage}

The calculated damage to the north wall from the more severe WTC 1 global impact analysis is shown in Figure E-36. A comparison of the north exterior wall observed (Figure E-28a) and calculated damage 
from the more severe WTC 1 global impact analysis (Figure E-36) indicated that the calculated and observed magnitude and mode of impact damage were still in good agreement.

The overall agreement with the observed damage to the north wall was good for the base case and the more severe case, with the base case analysis providing the better match to the observed damage. The differences in apparent damage were largely due to panels that may have severed columns in one case and were removed at the connections in another. Toward the wing tips, where the columns and spandrels were not completely severed, the more severe impact damage analysis calculated greater damage to the exterior wall panels. As would be expected, the base case analysis calculated less damage to the exterior wall than the more severe case near the wing tips.

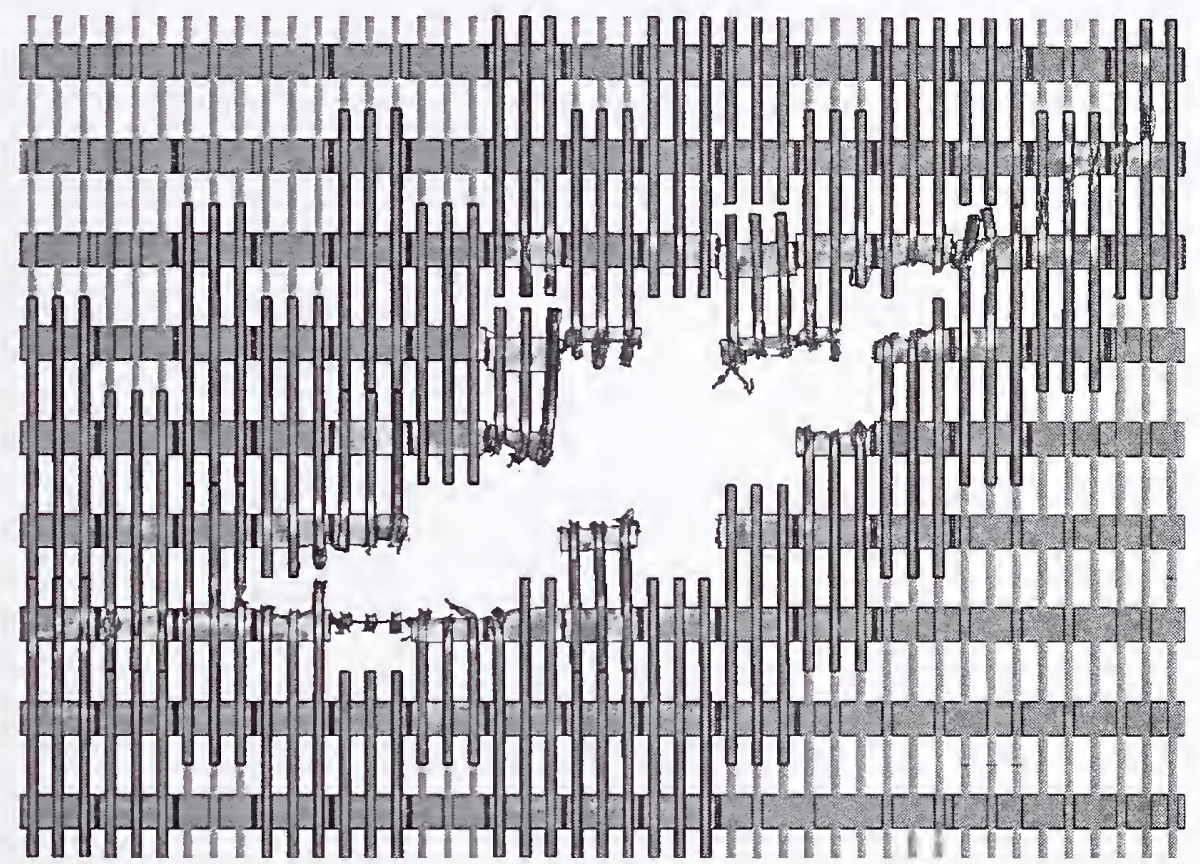

Figure E-36. Calculated more severe impact damage to the WTC 1 exterior wall.

\section{Core Structural Damage}

The core had extensive damage in the region close to the impact point. The columns in line with the aircraft fuselage failed on the impact side, and several of the core beams were also severely damaged or failed in the impact zone. In some cases, failure of the column splices located on floors 92, 95, and 98 contributed significantly to the failure of the core columns.

The calculated damage to the core columns by row is shown in Figure E-37, and the damage to the core framing for floors 95 and 96 is shown in Figure E-38. A total of six columns were severed, and three columns were heavily damaged in the more severe case, compared to three columns severed and four columns heavily damaged in the base case WTC 1 impact analysis. This shows a clear correlation between damage magnitude and impact severity. 


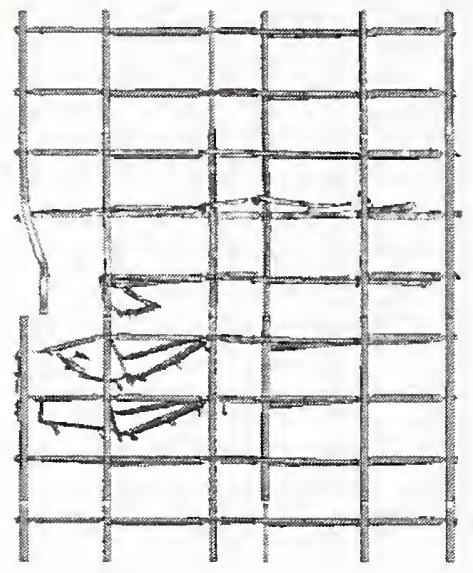

(a) Columns 503-1003

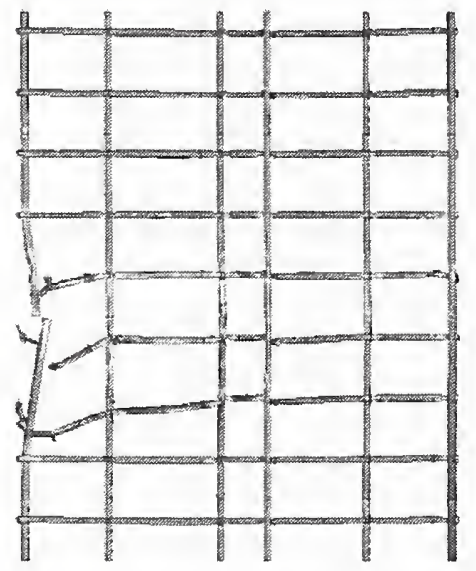

(c) Columns 505-1005

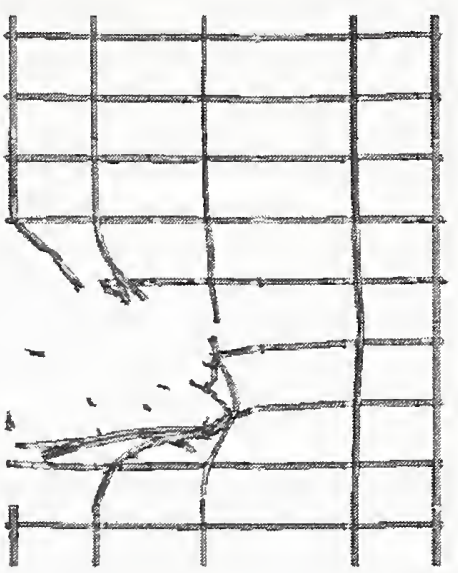

(b) Columns 504-1004

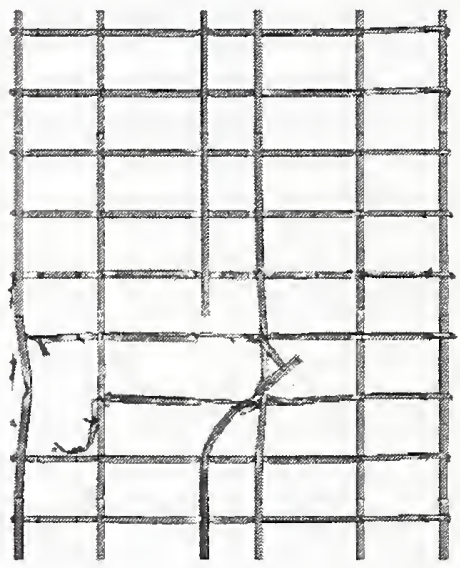

(d) Columns 506-1006
Fringe Levels

$5.000 \mathrm{e}-02$

$4.500 \mathrm{e}-02$

4.000e-02

3.500e-02

3.000e-02

2.500e-02

2.000e-02

$1.500 \mathrm{e}-02$

$1.000 \mathrm{e}-02$

5.000e-03

$0.000 \mathrm{e}+00$

(i) Reference scale

Figure E-37. More severe impact response of the WTC 1 core columns.

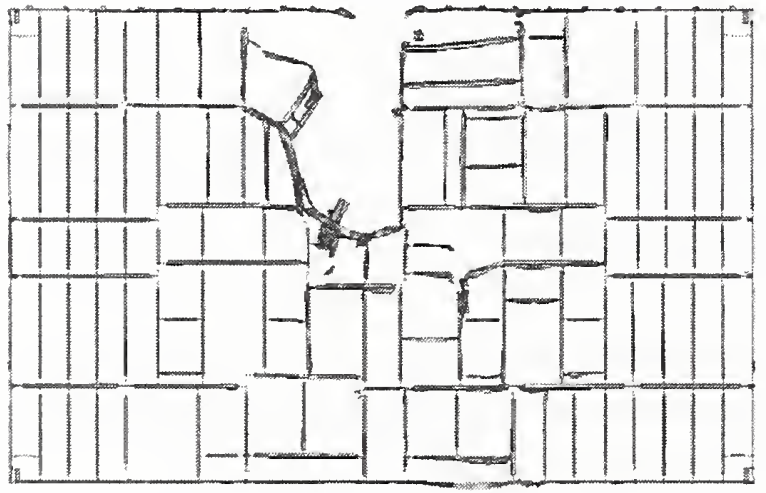

(a) Floor 95 core framing damage

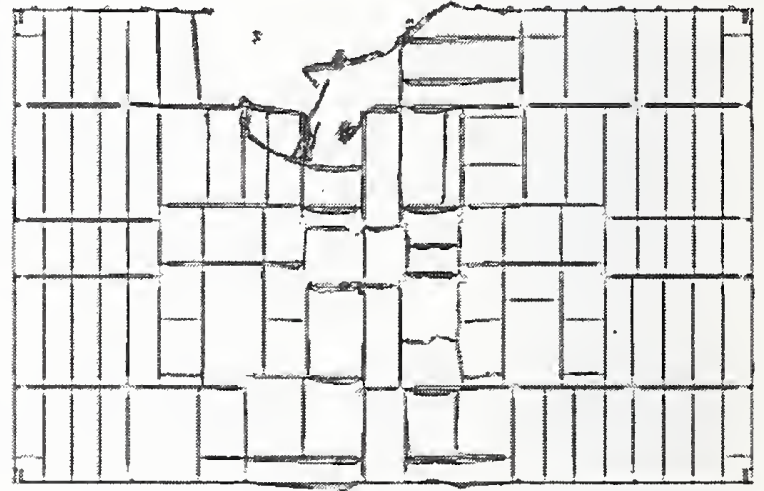

(b) Floor 96 core framing damage

Figure E-38. More severe impact damage to the core beams of floors 95 and 96 of WTC 1. 


\section{Floor Truss and Slab Damage}

An overall frontal view of the calculated more severe impact damage to the floor trusses is shown in Figure E-39. The figure shows that the trusses experienced significant damage in the impact zone. A plan view of the calculated damage to the truss on floors 95 and 96 is shown in Figure E-40. The calculated impact response produced severe damage to the truss structures in the primary impact path of the fuselage from the exterior wall to the core. The truss floor system on floors 94 through 96 were damaged and sagged downward as a result of the impact loading.

When the floor-by-floor damage was compared for the base case and more severe impact analyses, the damage appeared to be slightly less for the more severe impact analysis. The parameters used in the more severe global impact analysis would primarily contribute to an increased damage magnitude for the tower structures. However, the downward impact trajectory angle was reduced from the 10.6 degree angle in the base case analysis to a 7.6 degree angle in the more severe impact analysis. This would have the effect of directing more of the impact energy inward toward the tower core but reducing the normal downward force on the floor structures in the impact zone. As a result, the combined effects of the analysis parameter variations produced slightly less damage to the truss structure in the more severe impact analysis scenario.

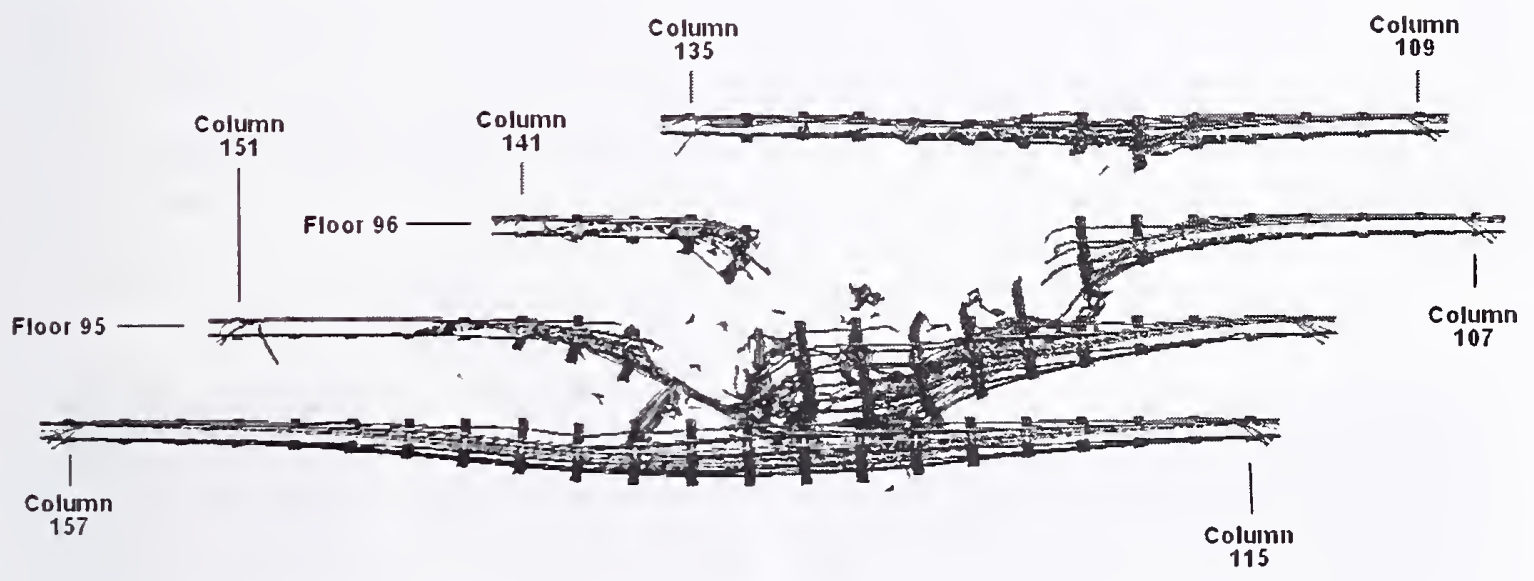

Figure E-39. Calculated more severe impact damage to the WTC 1 floor trusses (front view). 


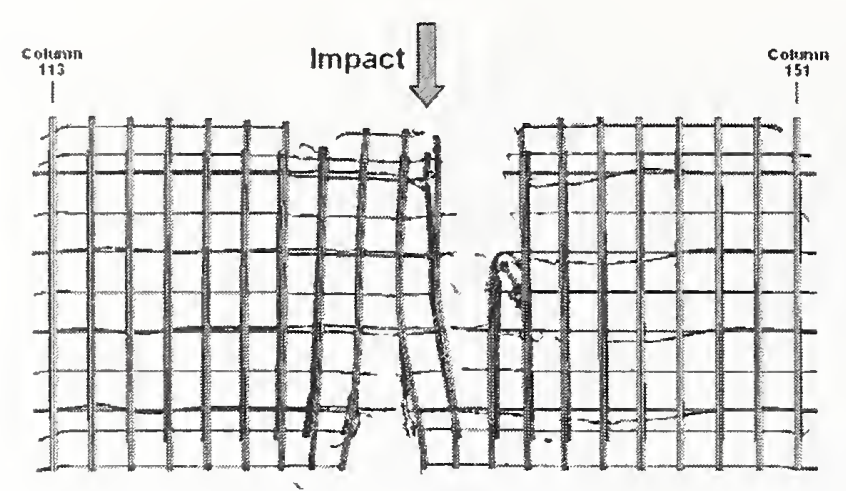

(a) Floor 95 truss damage

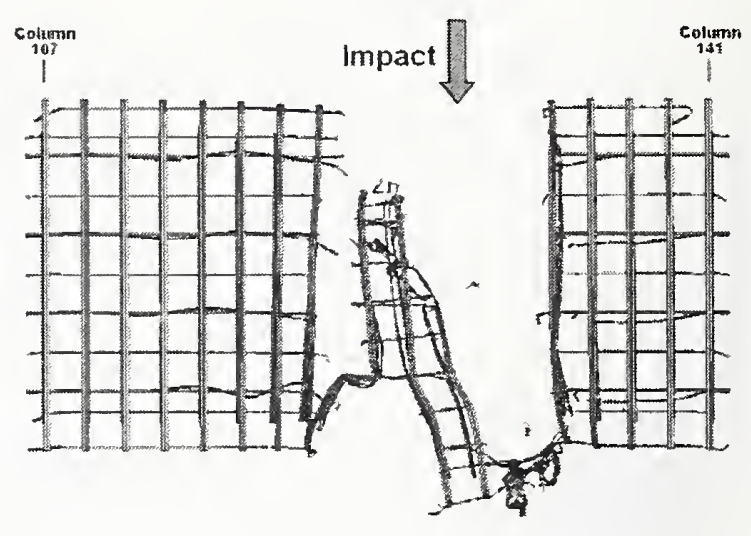

(b) Floor 96 truss damage

Figure E-40. More severe impact damage to the trusses on floors 95 and 96 of WTC 1 (plan view).

The calculated more severe impact damage to the floor slabs for floors 95 and 96 of WTC 1 is shown in Figure E-41. The magnitude of floor slab damage was, in general, very similar for the base case and more severe global impact analyses. When the floor-by-floor damage was compared for the two analyses, the damage appeared to be slightly less for the more severe impact analysis. Similar to the truss damage, the reduced damage in the floor slabs is believed to be the result of the reduction in the downward impact trajectory angle from 10.6 to 7.6 degrees in the more severe impact analysis, reducing the normal downward force on the floor structures.

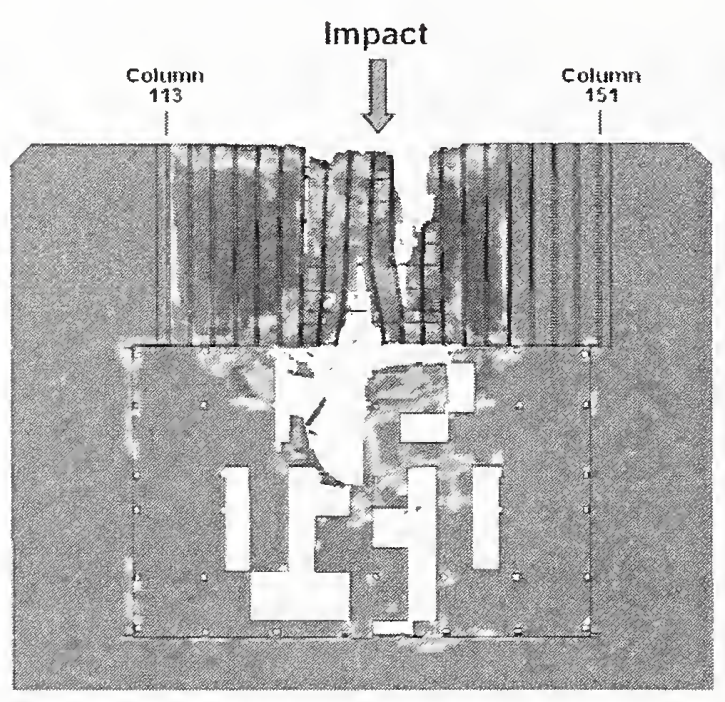

(a) Floor 95 slab damage

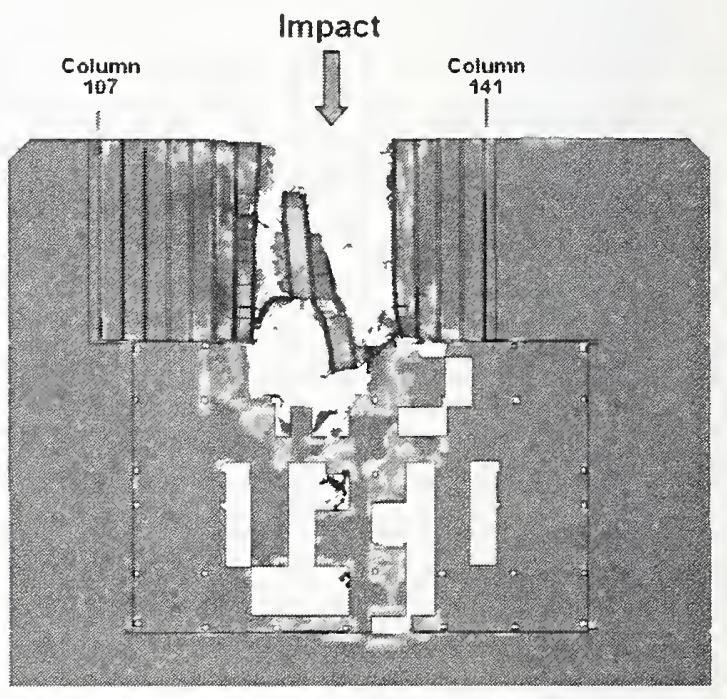

(b) Floor 96 slab damage

Figure E-41. More severe impact damage to the slabs on 1 floors 95 and 96 of WTC 1 (plan view). 


\section{Summary of Structural Damage}

Figure $\mathrm{E}-42$ presents the cumulative damage to WTC 1 on all affected floors and columns for the more severe case.

Severe Floor Damage

\begin{tabular}{l}
$\begin{array}{l}\text { Floor system } \\
\text { structural damage } \\
\text { Floor system } \\
\text { removed }\end{array}$ \\
\hline
\end{tabular}

Column Damage

Severed

Heavy Damage

Moderate Damage

Light Damage
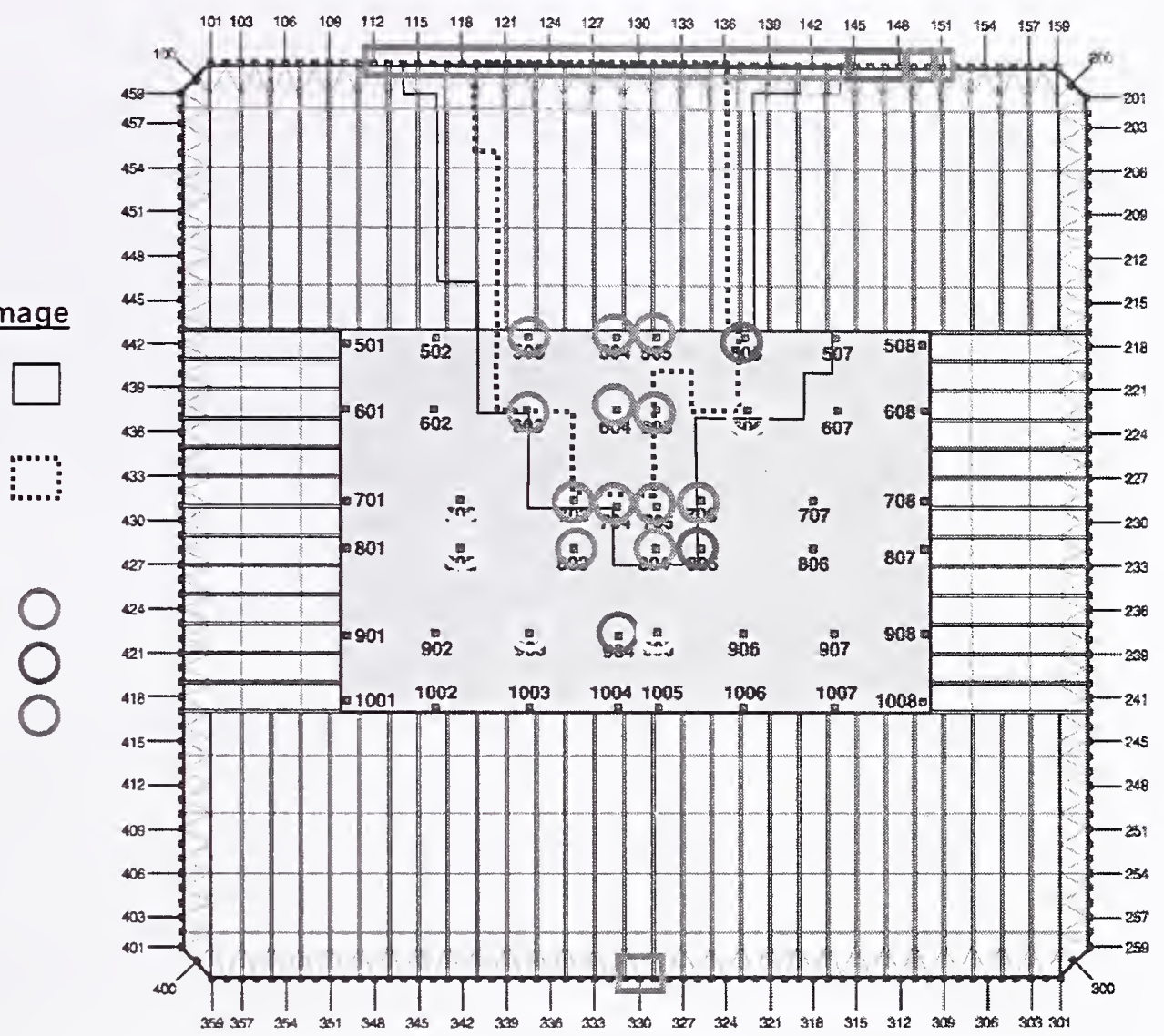

Figure E-42. Cumulative structural damage to the floors and columns of WTC 1 (more severe case).

\section{Fuel and Debris Distribution}

The distribution of the fuel in the tower calculated from the more severe case is shown in Figure E-43. A comparison to the calculated damage for the base case WTC 1 impact analysis indicated that the content damage zone is very similar in width but extended further south through the tower in the more severe impact. The more severe impact produced significantly greater content damage on the far side of the core and extended more fully through the tower. 
Time $=0.685$

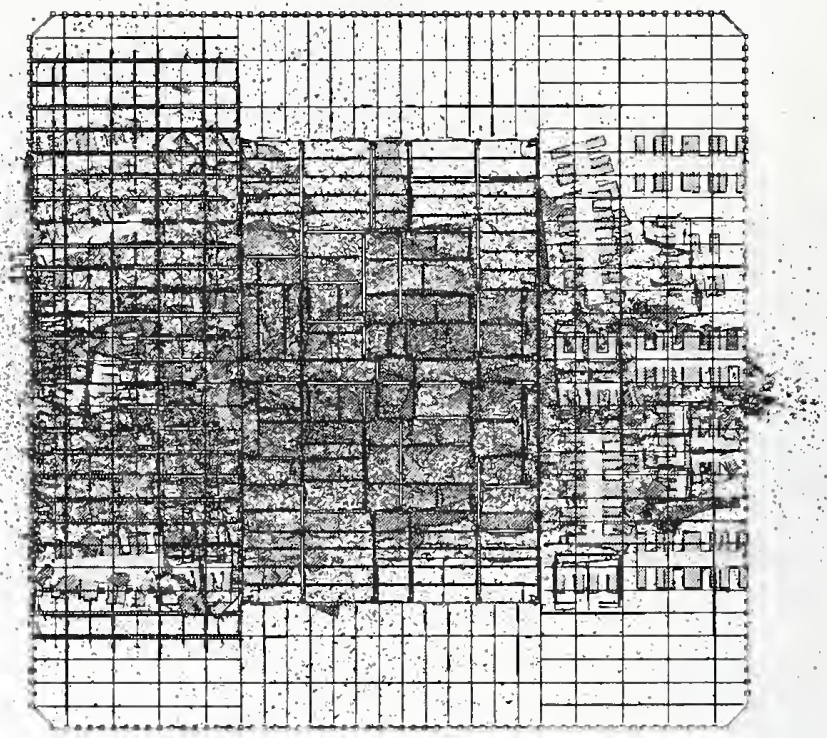

Figure E-43. Calculated fuel distribution and debris damage in the more severe WTC 1 analysis.

\section{E.7.3 WTC 1 Less Severe Impact Analysis}

For the north exterior wall of WTC 1, the magnitude and mode of impact damage were in good agreement with the observed damage for the less severe impact scenario. The core had a limited damage confined to the region nearest to the impact point. Only one column was severed, and two columns were heavily damaged for the less severe case, compared to three severed columns and four heavily damaged columns in the base case WTC 1 impact analysis.

The floor trusses experienced significant damage in the impact zone. The calculated impact response produced severe damage to the truss structures in the primary impact path of the fuselage. The truss structures were severely damaged from the exterior wall to the core. The truss floor system on floors 94 through 96 were damaged and sagged downward as a result of the impact loading. When compared with the base case, the magnitude of damage to the floor trusses and floor slabs was slightly increased for the less severe impact analysis. The parameters used in the less severe global impact analysis would primarily contribute to a reduced damage magnitude for the tower structures. However, the downward impact trajectory angle was increased from the 10.6 degree angle in the base case analysis to a 13.6 degree angle in the more severe impact analysis. This would have the effect of directing more of the impact energy downward, increasing the normal force on the floor structures in the impact zone. As a result, the combined effects of the analysis parameter variations produced a small increase in the damage to the truss structure in the less severe impact analysis scenario.

A comparison to the base case and less severe case indicated that the building contents damage zone was very similar in width but did not extend as far through the tower in the less severe impact. The less severe 
impact produced little content damage on the far side of the core and did not extend fully through the tower. No debris penetration of the south wall of the tower was observed for the less severe impact condition.

\section{E.7.4 WTC 2 Base Case Impact Analysis}

The WTC 2 base case impact analysis was performed for a $0.62 \mathrm{~s}$ duration following initial impact of the aircraft nose with the south exterior wall. The side view and top view of the base case WTC 2 global impact response is shown in Figure E-44 and Figure E-45, respectively. Full penetration of the aircraft into the tower was completed at $0.2 \mathrm{~s}$ after impact. The aircraft impact response was very similar to that of the WTC 1 impact and was dominated by the penetration and fragmentation of the airframe structures. The fuselage structures were severely damaged both from the penetration through the exterior columns and the penetration of the 81 st floor slab that sliced the fuselage structures in half. The downward trajectory of the aircraft structures caused the airframe to collapse against the floor, and the subsequent debris motion was redirected inward along a more horizontal trajectory parallel to the floor. The downward trajectory of the aircraft structures transferred sufficient vertical load that the truss floor structures on the 80 th and 81 st floors began to collapse in the impact zone by the end of the simulation.

The aircraft wing structures and fuel tank were fragmented by the impact with the tower exterior. The aircraft fuel cloud started to spread out immediately after impact, but the leading edge of the fuel remained relatively dense until passing approximately one-third of the lateral distance through the tower core (approximately $0.2 \mathrm{~s}$ after impact). At $0.3 \mathrm{~s}$ after impact, the aircraft fuel cloud had penetrated approximately two-thirds the distance through the core and was spreading out. Beyond this time, the subsequent motion of the aircraft fragments and fuel debris cloud was noticeably slowed. The spread of the fuel and debris cloud was more rapid and extensive in the open truss floor regions than through the core as a result of the open volume above the workstations in the truss floor zone. 


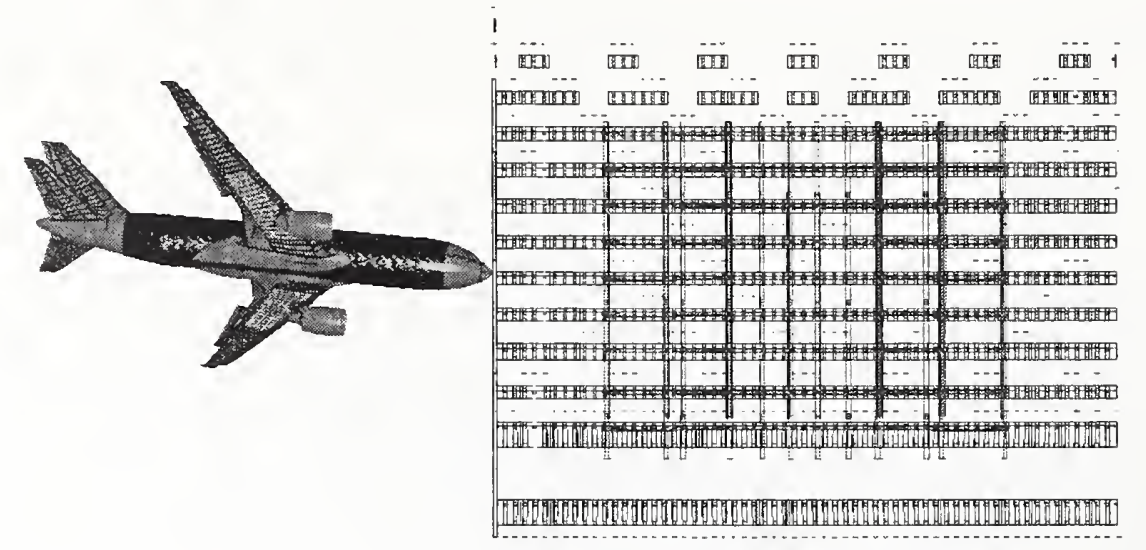

(a) Time $=0.00 \mathrm{~s}$

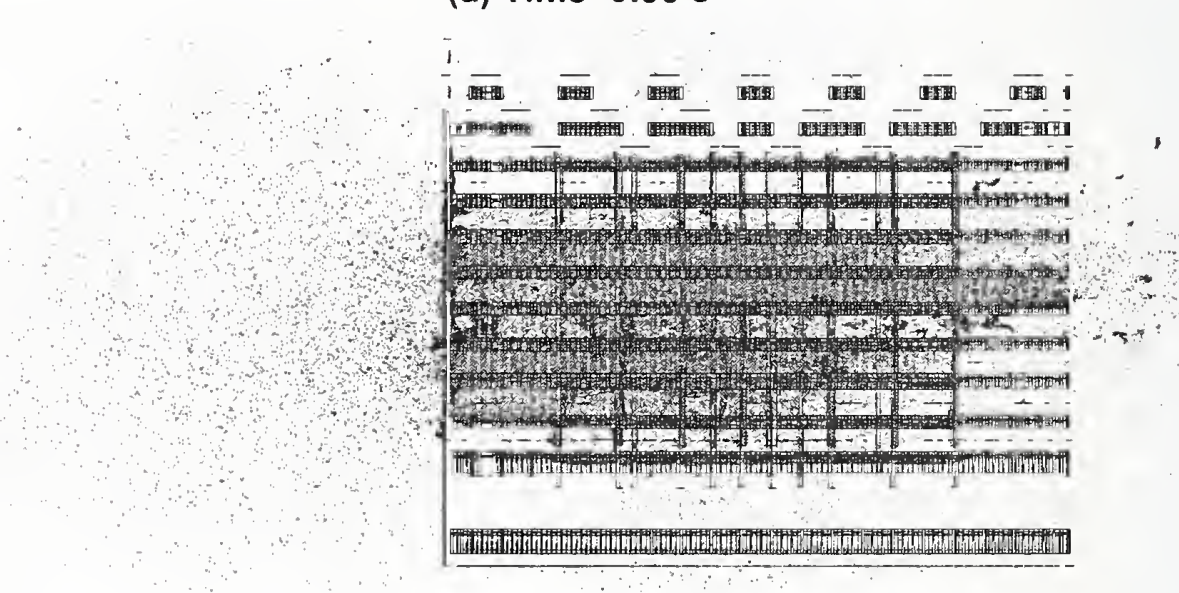

(b) Time $=0.50 \mathrm{~s}$

Figure E-44. WTC 2 base case global impact analysis - side view. 


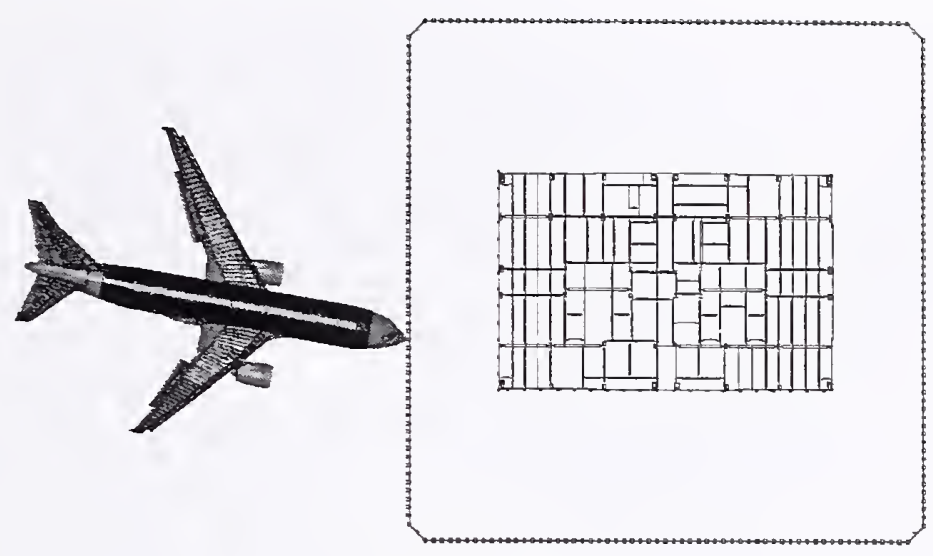

(a) Time $=0.00 \mathrm{~s}$

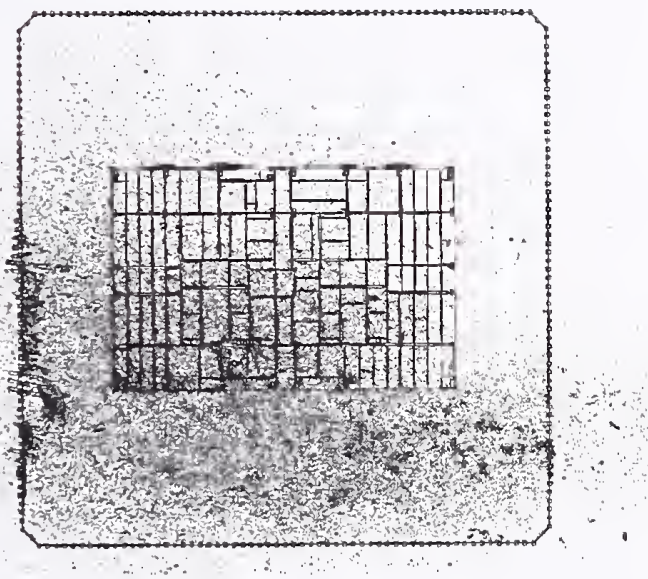

(b) Time $=0.50 \mathrm{~s}$

Figure E-45. WTC 2 base case global impact analysis - plan view.

\section{Exterior Wall Damage}

A comparison of the south exterior wall observed and calculated damage from the base case WTC 2 global impact analysis is shown in Figure E-46. The exterior wall completely failed in the regions of the fuselage, engine, and fuel-filled wing section impacts. Damage to the exterior wall extended to the wing tips, but the exterior columns were not completely failed in the outer wing and vertical stabilizer impact regions. Failure of the exterior columns occurred both at the bolted connections between column ends and at various locations in the column depending on the local severity of the impact load and the proximity of the bolted connection to the impact.

The comparison of the calculated and observed damage indicated that the geometry and location of the impact damage zone were in good agreement. This agreement served to validate the geometry of the aircraft model, including the aircraft orientation, trajectory, and flight distortions of the wings. The agreement of both the mode and magnitude of the impact damage served to partially validate the constitutive and damage modeling of the aircraft and exterior wall of the tower. 


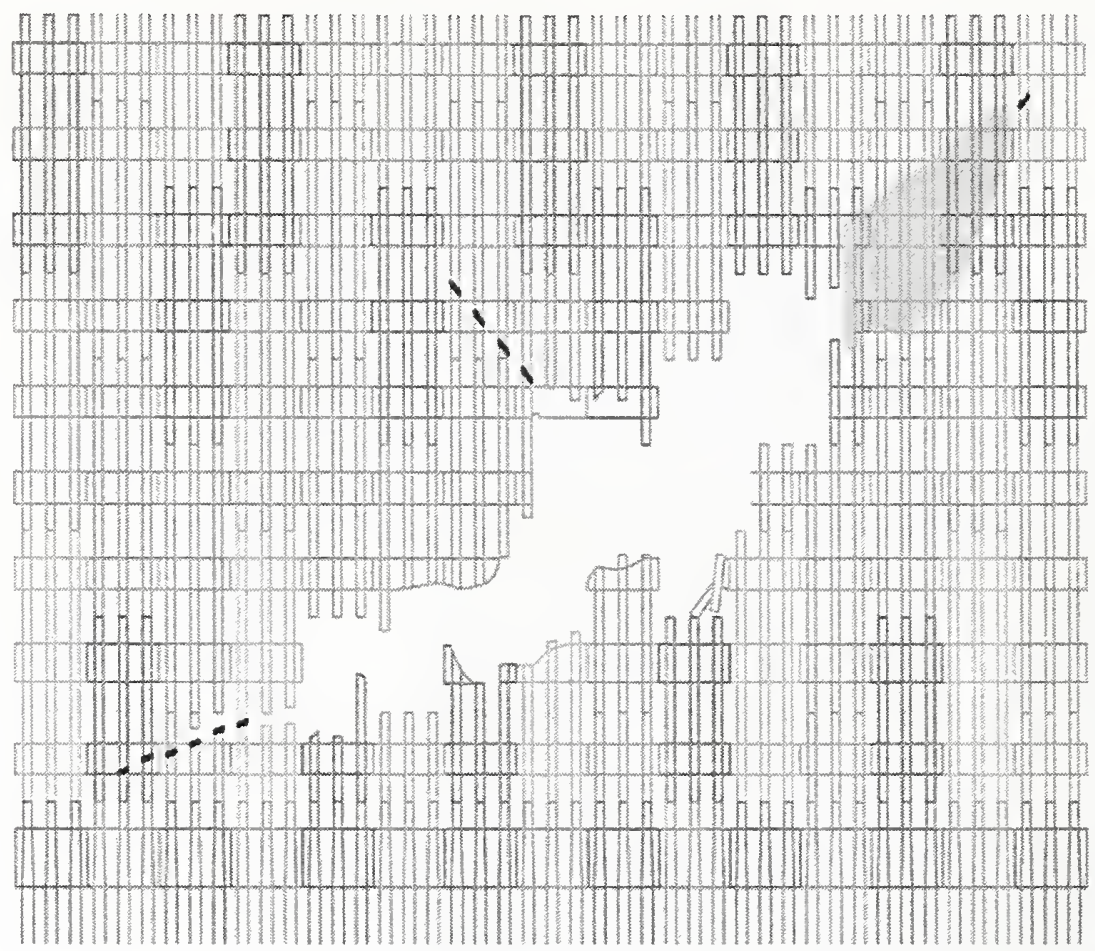

(a) Schematic of observed damage

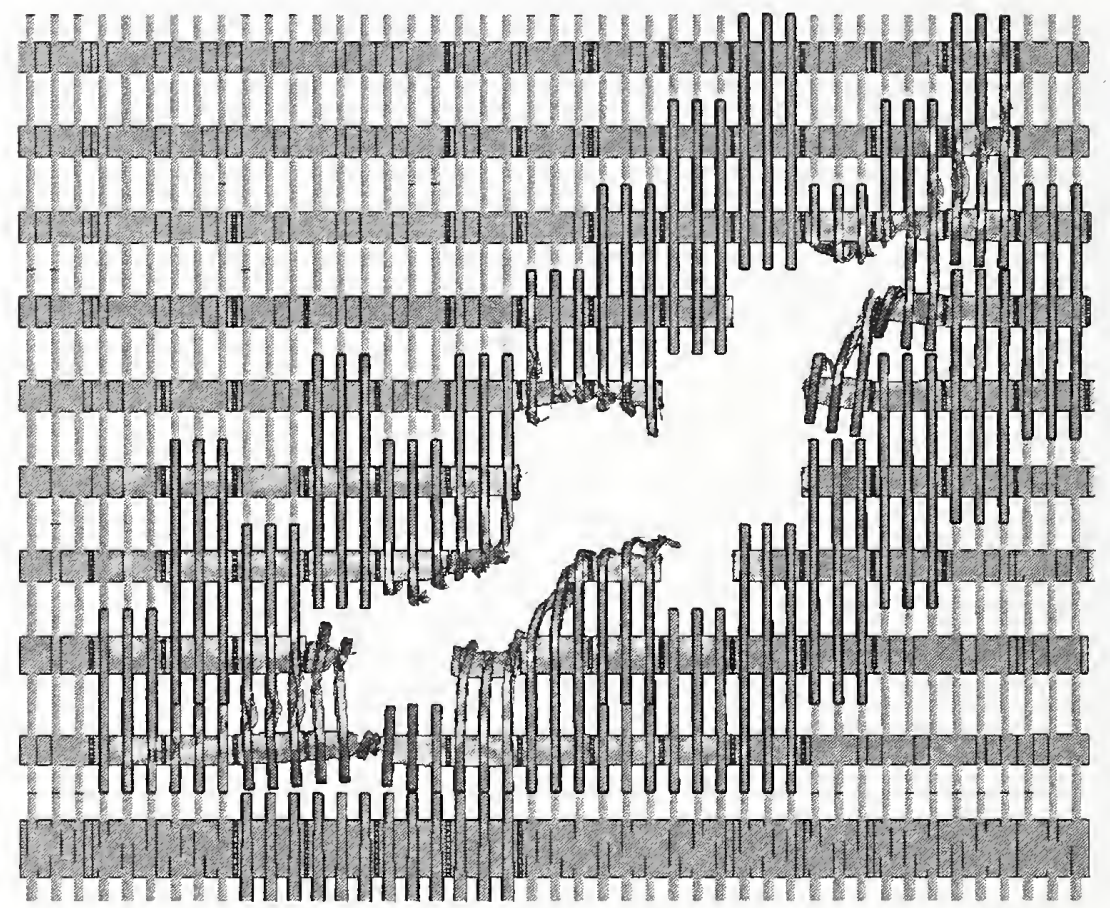

(b) Calculated damage

Figure E-46. Base case impact damage to the WTC 2 exterior wall. 


\section{Core Structural Damage}

The core had significant damage in the region close to the impact point, in particular the southeast corner of the core. The columns in line with the aircraft fuselage failed on the impact side, and several of the core beams were also severely damaged or failed in the impact zone. In some cases, failure of the column splices located on floors 77,80 , and 83 contributed significantly to the failure of the core columns. This was particularly true for the heavy column number 1001 at the southeast corner of the core that failed at the three splice locations.

The calculated damage to the core columns by row is shown in Figure E-47. A total of five columns were severed, and four columns were heavily damaged. The damage to the core beams for floors 80 and 81 is shown in Figure E-48.

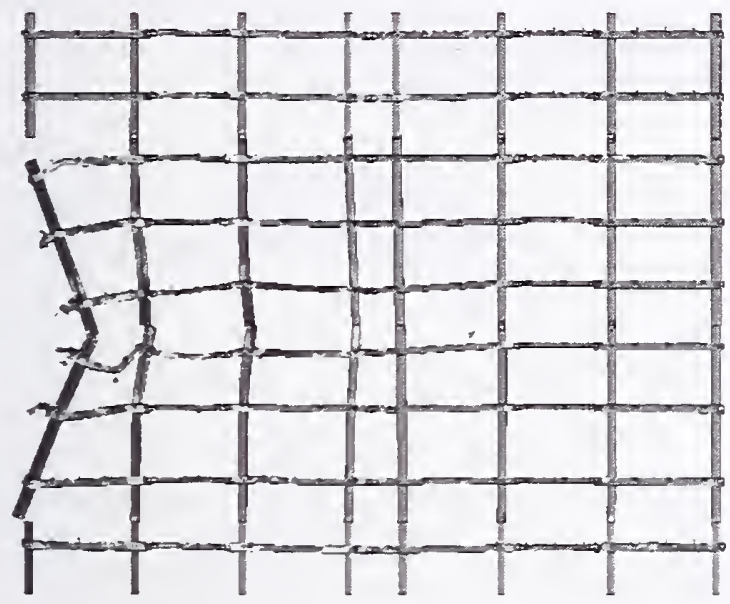

(a) Columns 1001-1008

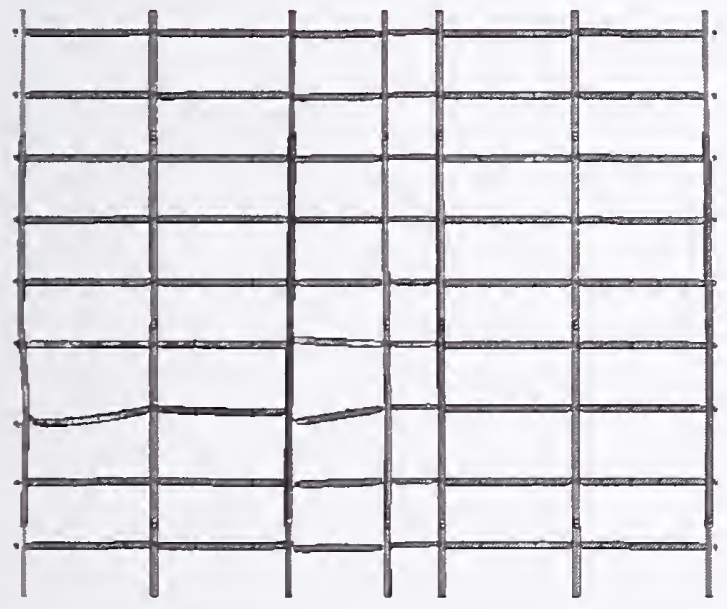

(c) Columns 801-807

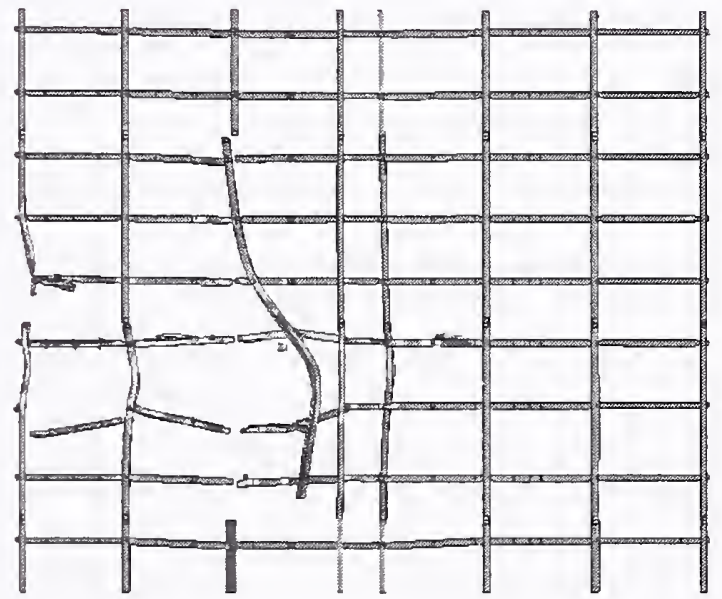

(b) Columns 901-908

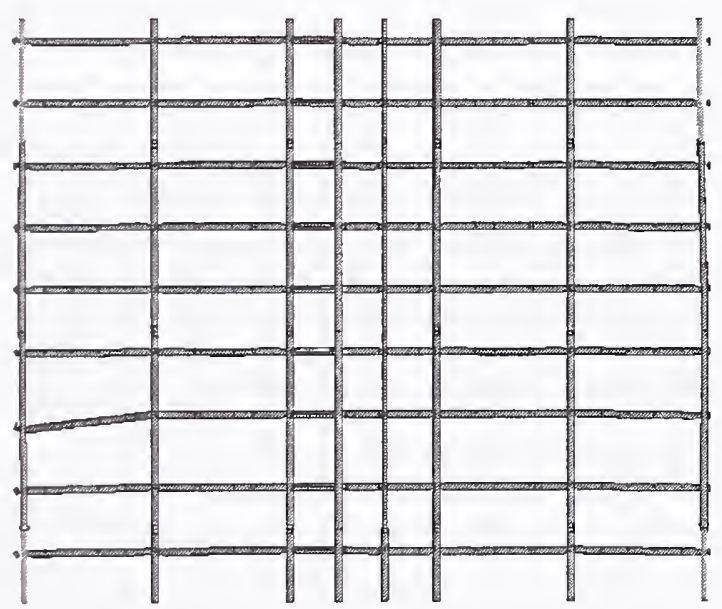

(d) Columns 701-708

Figure E-47. Base case impact damage to the WTC 2 core columns. 


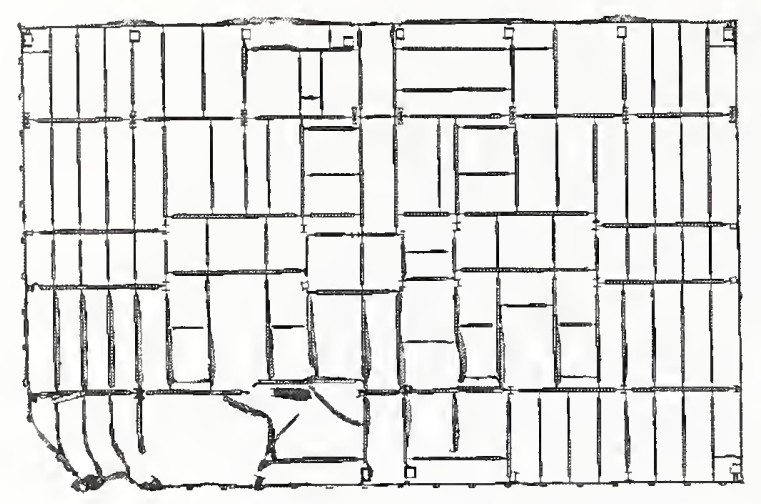

(a) Floor 80 core framing damage

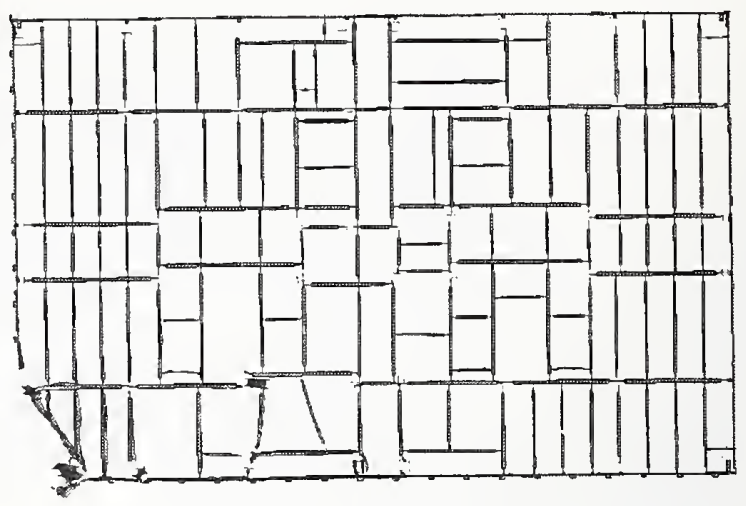

(b) Floor 81 core framing damage

Figure E-48. Base case impact damage to the core beams of floors 80 and 81 of WTC 2 .

\section{Floor Truss and Slab Damage}

An overall frontal view for the floor truss structure in the WTC 2 impact zone, along with the calculated base case impact damage to the trusses, is shown in Figure E-49. The figure shows that the trusses experienced significant damage in the impact zone, with the largest damage on floor 81. A plan view of the calculated damage to the trusses on floors 80 and 81 is shown in Figure E-50. The calculated impact response produced severe damage to the truss structures in the primary impact path of the fuselage. The truss structures were severely damaged from the exterior wall to the core. The truss floor system on floors 79 and 81 had sufficient damage from the impact that truss floor sections sagged downward. The calculated damage to the WTC 2 floor slabs for floors 80 and 81 is shown in Figure E-51, where a similar pattern of response to that observed in the trusses can be seen for the floor slabs. 
Floor 82

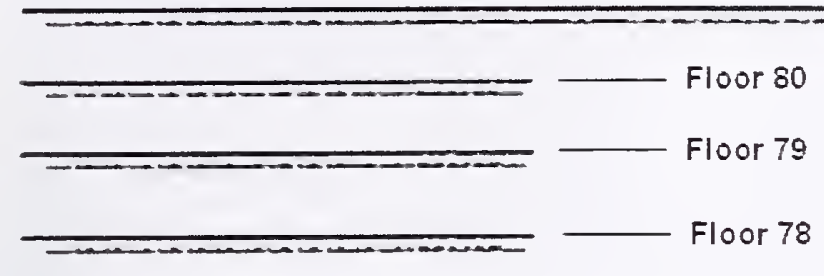

(a) Initial detailed truss structures

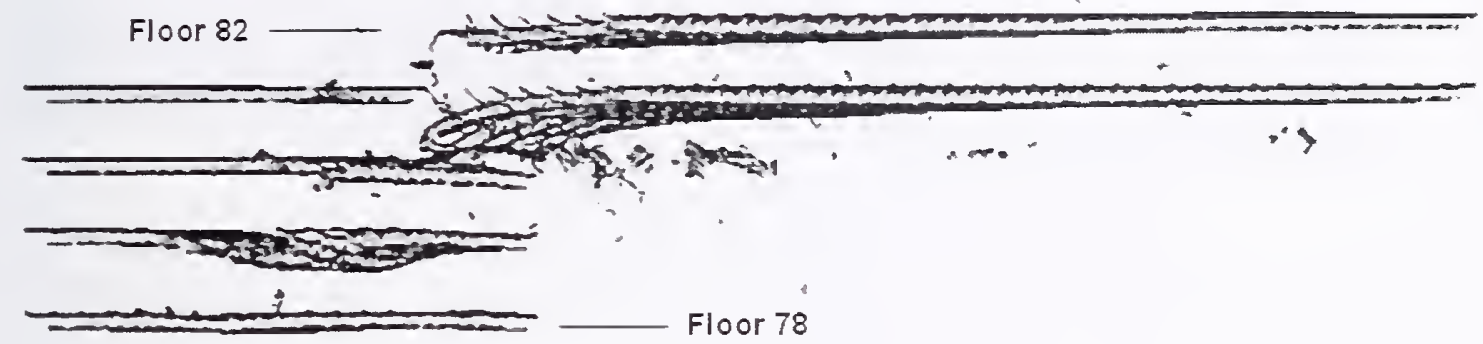

(b) Calculated damage

Figure E-49. Base case impact damage to the WTC 2 floor trusses (front view).
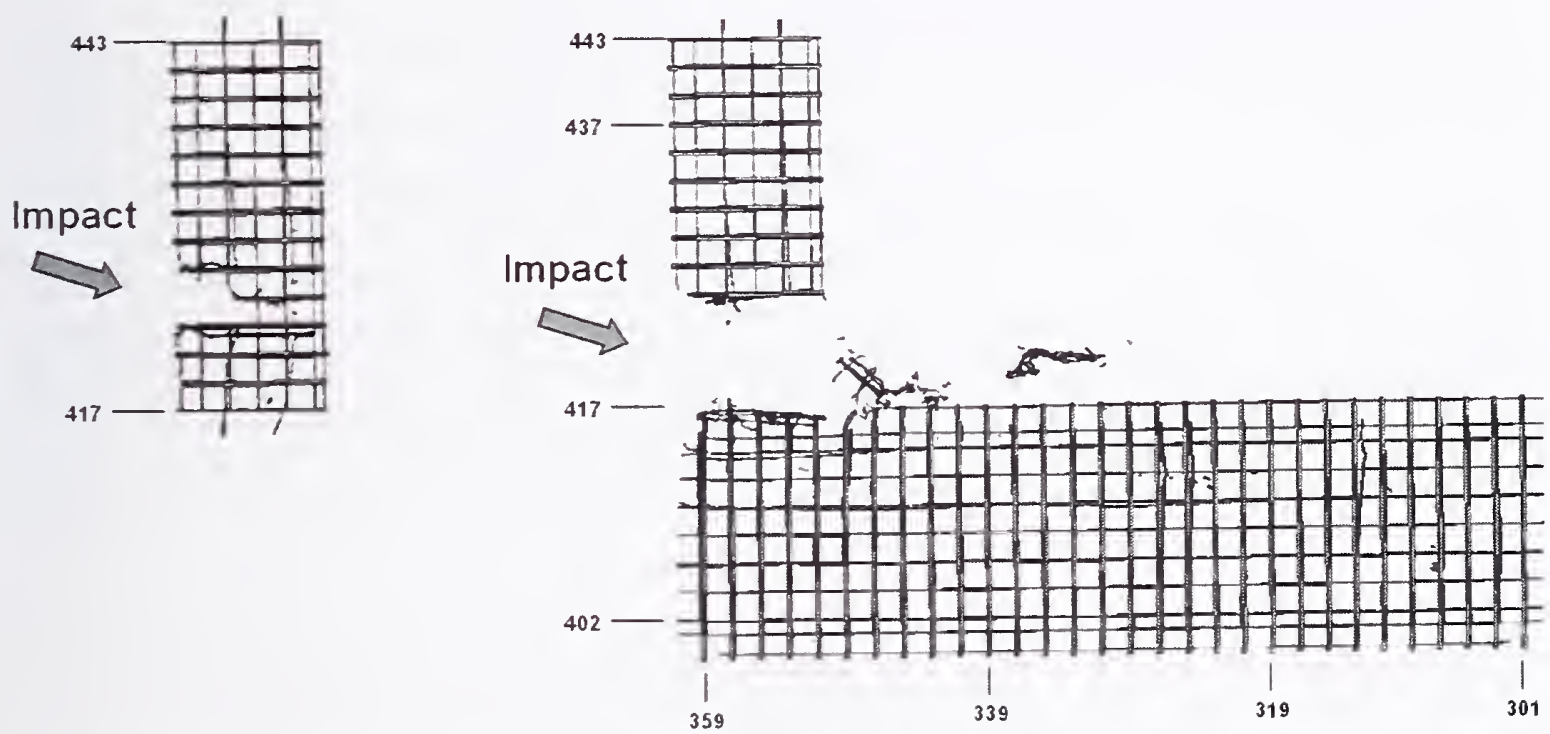

(a) Floor 80 truss damage

(b) Floor 81 truss damage

Figure E-50. Base case impact damage to the trusses on floors 80 and 81 of WTC 2 (plan view). 

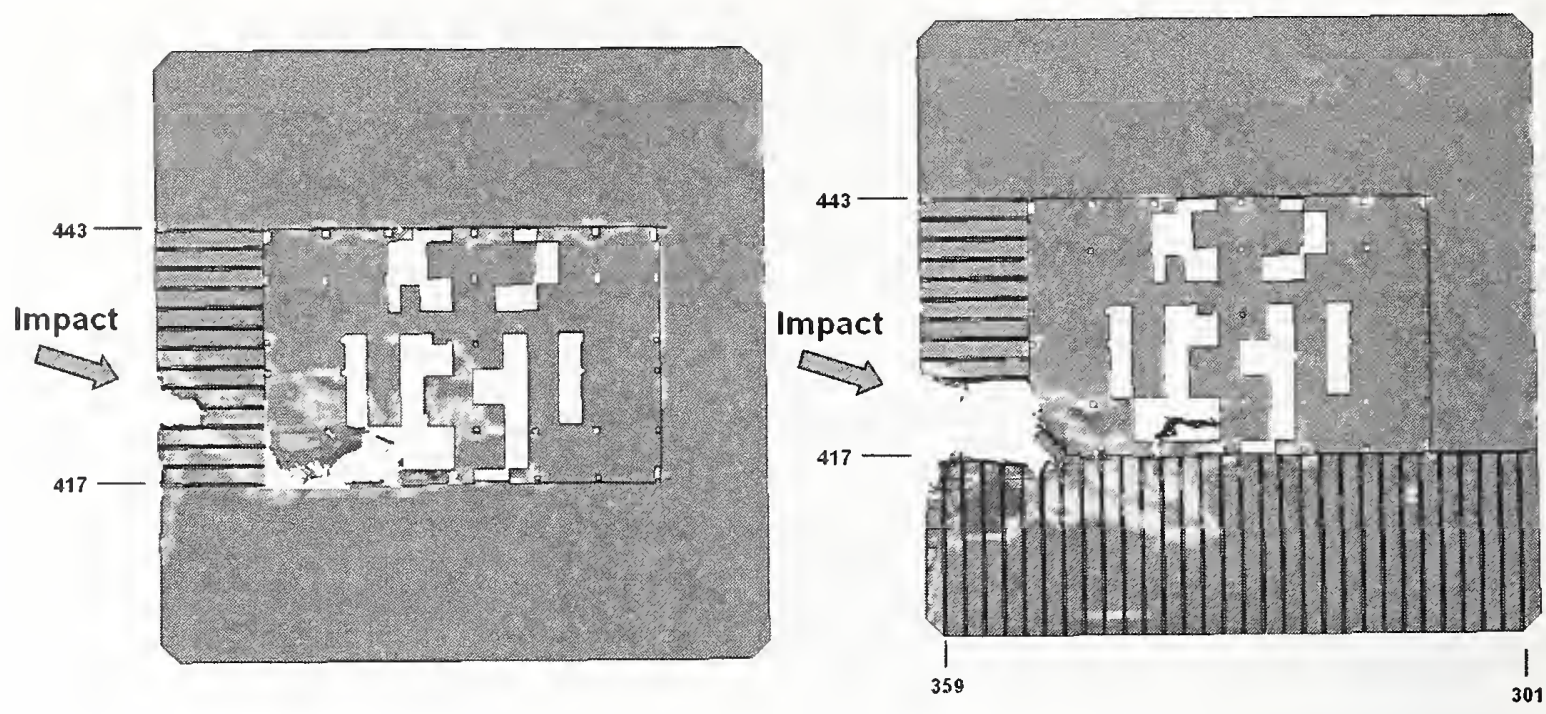

(a) Floor 80 slab damage (b) Floor 81 slab damage

Figure E-51. Base case impact damage to the slabs on floors 80 and 81 of WTC 2 (plan view).

\section{Summary of Structural Damage}

The impact-induced structural damage described above provided the initial conditions for the post-impact fire-structural analyscs. Figure E-52 presents the cumulative damage on all affected floors and columns. The damage to the columns at the various levels is identified by the color of the circles, where red, blue, green, and yellow signify severed, heavily damaged, moderately damaged, and lightly damaged columns, respectively. The dotted boxes on the figures indicate areas where the impact created an opening in the floor. These were used to identify slab openings in the fire dynamics simulations. The solid boxes indicate areas in the floor system that had severe structural damage. These areas were removed from the subsequent structural analyses. Figure E-52 also shows the damage to columns on the north perimeter wall, which the analysis did not capture due to the coarse mesh on the north wall. This damage was observed in photographs. As a result, this damage was accounted for in the subsequent structural analyses. 


\section{Severe Floor Damage \\ Floor system structural damage \\ Floor system removed \\ Column Damage \\ Severed \\ Heavy Damage \\ Moderate Damage}

Light Damage

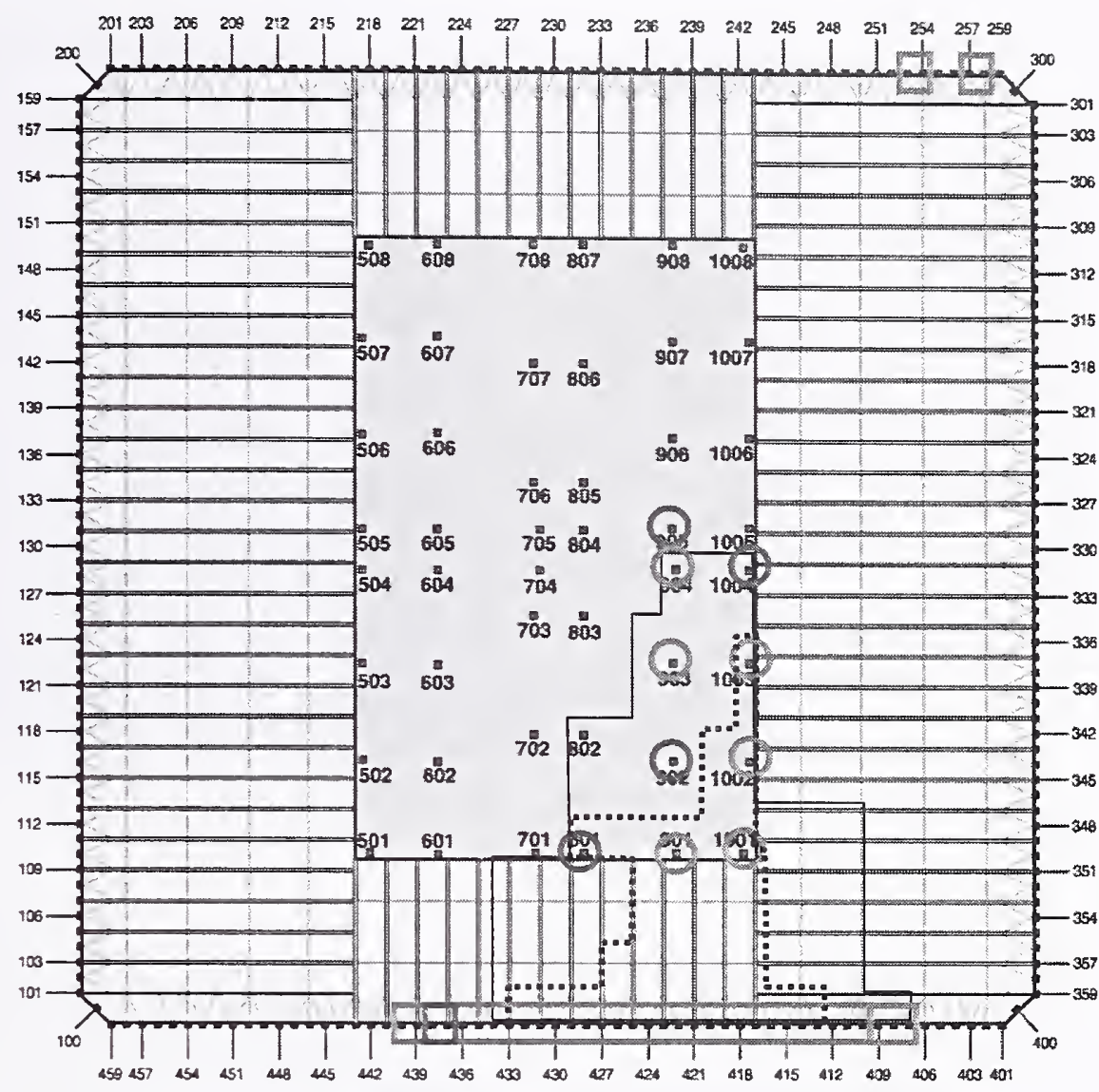

Figure E-52. Cumulative structural damage to the floors and columns of WTC 2 (base case).

\section{Fuel and Debris Distributions}

The calculated distribution of the aircraft debris and fuel cloud from the base case WTC 2 global impact analysis was shown previously in Figure E-44 and Figure E-45. Figure E-53 shows the distribution of fuel and damage to the building contents due to impact. The bulk of the aircraft debris and fuel was arrested prior to exiting the tower structures. However, a significant amount of aircraft debris was calculated to exit the north and east sides of the tower (Sides 300 and 200 of WTC 2).

The bulk of the fuel and aircraft debris was deposited in floors 78 through 80 , with the greatest concentration of aircraft debris on floor 80 , and the largest concentration of aircraft fuel on floors 79,81 , and 82 . The calculated debris distribution included $55,800 \mathrm{lbs}$ of debris and $10,600 \mathrm{lbs}$ of aircraft fuel outside of the tower at the end of the impact analysis, either rebounding from the impact face or passing through the tower. The calculated mass outside the tower is believed to be larger than is realistic, since the exterior walls were not modeled with windows that could contain the fuel cloud and small debris inside the tower. In addition, treatment of the aircraft fuel cloud did not include the ability to stick to, or wet, interior components. Rather, the aircraft fuel SPH particles tended to bounce off of internal structures. 


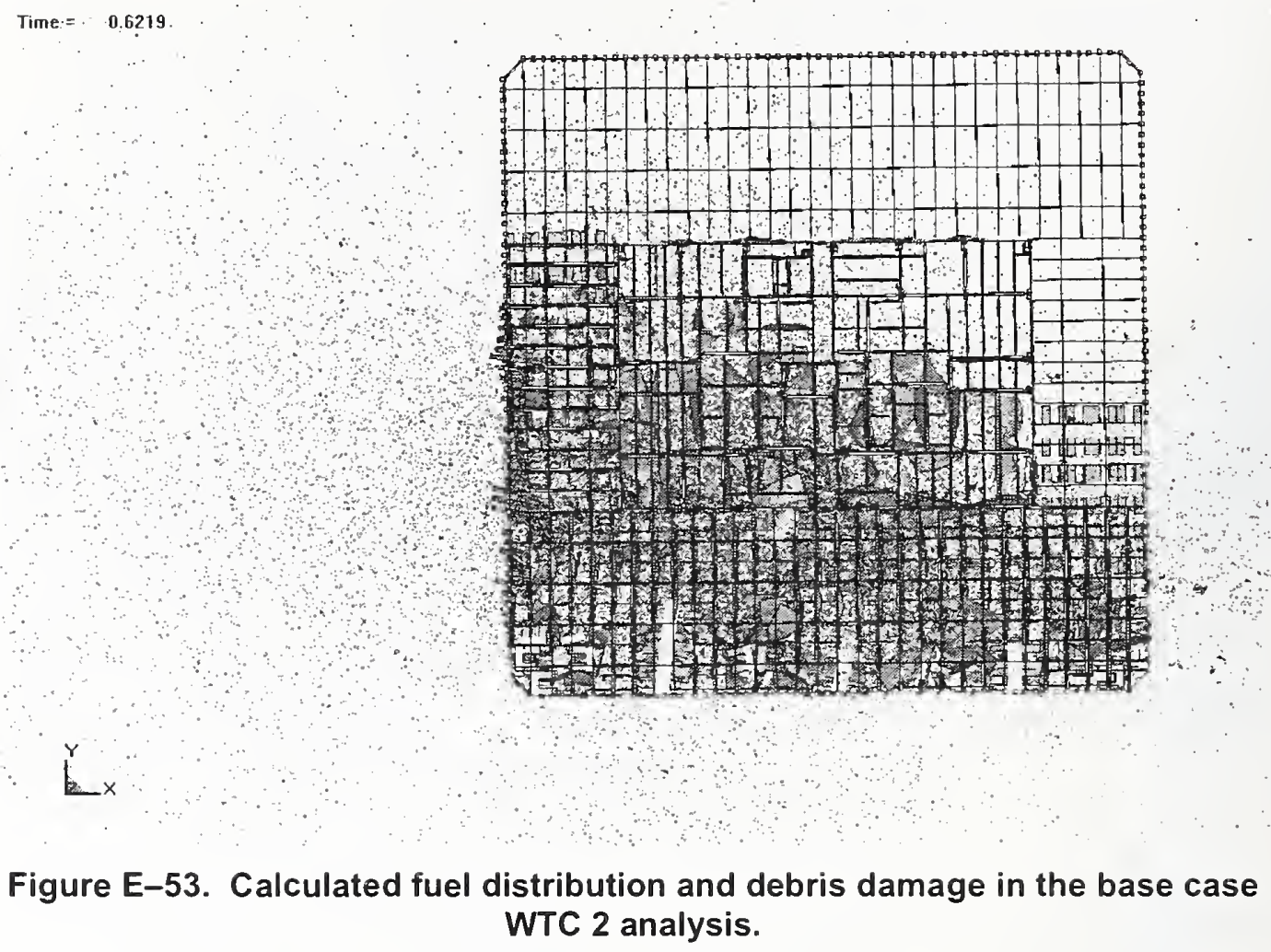

\section{E.7.5 WTC 2 More Severe Impact Analysis}

This section summarizes the results of the more severe impact analysis for WTC 2. The parameters for the more severe and less severe damage cases for WTC 2 were similar to those for WTC 1. Section E.7.6 provides a brief description of the WTC 2 less severe case.

\section{Exterior Wall Damage}

The calculated damage to the south wall from the more severe WTC 2 global impact analysis is shown in Figure E-54. A comparison of the south exterior wall observed (Figure E-46a) and calculated (Figure E-54) damage from the more severe WTC 2 global impact analysis indicated that the calculated and observed magnitude and mode of impact damage were still in good agreement.

As was the case for WTC 1, there were small differences in the damage estimates for the south wall of WTC 2 from the base case and the more severe case scenarios (compare Figure E-46b and Figure E-54). Overall, the agreement with the observed damage from photographs was very good for both cases. The most obvious differences were largely due to portions of panels that may have severed columns in one case or have been removed at the connections in another. 


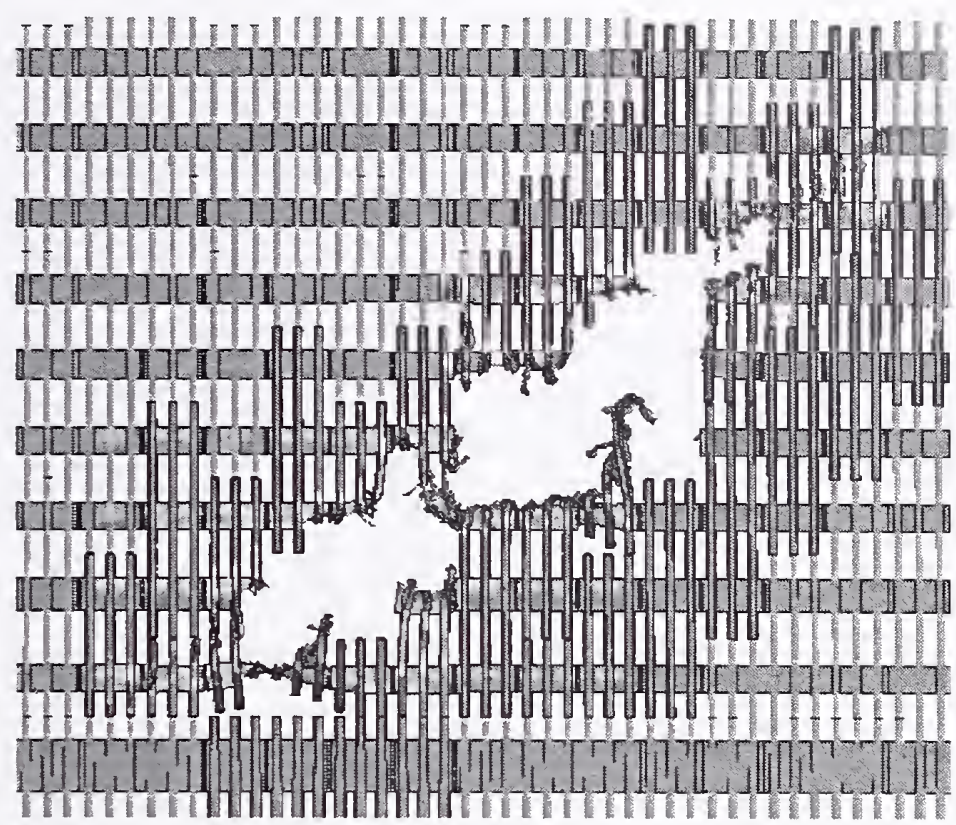

Figure E-54. Calculated more severe impact damage to the WTC 2 exterior wall.

\section{Core Structural Damage}

The core had extensive damage in the region close to the impact point. The columns in line with the aircraft fuselage failed on the impact side, and several of the core beams were also severely damaged or failed in the impact zone. In some cases, failure of the column splices located on floors 77,80 , and 83 contributed significantly to the failure of the core columns.

The calculated damage to the core columns by row is shown in Figure E-55, and the damage to the core framing at floors 80 and 81 is shown in Figure E-56. A total of ten columns were severed, and one column was heavily damaged in the WTC 2 more severe case, compared to five columns severcd and four columns heavily damaged in the base case WTC 2 impact analysis. This shows a clear correlation between damage magnitude and impact severity. 


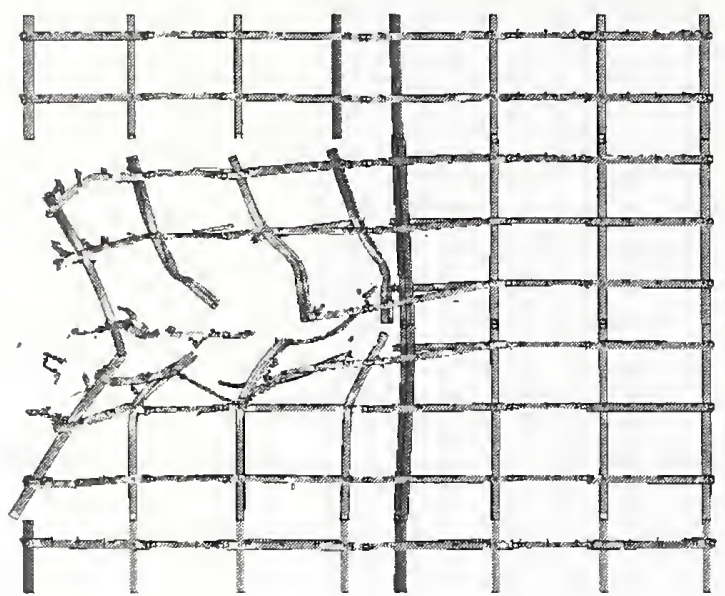

(a) Columns 1001-1008

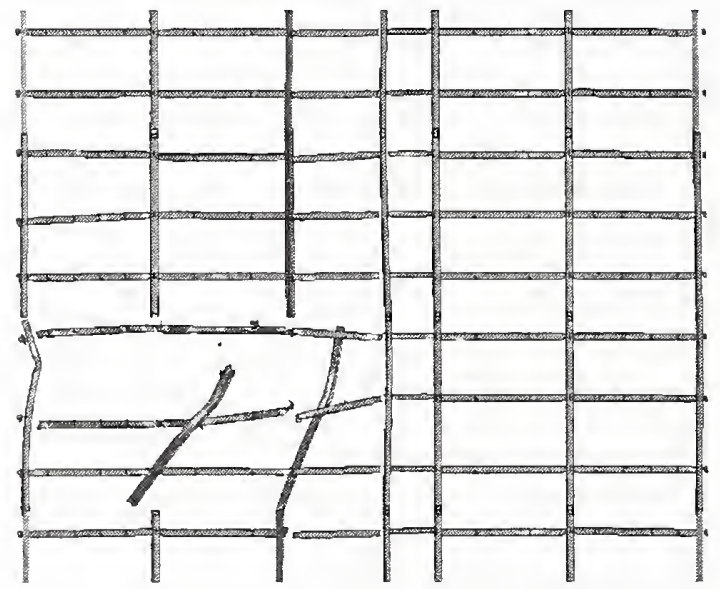

(c) Columns $801-807$

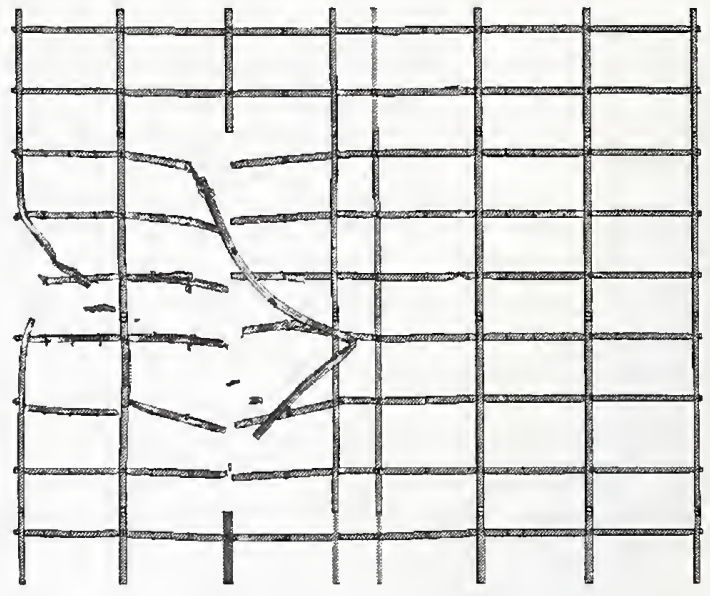

(b) Columns 901-908

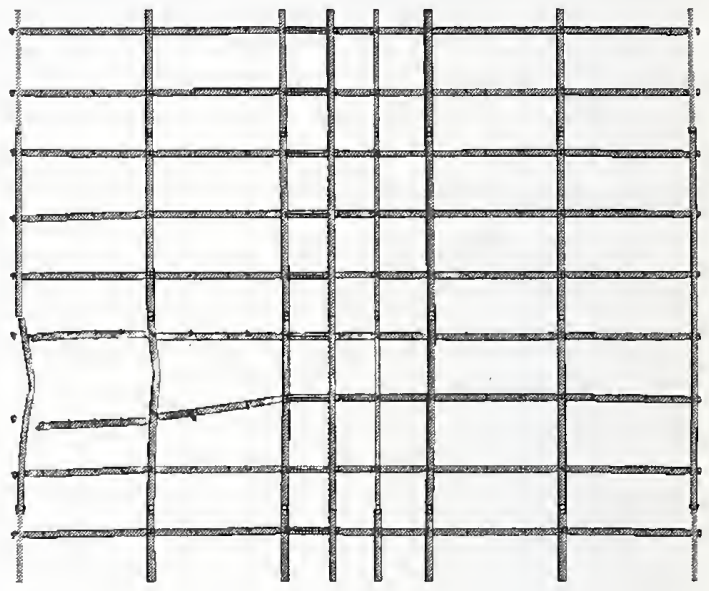

(d) Columns 701-708

Figure E-55. More severe impact damage to the WTC 2 core columns. 


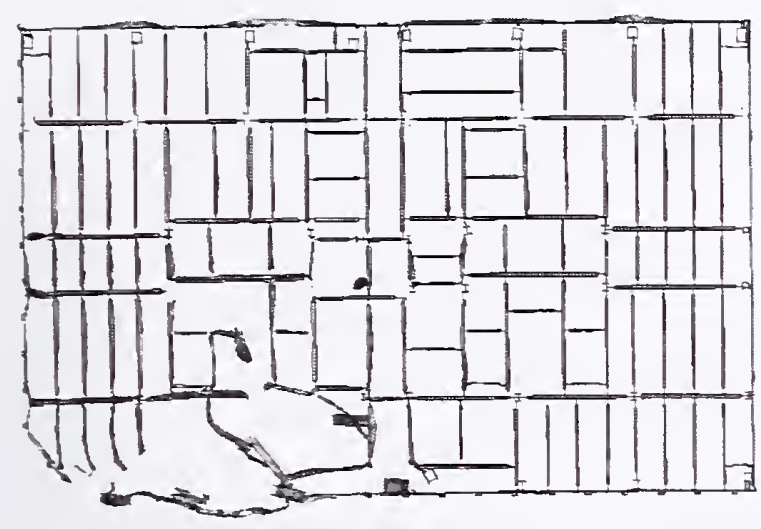

(a) Floor 80 core framing damage

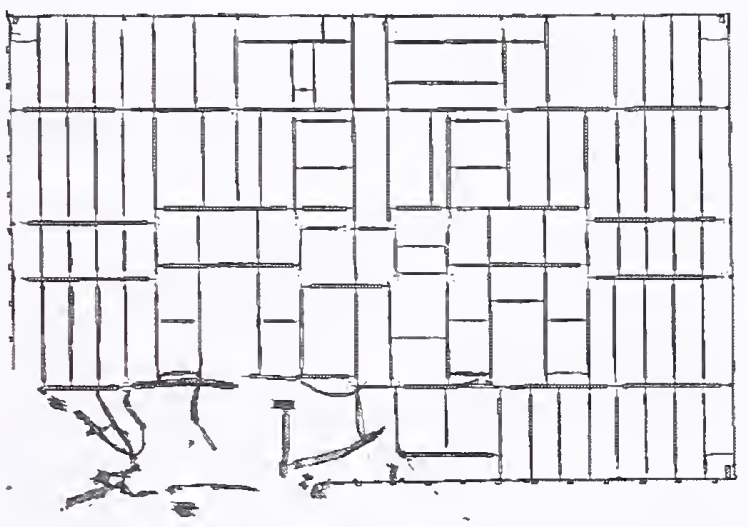

(b) Floor 81 core framing damage

Figure E-56. More severe impact damage to the core beams of floors 80 and 81 of WTC 2.

\section{Floor Truss and Slab Damage}

An overall frontal view for the calculated more severe impact damage to the trusses is shown in Figure E-57. The figure shows that the trusses experienced significant damage in the impact zone, with the heaviest damage on floor 81. A plan view of the calculated damage to the trusses on floors 80 and 81 is shown in Figure E-58. The calculated impact response produced severe damage to the truss structures in the primary impact path of the fuselage. The truss structures were severely damaged from the exterior wall to the core. The truss floor system on floors 79 through 82 had sufficient damage from the impact that portions of the truss floor sections sagged downward as a result of the impact.

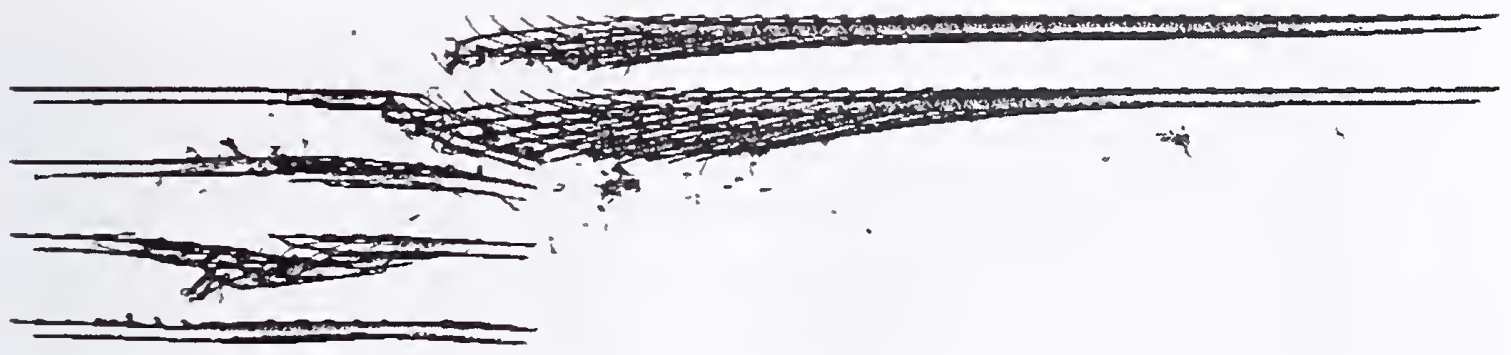

Figure E-57. Calculated more severe impact damage to the WTC 2 floor trusses (front view).

The magnitude of truss floor damage was very similar for the base case and more severe global impact analyses. The parameters used in the more severe global impact analysis would primarily contribute to an increased amount of damage for the tower structures. However, the downward impact trajectory angle was reduced from the 6 degree angle in the base case analysis to a 5 degree angle in the more severe impact analysis. This resulted in directing more of the impact energy inward toward the tower core, but reducing the normal downward force on the floor structures in the impact zone. As a result, the combined effects of the analysis parameter variations produced very similar damage to the truss structure. 
The calculated damage to the WTC 2 floor slab for floors 80 and 81 for the more severe impact is shown in Figure E-59. The magnitude of floor slab damage was very similar for the base case and more severe global impact analyses due to the reasons explained above for the floor trusses.
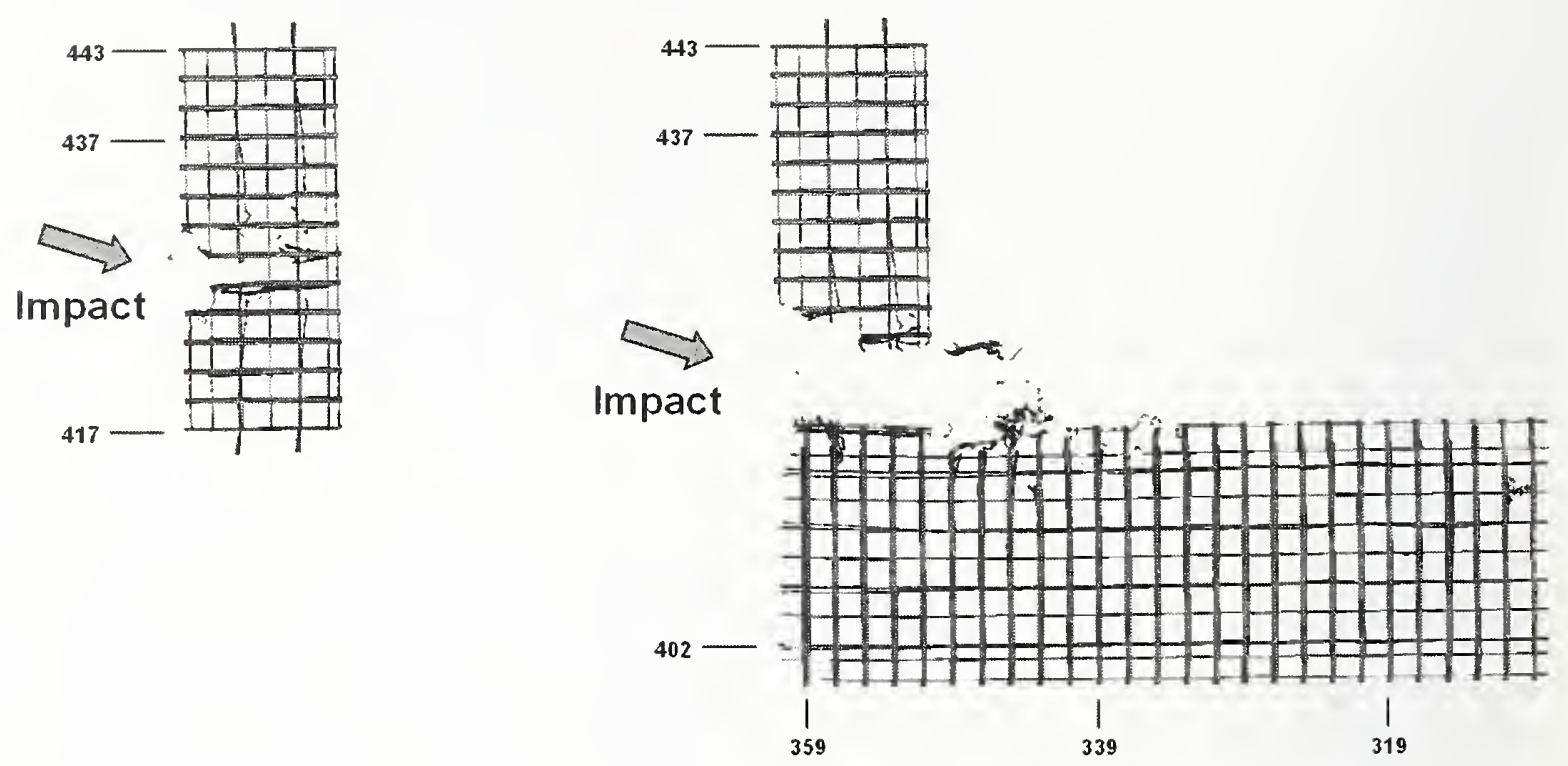

(a) Floor 80 truss damage

(b) Floor 81 truss damage

Figure E-58. More severe impact damage to the trusses on floors 80 and 81 of WTC 2 (plan view).

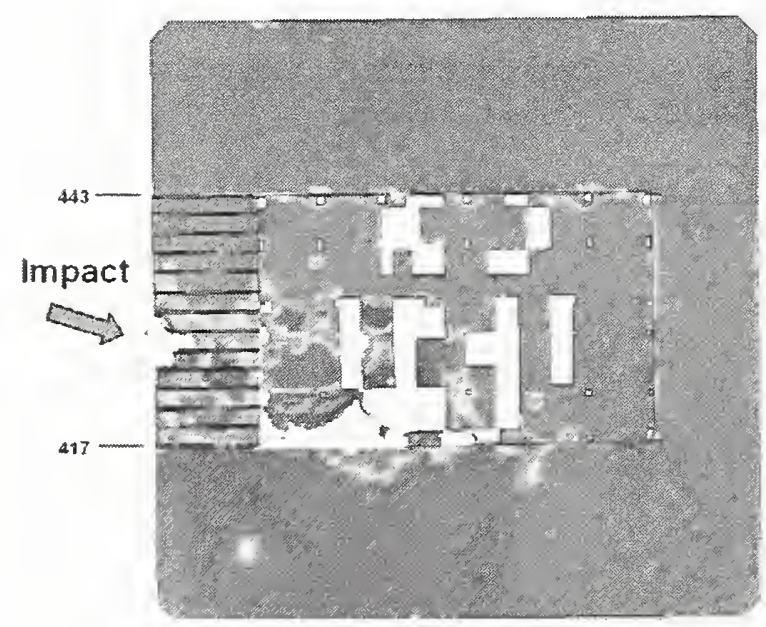

(a) Floor 80 slab damage

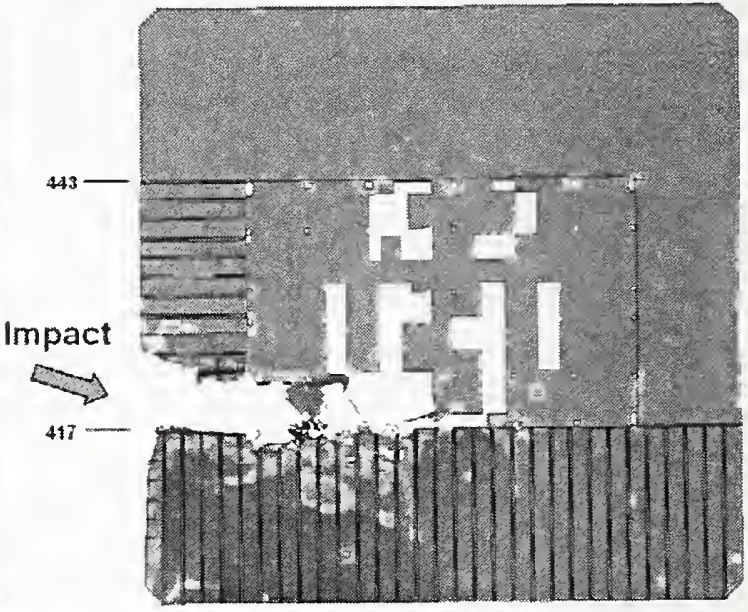

(b) Floor 81 slab damage

Figure E-59. More severe impact damage to the WTC 2 floor slab (plan view). 


\section{Summary of Structural Damage}

Figure E-60 presents the cumulative damage to WTC 2 on all affected floors and columns for the more severe case.

Severe Floor Damage
Floor system
structural damage $\square$

Floor system removed

\section{Column Damage \\ Severed \\ Heavy Damage \\ Moderate Damage}

Light Damage

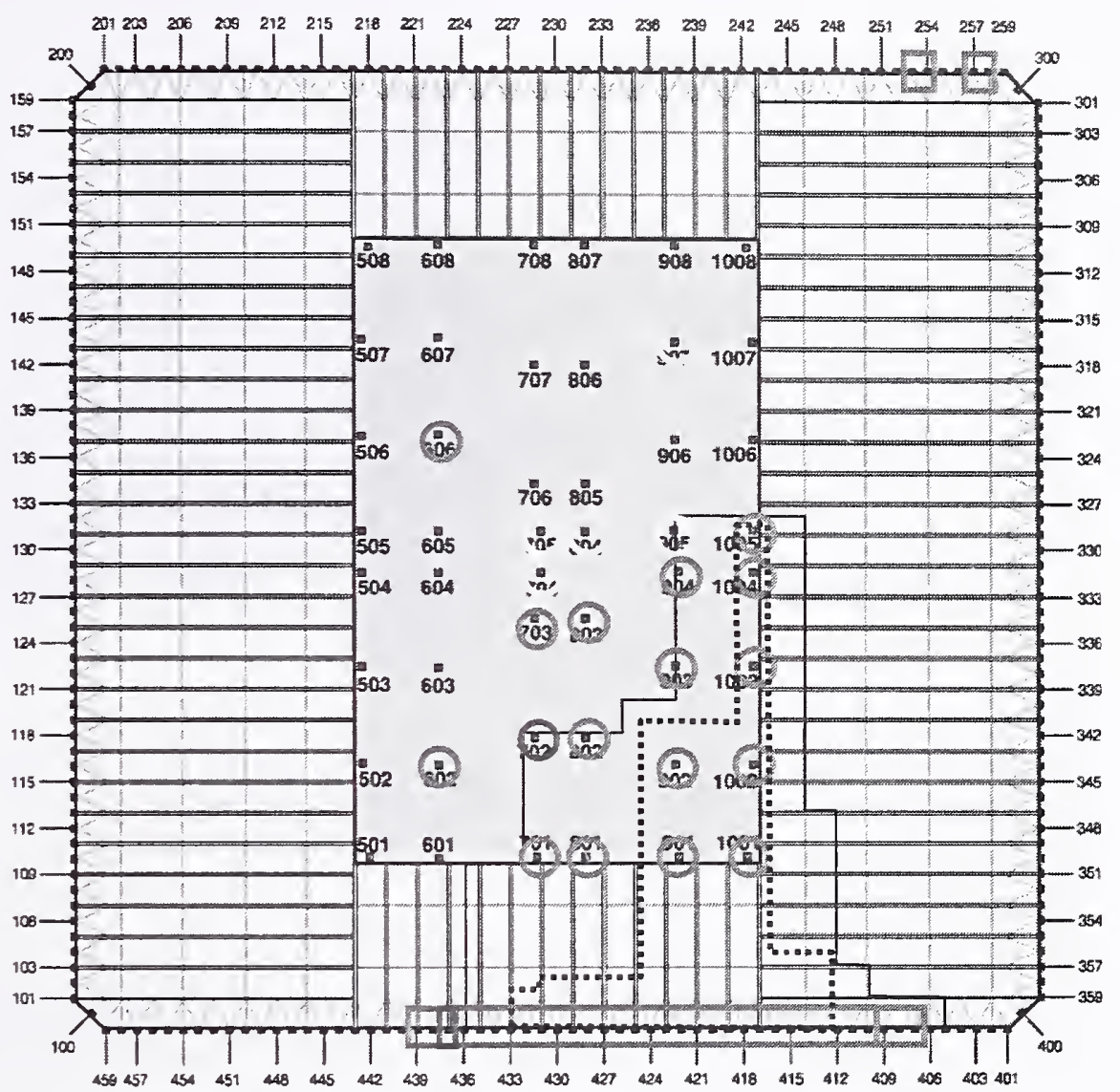

Figure E-60. Cumulative structural damage to the floors and columns of WTC 2 (more severe case).

\section{Fuel and Debris Distributions}

The distribution of the fuel in the tower calculated from the more severe case in a plan view and side view is shown in Figure E-61. A comparison to the calculated damage for the base case WTC 2 impact analysis indicated that the tower contents damage zone was similar, with a slight increase in damage for the more severe impact. 


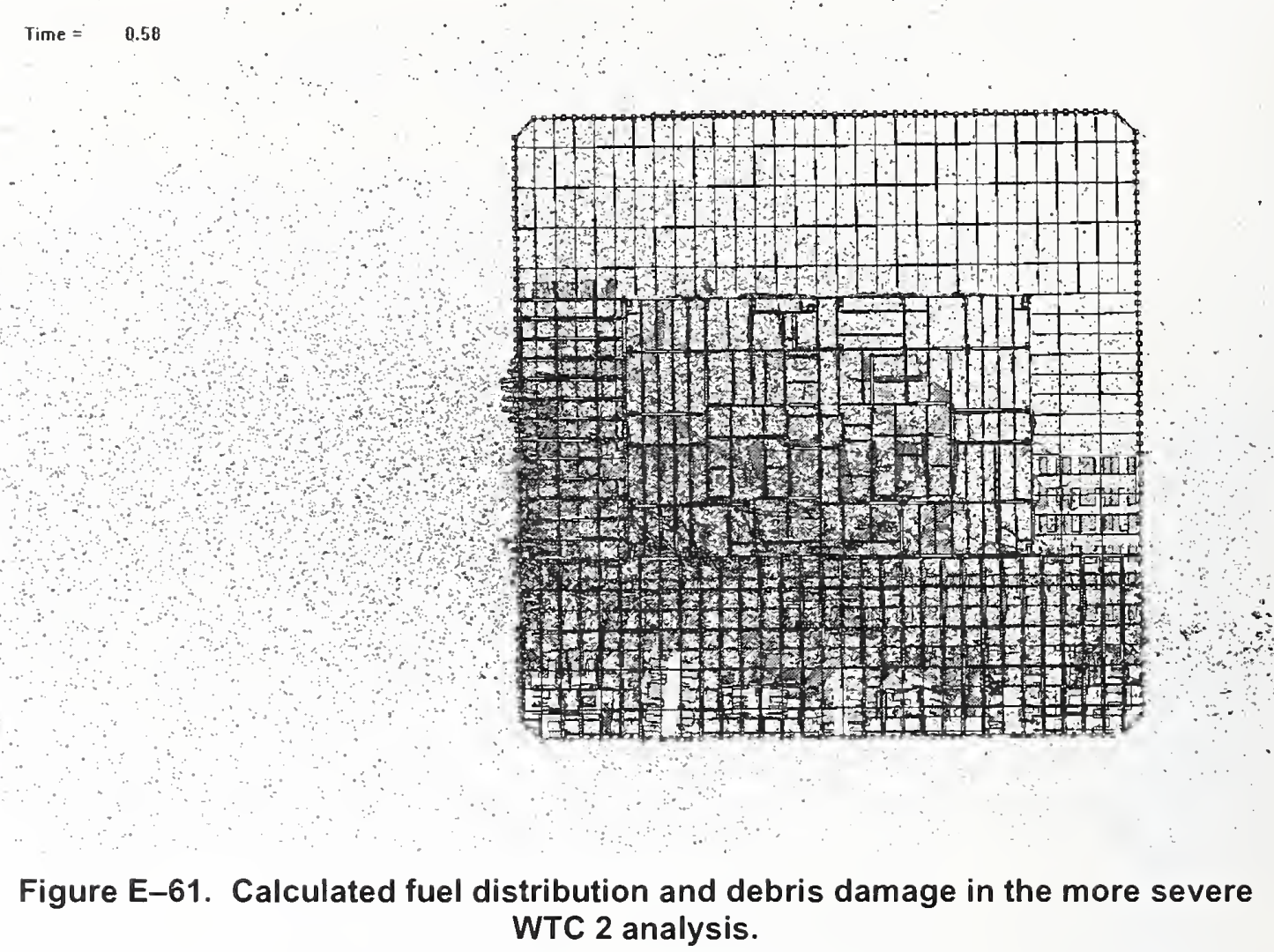

\section{E.7.6 WTC 2 Less Severe Impact Analysis}

For the south exterior wall of WTC 2, the magnitude and mode of impact damage were in good agreement with the observed damage for the less severe impact scenario. The core had significant damage in the region close to the impact point. The columns in line with the aircraft fuselage failed on the impact side, and several of the core beams were also severely damaged or failed in the impact zone. In some cases, failure of the column splices located on floors 77,80 , and 83 contributed significantly to the failure of the core columns. A total of three columns were severed, and two columns heavily damaged, compared to five severed columns and four heavily damaged columns in the base case WTC 2 impact analysis.

The truss floor system on floors 79 through 82 had sufficient damage from the impact that portions of the truss floor sections sagged downward as a result of the impact. The trusses experienced significant damage in the impact zone, with the heaviest damage on floor 81 . The calculated impact response produced severe damage to the truss structures in the primary path of the fuselage. The truss structures were completely destroyed along the impact path on floor 81 from the exterior wall to the core.

When compared with the base case, the magnitude of damage to the floor trusses and floor slabs was slightly increased for the less severe impact analysis. The parameters used in the less severe global impact analysis would primarily contribute to a reduced damage magnitude for the tower structures. However, the downward impact trajectory angle was increased from the 6 degree angle in the base case analysis to an 8 degree angle in the less severe impact analysis. This would have the effect of directing 
more of the impact energy downward, increasing the normal force on the floor structures in the impact zone. As a result, the combined effects of the analysis parameter variations produced very similar damage to the truss structure.

A comparison to the base case and less severe case indicated that the building contents damage zone was similar, with a slight reduction in damage for the less severe impact.

\section{E.7.7 Comparison with Observables}

The observables available to help validate the global impact analyses included the following:

- Damage to the building exterior (exterior walls and floors in the immediate vicinity of the impact) documented by photographic evidence.

- Aircraft debris external to the towers (landing gear for WTC 1 and a landing gear and an engine for WTC 2) as documented by photographic evidence.

- Eyewitness accounts from survivors who were inside the towers (blocked or passable stairwells).

An example of such comparisons was a detailed comparison between the observed and calculated damage (from the base case analysis) to the north wall of WTC 1 and the south wall of WTC 2. The comparison included the mode, magnitude, and location of failure around the hole created by the aircraft impact. The color code included the following: (1) green circles indicating a proper match of the failure mode and magnitude between the observed and calculated damage, (2) yellow circles indicating a proper match in the failure mode, but not the magnitude, (3) red circles indicating that the failure mode and magnitude predicted by the calculation did not match that was observed, and (4) black circles indicating that the observed damage was obscured by smoke, fire, or other factors. The comparisons shown in Figure E-62 and Figure E-63 for WTC 1 and WTC 2, respectively, indicate that the overall agreement with the observed damage was very good. 


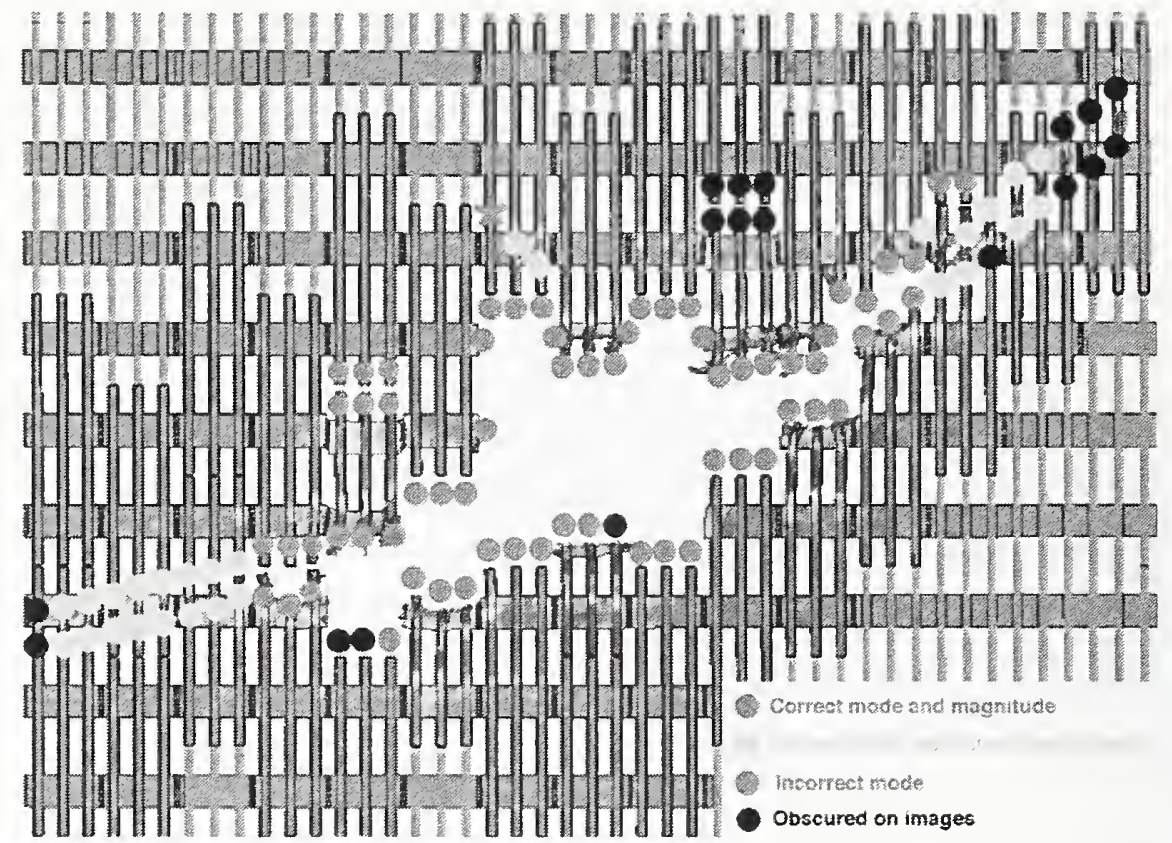

Figure E-62. Comparison of observable and calculated base case impact damage to the north wall of WTC 1.

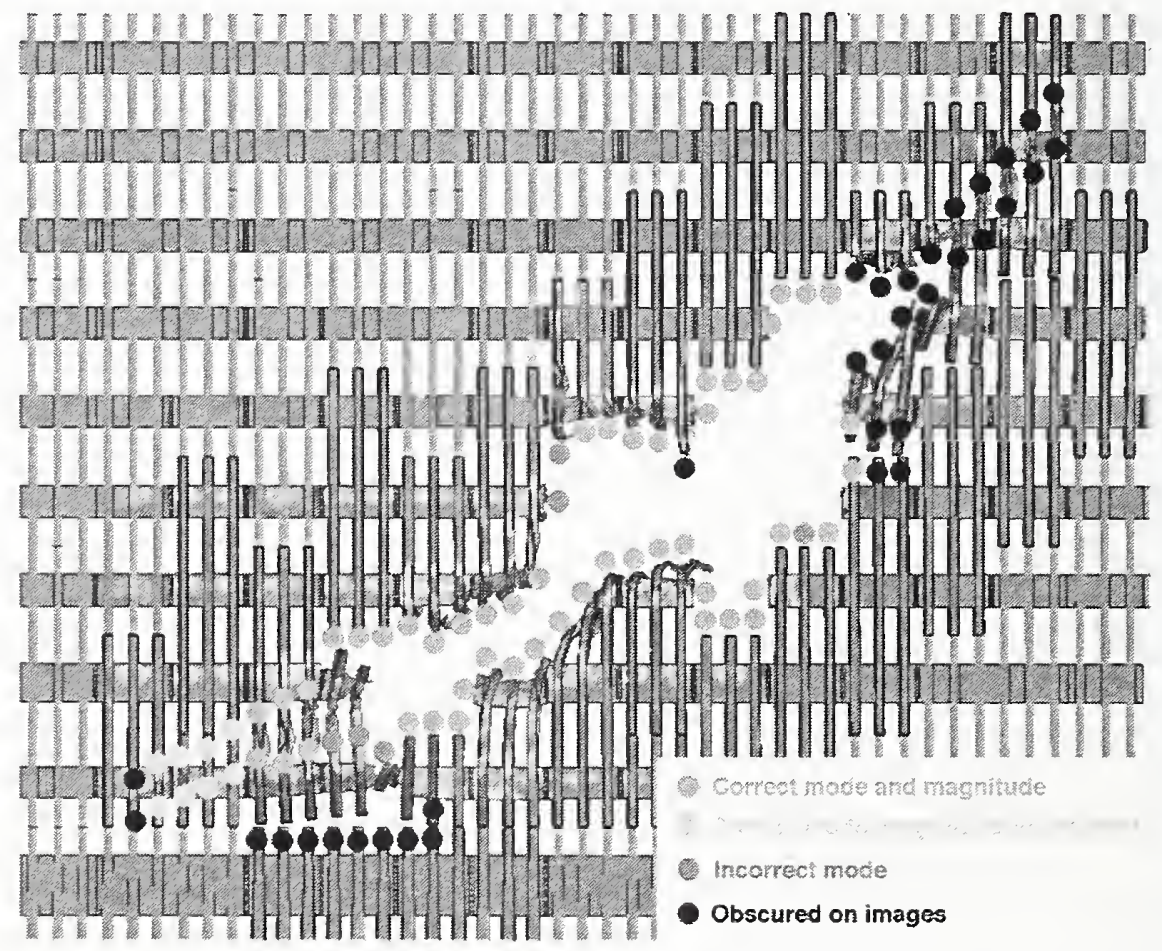

Figure E-63. Comparison of observable and calculated base case impact damage to the south wall of WTC 2. 
Not all of the observables were perfectly matched by the simulations due to the uncertainties in exact impact conditions, the imperfect knowledge of the interior tower contents, the chaotic behavior of the aircraft breakup and subsequent debris motion, and the limitations of the models. In general, however, the results of the simulations matched these observables reasonably well.

\section{E.8 FINDINGS}

Finding 1: The original design wind loads on the towers exceeded those established by NYCBC prior to 1968, when the WTC towers were designed, and up to and including 2001. The original design load estimates were also higher than those required by other selected building codes of the time, including the relevant national model building code (BOCA). The prescriptive approach in these codes is oversimplified, and as a result, these codes are not appropriate for super-tall building design.

Finding 2: In the majority of the cases, each of the two orthogonal shear components and of the two orthogonal overturning moment components at the base of the towers used in the original wind design were smaller than the CPP, RWDI, and refined NIST estimates. However, the most unfavorable combined peaks (resultant) from the original design were larger, or smaller, by at most 15 percent than estimates based on the CPP, RWDI, and NIST estimates. This is due to the conservative approach used to combine the loads in the original design.

Finding 3: The estimated wind-induced loads on the towers varied by as much as 40 percent between the wind tunnel/climatological studies conducted in 2002 by CPP and RWDI. The primary reasons for these differences were due to the different approaches used in those studies to (1) estimate extreme wind speeds; (2) estimate wind profiles; (3) integrate aerodynamic, dynamic, and extreme wind climatological information; and (4) combine wind effects in two orthogonal directions and in torsion. Such disparity is indicative of the limitations and inconsistencies associated with the current state of practice in wind engineering for tall buildings.

Finding 4: A comparison of wind speeds indicated significant differences among various specified design wind speeds. The basic wind speed specified in ASCE 7-02 for New York City is equivalent to an $88 \mathrm{mph}$ fastest-mile wind speed at $33 \mathrm{ft}$ above ground for open terrain exposure. The wind speed specified in the NYCBC (2001) is $80 \mathrm{mph}$ and is interpreted to be a fastest-mile wind speed at $33 \mathrm{ft}$ above ground. For the original WTC design, the design wind speed was $98 \mathrm{mph}$ averaged over 20 minutes at a height of 1,500 ft above ground, which is equivalent to a fastest-mile wind speed at $33 \mathrm{ft}$ above ground of between $67 \mathrm{mph}$ and $75 \mathrm{mph}$. The wind speed estimated by NIST for the three airports (La Guardia, Newark International Airport, and John F. Kennedy International Airport), regardless of direction, was equivalent to $96 \mathrm{mph}$ fastest-mile wind speed. An evaluation of the wind speed specifications and the development of improved design wind speeds, as well as protocols for selection of site-specific wind speeds and directionality, are, therefore, in order.

Finding 5: Under the original WTC design loads, the cumulative drifts at the top of the WTC towers ranged from $H / 263$ to $H / 335$. For the lower estimate state-of-the-practice case, those drifts ranged from $\mathrm{H} / 253$ to $\mathrm{H} / 306$. Under design loading conditions, the maximum inter-story drift was as high as $\mathrm{h} / 230$ and $\mathrm{h} / 200$ for WTC 1 and WTC 2, respectively. Maximum inter-story drifts under the state-of-the practice case were about $\mathrm{h} / 184$ and h/200 for WTC 1 and WTC 2, respectively. For the refined NIST estimate case, the cumulative and inter-story drifts were about 25 percent larger than those from the state- 
of-the-practice case. Total and inter-story drifts of the towers were larger than what is generally used in current practice.

Finding 6: DCRs estimated from the original WTC design load case were in general close to those obtained for the lower-estimate state-of-the practice case. For both cases, a fraction of the structural components had DCRs larger than 1.0. These were mainly observed in both towers at (1) the exterior walls: (a) at the columns around the corners, (b) where the hat truss connected to the exterior walls, and (c) below floor 9; and (2) the core columns on the 600 line between floors 80 and 106 and at core perimeter columns 901 and 908 for much of their height. The DCRs obtained for the refined NIST estimate case were higher than those for the original WTC design and the lower-estimate state-of-thepractice load cases.

Finding 7: The safety of the exterior walls, core columns, and hat truss members of the WTC towers on September 11, 2001, was most likely not affected by the fraction of members for which the demand exceeded allowable capacity.

Finding 8: The behavior of the lower portion of the towers at the basement floors was that of a braced frame, while the behavior of the super-structure was that of a framed tube system. Under a combination of the original WTC design dead and wind loads, tension forces developed in the exterior walls of both towers. The forces were largest at the base of the building and at the corners. The DCRs for the exterior wall splice connections under these tensile forces for both towers were shown to be less than 1.0.

Finding 9: For the towers' resistance to shear sliding under wind loads, the factor of safety was between 10 and 11.5 , while the factor of safety against overturning ranged from 1.9 to 2.7 for both towers.

Finding 10: For the typical truss-framed floor under the original WTC design gravity loads, the DCRs for all floor trusses were less than unity for 99.4 percent of the floor truss components, with a maximum of 1.14. Inside the core, the DCRs for all floor beams were less than 1.08 , and more than 99 percent of floor beams had a DCR of less than 1.0. The maximum mid-span deflections of the long span and short span zones under the original WTC design loads were about $\mathrm{L} / 400$ and $\mathrm{L} / 750$, respectively, where $\mathrm{L}$ is the floor span. For the typical beam-framed floor under the original WTC design gravity loads, the DCRs for all floor beams were less than 1.0, except for two core beams where the DCRs in shear were 1.125 and 1.09. The maximum mid-span deflections of the long span and short span zones under the original design loads were about $\mathrm{L} / 450$ and $\mathrm{L} / 600$, respectively.

Finding 11: Documents from The Port Authority of New York and New Jersey indicated that the safety of the WTC towers and their occupants in an aircraft collision was a consideration in the original design. The documents indicate that a Boeing 707, the largest commercial aircraft at the time, flying at $600 \mathrm{mph}$ was considered, and the analysis indicated that such collision would result in only local damage which could not cause collapse or substantial damage to the building and would not endanger the lives and safety of occupants not in the immediate area of impact. No documentary evidence of the aircraft impact analysis was available to review the criteria and methods used in the analysis of the aircraft impact into the WTC towers, or to provide details on the ability of the WTC towers to withstand such impacts.

Finding 12: The impact of a Boeing 767 engine at a speed of $500 \mathrm{mph}$ on an exterior wall panel resulted in a complete penetration of the engine through the exterior wall and failure of impacted exterior columns. 
Finding 13: Impact of an empty wing segment from approximately mid-span of the wing normal to the exterior wall produced significant damage to the exterior columns but not complete failure. Impact of the same wing section, but filled with fuel, resulted in extensive damage to the external panels of the tower, including complete failure of the exterior columns.

Finding 14: The response of the nonstructural building contents and the floor concrete slab to an aircraft engine impact was dominated by the mass of the workstations and the concrete slab, rather than by their strength.

Finding 15: The aircraft that impacted WTC 1 had a speed of $443 \pm 30 \mathrm{mph}$ with a roll angle of $25 \pm 2$ degrees (port wing downward). The vertical approach downward angle was $10.6 \pm 3$ degrees and the lateral approach angle was close to being normal to the north wall of the tower. For WTC 2, the impacting aircraft had a speed of $542 \pm 24 \mathrm{mph}$ with a roll angle of $38 \pm 2$ degrees (port wing downward). The vertical approach downward angle was $6 \pm 2$ degrees, and the lateral approach angle was $15 \pm 2$ degrees clockwise from the south wall of the tower.

Finding 16: The aircraft impact on WTC 1 resulted in extensive damage to the north wall of the towcr, which failed in the regions of the fuselage, engine, and fuel-filled wing section impacts. Damage to the exterior wall extended to the wing tips, but the exterior columns were not completely failed in the outer wing and vertical stabilizer impact regions. According to photographs, columns 112 to 144 along with column 151 were completely severed, while columns 145 to 148 were heavily damaged and columns 149 to 150 were moderately damaged (for reference, columns 101 and 159 are located on the west and east comer, respectively, of the north wall). The results of the impact analyses matched well with this damage pattern to the north wall. Photographic evidence also indicated that an exterior panel with columns 329 , 330 , and 331 on the south wall between floors 94 to 96 was dislodged. Failure of the exterior columns occurred both at the bolted connections between column ends and at various locations in the column depending on the local severity of the impact load and the proximity of the bolted connection to the impact. Subject to the uncertainties inherent in the models, the global impact simulations indicated that a total of three core columns were severed and four columns were heavily damaged in the base case, compared to six columns severed and three columns heavily damaged in the more sevcre case and one columns severed and two columns heavily damaged in the less severe case. In the analyses, the floor trusses, core beams, and floor slabs experienced significant impact-induced damagc on floors 94 to 96, particularly in the path of the fuselage. The analyses indicated that the wing structures were completely fragmented due to the interaction with the exterior wall and as a result, aircraft fuel was dispersed on multiple floors. In addition, aircraft debris resulted in substantial damage to the nonstructural building contents (partitions and workstations) and also in dislodging of fireproofing. The bulk of the fuel and aircraft debris was deposited in floors 93 through 97, with the largest concentration on floor 94.

Finding 17: The aircraft impact on WTC 2 resulted in extensive damage to the south wall of the tower, which failed in the regions of the fuselage, engine, and fuel-filled wing section impacts. Damage to the exterior wall extended to the wing tips, but the exterior columns were not completely failed in the outer wing and vertical stabilizer impact regions. According to photographs, columns 410 to 436 and columns 438 to 439 were completely severed, while column 437 was heavily damaged (for reference, columns 401 and 459 are located on the east and west corner, respectively, of the south wall). The results of the impact analyses matched well with this damage pattern to the south wall. In addition, columns 407 to 409 were obscured by smoke, but the analysis results indicated that these columns were moderately damaged. Photographic evidence also indicated that columns 253, 254, 257, and 258 on the north wall were failed. 
Failure of the exterior columns occurred both at the bolted connections between column ends and at various locations in the column depending on the local severity of the impact load and the proximity of the bolted connection to the impact. Subject to the uncertainties inherent in the models, the global impact simulations indicated that a total of five core columns were severed and four columns were heavily damaged in the base case, compared to ten columns severed and one column heavily damaged in the more severe case and three columns severed and two columns heavily damaged in the less severe case. In some cases, failure of the column splices located on floors 77,80 , and 83 contributed significantly to the failure of the core columns. In the analyses, the floor trusses, core beams, and floor slabs experienced significant impact-induced damage on floors 79 to 81 , particularly in the path of the fuselage. The analyses indicated that the wing structures were completely fragmented due to the interaction with the exterior wall, and as a result, aircraft fuel was dispersed on multiple floors. In addition, aircraft debris resulted in substantial damage to the nonstructural building contents (partitions and workstations) and also in dislodging of fireproofing. The bulk of the fuel was concentrated on floors 79,81 , and 82 , while the bulk of the aircraft debris was deposited in floors 78 through 80 , with the largest concentration on floor 80 .

Finding 18: Natural periods calculated from the reference global model of the WTC 1 tower matched well with those measured on the tower based on the analysis of data from accelerometers located atop WTC 1 . The calculated period of oscillation in the N-S direction of the reference global model of WTC 2 matched well with the period estimated immediately after aircraft impact based on a detailed analysis of the building motion, which was captured in a video footage of the WTC 2 impact. This indicated that the overall lateral stiffness of the tower was not affected appreciably by the impact damage. The maximum deflection at the top of the tower after impact was estimated from the footage to be more than $1 / 3$ of the drift resulting from the original design wind loads. This indicated that the tower still had reserve capacity after losing a number of columns and floor segments due to aircraft impact.

Finding 19: The towers sustained significant structural damage to the exterior walls, core columns, and floor systems due to aircraft impact. This structural damage contributed to the weakening of the tower structures, but did not, by itself, initiate building collapse. However, the aircraft impact damage contributed greatly to the subsequent fires and the thermal response of the tower structures that led ultimately to the collapse of the towers by: (1) dispersing jet fuel and igniting building contents over large areas, (2) creating large accumulations of combustible materials containing aircraft and building contents, and (3) increasing the air supply into the damaged buildings that permitted significantly higher energy release rates than would normally be seen in ventilation building fires, allowing the fires to spread rapidly on multiple floors. 


\section{Chapter 1 \\ INTRODUCTION}

\section{$1.1 \quad$ BACKGROUND}

As stated in the preface, the National Institute of Standards and Technology (NIST) investigation into the collapse of the World Trade Center (WTC) towers included eight interdependent projects (see Table P-1). The Baseline Structural Performance and Aircraft Impact Damage Analysis project had two primary tasks. These were:

1. To develop reference structural models of the towers and use these models to establish the baseline performance of each of the two towers under gravity and wind loads.

2. To estimate the damage to the towers due to aircraft impacts and establish the initial conditions for the fire dynamics modeling and the thermal-structural response and collapse initiation analyses.

This report presents the details of the studies related to both tasks. For each task, the report provides the following:

- Description of structural models: these include the reference structural models of the towers for the first task, and global impact models of the towers and a model of the aircraft for the second.

- Description of applied loads for analyses: these are gravity and wind load estimates for the first task, and aircraft impact initial conditions for the second.

- Analysis results: these include the baseline performance analyses of the towers for the first task, and a description of the impact-induced damage to the towers for the second.

The report is concluded by a set of findings (Chapter 8). The next sections provide the background, technical approach, and details for each task.

\subsection{REFERENCE MODELS AND BASELINE PERFORMANCE ANALYSIS}

The WTC towers used a structural system that, at the time of the design, incorporated a number of innovative features. Among these features were the use of a composite truss floor system to provide lateral stability and diaphragm action to the towers, the use of wind tunnel testing to estimate static and dynamic wind effects, and the use of viscoelastic dampers to reduce wind-induced vibrations. Wind loads were a governing factor in the design of the structural components that made up the frame-tube steel framing system. Wind load capacity is also a key factor in determining the overall strength of the towers and is important in determining not only the ability of the towers to withstand winds but also the reserve capacity of the towers to withstand unanticipated events such as a major fire or impact damage. 
Accurate estimation of the wind load on tall buildings is a challenging task, given that wind engineering is still an evolving teehnology. For example, as is shown later, estimates of the wind-induced response presented in two recent independent studies of the WTC towers differed from each other by about 40 percent. The primary reasons for these differences appear to lie in the different approaches used in those studies to estimate extreme wind speeds, to estimate wind profiles, to integrate aerodynamic, dynamic, and extreme wind climatological information, and to combine wind effects in two orthogonal directions and in torsion. In this study, NIST developed refined estimates of wind effects using information provided in the two studies, a critical assessment of that information, and independent information concerning the wind climate. Furthermore, as shown in this study, the available prescriptive codes specify wind loads (pressures) on tall buildings that are significantly lower than wind tunnel-based loads. This case study provided an opportunity to assess effectively the current design practices and various code provisions on wind loads.

The baseline performance of the WTC towers under gravity and wind loads were established in order to assess the towers' ability to withstand those loads safely and to evaluate the reserve capacity of the towers to withstand unanticipated events. The baseline performance study provides a measure of the behavior of the towers under design loading conditions, specifically: (1) total and inter-story drift (the sway of the building under design wind loads); (2) floor deflections under gravity loads; (3) the stress demand-tocapacity ratio for primary structural components of the towers such as exterior walls, core columns, and floor framing; (4) performance of exterior walls under wind loading, including distribution of axial stresses and presence of tensile forces; (5) performance of connections between exterior columns; and (6) resistance of the towers to shear sliding and overturning at the foundation level.

For the purpose of establishing the baseline performance of the towers, various wind loads were considered in this study, including wind loads used in the original WTC design, wind loads based on two recent wind tunnel studies conducted in 2002 by Cermak Peterka Peterson, Inc. (CPP) and Rowan Williams Davis and Irwin, Inc. (RWDI) for a insurance litigation concerning the towers, and wind loads estimated by NIST by critically assessing information obtained from the CPP and RWDI reports and by bringing to bear state-of-the-art considerations.

In order to develop the reference models and perform the baseline performance analyses, the following steps were undertaken:

- Develop structural databases for the primary structural components of the WTC 1 and WTC 2 towers from the original computer printouts of the structural design documents.

- Develop reference structural analysis models that capture the intended behavior of each of the two towers using the generated databases. These reference models were used to establish the baseline performance of the towers and also served as a reference for more detailed models for aircraft impact damage analysis and thermal-structural response and collapse initiation analysis. The models included: (1) two global models (one for each tower) of the major structural components and systems of the towers, and (2) floor models of a typical trussframed floor and a typical beam-framed floor. 
- Develop estimates of design gravity (dead and live loads) and wind loads on each of the two towers for implementation into the reference structural models. The following three loading cases were considered:

- Original WTC design loads case. Loads included dead and live loads as in original WTC design, in conjunction with original WTC design wind loads.

- State-of-the-practice case. Loads included dead loads, current New York City Building Code (NYCBC 2001) live loads, and wind loads from the RWDI wind tunnel study, scaled in accordance with NYCBC 200 I wind speed.

- Refined NIST estimate case. Loads included dead loads, live loads from the American Society of Civil Engineers (ASCE) 7-02 Standard (a national standard), and refined wind loads developed by NIST.

- Perform structural analyses to establish the baseline performance of each of the two towers under design gravity and wind loads.

The tasks outlined above were conducted by the firm of Leslie E. Robertson Associates, the firm responsible for the original structural engineering of the WTC towers, under contract to NIST for the development of the structural databases, reference structural models, and baseline performance analysis. NIST implemented a rigorous and comprehensive review procedure to ensure the integrity and objectivity of the output and results, including the structural databases, reference models, and baseline performance analysis. The review procedure included an in-house NIST review and a third-party review by the firm of Skidmore, Owings, and Merrill, under contract to NIST.

Chapters 2 through 4 provide a description of the structural modeling and analysis of the baseline performance of the towers. For further details, the reader is referred to NIST NCSTAR 1-2A. ${ }^{\prime}$

Chapter 2 presents the development of the reference structural models for WTC I and WTC 2, including the global tower models, typical floor models, and parametric studies conducted to support the development of the global models. The chapter provides a brief summary of the development of the structural databases. In addition, this chapter outlines the NIST and third-party review of the structural databases and reference models.

Chapter 3 provides a discussion on the loading cases used in the baseline performance analyses, and outlines the development of the gravity and wind loads on the global tower models. In this chapter, special emphasis is placed on the estimates of the wind load cases used in this study. These include the original design wind loads, the state-of-the-practice wind loads (the CPP and RWDI wind studies), and the refined NIST estimates. The chapter concludes with a comparison of the various wind studies.

Chapter 4 provides the results of the baseline performance analyses for the global tower models as well as the typical floor models. The results presented for the global models include total and inter-story drift, demand to capacity ratios for primary structural components of the towers, response of exterior walls

1 This footnote is to one of the companion documents from this Investigation. A list of these documents appears in the Preface to this report. 
under wind loading, performance of connections between exterior columns, and resistance of the towers to shear sliding and overturning. For the floor models, these results include floor mid-span deflections and demand to capacity ratios for primary floor framing members. The chapter also outlines the review process of the baseline performance analyses.

\subsection{AIRCRAFT IMPACT DAMAGE ANALYSIS}

Buildings are not specifically designed to withstand the impact of fuel-laden commercial aircraft, and building codes in the United States do not require building designs to consider aircraft impact. However, after the crash of a B-25 bomber into the Empire State Building in 1945, designers of high-rise buildings became aware of the potential of aircraft collision with buildings. Documents obtained from The Port Authority of New York and New Jersey (PANYNJ) indicated that the safety of the WTC towers and their occupants in an aircraft collision was a consideration in the original design. A three-page white paper "Salient points with regard to the structural design of the World Trade Center towers", February 1964, from the PANYNJ (see Appendix A) indicated that the impact of a Boeing 707 or DC 8 aircraft flying at a speed of $600 \mathrm{mph}$ was analyzed during the design stage of the WTC towers. The paper also addressed the life safety considerations following such impact. The paper stated that “... The Buildings have been investigated and found to be safe in an assumed collision with a large jet airliner (Boeing 707 - DC 8) traveling at 600 miles per hour. Analysis indicates that such collision would result in only local damage which could not cause collapse or substantial damage to the building and would not endanger the lives and safety of occupants not in the immediate area of impact."

A three-page document "Period of Vibration due to plane crash at $80^{\text {th }}$ floor," March 1964, from the PANYNJ included a calculation by the designer to estimate the period of vibration due to an aircraft impacting at the 80th floor of the towers. Although no conclusion was stated on the calculation sheet, it indicated that the design considered the possibility of aircraft impact on the towers. Aside from these two documents from the PANYNJ, no documentary evidence on the aircraft impact analysis was available to review the criteria and methods used in the analysis of the aircraft impact into the WTC towers or to provide details on the ability of the WTC towers to withstand such impacts.

The Federal Emergency Management Agency (FEMA) 403 (2002) report indicated that it was assumed in the 1960s design of the WTC towers that a Boeing 707 aircraft, lost in fog and seeking to land at a nearby airport, might strike the towers while low on fuel and at a landing speed of $180 \mathrm{mph}$.

A property risk assessment report, prepared for Silverstein Properties prior to leasing the WTC towers in 2001, identified the scenario of an aircraft striking a tower as one of the maximum foreseeable losses.

The assessment states "This scenario is within the realm of the possible, but highly unlikely. In the event [of] such an unlikely occurrence, what might result? The structural designers of the towers have publicly stated that in their opinion that either of the Towers could withstand such an impact from a large modern passenger aircraft. The ensuing fire would damage the skin in this scenario, as the spilled fuel would fall to the Plaza level where it would have to be extinguished by the NYC Fire Department."

While the documents from the PANYNJ indicated that aircraft impact was considered in the design, there were two views expressed by the building designers during media interviews on whether the effects of the 
subsequent fires and the implications on life safety were a consideration in the original design. One view ${ }^{2}$ suggested that an analysis was done indicating that the biggest problem would be the fact that all the fuel would dump into the building and there would be horrendous fire. For implications on life safety, this view suggested that a lot of people would be killed, but the building structure would still be there. The other vie $w^{3}$ suggested that the fuel load and the subsequent fire damage may not have been considered in the design stage.

For the events of September 11, 2001, the aircraft impact damage to the exterior of the WTC towers could be visibly identified from the video and photographic records collected. However, no visible information could be obtained for the extent of damage to the interior of the towers, including the structural system (floors and core columns), partition walls, and interior building contents. Such information was needed for the subsequent fire dynamics simulations and post-impact structural analyses. In addition, for the fire dynamics modeling, the dispersion of the jet fuel and the location of combustible aircraft debris were required. The estimate of the extent of damage to the fireproofing on the structural steel in the towers due to impact was essential for the thermal and structural analyses. The aircraft impact damage analyses were the primary tool by which most of the information on the tower damage could be estimated.

The focus of the analysis was to analyze the aircraft impacts into each of the WTC towers to provide the following: (1) estimates of probable damage to structural systems, including exterior walls, floor systems, and interior core columns; (2) estimates of the aircraft fuel dispersion during the impact; and (3) estimates of debris damage to the building nonstructural contents, including partitions and workstations. The analysis results were to be used to estimate the damage to fireproofing based on the predicted path of the debris field inside the towers. This analysis thus estimated the condition of the two WTC towers immediately following the aircraft impacts and established the initial conditions for the fire dynamics modeling and the thermal-structural response and collapse initiation analysis. The impact analyses were conducted at various levels of complexity including: (1) the component level, (2) the subassembly level, and (3) the global level to estimate the probable damage to the towers due to aircraft impact.

The WTC aircraft impact analysis was a challenging task for the following reasons:

- The need to develop a comprehensive aircraft model that properly captured the stiffness and mass distributions of the aircraft, as well as the large scale fracture and fragmentation of the aircraft components. No such model was available at the beginning of the study. Associated with this task was the collection of information on the structure of the Boeing 767 aircraft from documentary aircraft structural information and data from measurements on a Boeing aircraft.

- The towers and aircraft included a variety of materials that exhibited highly nonlinear, ratedependent behavior with failure that need to be included in the models. Also, the various joints and connections (bolts and weldments) in the tower and aircraft structures presented complex behavior and failure. The constitutive behavior of these materials and connections was included in the models based on testing of tower steels or from data available in the open literature.

2 J. Skilling in 1993 from James Glanz and Eric Lipton, "City in the Sky," Times Books, 2003.

3 L.E. Robertson in 2001 from "The Tower Builder" by John Seabrook, The New Yorker, November 19, 2001. 
- The WTC towers and Boeing 767 aircraft were large and complex structural systems. To include all of the primary structural components and details of both the aircraft and towers using refined finite element meshes in the impact models was prohibitive. As a result, coarser meshes were used in the impact simulations. That presented a challenge, since a very fine mesh was needed to properly capture the failure and fracture of components in these analyses. A large array of impact simulations at the component level were conducted to calibrate the failure and fragmentation of coarsely meshed aircraft and tower components against those models with fine meshes.

- A significant portion of the weight of a Boeing 767 wing was from the fuel in its integral fuel tanks. Upon impact, this fuel was responsible for large distributed loads on the exterior columns of the WTC towers and subsequently on interior structures, as it was dispersed inside the building. Modeling of the fluid-structure interaetion is complex, but was deemed necessary to predict the extent of damage and the fuel dispersion within the building and to help establish the initial conditions for the fire dynamics modeling. A number of modeling options were investigated for possible application in the global impact simulations.

- The impact analyses were subject to uncertainties in the input parameters such as initial impact conditions, material properties and failure criteria, aircraft mass and stiffness properties, connections response, the mass and strength of nonstructural contents, and modeling parameters. No information was available to determine a prior $i$ the sensitivity of the damage estimates to uncertainties in these parameters. Detailed sensitivity analyses using orthogonal factorial design were conducted at the component and subassembly levels to determine the most influential parameters that affect the damage estimates. The results of these analyses were used to provide a range of impact-induced damage estimates to the towers using the global models.

The analyses of the aircraft impacts performed for this investigation are believed to be the highest-fidelity simulations ever performed for this impact behavior using state-of-the art analysis methodologies. Wherever possible, the models were validated against observables or supporting test data developed by the WTC investigation.

In order to estimate the aircraft impact damage to the WTC towers, the following steps were undertaken:

- Constitutive relationships were developed to describe the actual behavior and failure of the materials under the dynamic impact conditions of the aircraft. These materials included the various grades of steels used in the exterior walls, core columns, and floor trusses of the towers, weldment metal, bolts, reinforced concrete, aircraft materials, and nonstructural contents.

- Global impact models were developed for the towers and aircraft: The tower models included the primary structural components of the towers in the impact zone, including exterior walls, floor systems, core columns, and connections, along with nonstructural building contents. A refined finite element mesh was used for the areas in the path of the aircraft, and a coarser mesh was used elsewhere. The aircraft model included the aircraft engines, wings, fuselage, empennage, and landing gear, as well as nonstructural components 
of the aircraft. The aircraft model also included a representation of the fuel using the smooth particle hydrodynamics approach.

- Component and subassembly impact analyses were conducted to support the development of the global impact models: The primary objectives of these analyses were to (1) develop an understanding of the interactive failure phenomenon of the aircraft and tower components, and (2) develop the simulation techniques required for the global analysis of the aircraft impacts into the WTC towers, including variations in mesh density and numerical tools for modeling fluid-structure interaction for fuel impact and dispersion. The component and subassembly analyses were used to determine model simplifications for reducing the overall model size while maintaining fidelity in the global analyses.

- Initial conditions were estimated for the impact of the aircraft into the WTC towers: These included the aircraft speed at impact, aircraft orientation and trajectory, and impact location of the aircraft nose. The estimates also included the uncertainties associated with these parameters. This step utilized the videos and photographs that captured the impact event and subsequent damage to the exterior of the towers.

- Sensitivity analyses were conducted at the component and subassembly levels to assess the effect of uncertainties on the level of damage to the towers due to impact and to determine the most influential parameters that affect the damage estimates. The analyses were used to reduce the number of parameters that would be varied in the global impact simulations.

- Analyses of aircraft impact into WTC 1 and WTC 2 were conducted using the global tower and aircraft models: The analysis results included the estimation of the structural damage that degraded the towers' strength and the condition and position of nonstructural contents such as partitions, workstations, aircraft fuel, and other debris that influenced the behavior of the subsequent fires in the towers. The global analyses included, for each tower, a "base case" based on reasonable initial estimates of all input parameters. They also provided a range of damage estimates based on variations of the most influential parameters.

- Approximate analyses were conducted to provide guidance to the global finite element impact analyses: These included: (1) the analysis of the overall aircraft impact forces and assessment of the relative importance of the airframe strength and weight distribution, (2) the evaluation of the potential effects of the energy in the rotating engine components on the calculated engine impact response, (3) the influence of the static preloads in the towers on the calculated impact damage and residual strength predictions, and (4) the analysis of the load characteristics required to damage core columns compared to the potential loading from impact of aircraft components.

The tasks outlined above were conducted in collaboration with experts from Applied Research Associates, Inc. under contract to NIST. Chapters 5 through 7 provide a summary of this study. For further details, the reader is referred to NIST NCSTAR 1-2B.

Chapter 5 describes the global tower and aircraft impact models. The chapter provides the methodology used in the development for the models and the contents of the models, including geometry, element types and sizes, and boundary conditions. The chapter also includes a summary of the constitutive relationships 
for the various materials used in the tower and aircraft models. Finally, the chapter provides a brief description of the components and subassembly models that were used to suppoit and provide guidance to the development of the global models.

Chapter 6 presents the methodology used to estimate the initial aircraft impact conditions. These included, for each aircraft, the impact speed, horizontal and vertical angles of incidence, roll angle, and impact location of the aircraft nose. Uncertainties in each of these parameters were also quantified. The estimates were based on videos that captured the approach of the impacting aircraft and photographs of the damage to the exterior walls of the towers.

Chapter 7 presents the results of the global analyses of aircraft impact into WTC 1 and WTC 2 using the global tower and aircraft models. The global analyses included, for each tower, a "base case" based on reasonable initial estimates of all input parameters. They also provided a range of damage estimates of the towers due to aircraft impact. The chapter also provides a comparison between the simulation results and observables obtained from video and photographic evidence and eyewitness interviews, and a comparison of damage estimates from this study with those from prior studies. 


\section{Chapter 2 \\ DEVELopment of RefERENCE StRuctural MOdels}

\section{$2.1 \quad$ INTRODUCTION}

This chapter outlines the development of the reference structural models of the World Trade Center (WTC) towers. The models were used (1) to establish the baseline performance of the towers under design gravity and wind loads, and (2) as a reference for more detailed models used in other phases of the National Institute of Standards and Technology (NIST) Investigation, including the aircraft impact analysis and the thermal-structural response and collapse initiation analysis. The reference models were developed to capture the intended behavior of the WTC towers under design loading conditions and included the following:

- A global model of the primary structural components and systems for each of the two towers.

- A model of a typical truss-framed floor (tenant floor) and a model of a typical beam-framed floor (mechanical level) within the impact and fire regions.

For the global models of the towers, the large amount of data required to construct the models dictated that a database of the primary structural components of the towers be developed from the original computer printouts of the structural design documents. The various databases, developed in Microsoft Excel format, were linked together using the relational database technique. The relational databases, developed using Microsoft Access, were generated in a format suitable for the development of the global finite element models of the towers.

For the floor models, typical truss-framed floors existed on tenant floors such as floors 10 to 24,26 to 40 , 50 to 58,60 to 66,68 to 74,84 to 91 , and 93 to 105 of WTC 1 ; and floors 14 to 24,26 to 40,50 to 58,60 to 74,84 to 91 , and 93 to 106 of WTC 2. Typical beam-framed floors existed on mechanical floors (floors 7, 41, 75, and 108) and near mechanical floors (floors 9, 43, 77, 107, 110, and roof) of both towers.

Included in this chapter are descriptions of the reference structural models of the WTC towers, including the global and typical floor models. These models were linearly elastic and three-dimensional, and were developed using the Computers and Structures, Inc. SAP2000 Software (SAP2000 2002), Version 8. SAP2000 is a finite element software package that is customarily used for the analysis and design of building structures.

This chapter describes the work conducted by Leslie E. Robertson Associates (LERA), the firm responsible for the original structural engineering of the WTC towers under contract to NIST, for the development of the structural databases and reference structural models. This chapter also summarizes the review process for the structural databases and reference models, including the third-party review by the firm of Skidmore, Owings, and Merrill (SOM) under contract to NIST and the in-house review by NIST. 
Section 2.2 presents an overview of the structural database development and contents. Section 2.3 describes the global models of the WTC 1 and WTC 2 towers. Sections 2.4 and 2.5 present the models for the typical truss-framed floor and beam-framed floor, respectively. Section 2.6 outlines the thirdparty review by SOM and the in-house review by NIST of the structural databases and reference models. Section 2.7 presents a summary of the chapter.

\section{$2.2 \quad$ DEVELOPMENT OF STRUCTURAL DATABASES}

The original structural drawings of the WTC towers were issued in two main formats: (1) large-size drawing sheets containing plan and elevation information, and (2) smaller book-sized drawings containing details and tabulated information of cross sectional dimensions and material properties. The large-size drawings referred to the structural drawing books in their notes, sections, and details. The structural databases, developed in Microsoft Excel file format, were generated from these drawing books and included modifications made after construction. The databases were generated for use in the development of the reference global models of the towers.

The structural databases primarily contained the computer and hand-tabulated data for the major structural components of the towers from the following drawing books:

- Drawing Book 1: exterior wall information, foundation to elevation $363 \mathrm{ft}$.

- Drawing Book 2: exterior wall information, elevation $363 \mathrm{ft}$ to floor 9.

- Drawing Book 3: core column information.

- Drawing Book 4: exterior wall information, floor 9 to floor 110.

- Drawing Book 5: beam schedule.

Some additional information from Drawing Book 6 (core bracing schedule) and Drawing Book 9 (beams in the hat truss region) were included in the database files as it was utilized in the modeling of the towers. Modifications made after construction that were implemented in the structural databases included:

- Strengthening of a number of core columns: This included core columns 501, 508, 703, 803, 904, 1002, 1006, and 1007 from floors 98 to 106 in both towers. These columns were reinforced using steel plates welded to the wide flange core columns.

- Reinforcing of two corner core columns (508 and 1008) at floors 45 to 97 of WTC 2 due to the construction of a concrete vault at floor 97 . The reinforcement consisted of plates welded to the flanges of the built-up box columns (floors 45 to 83 ) and the flanges of the rolled shape columns (floors 83 to 97 ).

The tasks that were undertaken to develop the structural databases included: (1) scanning and digitization of the original drawing books, (2) a four-step quality control procedure, (3) cross section property calculations, and (4) the development of the relational databases, using Microsoft Access, to link the generated database files into a format suitable for the development of the structural global models. 
For further details on the development of the structural databases, refer to Chapter 2 of NIST

NCSTAR 1-2A.

\subsection{GLOBAL MODELS OF THE TOWERS}

Three-dimensional models of the 110-story above-grade structure and 6-story below-grade structure within the footprint of each of the two towers were developed. The global models for the towers consisted of all primary structural elements in the towers, including exterior walls (exterior columns, spandrel beams, and bracings in the basement floors), core columns, hat trusses, and rigid and flexible diaphragms representing the floor systems.

For the development of the global models, each tower was divided into several sub-models that included:

- Exterior walls, which in turn was divided into

- Exterior wall, foundation to floor 4

- Exterior wall trees (floors 4 to 9)

- Exterior wall, floors 9 to 106

- Exterior wall, floors 107 to 110

- Core columns

- Hat truss

After these sub-models were assembled into a unified model, rigid and flexible diaphragms representing the floor systems, boundary conditions, gravity and wind loads, and masses were added to the unified model.

The development of the WTC 1 and WTC 2 models were separate and consecutive endeavors. The lessons learned in the assembly of the WTC 1 model were applied to the development of the WTC 2 model. While there were only minor differences in the basic structural systems of the two towers, there were significant differences in section and material properties, and additional column transfers at the basement levels in WTC 2 to create openings for the PATH subway line.

Isometric views of the complete WTC 1 model, with exterior walls, core columns, bracings, hat trusses, and flexible floor diaphragms, are shown in Fig. 2-1. Elevations of the complete WTC 2 model showing similar systems are shown in Fig. 2-2. A summary of the size of the global models of WTC 1 and WTC 2 is presented in Table 2-1. The following presents the details of each of the sub-models used in the development of the unified global models for WTC 1 and WTC 2. 

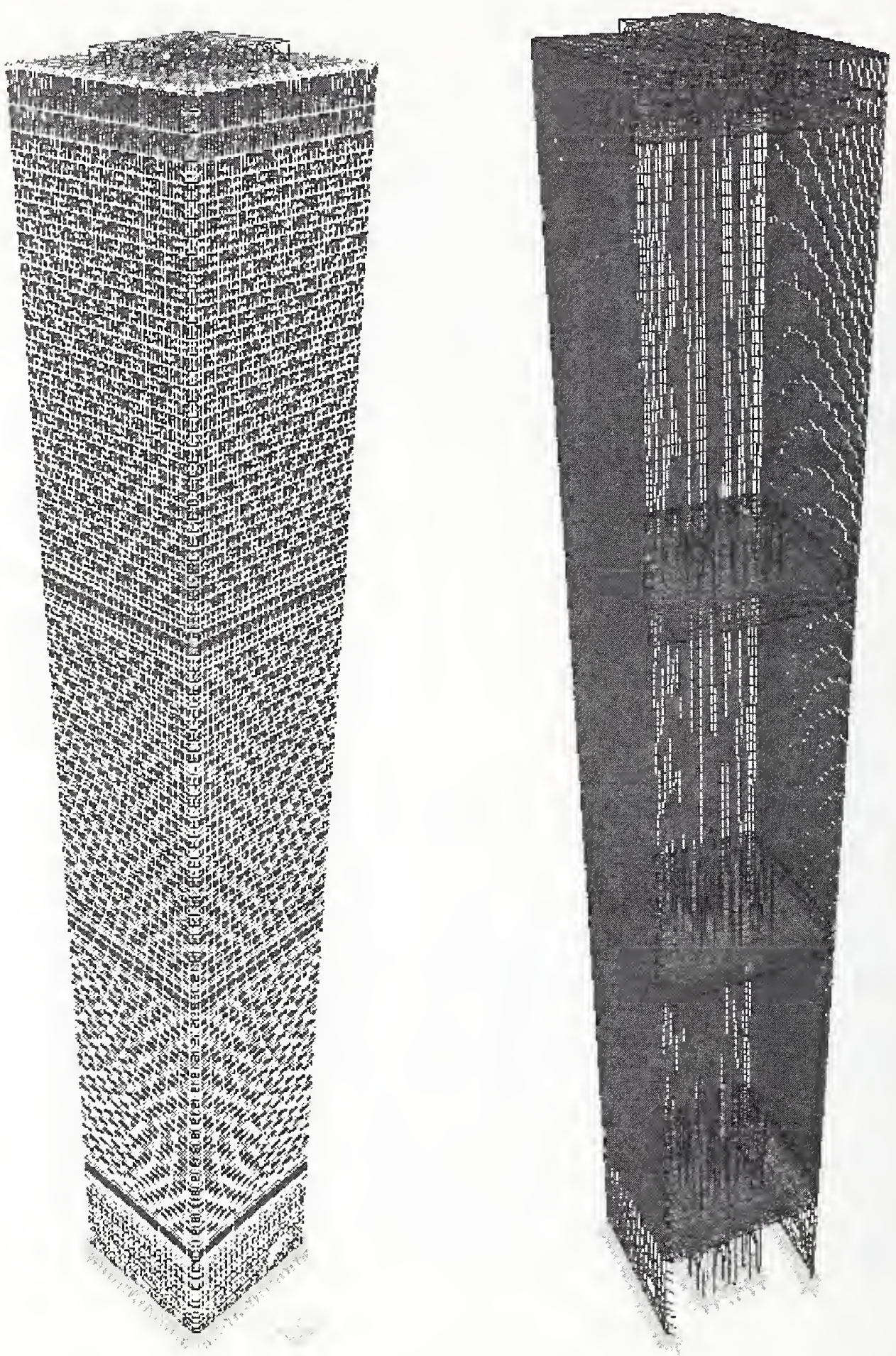

Figure 2-1. Rendered isometric views of the WTC 1 global model. 


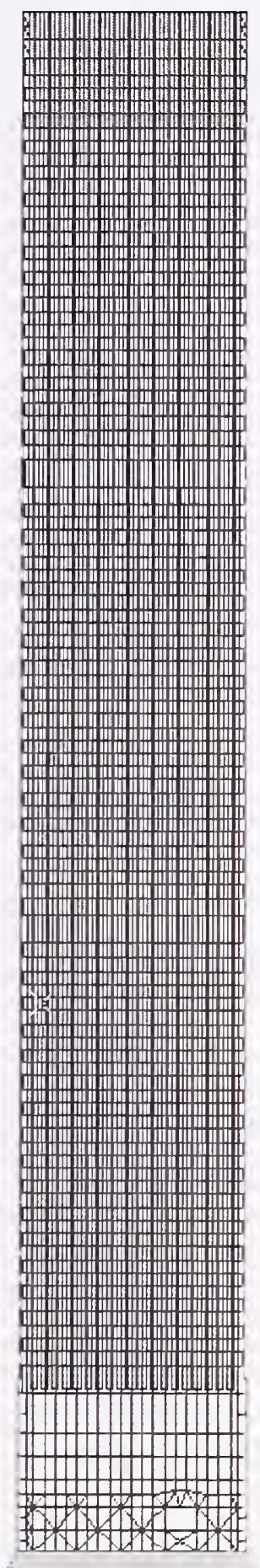

(a)

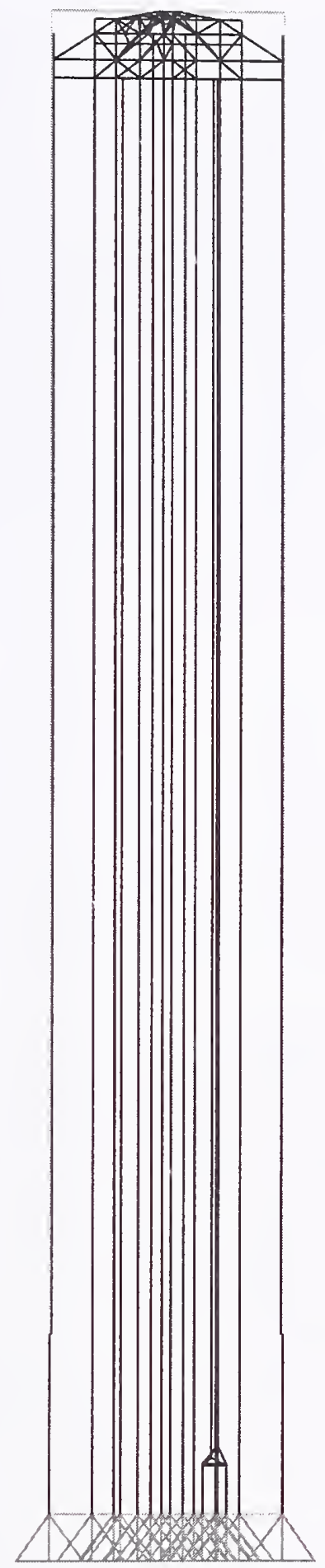

(b)

Figure 2-2. Frame view of the WTC 2 model: (a) exterior wall elevation, and (b) interior section. 
Table 2-1. Approximate size of the reference structural models (rounded).

\begin{tabular}{|l|c|c|c|c|c|}
\hline \multicolumn{1}{|c|}{ Model } & $\begin{array}{c}\text { Number of } \\
\text { Joints }\end{array}$ & $\begin{array}{c}\text { Degrees of } \\
\text { Freedom }\end{array}$ & $\begin{array}{c}\text { Number of } \\
\text { Frame Elements }\end{array}$ & $\begin{array}{c}\text { Number of } \\
\text { Shell Elements }\end{array}$ & $\begin{array}{c}\text { Total Number } \\
\text { of Elements }\end{array}$ \\
\hline WTC 1 global model $^{\mathrm{a}}$ & 53,700 & 218,700 & 73,900 & 10,000 & 83,900 \\
\hline WTC 2 global model $^{\mathrm{a}}$ & 51,200 & 200,000 & 73,700 & 4,800 & 78,500 \\
\hline Typical truss-framed model & 28,100 & 166,000 & 27,700 & 14,800 & 42,500 \\
\hline Typical beam-framed model & 6,500 & 35,700 & 7,500 & 4,600 & 12,100 \\
\hline
\end{tabular}

a. Model does not include floors except for flexible diaphragms at 17 floors as explained later.

\subsubsection{Exterior Wall Modeling}

The exterior walls of the WTC towers were intended to resist approximately 50 percent of the gravity loads and all of the lateral loads (primarily wind loads) on the towers. While the exterior wall between floors 9 to 106 represented repetitive typical panels, significant variations existed at the lower floors and the upper portion of the walls. The exterior wall columns from the foundation level up to elevation $363 \mathrm{ft}$ were spaced $10 \mathrm{ft} 0 \mathrm{in}$. on center. There were bracings in the plane of the exterior wall between the concourse level and the foundation. Between elevation $363 \mathrm{ft}$ and floor 7, the single exterior wall columns spaced $10 \mathrm{ft} 0 \mathrm{in}$. on center transitioned to three columns spaced at $3 \mathrm{ft} 4 \mathrm{in}$. on center. The exterior wall columns above floor 7 , that were spaced $3 \mathrm{ft} 4 \mathrm{in}$. on center, were connected to each other by spandrel plates, typically $52 \mathrm{in.} \mathrm{deep.} \mathrm{The} \mathrm{exterior} \mathrm{columns} \mathrm{and} \mathrm{spandrels} \mathrm{were} \mathrm{pre-assembled} \mathrm{into}$ exterior wall panels, typically three-columns wide by three-stories high.

The exterior wall model for WTC 1 and WTC 2 consisted of prismatic and non-prismatic beam elements representing columns, spandrels, and bracings. The following describes the various parts of the exterior wall model.

\section{Foundation to Floor 4}

The sub-model of the exterior wall from the foundation level up to elevation $363 \mathrm{ft}$ was developed using frame elements (also referred to as beam elements). Frame elements are typically used to model beams, columns, and truss members in planar and three-dimensional structures. They are modeled as straight lines connecting two nodes with six degrees of freedom (three translations and three rotations) at each node. The model was developed in a conventional manner, assigning joints and member connectivity as shown in the original WTC drawings. Below elevation $363 \mathrm{ft}$, columns were typically spaced at $10 \mathrm{ft}$ and braced with spandrels and diagonals. Joints were defined at all locations where diagonals braced the columns. When coordinates were not given in the drawings, joint coordinates were determined based on the geometry of the diagonal. Structural details showed that the column-diagonal intersections were continuous.

Spandrel centerline elevations were generally used to define joint coordinates. The SAP2000 program allows assignment of rigid zone factors to frame end offsets to account for the overlap of cross sections. At the intersection of columns and spandrels, 100 percent rigidity for the column and the spandrels were assigned due to the large size of both columns and spandrels. Figure 2-3 shows a frame and a rendered view of the exterior wall from foundation to floor 9 of the WTC 1 model. The figure also shows the core columns and core bracings. 

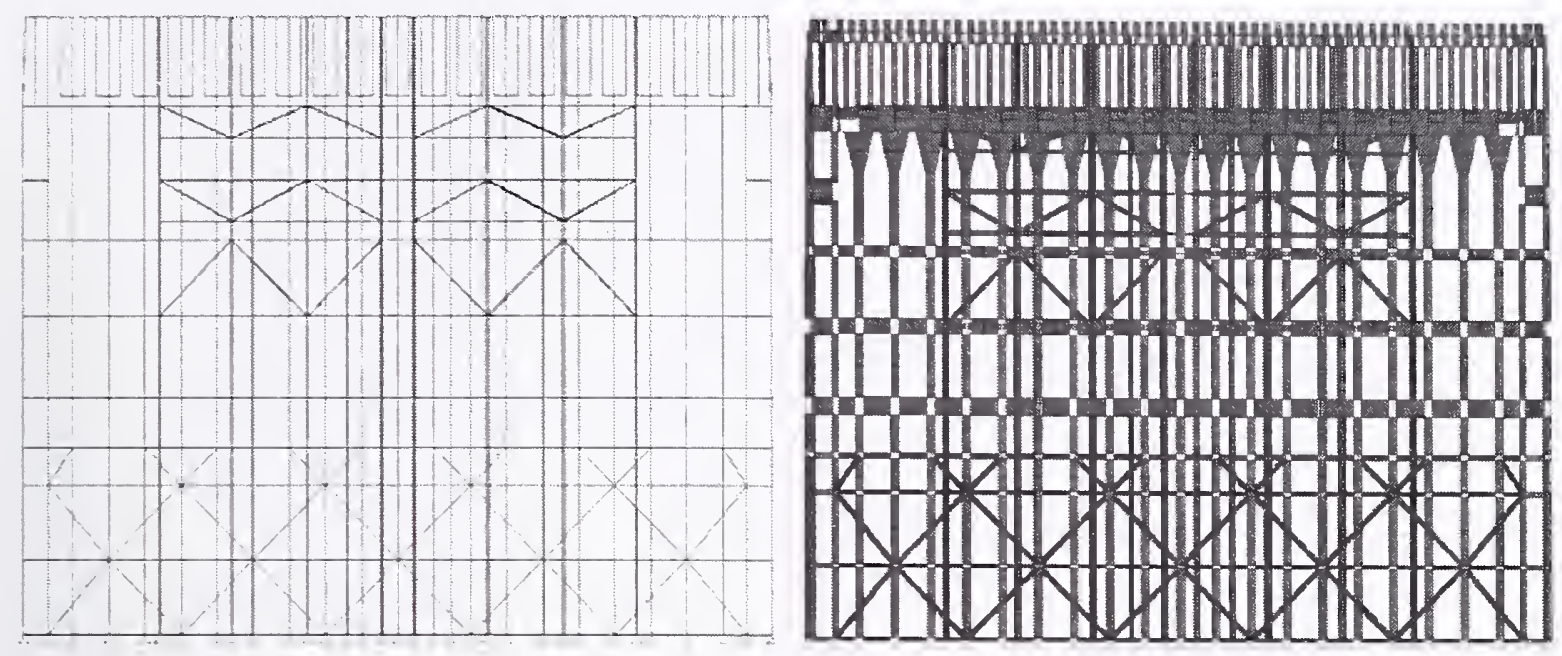

Figure 2-3. Frame view and rendered view of the WTC 1 model (foundation to floor 9).

\section{Exterior Wall Trees (Floor 4 to 9)}

The panels of the exterior walls between elevation $363 \mathrm{ft}$ and elevation $418 \mathrm{ft} 111 / 2 \mathrm{in}$. were called exterior wall trees. At the exterior wall trees, the typical exterior wall columns transitioned from a spacing of $10 \mathrm{ft}$ to a spacing of $3 \mathrm{ft} 4 \mathrm{in}$. A typical exterior wall tree panel was divided into five levels; level B, C, D, E, and F as shown in Fig. 2-4. For each panel in the model, the three exterior columns from above elevation $418 \mathrm{ft} 111 / 2 \mathrm{in}$. continued down to level $\mathrm{D}$. At that level, the three columns were connected by a horizontal rigid element to become one member, which extended down to elevation $363 \mathrm{ft}$.

Both prismatic and non-prismatic frame elements were used to model the exterior wall trees. Nonprismatic elements were used to accurately model the tapering columns as well as the complex geometry of the tress at the transition from three columns to a single column. For further details on the modeling details of the exterior wall trees, refer to Chapter 3 of NIST NCSTAR 1-2A. The final model of a typical tree is illustrated in Fig. 2-5. 


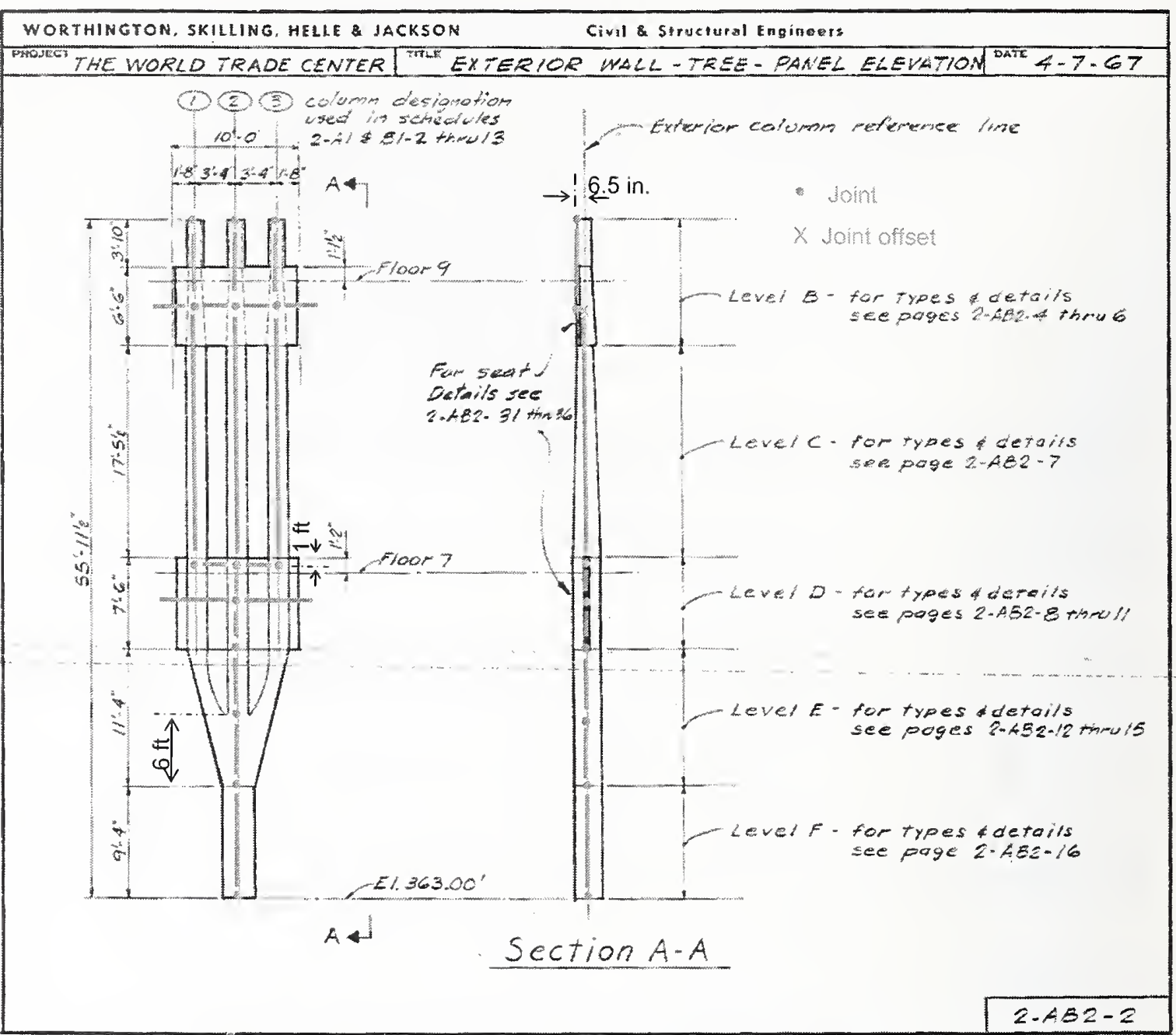

Source: Reproduced with permission of The Port Authority of New York and New Jersey. Enhanced by NIST.

Figure 2-4. Exterior wall tree panel (taken from Drawing Book 2, page 2-AB2-2). 

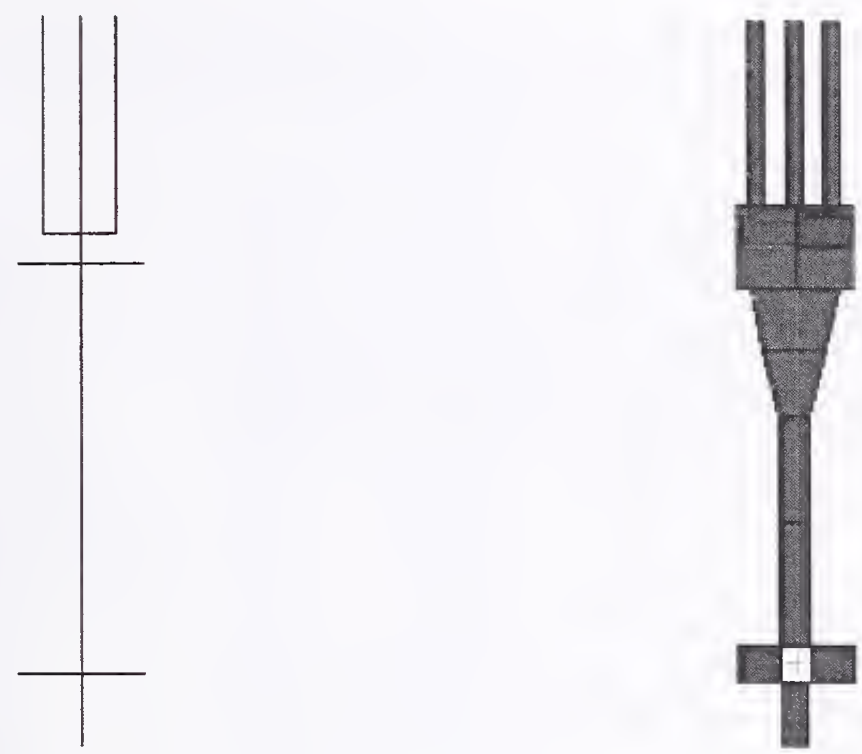

Figure 2-5. Frame and rendered view of an exterior wall tree.

\section{Floor 9 to 106}

The typical exterior panels were modeled using frame elements representing columns and spandrels. In plan, the columns and spandrels were joined at nodes located at the outside face of the spandrel, $61 / 2 \mathrm{in}$. from the exterior column reference line (Fig. 2-6). Thus the columns were offset horizontally, or 'inserted' at this node, using an insertion point located at the centerline of the interior plate 3 as shown in the figure. Insertion points were not adjusted for spandrel thickness. In elevation, the columns and spandrels were joined at the spandrel centerline, located typically $121 / 2 \mathrm{in}$. below the reference floor elevation (Fig. 2-6). The spandrels were then located correctly without the need for offsets to be defined.

As Fig. 2-6 indicates, nodes at five elevations were defined for a typical exterior wall panel. These included nodes at the three representative floor levels (defined at the spandrel centerlines), as well as the upper and lower column splices. 


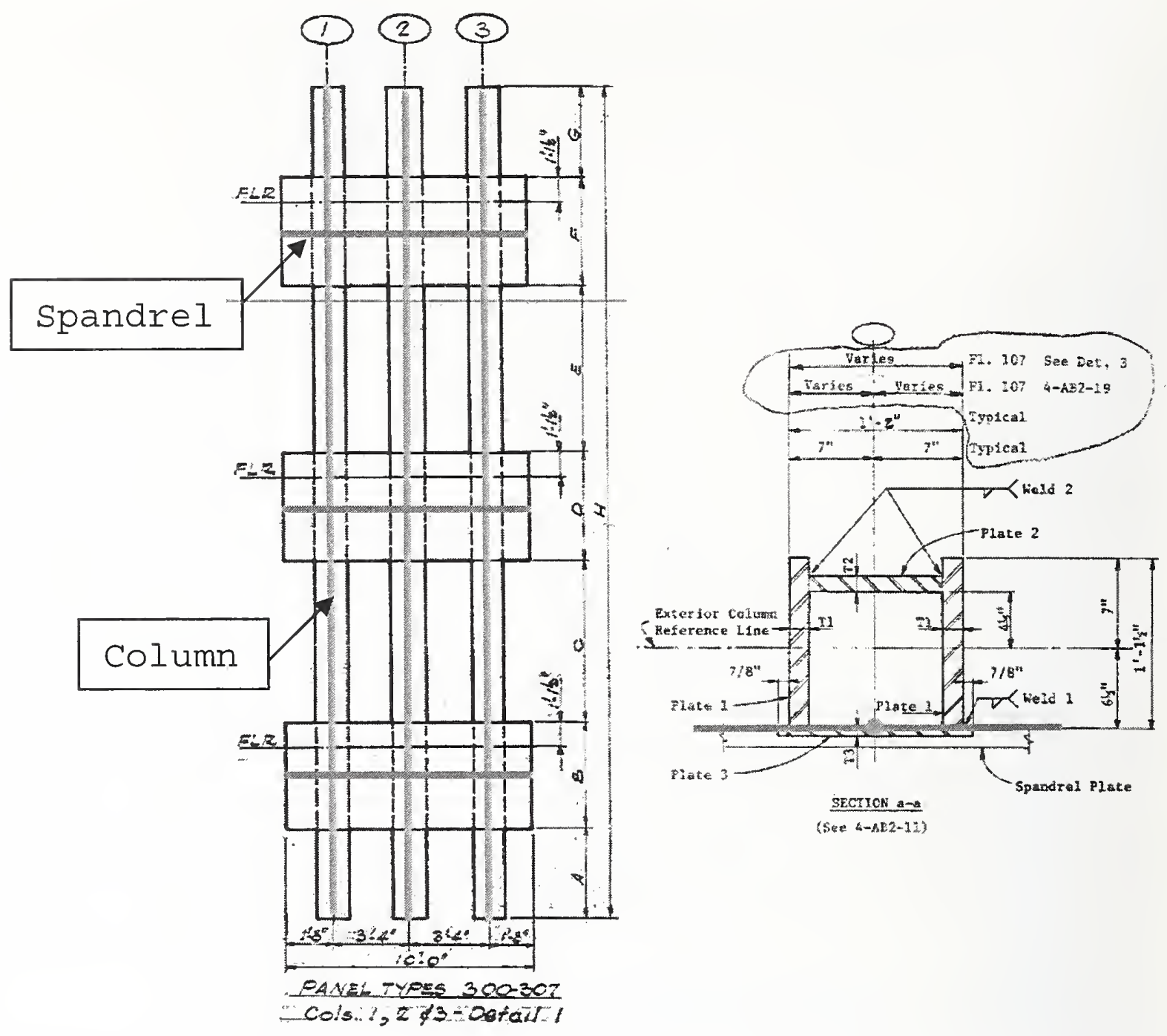

Source: Reproduced with permission of The Port Authority of New York and New Jersey. Enhanced by NIST.

Figure 2-6. Typical WTC tower exterior wall panel.

To develop a frame model of the exterior panel, a parametric study of typical three-column, threespandrel exterior wall panels was performed using two modeling techniques (see Fig. 2-7). The first model was a detailed shell element model of the panel, and the second was a simplified frame element model similar to that used throughout the global models. Shell elements are typically used to model the plate and membrane behaviors in planar and three-dimensional structures. They can be used in a three- or four-node formulation with six degrees of freedom (three translations and three rotations) at each node. For the detailed shell element model, each plate of each column and spandrel was explicitly modeled, including internal column stiffeners.

The parametric study assumed that the detailed shell model best represented the as-built performance of the panel, and therefore, was used to tune the performance of the simplified frame model. The purposes of the parametric study were to (1) match the axial stiffness of the frame model with the detailed shell 
model under gravity loads and (2) match the inter-story drift of the two models under lateral loads in the plane of the panel by modifying the rigidity of the column/spandrel intersections in the simplified frame model.

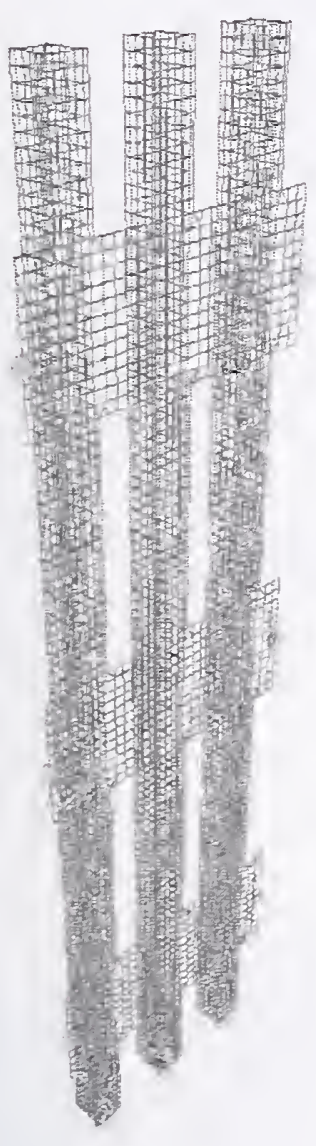

(a)

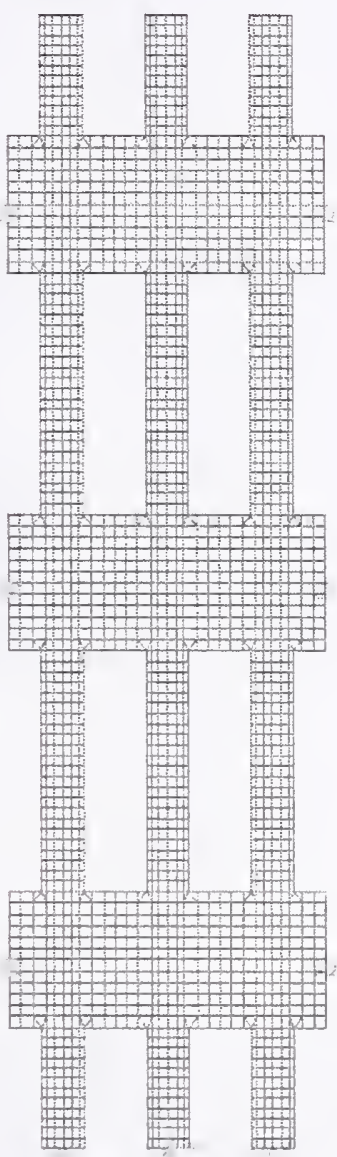

(b)

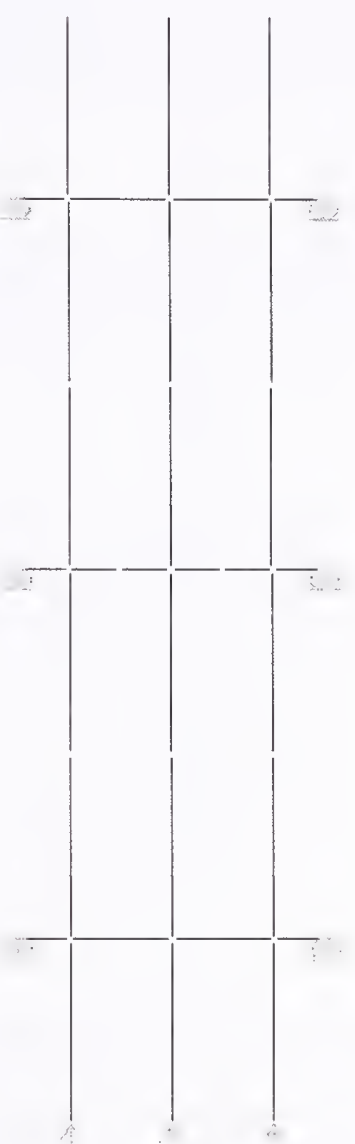

(c)

Figure 2-7. (a), (b) Shell element, and (c) frame element models of a typical exterior wall panel.

For comparing the axial stiffness of the simplified frame model of the panel with the detailed shell model, both models were loaded vertically by applying identical gravity loads to the three columns. The two models were simply supported at the bottom of the columns. The results indicated that the shell model was stiffer than the equivalent frame element model due to the contribution of the spandrel beams to the axial stiffness of the panel. This is due to the rigidity of the spandrel beams and the proximity between the columns. The parametric study on a wide range of panels over the height of the towers showed that the axial stiffness of the columns in the bottom third of the towers should be increased by a factor in the range of 25 percent to 28 percent, and the columns in the middle and upper thirds of towers should be increased by a factor in the range of 20 percent to 28 percent. Based on these figures, a 25 percent increase in the axial stiffness of exterior columns was selected as a reasonable representation for the panel vertical stiffness between floors 9 and 106. This was achieved using a frame property multiplier of 1.25 for the cross-sectional area of the exterior wall columns. 
For studying the lateral deformation of the exterior panels, panel properties were taken from three different areas of the building at floors 79 to 82,53 to 56 , and 23 to 26 . The deformations at points A, B, I, and II (Fig. 2-8) were studied for the three different panels. The top most columns were connected via a rigid link and loaded in the plane of the panel and perpendicular to the columns with a lateral load of 100 kip. The boundary conditions included roller supports at the spandrel ends and pin supports at the bottom of the columns as seen in Fig. 2-7.

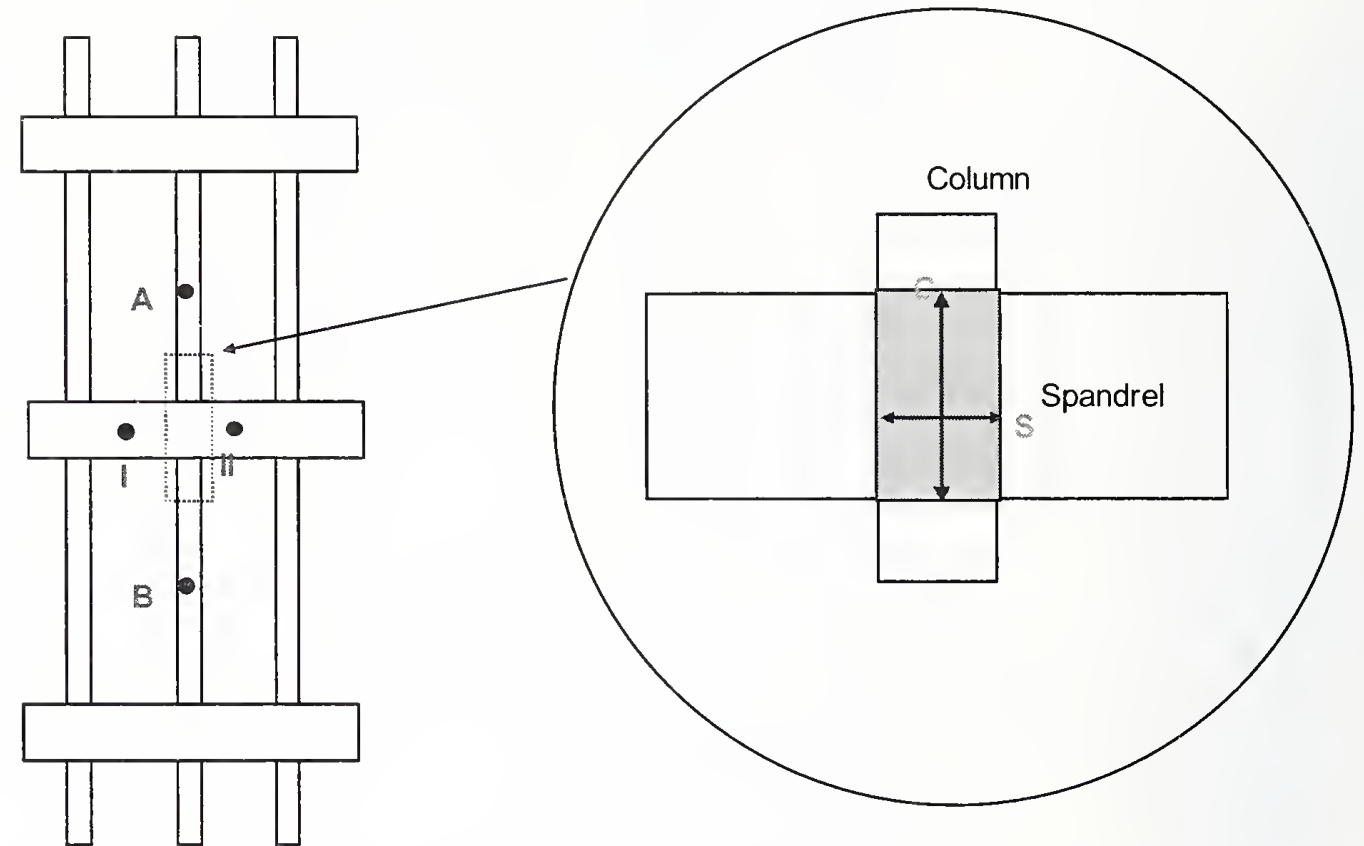

Figure 2-8. Selection of column and spandrel rigidity of typical exterior wall panel.

The lateral displacements calculated for the detailed shell and simplified frame models of typical exterior wall panels with varied column and spandrel intersection rigidities are shown in Table $2-2$. The table indicates that using a column rigidity of 50 percent and a spandrel rigidity of 100 percent in the frame model produced deflection results consistent with the shell model. This was achieved in the global models by assigning 50 percent rigidity for the columns and 100 percent rigidity for the spandrels at the column-spandrel intersection.

A similar study was conducted for the corner exterior panels to develop a simplified frame model that matched the behavior of a detailed shell element model of the corner panels. These models are shown in Fig. 2-9. For details of the study, refer to NIST NCSTAR 1-2A. Based on the results of this parametric study, 25 percent rigidity for the columns and 50 percent rigidity for the spandrels were assigned to the exterior wall comer panels. Also, an area modifier was used to provide a 25 percent increase in the axial stiffness of the two continuous columns of the corner panels. No modifier was used for the intermittent columns at the corners. 
Table 2-2. Lateral displacement (in.) for the shell and frame models of typical exterior wall panel with varied column and spandrel rigidities.

\begin{tabular}{|c|c|c|c|c|}
\hline & \multicolumn{4}{|c|}{ Lateral displacement (in) } \\
\hline & \multicolumn{4}{|c|}{ Floor 79-82 } \\
\hline & \multirow{2}{*}{ Shell model } & \multicolumn{3}{|c|}{ Frame model (Rigidity) } \\
\hline & & No rigidity & C:50\%, S:100\% & $\mathrm{C}: 100 \%, \mathrm{~S}: 100 \%$ \\
\hline$A$ & 0.60 & 1.04 & 0.59 & 0.35 \\
\hline$B$ & 0.28 & 0.52 & 0.29 & 0.18 \\
\hline 1 & 0.45 & 0.78 & 0.44 & 0.26 \\
\hline \multirow[t]{4}{*}{11} & 0.45 & 0.78 & 0.44 & 0.26 \\
\hline & \multicolumn{4}{|c|}{ Floor 53-56 } \\
\hline & \multirow{2}{*}{ Shell model } & \multicolumn{3}{|c|}{ Frame model (Rigidity) } \\
\hline & & No rigidity & C:50\%, S: $100 \%$ & C:100\%, S:100\% \\
\hline$A$ & 0.26 & 0.43 & 0.27 & 0.18 \\
\hline $\mathrm{B}$ & 0.12 & 0.22 & 0.14 & 0.11 \\
\hline 1 & 0.19 & 0.32 & 0.2 & 0.15 \\
\hline \multirow[t]{4}{*}{ II } & 0.19 & 0.32 & 0.2 & 0.15 \\
\hline & \multicolumn{4}{|c|}{ Floor 23-26 } \\
\hline & \multirow{2}{*}{ Shell model } & \multicolumn{3}{|c|}{ Frame model (Rigidity) } \\
\hline & & No rigidity & C:50\%, S: $100 \%$ & C: $100 \%, S: 100 \%$ \\
\hline$A$ & 0.21 & 0.37 & 0.21 & 0.12 \\
\hline $\mathrm{B}$ & 0.1 & 0.18 & 0.1 & 0.06 \\
\hline 1 & 0.16 & 0.28 & 0.16 & 0.09 \\
\hline II & 0.16 & 0.28 & 0.16 & 0.09 \\
\hline
\end{tabular}
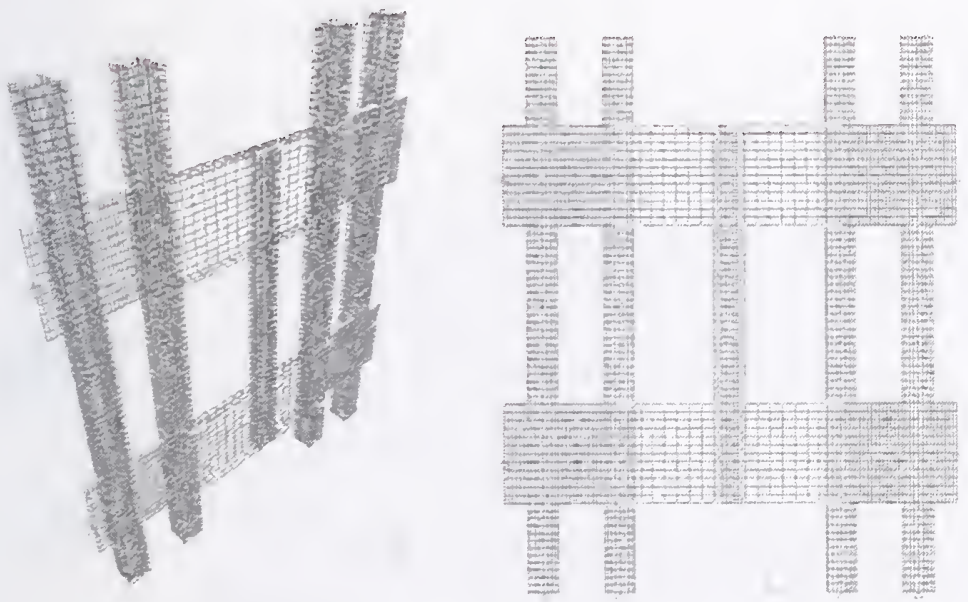

Figure 2-9. Shell element and frame models of typical exterior wall corner panel.

\section{Floor 107 to 110}

The exterior wall members from floors 107 to 110 were typically rolled shapes with a yield strength of $42 \mathrm{ksi}$ or $50 \mathrm{ksi}$ (where not shown in the drawings as $50 \mathrm{ksi}$, a yield strength of $42 \mathrm{ksi}$ was used). Frame elements were used to model the columns and spandrels of the exterior walls at these floors. Spandrel depths varied at floors 108 and 110. A weighted average of spandrel depth was calculated in order to 
define the average centerline elevation of the spandrels and, therefore, the node elevation for the entire floor.

\subsubsection{Core Columns Modeling}

The core columns were typically built-up box members at the lower floors and transitioned into rolled structural steel shapes at the upper floors for both towers. Core columns were modeled as frame elements spanning from node to node, defined at the representative floor elevations (centerline of spandrels). Splices in core columns occurred typically $3 \mathrm{ft}$ above the floor level. In the models, however, the splice was considered to occur at the floor level, and nodes were only defined at these levels. Most three-story column pieces were unique. In the model, a section for each three-story piece was defined and assigned to each of the three frame members that represented that column.

Core column coordinates were tabulatcd based on the structural drawings. Column locations were typically referenced at their centerlines. However, columns on lines 500 and 1000 were located in plan drawings along most of their height according to the face of the column into which the floor trusses connected (i.e., WTC 1 north face for 500 series columns and south face for 1000 series columns). The centerline of these columns was based on their dimensions given in the drawing books. Where these column centerlines varied along the height of the towers (typically $11 / 2 \mathrm{in}$. between three-story pieces), a representative location was chosen to define the column node. Thus, the column coordinate at floor 106 was used as a constant along the tower height because at this level, these columns aligned with the hat truss above.

\subsubsection{Hat Truss Modeling}

In both WTC 1 and WTC 2, a truss system referred to as a 'hat truss' was constructed between floor 107 and the roof. The hat truss system was intended to support the load of the antenna on top of the tower and to interconnect the exterior walls to the core. Four trusses spanning perpendicularly to the long direction of the core and four trusses spanning perpendicularly to the short direction of the core were constructed atop the towers (refer to Figs. 2-10 and 2-11). The wide flange core columns represented the vertical members of the hat trusses. The diagonals were primarily wide flange rolled sections, with the exception of the end diagonals between the core and the exterior walls, which were built-up box sections. The majority of the horizontal members in the hat truss system were wide flange and built-up box section floor beams.

Members of the hat truss were modeled using frame elements. These frame elements between floors 107 and 110 were assigned to the model according to plan and elevation drawings of the hat truss. Node locations were set to coincide with the centerline of spandrels at the exterior wall. All columns and diagonals shown in the drawings were included in the model. Floor beams that did not participate in the hat truss system were not included in the model, unless they were used to transfer truss chords to the core columns. Flexible floor diaphragms (see Section 2.3.4) were used to represent the floors within the hat truss area.

In general, diagonals and columns of the hat truss were assumed to be non-composite, and floor beams were assumed to be composite. Hat truss diagonals, main chords, and main columns were modeled with continuous joints. However, hat truss beams had pinned ends. 


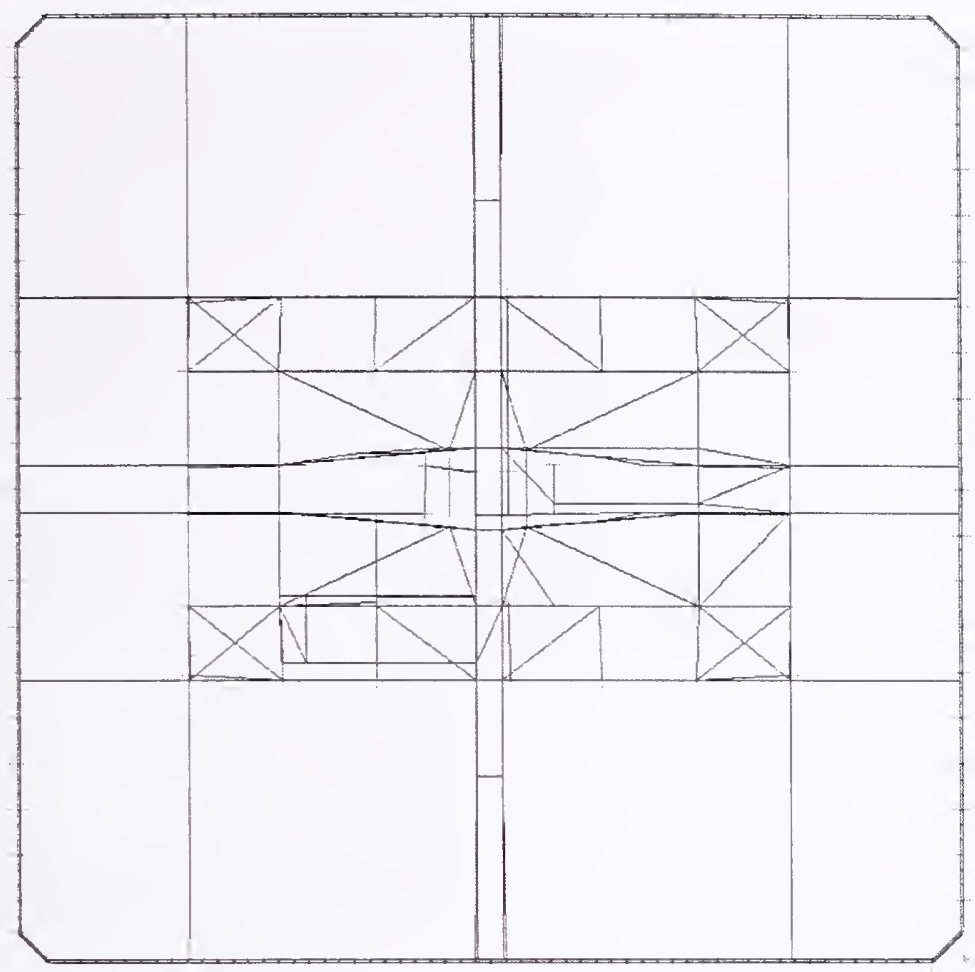

Figure 2-10. As-modeled plan of the WTC 1 hat truss.

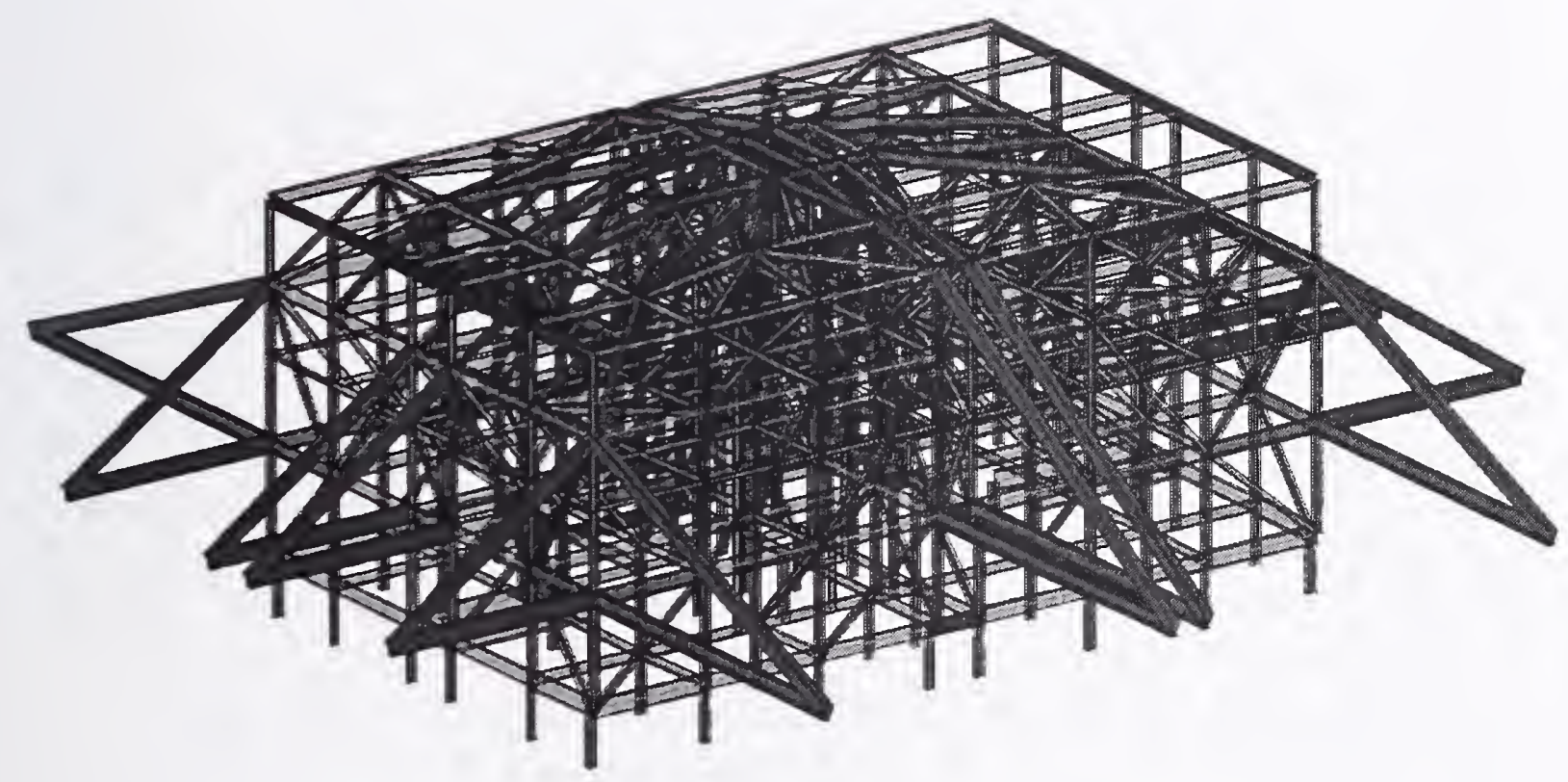

Figure 2-11. Rendered 3-D model of the WTC 1 hat truss. 


\subsubsection{Flexible and Rigid Floor Diaphragm Modeling}

For floors with high in-plane stiffness, a rigid diaphragm eonstraint causes all of its eonstrained joints to move together as a planar diaphragm that is rigid against in-plane deformation. This is customarily done in practice for lateral foree analyses to reduce the size of the building models. For most floors of the WTC towers, this eonstraint provided for a suffieiently accurate representation of the flow of forces and deformations for global struetural response. Where the flow of forees and deformations would be significantly affected by the use of rigid diaphragms in the global models, the floors were modeled as flexible diaphragms.

Flexible diaphragms were used at the floors of the towers in the core of the atrium area, in the mechanical floors, and in the floors of the hat trusses. The floors modeled using flexible diaphragms ineluded:

- Atrium levels: floors 3, 4, 5, 6, 7, and 9 .

- Mechanieal levels: floors $41,42,43,75,76$, and 77.

- Hat truss levels: floors 107, 108, 109, 110, and roof.

The flexible floor diaphragms consisted of equivalent shell element floor models attached to all exterior wall columns and eore columns.

The floor models developed as described in Sections 2.4 and 2.5 (see Fig. 2-12) were used to develop the flexible diaphragm stiffness used within the global models. For that purpose, parametric studies were condueted to eompare the diaphragm stiffness of the two different floor models for both the typical trussframed floor and the beam-framed floor. The simplified floor models duplicated the representation of the exterior wall columns and spandrels, eore columns, and their boundary conditions. The difference between the detailed and simplified models was that the floor framing for the simplified models, both inside and outside the core, was replaced by a course mesh of shell elements (see Fig. 2-13). The material properties of the simplified shell model matehed the properties of the conerete floor outside the eore in the respective floor model.

The detailed and simplified floor models were loaded in the plane of the floors with a lateral load of 180 $\mathrm{lb} / \mathrm{ft}$ on both the windward and leeward faces. The eolumn base supports were released for the exterior wall columns along the loaded faces and for all core columns to allow lateral translation only in the direction of loading. The horizontal defleetions of both floor models were ealculated on both the windward and leeward sides of the model. Both the total horizontal defleetion of the slab and the relative displacement between the windward and leeward sides were compared between the models. The shell thickness of the simplified model was modified to match the in-plane stiffness determined by the detailed floor models.

The deformations from the lateral load case using the 75th floor model of WTC 2 are illustrated in Fig. 2-12, while Fig. 2-13 shows the deformations of the simplified floor model. Figure 2-14 shows the lateral deflection of the north and south sides of the floor model under lateral load applied in the north direction using the detailed and equivalent floor models. 


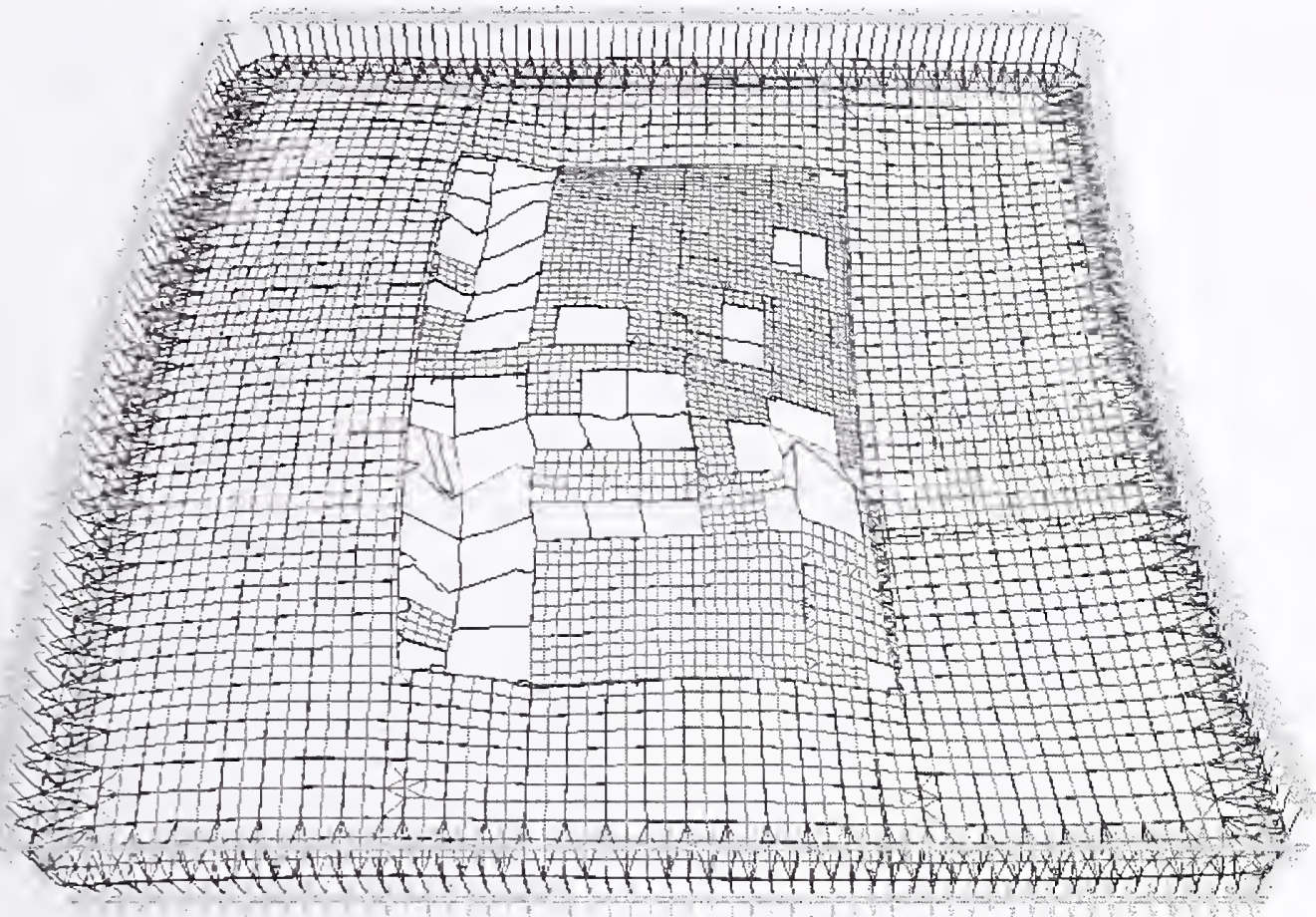

Figure 2-12. Deflection of typical beam-framed floor model due to lateral loading (exaggerated scale).

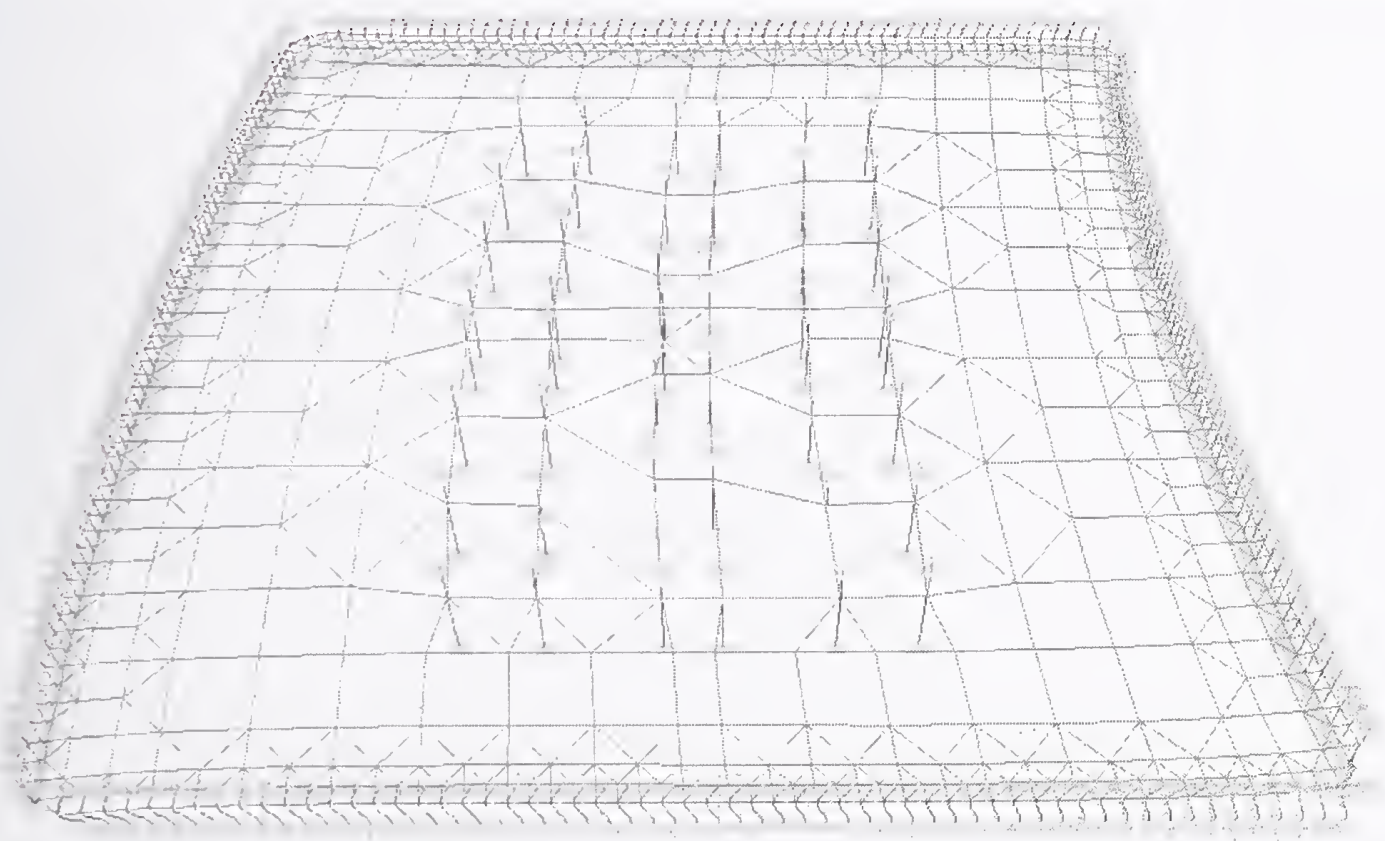

Figure 2-13. Deflection of equivalent floor model due to lateral loading (exaggerated scale). 


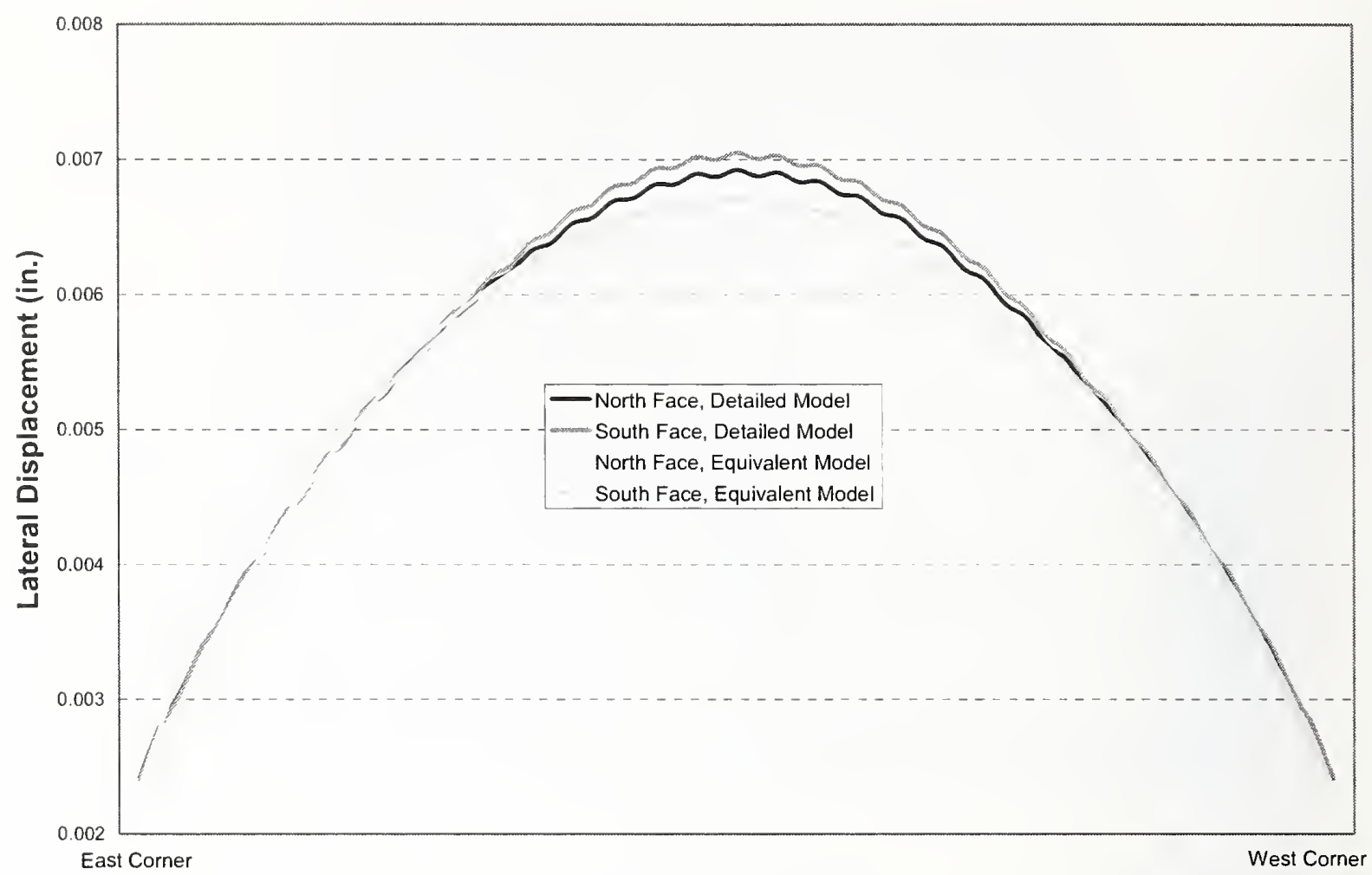

Figure 2-14. Deflections of the north and south faces of the floor for the detailed and equivalent floor models.

\subsubsection{Boundary Conditions}

The global models of the WTC 1 and WTC 2 towers were pin-supported at the bottom of the models, i.e., all translations were restrained and all rotations were permitted at the foundation level. No restraints were provided to account for the effect of floors at the basement levels outside the footprint of the towers.

\subsubsection{Results of Modal Analysis}

A modal analysis was conducted to estimate the natural frequencies of the WTC 1 and WTC 2 towers. The mass of the towers was estimated from the construction and superimposed dead loads only (see NIST NCSTAR 1-2A for further details). No live loads were used in estimating the floor masses for the modal analysis. The calculated first six periods and frequencies for WTC 1 and WTC 2 are presented in Table 2-3 without P- $\Delta$ effects and in Table 2-4 with P- $\Delta$ effects. P- $\Delta$ effects refer to secondary effects of column axial loads (designated $\mathrm{P}$ ) and lateral deflection (designated $\Delta$ ) on the moments in members, and hence the term P- $\Delta$. Results of modal analysis without P- $\Delta$ effects are relevant for small-amplitude vibrations, while those with $\mathrm{P}-\Delta$ effects are relevant for large-amplitude vibrations. As expected, the natural periods estimated with the P- $\Delta$ effects were longer than those without the P- $\Delta$ effects. The mode shapes can be found in Chapter 3 of NIST NCSTAR 1-2A. 
Table 2-3. Calculated first six periods and frequencies without P- $\Delta$ effects.

\begin{tabular}{|c|c|c|c|c|c|c|}
\hline \multirow{2}{*}{$\begin{array}{c}\text { Direction } \\
\text { of } \\
\text { Motion }\end{array}$} & \multicolumn{3}{|c|}{ WTC 1} & \multicolumn{3}{|c|}{ WTC 2} \\
\hline & Mode & $\begin{array}{c}\text { Frequency } \\
(\mathrm{Hz})\end{array}$ & $\begin{array}{l}\text { Period } \\
\text { (s) }\end{array}$ & Mode & $\begin{array}{c}\text { Frequency } \\
(\mathrm{Hz})\end{array}$ & $\begin{array}{l}\text { Period } \\
\text { (s) }\end{array}$ \\
\hline $\mathrm{N}-\mathrm{S}$ & 1 & 0.088 & 11.4 & 2 & 0.093 & 10.7 \\
\hline$E-W$ & 2 & 0.093 & 10.7 & 1 & 0.088 & 11.4 \\
\hline Torsion & 3 & 0.192 & 5.2 & 3 & 0.192 & 5.2 \\
\hline $\mathrm{N}-\mathrm{S}$ & 4 & 0.233 & 4.3 & 5 & 0.263 & 3.8 \\
\hline$E-W$ & 5 & 0.263 & 3.8 & 4 & 0.238 & 4.2 \\
\hline Torsion & 6 & 0.417 & 2.4 & 6 & 0.417 & 2.4 \\
\hline
\end{tabular}

Table 2-4. Calculated first six periods and frequencies with $P=\Delta$ effects.

\begin{tabular}{|c|c|c|c|c|c|c|}
\hline \multirow{2}{*}{$\begin{array}{c}\text { Direction } \\
\text { of } \\
\text { Motion }\end{array}$} & \multicolumn{3}{|c|}{ WTC 1} & \multicolumn{3}{|c|}{ WTC 2} \\
\hline & Mode & $\begin{array}{c}\text { Frequency } \\
(\mathrm{Hz})\end{array}$ & $\begin{array}{l}\text { Period } \\
\text { (s) }\end{array}$ & Mode & $\begin{array}{c}\text { Frequency } \\
(\mathrm{Hz})\end{array}$ & $\begin{array}{l}\text { Period } \\
\text { (s) }\end{array}$ \\
\hline $\mathrm{N}-\mathrm{S}$ & 1 & 0.083 & 12.1 & 2 & 0.089 & 11.2 \\
\hline$E-W$ & 2 & 0.088 & 11.3 & 1 & 0.083 & 12.1 \\
\hline Torsion & 3 & 0.189 & 5.3 & 3 & 0.192 & 5.2 \\
\hline $\mathrm{N}-\mathrm{S}$ & 4 & 0.227 & 4.4 & 5 & 0.250 & 4 \\
\hline$E-W$ & 5 & 0.250 & 4 & 4 & 0.227 & 4.4 \\
\hline Torsion & 8 & 0.455 & 2.2 & 8 & 0.455 & 2.2 \\
\hline
\end{tabular}

Table 2-5 presents a comparison of the calculated first three natural frequencies and periods $(\mathrm{N}-\mathrm{S}$ direction, E-W direction, and torsion) against measured frequencies and periods for WTC 1 . These measurements were based on analyzing acceleration records obtained from accelerometers installed atop WTC 1. The measurements were taken during the period from 1978 through 1994 for wind speeds ranging from $11.5 \mathrm{mph}$ to $41 \mathrm{mph}$. As the table indicates, the trend is for longer periods measured at larger wind speeds. The table also includes the values of the natural periods and frequencies predicted in the original design. The table shows good agreement between the calculated and measured periods, especially for the periods calculated without P- $\Delta$ effects (small amplitude vibrations). Thus, Table $2-5$ indicates that the reference global model provided a reasonable representation of the actual structure. 
Table 2-5. Comparison of measured and calculated natural frequencies and periods for WTC 1.

\begin{tabular}{|c|c|c|c|c|c|c|c|}
\hline \multirow{3}{*}{$\begin{array}{l}\text { Data Source/ } \\
\text { Event Date }\end{array}$} & \multirow{3}{*}{$\begin{array}{c}\text { Wind Speed \& } \\
\text { Direction }\end{array}$} & \multirow{2}{*}{\multicolumn{3}{|c|}{$\begin{array}{c}\text { Frequency }(\mathrm{HZ}) \\
\text { Direction of Motion }\end{array}$}} & \multicolumn{3}{|c|}{ Period (s) } \\
\hline & & & & & & on of $n$ & tion \\
\hline & & N-S & $E-W$ & Torsion & N-S & $E-W$ & Torsion \\
\hline \multicolumn{8}{|c|}{ Historical Data } \\
\hline October 11, 1978 & $11.5 \mathrm{mph}, \mathrm{E} / \mathrm{SE}$ & 0.098 & 0.105 & 0.211 & 10.2 & 9.5 & 4.7 \\
\hline January 24, 1979 & $33 \mathrm{mph}, \mathrm{E} / \mathrm{SE}$ & 0.089 & 0.093 & 0.203 & 11.2 & 10.8 & 4.9 \\
\hline March 21, 1980 & $41 \mathrm{mph}, \mathrm{E} / \mathrm{SE}$ & 0.085 & 0.092 & 0.201 & 11.8 & 10.9 & 5.0 \\
\hline December 11, 1992 & - & 0.087 & 0.092 & - & 11.5 & 10.9 & - \\
\hline February $2,1993^{1}$ & $20 \mathrm{mph}, \mathrm{NW}$ & 0.085 & 0.093 & 0.204 & 11.8 & 10.8 & 4.9 \\
\hline March $13,1993^{1}$ & $32 \mathrm{mph}, \mathrm{NW}$ & 0.085 & 0.094 & 0.199 & 11.8 & 10.6 & 5.0 \\
\hline March $10,1994^{1}$ & $14 \mathrm{mph}, \mathrm{W}$ & 0.094 & 0.094 & 0.196 & 10.6 & 10.6 & 5.1 \\
\hline December $25,1994^{2}$ & $\mathrm{~N}$ & 0.081 & 0.091 & - & 12.3 & 11.0 & - \\
\hline \multicolumn{8}{|c|}{ Average of Measured Data } \\
\hline Average & - & 0.088 & 0.094 & 0.202 & 11.4 & 10.6 & 4.9 \\
\hline \multicolumn{8}{|c|}{ Orginal Design - Predicted Values } \\
\hline Theoretical Value & - & 0.084 & 0.096 & - & 11.9 & 10.4 & - \\
\hline \multicolumn{8}{|c|}{ Reference Global Model } \\
\hline $\begin{array}{c}\text { LERA/NIST - WTC } 1 \\
\text { without P-Delta }\end{array}$ & & 0.088 & 0.093 & 0.192 & 11.4 & 10.7 & 5.2 \\
\hline $\begin{array}{c}\text { LERA/NIST - WTC } 1 \\
\text { with P-Delta }\end{array}$ & & 0.083 & 0.088 & 0.189 & 12.1 & 11.3 & 5.3 \\
\hline
\end{tabular}

Notes:

${ }^{1}$ Reported frequency value is the average of the SW corner, NE corner, and center core frequency measurements.

${ }^{2}$ Reported frequency is based on center core data only.

The period of oscillation in the N-S direction of WTC 2 was estimated immediately after aircraft impact based on a detailed analysis of the building motion, which was captured in video footage (Figure E-6 of Appendix E) of the WTC 2 impact (see NIST NCSTAR 1-5A). A frequency analysis of the displacement of the tower at the 70th floor, shown in Fig. 2-15, resulted in a fundamental mode in the N-S direction with a period of approximately $11.4 \mathrm{~s}$, a torsional mode with a period of $5.3 \mathrm{~s}$, and two higher translational modes with periods of 3.9 and $2.2 \mathrm{~s}$. Periods were accurate to within $\pm 0.1 \mathrm{~s}$. The measured fundamental period of $11.4 \mathrm{~s} \pm 0.1 \mathrm{~s}$ was nearly identical to the calculated period from the model ( $11.2 \mathrm{~s}$ with P- $\Delta$ effects for large-amplitude vibrations). Also, the measured torsional period and the higher translational period were almost identical to the calculated periods from the model with P- $\Delta$ effects $(5.2 \mathrm{~s}$ and $4.0 \mathrm{~s}$ for the torsional and higher translational modes, respectively).

The maximum displacement of the WTC 2 tower at floor 70 was measured to be about 12 in., while the maximum sway of the tower at the top was approximately 27 in. (NIST NCSTAR 1-5A). 


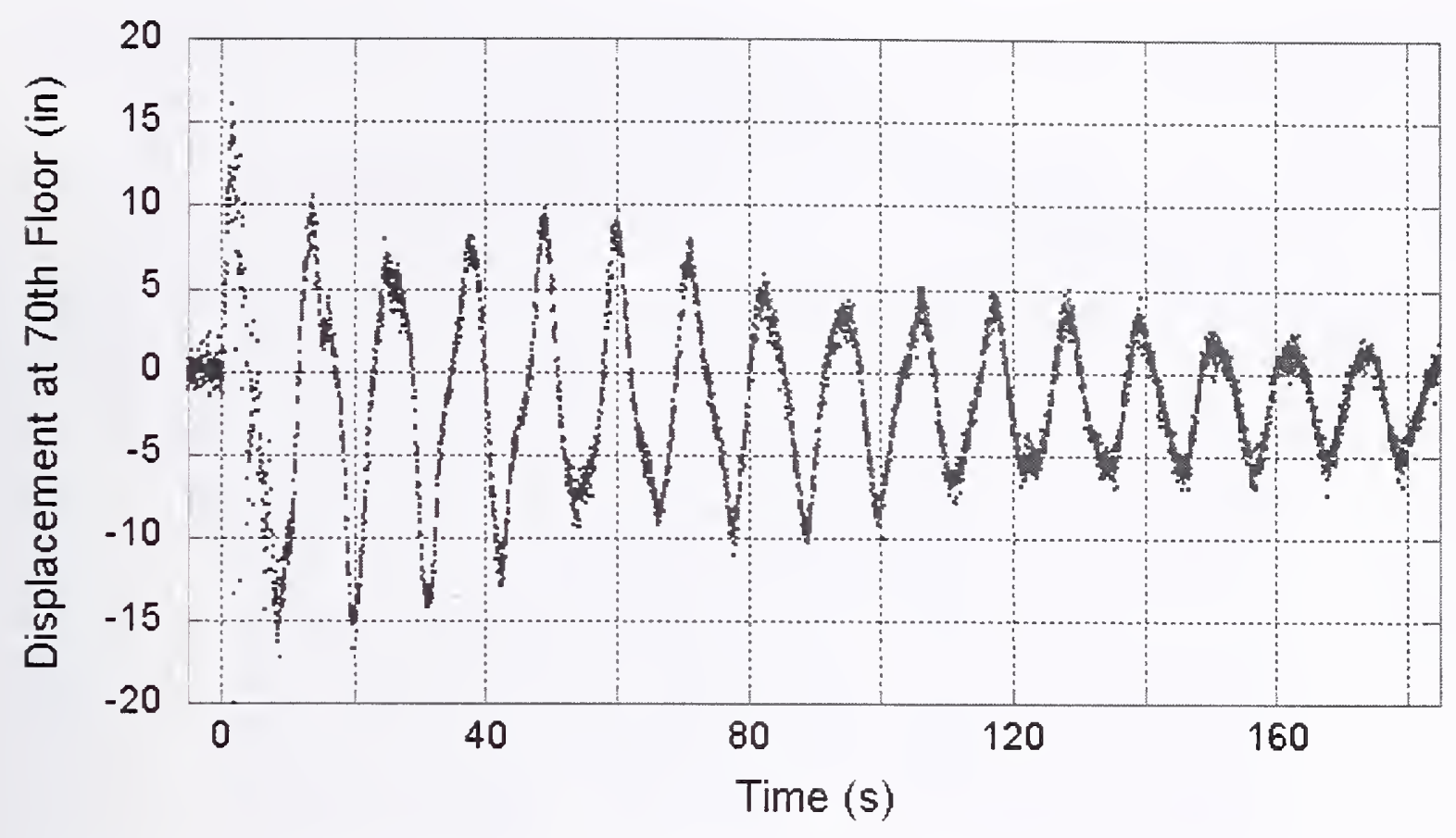

Figure 2-15. Displacement of floor 70 of WTC 2 after impact based on video analysis (NIST NCSTAR 1-5A).

The impact of the aircraft into WTC 2 caused the tower to sway back and forth for almost four minutes. The estimated period of oscillation was found to be nearly equal to the calculated first mode period of the undamaged structure, indicating that the overall lateral stiffness of the tower was not affected appreciably by the impact damage. The maximum deflection at the top of the tower was estimated to be more than $1 / 3$ of the drift resulting from the original design wind loads (about $65 \mathrm{in}$. in the $\mathrm{N}-\mathrm{S}$ direction) as calculated from the baseline analysis (see Chapter 4). Since the lateral stiffness of the building before and after impact was essentially the same, it can be concluded that the additional stresses in the columns due to this oscillation were roughly $1 / 3$ of the column stresses resulting from the original design wind loads, assuming linear behavior and assuming that the oscillation mode shape and the static deflected shape under design wind loads were identical. The building demonstrated an ability to carry this additional load and therefore, still had reserve capacity. This was confirmed by the structural analysis of the damaged towers reported in NIST NCSTAR 1-6.

\section{4} TYPICAL TRUSS-FRAMED FLOOR MODEL_FLOOR 96 OF WTC 1

The majority of the floors of the WTC towers were tenant floors, where the areas outside of the core were constructed of steel trusses acting in a composite fashion with concrete slabs cast over metal deck. The trusses consisted of double angle top and bottom chords with round bar webs that extended to the concrete slab to provide the composite action (shear knuckles). Two trusses were placed at every other exterior column line, resulting in a $6 \mathrm{ft} 8 \mathrm{in}$. spacing between truss pairs. The typical floor consisted of three truss zones: a long span zone, a short span zone, and a two-way zone as shown in Fig. 2-16. The span of the trusses was about $36 \mathrm{ft}$ in the short direction and $60 \mathrm{ft}$ in the long direction. The two-way zone included trusses in the long span direction (primary trusses) as well as bridging trusses (secondary 
trusses) normally found elsewhere. The secondary trusses had additional strength and connectivity to enable them to act in tandem with the long spanning trusses to form a two-way spanning truss grid. The floor trusses were pre-assembled into floor panels as defined in the contract drawings. The floor panels included primary trusses, bridging trusses, deck support angles, metal deck, and strap anchors. A typical composite beam and slab construction was used for the floors inside the core.

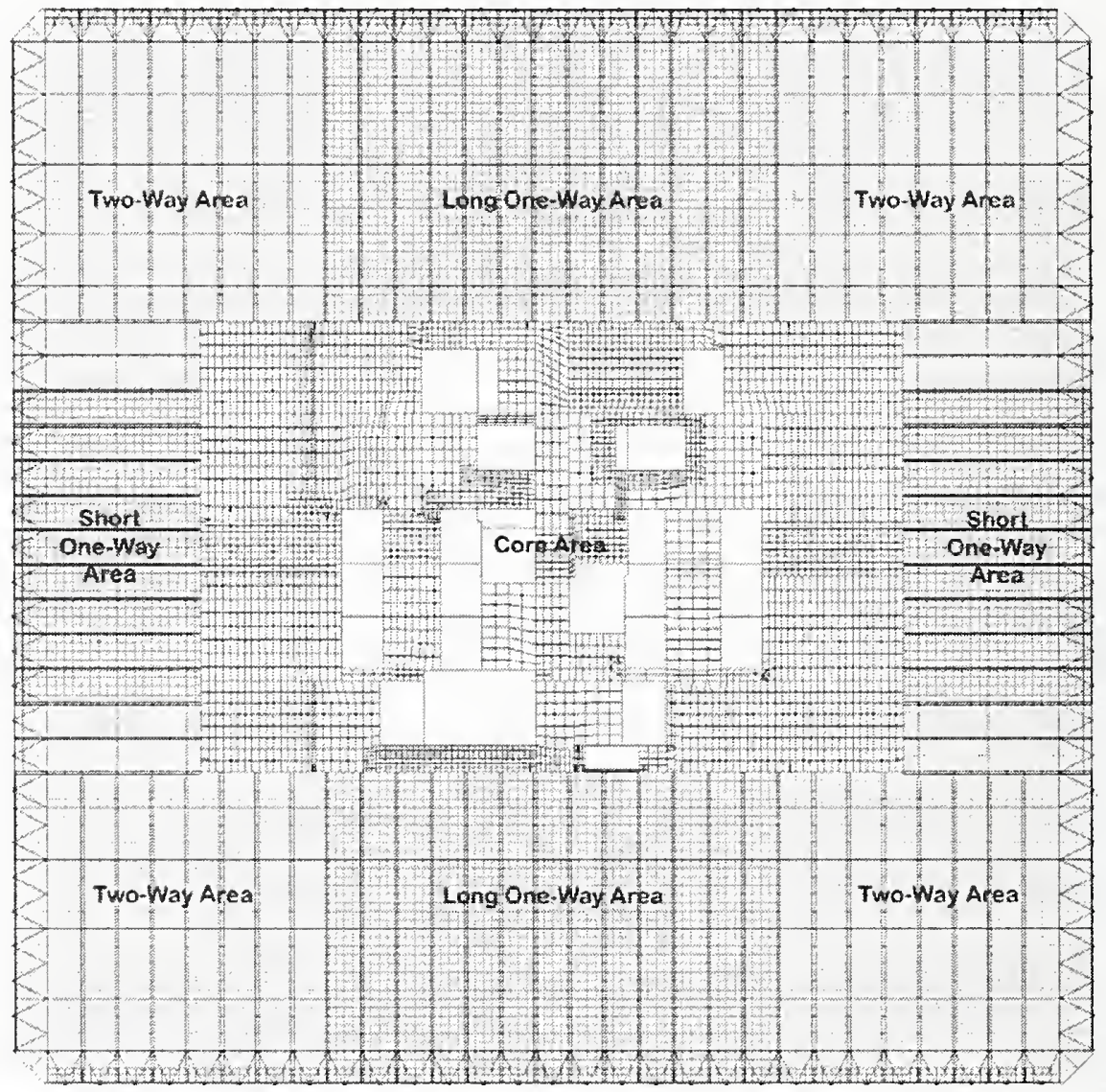

Figure 2-16. Typical floor truss framing zones.

In order to select the typical truss-framed floor within the expanded impact and fire zones of both towers, the drawings for floors 80 to 100 were reviewed to identify structural similarities. Appendix G of NIST NCSTAR 1-2A provides the details of this study. It was found that floor 96 of WTC 1 (96A) represented the typical truss-framed floor in the expanded impact and fire region for WTC 1 and WTC 2. An isometric view of the typical truss-framed floor model is shown in Fig. 2-17. Table 2-1 includes a summary of the size of the $96 \mathrm{~A}$ floor model. The floor model consisted primarily of frame elements with the exception of the floor slabs, which were modeled using shell elements. The following summarizes the major components of the typical truss-framed floor model. 


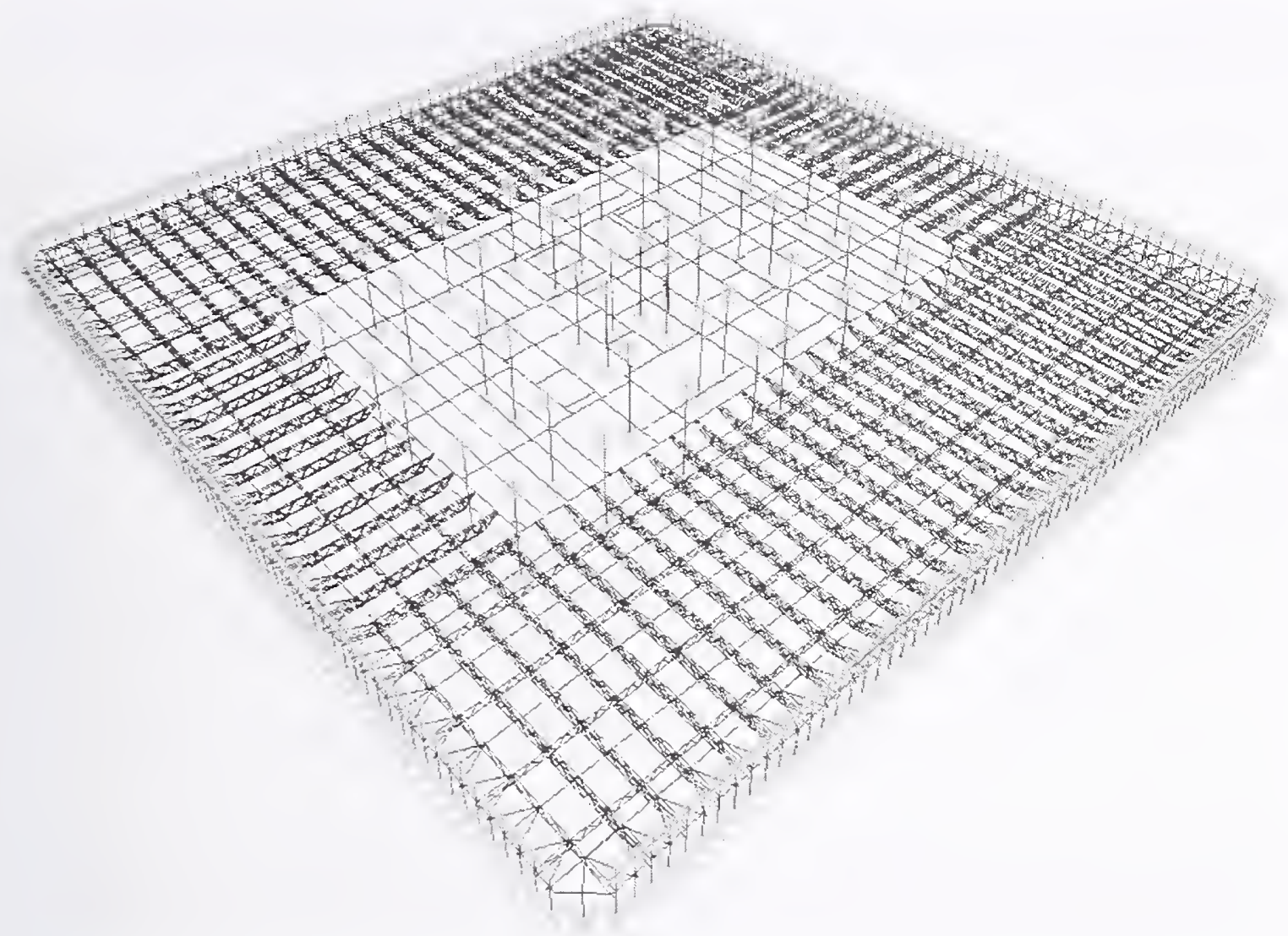

Figure 2-17. Typical truss-framed floor model (floor 96 of WTC 1), slab not shown.

\subsubsection{Primary Trusses}

The primary trusses consisted of double angle top and bottom chords, which were 29 in. out-to-out of the chords. The distance between the centroid of the two chords was $28.05 \mathrm{in}$. For a typical long-span truss, $\mathrm{C} 32 \mathrm{~T} 1$, the top chord consisted of two angles $2 \mathrm{in}$. by $1.5 \mathrm{in}$. by $0.25 \mathrm{in}$. and the bottom chord consisted of two angles 3 in. by 2 in. by 0.37 in.; both chords were short legs back-to-back. The top chords acted compositely with a 4 in. concrete slab on $11 / 2$ in. metal deck. The distance from the centroid of the top chord to the neutral axis of the transformed composite slab with top chord was calculated to be 1.93 in. In the model, therefore, $30.0 \mathrm{in}$. (28.05 in. $+1.93 \mathrm{in.}=29.98 \mathrm{in}$.) was assumed as the typical distance between the top and bottom chords for both short- and long-span primary trusses, see Fig. 2-18. The shell element representing the floor slab was located at the same level as the beam elements representing the top chord.

In the long-span truss zone, the two individual primary trusses, which were part of the same floor panel and attached to the same column, were separated, typically by a distance of $71 / 8 \mathrm{in}$. At the joint between panels, the distance between the abutting long-span trusses was $71 / 2 \mathrm{in}$. Therefore, in the model, $71 / 2$ in. was used as the spacing between all long-span primary trusses. In the short-span truss zone, two individual trusses which attached to the same column were separated by a distance that varied between $47 / 8$ in., 5 in., and $51 / 4$ in. In the model, the typical spacing between all short-span double trusses was 
$5 \mathrm{in.}$ The long span trusses in the two-way zone had an as-modeled length of $58 \mathrm{ft} 10 \mathrm{in}$., while the longspan trusses in the one-way zone had an as-modeled length of $59 \mathrm{ft} 8 \mathrm{in}$.

C32T1 (Primary Truss Section)

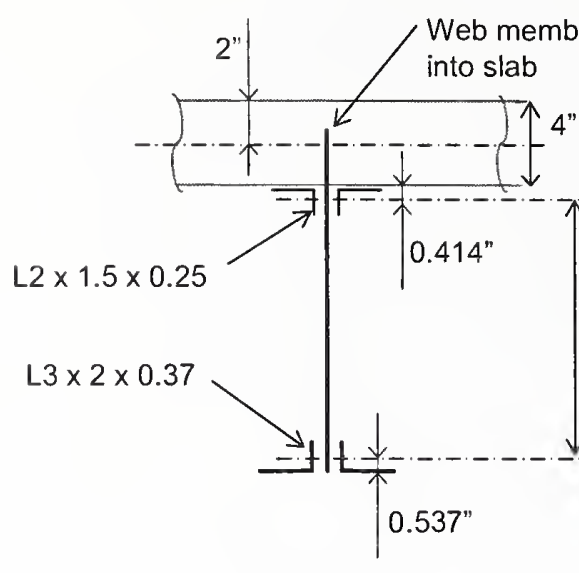

ACTUAL

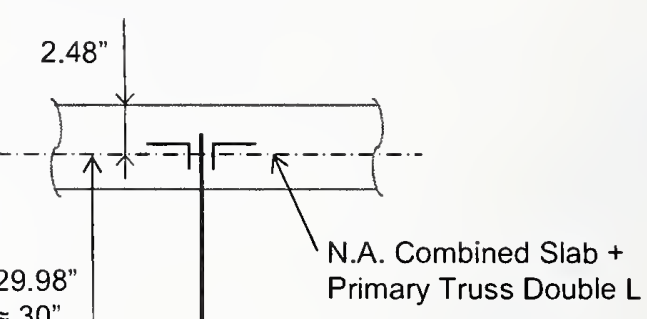

28.05" $\approx 30^{\prime \prime}$
Primary Truss Double L

(Note: $2^{\text {nd }}$ Truss of Pair Not Shown)

MODEL

Figure 2-18. Typical primary truss cross-section, as-designed and as-modeled.

The diagonal web bars for the primary trusses were most often 1.09 in. diameter bars. Therefore, for double angle shapes in the primary trusses, $1.09 \mathrm{in}$. was taken as the distance between the two angles. This holds true for primary trusses where bar diameters varied between $0.92 \mathrm{in}$. and $1.14 \mathrm{in}$. The asdesigned truss diagonals had end fixity, but were considered pinned in the model. Pinning the diagonals provided an upper bound of the gravity load stresses. To mitigate the effect of the pinned member approach, end length offsets were used for the truss diagonals to account for the difference between the as-built and the as-modeled unbraced length of the diagonal. A similar approach was used for the diagonals of the bridging trusses.

In 30 percent of the floor area, truss members were supplemented with cover plates. The members with additional plates included top chords, web members, and most typically bottom chords. The primary truss top chords were reinforced with an additional set of double angles at truss end connections. At these locations, the work points for the section were located at the centroid of the composite double angle and concrete slab. Plates $3 / 8$ in. by 3 in. connected the bottom chord of the primary truss pairs together at each end and at the intersection with a bridging truss. These plates were included in the model.

\subsubsection{Bridging Trusses}

The bridging trusses were $24 \mathrm{in}$. deep, edge-to-edge, with double angle chords. For a typical bridging truss, $24 \mathrm{~T} 11$, the top and bottom chords consisted of two angles $1.5 \mathrm{in}$. by $1.25 \mathrm{in}$. by $0.23 \mathrm{in}$. The distance between the centroid of the two chords was $23.26 \mathrm{in}$. The distance used as the offset between the top and bottom chords for all bridging trusses was taken as 23.25 in. (Fig. 2-19). The distance between the top chord of the bridging truss and the top chord of the primary trusses and equivalent slab plate for truss $24 \mathrm{~T} 11$ was calculated to be $3.39 \mathrm{in}$. and was selected to be $3.375 \mathrm{in}$. for all bridging trusses. As in the as-designed structure, the bridging truss was not connected along its length to the slab shell elements 
in the model. The intersection of the top chords of the primary and bridging trusses was modeled using vertical rigid links, connected in turn to the slab shell elements representing the concrete slab.

For bridging trusses in the model, a 0.75 in. angle gap was used for trusses with web bar diameters that varied between 0.75 in. and 0.98 in.

$\underline{24 T 11}$ (Bridging Truss Section)

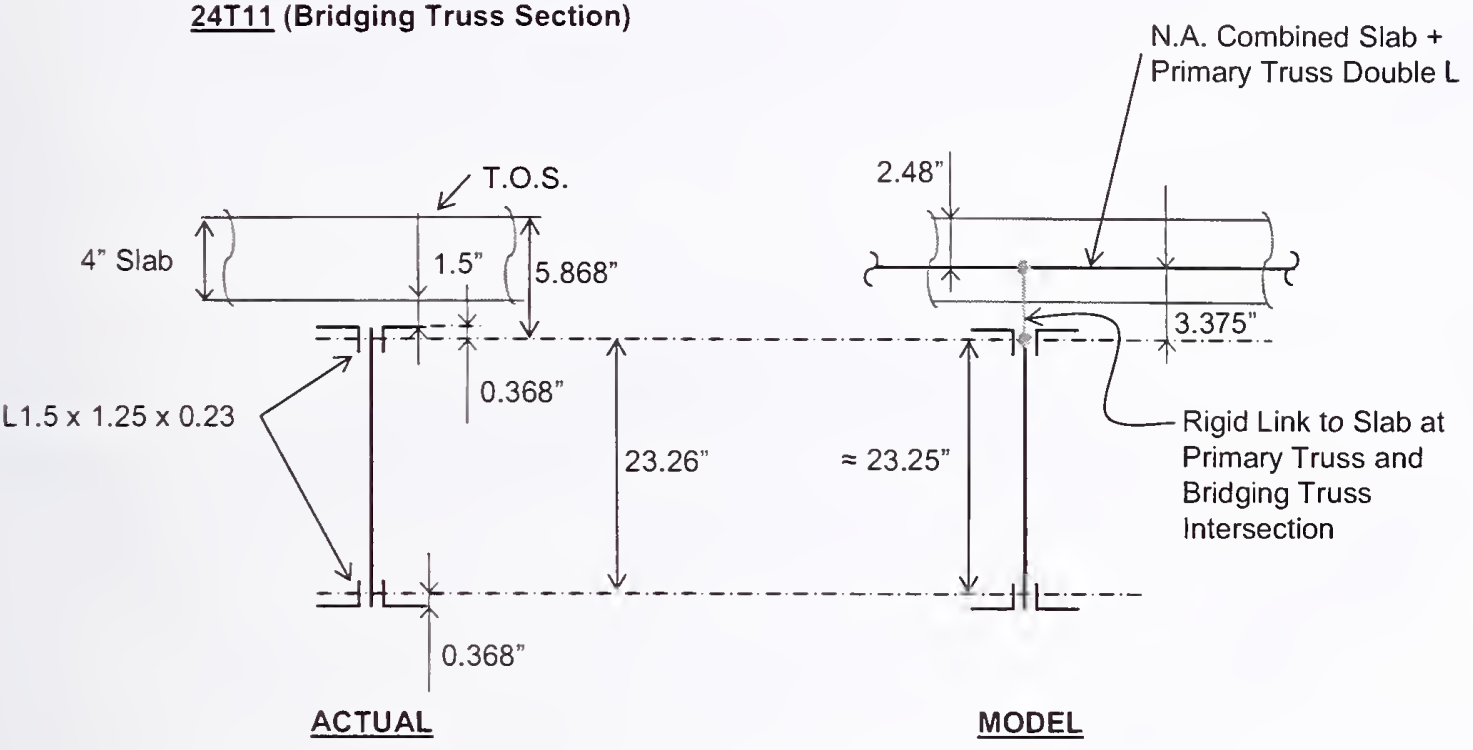

Figure 2-19. Typical bridging truss cross-section, as-designed and as-modeled.

\subsubsection{Concrete Slab and Metal Deck}

Outside the core, the primary trusses acted compositely with the 4 in. concrete slab on $11 / 2 \mathrm{in}$. metal deck. In the model, the average depth of the slab plus deck was modeled as $4.35 \mathrm{in}$. The concrete slab consisted of lightweight concrete with a self-weight of $100 \mathrm{pcf}$ and a design compressive strength, $f_{c}^{\prime}=3,000 \mathrm{psi}$. The concrete modulus of elasticity, $E_{c}$, was $1,810 \mathrm{ksi}$. These values were consistent with those included in the WTC Structural Design Criteria Book. In the as-designed structure, composite action was achieved by the shear connection provided by the web bar extending above the top chord and into the slab (shear knuckle). This composite action was modeled by assuming a rigid connection between the concrete slab and the top chord at the intersection with the diagonal (knuckle location).

Typically, inside the core, the beams acted compositely with a $41 / 2 \mathrm{in}$. formed concrete slab. The concrete slab consisted of normal weight concrete with a self-weight of $150 \mathrm{pcf}$ and a design compressive strength, $f_{c}^{\prime}=3,000 \mathrm{psi}$. The concrete modulus of elasticity, $E_{c}$, was $3,320 \mathrm{ksi}$. In the as-designed structure, composite action was achieved using shear stud connectors between the beam tops and the slab. This composite action was modeled by assuming a rigid connection between the concrete slab and the floor beams.

The floors of the WTC towers had an in-floor electrical distribution system of electrified metal deck and trench headers. The effects of the in-slab trench headers were included in the model by reducing the slab shell element thickness. A $1 \mathrm{ft} 8 \mathrm{in}$. wide shell panel (the typical truss-floor shell mesh size) was reduced in thickness from 4.35 in. to 2.35 in. or 1.35 in. at the trench header locations. 


\subsubsection{Viscoelastic Dampers}

Viscoelastic dampers were used to reduce the wind-induced vibrations and were located where the bottom chords of the long span, short span, and bridging trusses intersected the exterior columns. The dampers were defined in Drawing Book D. The dampers resisted static and quasi-static loads (such as gravity loads) at the time of load application. Immediately following load application, the dampers shed load until the stress in the dampers was dissipated. A placeholder element was located in the model at the damper location.

\subsubsection{Strap Anchors}

Exterior columns not supporting a truss or truss pair were anchored to the floor diaphragm by strap anchors. These strap anchors were connected to the columns by complete penetration welds. The strap anchors were then connected to the slab with shear stud connectors and to the top chords of the trusses by fillet welds. The straps were included in the model and located in the plane of the centroid of the composite top chord. Also, in the model the work points intersected with the centerline of the column and used a rigid link to attach back to the spandrel (see Fig. 2-20).

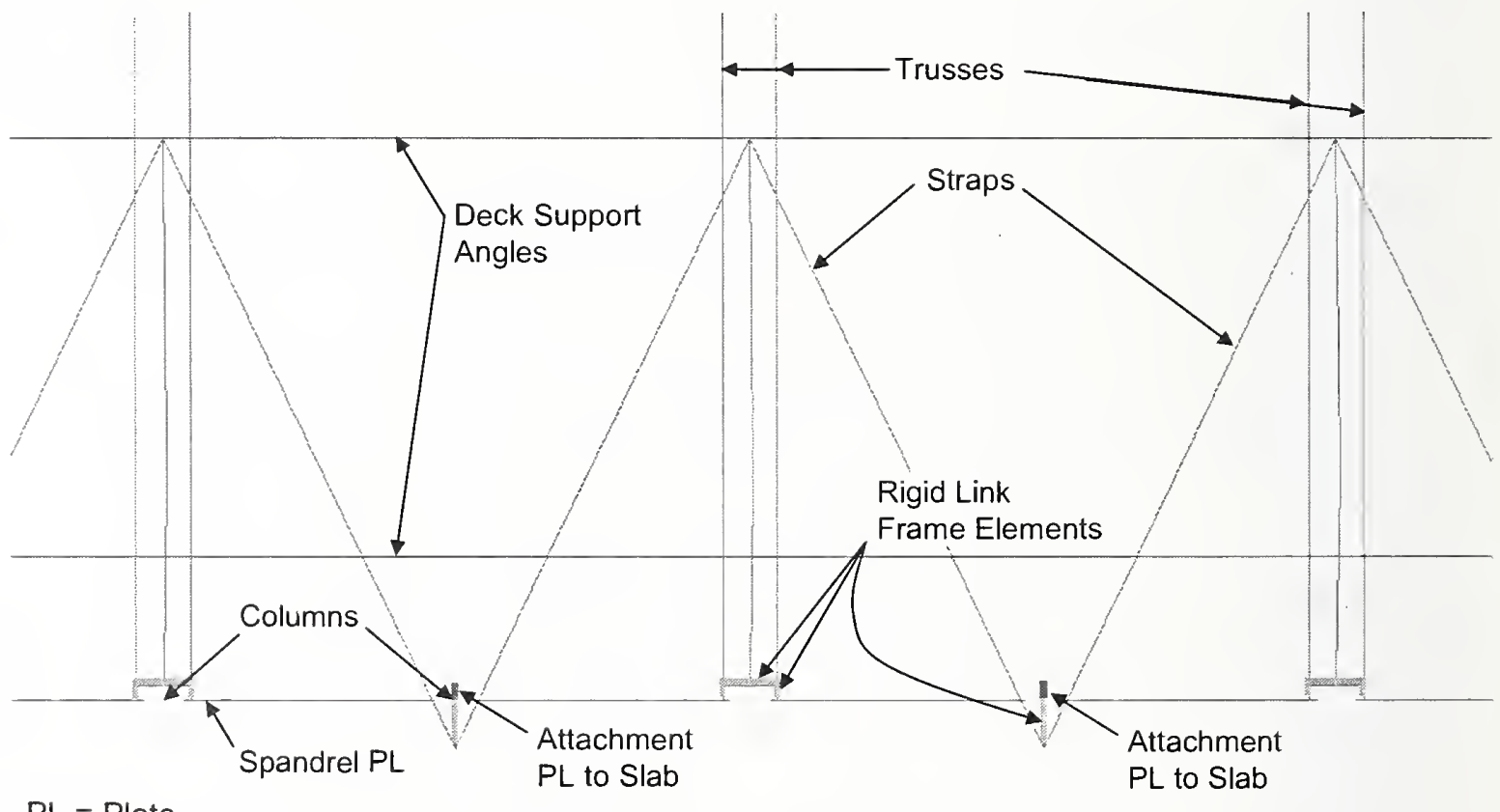

$\mathrm{PL}=$ Plate

Figure 2-20. Strap anchors modeling, slab not shown.

\section{$2.5 \quad$ TYPICAL BEAM-FRAMED FLOOR MODEL-FLOOR 75 OF WTC 2}

Beam-framed floors were used for the mechanical floors within the towers. These floors were constructed using rolled structural steel shapes. The beam framing for the typical floor system consisted of W27 and W16 beams in the long- and short-span regions, respectively. Typical beam spacing was $6 \mathrm{ft}$ 8 in. The steel beams acted in composite fashion with the normal weight concrete slab on metal deck. The deck spanned in the direction of the primary beams and was supported typically at $6 \mathrm{ft} 8 \mathrm{in}$. intervals by a 4 C 5.4 deck support channel. A 2 in. concrete topping slab was placed on top of the structural slab. 
The core area was framed similarly to the core of the truss-framed floors. but the steel beams were typically larger, and the concrete slab was 6 in. deep.

As described in Section 2.4 for truss-framed floors, the structural drawings were reviewed to identify structural similarities between the beam-framed floors within the expanded impact and fire zones of both towers (see Appendix G of NIST NCSTAR 1-2A). It was found that floor 75 of WTC 2 (75B) represented the typical beam-framed floor in the expanded impact zone for WTC 2 (floors 74B to 88B). There were no beam-framed floors within the expanded impact zone of WTC 1. An isometric view of the typical beam-framed floor model is presented in Fig. 2-21. Table 2-1 includes a summary of the size of the 75B floor model. The following presents the major structural systems and components of the beamframed floor model.

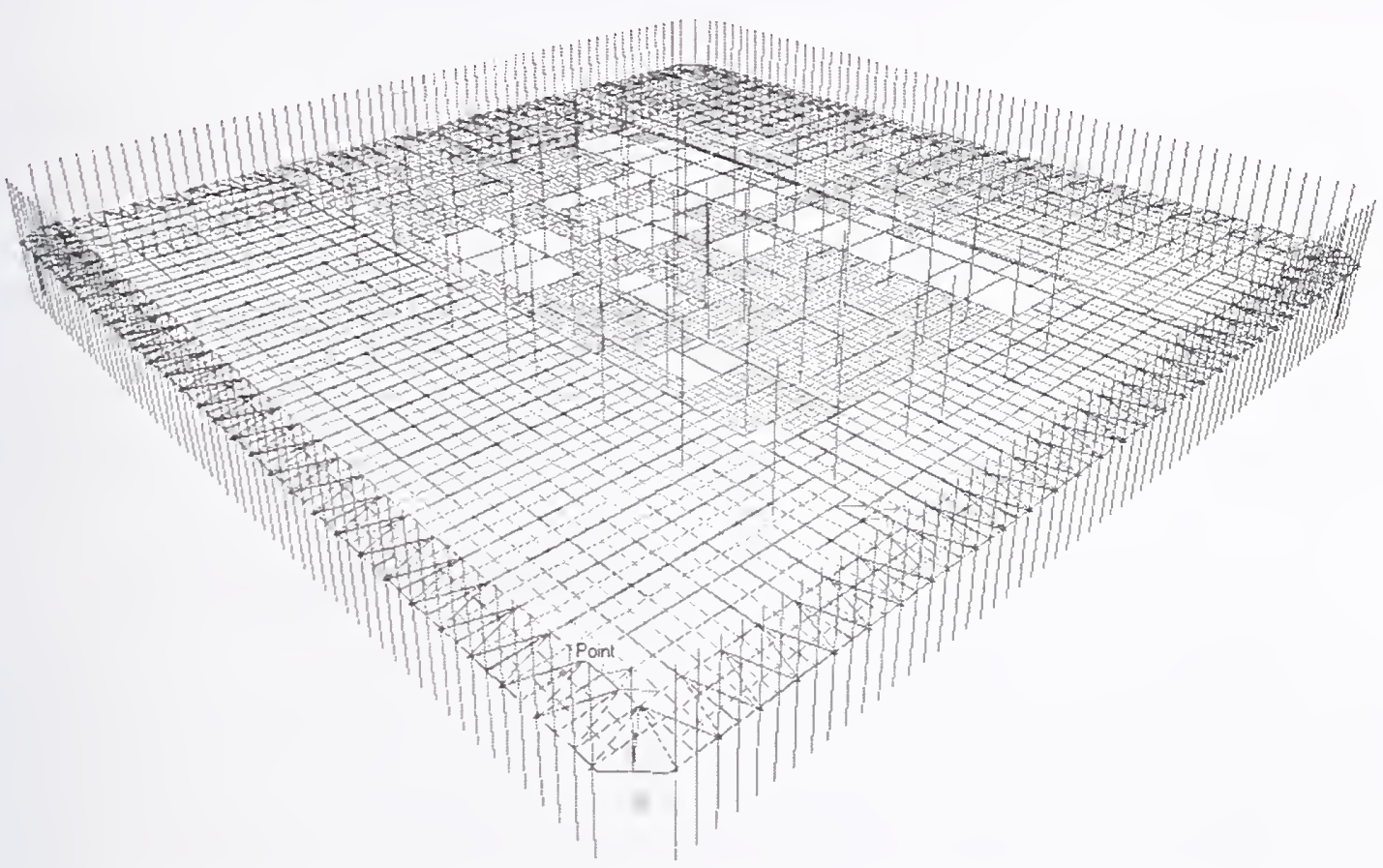

Figure 2-21. Typical beam-framed floor model (floor 75 of WTC 2).

\subsubsection{Composite Beams}

The beams in the model were located at the elevation of the centerline of the concrete slab. The insertion point for the beams was set at the beam top flange, and then the beam was offset down by one-half the thickness of the slab. The beam was rigidly linked with the slab to simulate the composite action. This option provided for accurate estimation of the composite stiffness of the floor.

\subsubsection{Horizontal Trusses}

Exterior columns that did not support a beam were connected to the floor for bracing purposes by horizontal trusses. These exterior horizontal trusses were anchored to the columns with complete joint penetration welds. The horizontal trusses were then connected with shear stud connectors to the slab. 
The truss angles (typically 4 in. by 4 in. by $5 / 16$ in.) were then connected to the top flange of the beams. In the model, the work points intersected with the centerline of the column and used a rigid link to attach back to the spandrel. The truss members were located in the plane of the centroid of the composite top chord (see Fig. 2-22).

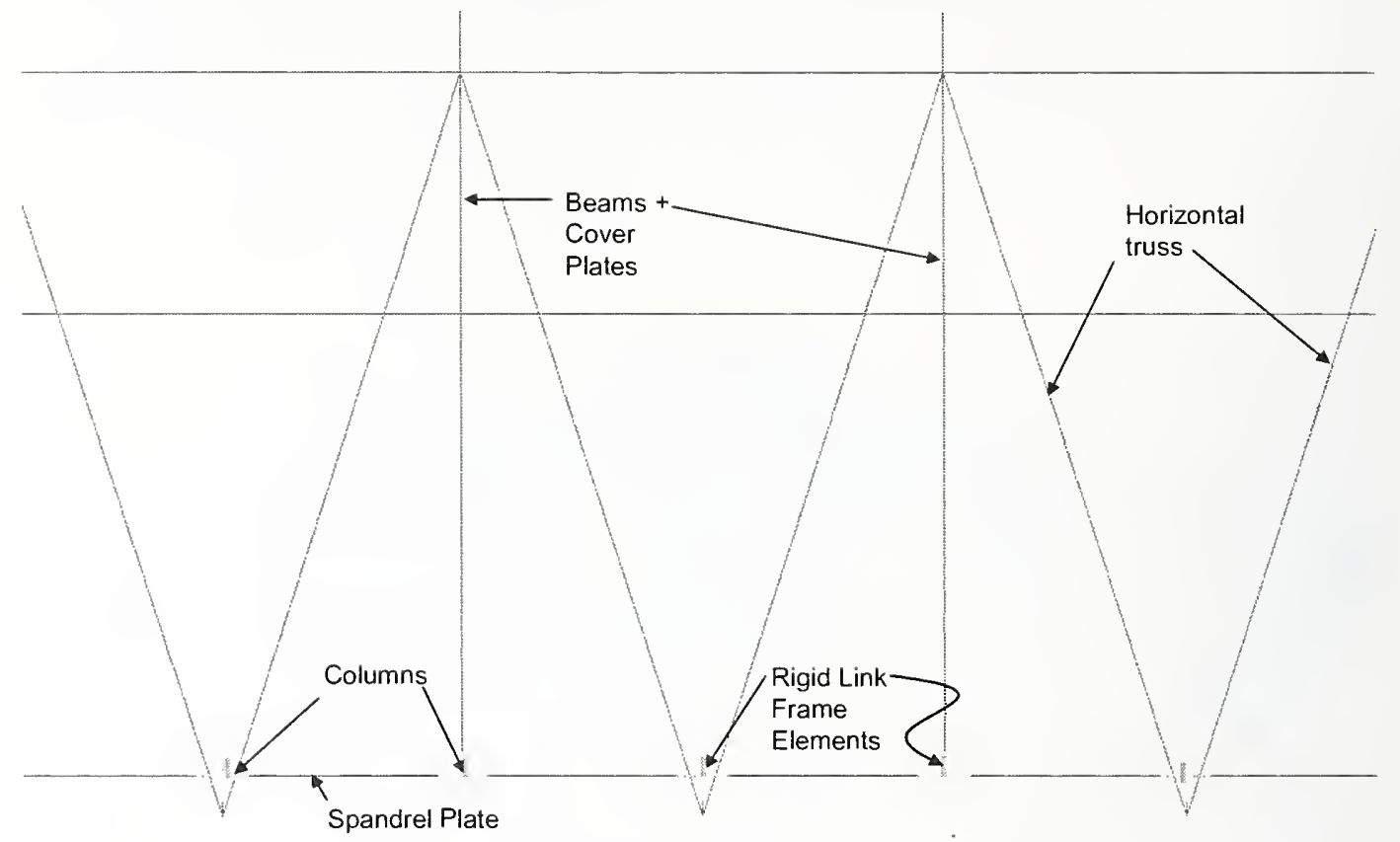

Figure 2-22. Horizontal truss modeling, slab not shown.

\subsubsection{Concrete Slab and Metal Deck}

Outside the core on the mechanical floors, the beams acted compositely with a $53 / 4$ in. concrete slab on $11 / 2 \mathrm{in}$. metal deck. The average depth of the slab in the model was taken as $6.1 \mathrm{in}$. The concrete slab consisted of normal weight concrete with a self-weight of $150 \mathrm{pcf}$ and a design compressive strength of typically $f_{c}^{\prime}=3,000 \mathrm{psi}$. The concrete modulus of elasticity, $E_{c}$, was $3,320 \mathrm{ksi}$. Typically, inside the core, the beams acted compositely with a 6 in. formed concrete slab. The concrete slab consisted of normal weight concrete with the same properties as concrete outside the core.

The mechanical floors had a 2 in. maximum depth topping slab, both inside and outside the core. The topping slab stiffness was not included in the models, but this dead weight was accounted for in the baseline performance analyses.

\subsubsection{Viscoelastic Dampers}

Viscoelastic dampers were located below the bottom flange of the beams where the beams intersected the exterior columns. Similar to the typical truss-framed floor model, a placeholder element was located in the model at the damper location. 


\subsection{REVIEW OF THE STRUCTURAL DATABASES AND REFERENCE MODELS OF THE TOWERS}

The following summarizes the results of the third-party review by the firm of SOM and the in-house NIST review for the developed structural databases and reference models.

\subsubsection{Structural Databases}

The third-party review by SOM included random checks of the digitized structural databases and cross section property calculations. The review indicated no discrepancies between the developed databases and the original drawing books. Also, for cross section property calculations, the review indicated good agreement (within 1 percent) between the properties in the developed databases and those estimated by SOM.

The in-house NIST review included the following steps: (1) line-by-line review of all database files, (2) random checks on the developed databases by the NIST investigator, and (3) calculation of all cross section properties and comparison with those in the developed databases. The review indicated minor discrepancies between the developed databases and the original drawing books. For cross section property calculations, good agreement was obtained between the properties in the developed databases and those estimated by NIST. The discrepancies between the developed databases and the original drawing books were reported to LERA, and they implemented the changes and modified the databases accordingly. Consequently, the structural databases were approved by NIST and were made available for other phases of the NIST investigation.

\subsubsection{Reference Structural Models}

The third-party review by SOM included: (1) random checks of the consistency of the developed reference models with the original structural drawings and drawing books, (2) verification and validation of the models (including reviewing assumptions and level of detail), and (3) performing analyses using various loading conditions to test the accuracy of the models. The review concluded that the developed models were consistent with the original design documents, and that, in general, the modeling assumptions and level of detail in the models were accurate and suitable for the purpose of the Investigation. The SOM review identified two areas where the models needed to be modified. The first was the effect of additional vertical stiffness of the exterior wall panels due to the presence of the spandrel beams (see Section 2.3.1). The second area was the modeling of the connections of the floor slab to the exterior columns of the 75B floor model (Section 2.5), where this connection appeared to be fixed while it would be appropriate to model it as pinned.

The in-house NIST review included: (1) checks on the consistency of the developed reference models with the original structural drawings and drawing books, (2) verification and validation of the models (including reviewing assumptions and level of detail), and (3) and performing analyses using various loading conditions to test the accuracy of the models. The review indicated minor discrepancies between the developed reference models and the original design documents. Similar to the third-party review, the in-house NIST review identified the proper modeling of the vertical stiffness of the exterior wall panels and the accurate modeling of the floor slab connections to the exterior columns in the $75 \mathrm{~B}$ floor model as areas that needed to be modified in the models. 
In addition, NIST conducted a workshop for NIST investigators and contractors to review the reference structural models developed by LERA. The workshop attendees included experts from LERA (two experts); SOM (two experts); Teng and Associates (one expert, contractors on probable structural collapse); Professor Kaspar Willam (contractor on thermal-structural analysis); Dr. David M. Parks (contractor on computational mechanics for aircraft impact analysis); Applied Research Associates (two experts, contractor on analysis of aircraft impact into the WTC towers), as well as all key investigators from NIST (17 experts). The purpose of the workshop was to discuss the methodology, assumptions, and details of the developed reference models. The feedback from the workshop was included in the final review of the models. The minutes of the workshop were made public.

The discrepancies between the developed models and the original design documents, as well as the areas identified by both the third-party and the NIST in-house review as needing modification, were reported to LERA, which implemented the changes and modified the models accordingly. Subsequently, the reference structural models were approved by NIST and were made available for use in other phases of the NIST investigation.

\section{$2.7 \quad$ SUMMARY}

This chapter described the development of the reference structural models for the WTC towers. These reference models were used to establish the baseline performance of the towers and also serve as a reference for more detailed models for the aircraft impact damage analysis and the thermal-structural response and collapse initiation analysis. The main types of the models developed were:

- Two global models of the towers, one each for WTC 1 and WTC 2. The models included all primary structural components in the towers, including exterior walls (columns and spandrel beams), core columns, exterior wall bracing in the basement floors, hat trusses, and rigid and flexible diaphragms representing the floor systems. To validate the global models, the calculated natural frequencies of WTC 1 were compared with those measured on the tower, and good agreement between the calculated and measured values was observed.

- One model each of a typical truss-framed floor (floor 96 of WTC 1) and a typical beam-framed floor (floor 75 of WTC 2) in the impact and fire zones in the two towers. The models included all primary structural components in the floor system, including primary and bridging trusses, beams, strap anchors and horizontal trusses, concrete slabs, and viscoelastic dampers. Both models were developed using frame elements, except for the concrete slabs which were modeled using shell elements with typical element sizes of $20 \mathrm{in}$. and $40 \mathrm{in}$. for the truss-framed floor and the beam framed floor, respectively.

Prior to the development of the reference models, databases of the primary structural components of the towers were developed from the original computer printouts of the structural design documents and modifications made after construction. These databases facilitated the development of the global models of the towers.

The structural databases and reference structural models were developed by LERA and were reviewed by SOM and NIST. 


\section{$2.8 \quad$ REFERENCES}

SAP2000 (2002), Linear and Nonlinear Static and Dynamic Analysis and Design of Three-Dimensional Structures Basic Analysis Reference, Computers \& Structures Inc., Berkeley, CA. 
This page intentionally left blank. 


\section{Chapter 3 \\ WIND LOADS ON THE WTC TOWERS ${ }^{1}$}

\section{$3.1 \quad$ INTRODUCTION}

Wind loads were a governing factor in the design of the World Trade Center (WTC) towers' perimeter frame-tube system. The study of the wind loads on the WTC towers was required for evaluating: (1) the baseline performance of the towers under design loading conditions, (2) the towers' reserve capacity to withstand unanticipated events such as a major fire or impact damage, and (3) design practices and procedures.

The accurate estimation of the wind loads on tall buildings is challenging, since wind engineering is still an evolving technology. As is shown in this chapter, estimates of the wind-induced response presented in two recent independent studies of the WTC towers differed from each other by about 40 percent. This discrepancy is indicative of limitations of the current state of practice in wind engineering for tall buildings. Also, as will be shown later in this chapter, wind loads (pressures) specified in current prescriptive codes differ significantly from the loads estimated from wind tunnel-based studies. The study of the wind loads on the WTC towers provided an opportunity to assess current design practices and various code provisions on wind loads.

This chapter outlines the loading cases applied to the reference global models of the WTC towers (Section 2.3) to establish the towers' baseline performance. The following sources were used to develop the loads for the various loading cases:

- Design Criteria document of the WTC towers, prepared by Worthington, Skilling, Helle \& Jackson (WSHJ) (henceforth referred to as Design Criteria).

- WTC architectural and structural drawings (henceforth WTC Dwgs).

- Wind reports prepared by WSHJ in the 1960 s, describing the development of design wind loads for the WTC towers (henceforth WSHJ Wind Reports).

- Reports from two independent wind tunnel studies concerning the WTC towers, conducted in 2002 by Cermak Peterka Peterson, Inc. (henceforth CPP) and Rowan Williams Davis and Irwin, Inc. (henceforth RWDI) for insurance litigation.

- Current New York City Building Code (henceforth NYCBC 2001).

- Current American Society of Civil Engineers (ASCE 7) Standard (henceforth ASCE 7-02).

1 This chapter was co-authored by Emil Simiu and Fahim Sadek of National Institute of Standards and Technology (NIST). 
Three loading cases were considered for the baseline performance analysis. They included:

- Original WTC design loads case: Dead and live loads as in original WTC design in accordance with the Design Criteria, and original WTC design wind loads from WSHJ Wind Reports.

- State-of-the-practice case: Dead loads as in original design; NYCBC 2001 live loads; and wind loads from RWDI wind tunnel study, scaled in accordance with NYCBC 2001 wind speed. This wind load was considered to be a lower estimate state-of-the-practice case. As will be explained later, the CPP wind tunnel study produced larger wind loads and was, therefore, considered to be an upper estimate state-of-the-practice case.

- Refined NIST estimate case: Dead loads as in original design; live loads from American Society of Civil Engineers (ASCE) 7-02 (a national standard); and wind loads developed by NIST from a critical assessment of information obtained from the RWDI and CPP reports, and state-of-the-art considerations.

The purpose of considering the original WTC design loads case was to evaluate structural performance under original design loading conditions and ascertain whether those loads and the corresponding design were adequate given the knowledge available at the time of the design. In addition, this loading case was useful in evaluating the towers' reserve capacity to withstand unanticipated events such as those of September 11, 2001. The purpose of considering the state-of-the-practice case and the refined NIST estimate case was to better understand and assess the effects of successive changes in standards, codes, and practices on wind design for tall buildings, with a view to helping improve standard provisions for wind loads in the future. The study provided a unique opportunity to achieve this objective.

The gravity loads applied to the global WTC models consisted of dead loads and live loads (LLs), appropriately combined as stipulated in the Design Criteria. Dead loads were applied to the reference global models in two parts: construction dead loads (CDLs) and superimposed dead loads (SDLs), based on the WTC Dwgs and the Design Criteria.

- CDL is defined as the self-weight of the structural system, including floor slabs, beams, truss members, columns, spandrel beams, and so forth.

- SDL is defined as the added dead load associated with architectural, mechanical, electrical, and plumbing systems; such as curtain walls, ceilings, partitions, floor finishes, mechanical equipment and ducts, transformers, and so forth.

Three independent sets of live loads were combined with the dead loads:

- The first set was taken from the Design Criteria and was used with the original WTC design loads case.

- The second set was taken from NYCBC 2001 and was used for the state-of-the-practice case.

- The third set was taken from ASCE 7-02 and was used for the refined NIST estimate case. The live loads given in ASCE 7-02 are essentially identical to the NYCBC 2001 live loads. 
For each live load set, live load reductions for column design were taken from their respective source. Refer to Chapter 4 of NIST NCSTAR 1-2A for further details on the estimation of gravity loads in the reference global models of WTC 1 and WTC 2.

Sections 3.2, 3.3, and 3.4 present, respectively, the original WTC design wind loads, the state-of-thepractice wind loads. and the refined NIST wind load estimates. Section 3.5 provides a comparison of the various wind loading cases.

\subsection{ORIGINAL WTC DESIGN WIND LOADS}

Wind loads were determined for the original design of the WTC towers through the development and implementation of a boundary-layer wind-tunnel study, which simulated the mean and fluctuating (turbulence) properties of the wind from ground to gradient height by using the knowledge and techniques available in the 1960s. Aeroelastic wind tunnel tests were conducted at a 1:500 scale at Colorado State University (CSU). and at a 1:400 scale at the National Physical Laboratory (NPL), Teddington, United Kingdom. Results from the tests conducted at NPL and CSU were in good qualitative and quantitative agreement. The original WTC wind loads were taken from summaries given in Part IV of the WSHJ Wind Reports. For further details, refer to NIST NCSTAR 1-lA.

Wind tunnel data were collected for each tower for wind approaching from 24 wind directions in 15 degree increments. Part IV of the WSHJ Wind Reports provided equations for the wind-induced shears and overturning moments in the towers at 21 elevations, $z$, along the building height, $H$, at increments of $0.05 \mathrm{H}$. For each wind direction, sets of coefficients were provided for use in these equations to obtain the static and the dynamic components of shear and overtuming moment in the $\mathrm{N}-\mathrm{S}$ and $\mathrm{E}-\mathrm{W}$ directions. Coefficients were also provided for calculating torsional moments. Based on these equations, shears in the two orthogonal directions $x$ and $y$, and torsions, were calculated for each wind direction. The equivalent effective static shear forces and overturning moments at each level consisted of sums of the respective static and dynamic components. For details see NIST NCSTAR 1-1. The wind speeds at 1,500 $\mathrm{ft}$ above ground averaged over $20 \mathrm{~min}$, used in the original design, were assumed to be independent of direction and were estimated to be $98 \mathrm{mph}$.

Considering the 24 different wind directions and the four combinations of the static and dynamic parts of the N-S and E-W components of the building forces listed below, there were 96 different wind load cases for each tower.

$$
\begin{aligned}
& \text { N-S (Static + Dynamic) and E-W (Static + Dynamic) } \\
& \text { N-S (Static + Dynamic) and E-W (Static - Dynamic) } \\
& \text { N-S (Static - Dynamic) and E-W (Static + Dynamic) } \\
& \text { N-S (Static - Dynamic) and E-W (Static - Dynamic) }
\end{aligned}
$$

The static and dynamic shears and overturning moments in the $\mathrm{N}-\mathrm{S}$ and $\mathrm{E}-\mathrm{W}$ directions were calculated for all 96 loading cases. In order to determine the most severe of the 96 loading cases for each tower, the wind-induced shears and overturning moments were compared, for each direction, at heights $z / H=0.75$, 
$0.50,0.25$ and 0 . The wind loading cases producing the maximum shears in either of the two orthogonal directions were identified for application to the global models.

To compare overturning moments for each loading case, the moments in the two orthogonal directions were combined vectorially (i.e., the magnitude of the resultant is equal to the square root of the sum of the squares of the components, and the direction $\beta$ of the resultant is the arc whose tangent is equal to the ratio of the $y$ - and $x$-components). The load cases were grouped by the angle $\beta$ using increments of 45 degrees, resulting in eight groups of load cases. For each $\beta$ group, at $z / H=0.75,0.50,0.25$, and 0 , the wind load cases that generated the maximum resultant moment were identified for application to the reference global models. Eight groups of maximum moment plus four directions of maximum shear at four heights in the towers would result in 48 different loading cases. Some individual wind load cases, however, produced a maximum resultant moment and/or a maximum shear at more than one elevation in the towers. As a result, 16 loading cases were identified for WTC 1, and 17 loading cases were identified for WTC 2.

For the floors modeled in the global models by rigid diaphragms, the wind forces were applied as concentrated loads at the geometric center of the building. The torsional moments were also taken into account. For the floors with flexible diaphragms (see Chapter 2), the forces based on tributary areas were resolved into point loads at the perimeter columns. At these floors, the torsional moment was represented by four identical concentrated forces applied parallel to the four faces of the tower at the center column of each face. For each loading case, the orthogonal wind forces were subdivided into windward and leeward forces based on the direction of the wind. The distribution of forces between the windward and leeward sides was based on Figure 6-6 of the ASCE 7-02 Standard (see Chapter 4 of NIST NCSTAR 1-2A for more details).

\subsection{STATE-OF-THE-PRACTICE WIND LOADS}

For the WTC towers, two wind tunnel tests and wind engineering studies based thereon were conducted in 2002 by independent laboratories as part of insurance litigation unrelated to the NIST investigation. The tests and studies were conducted by CPP and by RWDI. The results of both studies were made available to NIST. Since the CPP and RWDI studies are representative of current practices, their wind load estimates are considered "state-of-the-practice wind loads."

CPP study. The CPP wind tunnel tests modeled the terrain surrounding the WTC towers over an area with a radius of about 2,300 ft. Measurements were made only on the south tower. In one test the south tower was modeled by using a high-frequency force-balance (HFFB) device. In a second test the south tower was modeled aeroelastically. The test scale was 1:400, and testing was conducted for 36 wind directions at 10 degrees intervals. The wind-induced loads and responses were determined by combining the wind tunnel test data with (a) directional non-hurricane wind speed data recorded at three major airports in the New York area for periods of about 25 years, and (b) hurricane wind speed data (the source of the hurricane data was not indicated in the study). The directional wind tunnel and wind speed data were combined by using the sector-by-sector approach, described and assessed in Section 3.4 of this chapter. Wind effects corresponding to a damping ratio of 2.5 percent were provided for the south tower only, for nominal 50 year and 720 year mean recurrence intervals and consisted of peak shear force and bending moment components for two orthogonal directions and peak torsional moments. The peak components were combined in accordance with the "companion point-in-time" method, for example, by 
using the full peak load in one direction and the loads in the other direction and in torsion at the time of occurrence of that peak. The CPP report considered 10 such combinations.

RWDI study. The RWDI wind tunnel tests modeled the terrain surrounding the WTC towers over an area with a radius of about $4,000 \mathrm{ft}$. The tests used an HFFB model for each of the towers and an aeroelastic model for the north tower only. The test scale was 1:500, and testing was conducted for 36 wind directions at 10 degree intervals. Corrections were made to account for the effects on the flow of the presence of building models (i.e., of wind tunnel blockage). Estimates of the full-scale wind effects and responses were obtained by combining the wind tunnel test data with a statistical model of winds for New York City, including surface wind measurements taken at three airports between 1948 and 1995 and proprietary simulated hurricane winds provided by Applied Research Associates (Raleigh, NC). The directional wind tunnel and wind speed data were combined by using an out-crossing approach developed by RWDI. Two sets of wind effects on the towers were developed by scaling the wind loads to the design wind speeds provided in the NYCBC 2001 and to the basic wind speeds specified by the ASCE 7-98 Standard. The wind effects were obtained, for a damping ratio of 2.5 percent, as peak shear forces and bending moments for two orthogonal directions, and peak torsional moments. The peak components were combined using the "principle of companion loads" entailing weighting combination factors based on engineering judgment. The RWDI report considered 24 such combinations.

Note. For both the CPP and RWDI studies, tests were conducted for the two-tower configuration and for a single tower configuration. For the purposes of this investigation, only the two-tower configuration was considered. As was mentioned earlier, the CPP study provided results for the south tower only, while the RWDI study provided wind load estimates for both towers. In the absence of CPP estimates for the north tower, the state-of-the-practice wind loads considered in the baseline study for the north and south towers were selected to be the RWDI wind loads scaled in accordance with a wind speed equivalent to the NYCBC 2001 wind speed. The latter was interpreted to be the $80 \mathrm{mph}$ fastest-mile wind speed at $30 \mathrm{ft}$ elevation over open terrain. In the baseline performance study, these wind loads were applied to the reference global models using the directional and torsional load combination factors presented in the RWDI reports. The application of the wind loads at each floor of the global models was similar for the lower-estimate state-of-the-practice case and for the original WTC design case.

The wind loads from RWDI were smaller than those obtained from CPP for WTC 2 (see Section 3.4). Therefore, RWDI loads may be viewed in this study as a "lower-estimate state-of-the-practice" case.

\subsection{REFINED NIST ESTIMATE OF WIND EFFECTS}

NIST completed an independent analysis to estimate the wind loads that would be appropriate for use in designing the towers. The analysis was based on results provided by CPP and RWDI, with refinements that drew on the state of the art in wind engineering. The objective of this analysis was to better understand and assess the effects of successive changes in standards, codes, and practices, not to assess the adequacy of the original design wind loads. The analysis yielded refined estimates of wind effects for the north and south WTC towers. These estimates made use of independent extreme wind climatological estimates developed by NIST (Appendix B), based on airport wind speed data obtained from the National Climatic Data Center, National Oceanic and Atmospheric Administration, and on the NIST hurricane wind speed database - the only such database publicly available at present (see Appendix B for details). 
The estimates of wind-induced forces and moments provided in this report relied primarily on RWDI results, since no results for WTC 1 were available from CPP. However, the estimates took into account a comparative assessment of the RWDI and CPP results for WTC 2.

\subsubsection{Summary Comparison by Weidlinger Associates, Inc., of CPP and RWDI Estimates}

A useful summary comparison between CPP and RWDI estimates of maximum base moments and shear forces on WTC 2 induced by ASCE 7-98 wind loads is contained in a memorandum by Weidlinger and Associates. ${ }^{2}$ As indicated in that memorandum, the values presented in Table 3-1 are based on nominal basic wind speeds (i.e., $500 \mathrm{yr}$ speeds divided by square root of 1.5 for RWDI, and $720 \mathrm{yr}$ loads divided by 1.6 for $\mathrm{CPP}$ ).

Table 3-1. Approximate maximum base moments for WTC 2 induced by ASCE 7-98 standard wind loads.

\begin{tabular}{|c|c|c|}
\hline Wind Tunnel Study & $\left|M_{y}\right|$ (lb-ft) & $\left|M_{x}\right|$ (lb-ft) \\
\hline RWDI (Table 2a) & $10.1 \mathrm{e}+9$ & $11.1 \mathrm{e}+9$ \\
CPP (Upper Table, p. 21) & $14.0 \mathrm{e}+9$ & $15.5 \mathrm{e}+9$ \\
\hline
\end{tabular}

For the CPP results, the wind directions associated with the largest $\left|M_{y}\right|$ and $\left|M_{x}\right|$ moments were 205 degrees and 215 degrees, respectively (CPP report, Upper Table, p. 21; 0 degrees was defined as True North). Both RWDI and CPP results indicated that the critical base moments occurred for a wind direction of about 210 degrees. This agreement suggested that a comparison between those results was warranted in some detail for the 202.5 to 225 degree range. (The reason for the choice of this range was that hurricane data in the NIST database are provided for the 16 half-octants of the compass.) Such a comparison is presented in this report.

\subsubsection{Review of CPP Estimates}

Independent estimates by NIST of the $720 \mathrm{yr}, 3 \mathrm{~s}$ peak gust speeds for the 202.5 degree and 225 degree angles were $104.1 \mathrm{mph}$ and $91.1 \mathrm{mph}$, respectively (Appendix B, Fig. 1). Linear interpolation between these estimates yielded a $720 \mathrm{yr}, 3 \mathrm{~s}$ peak gust speed of $99.8 \mathrm{mph}$ for 210 degrees. CPP estimated the $720 \mathrm{yr}$ peak $3 \mathrm{~s}$ peak gust speed at 210 degrees to be about $117.5 \mathrm{mph}^{3}{ }^{3}$ Therefore, the CPP results were modified through multiplication by the factor $(99.8 / 117.5)^{2}=1 / 1.386$. Owing to the dynamic character of the response, multiplication by the squarc of the ratio of the speeds is not rigorously correct, but in the absence of sufficiently detailed information it can serve as a useful approximation. A similar conclusion was reached in a letter by RWDI to NIST. ${ }^{4}$

2 Memorandum on Comparison of RWDI and CPP Design Wind Loads, from N.N. Abboud and A. Jain, Weidlinger Associates, Inc., November 11, 2003.

3 This is obtained through multiplication of the $93 \mathrm{mph}$ speed (basis of design speeds for the 210 degree angle, CPP report, p. 10, upper curve) by the square root of 1.6.

4 Letter on World Trade Center wind tumnel investigations, by P.A. Irwin, RWDI, November 7, 2003. 
In addition to their multiplication by the factor $1 / 1.386$, the CPP results were modified to account for the use by CPP of the sector-by-sector approach to integrating aerodynamic data and extreme-wind climatological data. The sector-by-sector approach is not valid from a physical point of view. This was also noted by RWDI. ${ }^{5}$ In attempting to explain the differences between the CPP and RWDI estimates, RWDI assumed that the use of the sector-by-sector approach contributed to the overestimation of the response by CPP. This assumption was due to the difficulty of analyzing the CPP report. Such analysis required a special study by NIST, reported in Appendix $\mathrm{C}^{6}{ }^{6}$ which concluded that, in fact, the sector-bysector approach as applied by CPP underestimated the wind effects corresponding to a specified mean recurrence interval. According to preliminary estimates that would need to be confirmed by research using, e.g., Bonferroni bounds (see Appendix C), it was assumed that the underestimation was about 15 percent. Therefore, the CPP results, modified via multiplication by the factor $1 / 1.386$, were further modified via multiplication by the factor 1.15 . The reduction factor applied to the estimated CPP effects was, therefore, about $1.15 / 1.386 \approx 1 / 1.205$.

Conclusion. The CPP moments presented in Table 3-1 were reduced via application of the factor $1 / 1.205$ from approximately $14.0 \mathrm{e}+9 \mathrm{lb}-\mathrm{ft}$ and $15.5 \mathrm{e}+9 \mathrm{lb}-\mathrm{ft}$ to approximately $11.62 \mathrm{e}+9 \mathrm{lb}-\mathrm{ft}$ and $12.86 \mathrm{e}+9 \mathrm{lb}-\mathrm{ft}$, respectively. To within the limitations inherent in the information available for this investigation, and to within the approximations noted, these reduced values are reasonable estimates of the actual responses of interest.

\subsubsection{Review of RWDI Estimates}

According to the conclusion of Section 3.4 .2 concerning the modified CPP results, the RWDI results underestimated the moments for the directions being considered. This conclusion is consistent with the fact that RWDI assumed wind profiles in hurricanes to be flatter (to increase more slowly with height) than wind profiles in non-hurricane winds. This assumption, and its effect on the RWDI estimates, were confirmed in the RWDI Response to NIST's Questions, September 2003. ${ }^{7}$ The RWDI assumption regarding the relative flatness of hurricane wind profiles was based on a calculation of the ratio between wind speeds at $500 \mathrm{~m}$ and at $10 \mathrm{~m}$ over open terrain, based on the formula $V(500 \mathrm{~m}) / V(10 \mathrm{~m})=$ $(500 \mathrm{~m} / 10 \mathrm{~m})^{0.14}=1.73$. In this calculation it was assumed that, in the power law model of the atmospheric boundary layer over open terrain, wind speeds increase monotonically up to an elevation of at least $1,640 \mathrm{ft}(500 \mathrm{~m})$. This assumption is not consistent with accepted practice, according to which in the power law model the mean speed increases with elevation only up to a gradient height which, for open terrain, is about $900 \mathrm{ft}$ ( $275 \mathrm{~m}$ or so), rather than 1,640 ft (500 m) -- see, for example, the ASCE 7 Standard. An unconventional model such as the relatively flat hurricane profile model invoked by RWDI is not supported by measurements in the atmosphere. A recent article in Nature (Powell, Vickery, and Reinhold, 2003) indicated that the increase of hurricane wind speeds with height is consistent with the logarithmic law (see Figure 2 of the article). This is also true of extratropical storm winds. It is also noted that the ASCE 7 Standard does not differentiate between wind speed profiles in hurricane and non-

5 Letter on Review of Wind Tunnel tests, RWDI Reference \#02-1310 by P.A. Irwin to M. Levy of Weidlinger Associates, dated October 2, 2002.

6 See also E. Simiu and J. J. Filliben, "Wind Tunnel Testing and the Sector-by-Sector Approach to Wind Directionality Effects," J. Struct. Eng., ASCE. July 2005, pp. 1143-1145.

7 Responses to NIST's Questions on "Wind-Induced Structural Responses, World Trade Center, Project Number 02.1310A and 02.1310B. October 2002, by RWDI, Prepared for Hart-Weidlinger”, Hart-Weidlinger, September 12, 2003. 
hurricane winds, even though wind profiles affecting velocity pressures are defined therein up to $500 \mathrm{ft}$ above ground, where the effect of wind profile differences would be significant.

In response to a NIST query, ${ }^{8}$ the use of a ratio of approximately 1.1 between tower responses to $88 \mathrm{mph}$ and $80 \mathrm{mph}$ wind speeds (note 3 at the bottom of Tables $3 \mathrm{~b}$ and $3 \mathrm{c}$ in the RWDI report) was ascribed to the assumption that hurricane wind profiles are relatively flat. This justification is not viewed as satisfactory for the reasons indicated in the preceding paragraph. In view of the current state of the art, according to which hurricane and non-hurricane wind profiles are substantially similar, a ratio of approximately $(88 / 80)^{2}=1.21$ is more appropriate than the ratio of approximately 1.1 used by RWDI.

Also, it is not clear that the weighting of hurricane wind speeds in proportion to their squares, as used by RWDI in the out-crossing method, is warranted. No justification was provided in the RWDI report for the weighting procedure based on squares of speeds, nor did RWDI list any reference pertaining to this approach. In the standard Peaks-Over-Threshold approach applied to extreme wind speeds by, among others, Simiu and Heckert (1996), all data above a threshold are affected by the weighting factor 1, while all the data below the threshold are weighted by the factor zero; the analysis is carried out for a large number of thresholds to ascertain the range of thresholds for which the estimates being sought are stable. The use of data lower than the lowest acceptable threshold results in the underestimation of the extreme wind effects being sought. Therefore, it can be expected that the use of such data, albeit weighted in accordance with the RWDI procedure, will have a similar effect. More generally, "concerns that the crossing-rate" (i.e., the out-crossing) "method may underestimate extreme wind-induced effects which depend upon both on wind speed and wind direction" were noted by Isyumov et al. (2003).

The University of Western Ontario (UWO) conducted an independent estimate of wind effects which by and large were reasonably close to the RWDI results. ${ }^{9}$ It appears, however, that the assumptions used by UWO and RWDI with respect to hurricane wind profiles were the same or similar. According to UWO, the CPP directionality approach would appear to overestimate the 50 year response. This view is not consistent with the conclusions of Appendix $\mathrm{C}$ to this report.

A direct, full quantitative assessment and verification of the RWDI results was judged not to be possible given the information available. Nevertheless, as was shown earlier in connection with the wind profiles, a partial quantitative assessment was made, which indicated that the actual response would be higher than the RWDI estimated response. Given this assessment, and an estimate of the actual response based on the modified CPP estimates, the conclusion that the response was underestimated by RWDI by a factor of about 10 percent to 20 percent was judged to be warranted. The difference between the NIST estimate of the response and the RWDI estimate is smaller than the difference between the CPP estimate and the NIST estimate of the response.

Conclusion. Based on the discussion presented above, loads associated with the refined NIST estimates case and consistent with the design wind speed in the ASCE 7-98 and ASCE 7-02 Standards can be estimated approximately by using the RWDI results multiplied by a factor equal to the ratio of the modified CPP estimates (see Section 3.4.2) to the corresponding RWDI estimates. This factor varies

8 Letter on Response to NIST Questions of March 30, 2004, by N.N. Abboud, Weidlinger Associates, Inc., April 6, 2004.

9 Report Regarding the Review of the World Trade Center Twin Towers (NY) Wind Studies Carried Out by RWDI and CPP UWO File W020, cover letter to N. Abboud, Weidlinger Associates, dated November 3, 2003. 


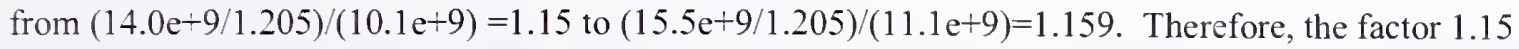
was recommended for baseline analysis. However, the actual factor could be anywhere between, say, 1.10 and 1.20 .

\subsubsection{Comments by Third Party Reviewer (Skidmore, Owings \& Merrill LLP - SOM) - Appendix D}

SOM served as a third party reviewer for the wind load estimation by NIST. According to SOM, it would have been desirable for the measured fundamental period of vibration of the north tower to be used in lieu of the calculated periods for either tower. According to the RWDI report, for the south tower the fundamental periods for the $x$-direction (a) not accounting for P- $\Delta$ effects, and (b) accounting for P- $\Delta$ effects were $12.341 \mathrm{~s}$ and $13.292 \mathrm{~s}$, respectively (Appendix A of RWDI report), the difference between them being about 7 percent. The respective estimated $x$-direction base shears in the RWDI report were $9.45 \mathrm{e}+06 \mathrm{lb}$ and $9.71 \mathrm{e}+06 \mathrm{lb}$, respectively, the difference in this case being about 2.7 percent. In the $y$-direction, the differences between the respective shears were less than 1 percent. In view of the uncertainties in the measurement and calculation of the natural periods it is concluded that the differences between shears inherent in the differences between natural periods noted by SOM are not significant.

With respect to the NIST assessment of the CPP and RWDI results, SOM stated that the approach taken by NIST was reasonable, but that SOM was not able to confirm the precise values put forth in the N1ST report. SOM noted that quantitative assessments and corrections were made by N1ST to the CPP report, and that NIST made only qualitative assessments of the RWDI report. As was indicated in Section 3.4.3, this is indeed the case, except for the quantitative assessment related to wind profiles. No other quantitative assessments were possible, either by NIST or SOM. SOM's inability to confirm precise values is understandable in view of the lack of sufficient clarity in portions of the CPP and RWDI reports. NIST's intent was to recommend reasonable estimates, not precise values. The estimates may be somewhat larger or smaller than the non-attainable precise values. In NIST's judgment approximate bounds to these estimates are defined by the interval of about 1.1 to 1.2 (see Conclusion to Section 3.4.3).

SOM emphasized the urgent need to put order in the field of wind tunnel testing and the estimation of wind effects through standards developed by consensus. N1ST fully agrees with this view. It also agrees with SOM's suggestion that the ASCE 7 Standard specify the use of an importance factor larger than unity for buildings representing a substantial hazard to human life in the event of failure. Currently, the ASCE 7 Standard specifies an importance factor larger than unity for buildings designed in accordance with the Standard's "analytical procedure." It does not require the use of the importance factor for buildings whose wind loads are estimated by the "wind tunnel procedure." In fact, neither the CPP nor the RWD1 wind loads were augmented by the use of a 1.15 importance factor. It is also noted that even if an importance factor of 1.15 were required to augment wind effects estimated by the wind tunnel method, there could be some confusion over the definition of " buildings ... where more than 300 people congregate in one area" (Table 1-1 of the ASCE 7 Standard), for which an importance factor of 1.15 is specified in the "analytical procedure." The question arises whether buildings like the WTC towers are included in that definition. This is not indicated clearly in the ASCE 7 Standard, in which the term "area" may be interpreted by some engineers as being restricted to, e.g., auditoria, rather than apartment buildings or other structures with an occupancy of more than 300 people. NIST also believes that the importance factor should be risk-based, rather than prescribed arbitrarily. 
An increase of the wind pressures by an importance factor of 1.15 to account for the large population of some tall buildings (over 5,000 individuals) is specified in Table 1604.5 of the 2003 International Building Code (1BC 2003), which is otherwise mostly based on ASCE 7-02. A consensus should be reached on whether 5,000 is the appropriate threshold.

In addition, it does not appear appropriate for a tall building with significant dynamic effects to have the same load factor as an ordinary, rigid building: the tall building response depends on dynamic response parameters with uncertainties, including, in particular, uncertainty with respect to damping, that should affect the wind load factor applicable to the tall building. This is cspecially true of buildings designed in accordance with the "wind tunnel procedure." Therefore, research into differences between wind load factors for rigid and flexible buildings is warranted.

\subsubsection{Summary}

The lateral wind loads on the towers, consistent with the ASCE 7-98 and ASCE 7-02 design wind speed requirements, were estimated by using the effective static floor-by-floor wind loads presented in Table 5a (without P- $\Delta$ effects) or Table $5 \mathrm{~b}$ (with P- $\Delta$ effects) of the RWDI report (north tower) for WTC 1 and Table $3 a$ (without P- $\Delta$ effects) or Table $3 b$ (with P- $\Delta$ effects) of the RWDI report (south tower) for WTC 2. ${ }^{10}$ These effective static floor-by-floor wind loads were multiplied by the factor 1.15 (see Section 3.4.3) and by the factors indicated in footnote (3) to Tables 3 and 5 in RWDI to account for the ratio between the ASCE 7 and NYCBC wind speeds. The loads so obtained were applied to the reference global model of each tower using the load combinations presented in Table 6a of RWDI (north tower) and Table 4a of RWDI (south tower). The loads put forth in this section were used along with the load factors given in Section 2 of ASCE 7-02.

It would have been desirable to perform more elaborate calculations providing more comprehensive and precise results than those presented in this document. However, given the information available, this was not practicable.

\subsection{COMPARISONS OF WIND LOADS, WIND SPEEDS, AND PRACTICES}

The purpose of this section is to provide comparisons among wind loads and wind speeds applicable to the WTC towers in accordance with various codes, standards, and estimation procedures. Sections 3.5.1 and 3.5.2 present comparisons among wind loads and among wind speeds, respectively. Section 3.5.3 compares wind engineering features used to perform the response estimates for the original design and the CPP, RWDI, and NIST estimates.

\subsubsection{Wind Loads}

Tables 3-2 and 3-3 provide a summary of the wind-induced base shears and base moments ${ }^{11}$ on WTC 1 and WTC 2, respectively, based on the 1938 and 1968 versions of the NYCBC, the RWDI study, the CPP study, the refined NIST estimates, and the original design. The wind loads are expressed in terms of two

\footnotetext{
${ }^{10}$ For the WTC 2 tower Tables $3 \mathrm{~b}$ and $3 \mathrm{c}$ in the RWDI report (South Tower) were inadvertently switched. The loads accounting for $\mathrm{P}-\Delta$ effects are in fact given in Table $3 c$ of the report.

${ }^{11}$ All base moments presented in this chapter are calculated at the foundation level.
} 
orthogonal components ( $\mathrm{N}-\mathrm{S}$ and $\mathrm{E}-\mathrm{W}$ for base shears, and about $\mathrm{N}-\mathrm{S}$ and about $\mathrm{E}-\mathrm{W}$ for base moments), and of vectorial measures of the most unfavorable combined peaks. The vectorial measures are an indication of the relative conservatism of various methods for combining wind effects in the $x$ and $y$ directions, and were defined as the largest of a set of vectorial sums of $x$ and $y$ components, as follows:

- For the RWD1 estimates, the set consisted of 24 vectorial sums, each corresponding to one of $24 x$ and $y$ load combinations considered in the RWDI report. The combined $x$ and $y$ values were weighted as indicated in Section 3.3.

- For the CPP estimates, the set consisted of 10 vectorial sums, each sum corresponding to one of $10 x$ and $y$ load combinations considered in the CPP report. The combined $x$ and $y$ values conformed to the "companion-load-in-time" approach described in Section 3.3.

- For the original WTC design estimates, the set consisted of 24 vectorial sums of peak $x$ and $y$ values, each corresponding to one of the 24 wind directions considered in the original design, as described in Section 3.2.

The N1ST estimates were in all cases equal to 1.15 times the RWDI estimates based on the ASCE 7-98 Standard.

Table 3-4 is a summary of design base shears and base moments based on prescriptive provisions at the time of the design in the 1938 and 1968 New York City Building Codes, the 1964 New York State Code, the 1965 Building Officials and Code Administrators Basic Building Code (BOCA/BBC), and the 1967 Chicago Municipal Code.

Tables 3-2 and 3-3 indicate that the two orthogonal components of the original design wind load estimates exceeded in all cases their counterparts based on the New York City Building Code (a prescriptive code) prior to 1968, when the WTC towers were designed, and from 1968 to date. Table 3-4 shows that the design values were also higher than those required by other prescriptive building codes of the time, including the relevant national model building code. It is noted, however, that the prescriptive approach in these codes is oversimplified, and that these codes are therefore not appropriate for super-tall building design. In fact, wind effects obtained from three separate wind-tunnel-based studies (for the original WTC design, the CPP, and the RWD1 studies) were in all cases higher than wind effects based on the prescriptive codes.

The two orthogonal base shear and base moment components used in the original design were in the majority of cases smaller than the CPP, RWD1, and NIST estimates. However, the vectorial measures of the most unfavorable combined peaks for the original design were larger, or smaller, by at most 10 percent or so, than those based on the CPP, RWD1, and N1ST estimates. This is due to the conservative procedure used to combine the loads in the original design. For example, N1ST estimates were higher by about 10 percent than the most unfavorable original design wind loads for WTC 1 , and lower by about 5 percent than the most unfavorable original design loads for WTC 2 . 
Table 3-2. Comparison of wind load estimates for WTC 1 based on various sources.

\begin{tabular}{|c|c|c|c|c|c|c|c|}
\hline \multirow[b]{2}{*}{ Source } & \multirow[b]{2}{*}{ Year } & \multicolumn{3}{|c|}{ Base Shear $10^{3}$ kip } & \multicolumn{3}{|c|}{ Base Moment $10^{6} \mathrm{kip} \cdot \mathrm{ft}$} \\
\hline & & $\mathrm{N}-\mathrm{S}$ & $E-W$ & $\begin{array}{c}\text { Most } \\
\text { unfavorable } \\
\text { combined } \\
\text { peak } \\
\end{array}$ & $\begin{array}{l}\text { About } \\
\mathrm{N}-\mathrm{S}\end{array}$ & $\begin{array}{l}\text { About } \\
\mathrm{E}-\mathrm{W}\end{array}$ & $\begin{array}{c}\text { Most } \\
\text { unfavorable } \\
\text { combined } \\
\text { peak }\end{array}$ \\
\hline NYC Building Code & 1938 & 5.3 & 5.3 & & 4.2 & 4.2 & \\
\hline NYC Building Code & $\begin{array}{l}1968 \text { to } \\
\text { date }\end{array}$ & 9.3 & 9.3 & & 7.7 & 7.7 & \\
\hline $\begin{array}{l}\text { RWDI / NYC Building } \\
\text { Code }\end{array}$ & 2002 & 11.4 & 10.5 & 13.0 & 10.1 & 10.5 & 12.2 \\
\hline RWDI / ASCE 7-98 & 2002 & 12.3 & 11.3 & 14.0 & 10.8 & 11.4 & 13.1 \\
\hline $\begin{array}{l}\text { CPP / NYC Building } \\
\text { Code }\end{array}$ & 2002 & NA & NA & NA & NA & NA & NA \\
\hline CPP / ASCE 7-98 & 2002 & NA & NA & NA & NA & NA & NA \\
\hline $\begin{array}{l}\text { NIST / third-party SOM } \\
\text { review }\end{array}$ & 2004 & 14.1 & 13.0 & 16.1 & 12.4 & 13.1 & 15.1 \\
\hline Original WTC Design & $1960 \mathrm{~s}$ & 9.8 & 10.6 & 14.0 & 10.3 & 9.1 & 13.7 \\
\hline
\end{tabular}


Table 3-3. Comparison of wind load estimates for WTC 2 based on various sources.

\begin{tabular}{|c|c|c|c|c|c|c|c|}
\hline \multirow[b]{2}{*}{ Source } & \multirow[b]{2}{*}{ Year } & \multicolumn{3}{|c|}{ Base Shear $10^{3} \mathrm{kip}$} & \multicolumn{3}{|c|}{ Base Moment $10^{6} \mathrm{kip} \cdot \mathrm{ft}$} \\
\hline & & $\mathrm{N}-\mathrm{S}$ & $E-W$ & $\begin{array}{c}\text { Most } \\
\text { unfavorable } \\
\text { combined } \\
\text { peak }\end{array}$ & $\begin{array}{l}\text { About } \\
\mathrm{N}-\mathrm{S}\end{array}$ & $\begin{array}{l}\text { About } \\
\text { E-W }\end{array}$ & $\begin{array}{c}\text { Most } \\
\text { unfavorable } \\
\text { combined } \\
\text { peak }\end{array}$ \\
\hline NYC Building Code & 1938 & 5.3 & 5.3 & & 4.2 & 4.2 & \\
\hline NYC Building Code & $\begin{array}{l}1968 \text { to } \\
\text { date }\end{array}$ & 9.3 & 9.3 & & 7.6 & 7.6 & \\
\hline $\begin{array}{l}\text { RWDI / NYC Building } \\
\text { Code }\end{array}$ & 2002 & 9.7 & 11.1 & 12.3 & 10.1 & 9.2 & 11.3 \\
\hline RWDI / ASCE 7-98 & 2002 & 10.6 & 12.2 & 13.5 & 11.1 & 10.1 & 12.4 \\
\hline $\begin{array}{l}\text { CPP / NYC Building } \\
\text { Code }\end{array}$ & 2002 & NA & NA & NA & NA & NA & NA \\
\hline CPP / ASCE 7-98 & 2002 & 15.1 & 15.3 & 17.1 & 15.5 & 14.0 & 17.0 \\
\hline $\begin{array}{l}\text { NiST / third-party SOM } \\
\text { review }\end{array}$ & 2004 & 12.2 & 14.0 & 15.5 & 12.8 & 11.6 & 14.3 \\
\hline Original WTC Design & $1960 \mathrm{~s}$ & 13.1 & 10.1 & 16.5 & 8.8 & 12.6 & 15.2 \\
\hline
\end{tabular}

a. Using ASCE 7-98 Sections 6.5.4.1 and 6.6.

Table 3-4. Base shears and base moments due to wind loads based on various building codes.

\begin{tabular}{|l|c|c|c|c|c|}
\hline Building Code & $\begin{array}{c}1938 \\
\text { NYC Code }\end{array}$ & $\begin{array}{c}1968 \text { to data } \\
\text { NYC Code }\end{array}$ & $\begin{array}{c}1964 \\
\text { NY State Code }\end{array}$ & $\begin{array}{c}1965 \\
\text { BOCA/BBC }\end{array}$ & $\begin{array}{c}1967 \\
\text { Chicago } \\
\text { Municipal Code }\end{array}$ \\
\hline $\begin{array}{l}\text { Base Shear } \\
\left(10^{3} \text { kip }\right)\end{array}$ & 5.3 & 9.3 & 9.5 & 9.8 & 8.7 \\
\hline $\begin{array}{l}\text { Base Moment } \\
\left(10^{6} \text { kip } \cdot f t\right)\end{array}$ & 4.2 & 7.7 & 7.6 & 8.5 & 7.5 \\
\hline
\end{tabular}

\subsubsection{Wind Speeds}

A comparison of wind speeds is presented in Table 3-5. The ASCE 7-02 Standard specifies a basic design wind speed for New York City of $104 \mathrm{mph}$ at $33 \mathrm{ft}$ above ground for open terrain exposure. This speed is equivalent to an $88 \mathrm{mph}$ fastest-mile wind speed at $33 \mathrm{ft}$ above ground. The wind speed specified by the NYCBC 2001 is $80 \mathrm{mph}$ and is interpreted to be a fastest-mile wind speed at $33 \mathrm{ft}$ above ground. For the original WTC design, a design wind speed of $98 \mathrm{mph}$ averaged over 20 minutes at a height of $1,500 \mathrm{ft}$ above ground was used. This speed is equivalent to a fastest-mile wind speed at $33 \mathrm{ft}$ above 
ground in open terrain of about $67 \mathrm{mph}$, based on wind tunnel measurements by $\mathrm{CPP}^{12}$, and of about 75 mph, based on the National Building Code of Canada (NBC) provision for centers of large cities ${ }^{13}$. (A similar provision was deleted from ASCE 7 due to its uncertainty.) The $50 \mathrm{yr} 3 \mathrm{~s}$ peak gust speed estimated by NIST for the three airports (La Guardia, Newark International Airport, and John F. Kennedy International airport), including hurricanes, was about $112 \mathrm{mph}$ (see Figure 2 of Appendix B), regardless of direction. This speed is equivalent to a $96 \mathrm{mph}$ fastest-mile wind speed. Note that the ASCE 7 basic wind speed does not correspond to a $50 \mathrm{yr}$ event. Basic wind spceds in the ASCE 7 Standard are defined as wind speed estimates corresponding to a 500 year mean recurrence interval, divided by the square root of the load factor 1.5. For hurricane-prone regions, the ratio of 500 year speeds to 50 year speeds is typically larger than $\sqrt{1.5}$. Therefore, the mean recurrence intervals of basic speeds in hurricane-prone regions typically exceed 50 years. Table $3-5$ shows that significant differences exist among various specified design wind speeds, just as significant differences were noted between, say, base shears and moments estimated by different laboratories for various wind directions. An evaluation of the wind speed specifications and the estimation of improved design wind speeds, as well as protocols for selection of site-specific wind speeds as functions of direction, are, therefore, in order.

${ }^{12}$ A $98 \mathrm{mph}$ wind speed averaged over 20 minutes at a height of $1.500 \mathrm{ft}$ above ground is equivalent to a wind speed averaged over $1 \mathrm{hr}$ at $1.500 \mathrm{ft}$ above ground at the building site, of 98/1.03=95 mph (see Fig. C6-2. ASCE 7-02 Commentary). By using the power law applied to centers of large cities, this speed is approximately equivalent to an hourly mean wind speed at $1,000 \mathrm{ft}$ above ground at the building site of $95(1000 / 1500)^{0.4}=81 \mathrm{mph}$. According to wind tunnel measurements in the CPP report, this is equivalent to a $3 \mathrm{~s}$ peak gust at $33 \mathrm{ft}$ above ground in open terrain of about $81 \mathrm{mph}$, or to a fastest-mile wind speed at $33 \mathrm{ft}$ above ground over open terrain of $81 / 1.26=64 \mathrm{mph}$. As a check, the averaging time for a $64 \mathrm{mph}$ fastest-mile wind speed is $3,600 / 64=56 \mathrm{~s}$. The ratio of wind speed averaged over $56 \mathrm{~s}$ to the hourly mean speed is 1.26 (ASCE 7-02 Commentary). The ratio of the $3 \mathrm{~s}$ speed to the hourly speed is about 1.525 . The ratio of the $3 \mathrm{~s}$ speed to the fastest-mile speed averaged over $56 \mathrm{~s}$ is, therefore, about 1.21 . Therefore, a $81 / 1.21=67 \mathrm{mph}$ fastest-mile wind speed at $33 \mathrm{ft}$ above ground in open terrain corresponds approximately to a $98 \mathrm{mph} 20$-min speed at $1,500 \mathrm{ft}$ elevation at the building site.

${ }^{13}$ The hourly wind speed at $1,700 \mathrm{ft}$ above ground at the building site (gradient height for centers of large cities according to NBC Canada) is $(1,700 / 1,500)^{0.4} \times 95=100 \mathrm{mph}$ (gradient mean hourly speed). The nominal hourly mean speed at $33 \mathrm{ft}$ above ground in open terrain is $(33 / 900)^{0.16} \times 100=59 \mathrm{mph}$. The fastest-mile wind speed at $33 \mathrm{ft}$ above ground in open terrain is, to a first approximation, $59 \times 1.22=72 \mathrm{mph}$. As a check, the averaging time for a $72 \mathrm{mph}$ fastest-mile wind speed is $3,600 / 72=50 \mathrm{~s}$ The ratio of the fastest-mile speed to the mean hourly speed is 1.265 . Therefore, $59 \times 1.265=75$ mph fastest-mile wind speed at $33 \mathrm{ft}$ above ground in open terrain corresponds to a $98 \mathrm{mph} 20$-min speed at $1,500 \mathrm{ft}$ elevation above the building site. 
Table 3-5. Comparison between various design wind speeds.

\begin{tabular}{|c|c|}
\hline Source & $\begin{array}{c}\text { Wind Speed (fastest-mile at 33 ft above ground over } \\
\text { open terrain) }\end{array}$ \\
\hline ASCE 7-02 & $88 \mathrm{mph}$ \\
\hline NYCBC & $80 \mathrm{mph}^{\mathrm{a}}$ \\
\hline Original WTC design & $67-75 \mathrm{mph}$ \\
\hline NIST estimate & $96 \mathrm{mph}$ \\
\hline
\end{tabular}

a. This wind speed is assumed to be defined as a fastest-mile speed, even though no such definition is explicitly included in the NYCBC.

\subsubsection{Wind Engineering Practices Pertaining to Tall Buildings}

Table 3-3 shows that, for reasons explained in Section 3.4, the wind-induced loads on the towers estimated by CPP and RWDI differ by about 40 percent. Table 3-6 shows differences among wind engineering features of the original design, the CPP study, the RWDI study, and the refined NIST estimates.

Table 3-6. Comparison between the various wind studies.

\begin{tabular}{|l|c|c|c|}
\hline Wind Study & $\begin{array}{c}\text { Type of Wind Tunnel } \\
\text { Testing }\end{array}$ & Wind Profile & $\begin{array}{c}\text { Integration of } \\
\text { Aerodynamics with } \\
\text { Climatology }\end{array}$ \\
\hline \hline Original Design & Aeroelastic & $\begin{array}{c}\text { Conventional hurricane wind } \\
\text { profile }\end{array}$ & $\begin{array}{c}\text { Extreme wind rosette } \\
\text { assumed circular }\end{array}$ \\
\hline CPP & HFFB and aeroelastic & $\begin{array}{c}\text { Conventional hurricane } \\
\text { wind profile }\end{array}$ & Sector-by-sector approach \\
\hline RWDI & HFFB and aeroelastic & $\begin{array}{c}\text { Hurricane profile flatter than } \\
\text { conventional profile }\end{array}$ & $\begin{array}{c}\text { Out-crossing based on } \\
\text { sample including weighted } \\
\text { low wind speeds }\end{array}$ \\
\hline $\begin{array}{l}\text { Refined NIST } \\
\text { Estimates }\end{array}$ & $\begin{array}{c}\text { Estimates based on RWDI } \\
\text { and CPP tests }\end{array}$ & $\begin{array}{c}\text { Conventional hurricane wind } \\
\text { profile }\end{array}$ & $\begin{array}{c}\text { Correction to sector-by- } \\
\text { sector approach }\end{array}$ \\
\hline
\end{tabular}

Such differences highlight the limitations of the current state of practice in wind engineering for tall buildings and the need to put order in the field of wind tunnel testing and wind effects estimation.

The state of the practice with respect to wind loading and response is defined by the relevant assumptions, procedures, and methodologies accepted by professionals engaged in the design of super-tall buildings. Such professionals are structural engineers with unique experience in structural matters, but no special expertise in wind engineering. Therefore, they must rely for definitions of wind loading and response on specialized wind engineering practitioners. The state of practice is therefore de facto defined by the advice accepted by practicing structural engineers from wind engineering specialists.

North American structural engineers rely primarily on design wind loads estimated, from wind tunnel tests and extreme wind speed data, by three commercial wind engineering organizations: The Boundary 
Layer Wind Tunnel of UWO (London, Ontario), RWDI (Guelph, Ontario), and CPP (Fort Collins, Colorado). Wind load estimates by these three organizations are not necessarily mutually compatible. Therefore, what the state of the practice depends largely upon the preferences structural engineers have for the practices implicit in the advice offered by these organizations, as well as upon prior experience in working with any of them, and wind-study cost considerations. Although some criteria for wind tunnel testing are available in Sect. 6. 6 of ASCE 7-02 and in the ASCE Manual Wind Tunnel Studies of Buildings and Structures (1999), they are not sufficient to guide these preferences.

No consensus exists on the wind loading estimates provided by the wind engineering experts. In addition, because, in general, the estimates are proprietary and confidential, no scrutiny of the technical basis of the estimates being provided is generally possible, nor are building inspectors equipped to offer such scrutiny. Finally, and most importantly, the basis for the estimates provided to the structural engineer is commonly presented in a manner that, according to some users, lacks clarity, transparency, and sufficient detail, so that not only the structural engincering user but even specialized wind engineering experts can have difficulty in following and checking key aspects of the calculations on which the estimates are based.

The state of the art in wind engineering for tall buildings is more advanced than the state of the practice. It offers the potential for developing a consensus of acceptable practices based on information and procedures representing the advanced knowledge currently available. Such consensus requires the use of publicly accessible data and methodologies. The realization that transparency and public scrutiny of wind engineering models is in the public interest is illustrated by the recent decision of the Florida Department of Insurance to forgo the use of mutually inconsistent "black box" models for which justifications are not available in any detail, in favor of the development of an open, public model of hurricane-induced losses.

For the reasons discussed in this section it is necessary that the following issues be considered:

- Methods for estimating wind effects with specified mean recurrence intervals that account for the directionality of extreme wind speeds, the aerodynamic response, and the dynamic response.

- Protocols for conducting wind tunnel tests.

- Criteria for flow structure modeling, including mean wind profiles and turbulence features, for various types of wind storms, including hurricanes.

- Protocols for site-specific estimation of extreme wind speeds from National Oceanic Atmospheric Administration (NOAA) and other sources of data for non-hurricane winds.

- Estimates of hurricane wind speeds for all U.S. hurricane-prone regions, similar to estimates currently performed for Florida by NOAA's Hurricane Research Division.

- Load combinations, and material-specific (e.g., steel, concrete, and composites) responses to peak loads.

Consensus standards need to be developed that would ensure that the current state of practice will be brought to a level consistent with the state of the art. 


\subsection{REFERENCES}

ASCE 7-02: American Society of Civil Engineers, ASCE 7 Standard Minimum Design Loads for Buildings and Other Structures, Reston, VA, 2002.

BOCA/BBC 1965: BOCA Basic Building Code, Fourth Edition, Building Officials and Code Administrators, Chicago, IL.

CPP report: Data Report, Wind-Tunnel Tests - World Trade Center, Cermak Peterka Petersen, Inc. August 2002.

Design Criteria: Design Criteria document for the WTC towers developed by Worthington, Skilling, Helle \& Jackson.

IBC 2003: International Building Code, International Code Council, Falls Church, VA, 2003.

Isyumov, N., Mikitiuk, M.J., Case, P.C., Lythe, G.R., and Welburn, A., (2003), "Predictions of Wind Loads and Responses from Simulated Tropical Storm Passages," Proceedings of the Eleventh International Conference on Wind Engineering, June 2-5 2003, Lubbock, TX, D.A. Smith and C.W. Letchford, eds, Texas Tech University, Lubbock, TX, USA.

Municipal Code of Chicago Relating to Buildings (as amended to and including January 1, 1967), 1967 Index Publishing Corp., Chicago, IL

New York State Building Code, 1964, State Building Construction Code Applicable to General Building Construction, Building Code Bureau, State of New York, New York, NY.

NYCBC 2001: Building Code of the City of New York, 2001 Edition, Gould Publications, Binghamton, NY.

Powell, M.D., Vickery, P.J., and Reinhold, T.A., (2003), "Reduced drag coefficients for high wind speeds in tropical cyclones, Nature, Vol. 422, pp. 279-283.

RWDI report: (South Tower) Final Report, Wind-Induced Structural Responses, World Trade CenterTower 2, Rowan Williams Davis and Irwin, Inc., October 4, 2002.

RWDI report: (North Tower) Final Report, Wind-Induced Structural Responses, World Trade Center Tower 1, Rowan Williams Davis and Irwin, Inc., October 4, 2002.

Simiu, E. and Heckert, N.A., (1996), "Extreme Wind Distribution Tails: A Peaks Over Threshold Approach," J. Struct. Eng. 122 539-547.

Wind Tunnel Studies of Buildings and Structures (1999), ASCE Manuals and Reports on Engineering Practice No. 67, N. Isyumov (ed.), American Society of Civil Engineers, Reston, VA.

WSHJ Wind Reports: A series of wind reports developed by Worthington, Skilling, Helle \& Jackson, outlining the development of design wind loads for the WTC towers (see NIST NCSTAR 1-1). 
WTC Dwgs: WTC architectural and structural drawings. 


\section{Chapter 4 \\ Baseline Performance of the WTC TOWERs}

\section{$4.1 \quad$ INTRODUCTION}

This chapter presents the results of the baseline performance analysis for the World Trade Center (WTC) towers. Results are presented for the global models under the three gravity and wind loading cases described in Chapter 3. These cases included the original WTC design load case (henceforth referred to as original design case), the lower-estimate state-of-the-practice case (henceforth SOP case), and the refined National Institute of Standards and Technology (NIST) estimate case (henceforth refined NIST case). Baseline performance results are also presented for the typical truss-framed and beam-framed floor models under gravity loads only. Baseline performance results include basic information about the towers' behavior under design loading conditions, pertaining to total and inter-story drift (the maximum sway of the building under design wind loads), floor deflections, demand/capacity ratios of primary structural components, exterior columns response (shear lag effects and presence of tensile forces), performance of connections, and resistance of the towers to shear sliding and overturning. The baseline performance analyses in this chapter were conducted under design loading conditions. Analyses under inservice loads of the towers before and after aircraft impact were conducted and reported in NIST NCSTAR $1-6$.

This chapter reports on the work conducted by the firm of Leslie E. Robertson Associates (LERA) on the baseline performance analyses. The results were reviewed by Skidmore, Owings, and Merrill (SOM) and NIST. The reviews included checking the various load vectors, analysis procedure and results, and design parameters.

Section 4.2 presents the results of the baseline performance analysis for the global WTC 1 and WTC 2 models under the three loading cases. Similarly, Section 4.3 presents the baseline performance results for the two typical floor models. Section 4.4 outlines the third-party review by SOM and the in-house review by NIST of the baseline performance analyses. Section 4.5 presents a summary of the chapter.

\subsection{BASELINE PERFORMANCE OF THE GLOBAL MODELS}

\subsubsection{Analysis Methodology}

This section presents the details of the analysis procedure, including staged construction analysis, the load combinations, and method of estimation of the demand/capacity ratios (DCRs) for the structural components.

The global models were analyzed under the three loading cases identified in Chapter 3. For applying the gravity loads to the global models, the nonlinear staged construction analysis function in SAP2000 was used. The purpose of using the staged construction methodology in the analysis was to provide, at the top of the towers, a reasonably accurate distribution of dead loads between the core columns and the exterior walls. The hat truss system that was installed atop the towers distributed gravity and wind loads between the core and the exterior walls. The construction dead loads (CDLs) and superimposed dead loads 
(SDLs), put in place prior to the completion of the hat truss system, were not distributed through the hat truss. In order reasonably to differentiate between those loads distributed through the hat truss system and those that were not, the construction sequence was considered in the analysis.

The global model of each tower was subdivided into two portions: floor 106 and below, and the area above floor 106 that included the hat truss. In the first stage, the lower portion of the global model was loaded with all of the CDL and SDL associated with floor 106 and below. In the second stage, the portion of the full model above floor 106 was activated, and the CDL and SDL associated with the upper floors were placed on the full computer model. Live loads on the whole model were applied to the full building with the hat truss engaged in the second stage. This methodology approximated well the way in which the towers were constructed.

For all analysis cases, the DCRs for structural components were estimated using the Allowable Stress Design (ASD) procedure as specified in the American Institute of Steel Construction (AISC)

Specification for Structural Steel Buildings - Allowable Stress Design and Plastic Design - $9^{\text {th }}$ Edition, 1989. The DCRs were calculated by dividing component demands by component capacities, taken at unfactored (working) loads and at working stresses, not at ultimate loads or yield stresses. These DCRs for the structural components were determined as follows:

1. The component demands were obtained from the results of the baseline performance analysis using the reference global models, and working loads based on the following load combinations:

- For the original WTC design loading case and for the lower estimate, state-of-thepractice case, the load combinations were those specified by the AISC Specification (1989) and the New York City Building Code (NYCBC) 2001:

Dead Load

Dead Load + Live Load

Dead Load + Live Load + Wind Load

Dead Load + Wind Load

- For the refined NIST estimate case, the load combinations were those specified by the American Society of Civil Engineers (ASCE 7-02) Standard:

$$
\begin{aligned}
& \text { Dead Load } \\
& \text { Dead Load + Live Load } \\
& \text { Dead Load + Wind Load } \\
& \text { Dead Load + } 0.75 \text { x (Live Load + Wind Load) } \\
& 0.6 \text { x Dead Load + Wind Load }
\end{aligned}
$$

2. The component capacities were based on the nominal steel strength as specified in the original design documents and using the AISC Specification (1989):

- For the original design loading case and for the lower estimate, state-of-the-practice case (consistent with NYCBC 2001), a one-third increase in the allowable stress was 
considered for load cases that included wind, as specified at the time of the design and as is currently specified in NYCBC 2001 and AISC Specification (1989).

- For the refined NIST estimate case, where loads were based on the ASCE 7-02 Standard, load combinations were taken from the ASCE 7-02 Standard, which does not allow the one-third increase in allowable stresses.

The interaction equation in AISC Specifications (1989) estimates the DCR as the larger of the following two equations for members subjected to both axial compression and bending stresses:

$$
\begin{aligned}
& D C R=\frac{f_{a}}{F_{a}}+\frac{C_{m x} f_{b x}}{\left(1-\frac{f_{a}}{F_{e x}^{\prime}}\right) F_{b x}}+\frac{C_{m y} f_{b y}}{\left(1-\frac{f_{a}}{F_{c y}^{\prime}}\right) F_{b y}} \\
& D C R=\frac{f_{a}}{0.60 F_{y}}+\frac{f_{b x}}{F_{b x}}+\frac{f_{b y}}{F_{b y}}
\end{aligned}
$$

For the case when $f_{a} / F_{a} \leq 0.15$, the following equation is permitted in lieu of the previous two equations:

$$
D C R=\frac{f_{a}}{F_{a}}+\frac{f_{h x}}{F_{b x}}+\frac{f_{b y}}{F_{b y}}
$$

where the subscripts $x$ and $y$ indicate the axis of bending about which a particular stress or design property applies, and

$F_{a}$ and $F_{b}$ are the axial compressive stress and compressive bending stress, respectively, that would be permitted if axial force alone or if bending moment alone existed.

$f_{a}$ and $f_{b}$ are the computed axial stress and compressive bending stress at a given point, respectively.

$F_{e}^{\prime}$ is the Euler buckling stress divided by a factor of safety.

$C_{m}$ is a coefficient that depends on column curvature caused by applied moment.

A review of the basic design equations and allowable stresses for combined axial and bending stresses for the 6th Edition of the AISC Specifications (1963), which was in effect at the time of the design, indicated that they are essentially identical to those of the 9th Edition (1989) design equations and allowable stresses. There are, however, some variations between the 6th and 9th Editions of the specification. The 1963 Specification did not specifically address biaxial bending in the combined stress equations. In addition, the allowable stress formulations for bending with lateral torsional buckling are somewhat different between the two design specifications.

For the original design loading case, the SAP2000 program was used directly to estimate the DCRs using the equations presented above. For the lower-estimate, state-of-the-practice case and the refined NIST estimate case, a second order analysis that accounted for P- $\Delta$ effects was used to estimate member 
demands under the applied gravity and wind loads. The P- $\Delta$ analysis resulted in a moment magnification in the components of the global models; and as a result, the terms $C_{m}$ and $\left(1-f_{a} / F_{e}^{\prime}\right)$ were assigned a unit value in the above equations to estimate component DCRs. For these cases, DCRs were calculated in Excel spreadsheets using results obtained by the SAP2000 computer program.

For further details, see Chapter 5 of NIST NCSTAR 1-2A.

\subsubsection{Total and Inter-Story Drift}

The calculated total drift of both WTC 1 and WTC 2 induced by the three loading cases is presented in Table 4-1. The table lists calculated total drift values at the top of the tower, in absolute terms and as a fraction of the height, $\mathrm{H}$, from the foundation level to the roof (referred to in the table as the drift ratio). According to LERA, limiting total building drift under wind loads was not part of the original WTC design criteria (see NIST NCSTAR 1-2A). Instead, inter-story drifts were determined at the design stage and were compared with the ability of the architectural building systems such as the partitions and the exterior cladding, to accommodate these inter-story drifts. Accordingly, there is no project-specific data available to which the total drifts may be compared. Figure 4-1 presents the deflected shape of WTC 1 under the three loading cases. Similarly, Fig. 4-2 shows the inter-story drift distribution along the height of the tower, normalized to the story height. The plots are presented for the E-W and N-S directions for the wind load combination that produced the maximum cumulative drift for each case. Similar plots for WTC 2 can be found in Chapter 5 of NIST NCSTAR 1-2A.

Table 4-1. Total drift for WTC 1 and WTC 2 under the three loading cases.

\begin{tabular}{|l||c|c|c|c||c|c|c|c||}
\hline \multirow{2}{*}{$\begin{array}{l}\text { Loading } \\
\text { Case }\end{array}$} & \multicolumn{4}{|c||}{ WTC 1 } & \multicolumn{3}{c||}{ WTC 2 } \\
\cline { 2 - 9 } & $\begin{array}{c}\text { Total } \\
\text { Drift (in.) }\end{array}$ & $\begin{array}{c}\text { Drift } \\
\text { Ratio }\end{array}$ & $\begin{array}{c}\text { Total } \\
\text { Drift (in.) }\end{array}$ & $\begin{array}{c}\text { Drift } \\
\text { Ratio }\end{array}$ & $\begin{array}{c}\text { Total } \\
\text { Drift (in.) }\end{array}$ & $\begin{array}{c}\text { Drift } \\
\text { Ratio }\end{array}$ & $\begin{array}{c}\text { Total } \\
\text { Drift (in.) }\end{array}$ & $\begin{array}{c}\text { Drift } \\
\text { Ratio }\end{array}$ \\
\hline $\begin{array}{l}\text { Original } \\
\text { design case }\end{array}$ & 56.6 & $\mathrm{H} / 304$ & 55.7 & $\mathrm{H} / 309$ & 51.2 & $\mathrm{H} / 335$ & 65.3 & $\mathrm{H} / 263$ \\
\hline SOP case & 56.8 & $\mathrm{H} / 303$ & 68.1 & $\mathrm{H} / 253$ & 59.7 & $\mathrm{H} / 287$ & 56.1 & $\mathrm{H} / 306$ \\
\hline $\begin{array}{l}\text { Refined } \\
\text { NIST case }\end{array}$ & 70.6 & $\mathrm{H} / 244$ & 83.9 & $\mathrm{H} / 205$ & 75.6 & $\mathrm{H} / 227$ & 71.0 & $\mathrm{H} / 242$ \\
\hline
\end{tabular}

Under the original WTC design loads, the cumulative drifts at the top of the WTC 1 tower were about 56.6 in. $(\mathrm{H} / 304)$ and 55.7 in. $(\mathrm{H} / 309)$ in the E-W and N-S direction, respectively. For WTC 2 the drifts were about 51.2 in. $(\mathrm{H} / 335)$ in the $\mathrm{E}-\mathrm{W}$ direction and 65.3 in. $(\mathrm{H} / 263)$ in the $\mathrm{N}-\mathrm{S}$ direction. For the stateof-the-practice case, the drifts for WTC 1 were larger than those from the original design case by about 0.5 percent and 22 percent for the E-W and N-S directions, respectively; for WTC 2 the drift was larger than that from the original design case by about 16 percent and 15 percent for the $\mathrm{E}-\mathrm{W}$ and $\mathrm{N}-\mathrm{S}$ drift, respectively. These differences are commensurate with those between the base shears for the two cases. 
The drifts obtained from the refined NIST estimate case were about 25 percent larger than those from the state-of-the practice case for both towers.

As Fig. 4-2 indicates, the inter-story drift varied over the height of the tower. Under the original design loading case, the maximum inter-story drift was as high as $h / 225$ and $h / 195$ for WTC 1 and WTC 2, respectively, where $\mathrm{h}$ is the story height. Maximum inter-story drifts under the state-of-the practice case were about $\mathrm{h} / 185$ and h/200 for WTC 1 and WTC 2. respectively. For the refined NIST estimate case, these inter-story drifts were about 25 percent larger than those from the state-of-the practice case for both towers.

Currently no building codes specify a drift limit for wind design. The ASCE 7-02 Standard states in Section B.1.2 that the drift of structures due to wind effects shall not impair the serviceability of the structure. The commentary to this section of the standard indicates that drift limits in common usage for building design are on the order of 1/400 to $1 / 600$ of the building (for total drift) or story height (for interstory drift) to minimize damage to cladding and nonstructural walls and partitions. Structural engineers often use in their practice the criterion that total drift ratios should not exceed $H / 400$ to $H / 500$ for serviceability considerations and to enhance overall safety and stability (including P- $\Delta$ effects). Typical drift limits used in practice ( $\mathrm{H} / 400$ to $\mathrm{H} / 500)$ are superimposed on the drift plots shown as the shaded areas in Fig. 4-1. Reducing the drift of the WTC towers to the range of $H / 400$ to $H / 500$ (about 43 in. to $34 \mathrm{in.)}$ would entail enhancing the stiffness and/or the damping capacity of the towers.

For inter-story drifts, structural engineers often use in their practice an inter-story drift limit in the range of $\mathrm{h} / 300$ to $\mathrm{h} / 400$. This is primarily done for serviceability considerations. Typical inter-story drift limits used in practice ( $\mathrm{h} / 300$ to $\mathrm{h} / 400$ ) are superimposed on the inter-story drift plots shown as the shaded areas in Fig. 4-2. Similar to total drift, inter-story drifts of the towers were larger than what is generally used in practice today.

\subsubsection{Demand/Capacity Ratios}

The DCR statistics for WTC 1 obtained from the reference global model under the original WTC design loading case, the lower-estimate state-of-the-practice case, and the refined NIST estimate case are summarized in Tables 4-2, 4-3, and 4-4, respectively. The statistics include, for each member category, the total number of members, the mean value of the DCRs, their coefficient of variation (C.O.V.), the percentage of components with DCR greater than 1.0 and greater than 1.05 , the number of components with a DCR greater than 1.05, and the maximum calculated DCR. The DCR statistics for WTC 2 under the three loading cases were comparable to those presented herein for WTC 1. See Chapter 5 of NIST NCSTAR 1-2A for details.

Fig. 4-3 shows the distribution of DCRs for the four exterior walls of WTC 1 under the original design load case. Close-up views are shown for the exterior walls below floor 9 in Fig. 4-4. DCRs for the WTC 1 core columns are provided in Fig. 4-5. Similar plots for WTC 2 DCRs can be found in Chapter 5 of NIST NCSTAR 1-2A. 

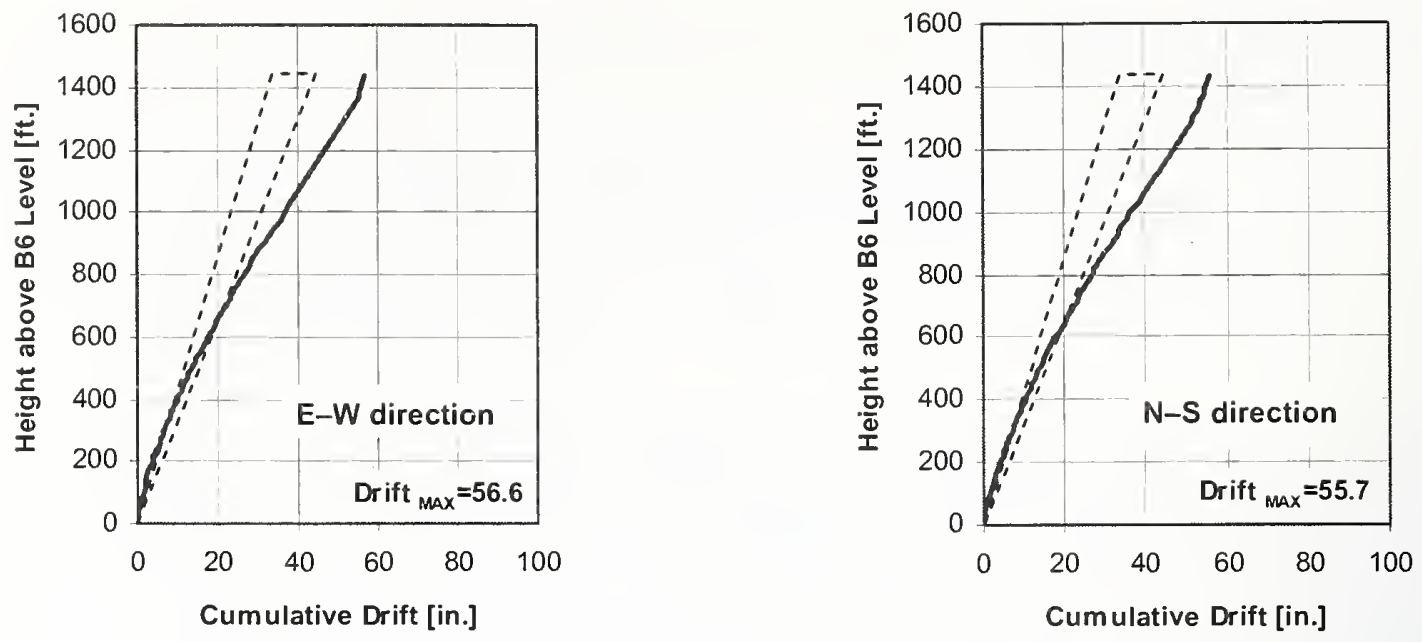

(a) Original WTC design wind loads
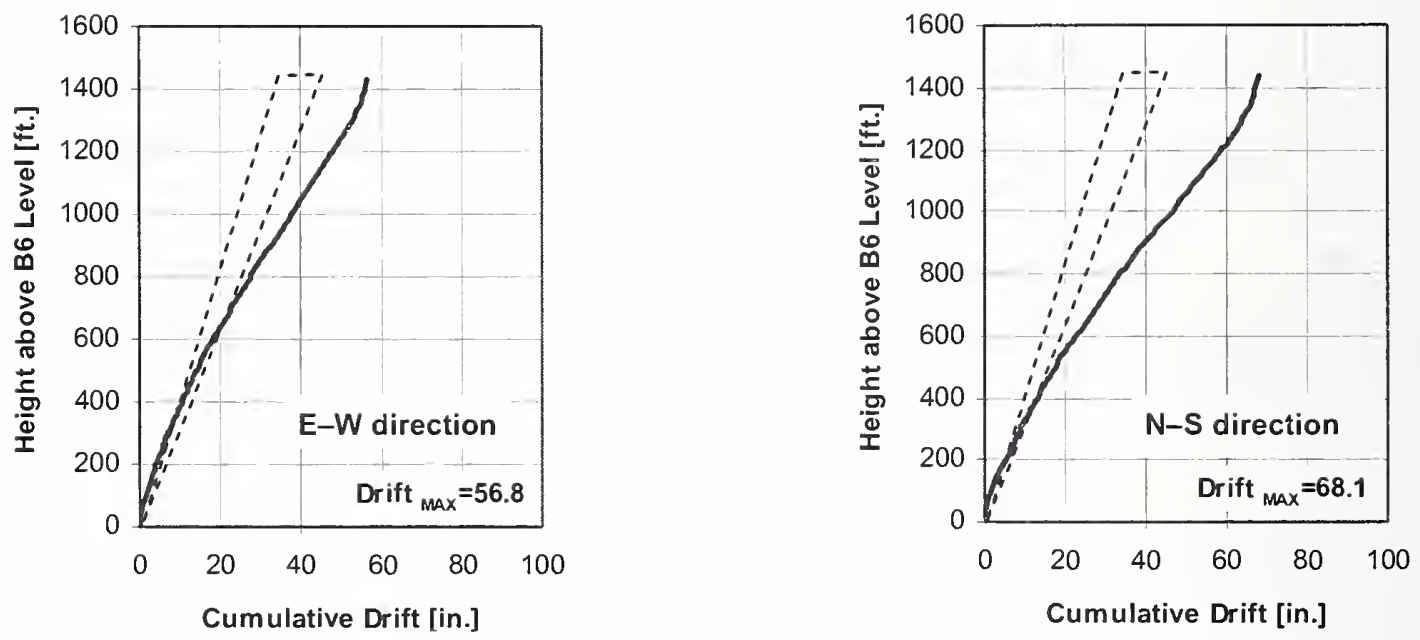

(b) Lower estimate, state-of-the-practice wind loads
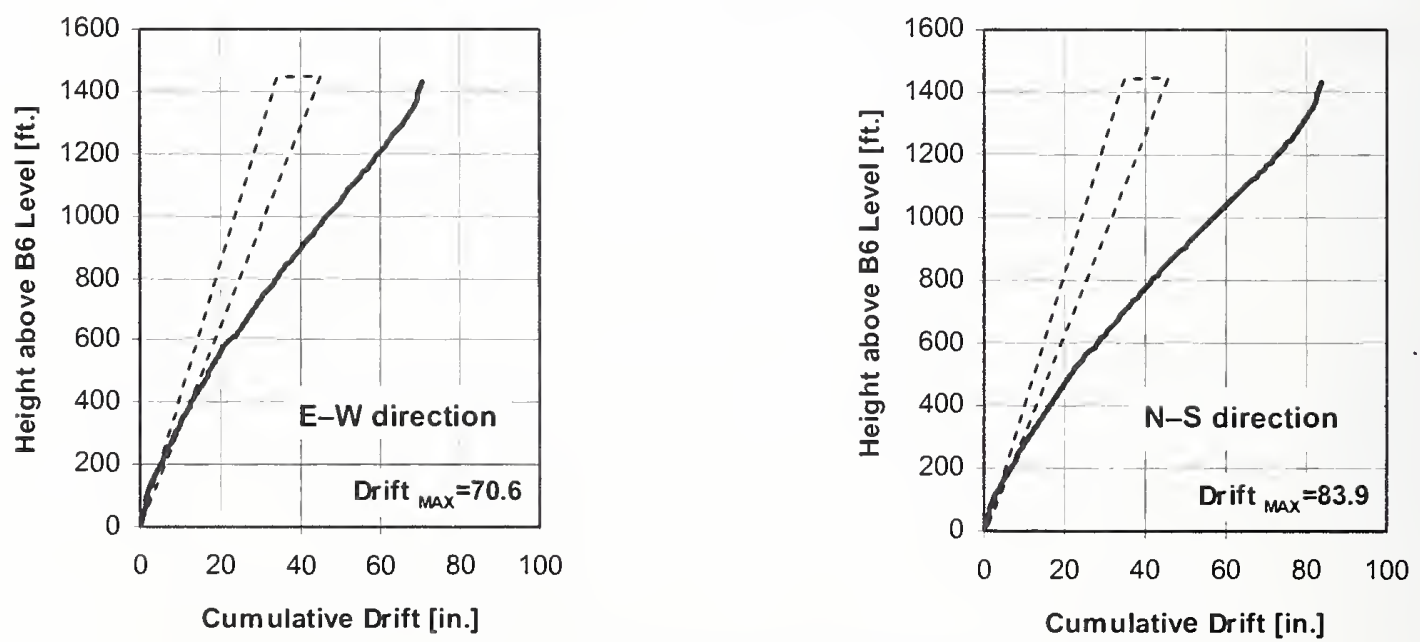

(c) Refined NIST wind loads

Figure 4-1. Cumulative drift diagrams for WTC 1 under the three wind loading cases. 


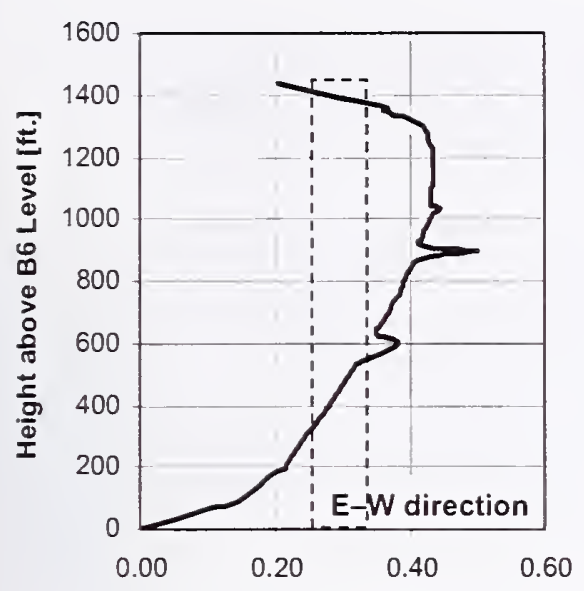

Interstory Drift/Story Height [\%]

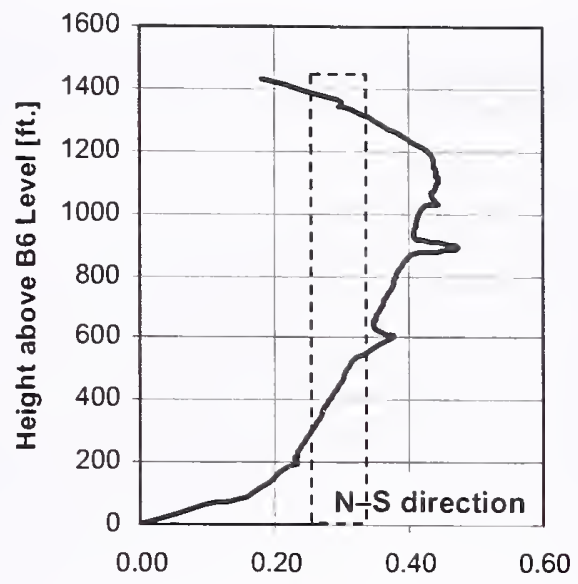

Interstory Drift/Story He ight [\%]

(a) Original WTC design wind loads
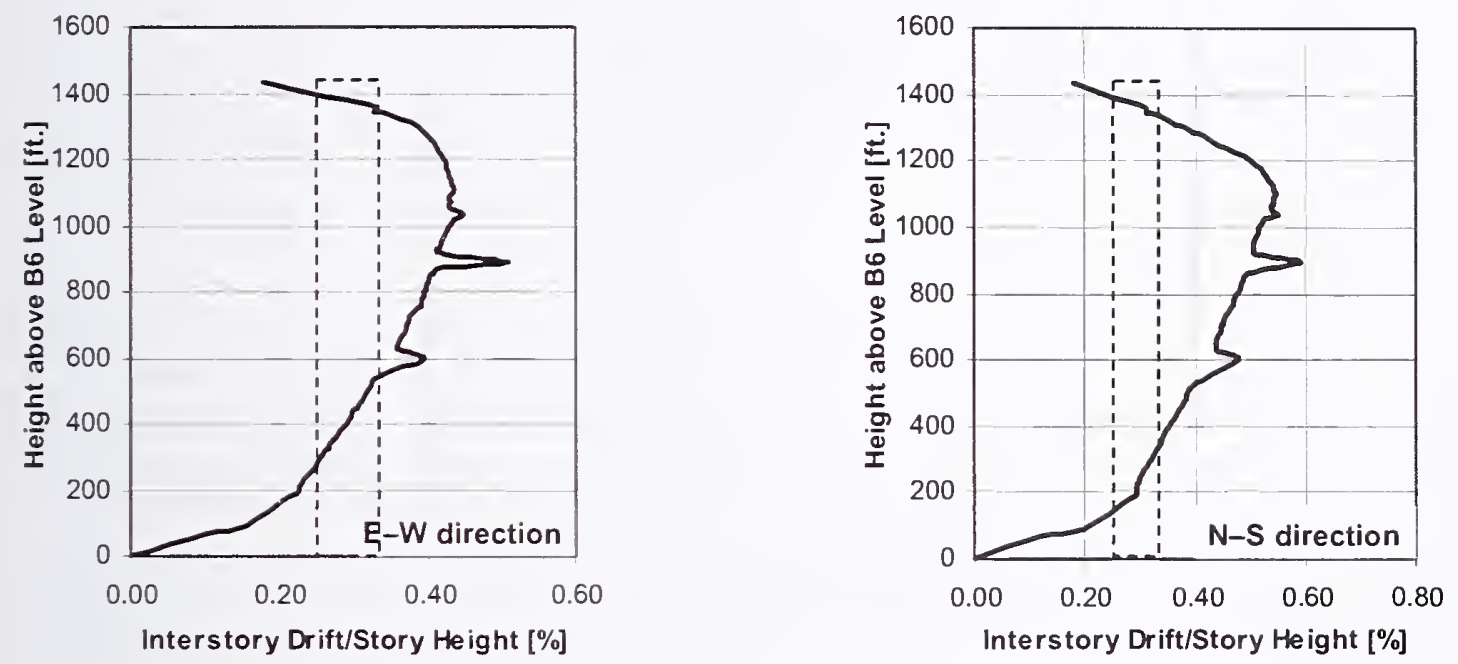

(b) Lower estimate, state-of-the-practice wind loads

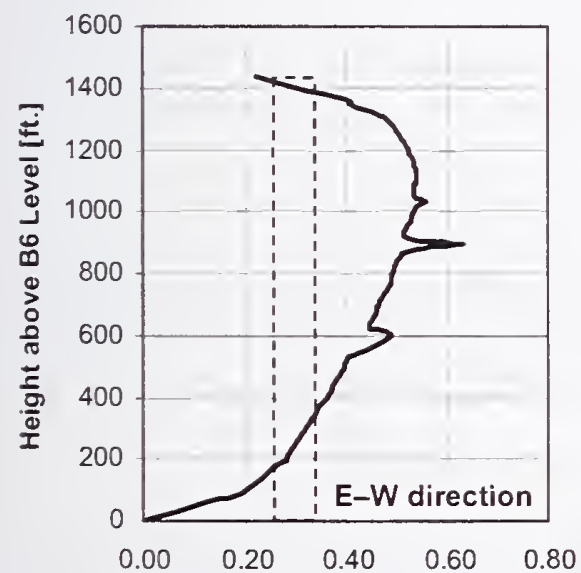

Interstory Drift/Story Height [\%]

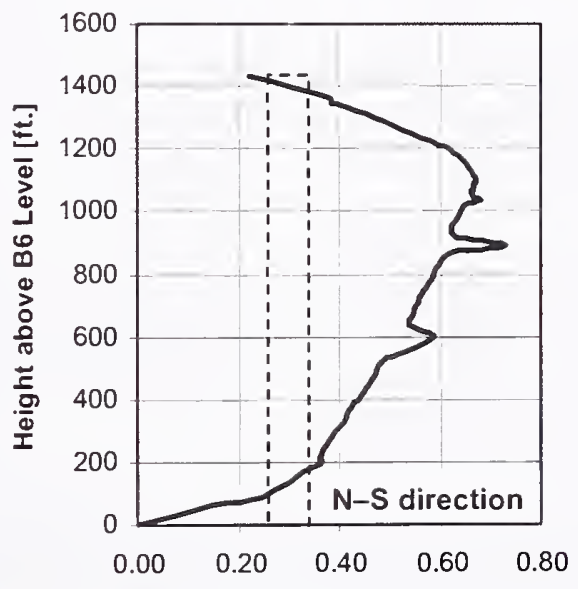

Interstory Drift/Story He ight [\%]

(c) Refined NIST wind loads

Figure 4-2. Inter-story drift diagrams for WTC 1 under the three wind loading cases. 
Table 4-2 and Figures 4-3 through 4-5 indicate that under the original WTC design loading case, most structural members had a DCR of less than 1.0. A fraction of the structural members had DCRs in excess of 1.0. These were mainly observed in the exterior walls and core columns.

The types of members in the exterior walls that had DCRs larger than 1.0 were calculated for a combination of axial load and bending under the combination of gravity and wind loads. These included: (1) columns at the corners, (2) where the hat truss connected to the exterior wall, and (3) below floor 9. The members in these locations would be expected to experience a large degree of stress. The corner columns had some of the highest calculated forces under wind loading. The hat truss-to-exterior wall connections interconnected two major structural systems with large concentrated load transfers. The exterior wall below floor 9 was a highly variable and articulated structural system that had large calculated forces.

The core columns that had DCRs larger than 1.0 were calculated for axial stresses due to gravity loads and were generally located: (1) on the 600 column line between floors 80 and 106, and (2) at core perimeter columns 901 and 908 for much of their height. The gravity loads on these columns were affected significantly by assumptions about tributary areas, construction dcad loads and superimposed dead loads, and the sequence of construction of the hat truss. According to LERA, the high degree of stress calculated at these core columns was likely associated with differences in these assumptions between the original and current computations.

The results indicated a number of members throughout the structures with DCRs larger than unity, which is inconsistent with the design requirements of the AISC, ASD Specification. One possible explanation may lie in the computcr-based structural analysis and software techniques employed for this baseline performance study in comparison with those utilized in the original design nearly forty years ago. An examplc is the contribution of secondary moments in the various elements, which may have gone undetected in the original analysis and design. The exterior walls of the towers might have the potential for significant redistribution of the loads of members with large DCRs to adjacent members. Demandcapacity ratios greater than 1.0 detected in core columns and hat truss members are less easily resolved as the ability for redistribution may be limited.

While it is a normal design practice to achieve a DCR less than unity, the safety of the WTC towers on Septembcr 11, 2001, was most likely not affected by the fraction of members for which the demand exceeded capacity due to the following reasons:

- The allowable stress design method has an inherent factor of safety for structural components. The safety factor is about 1.67 and 1.92 for yielding and buckling, respectively, for components subjected primarily to gravity loads, such as core columns. The factor of safety is reduced by $1 / 3$ for components subjected to wind loads, such as the exterior walls, due to the $1 / 3$ increase in the allowable stresses.

- After reaching the yield strength, structural steel components continue to possess significant reserve capacity, thus allowing for load redistribution to other components that may still be in the elastic range. 
- The DCRs presented herein were estimated using the design live loads. On September 11, 2001, the towers were subjected to in-service live loads, which are considered to be approximately 25 percent of the design live loads.

- On September 11,2001, the wind loads were minimal, thus providing significantly more reserve capacity for the exterior walls.

A comparison between Tables 4-2 and 4-3 indicates that the DCRs estimated from the original WTC design load case were, in general, close to those obtained for the lower-estimate state-of-the practice case for WTC 1. Comparing Tables 4-2 through 4-4, it was found that the DCRs obtained for the refined NIST estimate loading case were higher than those from the original WTC design and the lower-estimate state-of-the-practice load cases, owing to the following reasons:

- The refined NIST estimated wind loads were higher than those used in the lower-estimate stateof-the-practice case by about 25 percent (about 10 percent difference between the RWDI loads scaled to the NYCBC 2001 wind speed and RWDI loads scaled to the ASCE 7-02 wind speed, in addition to the 15 percent increase estimated by NIST, Section 3.4). It is noted that the NIST estimated wind loads were about 20 percent smaller than those estimated by CPP (an upperestimate state-of-the practice case, see Chapter 3).

- The original WTC design and the state-of-the-practice cases used NYCBC load combinations, which result in lower DCRs than the ASCE 7-02 load combinations used for the refined NIST case.

Similar observations and conclusions could be made for the DCRs estimated for WTC 2 for the three loading cases, see NIST NCSTAR 1-2A.

As part of the in-house NIST review into the baseline performance analyses, the DCRs were estimated using the Strength Design procedure as specified in the AISC Load \& Resistance Factor Design (LRFD) Specification for Structural Steel Buildings (1993). The analysis was conducted for the exterior wall columns from floor 9 to floor 106, and for core columns of WTC 1 for the refined NIST estimate case. For this analysis, the load combinations were those specified by the ASCE 7-02 Standard:

$$
\begin{aligned}
& \text { 1.4 Dead Load } \\
& \text { 1.2 Dead Load + 1.6 Live Load } \\
& \text { 1.2 Dead Load + 0.8 Wind Load } \\
& \text { 1.2 Dead Load + Live Load + 1.6 Wind Load } \\
& \text { 0.9 Dead Load + 1.6 Wind Load }
\end{aligned}
$$

The DCRs estimated using LRFD for the refined NIST case are presented in Table 4-5, along with the DCRs obtained from the ASD method. The results indicate that the mean DCRs estimated using the LRFD procedure were smaller than those using the ASD procedure by about 15 percent. 
Table 4-2. Statistics of DCRs for WTC 1 under original design load case.

\begin{tabular}{|c|c|c|c|c|c|c|c|}
\hline Member Type & $\begin{array}{l}\text { Number of } \\
\text { Members }\end{array}$ & $\begin{array}{c}\text { Mean } \\
\text { Calculated } \\
\text { DCR }\end{array}$ & $\begin{array}{c}\text { C.O.V. } \\
\text { of } \\
\text { DCR }\end{array}$ & $\begin{array}{c}\text { Percentage } \\
\text { of } \\
\text { components } \\
\text { with DCR > } \\
1.0\end{array}$ & $\begin{array}{c}\text { Percentage } \\
\text { of } \\
\text { components } \\
\text { with DCR > } \\
1.05\end{array}$ & $\begin{array}{c}\text { Number of } \\
\text { components } \\
\text { with DCR > } \\
1.05\end{array}$ & $\begin{array}{c}\text { Maximum } \\
\text { Calculated } \\
\text { DCR }\end{array}$ \\
\hline \multicolumn{8}{|l|}{$\begin{array}{l}\text { Exterior Wall } \\
\text { Columns }\end{array}$} \\
\hline Below floor 1 & 628 & 0.77 & 0.19 & 4.3 & 2.7 & 17 & 1.36 \\
\hline Floor 1 to 9 & 1,122 & 0.74 & 0.25 & 3.3 & 0.5 & 6 & 1.27 \\
\hline Floor 9 to 106 & 31,086 & 0.76 & 0.12 & 1.1 & 0.4 & 121 & 1.31 \\
\hline Above floor 106 & 578 & 0.73 & 0.31 & 12.3 & 10.0 & 58 & 1.46 \\
\hline \multicolumn{8}{|l|}{$\begin{array}{l}\text { Exterior Wall } \\
\text { Spandrels }\end{array}$} \\
\hline Below floor 1 & 420 & 0.44 & 0.46 & 0.7 & 0.7 & 3 & 1.28 \\
\hline Floor 1 to 9 & 610 & 0.34 & 0.45 & 1.1 & 1.0 & 6 & 1.30 \\
\hline Floor 9 to 106 & 31,160 & 0.31 & 0.30 & 0 & 0 & 0 & 0.83 \\
\hline Above floor 106 & 836 & 0.35 & 0.69 & 1.9 & 1.7 & 14 & 1.55 \\
\hline Core Columns & 5,219 & 0.86 & 0.14 & 10 & 5.3 & 278 & 1.36 \\
\hline \multicolumn{8}{|l|}{ Hat Truss System } \\
\hline Columns & 239 & 0.47 & 0.45 & 0.4 & 0.4 & 1 & 1.26 \\
\hline Beams & 499 & 0.24 & 0.87 & 0.4 & 0.2 & 1 & 1.07 \\
\hline Braces & 279 & 0.47 & 0.53 & 2.5 & 0.7 & 2 & 1.06 \\
\hline \multicolumn{8}{|l|}{$\begin{array}{l}\text { Exterior Wall } \\
\text { Bracing }\end{array}$} \\
\hline Below floor 1 & 200 & 0.72 & 0.16 & 2 & 1 & 2 & 1.16 \\
\hline Above floor 106 & 12 & 0.40 & 0.52 & 0 & 0 & 0 & 0.75 \\
\hline
\end{tabular}


Table 4-3. Statistics of DCRs for WTC 1 under the lower estimate, state-of-the practice case

\begin{tabular}{|c|c|c|c|c|c|c|c|}
\hline Member Type & $\begin{array}{c}\text { Number } \\
\text { of } \\
\text { Nembers }\end{array}$ & $\begin{array}{c}\text { Mean } \\
\text { Calculated } \\
\text { DCR } \\
\end{array}$ & $\begin{array}{c}\text { C.O.V. } \\
\text { of } \\
\text { DCR }\end{array}$ & $\begin{array}{c}\text { Percentage } \\
\text { of } \\
\text { components } \\
\text { with DCR > } \\
1.0 \\
\end{array}$ & $\begin{array}{c}\text { Percentage } \\
\text { of } \\
\text { components } \\
\text { with DCR > } \\
1.05 \\
\end{array}$ & $\begin{array}{c}\text { Number of } \\
\text { components } \\
\text { with DCR > } \\
1.05 \\
\end{array}$ & $\begin{array}{c}\text { Maximum } \\
\text { Calculated } \\
\text { DCR }\end{array}$ \\
\hline \multicolumn{8}{|l|}{$\begin{array}{l}\text { Exterior Wall } \\
\text { Columns }\end{array}$} \\
\hline Below floor 1 & 628 & 0.77 & 0.19 & 6.1 & 4.0 & 25 & 1.30 \\
\hline Floor 1 to 9 & 1,122 & 0.78 & 0.26 & 13.1 & 5.2 & 58 & 1.15 \\
\hline Floor 9 to 106 & 31.086 & 0.78 & 0.13 & 2 & 0.9 & 281 & 1.44 \\
\hline Above floor 106 & 578 & 0.71 & 0.31 & 10.7 & 7.6 & 44 & 1.36 \\
\hline \multicolumn{8}{|l|}{$\begin{array}{l}\text { Exterior Wall } \\
\text { Spandrels }\end{array}$} \\
\hline Below floor 1 & 420 & 0.49 & 0.46 & 4 & 2.4 & 10 & 1.26 \\
\hline Floor 1 to 9 & 610 & 0.37 & 0.45 & 1.3 & 1.1 & 7 & 1.22 \\
\hline Floor 9 to 106 & 31.160 & 0.32 & 0.29 & 0 & 0 & 0 & 0.80 \\
\hline Above floor 106 & 836 & 0.35 & 0.70 & 1.9 & 1.7 & 14 & 1.57 \\
\hline Core Columns & 5,219 & 0.86 & 0.14 & 9.9 & 5.3 & 278 & 1.36 \\
\hline \multicolumn{8}{|l|}{ Hat Truss System } \\
\hline Columns & 239 & 0.45 & 0.50 & 0.4 & 0.4 & 1 & 1.26 \\
\hline Beams & 499 & 0.23 & 0.93 & 0.2 & 0.2 & 1 & 1.07 \\
\hline Braces & 279 & 0.41 & 0.60 & 1.1 & 0 & 0 & 1.03 \\
\hline \multicolumn{8}{|l|}{$\begin{array}{l}\text { Exterior Wall } \\
\text { Bracing }\end{array}$} \\
\hline Below floor 1 & 200 & 0.76 & 0.16 & 2.5 & 2 & 4 & 1.18 \\
\hline Above floor 106 & 12 & 0.35 & 0.47 & 0 & 0 & 0 & 0.64 \\
\hline
\end{tabular}


Table 4-4. Statistics of DCRs for WTC 1 under the refined NIST estimate case.

\begin{tabular}{|c|c|c|c|c|c|c|c|}
\hline Member Type & $\begin{array}{c}\text { Number } \\
\text { of } \\
\text { Members }\end{array}$ & $\begin{array}{c}\text { Mean } \\
\text { Calculated } \\
\text { DCR }\end{array}$ & $\begin{array}{c}\text { C.O.V. } \\
\text { of } \\
\text { DCR }\end{array}$ & $\begin{array}{c}\text { Percentage } \\
\text { of } \\
\text { components } \\
\text { with DCR > } \\
1.0\end{array}$ & $\begin{array}{c}\text { Percentage } \\
\text { of } \\
\text { components } \\
\text { with DCR > } \\
1.05\end{array}$ & $\begin{array}{c}\text { Number of } \\
\text { components } \\
\text { with DCR > } \\
1.05\end{array}$ & $\begin{array}{c}\text { Maximum } \\
\text { Calculated } \\
\text { DCR }\end{array}$ \\
\hline \multicolumn{8}{|l|}{$\begin{array}{l}\text { Exterior Wall } \\
\text { Columns }\end{array}$} \\
\hline Below floor 1 & 628 & 1.04 & 0.24 & 52.5 & 47.3 & 297 & 1.95 \\
\hline Floor 1 to 9 & 1,122 & 1.11 & 0.27 & 69.0 & 63.6 & 714 & 1.69 \\
\hline Floor 9 to 106 & 31,086 & 1.10 & 0.14 & 72.1 & 59.7 & 18572 & 2.05 \\
\hline Above floor 106 & 578 & 0.81 & 0.28 & 19.7 & 14.2 & 82 & 1.57 \\
\hline \multicolumn{8}{|l|}{$\begin{array}{l}\text { Exterior Wall } \\
\text { Spandrels }\end{array}$} \\
\hline Below floor 1 & 420 & 0.81 & 0.46 & 22.1 & 21.4 & 90 & 2.05 \\
\hline Floor 1 to 9 & 610 & 0.61 & 0.45 & 8.0 & 4.3 & 26 & 2.03 \\
\hline Floor 9 to 106 & 31,160 & 0.52 & 0.29 & 0.5 & 0.3 & 109 & 1.32 \\
\hline Above floor 106 & 836 & 0.41 & 0.68 & 2.4 & 1.9 & 16 & 1.82 \\
\hline Core Columns & 5219 & 0.84 & 0.15 & 8.9 & 5.2 & 270 & 1.40 \\
\hline \multicolumn{8}{|l|}{ Hat Truss System } \\
\hline Columns & 239 & 0.53 & 0.49 & 3.8 & 0.8 & 2 & 1.26 \\
\hline Beams & 499 & 0.26 & 0.93 & 1.8 & 1.4 & 7 & 1.30 \\
\hline Braces & 279 & 0.49 & 0.55 & 6.1 & 2.5 & 7 & 1.10 \\
\hline \multicolumn{8}{|l|}{$\begin{array}{l}\text { Exterior Wall } \\
\text { Bracing }\end{array}$} \\
\hline Below floor 1 & 200 & 1.11 & 0.18 & 73.0 & 62.0 & 124 & 1.76 \\
\hline Above floor 106 & 12 & 0.52 & 0.42 & 0 & 0 & 0 & 0.90 \\
\hline
\end{tabular}




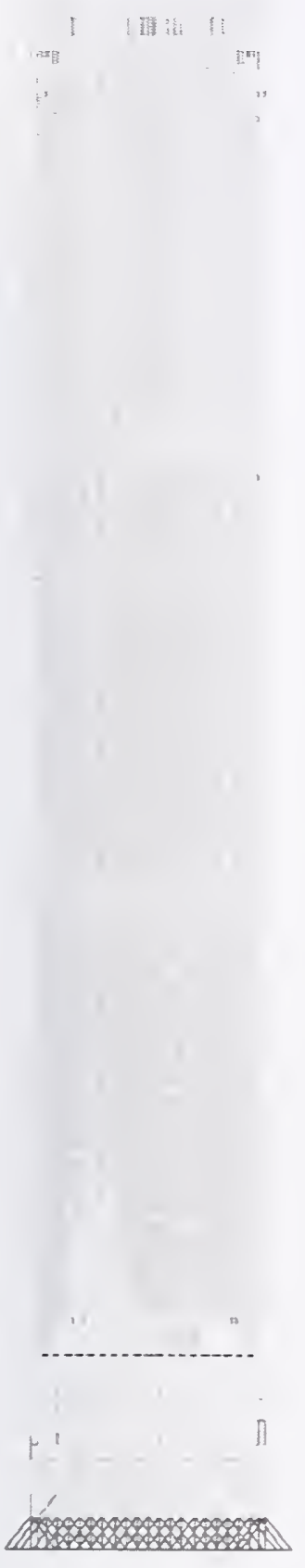

(c)

(d)

(a)

(b)

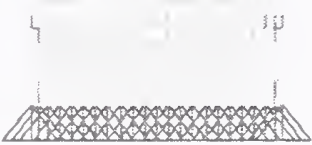

\begin{tabular}{|l|l|l|l|l|l|l|l|}
\hline & 9.00 & 0.50 & 0.75 & 1.00 & 1.08 & \\
\hline
\end{tabular}

Figure 4-3. DCRs for the exterior walls of WTC 1 under original design case, (a) north elevation, (b) east elevation, (c) south elevation, and (d) west elevation. 


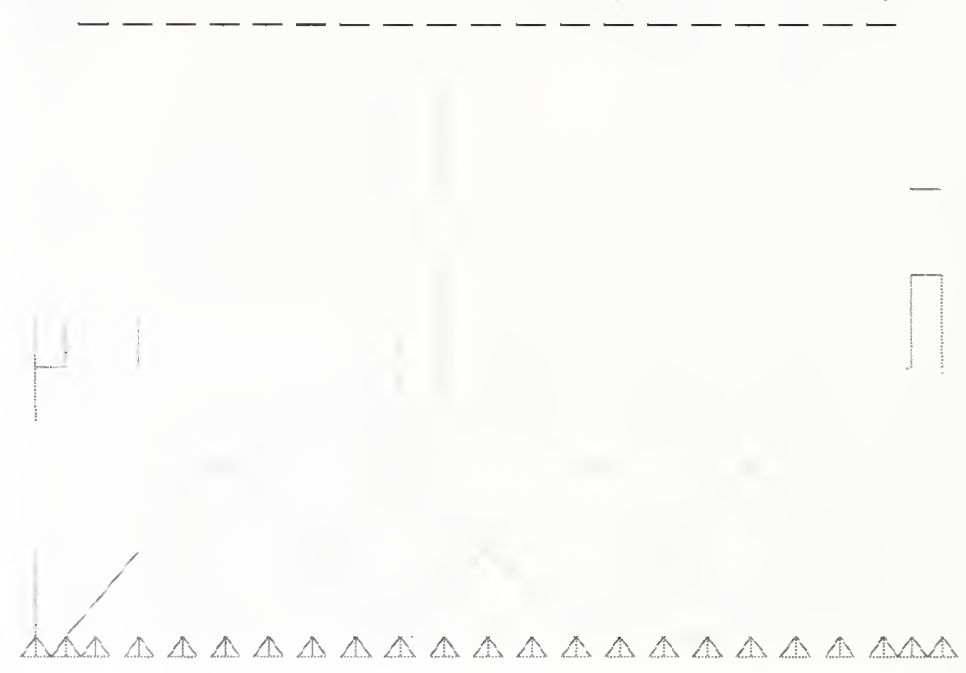

(a)

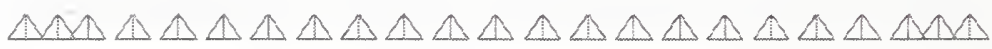

(b)

\begin{tabular}{|l|l|l|l|l|l|l|}
\hline & 0.00 & 0.50 & 0.75 & 1.00 & 1.08 & \\
\hline
\end{tabular}

Figure 4-4. RCRs for WTC 1 under original design loads below floor 9, (a) north elevation, and (b) east elevation. 
(c)

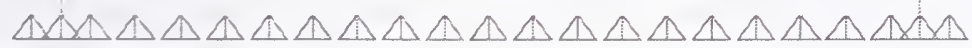

(d)

\begin{tabular}{|l|l|l|l|l|l|l|}
\hline$\therefore$ & 0.00 & 0.50 & 0.75 & 1.00 & 1.08 \\
\hline
\end{tabular}

Figure 4-4. (c) south elevation, and (d) west elevation (continued). 


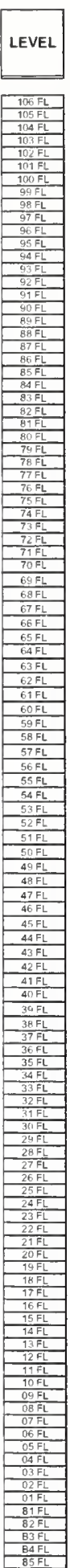

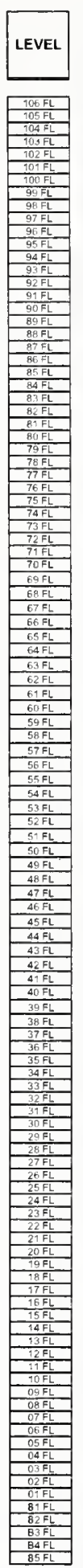

(a)
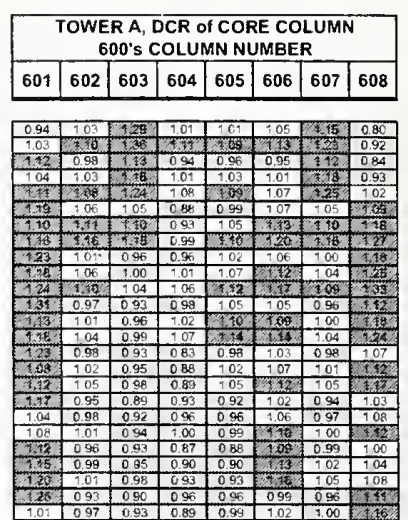

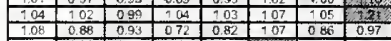
\begin{tabular}{|c|c|c|c|c|c|c|c|}
\hline 1.04 & 090 & 0.98 & 0.74 & 0.84 & 8.64 & 0.88 & 1.01 \\
\hline 108 & 0.92 & 0.98 & 0.76 & 0.87 & 1520 & 0.90 & 105 \\
\hline 076 & 083 & 0.66 & 0.62 & 0.89 & 0.65 & 0.66 & 0.85 \\
\hline
\end{tabular} \begin{tabular}{|l|l|l|l|l|l|l|l|}
\hline 078 & 0.67 & 070 & 0.65 & 0.70 & 0.68 & 070 & 0.86 \\
\hline
\end{tabular} \begin{tabular}{|c|c|c|c|c|c|c|c|}
\hline 0.97 & 084 & 089 & 0.22 & 0.91 & 0.86 & 0.86 & 1.0 \\
\hline 0.97 & 085 & 089 & 0.22 & 092 & 0.86 & 0.86 & 1.01 \\
\hline 100 & 086 & 091 & 0.84 & 0.93 & 0.88 & 0.88 & 1.04 \\
\hline
\end{tabular} \begin{tabular}{c|c|c|c|c|c|c|c|}
\hline 100 & 083 & 087 & 0.82 & 0.85 & 0.83 & 0.85 & 0.99 \\
\hline 1.03 & 0.84 & 088 & 0.83 & 0.86 & 0.84 & 0.86 & 1.02 \\
\hline 105 & 0.5 & 0.96 & 0.5 & 0.8 & 0.86 & 388 & 104 \\
\hline
\end{tabular}

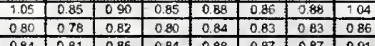
\begin{tabular}{|c|c|c|c|c|c|c|c|}
\hline 0.84 & 0.81 & 0.85 & 0.84 & 0.88 & 0.87 & 0.87 & 0.91 \\
\hline 0.83 & 080 & 0.85 & 0.84 & 0.87 & 0.86 & 0.86 & 0.90 \\
\hline
\end{tabular} \begin{tabular}{|l|l|l|l|l|l|l|l|}
\hline 0.89 & 0.82 & 0.89 & 0.97 & 0.89 & 0.88 & 0.89 & 1.07 \\
\hline
\end{tabular}

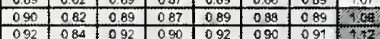
\begin{tabular}{l|l|l|l|l|l|l|l|l|}
0.90 & 0.81 & 0.89 & 0.86 & 0.88 & 0.87 & 0.88 & 0.99 \\
\hline
\end{tabular} \begin{tabular}{|l|l|l|l|l|l|l|l|}
\hline 099 & 0.83 & 0.90 & 088 & 0.89 & 0.88 & 089 & 109 \\
\hline 093 & 0.9 & 092 & 0.9 & 099 & 0.89 & 091 & 109 \\
\hline
\end{tabular} \begin{tabular}{|l|l|l|l|l|l|l|l|}
\hline 0.93 & 0.84 & 0.92 & 0.89 & 0.91 & 0.89 & 0.91 & 10.3 \\
\hline 0.90 & 081 & 0.88 & 0.90 & 0.87 & 0.87 & 0.87 & 105 \\
\hline
\end{tabular}

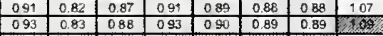
\begin{tabular}{|l|l|l|l|l|l|l|l|}
\hline 0.80 & 081 & 0.86 & 0.90 & 087 & 088 & 0.86 & 105 \\
\hline 0.92 & 082 & 0.87 & 0.92 & 088 & 0.87 & 087 & 107 \\
\hline
\end{tabular}

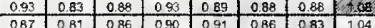

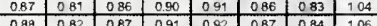

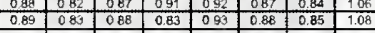

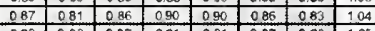
\begin{tabular}{|l|l|l|l|l|l|l|l|}
\hline 0.89 & 0.82 & 0.87 & 0.91 & 0.91 & 0.87 & 0.83 & 1.05 \\
\hline 090 & 083 & 0.89 & 0.92 & 0.9 & 0.88 & 0.4 & 1.07 \\
\hline
\end{tabular} \begin{tabular}{|l|l|l|l|l|l|l|l|}
\hline 0.88 & 0.81 & 0.86 & 0.93 & 0.90 & 0.84 & 0.82 & 1.03 \\
\hline 0.99 & 02 & 0.97 & 0.9 & 0.91 & 0.5 & 0.83 & 1.05 \\
\hline
\end{tabular}

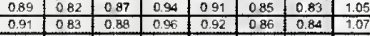

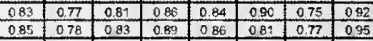
\begin{tabular}{|c|c|c|c|c|c|c|c|}
\hline 0.85 & 078 & 0.93 & 0.89 & 0.85 & 0.83 & 0.77 & 0.95 \\
\hline 0.64 & 0.56 & 0.60 & 0.65 & 0.65 & 0.61 & 0.53 & 0.70 \\
\hline
\end{tabular} \begin{tabular}{l|l|l|l|l|l|l|l|l|l}
\hline 066 & 0.56 & 0.63 & 0.68 & 0.68 & 0.64 & 0.64 & 072 \\
\hline
\end{tabular} \begin{tabular}{|l|l|l|l|l|l|l|l|}
\hline 085 & 077 & 083 & 088 & 090 & 084 & 0.81 & 0.92 \\
\hline 0.85 & 0.76 & 082 & 088 & 090 & 084 & 0.81 & 092 \\
\hline 0.49 & 077 & 082 & 089 & 088 & 0.84 & 0.80 & 0.90 \\
\hline
\end{tabular} \begin{tabular}{|l|l|l|l|l|l|l|l|}
\hline 084 & 077 & 082 & 088 & 088 & 084 & 080 & 090 \\
\hline 085 & 079 & 083 & 096 & 089 & 0.85 & 084 & 091 \\
\hline
\end{tabular} \begin{tabular}{|c|c|c|c|c|c|c|c|}
\hline 087 & 0.79 & 0.54 & 0.91 & 050 & 0.86 & 082 & 0.99 \\
\hline 085 & 078 & 081 & 0.89 & 0.87 & 0.84 & 0.81 & 0.91 \\
\hline
\end{tabular} \begin{tabular}{|c|c|c|c|c|c|c|c|}
\hline 0.86 & 079 & 0.82 & 0.89 & 088 & 085 & 0.82 & 0.92 \\
\hline 088 & 0.80 & 0.92 & 0.97 & 0.90 & 086 & 082 & 093 \\
\hline 084 & 0.77 & 081 & 089 & 0.87 & 0.83 & 080 & 092 \\
\hline
\end{tabular}

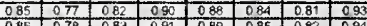
\begin{tabular}{|l|l|l|l|l|l|l|l|}
\hline 0.86 & 0778 & 0.83 & 0.91 & 089 & 085 & 0.82 & 099 \\
\hline 0.82 & 0.77 & 082 & 0.89 & 087 & 0.84 & 081 & 0.82 \\
\hline & 0.87 & 0.82 & 0.09 & 0.88 & 0.85 & 0.82 & 0.94 \\
\hline
\end{tabular}

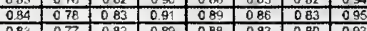

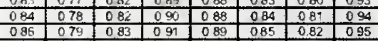

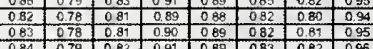

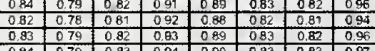

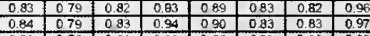

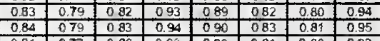
\begin{tabular}{|l|l|l|l|l|l|l|l}
0.81 & 0.77 & 0.80 & 0.93 & 0.90 & 0.31 & 0.80 & 093 \\
\hline 0.82 & 0.78 & 0.81 & 0.93 & 0.91 & 0.32 & 0.80 & 0.94 \\
\hline
\end{tabular} \begin{tabular}{|c|c|c|c|c|c|c|c|}
\hline 083 & 0.79 & 0.82 & 094 & 092 & 0.82 & 0.81 & 0.95 \\
\hline 0.82 & 0.78 & 0.81 & 0.93 & 090 & 0.82 & 0.79 & 0.34 \\
\hline 083 & 078 & 0.82 & 0.94 & 0.94 & 0.82 & 079 & 0.95 \\
\hline
\end{tabular} \begin{tabular}{|l|l|l|l|l|l|l|l|}
\hline 083 & 078 & 0.82 & 0.94 & 0.94 & 0.82 & 079 & 0.95 \\
\hline 0.84 & 0.80 & 0.83 & 0.96 & 0.92 & 0.84 & 0.80 & 0.96 \\
\hline
\end{tabular}

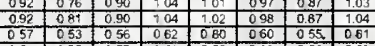
\begin{tabular}{|c|c|c|c|c|c|c|c|}
\hline 059 & 5.55 & 0.57 & 0.63 & 0.62 & 0.62 & 0.56 & 0.62 \\
\hline 059 & 0.55 & 0.53 & 0.64 & 0.63 & 0.63 & 0.57 & 0.62 \\
\hline
\end{tabular} \begin{tabular}{|l|l|l|l|l|l|l|l|}
\hline 0.57 & 0.54 & 056 & 0.52 & 061 & 066 & 0.55 & 0.50 \\
\hline 066 & 0.61 & 064 & 0.77 & 070 & 0.69 & 063 & 0.89 \\
\hline
\end{tabular} \begin{tabular}{|l|l|l|l|l|l|l|l|}
\hline 069 & 0.62 & 066 & 074 & 0.72 & 0.71 & 064 & 072 \\
\hline 0.80 & 079 & 0.82 & 0.82 & 0.90 & 086 & 0.79 & 0.88 \\
\hline 079 & 078 & 0.91 & 0.99 & 0.99 & 0.37 & 0.79 & 0.89 \\
\hline
\end{tabular} \begin{tabular}{|c|c|c|c|c|c|c|c|}
\hline 079 & 078 & 0.81 & 0.91 & 089 & 0.87 & 0.79 & 0.83 \\
\hline 087 & 0.79 & 0.82 & 093 & 090 & 0.88 & 0.80 & 0.89 \\
\hline 077 & 075 & 0.81 & 0.89 & 0.87 & 0.87 & 078 & 084 \\
\hline 0.79 & 0.83 & 0.89 & 0.99 & 097 & 0.95 & 0.86 & 095 \\
\hline
\end{tabular} (b)

\begin{tabular}{|l|l|l|l|l|l|}
\hline 0.00 & 0.50 & 0.75 & 1.00 & 1.08 & \\
\hline
\end{tabular}

Figure 4-5. DCRs for WTC 1 core columns under original design loads, (a) 500 line, and (b) 600 line. 


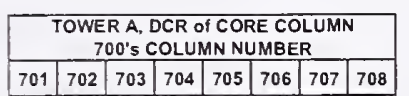

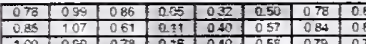

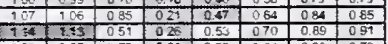
\begin{tabular}{l|l|l|l|l|l|l|l|}
\hline 0.53 & 0.87 & 0.79 & 0.31 & 060 & 0.61 & 080 & 0.72 \\
\hline
\end{tabular}

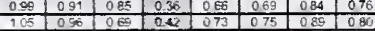

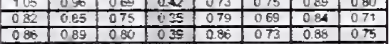
\begin{tabular}{|l|l|l|l|l|l|l|l|}
\hline 050 & 0.53 & 0.54 & 044 & 0.93 & 078 & 052 & 079 \\
\hline 0.56 & 0.80 & 0.74 & 0.37 & 0.82 & 072 & 0.83 & 082 \\
\hline
\end{tabular} \begin{tabular}{|l|l|l|l|l|l|l|l|}
\hline 0.94 & 0.87 & 0.79 & 0.44 & 0.93 & 0.81 & 0.97 & 0.90 \\
\hline 0.90 & 080 & 0.74 & 0.42 & 0.89 & 075 & 0.33 & 0.76 \\
\hline
\end{tabular}

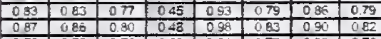
\begin{tabular}{|l|l|l|l|l|l|l|l|}
\hline 078 & 079 & 0.76 & 0.62 & 0.81 & 078 & 0.35 & 075 \\
\hline 081 & 0.32 & 0.79 & 0.65 & 0.85 & 0.81 & 0.86 & 078 \\
\hline
\end{tabular}

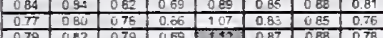
\begin{tabular}{|l|l|l|l|l|l|l|l|}
\hline 079 & 0.82 & 079 & 0.69 & 1.2 & 0.87 & 0.88 & 0.78 \\
\hline 0.82 & 0.85 & 0.82 & 0.73 & $t .5$ & 0.90 & 0.91 & 0.87 \\
\hline
\end{tabular}

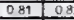

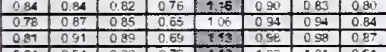
\begin{tabular}{|c|c|c|c|c|c|c|c|}
\hline 081 & 091 & 089 & 0.69 & 189 & 058 & 098 & 0.87 \\
\hline 0.34 & 0.94 & 092 & 0.75 & 15 & 102 & 109 & 0.51 \\
\hline
\end{tabular}

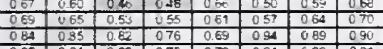

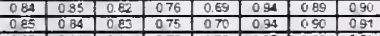
\begin{tabular}{|l|l|l|l|l|l|l|l|}
\hline 0.87 & 0.86 & 0.84 & 0.76 & 0.72 & 0.97 & 0.92 & 0.93 \\
\hline 0.55 & 081 & 0.79 & 072 & 0.69 & 0.92 & 0.87 & 0.91 \\
\hline 0.87 & 0.83 & 0.80 & 074 & 072 & 0.94 & 0.99 & 0.93 \\
\hline
\end{tabular}

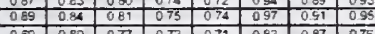
\begin{tabular}{|l|l|l|l|l|l|l|l|}
\hline 0.69 & 0.00 & 077 & 072 & 071 & 083 & 0.87 & 0.76 \\
\hline
\end{tabular}

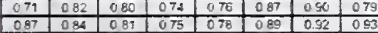
\begin{tabular}{|l|l|l|l|l|l|l|l|}
\hline 0.36 & 084 & 0.81 & 0.76 & 078 & 0.89 & 0.92 & 0.94 \\
\hline 033 & 086 & 0.83 & 078 & 083 & 093 & 035 & 097 \\
\hline
\end{tabular} \begin{tabular}{|l|l|l|l|l|l|l|l|}
\hline 0.87 & 079 & 0.83 & 0.79 & 080 & 087 & 0.90 & 0.95 \\
\hline 0.89 & 081 & 084 & 081 & 082 & 0.89 & 092 & 0.96 \\
\hline
\end{tabular} \begin{tabular}{lllllllllll}
0.91 & 0.82 & 0.85 & 0.82 & 0.84 & 0.89 & 0.93 & 0.98 \\
\hline
\end{tabular}

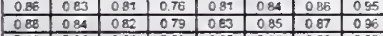
\begin{tabular}{|l|l|l|l|l|l|l|l|}
\hline 0.87 & 0.79 & 0.81 & 0.77 & 0.39 & 0.87 & 0.90 & 0.92 \\
\hline
\end{tabular} \begin{tabular}{|l|l|l|l|l|l|l|l|}
\hline 090 & 081 & 083 & 079 & 085 & 089 & 092 & 0.95 \\
\hline 098 & 092 & 090 & 075 & 0.5 & 04 & 0.4 & 0992 \\
\hline
\end{tabular}

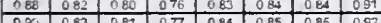
\begin{tabular}{|l|l|l|l|l|l|l|l|}
\hline 0.9 & 0.83 & 0.87 & 077 & 084 & 085 & 085 & 092 \\
\hline 091 & 0.84 & 082 & 078 & 088 & 087 & 088 & 0.93 \\
\hline
\end{tabular} \begin{tabular}{|l|l|l|l|l|l|l|l|}
\hline 089 & 078 & 079 & 075 & 084 & 082 & 087 & 092 \\
\hline 09 & 079 & 08 & 07 & 065 & 0. & 089 & 028 \\
\hline
\end{tabular} \begin{tabular}{|l|l|l|l|l|l|l|l|}
\hline 091 & 079 & 080 & 076 & 085 & 083 & 088 & 023 \\
\hline 092 & 080 & 081 & 077 & 087 & 084 & 089 & 094 \\
\hline 090 & 081 & 079 & 074 & 084 & 085 & 082 & 098 \\
\hline
\end{tabular} \begin{tabular}{|l|l|l|l|l|l|l|l|}
\hline 030 & 081 & 078 & 074 & 084 & 085 & 082 & 092 \\
\hline 032 & 082 & 079 & 075 & 008 & 08 & 083 & 094 \\
\hline
\end{tabular}

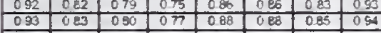
\begin{tabular}{|l|l|l|l|l|l|l|l|}
\hline 092 & 07 & 073 & 072 & 079 & 089 & 079 & 086 \\
\hline 055 & 0.89 & 076 & 075 & 0.82 & 083 & 081 & 089 \\
\hline
\end{tabular}

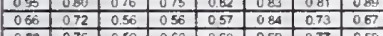

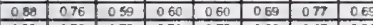

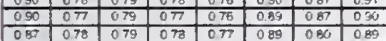
\begin{tabular}{|l|l|l|l|l|l|l|l|}
\hline 0.97 & 078 & 079 & 078 & 077 & 089 & 086 & 089 \\
\hline 038 & 079 & 079 & 079 & 079 & 090 & 0.91 & 0.99 \\
\hline
\end{tabular}

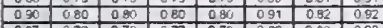

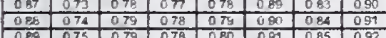

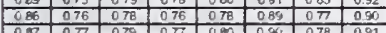

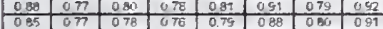
\begin{tabular}{|l|l|l|l|l|l|l|l|}
\hline 086 & 078 & 078 & 075 & 0.80 & 0.89 & 0.81 & 0.92 \\
\hline \hline
\end{tabular}

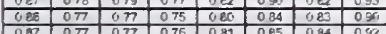

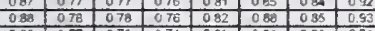

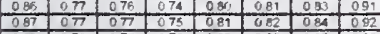

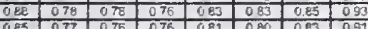

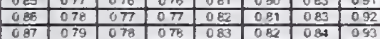
\begin{tabular}{|l|l|l|l|l|l|l|l|}
\hline 087 & 079 & 078 & 073 & 0.83 & 0.82 & 084 & 093 \\
\hline 0.56 & 077 & 076 & 0.88 & 078 & 0.79 & 081 & 0.89 \\
\hline
\end{tabular} \begin{tabular}{|l|l|l|l|l|l|l|l|}
\hline 017 & 078 & 077 & 077 & 079 & 080 & 082 & 090 \\
\hline 084 & 073 & 07 & 07 & 0.4 & 089 & 083 & 091 \\
\hline
\end{tabular}

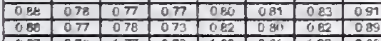

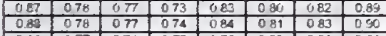
\begin{tabular}{|l|l|l|l|l|l|l|l|}
\hline 0.86 & 077 & 074 & 075 & 078 & 080 & 051 & 0.80 \\
\hline 087 & 078 & 073 & 075 & 079 & 081 & 0.82 & 08 \\
\hline
\end{tabular} \begin{tabular}{|l|l|l|l|l|l|l|l}
\hline 089 & 079 & 076 & 077 & 081 & 082 & 054 & 0.90 \\
\hline 0
\end{tabular}

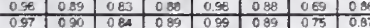

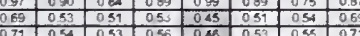

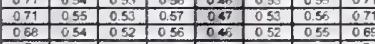
\begin{tabular}{|l|l|l|l|l|l|l|l|}
\hline 078 & 055 & 0.59 & 0.67 & 0.51 & 059 & 059 & 079 \\
\hline
\end{tabular} \begin{tabular}{|l|l|l|l|l|l|l|l|}
\hline 0.83 & 076 & 075 & 0.63 & 0.90 & 0.82 & 0.80 & 0.87 \\
\hline 0.5
\end{tabular}

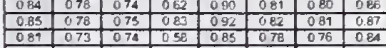
\begin{tabular}{|c|c|c|c|c|c|c|c|}
\hline 083 & 077 & 0.81 & 067 & 092 & 0.83 & 081 & 0.54 \\
\hline 084 & 078 & 0.82 & 067 & 0.93 & 0.86 & 0.81 & 094 \\
\hline
\end{tabular}

(c)

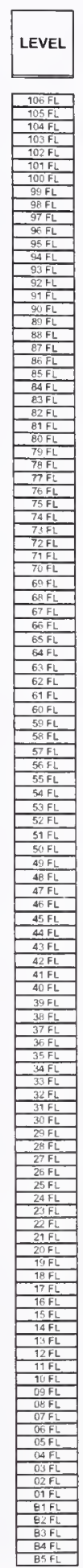

\begin{tabular}{|l|l|l|l|l|l|l|}
\hline \multicolumn{6}{|c|}{ TOWER A, DCR Of CORE COLUMN } \\
\hline \multicolumn{6}{|c|}{800 's COLUMN NUMBER } \\
\hline 801 & 802 & 803 & 804 & 805 & 806 & 807 \\
\hline \hline
\end{tabular}

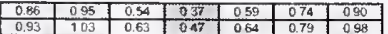

\begin{tabular}{|c|c|c|c|c|c|c|}
\hline 0.93 & 103 & 0.63 & 0.77 & 0.64 & 0.79 & 0.98 \\
\hline 0.82 & 0.89 & 0.59 & 0.43 & 0.58 & 0.73 & 090 \\
\hline 0.87 & 0.95 & 0.66 & 0.55 & 0.52 & 077 & 0.97 \\
\hline 0.93 & 101 & 0.47 & 0.54 & 0.65 & 0.91 & 1.04 \\
\hline
\end{tabular} \begin{tabular}{|c|c|c|c|c|c|c|}
\hline 073 & 079 & 0.51 & 0.49 & 060 & 076 & 0.90 \\
\hline 0.7 & 082 & 0.55 & 0.55 & 0.54 & 0.80 & 0.95 \\
\hline 081 & 085 & 0.58 & 060 & 0.67 & 0.84 & 101 \\
\hline
\end{tabular} \begin{tabular}{|c|c|c|c|c|c|c|}
\hline 0.85 & 080 & 0.55 & 062 & 053 & 0.75 & 074 \\
\hline 0.89 & 0.83 & 0.58 & 0.68 & 055 & 078 & 0.78 \\
\hline
\end{tabular} \begin{tabular}{|l|l|l|l|l|l|l|}
\hline 0.94 & 0.86 & 061 & 0.73 & 058 & 0.91 & 0.82 \\
\hline 071 & 0.99 & 053 & 0.77 & 059 & 07 & 0.74 \\
\hline
\end{tabular} \begin{tabular}{|c|c|c|c|c|c|c|}
\hline 0.73 & 0671 & 0.56 & 0.72 & 0.59 & 0.80 & 078 \\
\hline 0.76 & 0.73 & 054 & 0.77 & 062 & 0.83 & 0.81 \\
\hline 0.71 & 065 & 0.54 & 0.70 & 0.57 & 0.75 & 0.77 \\
\hline
\end{tabular}

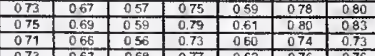
\begin{tabular}{|l|l|l|l|l|l|l|}
\hline 071 & 066 & 056 & 0.73 & 060 & 074 & 0.73 \\
\hline 073 & 067 & 058 & 0.77 & 0.62 & 0.76 & 076 \\
\hline 075 & 069 & 060 & 0.80 & 0.65 & 0.79 & 078 \\
\hline
\end{tabular} \begin{tabular}{|c|c|c|c|c|c|c|}
\hline 0.74 & 0.71 & 0.70 & 0.76 & 073 & 0.72 & 0.73 \\
\hline 0.76 & 0.73 & 072 & 0.79 & 0.76 & 074 & 0.75 \\
\hline 0.78 & 0.75 & 075 & 0.82 & 0.78 & 0.76 & 0.78 \\
\hline
\end{tabular} \begin{tabular}{l|l|l|l|l|l|l|}
0.78 & 0.75 & 075 & 0.82 & 0.78 & 076 & 0.78 \\
\hline 0.74 & 0.70 & 071 & 0.70 & 0.76 & 072 & 0.74 \\
\hline 076 & 0.72 & 0.73 & 0.73 & 079 & 0.74 & 0.76 \\
\hline
\end{tabular} \begin{tabular}{l|l|l|l|l|l|l|}
\hline 076 & 0.72 & 0.73 & 073 & 079 & 0.74 & 076 \\
\hline 078 & 0.74 & 0.75 & 0.76 & 081 & 0.76 & 0.78 \\
\hline 084 & 0.64 & 0.80 & 0.79 & 0.84 & 0.78 & 0.80 \\
\hline
\end{tabular} \begin{tabular}{|l|l|l|l|l|l|l|}
\hline 084 & 0.64 & 0.80 & 079 & 0.84 & 0.78 & 080 \\
\hline 0.87 & 0.67 & 083 & 0.83 & 0.87 & 0.81 & 0.82 \\
\hline 0.90 & 0.69 & 086 & 0.87 & 0.90 & 0.83 & 0.85 \\
\hline
\end{tabular} \begin{tabular}{|l|l|l|l|l|l|l|}
\hline 069 & 0.45 & 0.56 & 062 & 0.54 & 0.50 & 0.68 \\
\hline
\end{tabular} \begin{tabular}{|l|l|l|l|l|l|l|}
\hline 0.89 & 074 & 0.73 & 073 & 099 & 0.80 & 0.90 \\
\hline 0.90 & 074 & 0.74 & 073 & 0.91 & 0.80 & 091 \\
\hline 0.92 & 076 & 076 & 075 & 091 & 0.87 & 093 \\
\hline
\end{tabular} \begin{tabular}{|c|c|c|c|c|c|c|}
\hline 0.92 & 076 & 0.76 & 0.75 & 0.94 & 0.82 & 0.93 \\
\hline 089 & 0.72 & 0.73 & 0.73 & 0.85 & 0.78 & 0.87 \\
\hline 0.99 & 0.74 & 075 & 0.75 & 0.88 & 0.80 & 0.89 \\
\hline
\end{tabular} \begin{tabular}{l|l|l|l|l|l|l|l|}
0.91 & 0.74 & 075 & 0.75 & 0.88 & 0.80 & 0.89 \\
\hline 0.93 & 0.76 & 0.77 & 0.77 & 0.90 & 0.82 & 099 \\
\hline
\end{tabular} \begin{tabular}{|c|c|c|c|c|c|c|}
\hline 0.93 & 0.76 & 0.77 & 0.77 & 0.90 & 0.82 & 091 \\
\hline 0.73 & 0.72 & 074 & 0.72 & 0.85 & 078 & 0.76 \\
\hline 0.76 & 0.77 & 0.78 & 0.79 & 0.92 & 0.83 & 0.79 \\
\hline
\end{tabular} \begin{tabular}{|c|c|c|c|c|c|c|}
\hline 076 & 075 & 078 & 0.76 & 0.90 & 082 & 079 \\
\hline 090 & 0.77 & 080 & 0.78 & 0.86 & 0.83 & 0.93 \\
\hline 097 & 0.7 & 080 & 0.78 & 0.96 & 0.84 & 0.84 \\
\hline
\end{tabular}

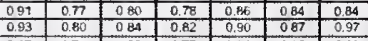
\begin{tabular}{|l|l|l|l|l|l|l|}
\hline 0.97 & 0.74 & 0.80 & 077 & 0.95 & 0.82 & 092 \\
\hline 0.89 & 076 & 082 & 079 & 0.96 & 0.84 & 0.94 \\
\hline
\end{tabular} \begin{tabular}{|l|l|l|l|l|l|l|}
\hline 097 & 077 & 0.84 & 0.80 & 088 & 0.95 & 0.95 \\
\hline
\end{tabular} \begin{tabular}{l|l|l|l|l|l|l|}
\hline 0.88 & 0.79 & 0.81 & 0.78 & 0.82 & 0.79 & 0.93 \\
\hline 090 & 080 & 083 & 081 & 0.83 & 0.81 & 095 \\
\hline & 0.92 & 085 & 0.83 & 0.5 & 0.92 & 095 \\
\hline
\end{tabular} \begin{tabular}{l|l|l|l|l|l|l|}
\hline 0.92 & 0.72 & 0.85 & 0.83 & 0.98 & 0.97 \\
\hline 088 & 0.75 & 082 & 078 & 088 & 083 & 0.34 \\
\hline
\end{tabular} \begin{tabular}{l|l|l|l|l|l|l|}
\hline 088 & 0.75 & 082 & 078 & 088 & 083 & 0.94 \\
\hline 089 & 0.7 & 084 & 080 & 087 & 0.95 & 0.95 \\
\hline 091 & 0.78 & 0.85 & 081 & 089 & 0.95 & 0.97 \\
\hline
\end{tabular} \begin{tabular}{|c|c|c|c|c|c|c|}
\hline 091 & 0.78 & 085 & 0.81 & 089 & 0.86 & 0.97 \\
\hline 0.67 & 0.80 & 0.83 & 0.80 & 0.83 & 0.79 & 0.92 \\
\hline 0.09 & 0.1 & 0.84 & 0.81 & 0.85 & 0.81 & 094 \\
\hline
\end{tabular}

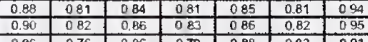

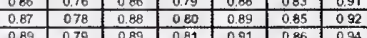
\begin{tabular}{l|l|l|l|l|l|l|}
0.889 & 079 & 0.89 & 081 & 0.91 & 0.86 & 094 \\
\hline 0.87 & 0.80 & 0.87 & 076 & 0.85 & 0.80 & 0.91 \\
\hline
\end{tabular} \begin{tabular}{|l|l|l|l|l|l|l}
\hline 089 & 0.81 & 088 & 078 & 0.87 & 081 & 0.93 \\
\hline 091 & 0.83 & 090 & 0.79 & 088 & 0.82 & 0.94 \\
\hline
\end{tabular} \begin{tabular}{|c|c|c|c|c|c|c|}
\hline 0.70 & 0.78 & 0.82 & 0.76 & 079 & 0.77 & 0.73 \\
\hline 0.73 & 0.80 & 0.85 & 0.78 & 0.82 & 0.80 & 0.76 \\
\hline
\end{tabular} \begin{tabular}{|l|l|l|l|l|l|l|}
\hline 063 & 071 & 0.60 & 0.55 & 0.70 & 0.62 & 066 \\
\hline 0
\end{tabular} \begin{tabular}{|l|l|l|l|l|l|l|l|}
\hline 065 & 075 & 062 & 0.58 & 074 & 064 & 06 \\
\hline 0.87 & 0.76 & 0.81 & 0.80 & 0.87 & 083 & 0.91 \\
\hline
\end{tabular} \begin{tabular}{|l|l|l|l|l|l|l|}
\hline 087 & 0.75 & 081 & 0.78 & 0.86 & 093 & 0.9 \\
\hline 086 & 077 & 0.83 & 0.73 & 0.87 & 0.84 & 0 \\
\hline
\end{tabular}
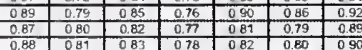

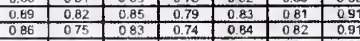
\begin{tabular}{|c|c|c|c|c|c|c|}
\hline 086 & 0.76 & 084 & 0.75 & 0.86 & 083 & \\
\hline 083 & 0.75 & \\
\hline
\end{tabular} \begin{tabular}{|c|c|c|c|c|c|c|}
\hline 0.89 & 0.77 & 0.85 & 0.76 & 0.87 & 084 & 0.93 \\
\hline 0.86 & 078 & 0.64 & 0.78 & 0.87 & 0.85 & 0.90 \\
\hline 0.87 & 077 & 0.85 & 0.79 & 0.88 & 0.86 & 0.91 \\
\hline
\end{tabular} \begin{tabular}{|c|c|c|c|c|c|c|}
\hline 0.87 & 078 & 0.85 & 079 & 0.88 & 086 & 051 \\
\hline 0.88 & 0.79 & 086 & 0.80 & 0.89 & 0.87 & 092 \\
\hline 088 & 0.80 & 0.85 & 0.81 & 085 & 0.80 & 0.91 \\
\hline
\end{tabular} \begin{tabular}{c|c|c|c|c|c|c|}
\hline 0.89 & 0.81 & 0.86 & 0.82 & 0.86 & 0.80 & 0.92 \\
\hline 090 & 0.42 & 0.87 & 0.83 & 0.87 & 0.82 & 0.93 \\
\hline 0.88 & 0.81 & 0.84 & 0.78 & 0.88 & 0.83 & 091 \\
\hline
\end{tabular}

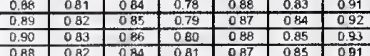
\begin{tabular}{|c|c|c|c|c|c|c|}
\hline 088 & 0.82 & 084 & 0.81 & 087 & 0.8 & \\
\hline 0.99 & 0.83 & 0.85 & 0.82 & 086 & 086 & 0.92 \\
\hline 0.90 & 0.84 & 0.87 & 0.83 & 0.89 & 0.67 & 093 \\
\hline 0.99 & 0.92 & 0.85 & 0.79 & 0.86 & 0.84 & 0.89 \\
\hline
\end{tabular}

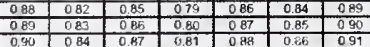

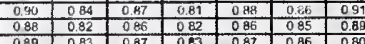

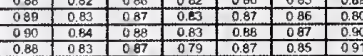
\begin{tabular}{|c|c|c|c|c|c|c|}
\hline 0.88 & 083 & 0.87 & 079 & 0.87 & 0.95 & 091 \\
\hline 0.89 & 0.83 & 0.88 & 0.80 & 0.88 & 0.86 & 0.92 \\
\hline 0.91 & 0.85 & 0.90 & 0.82 & 0.89 & 0.88 & 0.93 \\
\hline
\end{tabular} \begin{tabular}{c|c|c|c|c|c|c|}
\hline 075 & 0.94 & 0.97 & 0.67 & 0.90 & 072 & 0.88 \\
\hline 080 & 0.95 & 097 & 0.83 & 0.91 & 078 & 0.8 \\
\hline
\end{tabular}

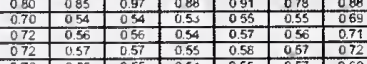
\begin{tabular}{|l|l|l|l|l|l|l|}
\hline 0.70 & 0.56 & 0.55 & 0.54 & 0.56 & 0.57 & 0.69 \\
\hline 0.80 & 060 & 0.63 & 0.60 & 0.63 & 0.61 & 0.80 \\
\hline 0.23 & 0.82 & 0.55 & 0.62 & 0.65 & 0.52 & 0.83 \\
\hline
\end{tabular}

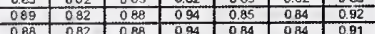

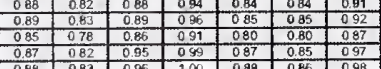

(d)

\begin{tabular}{|l|l|l|l|l|l|l|l|}
\hline 0.00 & 0.50 & 0.75 & 1.00 & 1.08 \\
\hline
\end{tabular}

Figure 4-5. (c) 700 line, and (d) 800 line (continued). 


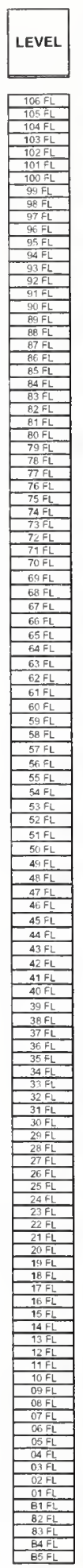

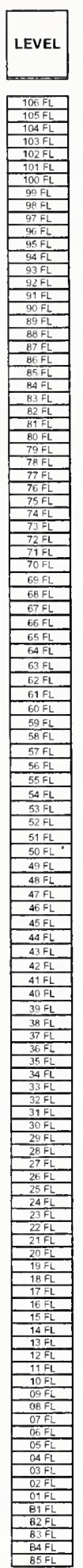

(e)

\begin{tabular}{|c|c|c|c|c|}
\hline \multicolumn{5}{|c|}{$\begin{array}{l}\text { TOWER A, DCR of CORE COLUMN } \\
1000 \text { 's COLUMN NUMBER }\end{array}$} \\
\hline 1001 & \begin{tabular}{|l|l|}
1002 \\
\end{tabular} & \begin{tabular}{|l|l|}
1003 & 1004 \\
\end{tabular} & \begin{tabular}{|l|l|l|}
1006 & 1006
\end{tabular} & \begin{tabular}{|l|l}
1007 \\
\end{tabular} \\
\hline
\end{tabular}

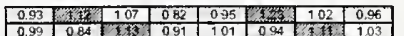

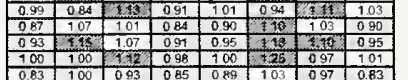

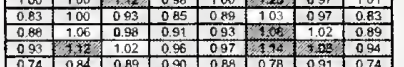

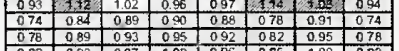
\begin{tabular}{|l|l|l|l|l|l|l|l|}
\hline 0.82 & 0.93 & 0.77 & 100 & 096 & 0.86 & 100 & 0.82 \\
\hline 0.66 & 0.82 & 0.75 & 0.87 & 0.85 & 0.76 & 0.83 & 0.66 \\
\hline
\end{tabular}

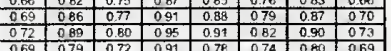
\begin{tabular}{|l|l|l|l|l|l|l|l|}
\hline 069 & 079 & 0.72 & 091 & 078 & 074 & 080 & 069 \\
\hline 0.71 & 082 & 075 & 0.55 & 080 & 0.77 & 083 & 0.72 \\
\hline 074 & 085 & 077 & 0.98 & 083 & 0.80 & 086 & 0.74 \\
\hline
\end{tabular}

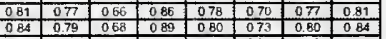
\begin{tabular}{|l|l|l|l|l|l|l|l|}
\hline 0.87 & 0.82 & 070 & 0.92 & 0.83 & 075 & 0.83 & 0.87 \\
\hline 0.82 & 0.92 & 076 & 0.91 & 0.78 & 0.81 & 0.93 & 0.82 \\
\hline
\end{tabular} \begin{tabular}{|l|l|l|l|l|l|l|l|}
\hline 0.85 & 095 & 076 & 0.914 & 078 & 0.81 & 0.93 & 0.82 \\
\hline 0.87 & 0.98 & 0.80 & 0.97 & 0.83 & 0.84 & 0.96 & 0.85 \\
\hline
\end{tabular}

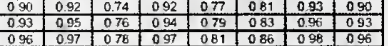
\begin{tabular}{|c|c|c|c|c|c|c|c|}
\hline 096 & 0.97 & 076 & 097 & 081 & 086 & 096 & 096 \\
\hline 0.91 & 101 & 070 & 100 & 087 & 0.89 & 1.02 & 0.91 \\
\hline
\end{tabular}

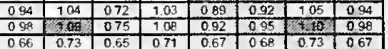
\begin{tabular}{|l|l|l|l|l|l|l|l|}
\hline 066 & 0.73 & 0.65 & 077 & 0.67 & 0.68 & 0.73 & 0.67 \\
\hline 068 & 0.74 & 067 & 070 & 0.72 & 0.70 & 0.75 & 068 \\
\hline
\end{tabular} \begin{tabular}{|c|c|c|c|c|c|c|c|}
\hline 088 & 091 & 0.86 & 093 & 093 & 0.89 & 092 & 0.89 \\
\hline 089 & 092 & 0.86 & 095 & 0.84 & 0.90 & 0.93 & 0.90 \\
\hline
\end{tabular} \begin{tabular}{|c|c|c|c|c|c|c|c|}
\hline 0.91 & 0.94 & 0.89 & 0.97 & 0.95 & 092 & 0.96 & 092 \\
\hline 087 & 0.89 & 0.84 & 0.91 & 0.69 & 0.87 & 0.91 & 0.87 \\
\hline
\end{tabular} \begin{tabular}{|l|l|l|l|l|l|l|l|}
\hline 089 & 091 & 0.85 & 0.94 & 0.91 & 089 & 0.93 & 0.89 \\
\hline 091 & 093 & 0.87 & 0.95 & 0.93 & 081 & 0.95 & 0.91 \\
\hline
\end{tabular} \begin{tabular}{|l|l|l|l|l|l|l|l|}
\hline 0.84 & 0.87 & 084 & 0.92 & 0.88 & 0.84 & 0.88 & 0.84 \\
\hline 0.87 & 09 & 0.87 & 0.05 & 0.91 & 0.87 & 0.92 & 0.87 \\
\hline
\end{tabular} \begin{tabular}{|l|l|l|l|l|l|l|l|}
\hline 087 & 0.91 & 0.87 & 0.96 & 0.91 & 0.89 & 0.92 & 0.88 \\
\hline 09 & 093 & 0.6 & 0.99 & 0.5 & 0.92 & 0.55 & 0.91 \\
\hline
\end{tabular} \begin{tabular}{|l|l|l|l|l|l|l|l|}
\hline 097 & 093 & 086 & 099 & 095 & 0.90 & 096 & 0.91 \\
\hline 092 & 095 & 0.97 & 109 & 096 & 0.92 & 0.96 & 0.93 \\
\hline
\end{tabular}

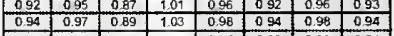

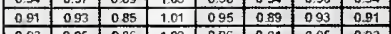
\begin{tabular}{|c|c|c|c|c|c|c|c|}
\hline 0.93 & 0.95 & 0.86 & 103 & 0.96 & 0.91 & 0.95 & 0.93 \\
\hline 0.94 & 0.97 & 0.88 & 105 & 0.98 & 0.92 & 0.97 & 0.95 \\
\hline
\end{tabular}

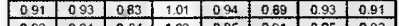
\begin{tabular}{|l|l|l|l|l|l|l|l|}
\hline 092 & 0.84 & 0.84 & 103 & 0.95 & 0.91 & 0.95 & 0.92 \\
\hline 0.94 & 0.96 & 0.86 & 105 & 0.97 & 092 & 0.97 & 0.94 \\
\hline
\end{tabular} \begin{tabular}{|l|l|l|l|l|l|l|l|}
\hline 0.92 & 093 & 083 & 102 & 0.94 & 089 & 0.93 & 0.92 \\
\hline
\end{tabular} \begin{tabular}{|l|l|l|l|l|l|l|l|l|}
\hline 093 & 0.94 & 084 & 104 & 095 & 090 & 095 & 093 \\
\hline 095 & 0.96 & 0.85 & 105 & 097 & 0.92 & 0.97 & 0.95 \\
\hline
\end{tabular} \begin{tabular}{|l|l|l|l|l|l|l|l|}
\hline 089 & 0.93 & 0.82 & 103 & 0.94 & 0.89 & 0.93 & 0.89 \\
\hline
\end{tabular} \begin{tabular}{|l|l|l|l|l|l|l|l|}
\hline 099 & 0.94 & 083 & 104 & 0.95 & 0.90 & 0.95 & 0.91 \\
\hline 09 & 095 & 034 & 106 & 0.56 & 0.91 & 096 & 092 \\
\hline
\end{tabular}

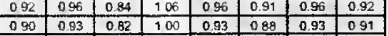
\begin{tabular}{|l|l|l|l|l|l|l|l|}
\hline 0.92 & 0.94 & 0.83 & 1.02 & 0.95 & 0.89 & 095 & 0.92 \\
\hline 0.93 & 0.95 & 0.84 & 1.04 & 0.96 & 0.91 & 0.96 & 0.93 \\
\hline
\end{tabular} \begin{tabular}{|l|l|l|l|l|l|l|l|}
\hline 093 & 095 & 0.84 & 1.04 & 096 & 091 & 096 & 093 \\
\hline 0.89 & 090 & 0.80 & 1.01 & 0.90 & 0.85 & 0.89 & 089 \\
\hline
\end{tabular} \begin{tabular}{|l|l|l|l|l|l|l|l|}
\hline 0.50 & 0.92 & 0.81 & 1.03 & 0.91 & 0.86 & 090 & 0.90 \\
\hline 091 & 935 & 082 & 1.5 & 093 & 097 & 092 & 0.94 \\
\hline
\end{tabular} \begin{tabular}{|l|l|l|l|l|l|l|l|}
\hline 083 & 0.54 & 074 & 096 & 086 & 079 & 082 & 083 \\
\hline
\end{tabular} \begin{tabular}{l|l|l|l|l|l|l|l|}
\hline 085 & 086 & 0.76 & 0.99 & 088 & 0.81 & 084 & 0.85 \\
\hline 0 & 0.5 & 0.9 & 074 & 08 & 0.2 & 0.4 & 0.68 \\
\hline
\end{tabular} \begin{tabular}{|l|l|l|l|l|l|l|l|l|}
\hline 066 & 0.65 & 059 & 074 & 0.68 & 0.62 & 0.64 & 0.66 \\
\hline 00 & 0 & 0 & 07 & 070 & 0.3 & 0.5 & 0.69 \\
\hline
\end{tabular} \begin{tabular}{|l|l|l|l|l|l|l|l|}
\hline 068 & 066 & 0.60 & 0.75 & 070 & 0.63 & 065 & 0.69 \\
\hline 089 & 088 & 0.0 & 0.97 & 0.68 & 0.83 & 0.87 & 0.89 \\
\hline
\end{tabular} \begin{tabular}{|l|l|l|l|l|l|l|l|}
\hline 0.89 & 0.88 & 0.80 & 0.97 & 0.88 & 0.33 & 0.87 & 0.89 \\
\hline 089 & 0.88 & 0.80 & 0.38 & 0.89 & 0.83 & 0.88 & 0.90 \\
\hline 0
\end{tabular}

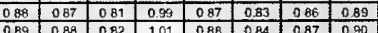
\begin{tabular}{|c|c|c|c|c|c|c|c|}
\hline 097 & 0.88 & 0.82 & 1.01 & $0.8 B$ & 088 & 087 & 0.90 \\
\hline 081 & 089 & 083 & 102 & 089 & 0.85 & 088 & 0.91 \\
\hline
\end{tabular} \begin{tabular}{l|l|l|l|l|l|l|l|l}
\hline 0.89 & 0.87 & 0.81 & 0.97 & 0.87 & 0.83 & 0.85 & 0.90 \\
\hline 0.91 & 0.88 & 0.82 & 099 & 0.87 & 0.84 & 0.86 & 0.91 \\
\hline
\end{tabular} \begin{tabular}{|c|c|c|c|c|c|c|c|}
\hline 0.92 & 0.89 & 0.83 & 100 & 0.88 & 0.85 & 0.88 & 0.92 \\
\hline 0.88 & 0.87 & 0.81 & 0.98 & 0.85 & 0.84 & 0.86 & 0.89 \\
\hline
\end{tabular} \begin{tabular}{l|l|l|l|l|l|l|l|}
\hline 0 B9 & 0.88 & 0.82 & 1.00 & 086 & 0.85 & 0.87 & 0.9 \\
\hline 091 & 089 & 0.83 & 101 & 0.87 & 0.86 & 0.88 & 0.91 \\
\hline 099 & 0.85 & 079 & 0.99 & 0.85 & 0.84 & 0.84 & 0.90 \\
\hline
\end{tabular} \begin{tabular}{|l|l|l|l|l|l|l|l|}
\hline 090 & 0.85 & 079 & 0.99 & 0.85 & 0.84 & 0.84 & 0.90 \\
\hline 0.91 & 0.36 & 0.80 & 101 & 0.86 & 0.85 & 0.85 & 0.91 \\
\hline
\end{tabular}

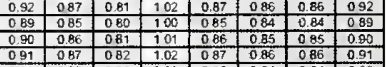
\begin{tabular}{|l|l|l|l|l|l|l|l|}
\hline 0.086 & 0.85 & 080 & 0.99 & 0.85 & 0.84 & 0.84 & 0.88 \\
\hline 0.89 & 0.86 & 0.87 & 100 & 0.86 & 0.85 & 0.85 & 088 \\
\hline
\end{tabular}

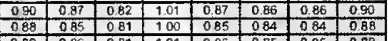

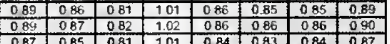

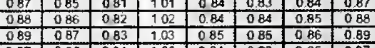
\begin{tabular}{|c|c|c|c|c|c|c|c|}
\hline 089 & 087 & 0.83 & 1.03 & 085 & 0.85 & 0.86 & 0.89 \\
\hline 0.87 & 085 & 0.81 & 1.00 & 0.84 & 0.83 & 0.85 & 0.87 \\
\hline 0.88 & 0.86 & 0.82 & 1.01 & 0.85 & 0.84 & 0.85 & 0.88 \\
\hline
\end{tabular} \begin{tabular}{|l|l|l|l|l|l|l|l|}
\hline 089 & 0.87 & 083 & 1.02 & 0.85 & 0.85 & 086 & 089 \\
\hline 0.88 & 0.85 & 0.82 & 101 & 0.84 & 084 & 0.85 & 0.88 \\
\hline
\end{tabular}

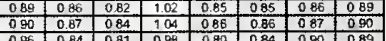

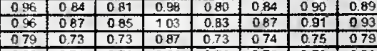
\begin{tabular}{|l|l|l|l|l|l|l|l|}
\hline 079 & 0.73 & 0.73 & 0.87 & 0.73 & 074 & 0.75 & 079 \\
\hline 080 & 0.74 & 0.74 & 0.88 & 0.74 & 0776 & 076 & 0.81 \\
\hline 081 & 075 & 0.75 & 0.89 & 074 & 0.76 & 077 & 0.81 \\
\hline
\end{tabular} \begin{tabular}{|l|l|l|l|l|l|l|l|}
\hline 0.79 & 0.73 & 073 & 0.86 & 073 & 0.74 & 075 & 0.79 \\
\hline 0 & 0 & 079 & 094 & 078 & 0.80 & 0.81 & 0.86 \\
\hline
\end{tabular}

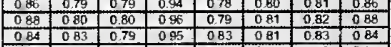
\begin{tabular}{|c|c|c|c|c|c|c|c|}
\hline 0.83 & 0.82 & 0.78 & 094 & 0.83 & 0.80 & 0.82 & 0.33 \\
\hline 0.84 & 0.83 & 0.79 & 0.95 & 084 & 0.81 & 0.83 & 0.84 \\
\hline 0.86 & 082 & 079 & 0.92 & 0.81 & 082 & 080 & 0.87 \\
\hline
\end{tabular}

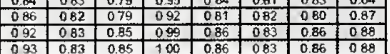
(f)

\begin{tabular}{|r|l|l|l|l|l|l|}
\hline & 0.00 & 0.50 & 0.75 & 1.00 & 1.08 & \\
\hline
\end{tabular}

Figure 4-5. (e) 900 line, and (f) 1000 line (continued). 
Table 4-5. Statistics of DCRs for WTC 1 under the refined NIST estimate case using LRFD and ASD.

\begin{tabular}{|r|c|c|c|c|c|c|c|}
\hline & Number & $\begin{array}{c}\text { Mean } \\
\text { of } \\
\text { Calculated } \\
\text { DCR }\end{array}$ & $\begin{array}{c}\text { C.O.V. } \\
\text { of } \\
\text { DCR }\end{array}$ & $\begin{array}{c}\text { Percentage } \\
\text { of } \\
\text { components } \\
\text { with DCR }> \\
\mathbf{1 . 0}\end{array}$ & $\begin{array}{c}\text { Percentage } \\
\text { of } \\
\text { components } \\
\text { with DCR }> \\
\mathbf{1 . 0 5}\end{array}$ & $\begin{array}{c}\text { Number of } \\
\text { components } \\
\text { with DCR }> \\
1.05\end{array}$ & $\begin{array}{c}\text { Maximum } \\
\text { Calculated } \\
\text { DCR }\end{array}$ \\
\hline $\begin{array}{r}\text { Exterior Wall } \\
\text { Columns, floor 9-106 }\end{array}$ & & & & & & & \\
LRFD & 31,086 & 0.96 & 0.15 & 35.6 & 24.0 & 7,461 & 1.72 \\
ASD & 31,086 & 1.10 & 0.14 & 72.1 & 59.7 & 18,572 & 2.05 \\
\hline Core Columns & & & & & & & \\
ASD & 5.219 & 0.73 & 0.16 & 2.9 & 1.8 & 92 & 1.26 \\
\hline
\end{tabular}

\subsubsection{Exterior Columns Axial Loads and Stresses}

The distribution of the normal stresses due to axial loads (axial column load divided by column cross sectional area) in the four exterior wall columns of WTC 1 due to wind loads only is presented in Fig. 4-6. The stresses are presented for the original design wind loads blowing from west to east and do not include the influence of gravity loads. The axial stresses are presented for the exterior wall columns at level B6 and floor 39. Fig. 4-7 shows a 3-dimensional plot of the same stresses at floors B6 and 39. The plots show both the tensile and compressive stresses on the columns induced by wind loading, where the shear lag effects can be observed. Similar plots were obtained for WTC 2 (NIST NCSTAR 1-2A).

At the B6 level, the plots indicate that there were significant differences in stresses between the two columns at a given corner. For example, at the southwest corner at level B6, the stresses at columns 359 (south wall) and 401 (east wall) were about $25 \mathrm{ksi}$ and $15 \mathrm{ksi}$, respectively. This indicates significant deformations in the corner panels at the basement floors. Much smaller differences were observed in the stresses at the floor 39. This indicates that the behavior of the lower portion of the tower at the basement floors resembled that of a braced frame, while the behavior of the super-structure resembled that of a framed tube system.

A framed tube structure consists of closely spaced exterior columns tied together at each floor with deep spandrel beams, thereby creating a rigid wall-like structure around the building exterior (i.e., a hollow tube with perforated openings for windows) (Khan and Amin 1973; Taranath 1988). The behavior of the framed tube structure is hybrid, showing characteristics of both pure tube and pure frame behaviors. The overturning moments of the lateral loads are primarily resisted by the tube action, i.e., axial shortening (compression) and elongation (tension) of the columns on all sides of the tube. The shear from the lateral loads is primarily resisted by the frame action (in-plane bending of columns and spandrels) of the two sides of the building parallel to the direction of the lateral load (webs). Since the perimeter walls have a tendency to behave as a thin-walled tube structure, shear stresses and strains are large, and as a result the distribution of bending stresses is affected. Therefore, the bending stresses in the side walls (webs) are no longer proportional to the distance from the neutral axis and are larger near the flanges. The same large stresses occur in the flanges near the webs, and the stresses at the center of the flanges (normal to the lateral load) are reduced or 'lag' behind the stresses near the webs (parallel to load). Bending stresses in 
the webs are also affected in a similar manner. This phenomenon is known as shear lag and can be clearly shown in Fig. 4-6(b). In the framed tube system, the floor diaphragins play a key role since they carry lateral forces to the side walls of the building, thereby allowing for the tube action to take place. In addition, floor diaphragms provide lateral support for the stability of the columns, and under torsion, they assure that the cross-sectional shape of the structure is maintained at each level by their in-plane shearing resistance.

An investigation into the behavior of the exterior wall columns indicated that under the original WTC design dead and wind loads (no live loads were considered), tension forces were developed in the exterior walls of the towers. The tension forces from the combination of dead and wind loads for the four exterior walls of WTC 1 are illustrated in Fig. 4-8. Similar plots for WTC 2 can be seen at Chapter 5 of NIST NCSTAR 1-2A. As the figure indicates, the tensile forces were largest at the base of the building and at the corners.
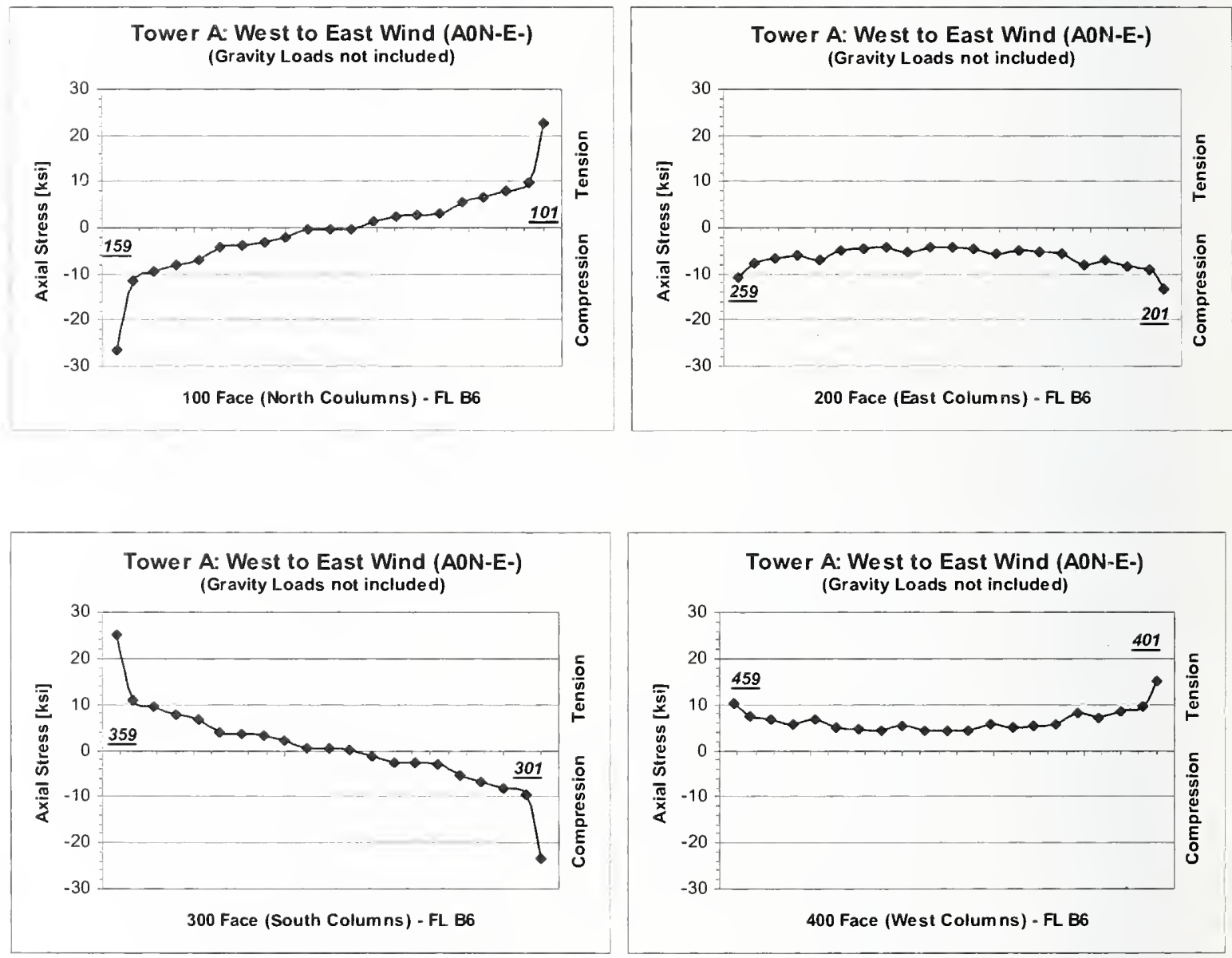

\section{(a) Floor B6}

Figure 4-6. Distribution of normal stresses in the exterior walls of WTC 1 due to original WTC wind loads only at (a) floor B6, and (b) floor 39. 

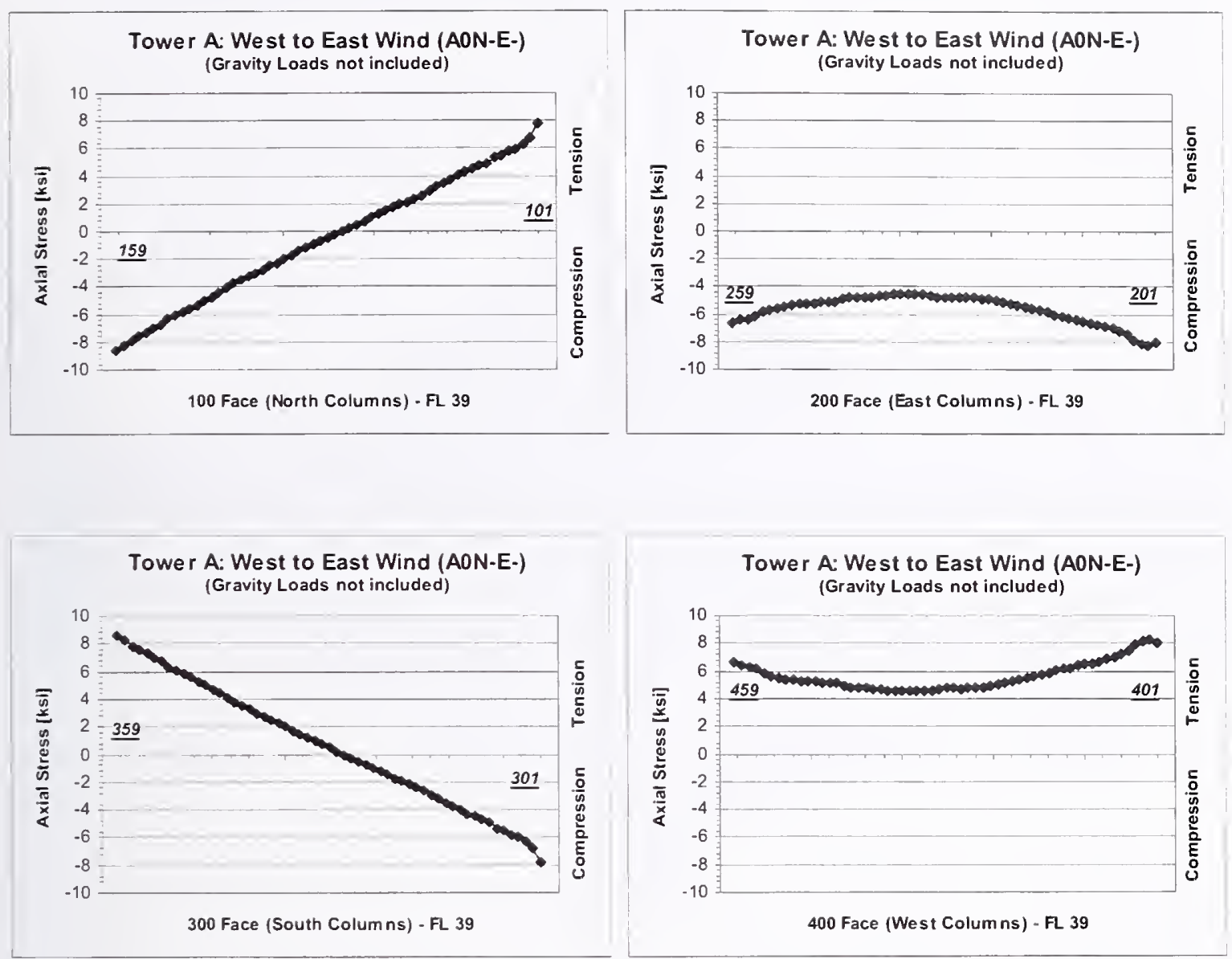

(b) Floor 39

Figure 4-6. Distribution of normal stresses in the exterior walls of WTC 1 due to original WTC wind loads only at (a) floor B6, and (b) floor 39 (continued). 


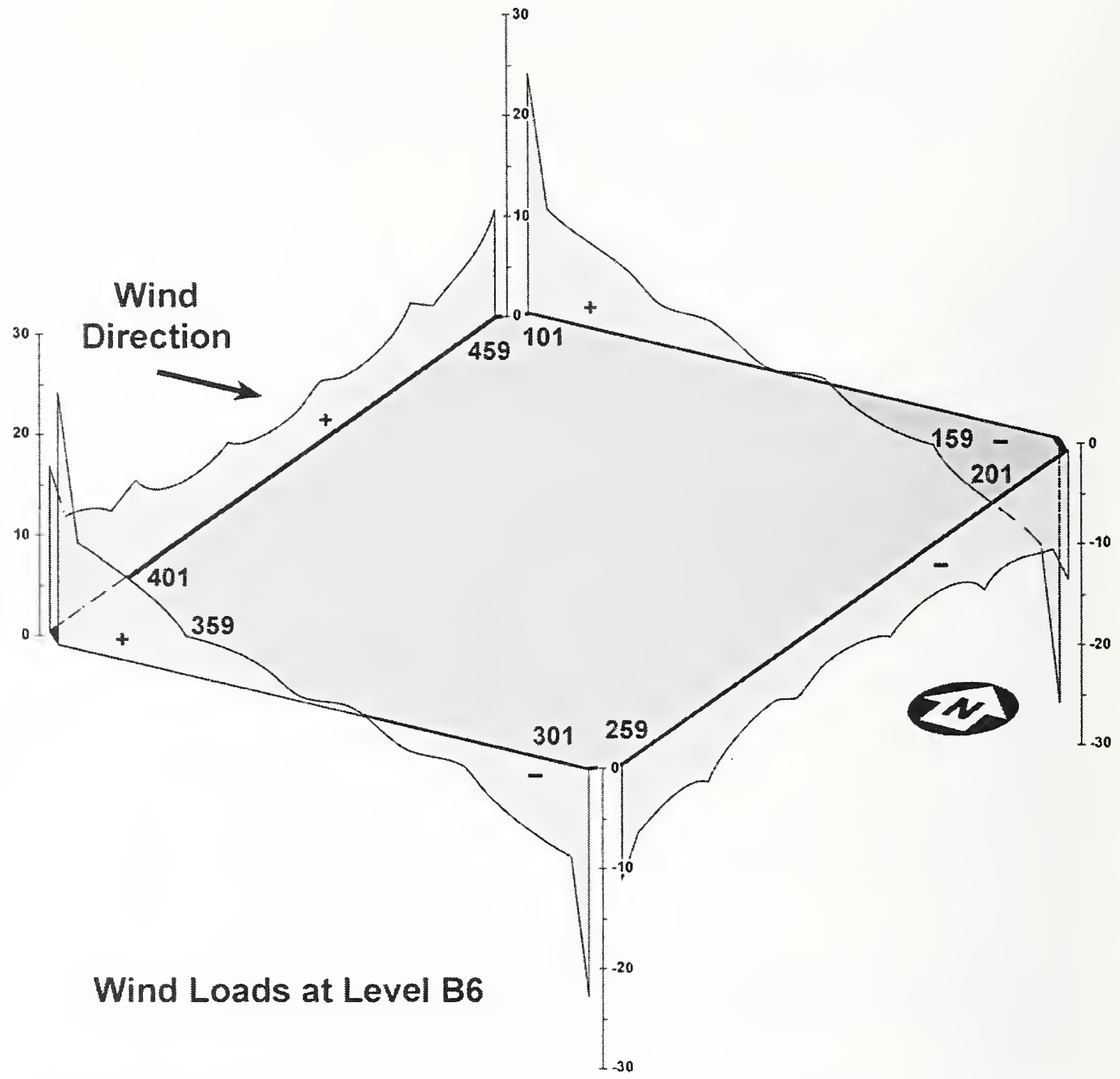

Figure 4-7. Three-dimensional distribution of normal stresses in the exterior walls of WTC 1 due to original WTC wind loads only at floors B6 and 39. 


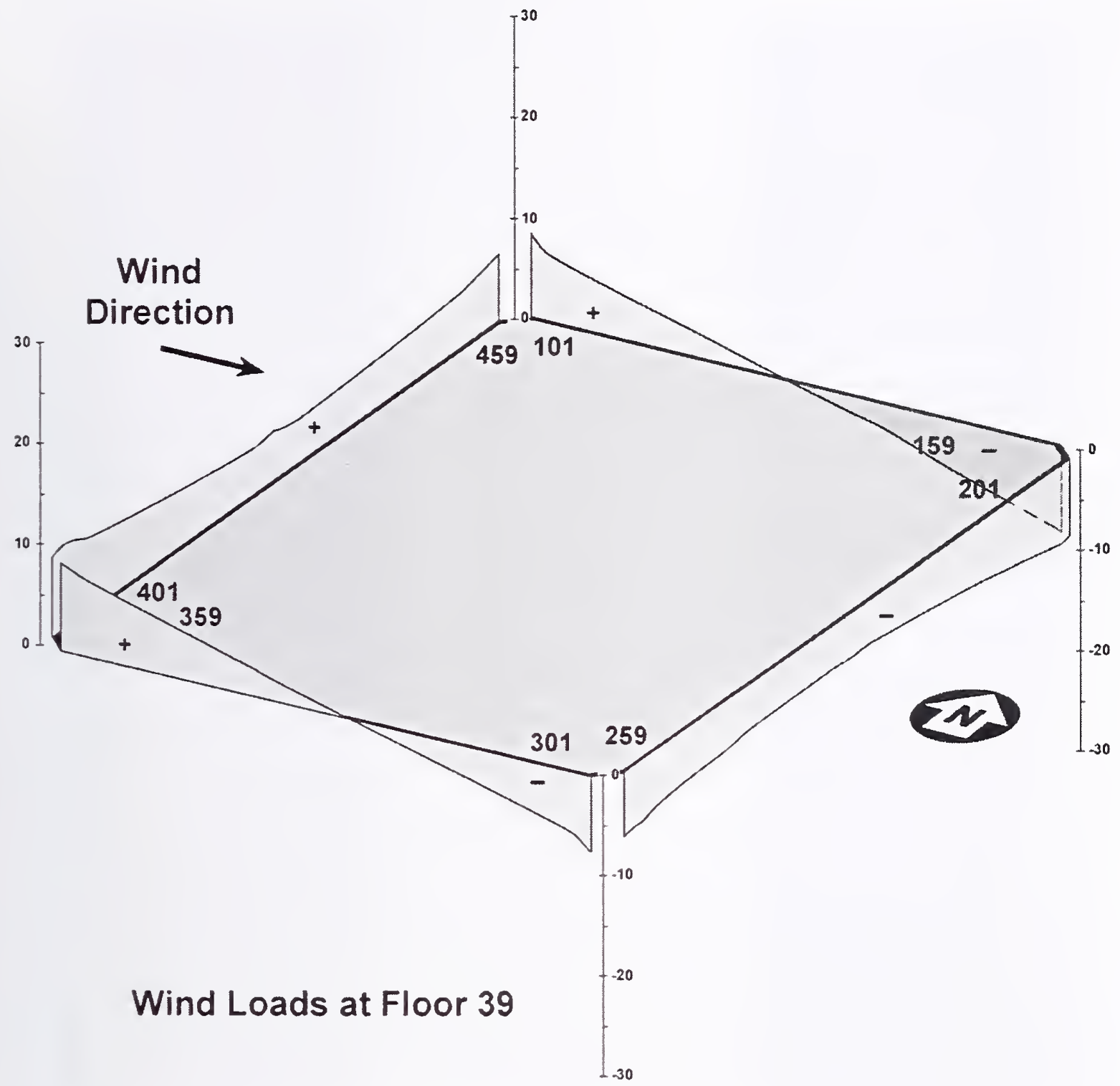

Figure 4-7. Three-dimensional distribution of normal stresses in the exterior walls of WTC 1 due to original WTC wind loads only at floors B6 and 39 (continued). 


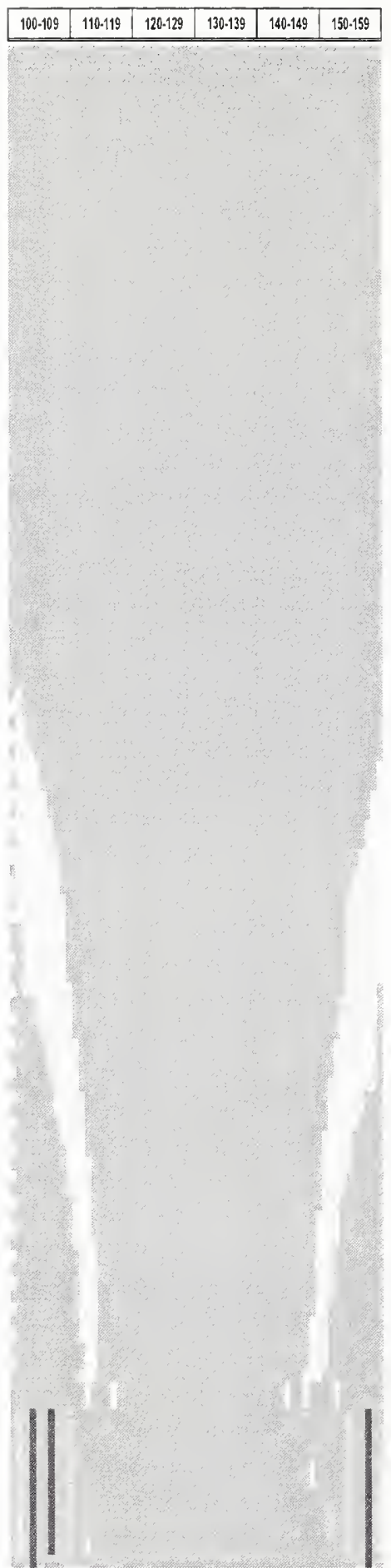

(a)

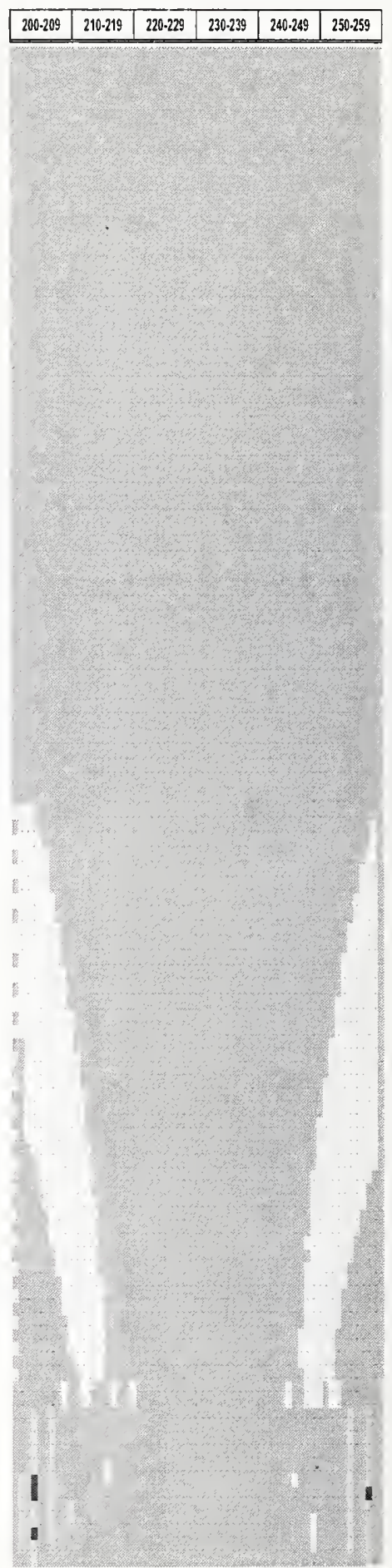

(b)

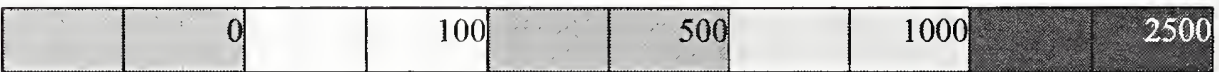

Figure 4-8. Tension force distribution (kip) in the exterior wall columns of WTC 1 under original design dead and wind loads (no live loads included), (a) 100 face (north), and (b) 200 face (east). 

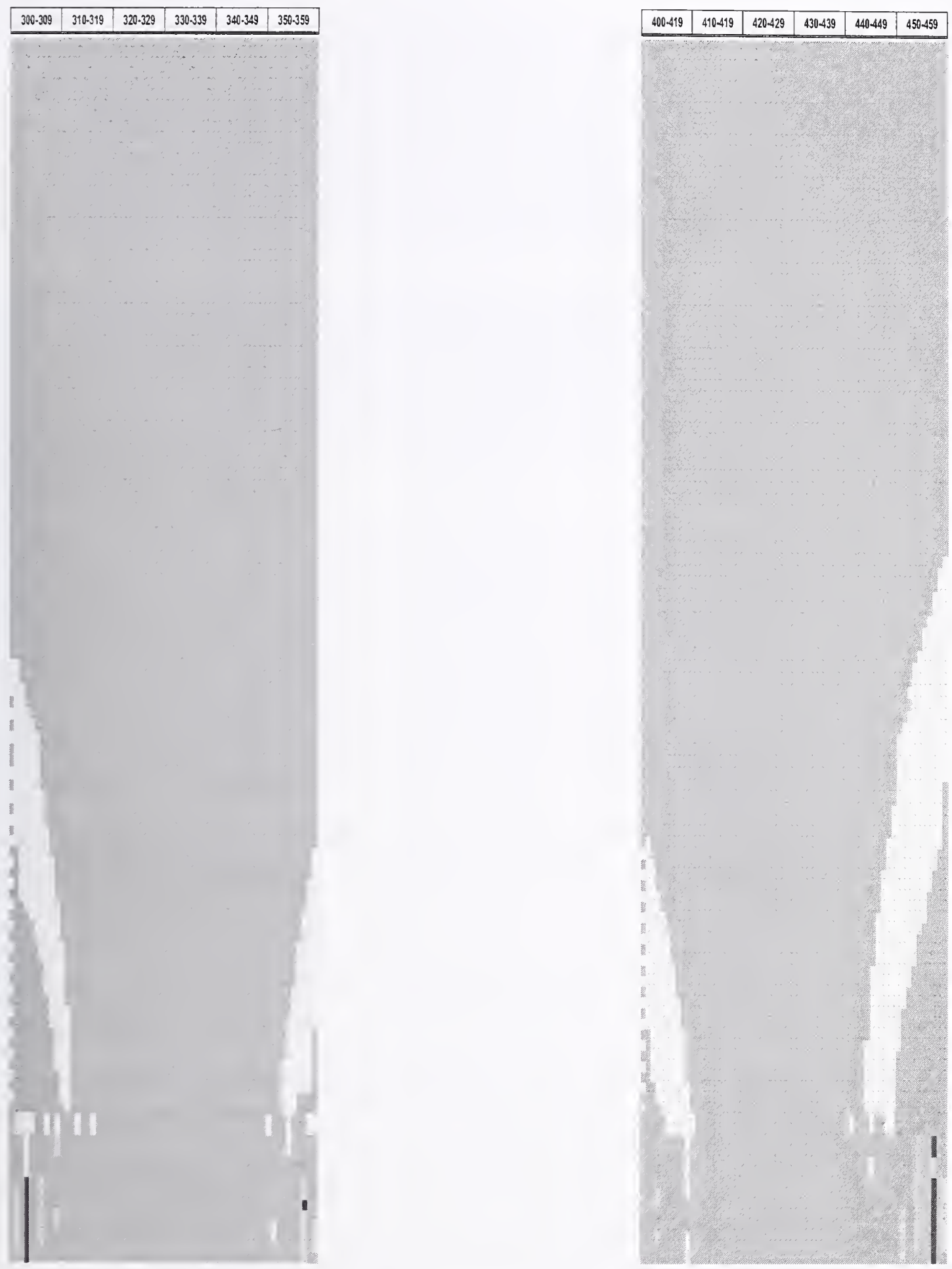

(c)

(d)

\begin{tabular}{|l|l|l|l|l|l|}
\hline & 0 & 100 & 500 & 1000 & 2500 \\
\hline
\end{tabular}

Figure 4-8. (c) 300 face (south), and (d) 400 face (west) (continued). 


\subsubsection{Exterior Columns Splice Connection}

The axial tensile column loads estimated in Section 4.2.4 under dead and wind loads were transferred from one panel to another through the column splices. The exterior wall column splice capacities were calculated from the original details and compared to the tension forces for all four faces of WTC 1. The DCRs for the exterior wall splice connections for WTC 1 are summarized in Table 4-6. As can be observed from Table 4-6 and from a similar table for WTC 2 (NIST NCSTAR 1-2A), the DCRs were less than unity for all walls of both towers.

Table 4-6. Maximum calculated DCRs for exterior wall column splices for WTC 1 under original design dead and wind load case.

\begin{tabular}{|l|r|c|}
\hline $\begin{array}{c}\text { Exterior Wall } \\
\text { Face }\end{array}$ & $\begin{array}{r}\text { Exterior Wall } \\
\text { Column Splices }\end{array}$ & $\begin{array}{c}\text { Maximum } \\
\text { Calculated DCR }\end{array}$ \\
\hline 100 Face & Below floor 1 & 0.64 \\
(North) & Floor 1 to 9 & 0.31 \\
& Floor 10 to 41 & 0.96 \\
& Above floor 42 & 0.26 \\
\hline \multirow{3}{*}{ 200 Face } & Below floor 1 & 0.53 \\
(East) & Floor 1 to 9 & 0.32 \\
& Floor 10 to 41 & 0.63 \\
& Above floor 42 & 0.14 \\
300 Face & Below floor 1 & 0.54 \\
(South) & Floor 1 to 9 & 0.26 \\
& Floor 10 to 41 & 0.77 \\
& Above floor 42 & 0.15 \\
\hline \multirow{2}{*}{ 400 Face } & Below floor 1 & 0.59 \\
(West) & Floor 1 to 9 & 0.36 \\
& Floor 10 to 41 & 0.84 \\
& Above floor 42 & 0.26 \\
\hline
\end{tabular}

\subsubsection{Resistance of the Towers to Shear Sliding and Overturning Moment}

The dead loads that acted on the exterior walls of the towers provided resistance to shear sliding and overturning induced by wind loads. Considering the resistance to shear sliding under wind loads, the factor of safety was estimated to be approximately 11.5 and 10 for WTC 1 and WTC 2, respectively. This was calculated by dividing the resisting force due to dead load on the exterior walls (a coefficient of friction of 0.7 was used) by the wind shear (maximum base shear) at the foundation level.

For the resistance of the towers to overturning due to wind loads, the factors of safety for WTC 1 were estimated to be approximately 2.3 and 2.6 for overturning about a north-south axis and an east-west axis, respectively. For WTC 2, these factors of safety were about 1.9 and 2.7 for overturning about a northsouth axis and an east-west axis, respectively. These factors of safety were calculated by dividing the 
resisting moment due to dead load on the exterior walls by the overturning moment due to wind loads taken at the foundation level (maximum base moments).

\subsection{BASELINE PERFORMANCE OF THE TYPICAL FLOOR MODELS}

This section presents the results of the baseline performance analysis for the typical floor models under gravity (dead and live) loads. These models included the typical truss-framed floor (floor 96 of WTC 1, see Section 2.4) and the typical beam-framed floor (floor 75 of WTC 2, see Section 2.5).

For application to the floor models, gravity loads were separated into three categories: CDLs, SDLs, and live loads (LLs). CDL is defined as the self-weight of the structural system, including floor trusses, floor beams. and concrete slabs. SDL is defined as the added dead load associated with architectural and mechanical/electrical/plumbing systems (curtain wall, floor finishes, mechanical equipment and ducts, transformers, etc.) The CDL and SDL were based on the WTC architectural and structural drawings and on the original WTC Design Criteria. For the estimation of the dead loads on the floor models, see Chapter 6 of NIST NCSTAR 1-2A.

Two independent sets of live loads were applied in combination with the dead loads. The first was taken from the original WTC Design Criteria and the second from the ASCE 7-02 Standard. The live loads in the NYCBC 2001 are essentially identical to the ASCE 7-02 live loads. Live load reductions were taken from the original WTC Design Criteria and from the ASCE 7-02 Standard, each for use with its respective live loads. For the typical beam-framed floor, it was found that the original WTC design criteria live loads, NYCBC 2001 loads, and the ASCE7-02 Standard loads were nearly identical. The only difference was that the live load for the corridors within the core was $100 \mathrm{psf}$ in the original WTC design criteria, 75 psf in NYCBC 2001, and 80 psf in ASCE 7-02. As a result, only the original WTC design criteria loads were applied to the beam-framed floor model.

For the baseline performance analysis for the floor systems, DCRs for structural components were estimated using the ASD procedure as specified in the AISC Specification (1989), see Section 4.2.1.

\subsubsection{Typical Truss-Framed Floor}

For the CDL, SDL, and LL applied to this floor and for the selection of the design parameters for estimating the DCRs, see Chapter 6 of NIST NCSTAR 1-2A.

The maximum mid-span deflections for each of the long-span, short-span, and two-way zones for the original WTC Design Criteria and ASCE-7-02 total loads are provided in Table 4-7. 
Table 4-7. Summary of maximum deflections for typical truss-framed floor under dead and live loads for areas outside of core.

\begin{tabular}{|c|c|c|c|}
\hline Criteria & Two-Way Zone & Long Span & Short Span \\
\hline $\begin{array}{c}\text { WTC Design } \\
\text { Criteria }\end{array}$ & 1.44 in. & 1.79 in. $\approx \mathrm{L} / 400$ & 0.57 in. $\approx \mathrm{L} / 750$ \\
\hline ASCE 7-02 & 1.14 in. & 1.43 in. $\approx \mathrm{L} / 500$ & 0.44 in. $\approx \mathrm{L} / 980$ \\
\hline
\end{tabular}

The Design Criteria for the towers specified that the floor trusses were to be cambered for construction dead loads and proportioned such that the deflection under SDL and LL did not exceed L/360. Table 4-7 clearly shows that this criterion was met.

For the components of the truss-framed floors, DCRs were calculated using the SAP2000 program. Calculations were made for the bottom chords, the diagonals and the verticals of the trusses, and for the beams and girders of the core.

DCR statistics for the truss-framed floor model are summarized in Table 4-8 for the original design loading case and in Table 4-9 for the ASCE 7-02 loading case. For the area outside the core, the DCRs for all floor trusses were less than 1.14 for the original WTC design loads and less than 0.86 for the ASCE 7-02 loading and (by comparison) for the NYCBC 2001 loading. Under the original WTC design loading, the DCR was less than 1.00 for 99.4 percent of the floor truss components. Inside the core, the DCRs for all floor beams werc less than 1.08, and more than 99 percent of the members had a DCR of less than 1.0 .

For the area outside the core, the average ratio of the DCRs estimated from the ASCE 7-02 loading to the DCRs from the original WTC design loading for all floor trusses was about 0.80 . 
Table 4-8. DCR statistics for the typical truss-framed floor under the original design

load case.

\begin{tabular}{|c|c|c|c|c|c|c|c|}
\hline Member Type & $\begin{array}{c}\text { Number } \\
\text { of } \\
\text { Members }\end{array}$ & $\begin{array}{c}\text { Mean } \\
\text { Calculated } \\
\text { DCR }\end{array}$ & $\begin{array}{l}\text { C.O.V. } \\
\text { of DCR }\end{array}$ & $\begin{array}{c}\text { Percentage } \\
\text { of } \\
\text { components } \\
\text { with DCR > } \\
1.0 \\
\end{array}$ & $\begin{array}{c}\text { Percentage } \\
\text { of } \\
\text { components } \\
\text { with DCR > } \\
1.05 \\
\end{array}$ & $\begin{array}{c}\text { Number of } \\
\text { components } \\
\text { with DCR > } \\
1.05\end{array}$ & $\begin{array}{c}\text { Maximum } \\
\text { Calculated } \\
\text { DCR }\end{array}$ \\
\hline \multicolumn{8}{|l|}{$\begin{array}{l}\text { One-Way Long } \\
\text { Span Zone }\end{array}$} \\
\hline Web members & 1,792 & 0.44 & 0.61 & 3.7 & 1.28 & 23 & 1.14 \\
\hline $\begin{array}{r}\text { Bottom chord } \\
\text { members }\end{array}$ & 1,038 & 0.74 & 0.26 & 0 & 0 & 0 & 0.99 \\
\hline \multicolumn{8}{|l|}{$\begin{array}{l}\text { One-IVay Short } \\
\text { Span Zone }\end{array}$} \\
\hline Web members & 640 & 0.33 & 0.61 & 0 & 0 & 0 & 0.92 \\
\hline $\begin{array}{r}\text { Bottom chord } \\
\text { members }\end{array}$ & 288 & 0.37 & 0.32 & 0 & 0 & 0 & 0.55 \\
\hline \multicolumn{8}{|l|}{ Two-Way Zone } \\
\hline Web members & 3,086 & 0.30 & 0.80 & 0.3 & 0.26 & 8 & 1.06 \\
\hline $\begin{array}{r}\text { Bottom chord } \\
\text { members }\end{array}$ & 2,035 & 0.48 & 0.54 & 0 & 0 & 0 & 0.94 \\
\hline \multicolumn{8}{|l|}{$\begin{array}{l}\text { Bridging Trusses } \\
\text { within One-Way } \\
\text { Span Zones }\end{array}$} \\
\hline Web members & 692 & 0.16 & 1.25 & 1 & 0 & 0 & 1.02 \\
\hline $\begin{array}{r}\text { Bottom chord } \\
\text { members }\end{array}$ & 327 & 0.12 & 1.33 & 0 & 0 & 0 & 0.95 \\
\hline \multicolumn{8}{|l|}{ Core Beams } \\
\hline Beams within core & 1,361 & 0.33 & 0.67 & 0.9 & 0.3 & 4 & 1.07 \\
\hline $\begin{array}{r}\text { Core perimeter } \\
\text { channels }\end{array}$ & 686 & 0.36 & 0.58 & 1.0 & 0.6 & 4 & 1.08 \\
\hline
\end{tabular}


Table 4-9. DCR statistics for floor the typical truss-framed floor under the ASCE 7-02 loading case.

\begin{tabular}{|c|c|c|c|c|c|c|}
\hline Member Type & $\begin{array}{l}\text { Number } \\
\text { of } \\
\text { Members }\end{array}$ & $\begin{array}{c}\text { Mean } \\
\text { Calculated } \\
\text { DCR }\end{array}$ & $\begin{array}{c}\text { C.O.V. of } \\
\text { DCR }\end{array}$ & $\begin{array}{c}\text { Percentage } \\
\text { of } \\
\text { components } \\
\text { with DCR }>\text {. } \\
1.0\end{array}$ & $\begin{array}{c}\text { Percentage } \\
\text { of } \\
\text { components } \\
\text { with DCR > } \\
1.05\end{array}$ & $\begin{array}{l}\text { Maximum } \\
\text { Calculated } \\
\text { DCR }\end{array}$ \\
\hline \multicolumn{7}{|l|}{$\begin{array}{l}\text { One-Way Long Span } \\
\text { Zone }\end{array}$} \\
\hline Web members & 1,792 & 0.35 & 0.60 & 0 & 0 & 0.86 \\
\hline Bottom chord members & 1,038 & 0.59 & 0.25 & 0 & 0 & 0.80 \\
\hline \multicolumn{7}{|l|}{$\begin{array}{l}\text { One-Way Short Span } \\
\text { Zone }\end{array}$} \\
\hline Web members & 640 & 0.26 & 0.65 & 0 & 0 & 0.69 \\
\hline Bottom chord members & 288 & 0.30 & 0.33 & 0 & 0 & 0.43 \\
\hline \multicolumn{7}{|l|}{ Two-Way Zone } \\
\hline Web members & 3,086 & 0.24 & 0.79 & 0 & 0 & 0.78 \\
\hline Bottom chord members & 2,035 & 0.38 & 0.55 & 0 & 0 & 0.74 \\
\hline \multicolumn{7}{|l|}{$\begin{array}{l}\text { Bridging Trusses within } \\
\text { One-Way Span Zones } \\
\text { Web members }\end{array}$} \\
\hline Bottom chord members & 692 & 0.11 & 1.55 & 0 & 0 & 0.95 \\
\hline & 327 & 0.09 & 1.44 & 0 & 0 & 0.81 \\
\hline \multicolumn{7}{|l|}{ Core Beams } \\
\hline Beams within core & 1,361 & 0.28 & 0.64 & 0.1 & 0.1 & 1.05 \\
\hline Core perimeter channels & 686 & 0.28 & 0.61 & 0 & 0 & 0.86 \\
\hline
\end{tabular}




\subsubsection{Typical Beam-Framed Floor}

For the CDL, SDL, and LL applied to this floor, see Chapter 6 of NIST NCSTAR 1-2A.

The maximum mid-span deflections of the long-span and short-span zones under the original WTC design loads were approximately 1.55 in. $(\approx L / 450)$ and 0.70 in. $(\approx L / 600)$, respectively. The Design Criteria for the towers specified that the floor beams be proportioned such that the deflection would not exceed $\mathrm{L} / 360$ under total load. If the beams were cambered for construction dead loads, the final deflection could not exceed L/360 under SDL + LL. The calculated deflections clearly showed that this criterion was met.

Using the SAP2000 computer program, DCRs were calculated for the components of the floor framing. Only two beams running in the east-west direction and cantilevering off of corner core columns 501 and 508 had DCRs larger than 1.0 under the original WTC design loading. For these two beams, the DCRs from the axial load and moment interaction equation were less than 1.0, while the DCRs in shear were 1.125 and 1.09 .

Fig. 4-9 shows the distribution of DCRs for the floor framing. The figure shows the location of the two beams with DCR greater than 1.0. DCR statistics for the beam-framed floor model are summarized in Table 4-10 for the original design loading case. The statistics are provided for member groups that are shown in Fig. 4-10.
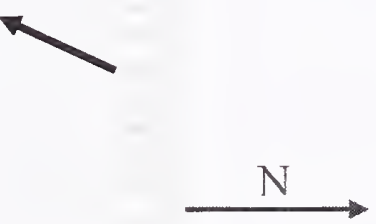

\begin{tabular}{|l|l|l|l|l|l|l|l|}
\hline & 0.00 & 0.50 & 0.75 & 1.00 & 1.08 & \\
\hline
\end{tabular}

Figure 4-9. DCRs for the typical beam-framed floor under original WTC design criteria loading. 


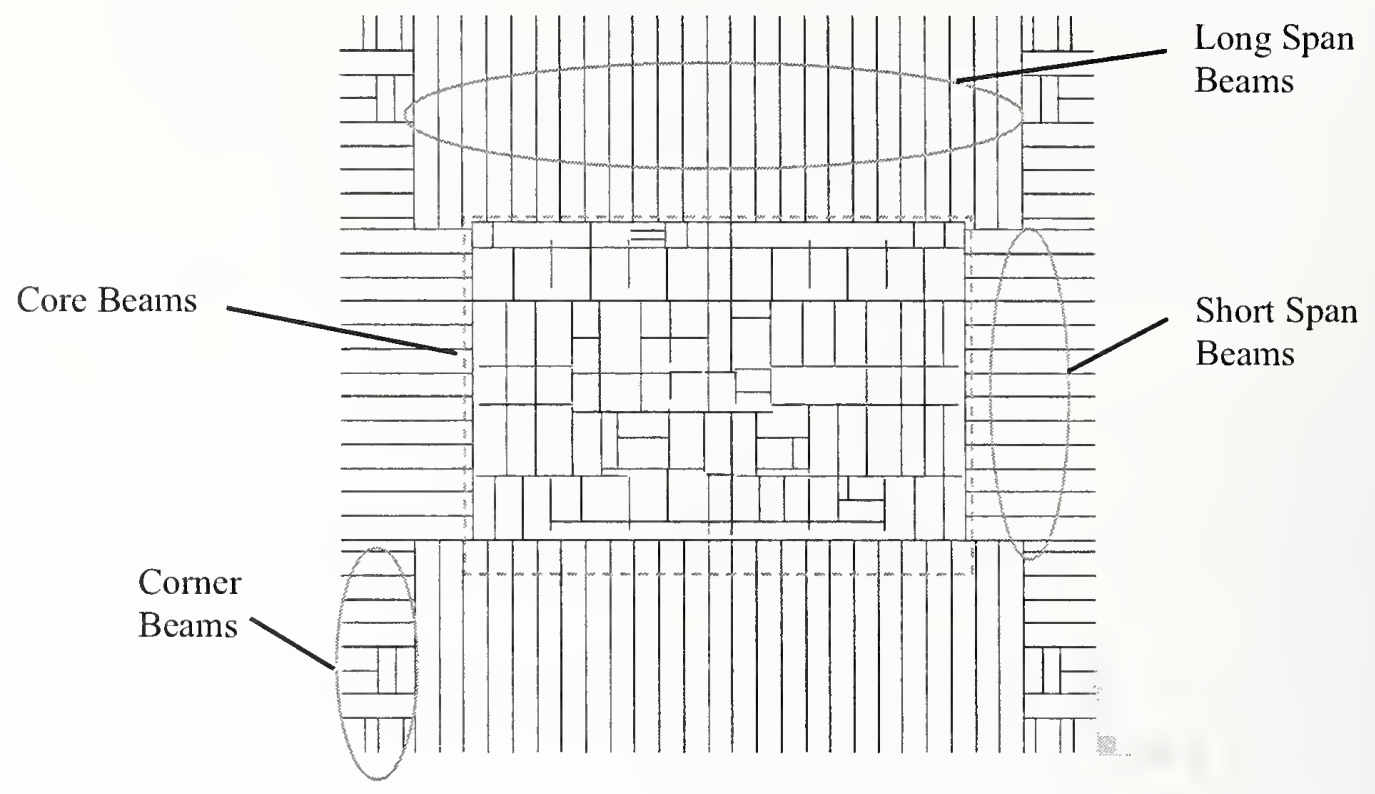

Figure 4-10. Beam-framed floor member groups.

Table 4-10. DCR statistics for the typical beam-framed floor under the original design loading case.

\begin{tabular}{|l|c|c|c|c|}
\hline Member Type & $\begin{array}{c}\text { Number of } \\
\text { Members }\end{array}$ & $\begin{array}{c}\text { Mean Calculated } \\
\text { DCR }\end{array}$ & $\begin{array}{c}\text { C.O.V. of } \\
\text { DCR }\end{array}$ & $\begin{array}{c}\text { Maximum } \\
\text { Calculated DCR }\end{array}$ \\
\hline Long Span Beams & 156 & 0.64 & 0.16 & 0.83 \\
\hline Short Span Beams & 84 & 0.65 & 0.12 & 0.89 \\
\hline Core Beams & 156 & 0.31 & 0.77 & 1.13 \\
\hline Corner Beams & 32 & 0.49 & 0.35 & 0.90 \\
\hline
\end{tabular}

\subsection{REVIEW OF BASELINE PERFORMANCE ANALYSES}

As was the case for the structural databases and models, the baseline performance analyses outlined in this chapter for the global WTC models and the floor models were reviewed by SOM and NIST. The reviews included the following: (1) checks on the accuracy of load vectors (gravity and wind) as developed in Chapter 3; (2) reviews of the adequacy of the analysis procedures, including staged construction analysis, P- $\Delta$ effects, modal analysis, etc.; and (3) checks on the proper use of load combinations and component capacity estimates. The reviews indicated that the baseline performance analyses were appropriate. The reviews also included a thorough review of the report on baseline performance analysis, that resulted in substantial modifications to the report.

\subsection{SUMMARY}

This chapter presented the results of the baseline performance analysis for the WTC 1 and WTC 2 towers. For the global models of the towers, three gravity and wind loading cases were considered: (1) the 
original WTC design load case, (2) the lower-estimate state-of-the-practices case, and (3) the refined NIST estimate case.

Under the original WTC design loads, the cumulative drifts at the top of the WTC towers ranged from $\mathrm{H} / 263$ to $\mathrm{H} / 335$. For the lower-estimate state-of-the-practice case, those drifts ranged from $\mathrm{H} / 253$ to $\mathrm{H} / 306$. The drifts obtained from the refined N1ST estimate case were about 25 percent larger than those from the state-of-the practice case. While currently no building codes specify a drift limit for wind design, structural engineers often use in their practice the criterion that drift ratios should not exceed $\mathrm{H} / 400$ to $\mathrm{H} / 500$ for serviceability considerations and to enhance overall safety and stability (including $\mathrm{P}-\Delta$ effects). Reducing the drift of the WTC towers to the range of $\mathrm{H} / 400$ to $\mathrm{H} / 500$ would entail enhancing the stiffness and/or damping characteristics of the buildings.

Structural engineers often use in their practice an inter-story drift limit in the range of $h / 300$ to $h / 400$ for serviceability considerations. Under design loading conditions, the maximum inter-story drift was as high as h/230 and h/200 for WTC 1 and WTC 2, respectively. Maximum inter-story drifts under the state-ofthe practice case were about $\mathrm{h} / 184$ and $\mathrm{h} / 200$ for WTC 1 and WTC 2 , respectively. For the refined NIST estimate case, these inter-story drifts were about 25 percent larger than those from the state-of-the practice case. Similar to total drift, inter-story drifts of the towers were larger than what is generally used in practice.

The DCRs were based on the allowable stress design (ASD) procedure and were estimated using the AISC Specifications (1989). The results indicated that DCRs estimated from the original WTC design load case were, in general, close to those obtained for the lower estimate state-of-the practice case. For both cases, a fraction of structural components had DCRs larger than 1.0. These were mainly observed in both towers at (1) the exterior walls at the columns around the corners, where the hat truss connected to the exterior walls, and below floor 9; and (2) the core columns on the 600 line between floors 80 and 106 and at core perimeter columns 901 and 908 for much of their height. The DCRs obtained for the refined N1ST estimate case were higher than those from the original WTC design and the lower-estimate state-ofthe-practice load cases, owing to the following reasons: (1) the N1ST estimated wind loads were higher than those used in the state-of-the-practice case by about 25 percent, and (2) the original WTC design and the state-of-the-practice cases used NYCBC load combinations, which result in lower DCRs than the ASCE 7-02 load combinations used for the refined N1ST case. The DCRs estimated using the load and resistance factor design (LRFD) procedure for exterior and core columns were, on average, smaller than those using the ASD procedure by about 15 percent.

While it is a normal design practice to achieve a DCR less than unity, the safety of the WTC towers on September 11,2001, was most likely not affected by the fraction of members for which the demand exceeded capacity due to the following: (1) The inherent factor of safety in the allowable stress design method, (2) the load redistribution capability of ductile steel structures, and (3) on the day of the attack, the towers were subjected to in-service live loads (a fraction of the design live loads) and minimal wind loads.

Analysis of the axial stress distribution in the columns under lateral wind loads indicated that the behavior of the lower portion of the towers at the basement floors was that of a braced frame, while the behavior of the super-structure was that of a framed tube system. Under a combination of the original WTC design dead and wind loads, tension forces were developed in the exterior walls of both towers. The forces were largest at the base of the building and at the corners. These tensile column loads were transferred from 
one panel to another through the column splices. The DCRs for the exterior wall splice connections under these tensile forces for both towers were shown to be less than 1.0.

The resistance of the towers to shear sliding and overturning due to wind was provided by the dead loads that acted on the exterior walls of the towers. Considering the resistance to shear sliding under wind load, the factor of safety was calculated to be between 10 and 11.5 , while the factor of safety against overturning ranged from 1.9 to 2.7 for both towers.

Two typical floor models were each analyzed under gravity loads. The following is a summary of the results:

- For the typical truss-framed floor, the DCRs for all floor trusses were less than 1.14 for the original WTC design loads and less than 0.86 for the ASCE 7-02 loading. Under the original WTC design loads, the DCR was less than 1.00 for 99.4 percent of the floor truss components. Inside the core, the DCRs for all floor beams were less than 1.08, and more than 99 percent of the floor beams had a DCR of less than 1.0. The maximum mid-span deflections of the long-span and short-span zones under the original WTC design loads were approximately 1.79 in. $(\approx \mathrm{L} / 400)$ and 0.57 in. $(\approx \mathrm{L} / 750)$, respectively.

- For the typical beam-framed floor under the original WTC design loads, the DCRs for all floor beams were less than 1.0 except for two core beams where the DCRs in shear were 1.125 and 1.09. The maximum mid-span deflections of the long-span and short-span zones under the original design loads were approximately 1.55 in. $(\approx L / 450)$ and 0.70 in. $(\approx L / 600)$, respectively.

\subsection{REFERENCES}

AISC Specification (1989): American Institute of Steel Construction, Specification for Structural Steel Buildings - Allowable Stress Design and Plastic Design $-9^{\text {th }}$ Edition, Chicago, IL, 1989.

AISC Specification (1993): American Institute of Steel Construction, Specification for Structural Steel Buildings - Load \& Resistance Factor - 2nd Edition, Chicago, IL, 1993.

ASCE 7-02: American Society of Civil Engineers, ASCE 7 Standard Minimum Design Loads for Buildings and Other Structures, Reston, VA, 2002.

Khan, F.R., and Amin, N.R., (1973), "Analysis and Design of Framed Tube Structures for Tall Concrete Buildings," The Structural Engineer, 51(3), pp. 85-92.

NYCBC 2001: Building Code of the City of New York, 2001 Edition, Gould Publications, Binghamton, NY.

Taranath, B.S., (1988), Structural Analysis \& Design of Tall Buildings, McGraw-Hill, Inc., New York, USA. 


\section{Chapter 5 \\ DEVELOPMENT OF TOWER AND AIRCRAFT IMPACT MODELS}

\section{$5.1 \quad$ INTRODUCTION}

This chapter describes the structural models used in the analysis of aircraft impact into the World Trade Center (WTC) towers. The WTC tower models for the impact analysis required considerably greater sophistication and detail than was required for the reference models described in Chapter 2. The reference models provided the basis for the more detailed models required for the impact simulations. The impact models of the towers, which utilized the structural databases described in Chapter 2 (see also NIST NCSTAR 1-2A), included the following refinements:

- The material properties used in the impact models accounted for the highly nonlinear behavior of the tower and aircraft materials, including softening and failure of components, and strain rate sensitivity.

- The impact simulations required a much higher level of detail than that in the reference global models. For instance, the impact analyses necessitated that the floors inside and outside the core in the impact region, as well as connections, be modeled in detail. In addition, structural components in the exterior walls and core of the towers were modeled using shell elements (instead of beam elements in the reference models) to properly capture the impact-induced damage to these components.

- The size of the impact models required a very large mesh (more than ten million degrees of freedom). The SAP2000 program cannot accommodate this model size.

- Contact and erosion algorithms were required for the impact analyses. That necessitated the use of appropriate software, specifically LS-DYNA (LS-DYNA 2003), for the development of the impact models.

Three separate models were developed for conducting the impact analyses. The first two were detailed models of the WTC 1 and WTC 2 towers in the impact region. The third model was a comprehensive model of the Boeing 767 aircraft. All models were developed for the LS-DYNA finite element code, which is a commercially available nonlinear explicit finite element code for the dynamic analysis of structures. The code has been used for a wide variety of crash, blast, and impact applications. The models were developed using the TrueGrid model generation program (TrueGrid Manual 2001). The input data for TrueGrid included a set of commands that defined the model geometry, material properties, boundary conditions, and mesh sizes. The output from TrueGrid was a complete LS-DYNA input file for the desired analysis.

One of the significant challenges in developing the tower and aircraft models for the global impact analyses was to minimize the model size while keeping sufficient fidelity in the impact zone to properly capture the characteristics of the impact response. The limitation was a model size that could be run on a 32-bit computer, since additional memory was needed to decompose a model with greater than 
2.3 million nodes. Based on this limitation, each combined aircraft and tower model could not exceed 2.3 million nodes. These were distributed between the global WTC tower model and the aircraft so that the tower model would be about 1.5 million nodes and the aircraft about 0.8 million nodes. The approach used to meet this objective was to develop models for the various tower components at different levels of refinement. Components in the path of the impact and debris field were meshed with a higher resolution to capture the local impact damage and failure, while components outside the impact zone were meshed more coarsely to primarily capture their structural stiffness and inertial properties. As a result, an array of component and subassembly analyses were performed to optimize the finite element mesh densities and study the influence of a number of modeling options on the calculated response.

Section 5.2 and 5.3 provide the details and methodology used to develop the global tower and aircraft models, respectively, including constitutive relationships used for the various materials in the towers and aircraft. Section 5.4 provides a summary of the component level and subassembly analyses used to support the development of the global tower and aircraft models. Section 5.5 is a summary of the chapter.

\subsection{DEVELOPMENT OF TOWER IMPACT MODELS}

Given the complexity of the towers' structure, a key aspect of developing the global models was automating the mesh generation process. The component model generation files were developed in a parameterized format to support automated mesh generation. For that purpose, the electronic structural databases developed by the firm of Leslie E. Robertson Associates, R.L.L.P. under contract to NIST within the framework of Project 2, and reviewed and approved by NIST (see Chapter 2), were utilized. Visual Basic programs were developed to interface with the structural databases and to automatically write master level TrueGrid input files for mesh generation. These programs werc used to generate the models for the core columns and exterior walls.

An example of such programs is presented in Figure 5-1, which shows the user interface for the program that generated the models of the exterior wall panels. In this program, the user identified the tower, upper and lower floor boundaries, and left and right (as viewed from outside the building) panel numbers. Additionally, the user could specify a fine mesh region, typically in the area of the aircraft impact. This program extracted information from the database and wrote a master TrueGrid file. Information not available in the database but included in the drawing books, such as the weld specifications, were included in the program. The automatically generated TrueGrid files included the geometry and material specification for the columns, butt plates, spandrels, welds, bolts, and spandrel splice plates. Node tolerance specifications (nodal merging commands) were also automatically generated to define the connectivity of adjacent parts in the model.

A summary of the model size and element types for the global tower models is presented in Table 5-1. The following sections provide the details of the various components used in the tower models. 


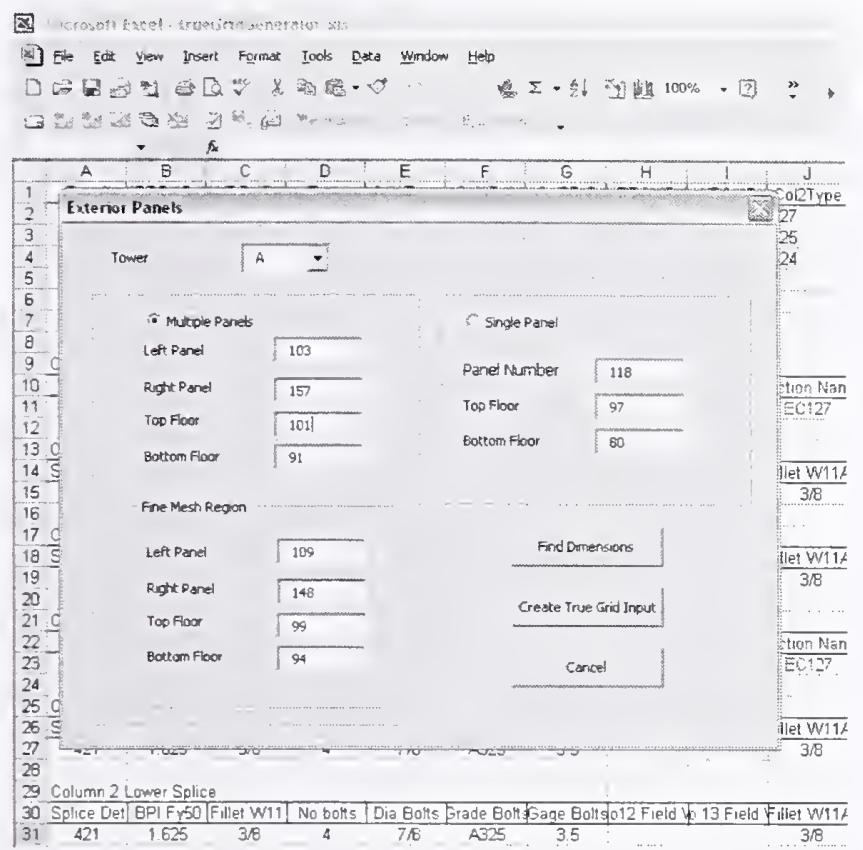

Figure 5-1. User interface for exterior panel generator.

Table 5-1. Summary of the size of the global impact tower models.

\begin{tabular}{|l|c|c|}
\hline & WTC 1 Tower Model & WTC 2 Tower Model \\
\hline Number of Nodes & $1,300,537$ & $1,312,092$ \\
\hline Hughes-Liu Beam Elements & 47,952 & 53,488 \\
\hline Belytschko-Tsay Shell Elements & $1,156,947$ & $1,155,815$ \\
\hline Constant Stress Solid Elements & 2,805 & 2,498 \\
\hline
\end{tabular}

\subsubsection{Exterior Wall Model Development}

The exterior walls were constructed as an assembly of panels. The most common panel types on the exterior of the towers consisted of three columns and spans over three floors. The columns in each panel were attached together by spandrel plates, typically at each floor level. The construction of the exterior wall model required the generation of a parameterized model for each panel type that was located in the tower regions near the impact zones.

The complete exterior wall model in the impact zone for each tower was generated by placing the various panels in the actual locations with their dimensions and material specifications. The impact face for the global WTC 1 (north wall) and WTC 2 tower (south face) models are shown in Figure 5-2 and Figure 5-3, respectively. A refined mesh was used in the immediate impact zone for improved accuracy of the impact response, and a coarse mesh was used outside the impact zone for improved computational efficiency. All panels were primarily constructed from Belytschko-Tsay shell elements. The reader is 
referred to the LS-DYNA Theoretical Manual for a complete description of this element type. For modeling the bolted column connection between columns, constant stress brick elements were used to model the butt plates in the refined panels, and Hughes-Liu beam elements were used for the bolts connecting the butt plates in the refined impact zone. Section 5.4.2 describes the details of the model for the exterior column connections. The column ends for the coarse far field exterior wall panels were merged together to create a perfect bond between column ends.

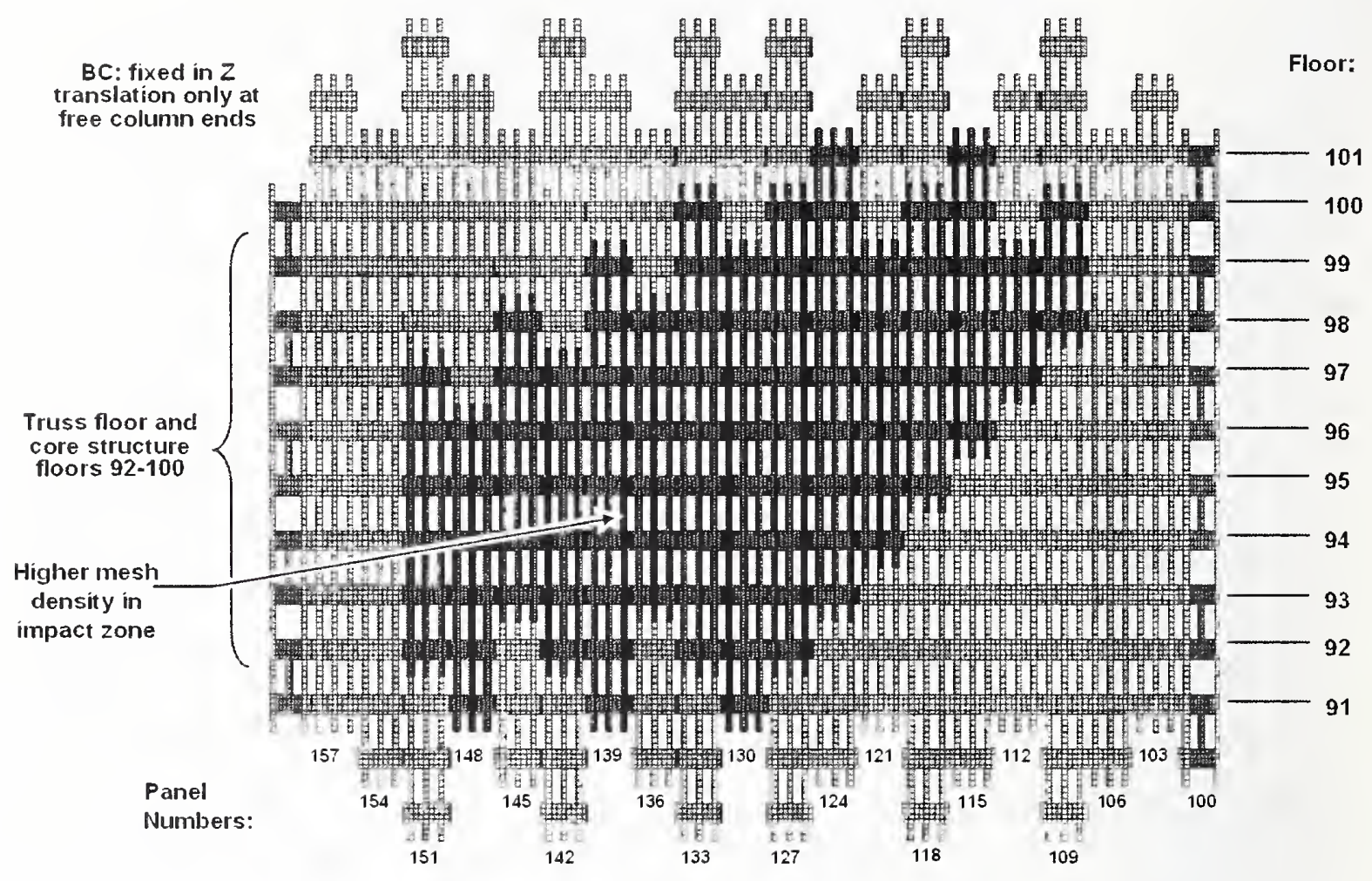

Figure 5-2. Impact face of the WTC 1 global model, floors 91-101. 


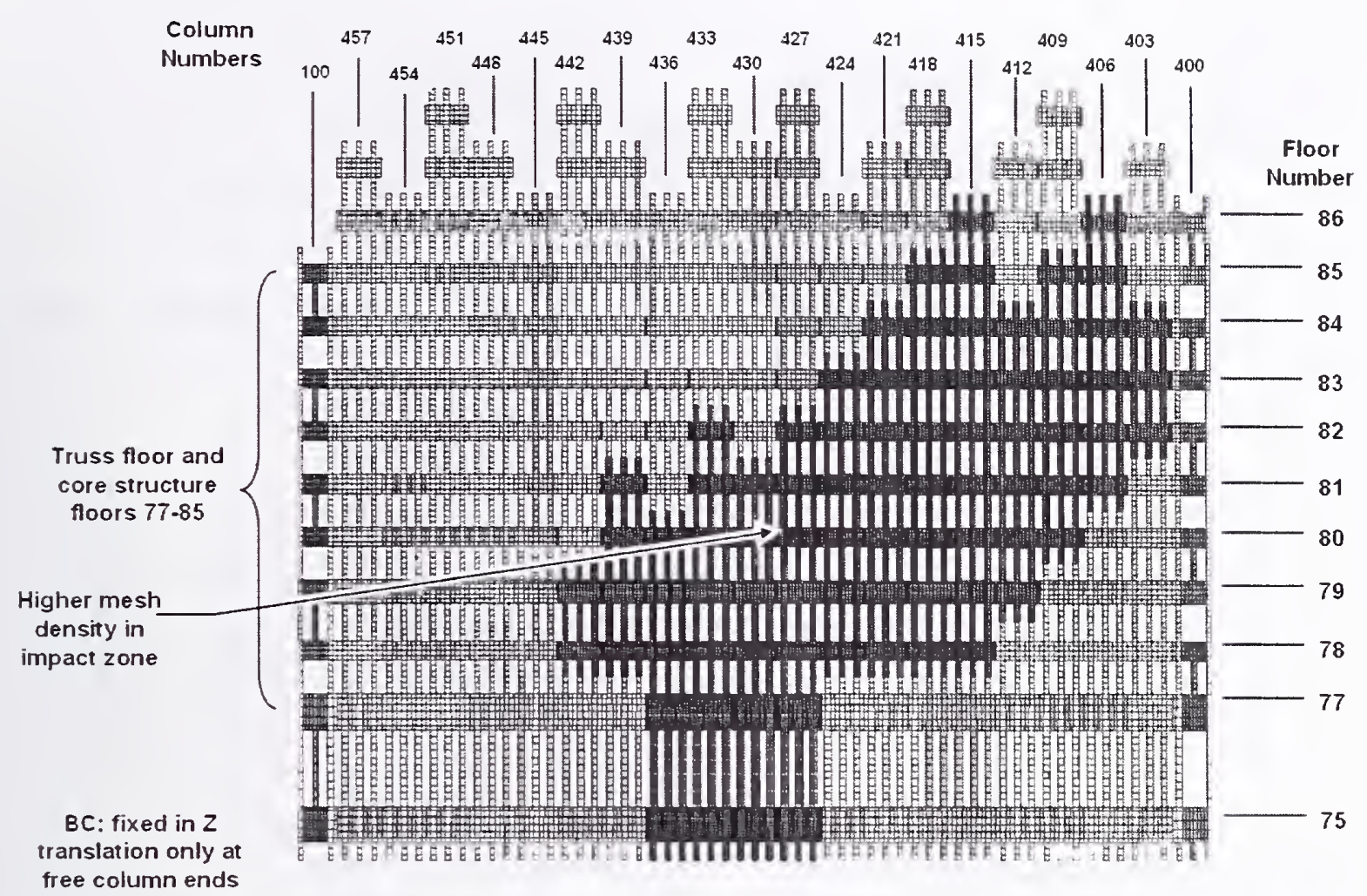

Figure 5-3. Impact face of the WTC 2 global model, floors 75-86.

The model of the spandrel splice plate connection is shown in Figure 5-4. Twelve nodes on the splice plate were attached to the spandrels using the spot weld tied node algorithm (LS-DYNA Type 7 tied interface). The spot weld approximated the connection of the individual bolts connecting the spandrel splice plates. Failure of these connections occurred through deformation of the splice plates and/or spandrel and ductile failure of the materials. The placement of the spandrel splice plates was limited to the higher resolution impact zone for the exterior wall. The far-field coarse panel models were merged together as shown in Figure 5-5. The influence of the spandrel splice connection on the impact response and exterior wall damage was investigated using engine component impact analyses (see Chapter 5 of NIST NCSTAR 1-2B).

Each three-column, three story panel in the impact zone contained 5,304 nodes, 5,202 shell elements, 78 brick elements, and 12 beam elements. The corresponding element sizes in the impact zone were a $1 \mathrm{in.} \mathrm{element} \mathrm{for} \mathrm{the} \mathrm{weld} \mathrm{zone} \mathrm{and} 4$ in. elements for the exterior column. A typical element dimension for the far field exterior panels was 14 in.

The boundary conditions at the top and bottom of the exterior wall were constrained vertical displacements. The lateral degrees of freedom and rotation about the vertical axis were not constrained. The free lateral displacements at the model boundary allowed for the tower model to have a rigid body velocity following the impact. Since the natural period of the tower was in the range of 10 to $11 \mathrm{~s}$ (see Chapter 2), the tower provided little structural resistance to the translation at the model boundary during the less than one second impact event. 


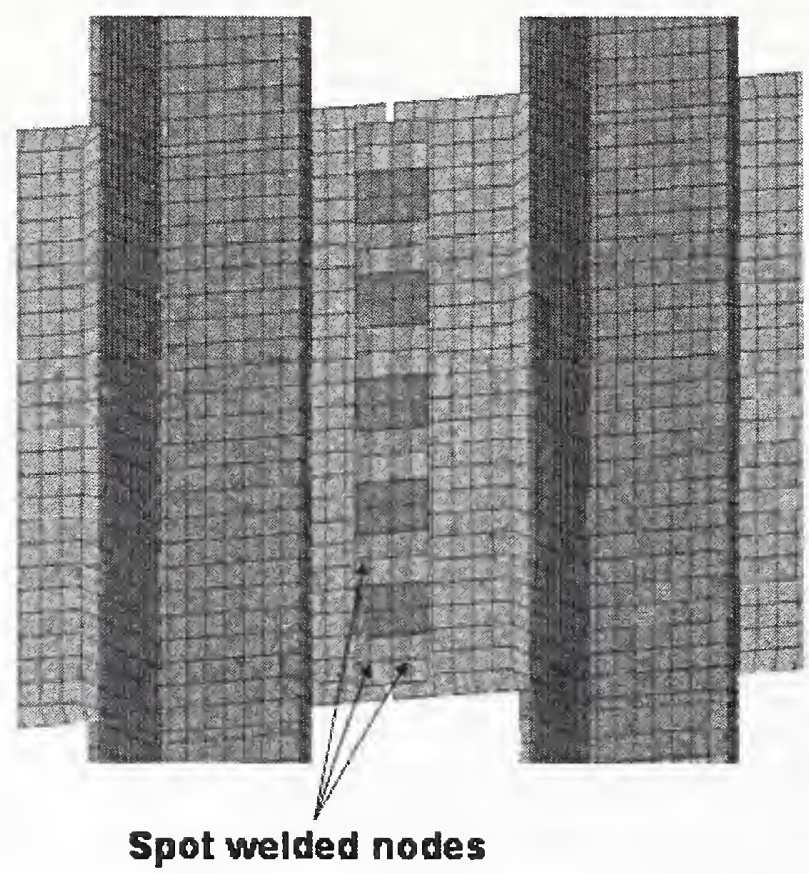

Figure 5-4. Model of the spandrel splice plate connection.

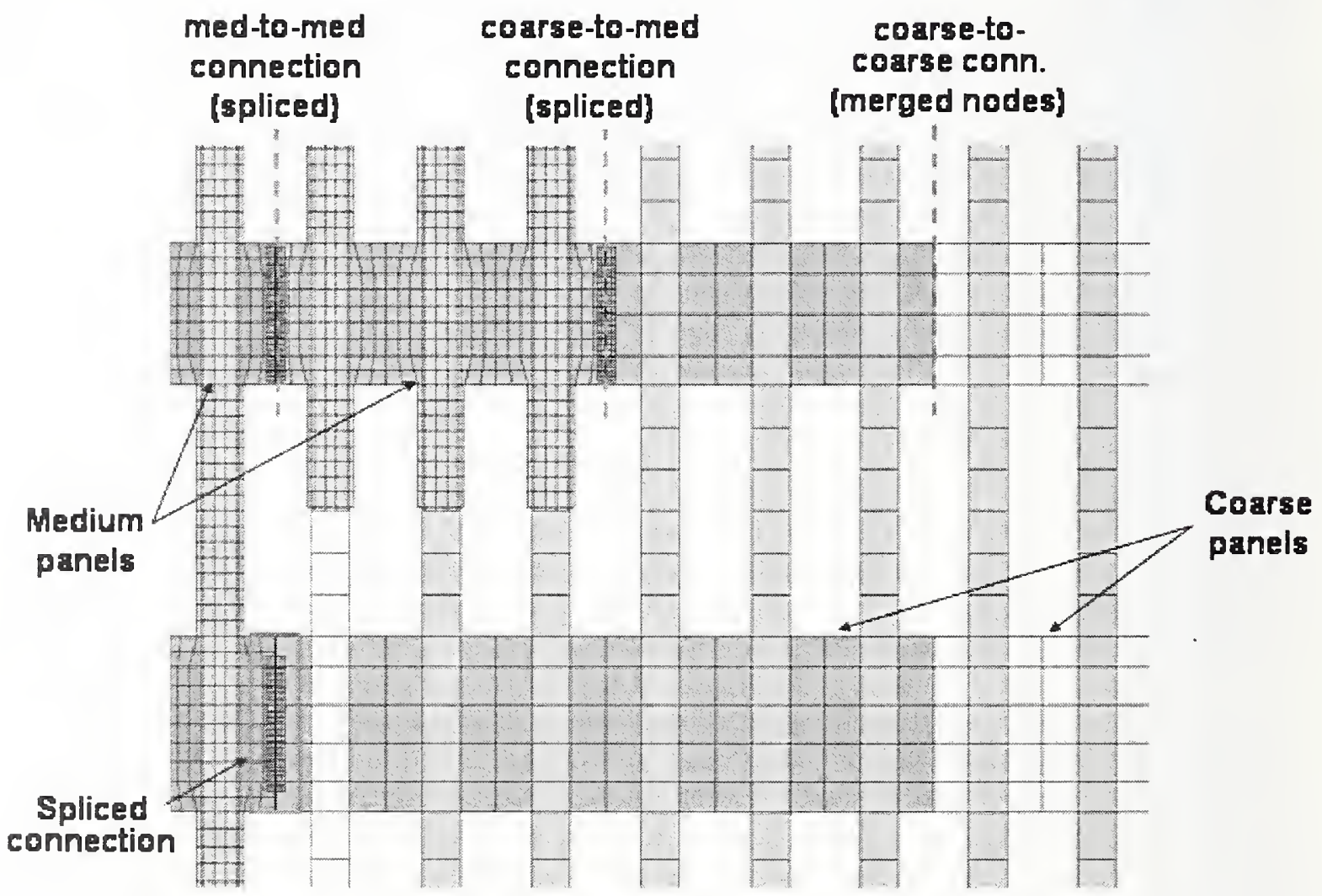

Figure 5-5. Placement of spandrel splice plates in the exterior wall model. 


\subsubsection{Core Columns and Floors Model Development}

Core column models were generated as a group in single floor sections. Dimensions and material specifications were assigned automatically, as specified in the WTC structural databases. The boundary conditions at the top and bottom of the core model and the column splices were automatically generated. An example of the model of the WTC 1 core columns for floors 95 to 97 is shown in Figure 5-6. Different colors correspond to different material assignments for the various column sections.

\section{Core Columns: Floors 95-97}

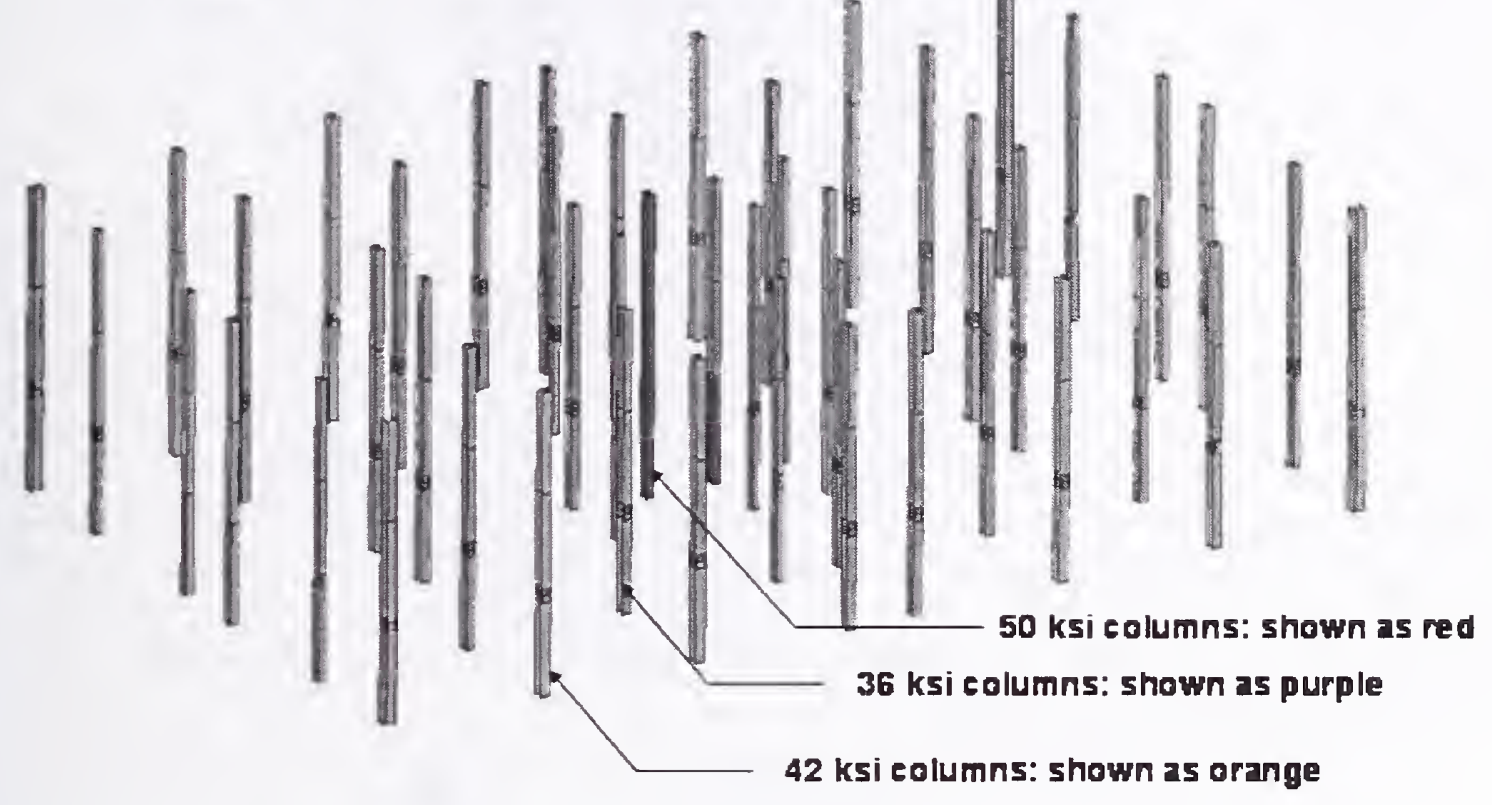

Figure 5-6. Model of the WTC 1 core columns and connections, floors 95-97.

Both wide flange and box core columns were modeled with Belytschko-Tsay shell elements. Two mesh densities were used in the model, a refined density in the direct impact area and a coarse far field density elsewhere. Typical element dimensions were 2 in. and 8 in. for the impact zone and far field, respectively. A single wide flange column in the impact zone had 552 shell elements and 600 nodes per floor, while a box column in the impact zone had 864 shell elements and 900 nodes per floor.

The wide flange-to-wide flange core column connections were modeled by splice plates placed on the outer side of each flange, as shown in Figure 5-7. The connection between the splice plate and column flange was modeled with a surface-to-surface tied interface without failure, which resulted in a perfect bond between the nodes of the splice plate and the flange of the adjacent column. If the columns were pulled apart, the elements at the splice plate spanning the gap between column ends would be stretched. Failure of the splice plate in the model resulted from ductile failure of the splice plate in the elements spanning the connection. 

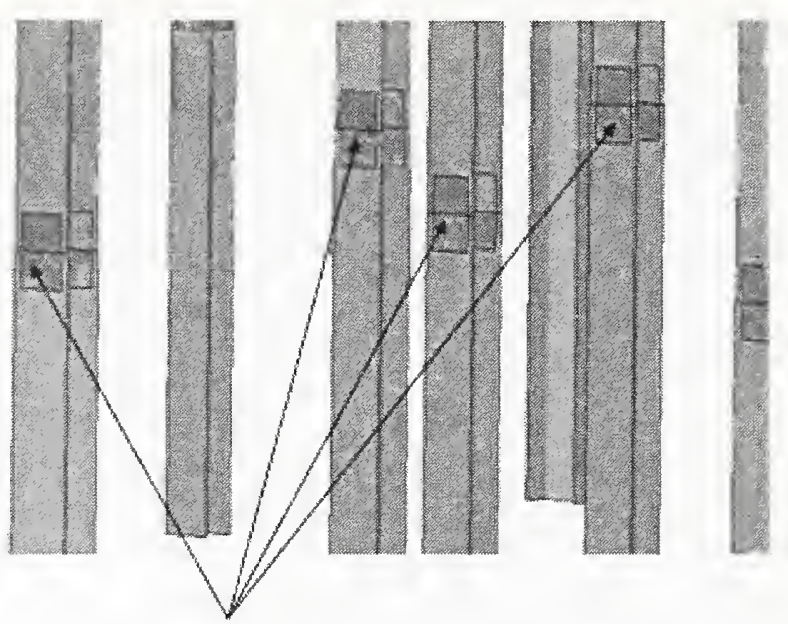

Splice Plates

Figure 5-7. Detail of wide flange core columns splices

A typical box column-to-wide flange column connection is shown in Figure 5-8. The thick box column cap was modeled with shell elements and was perfectly merged into the lower box column. The connection between the wide flange column and the box column cap was an edge-to-surface tied interface without failure, which resulted in a perfect bond between the nodes of the wide flange column and the element segments of the box column cap plate. Failure of this connection would occur only when deformations and strains of this connection were sufficiently high to fail the elements in the columns adjacent to the joint.

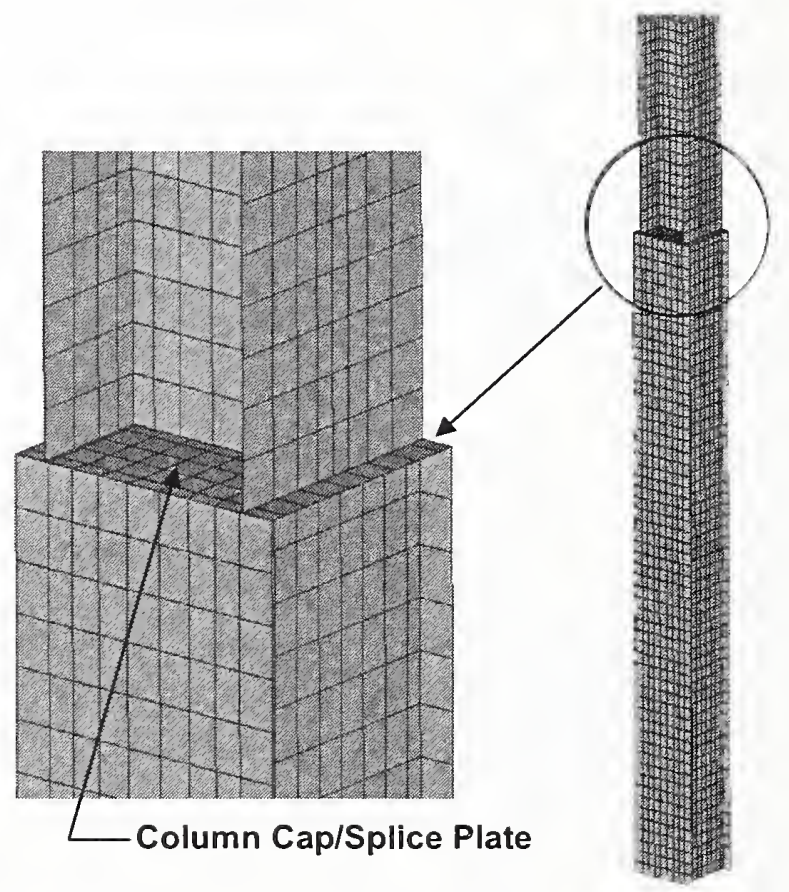

Figure 5-8. Detail of box column-to-wide flange core columns connection. 
The approach for assembling the core floors in the global model was to generate models of typical floors in the impact zone and repeat them in the surrounding floors. For WTC 1, a model of floor 96 inside the core was developed and used for modeling floors 92 through 100. This approach was also used for floors 77 through 85 as the impact zone in WTC 2. Figure 5-9 shows the WTC 1 core prototype of the 96th floor with and without the concrete floor slab. The entire model was developed with Belytschko-Tsay shell elements. Mesh density was set independently from floor to floor to obtain higher accuracy in the impact zone and computational economy in the surrounding floors. A typical core floor with the higher impact zone mesh density had approximately 66,000 shell elements and 76,000 nodes. This included core floor slab, floor beams, connections, and core columns over a height of one floor.

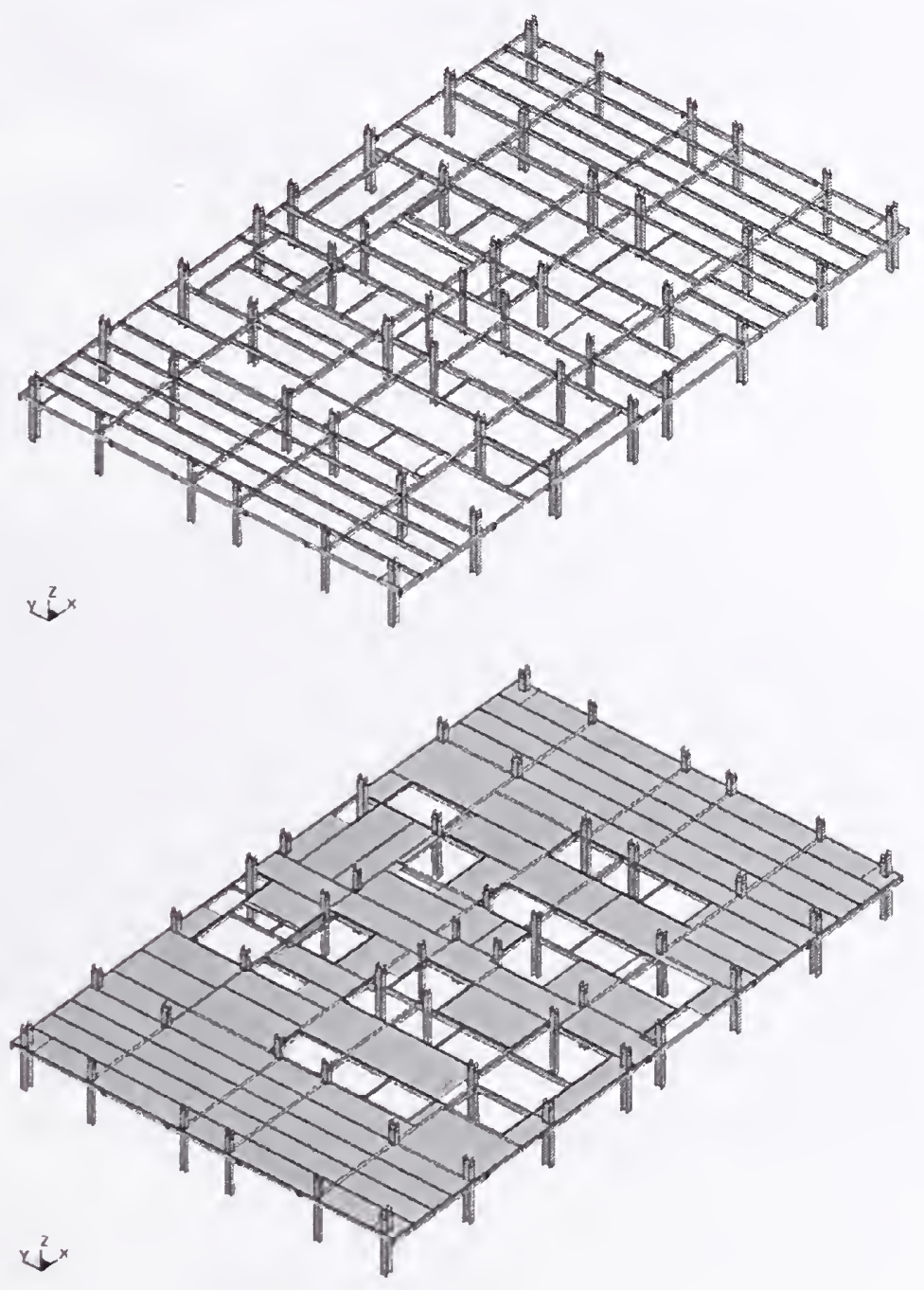

Figure 5-9. Model of the core of floor 96 of WTC 1 (with and without floor slab).

The various connection details between core beams are illustrated in Figure 5-10. Core perimeter beams were joined with splice plates in the same manner as the wide flange column end connections described above. Interior beams were connected with node-to-surface tied connections. This contact algorithm constrained the nodes to move with the same relative motions as the adjacent surface elements and was 
appropriate for modeling a strong welded connection. An automatically generated model for the assembly of WTC 1 core floors 94 through 98 is shown in Figure 5-11.

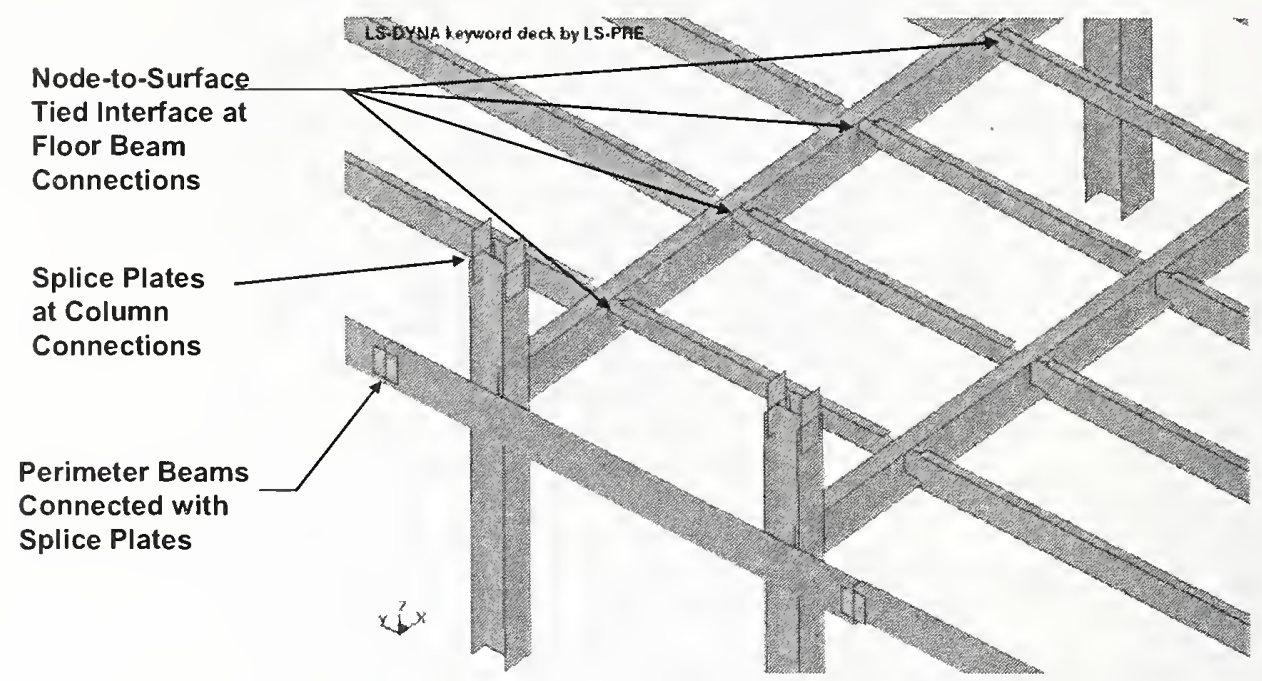

Figure 5-10. Model detail of core column and beam connections.

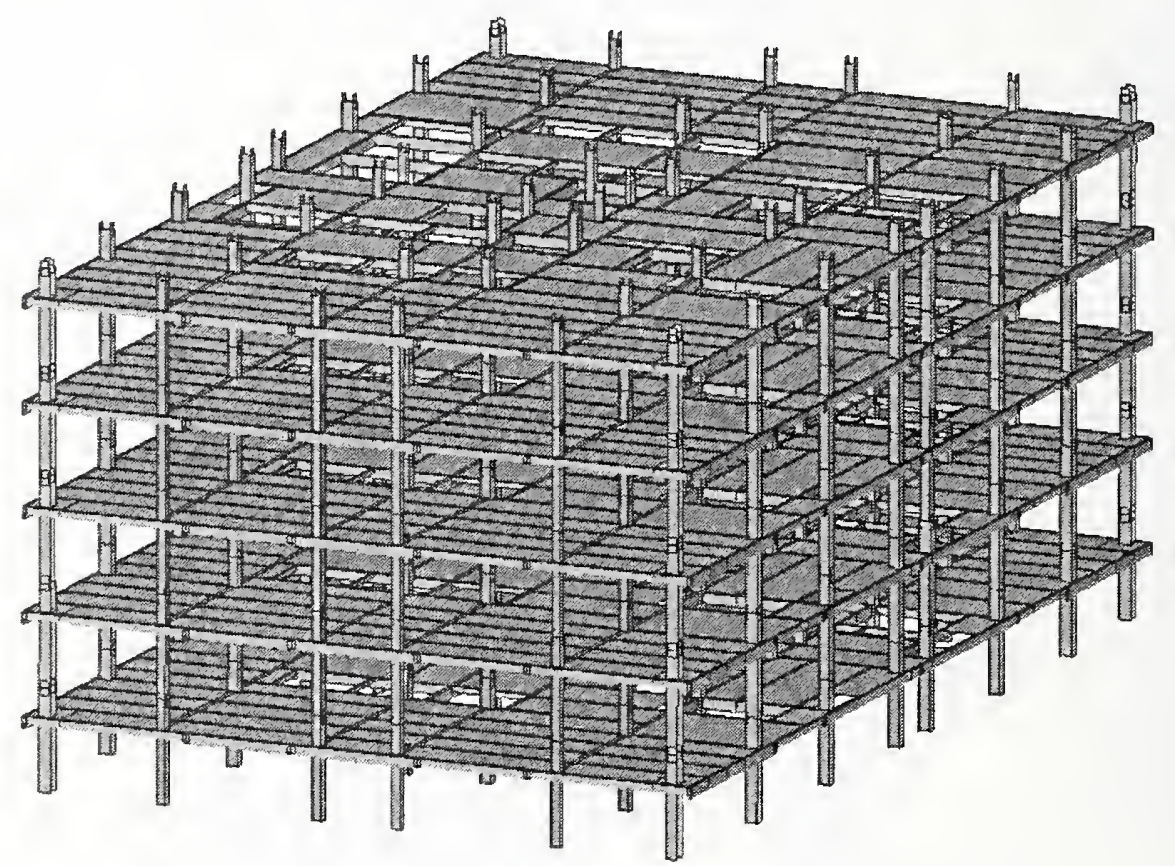

Figure 5-11. Model of the WTC 1 core, floors 94-98.

\subsubsection{Truss Floor Model Development}

The approach to the development of the truss floor model was very similar to other portions of the tower structure. Initially, parameterized component models were developed for segments of long-span trusses, short-span trusses, and corner two-way trusses. These parameterized models were then called repeatedly for generation and placement of the floor truss segments within the complete tower models. The 
individual truss floor segments spanned the distance from the exterior wall to the core. An example of a truss floor segment used in the global model is shown in Figure 5-12. In the double truss sections, the two trusses were modeled explicitly with the proper dimensions.

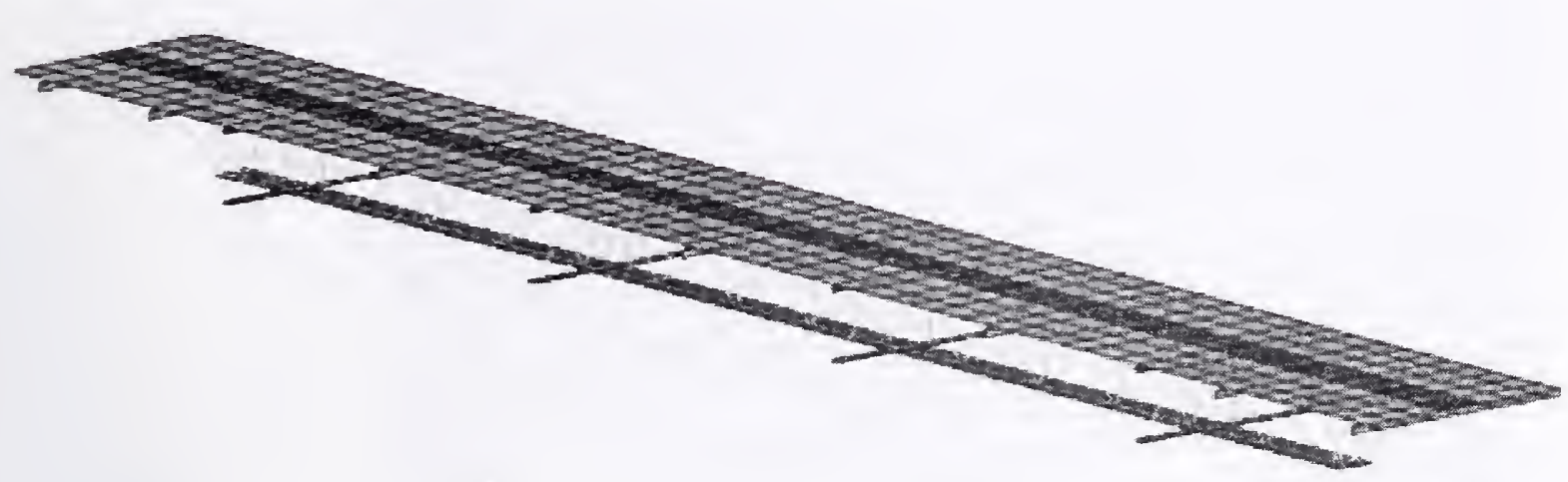

Figure 5-12. Model of a truss floor segment.

The floor truss model was developed using a uniform layer of Belytschko-Tsay shell elements for the combined floor slab and metal decking, Belytschko-Tsay shell elements for the truss upper and lower chord components, and Hughes-Liu beam elements for the round bar truss diagonals. The upper chord was attached to the floor slab using a tied interface. This approach, using shell elements as opposed to solid brick elements for the floor slab, was adapted to reduce the model size requirements. Development of a model with matching mesh density in the slab and truss structures (nodal alignment for a merged connection) resulted in a much larger model size. Bridging trusses were modeled in a similar fashion to the primary trusses.

A series of dampers were installed in the WTC towers between the floor truss lower chord and the spandrel on the exterior wall. The primary function of these dampers was to reduce the vibration of the building under wind loading. These dampers, however, were of low mass and the arrangement of the damper and saddle (member attaching the damper to the bottom chord of the truss), along with their connections, had virtually no strength in the transverse direction. Under impact conditions, the aircraft applied transverse forces to the damper assembly due to the downward motion of the aircraft (see Chapter 6). Also, due to the short duration of the impact event (less then one second), damping was not included in the analyses. As a result, the dampers were considered to have sufficiently low mass and strength and were therefore not included in the impact analyses.

The mesh refinement used in this model for the truss floor would result in a very large global tower model size if used throughout the structure. The model for the long-span truss floor segment (Figure 5-12) contained 2,737 nodes, 362 beam elements, and 1,878 shell elements. Constructing a global impact tower model with these detailed floor segments was not practical due to model size limitations. A complete floor would result in approximately 200,000 nodes for a single truss floor structure. As a result, detailed floor segments were used only in the impact zone, and a simplified floor truss model was used elsewhere. The far-field floor truss was modeled with a significantly reduced mesh resolution, as shown in Figure 5-13, and provided the appropriate inertial properties and structural stiffness of the floor. The trusses were modeled with an effective shell element in place of the vertical truss structure and a beam element along the lower chord. These element dimensions were on the order of $30 \mathrm{in}$. and would not be able to accurately model a local collapse behavior of the trusses. The floor slab model was similar to the 
floor slab in the impact zone, but with a typical element dimension of $30 \mathrm{in}$. compared to an element dimension of approximately $10 \mathrm{in.}$ in the impact zone.

Figure 5-14 and Figure 5-15 show the truss floor connection details at the exterior and core, respectively. The models for the truss seat connections were developed using shell elements and attached using the tied interface algorithm. The failure of these seats occurred only as a result of exceeding the ductility of the seat or truss structures. A detailed model of floor 96 of WTC 1 is shown in Figure 5-16.

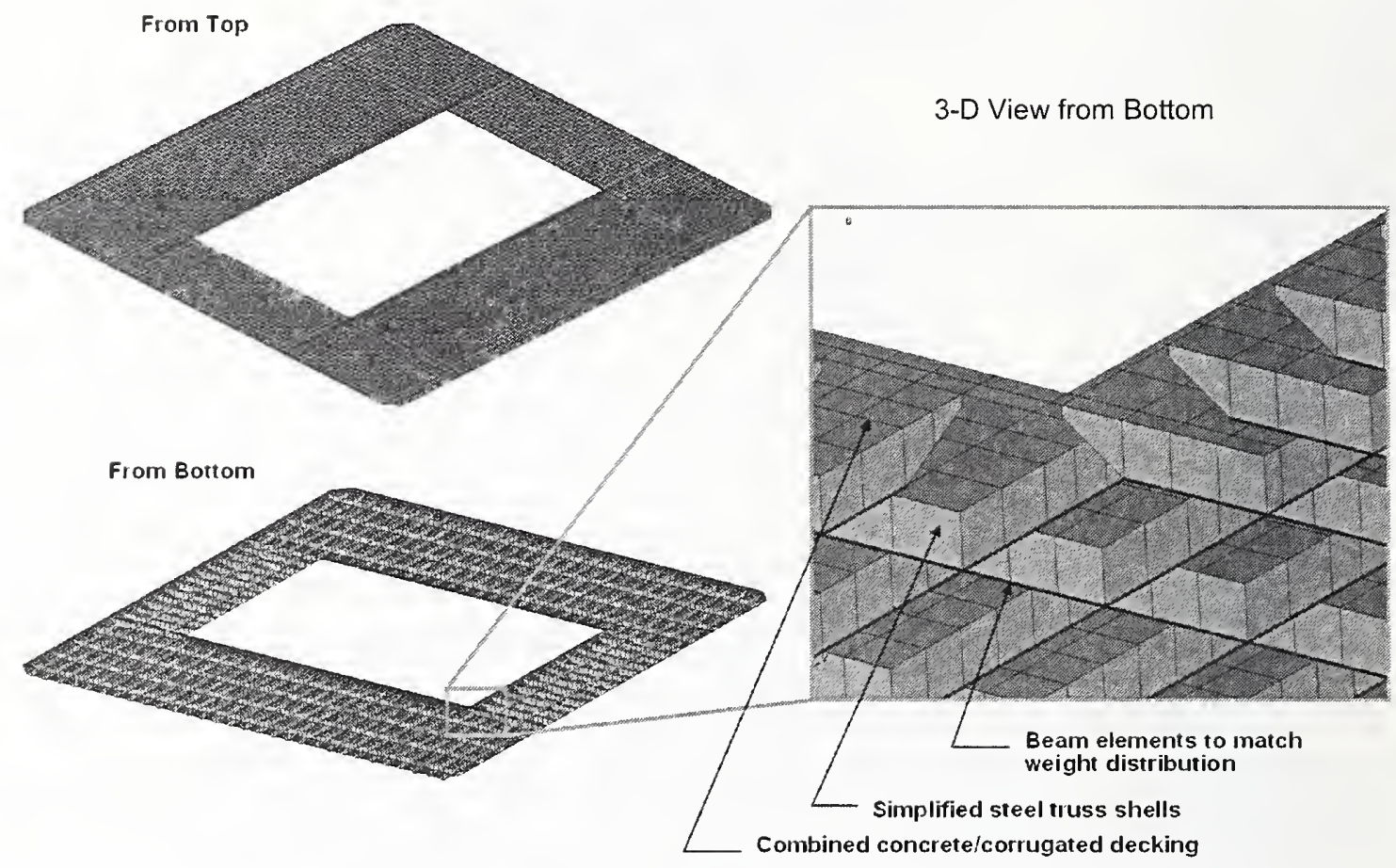

Figure 5-13. Simplified far field truss floor model.

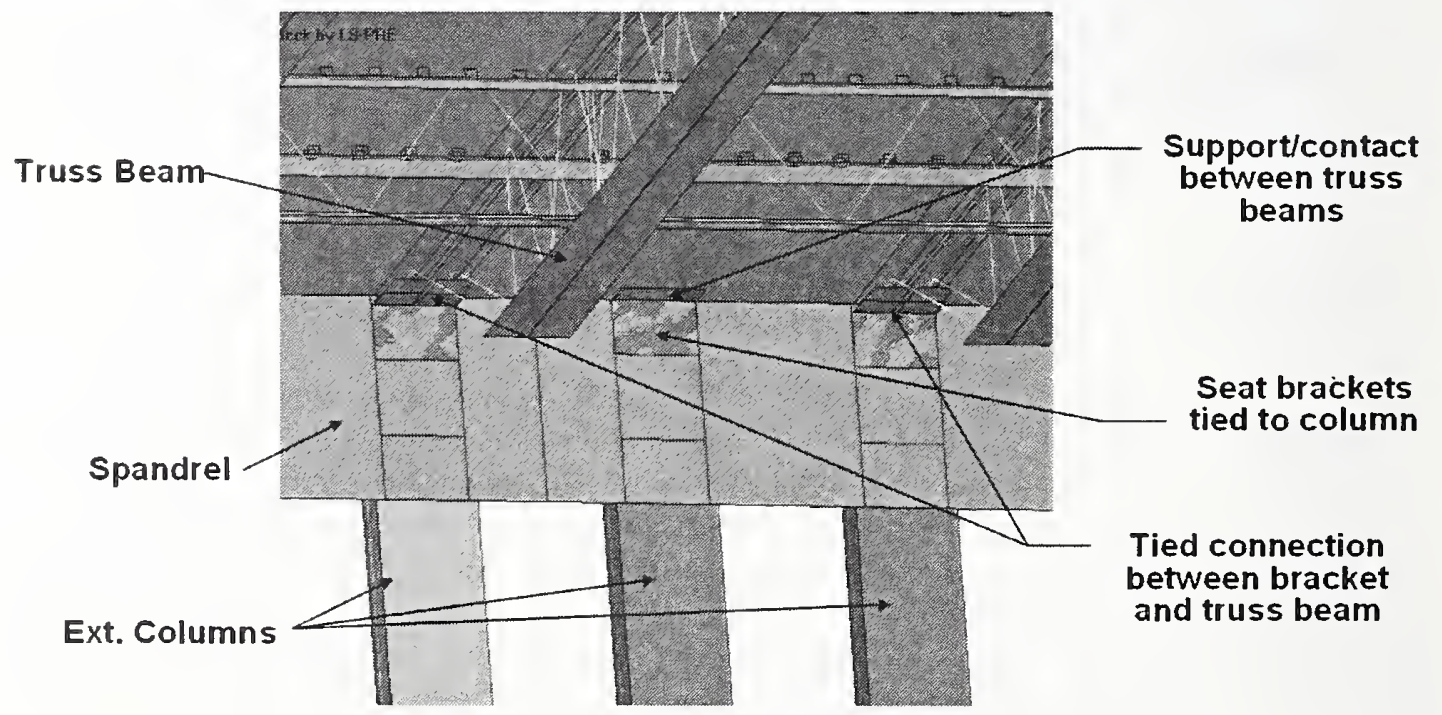

Figure 5-14. Truss floor connection detail at exterior wall. 


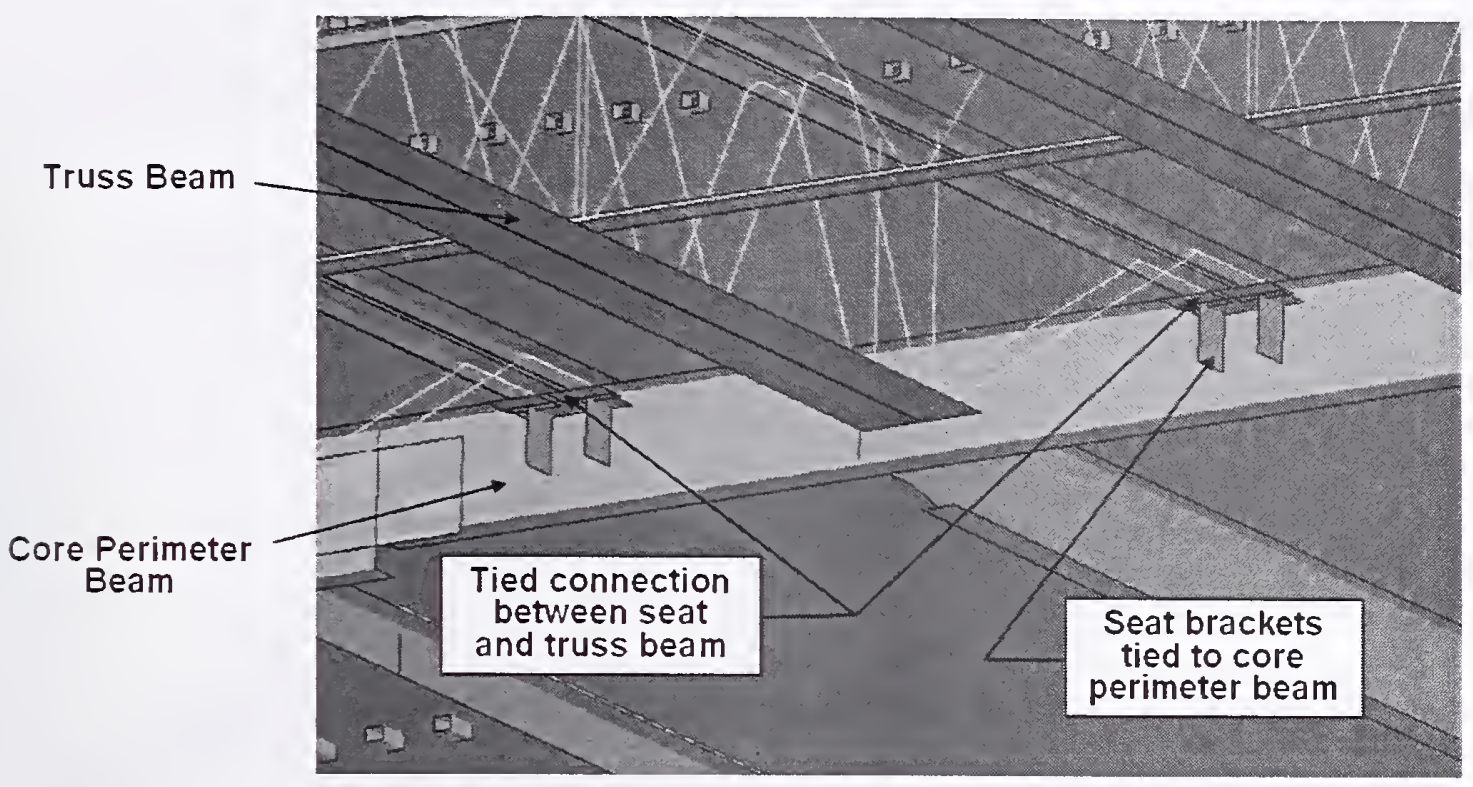

Figure 5-15. Truss floor connection detail at core perimeter.

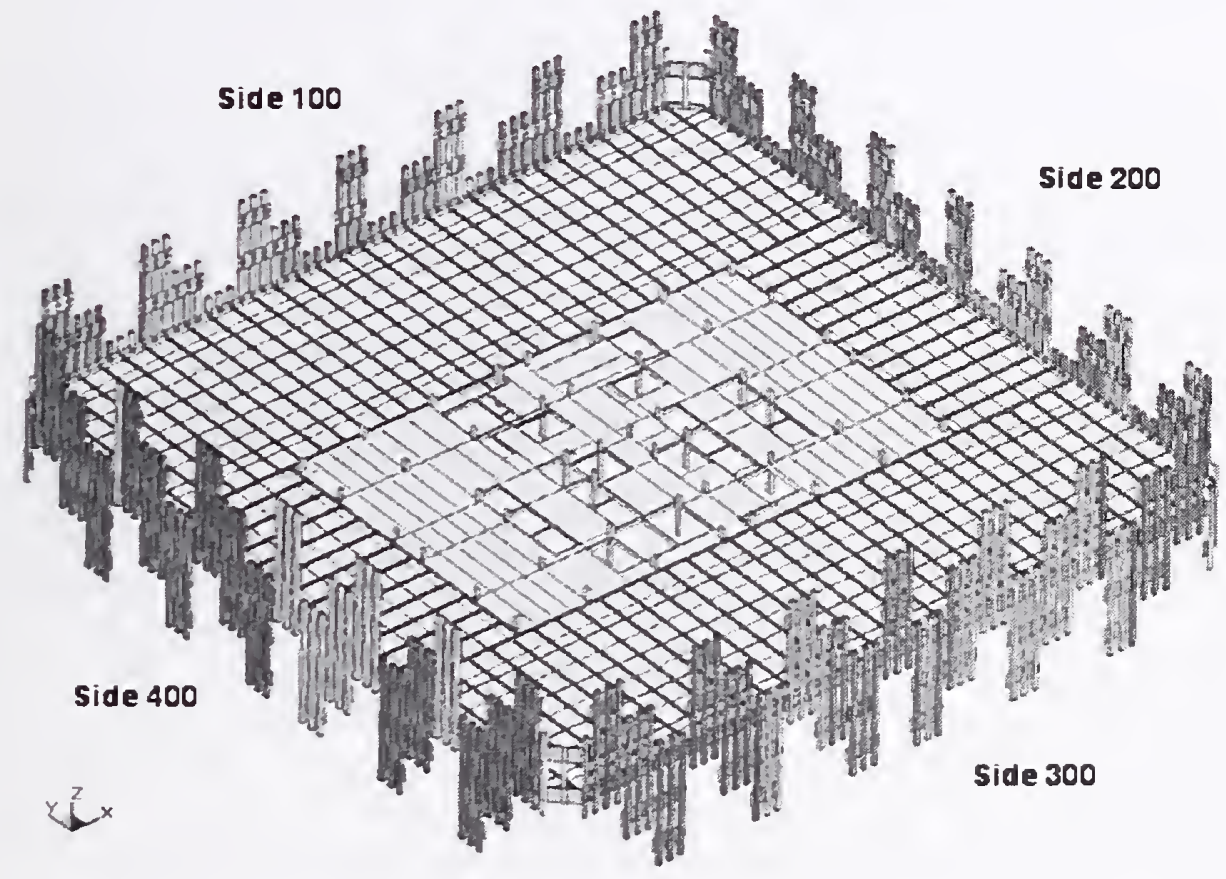

Figure 5-16. Detailed model of floor 96 of WTC 1.

\subsubsection{Interior Contents Model Development}

The interior nonstructural contents of the towers were modeled explicitly in the tower models used for the global impact analyses. The live load weight was distributed between gypsum walls and cubicle workstations that covered the truss floor area. The distribution of the gypsum walls was obtained from 
architectural drawings and other information gathered as part of Project 5 of the NIST investigation (NIST NCSTAR 1-5). Similarly, data gathered by NIST for the floor layout plans in the impact zone were used to develop the approximate placement of workstations over the truss floor area. The resulting model of a floor with interior contents is shown in Figure 5-17.

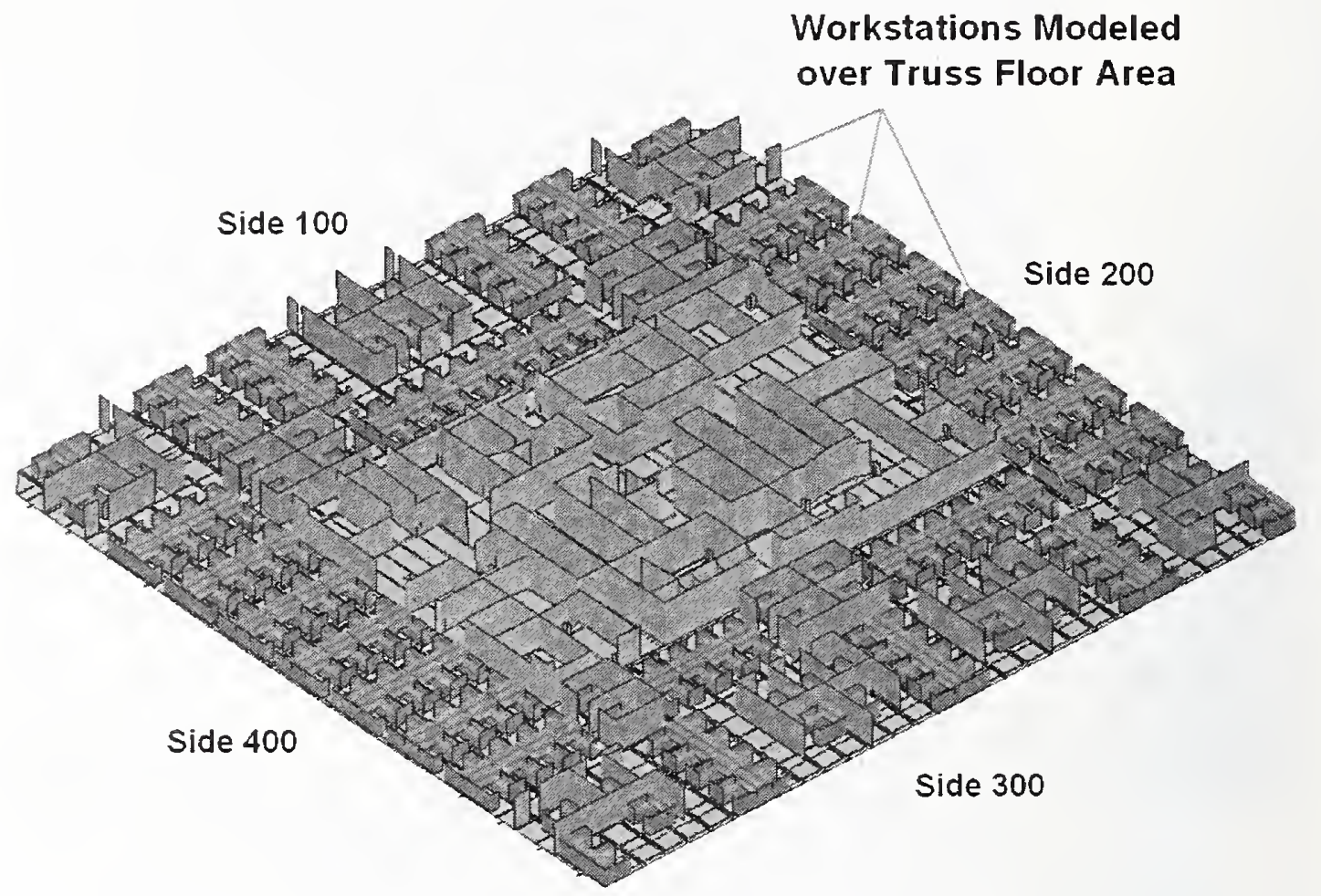

Figure 5-17. Model of floor 96 of WTC 1, including interior contents.

The densities of specific materials were scaled to obtain the desired magnitudes for the service live loads and superimposed dead loads. The densities of the tower contents (workstations and gypsum walls) were scaled by the appropriate ratios to obtain the desired distribution of live loads in the core and truss floor areas. The densities of all the remaining tower structural components were scaled proportionately to obtain the desired superimposed dead loads. These additional loads were important for obtaining an accurate mass distribution in the towers and inertial effects in the impact response. The in-service live load used was assumed to be 25 percent of the design live load on the floors inside and outside the core. The in-service live load was selected based on a survey of live loads in office buildings (Culver 1976) and on engineering judgment. The uncertainty in the amount of in-service live load was accounted for in the sensitivity analyses (Chapter 8 of NIST NCSTAR 1-2B) and in the global impact simulations (Chapter 7 of this report).

The partitions and workstations were modeled using shell elements. The model of the building contents (partitions and workstations) over a single floor, as shown in Figure 5-17, had 101,733 nodes and 97,284 shell elements. To include the complete distribution of the building contents over five floors in the global impact model would require approximately 500,000 nodes. As a result, the global models included the partitions and workstations only in the region of each floor directly in the path of the aircraft impact and debris. Using this approach significantly reduced the computational requirements needed to 
include the building contents' inertial contributions. For example, the WTC 1 global impact model included only 160,410 nodes and 148,858 shell elements for the partitions and workstations in the impact path over five floors. These building content distributions for both tower models are shown in the following section.

\subsubsection{Global Impact Models Assembly}

The multiple floor global model of the impact zone in WTC 1 is shown in Figure 5-18. The model included the complete floors inside and outside the core, the exterior walls, and core structures for floors 92 through 100 . The boundary conditions at the top and bottom of the exterior and core columns were constrained vertical displacements. This allowed for free translations of the tower structure in the longitudinal and lateral directions and rotation about the vertical axis. The higher resolution exterior wall panels in the impact zone can be seen on the impact face of the tower model (side 100).

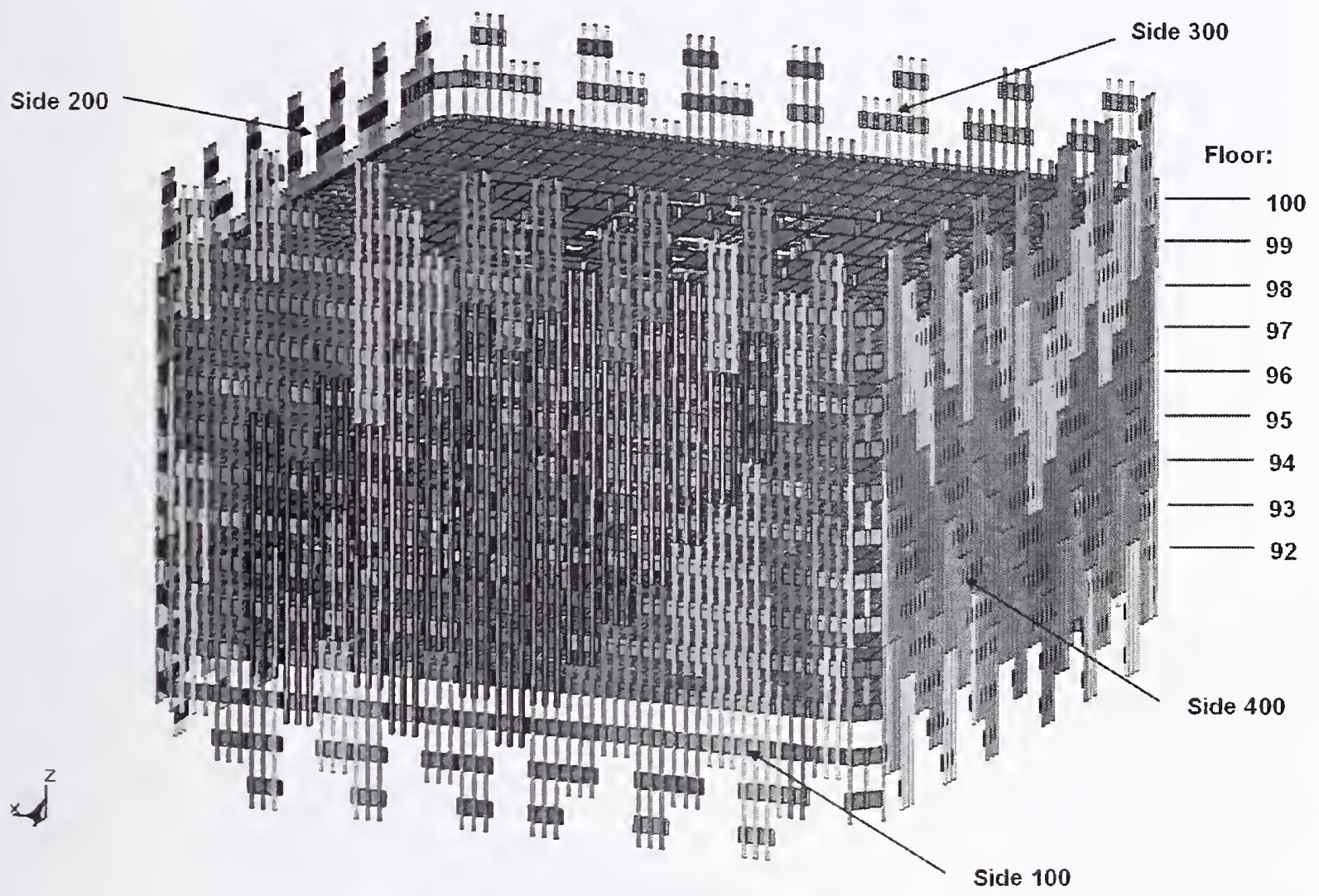

Figure 5-18. Global impact model of the WTC 1 tower.

The WTC 1 global impact model with the exterior wall removed is shown in Figure 5-19. The figure shows how the model was optimized to reduce mesh size and eliminate computational requirements outside of the immediate impact and damage zone. The nonstructural building contents (partitions and workstations) were modeled only in the path of the aircraft impact and debris cloud. These components are shown separately in Figure 5-20. 
In the assembled global model, the core columns for floors 93 through 98 of WTC 1 were modeled with higher resolution than that in the floors above and below the direct impact zone. This higher mesh resolution was needed to capture the local damage that occurred from direct impact of aircraft structures and debris.

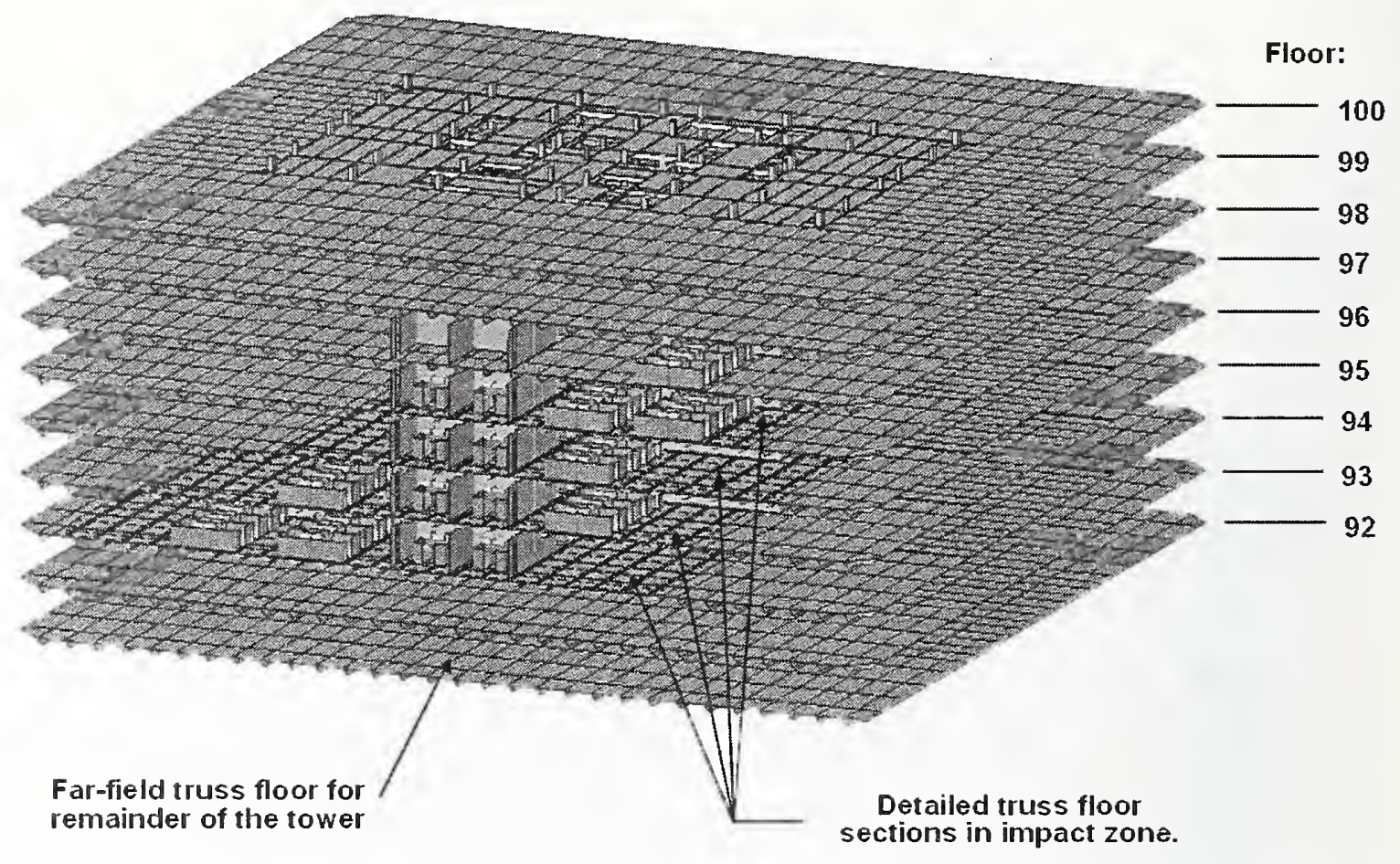

Figure 5-19. Interior structures and contents of the WTC 1 global impact model.

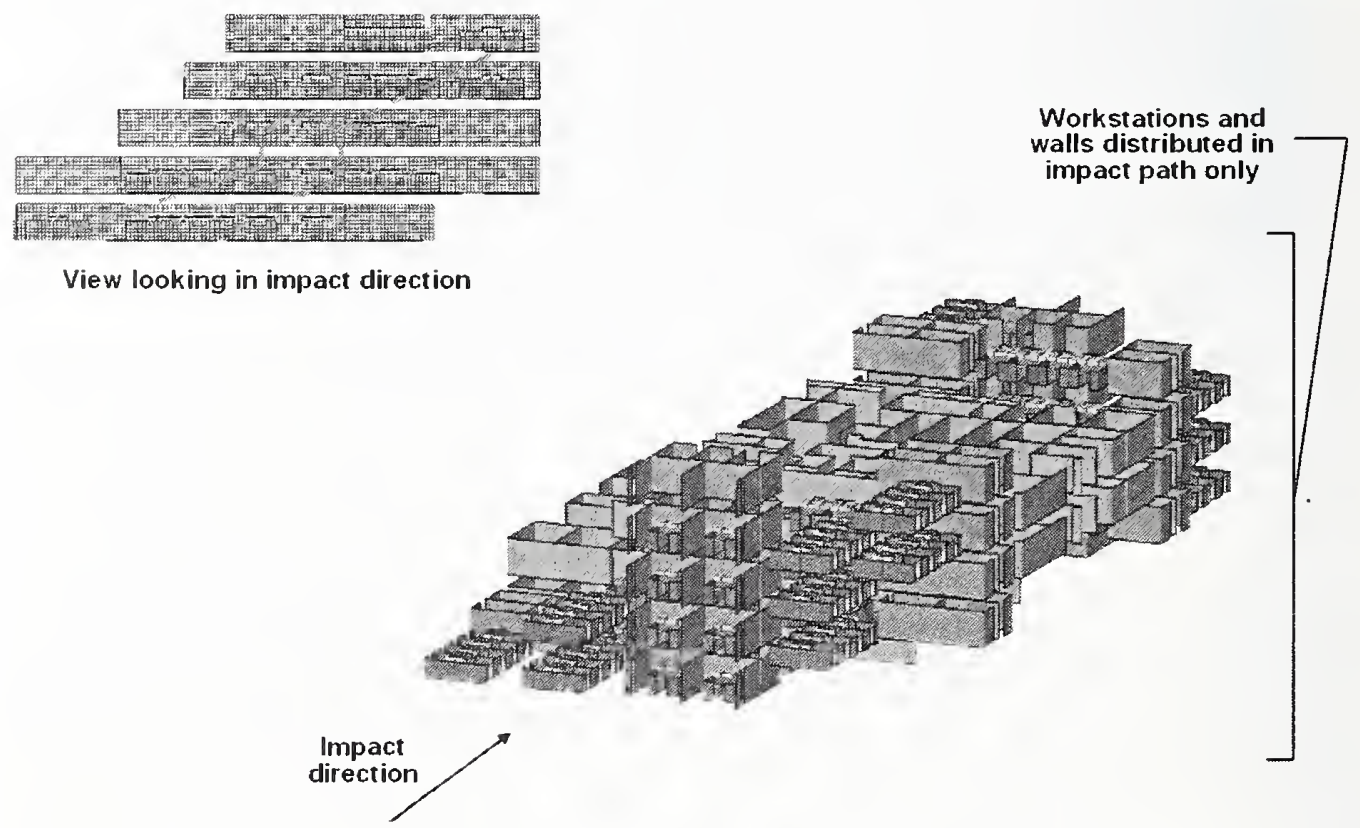

Figure 5-20. Nonstructural building contents in the WTC 1 global impact model. 
The WTC 2 global impact model is shown in Figure 5-21. The model included the complete floor inside and outside the core for floors 77 through 85 . The exterior wall panels at the bottom end of the model extended downward below floor 75. The boundary conditions at the top and bottom of the exterior and core columns were the same as those for the WTC 1 model. The higher resolution exterior wall panels in the impact zone can be seen on the impact face of the WTC 2 tower model (Side 400).

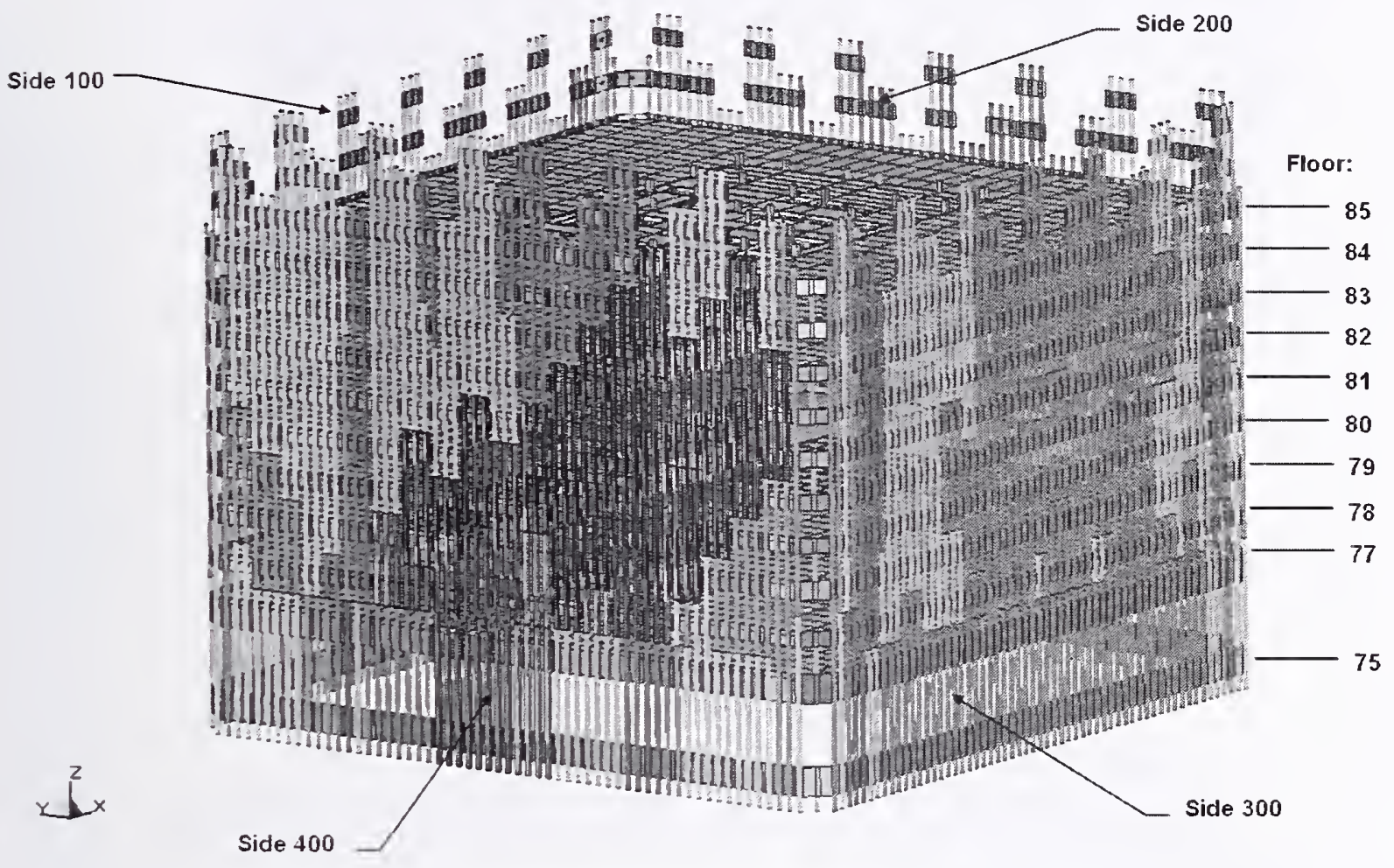

Figure 5-21. Global impact model of the WTC 2 tower.

The WTC 2 global impact model with the exterior wall removed is shown in Figure 5-22. The nonstructural building contents were again modeled only in the path of the aircraft impact and debris cloud. These components are shown separately in Figure 5-23. Similarly, the truss floor structures near the impact zone were modeled in greater detail as seen in Figure 5-22. These detailed sections of the truss floor were positioned adjacent to Side 400 (south face) for floors 78 through 81 and side 300 (east face) for floors 81 and 82 . The surrounding truss floor structures were modeled with the far-field truss model. 


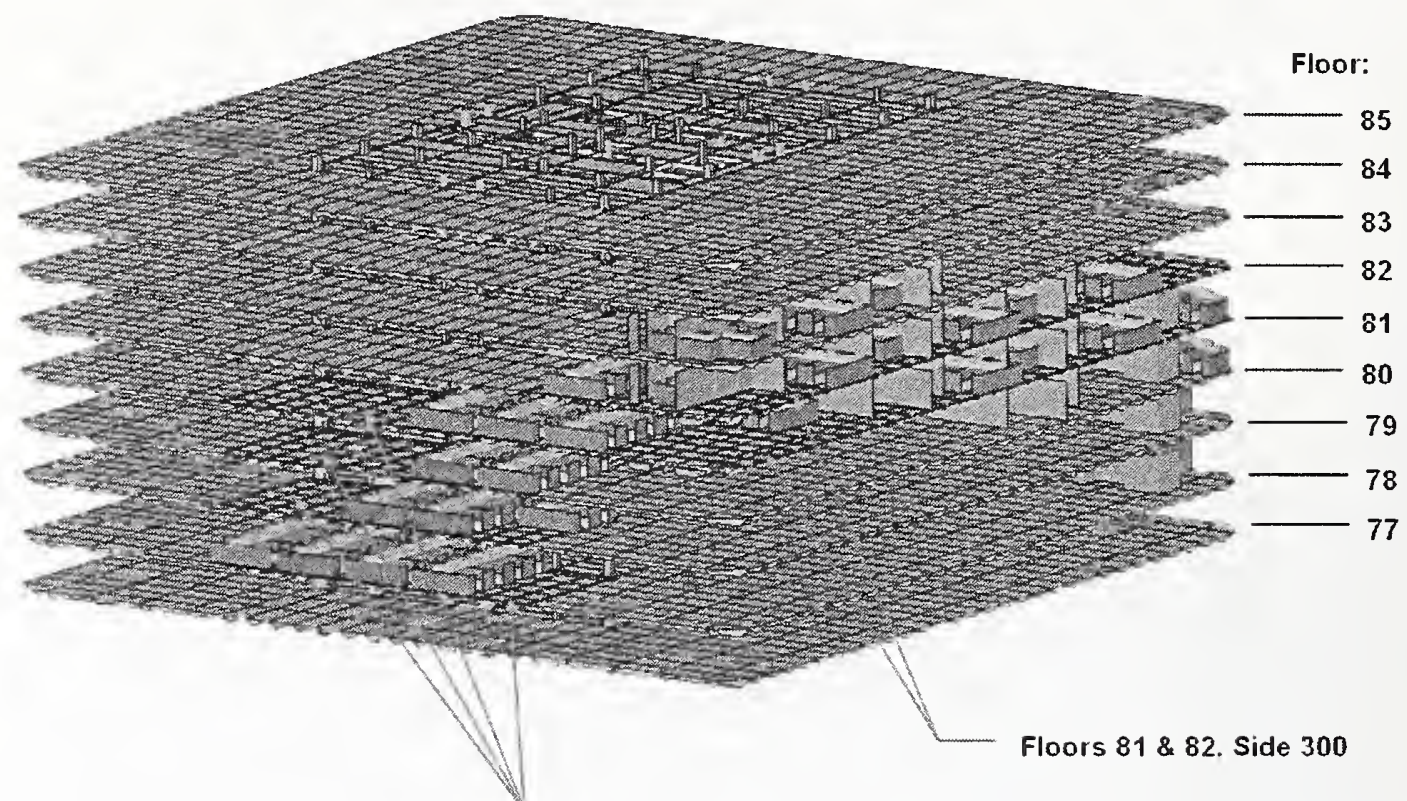

Floors $78-81$. Side 400

Figure 5-22. Interior structures and contents of the WTC 2 global impact model.

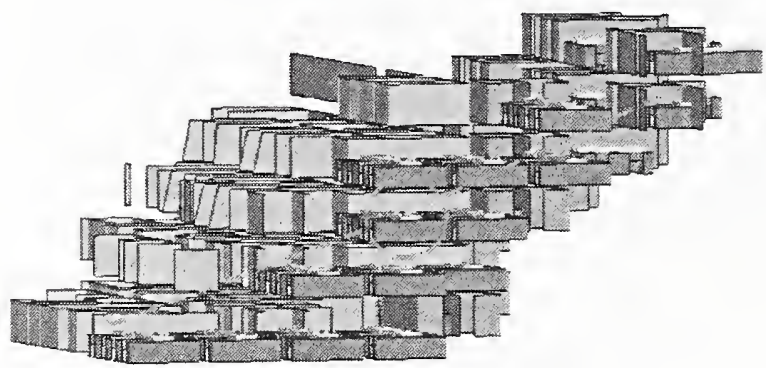
Workstations and
walls distributed in
impact path only

View looking in approximate impact direction
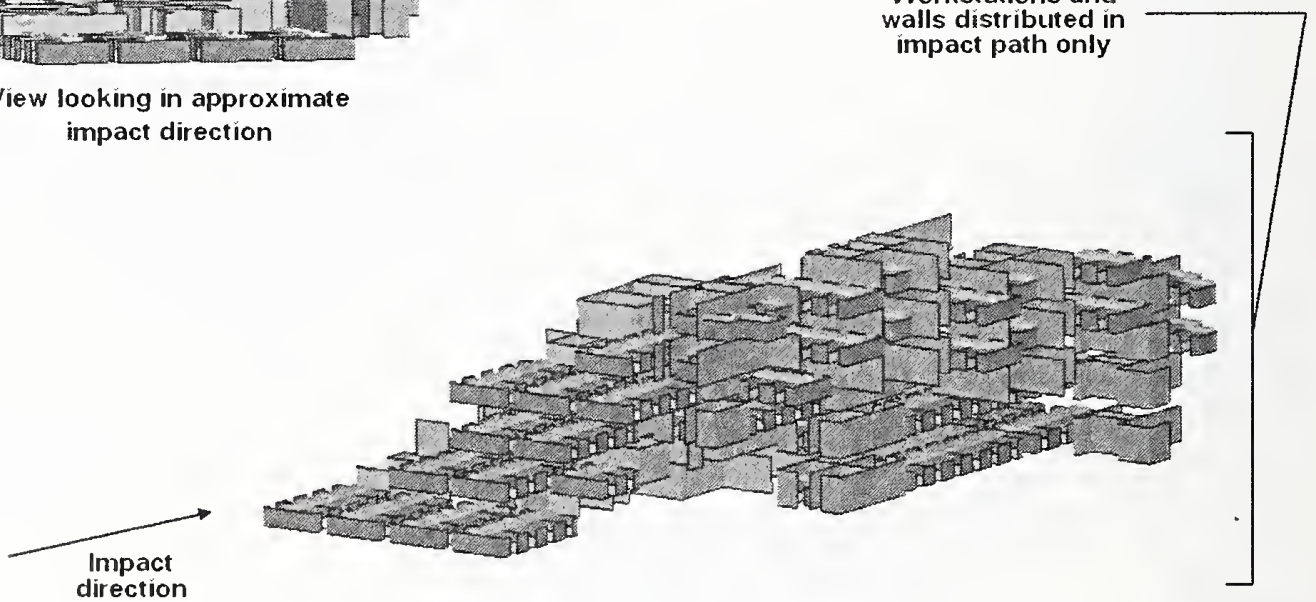

Figure 5-23. Nonstructural building contents in the WTC 2 global impact model.

\subsubsection{Tower Material Constitutive Models}

The development of constitutive models that properly captured the actual behavior of the WTC towers under the dynamic aircraft impact conditions was an important requirement for high fidelity simulation of 
the aircraft impact damage. The primary materials that were considered included: (1) the several grades of steel used in the columns, spandrels, and floor trusses and beams of the WTC towers; (2) the concretc floor slabs; and (3) the nonstructural contents of the towers. These materials exhibit significant nonlincar rate-dependent deformation and failure behavior over the range of strain rates expected in the impact scenario. The following is a brief summary of the constitutive models used for these materials. Additional details can be found in Chapter 2 of NIST NCSTAR 1-2B, where constitutive modcls werc described for bolt material and weldments. It also includes a discussion on the effect of mesh size on failure criteria.

\section{WTC Tower Steel Constitutive Models}

The primary constitutive model used for the several grades of the tower steels was the Piecewise Linear Plasticity model. This model is sufficient to model the nonlinear dynamic deformation and failure of stecl structures. A tabular effective stress versus effective strain curve can be used in this modcl with various definitions of strain rate dependency. The constitutive model parameters for each grade of steel were based on engineering stress-strain data provided by the mechanical and metallurgical analysis of structural steels part of the NIST Investigation (see NIST NCSTAR 1-3D). Finite element analyses of the test specimens (ASTM Designation A 370-03a) were conducted with a fine and a medium mesh (similar to that used in the component level analysis) to capture the nonlinear material behavior up to failure, see Figure 5-24. The finite element analysis also provided a validation that the constitutive model parameters were defined accurately and that the model could reproduce the measured response for the test conditions.

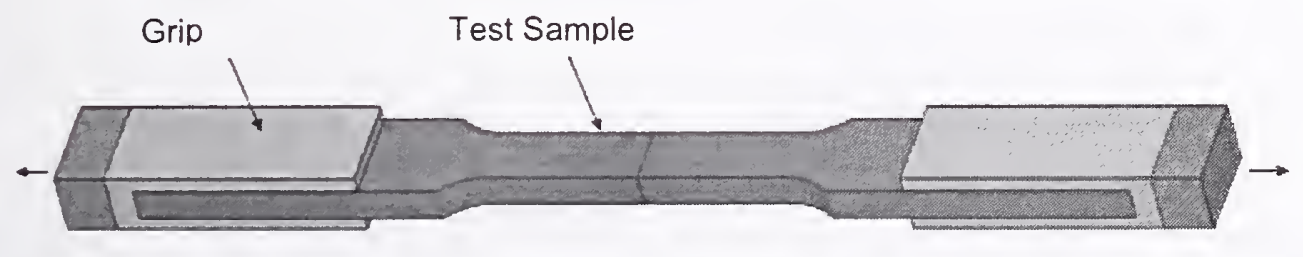

Fine Mesh
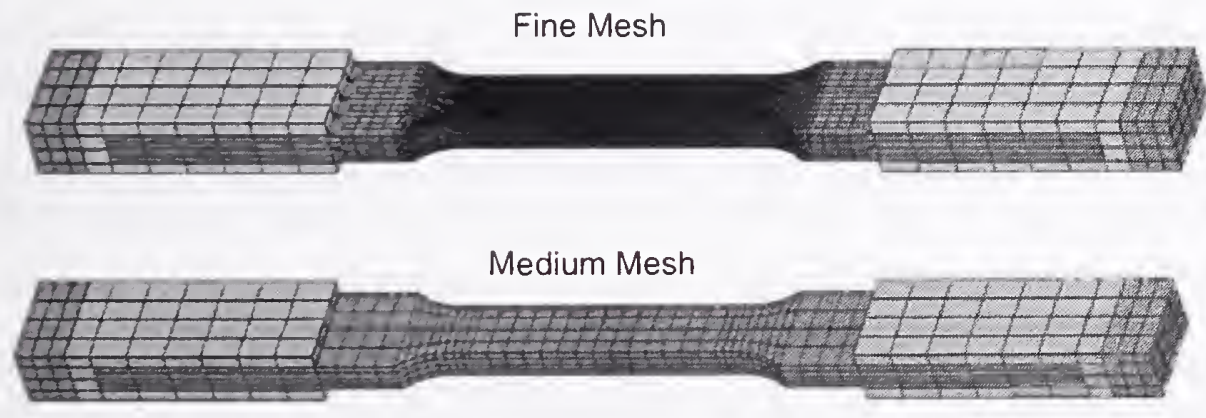

Figure 5-24. Finite element models of the ASTM 370 rectangular tensile specimen.

The first step in the constitutive model development process was to obtain a true stress-true strain curve. The typical approach was to select a representative test for each grade of steel and convert the engineering stress-strain curve to true stress-strain. The true stress-strain curve was extrapolated beyond the point of necking onset. This true stress-strain curve was then approximated by a piecewise linear curve in tabular 
form, which was used to specify the mechanical behavior in the constitutive model. The final step was to simulate the tensile test (Figure 5-24). If necessary, the extrapolation of the true stress-strain behavior was adjusted until the simulation matched the measured engineering stress-strain response including necking and failure (the portion of the stress-strain curve beyond the maximum engineering stress). The true stress-strain curves used in the constitutive models for the various WTC tower steels are summarized in Figure 5-25.

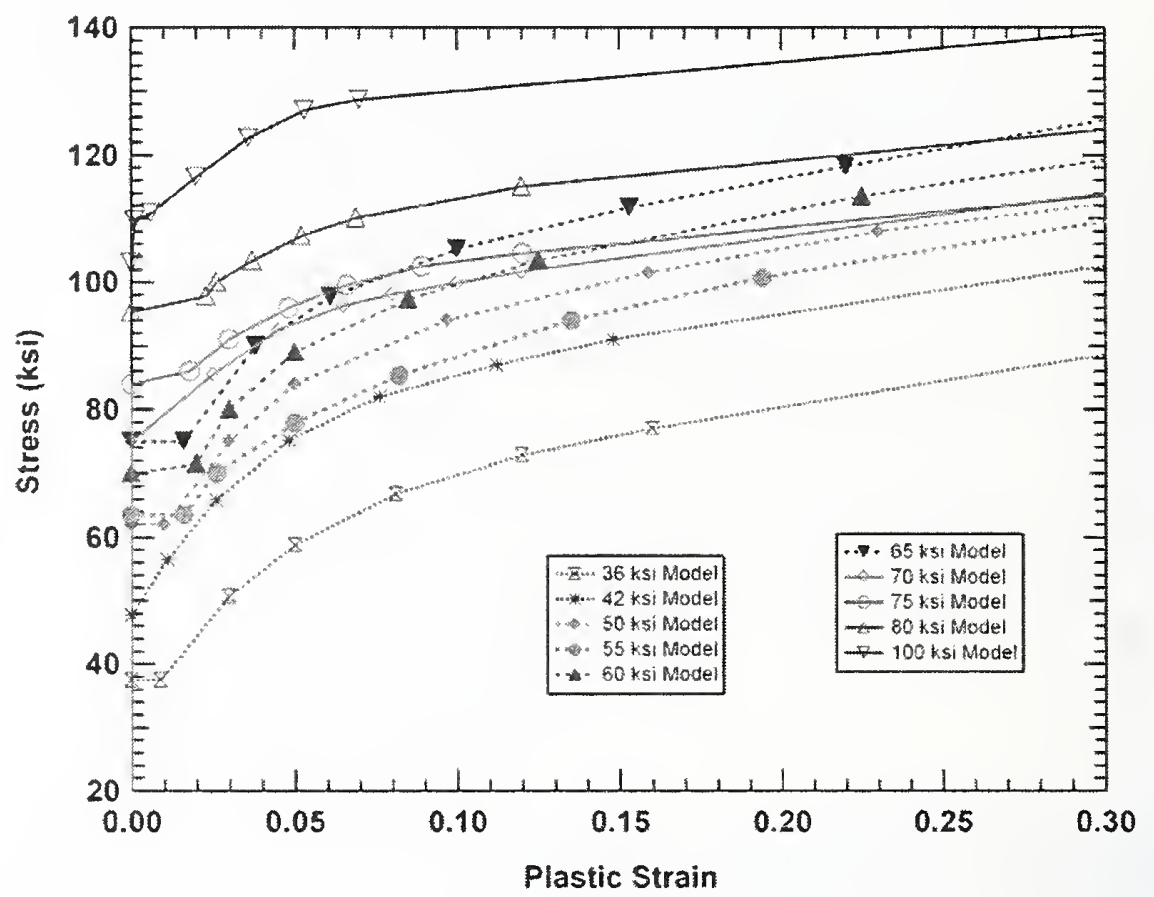

Figure 5-25. Tabular true stress-strain constitutive model curves for the tower steels.

Elevated strain rates can influence the strength and ductility of structural materials. For the materials and strain rates of the WTC tower impact analyses, these strain rate effects are expected to be somewhat small compared to the effects of the baseline (static) strength and failure modeling. Strain-rate effects on the steel yield strength were included in the constitutive model for tower steels with the Cowper and Symonds rate effect model. The functional form for the rate effects on strength is governed by the equation:

$$
\sigma_{y}=\sigma_{y_{0}}\left[1+\left(\frac{\dot{\varepsilon}}{C}\right)^{1 / p}\right]
$$

where $\sigma_{y}$ and $\sigma_{y_{0}}$ are the yield strengths at strain rates of $\dot{\varepsilon}$ and zero, respectively. $C$ and $p$ are the Cowper and Symonds parameters.

A series of high-rate characterization tests was performed on tower steels by the mechanical and metallurgical analysis of structural steels part of the NIST Investigation (NIST NCSTAR 1-3D) at strain rates between 100 and $1000 \mathrm{~s}^{-1}$. The Cowper and Symonds model parameters $C$ 
and $p$ were then fit to the test data and were provided in the following functional form for a strain rate in $\mathrm{s}^{-1}$ and a yield strength in ksi:

- $\log (\mathrm{C})=-7.55+0.324 \sigma_{\mathrm{yo}}-0.00153\left(\sigma_{\mathrm{yo}}\right)^{2}$

- $p=6.7824$

The resulting rate effects used in the constitutive modeling of tower steels based on the Cowper and Symonds model are compared to the measured high rate test data for the $50 \mathrm{ksi}, 75 \mathrm{ksi}$, and $100 \mathrm{ksi}$ tower steels in Figure 5-26. The comparison shows that the Cowper and Symonds model was capable of reproducing the rate effects for the range of data available.

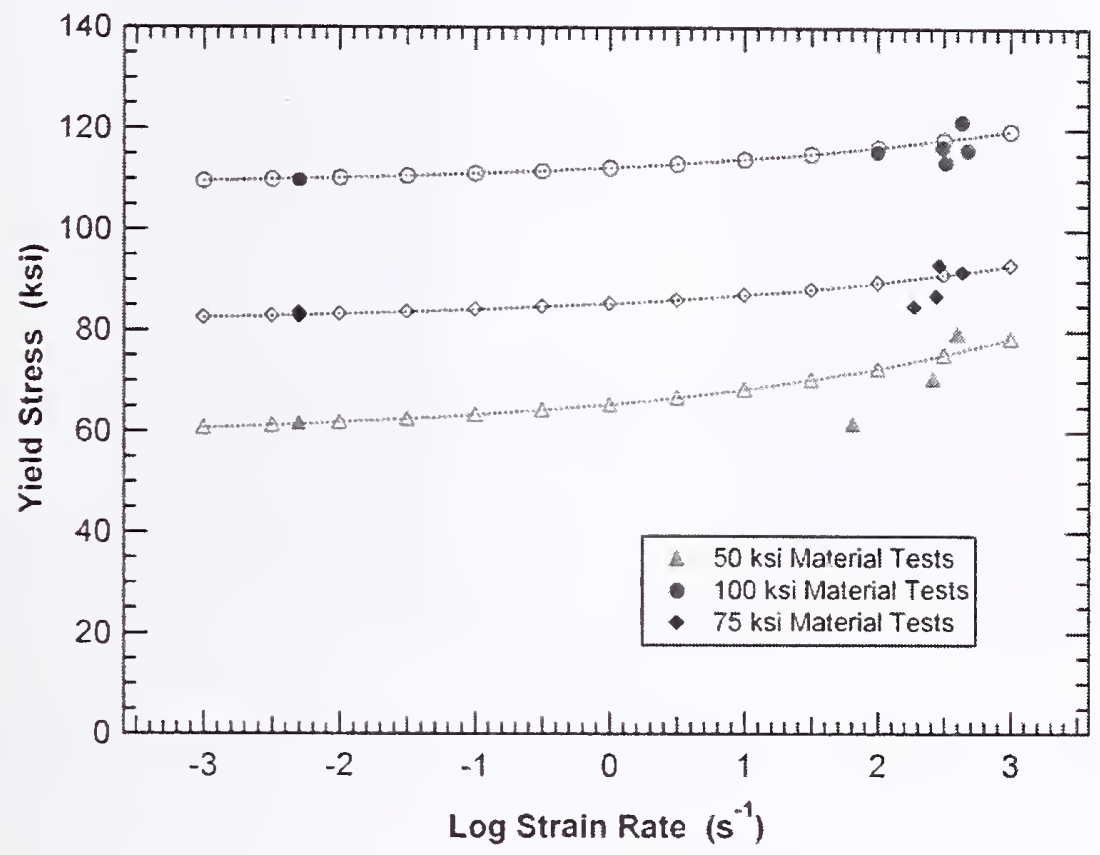

Figure 5-26. Comparison of rate effects model and test data.

\section{Concrete Constitutive Models}

The LS-DYNA material Type 16 (pseudo-tensor concrete model) was selected for modeling the concrete floor slabs due to its ability to accurately model the damage and softening of concrete, associated with low confinement. The model used two pressure-dependent yield functions and a damage-dependent function to migrate between curves. This allowed for implementation of tensile failure and damage scaling, which are more dominant material behaviors at low confinement. The pseudo-tensor model also accounted for the sensitivity of concrete to high strain rates. The reader is the reader is referred to the LS-DYNA user's manual (2003) for a detailed description of the model, and to NIST NCSTAR 1-2B for the model parameters used in the analysis.

Material constitutive parameters for the pseudo-tensor model were developed for both $3 \mathrm{ksi}$ and $4 \mathrm{ksi}$ compressive strength lightweight concrete. A simulation was performed of a standard unconfined concrete compression test to check the constitutive model behavior. The simulated behavior of the 
concrete specimen is shown in Figure 5-27. The calculated compressive stress-strain response for the $3 \mathrm{ksi}$ concrete was compared to measured compression data for $2.3 \mathrm{ksi}$ and $3.8 \mathrm{ksi}$ strength concretes in Figure 5-28 (Wischers 1978).

For subsequent global analyses, a 4 ksi concrete was used, instead of the $3 \mathrm{ksi}$ concrete strength specified in the original design, to account for factors such as aging and the difference between specified nominal and actual concrete strength. The same material parameters were used for the concrete in both the core (normal weight concrete) and truss floor (lightweight concrete) areas.

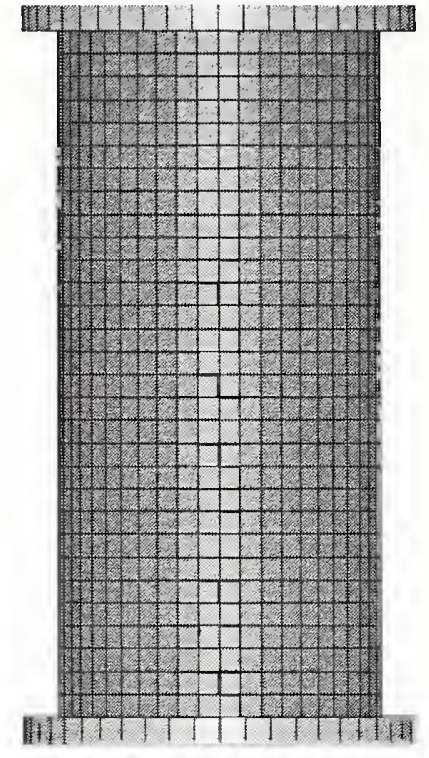

Initial configuration

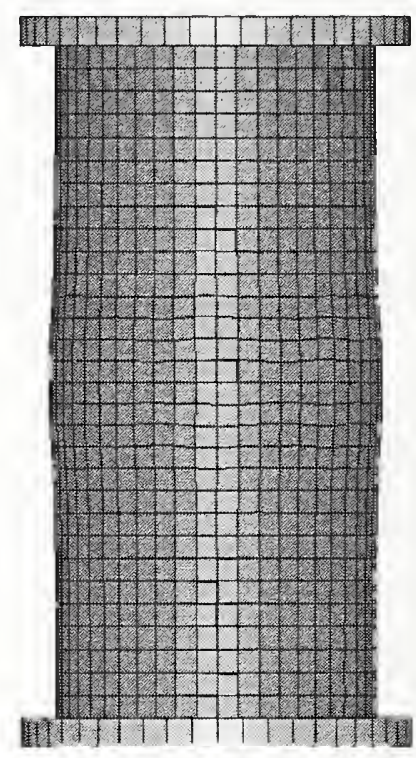

$2 \%$ compression

Figure 5-27. Finite element analysis of the unconfined compression test. 


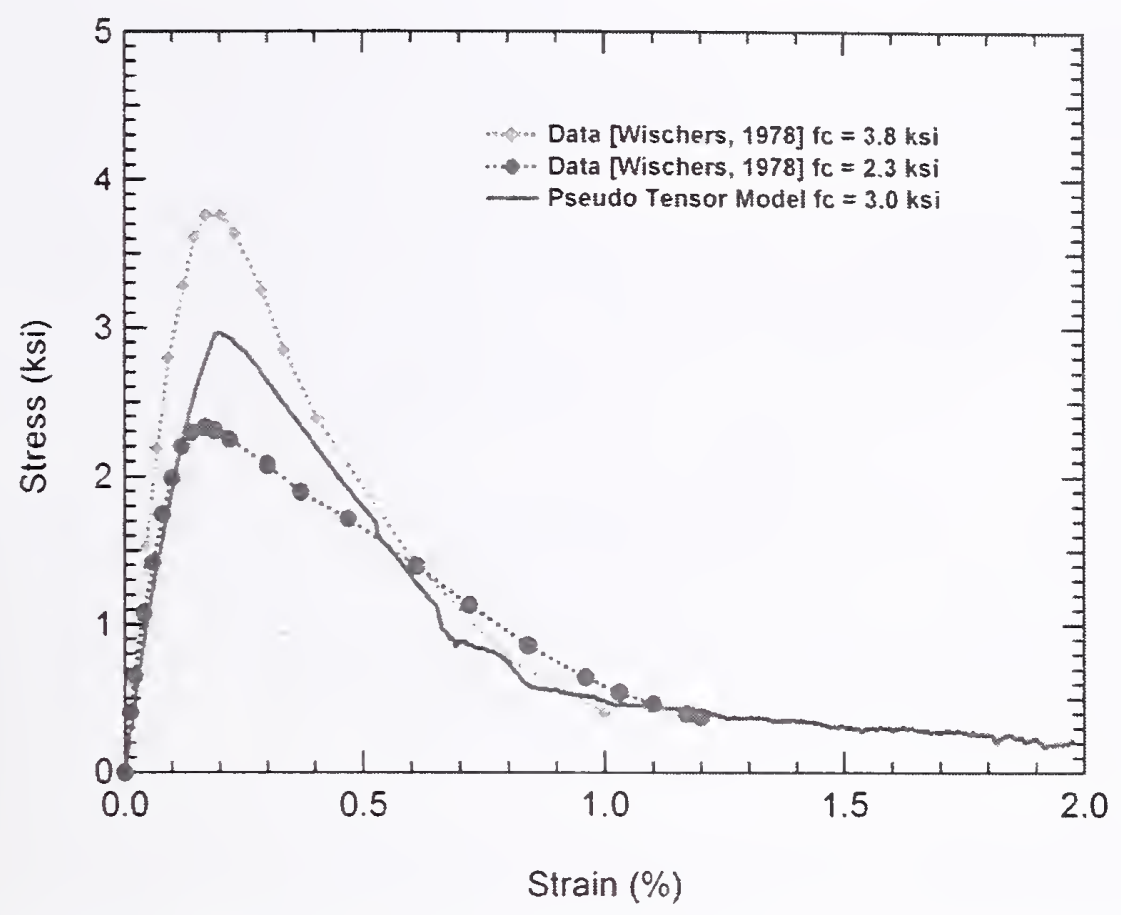

Figure 5-28. Comparison of the calculated unconfined compression behavior with concrete compression test data.

Experimental characterization of the strain rate effects on concrete is difficult, and there is a wide scatter in data that is influenced by concrete type, strength, and the testing methods applied. In general, elevated strain rate loading has a greater influence on the tensile strength than on the compressive strength.

However, in the aircraft impact response of the WTC towers, the majority of the high-rate damage occurs with impact and penetration of the floor slab by hard components such as the aircraft engine. As a result, the strain rate effects for compressive loading were used for the constitutive model. The strain rate effects were added to the model in tabular form. The rate effects curve used in the model is shown in Figure 5-29, based on the work of Bischoff and Perry (1991) and Ross et al. (1992). The curve was selected to provide a relatively smooth fit to the available compressive rate effects data on compressive strength. 


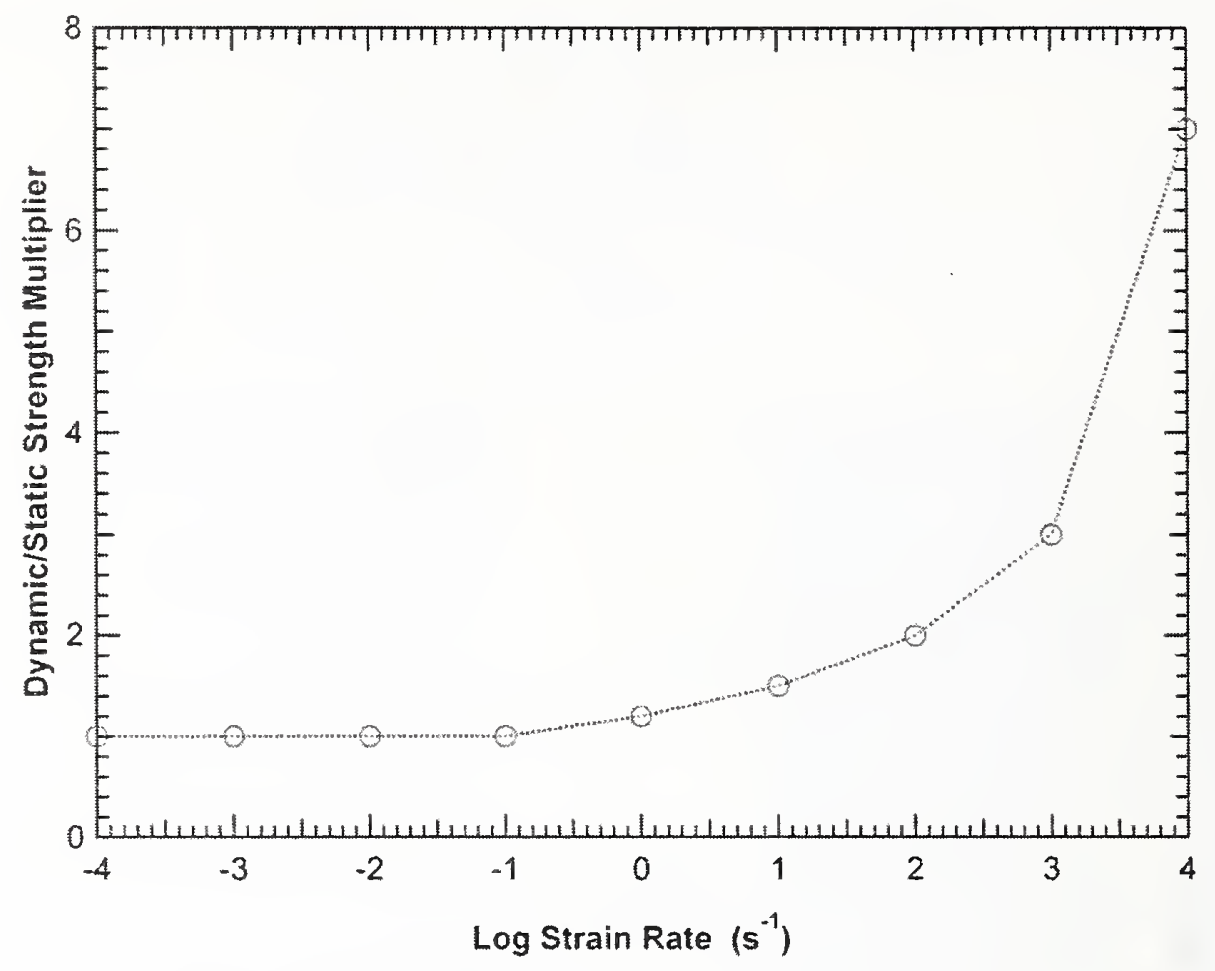

Figure 5-29. Tabular concrete strain rate effects curve.

\section{Nonstructural Materials Constitutive Models}

In general, the primary influence of the nonstructural components on the impact behavior was their inertial (mass) contribution. The effects of their strength were small. As a result, relatively simple approximations of their constitutive behavior were used. Typically, a simple elastic-plastic model was applied for these materials to allow for efficient modeling of deformation and subsequent erosion from the calculations as their distortions became large. The ability to include material failure and erosion of these soft materials was important for the stability of the impact analyses.

Based on a survey on the strength of various nonstructural building components (see Chapter 2 of NIST NCSTAR 1-2B), a bilinear elastic-plastic constitutive model with a yield strength of 500 psi and a failure strain of 60 percent was used. The large failure strain for these materials was used to prevent large scale erosion of the contents before the momentum transfer from the aircraft debris had occurred.

\subsection{DEVELOPMENT OF AIRCRAFT MODEL}

The finite element model of the Boeing 767-200ER aircraft was constructed through a three-step process: (1) data collection, (2) data interpretation and engineering analysis, and (3) meshing of the structure. A major focus of this effort was gathering sufficient structural data and including adequate detail in the aircraft model so that the mass and strength distribution of the aircraft and its contents were properly captured for implementation in the impact analyses. Structural data were collected for the Boeing 767-200ER aircraft from: (1) documentary aircraft structural information, and (2) data from measurements on Boeing 767 aircraft. 
The objective of the aircraft model development was to properly simulate the impact damage and aircraft breakup, and their effects on the WTC towers. Key requirements were to simulate the mass distribution, dynamic impact response, fragmentation, and progress of the aircraft components and debris into and through the towers. The modeling approach was to model the airframe completely using shell elements as opposed to a shell element skin and beam elements for the airframe. Shell elements in the airframe provided higher fidelity simulation of the impact response and fragmentation behavior. As a result of the model size constraints, some of the details and smaller structural elements were not modeled explicitly. Where modeling simplifications were required, component analyses were applied to ensure that the impact strength and breakup behavior were maintained.

An example of this approach was the development of the wing model. A section of the aircraft wing structure was first modeled with a very fine mesh of the detailed wing structure to establish a baseline behavior for aircraft structural failure and fragmentation upon impacting the exterior wall of the WTC towers. A coarser and simplified version of the same wing section was subsequently developed, and the failure criteria were modified to obtain similar impact and fragmentation behavior to the fine, detailed version. Section 5.3.2 describes how this model was constructed and the methodology used for developing the coarsely meshed wing section. A similar mesh resolution and failure criteria were used throughout the rest of the aircraft model.

Similar to the global towers structural model, the LS-DYNA model of the aircraft was generated and meshed using the TrueGrid software (TrueGrid Manual 2001). The complete model for the Boeing 767 200ER is shown in Figure 5-30. A summary of the model size and weight parameters for the aircraft that impacted WTC 1 (American Airlines flight 11 [AA 11]) and the aircraft that impacted WTC 2 (United Airlines flight 175 [UAL 175]) is presented in Table 5-2. The weight cited for the unit load device (ULD) and seats included the empty weights plus the passenger or cargo weight. Carry on luggage and catering weight was distributed to the seats, and freight and cargo luggage weight was distributed to the ULD.

Fuel was distributed in the wings as shown in Figure 5-31, based on a detailed analysis of the fuel distribution in the aircraft wings at the time of impact (see Chapter 4 of NIST NCSTAR 1-2B for analysis details). The wings of the aircraft were also deflected from the surface model geometry to represent their in-flight condition, as shown in Figure 5-32. A cubic function of the wing span was used with a tip deflection of approximately $52 \mathrm{in}$., which was estimated from the impact pattern seen in photographs of the WTC towers and from the damage documented on the exterior panels.

The following sections outline the overall aircraft model developed for the impact analysis. Details in modeling each major component including the wings, engines, fuselage, empennage, and landing gear are provided. 
Table 5-2. Boeing 767-200ER aircraft model parameters.

\begin{tabular}{|c|c|c|}
\hline & AA 11 & UAL 175 \\
\hline No. Brick Elements & 70,000 & 70,000 \\
\hline No. Shell Elements & 562,000 & 562,000 \\
\hline No. SPH Fuel Particles & 60,672 & 60,672 \\
\hline Total Nodes & 740,000 & 740,000 \\
\hline Total Weight (Empty) & $183,500 \mathrm{lb}$ & $183,500 \mathrm{lb}$ \\
\hline ULD/Cargo Weight & $12,420 \mathrm{lb}$ & $21,660 \mathrm{lb}$ \\
\hline Cabin Contents Weight & $21,580 \mathrm{lb}$ & $10,420 \mathrm{lb}$ \\
\hline Fuel Weight & $66,100 \mathrm{lb}$ & $62,000 \mathrm{lb}$ \\
\hline Total Weight (Loaded) & $\mathbf{2 8 3 , 6 0 0 ~ l b}$ & $\mathbf{2 7 7 , 5 8 0 ~ l b}$ \\
\hline
\end{tabular}




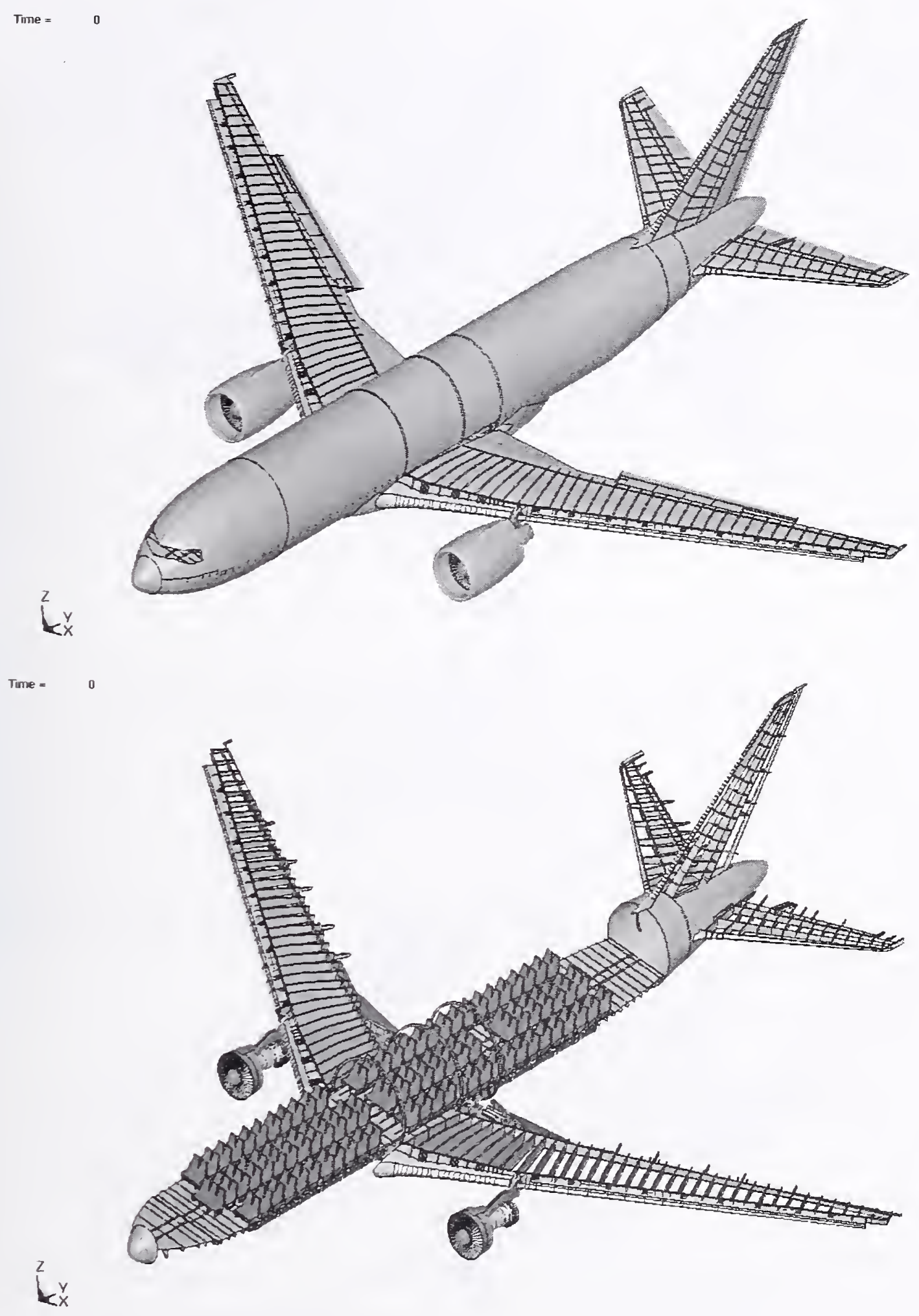

Figure 5-30. Finite element model of the Boeing 767-200ER. 


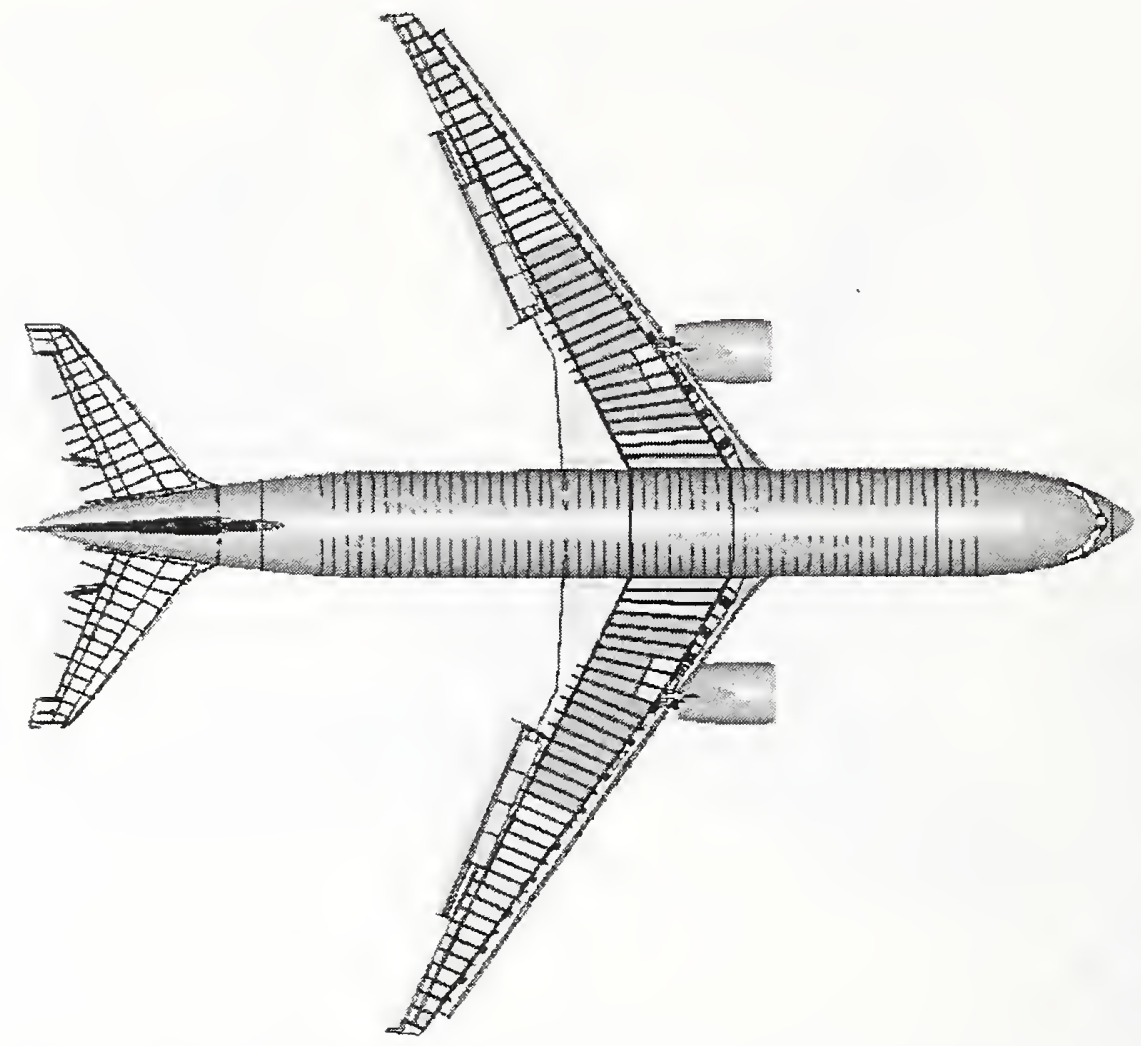

Figure 5-31. Boeing 767-200ER with fuel load at time of impact.

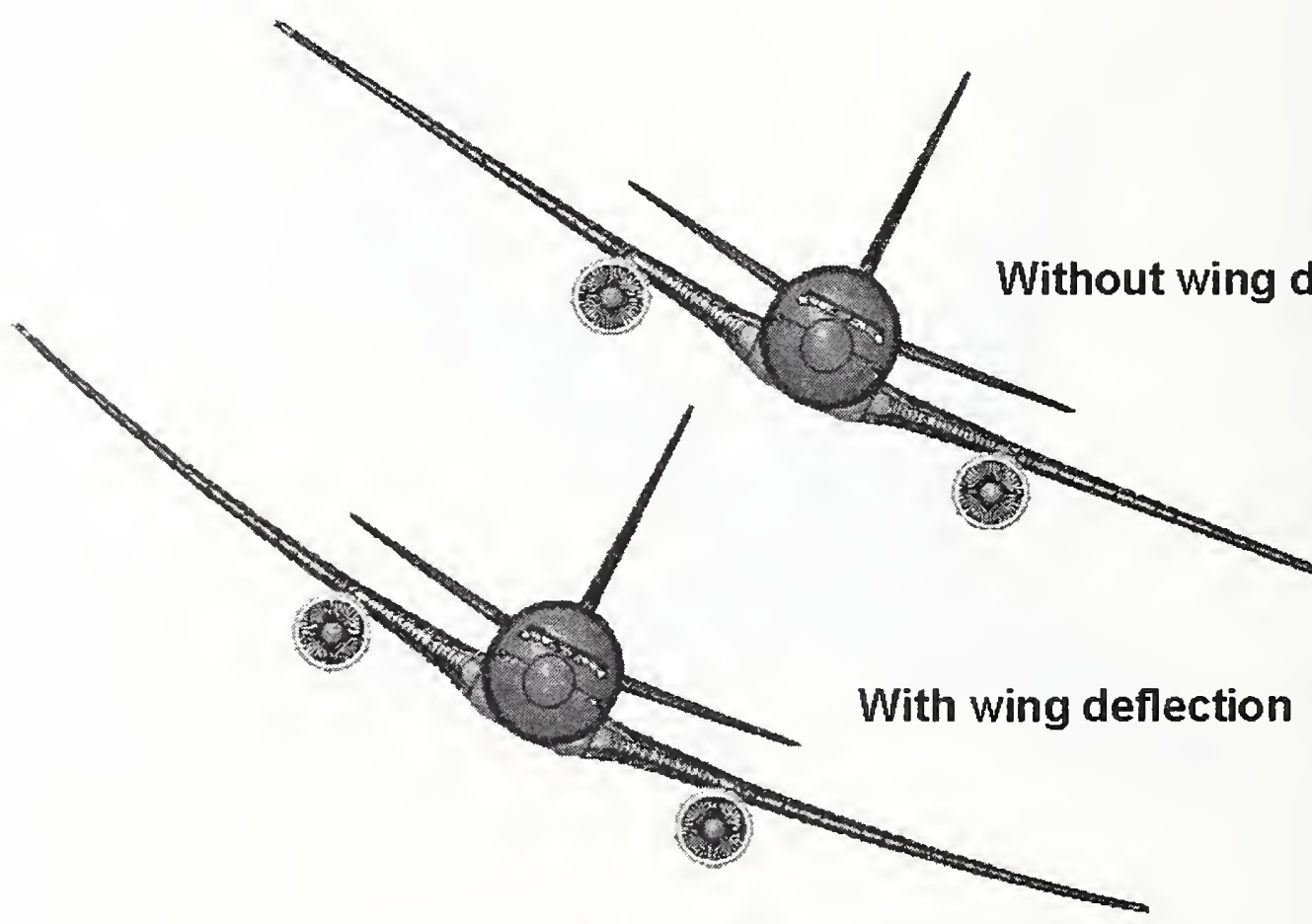

Figure 5-32. Boeing 767-200ER model wing deflections. 


\subsubsection{Airframe Model Development}

The airframe model developed for the Boeing 767-200ER contained most of the significant structural components in the aircraft. The models of the fuselage, empennage, and wing structures were developed completely using Belytschko-Tsay shell elements. Models for the landing gear and engines were primarily developed using shell elements, but contained some brick elements as well. The model was developed in a parameterized form, where the mesh resolution was determined by a single element characteristic size parameter. This approach was selected early in the development to allow flexibility in the model size and resolution as the model development and impact analyses progressed. The objective was to develop a mesh with typical element dimensions between one and two in. for small components, such as spar or rib flanges, and element dimensions of three to four in. for large parts such as the wing or fuselage skin.

Detailed models of the empennage and landing gear are shown in Figure 5-33 and Figure 5-34, respectively. Ribs, spars, rudder, and elevator were all modeled in detail in the empennage. Tires and hubs, the main strut and truck, and support bracing were all included in the landing gear model. The underside of the airframe in the model is shown in Figure 5-35, illustrating the position of the retracted main landing gear in the wheel well. Also shown in the figure are the Unit Load Devices (ULDs shown in red with blue edges). The density of these containers was scaled to include the weight of the cargo.

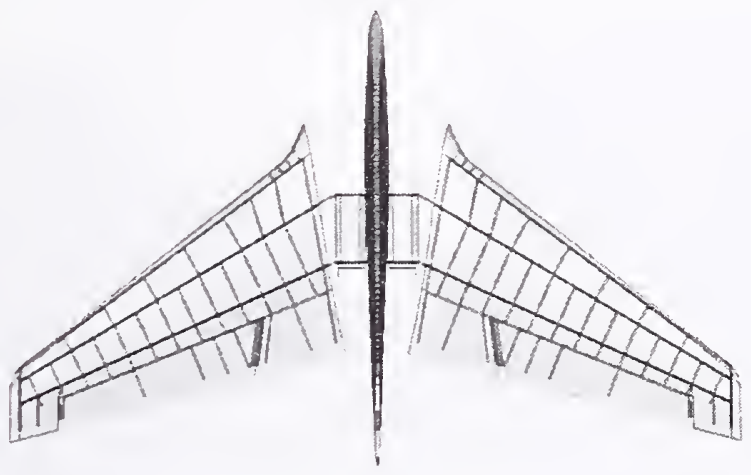

(a) Top view

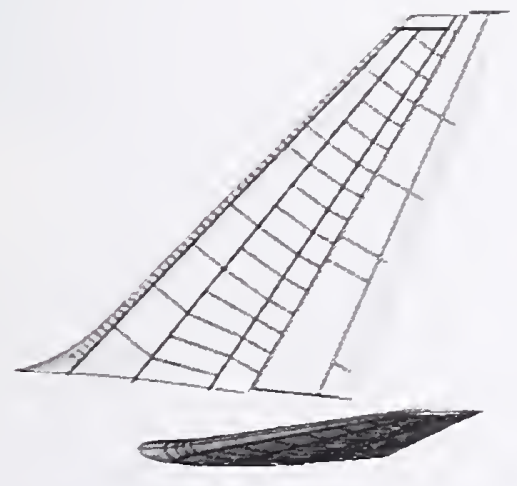

(b) Side view

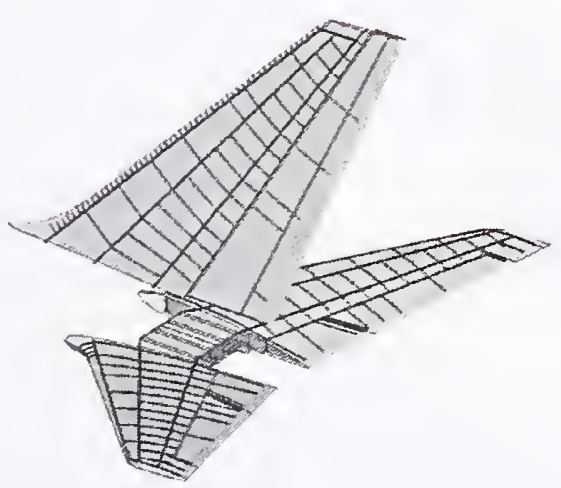

(c) Oblique view

Figure 5-33. Empennage model of the 767-200ER aircraft. 


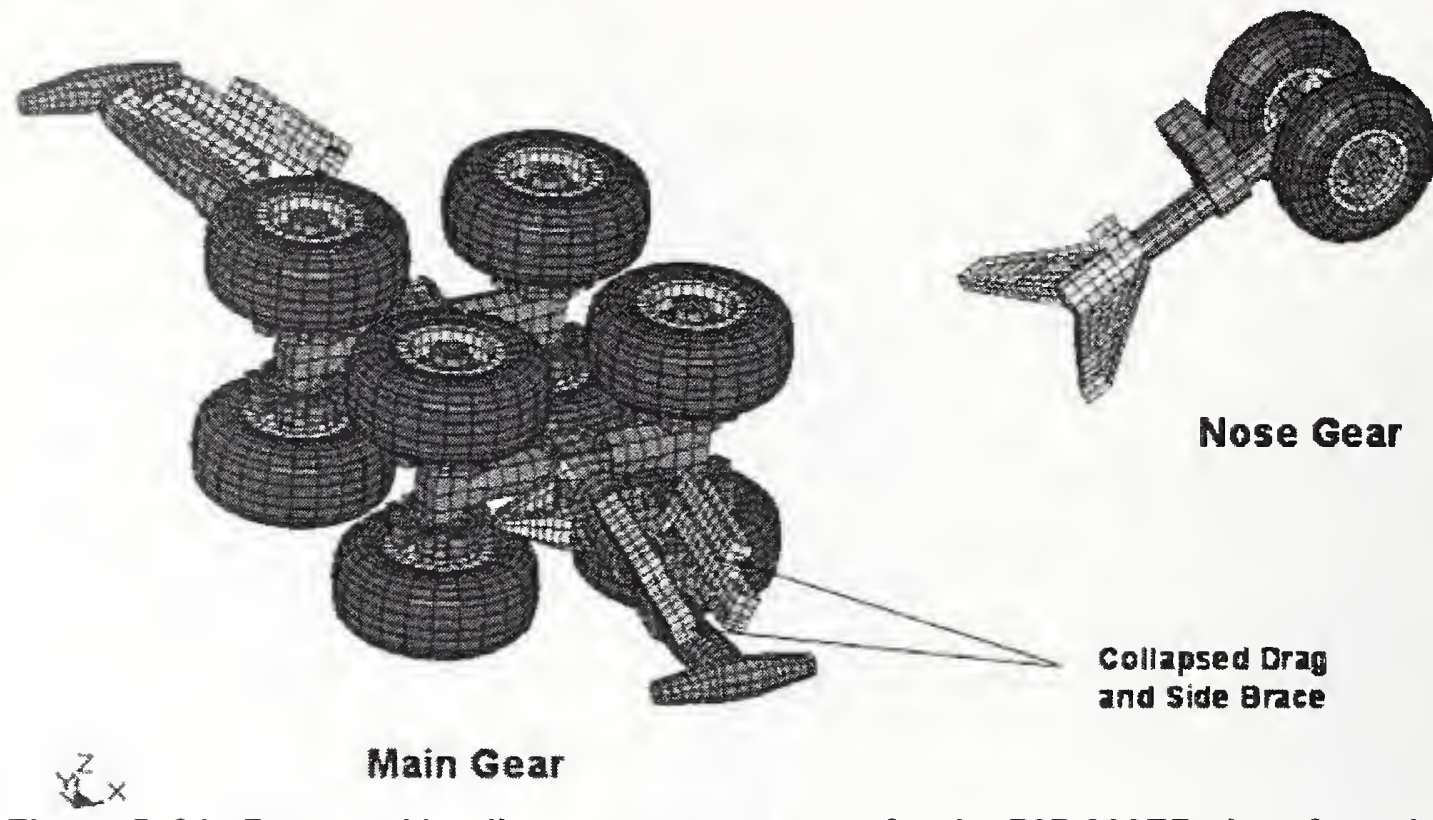

Figure 5-34. Retracted landing gear components for the 767-200ER aircraft model.

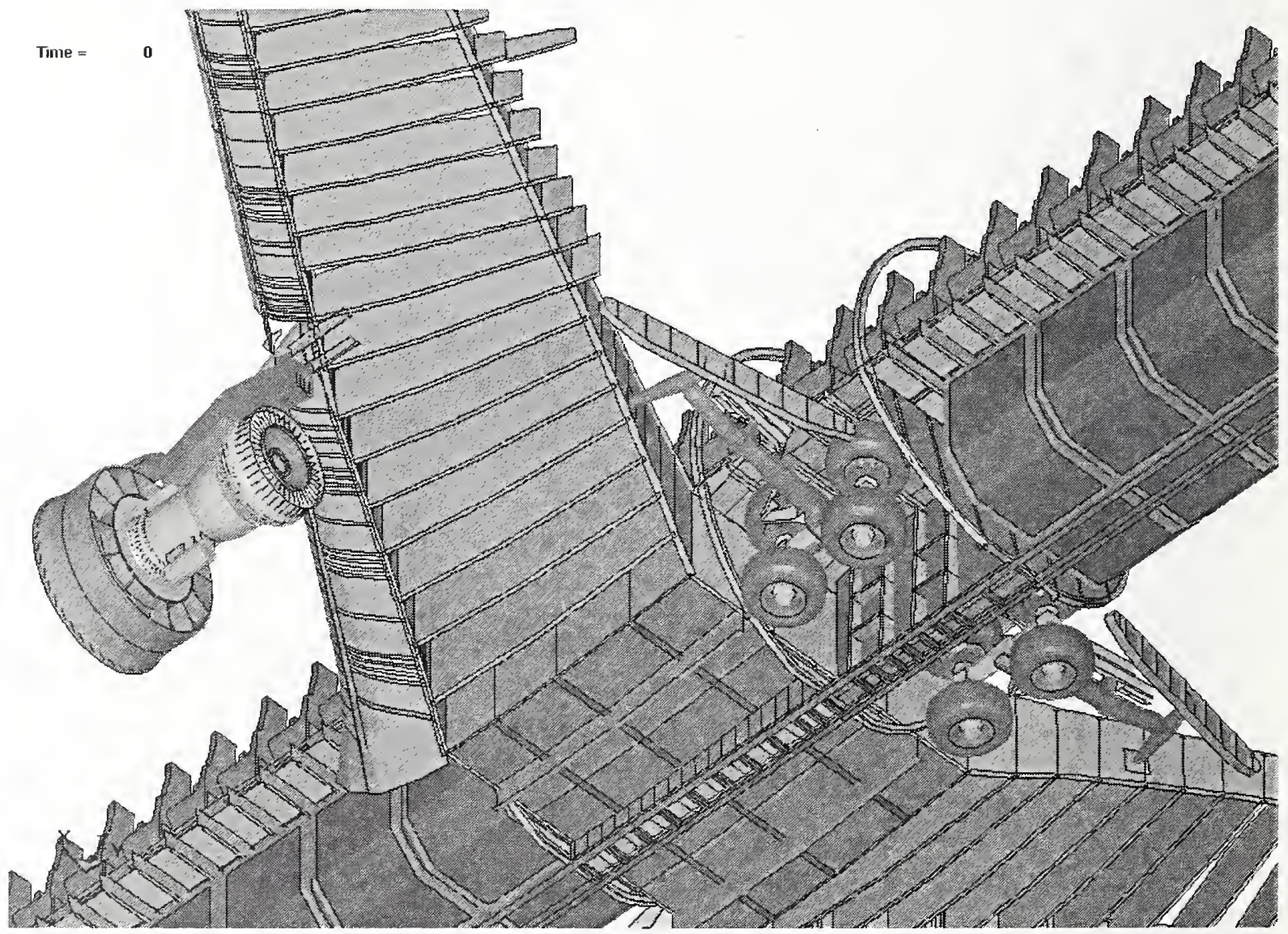

Figure 5-35. Underside of the 767 airframe model (skin removed) showing retracted landing gear, engine, and ULDs. 
Figure 5-36 shows the model of the wing structure, including the center wing, which attaches the port and starboard wings. The wing stringers were not explicitly modeled to help reduce the size of the model.

The stringers have a z-section geometry with typical dimensions of approximately one in. flanges and a two in. web with a thickness of approximately $1 / 8$ in. These stringers run along the wing span over the top and bottom of the wing ribs. To account for the weight and strength of the riveted skin/stringer construction, an 'effective' wing skin was used, as discussed in Section 5.3.2.

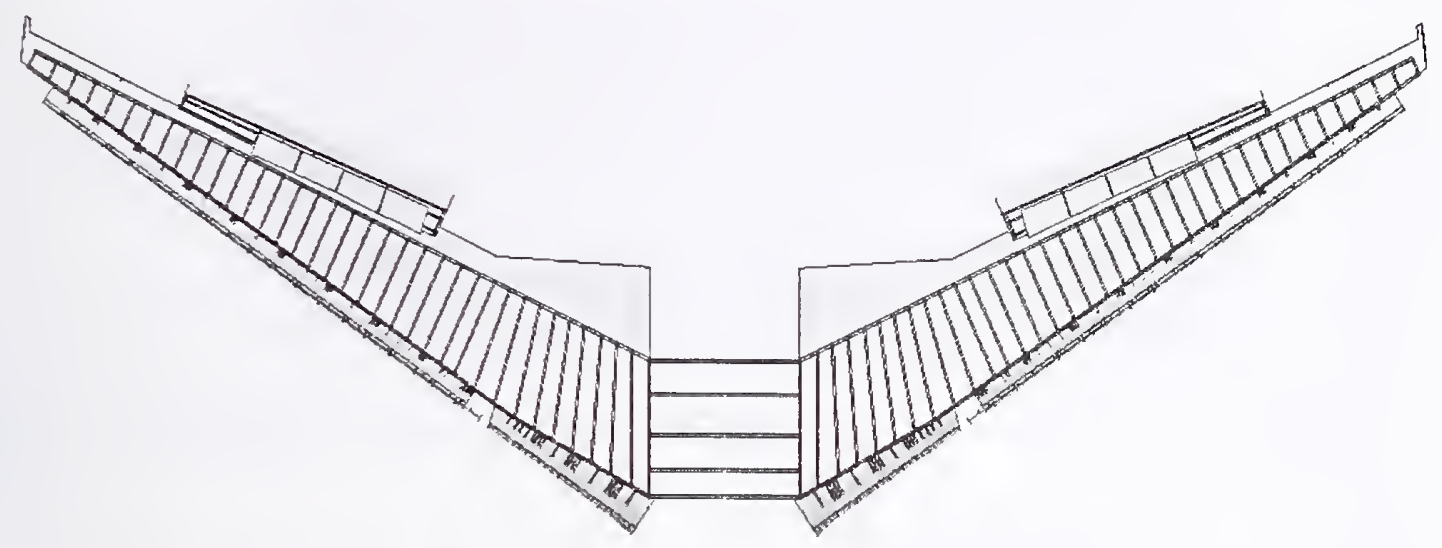

(a) Complete wing model
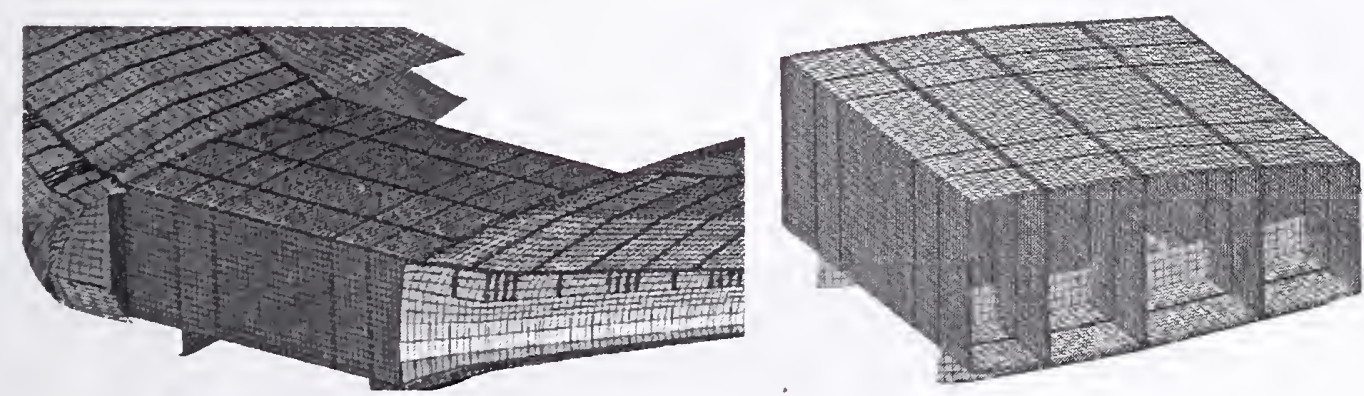

(b) Center wing structures

Figure 5-36. Complete wing structures for the 767 aircraft model.

A model of the fuselage was assembled with a stringer and frame construction supporting the external skin, as shown in Figure 5-37. A tied interface was used to connect the stringers to the frames and skin using the tied surface-to-surface algorithm in LS-DYNA, where nodes on a slave surface were constrained to nodes on a master surface, provided they were within a certain distance of the master surface node. This distance was a function of the element thickness or diagonal length. The wing was integrated into the fuselage structure through attachment of the center wing to the keel and front and rear spar bulkheads, as shown in Figure 5-38. These components were also attached using a tied interface. Due to model size constraints, the forward and aft portions of the fuselage were modeled without the detailed stringer/frame construction. Instead, the weight of these components was smeared into the skin by increasing the skin thickness and scaling down the strength by a factor of 40 percent, as described in the component analyses (see Chapter 4 of NIST NCSTAR 1-2B). 


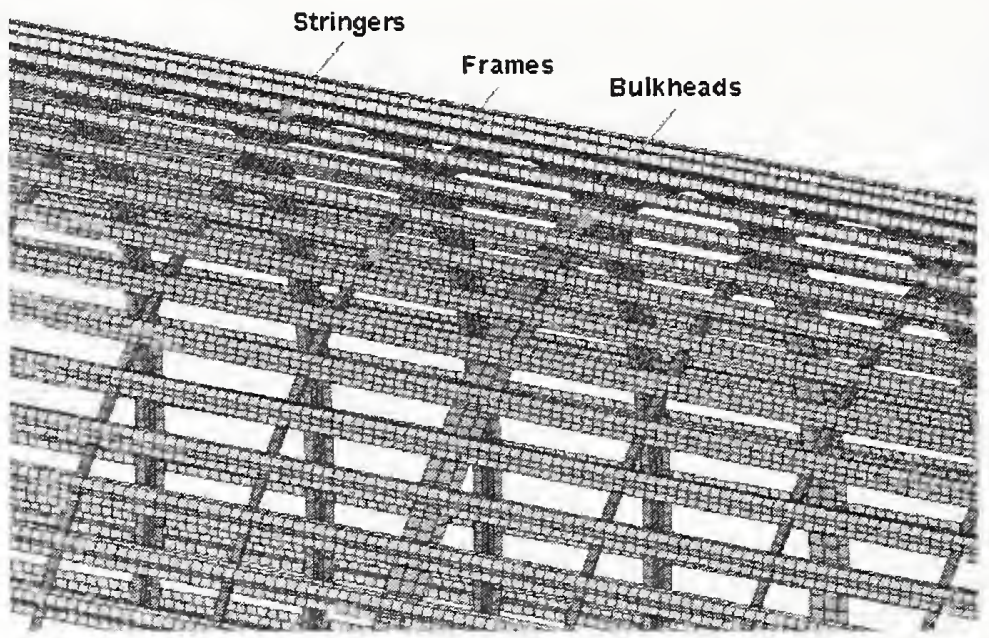

Figure 5-37. Model of fuselage interior frame and stringer construction.

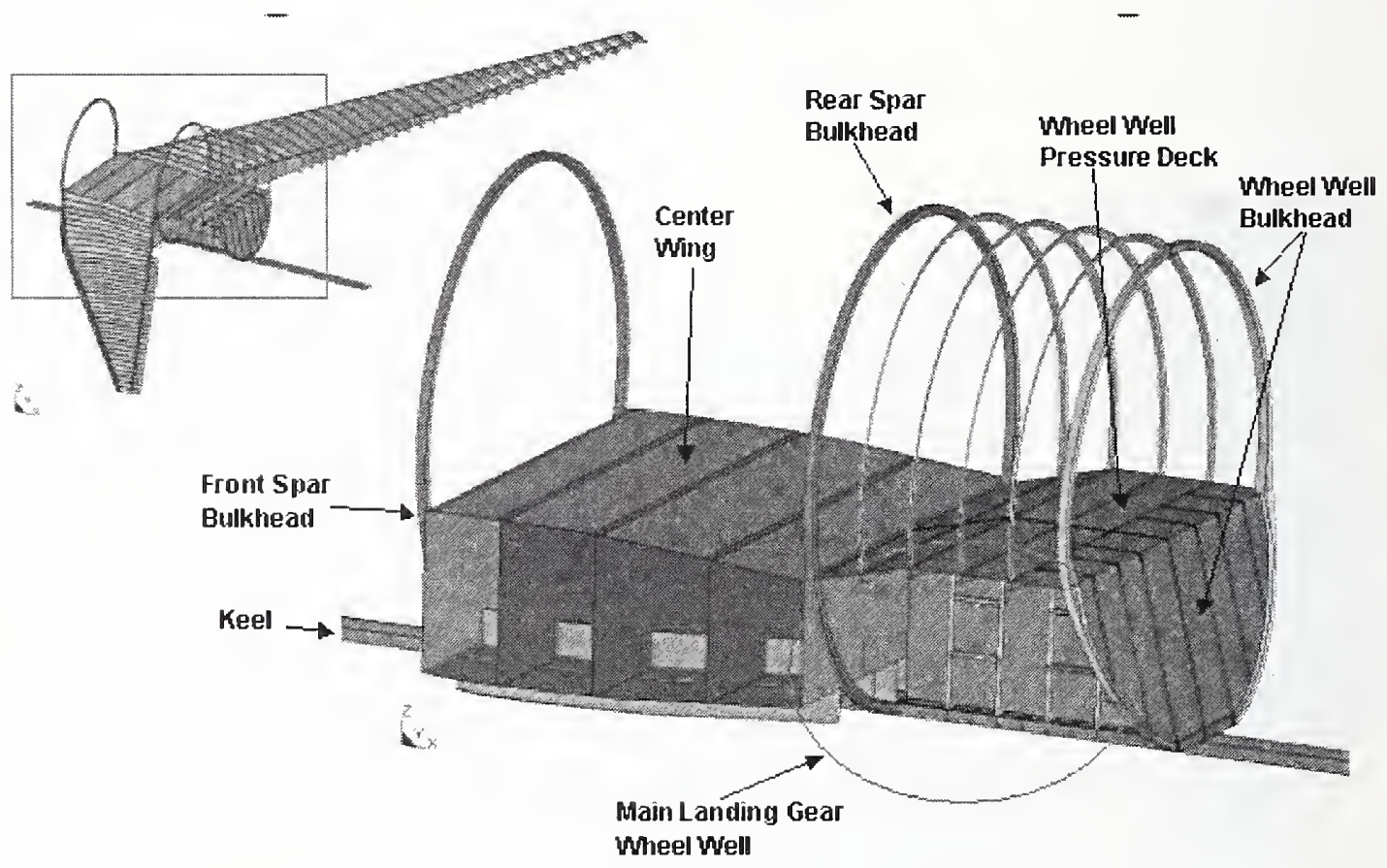

Figure 5-38. Integration of the fuselage and wing structures.

The density of various parts of the aircraft was increased to account for the mass of structural and nonstructural components not specifically modelcd. Density scale factors and total weights for each major component are shown in Table 5-3. The difference in scale factors for flights AA 11 and UAL 175 were due to differences in passenger and cargo weight. In both cases, the weight of the cargo, passengers, and crew were incorporated in the ULD (cargo weight) and the seats (passenger, crew and carry on luggage weight). The weight of the modeled wings and empennage were doubled to account for the weight of small structural details, such as stiffeners, not specifically modeled, as well as hydraulic lines and fluid pumps, actuators, inboard flaps and outboard ailerons, flap and rudder connections, and other 
nonstructural components. The weight of the landing gear was increased by a smaller amount (1.5) to account for hydraulic fluid and smaller structural components not included in the model. The weight of the fuselage was adjusted to match the published empty weight for the aircraft. That the scale factor for the fuselage was larger than for other components was reasonable as many heavy items in the fuselage were not specifically modeled (e.g. electronics, air conditioning, power units, ductwork, electronic wiring, cargo floor, actuator motors, insulation, hydraulics, galley and lavatories). These structural and nonstructural components could not be modeled in detail due to the constraints on model size.

Table 5-3. Density scale factors and weights for aircraft components

\begin{tabular}{|c|c|c|c|c|}
\hline $\begin{array}{c}\text { Major Aircraft } \\
\text { Component }\end{array}$ & $\begin{array}{c}\text { Density Scale } \\
\text { Factor (AA 11) }\end{array}$ & $\begin{array}{c}\text { Total Weight } \\
\text { (AA 11) }\end{array}$ & $\begin{array}{c}\text { Density Scale } \\
\text { Factor (UAL 175) }\end{array}$ & $\begin{array}{c}\text { Total Weight } \\
\text { (UAL 175) }\end{array}$ \\
\hline Wings & 2.0 & $37,000 \mathrm{lb}$ & 2.0 & $37,000 \mathrm{lb}$ \\
\hline Empennage & 2.0 & $8,350 \mathrm{lb}$ & 2.0 & $8,350 \mathrm{lb}$ \\
\hline Fuselage & 6.68 & $103.050 \mathrm{lb}$ & 6.68 & $103,050 \mathrm{lb}$ \\
\hline Landing Gear & 1.5 & $8,400 \mathrm{lb}$ & 1.5 & $8,400 \mathrm{lb}$ \\
\hline Engines (with cowlings) & 1.2 & $20,100 \mathrm{lb}$ & 1.2 & $20,100 \mathrm{lb}$ \\
\hline ULD & 1.43 & $12.400 \mathrm{lb}$ & 2.50 & $21,650 \mathrm{lb}$ \\
\hline Seats & 1.29 & $28.200 \mathrm{lb}$ & 0.78 & $17,050 \mathrm{lb}$ \\
\hline Fuel & 1.0 & $66,100 \mathrm{lb}$ & 1.0 & $62,000 \mathrm{lb}$ \\
\hline Total Weight & & $283,600 \mathrm{lb}$ & & $277,600 \mathrm{lb}$ \\
\hline
\end{tabular}

\subsubsection{Wing Section Component Model Development}

A wing section model was developed to perform the component and subassembly level analyses (See Chapters 5 and 6, respectively, of NIST NCSTAR 1-2B). The full wing contained 35 ribs, with rib 1 closest to the fuselage and rib 35 near the wing tip. The wing section model described herein included the section of the wing from rib 14 to rib 18 and is shown in Figure 5-39.

The wing structure of the Boeing 767 contains a riveted stringer-skin construction between the front and rear spars. This part of the structure was not included in the wing model as it added significant complexity and size to the model. In order to reduce the size of the model for the global impact analysis, an 'effective' wing skin was developed to account for the weight and strength of the riveted skin/stringer construction. A simplified wing section model, containing a uniform stringer-skin construction and a simple rectangular cross-section, was also developed to determine the strength and weight of the effective skin. Both wing section component models utilized Belytschko-Tsay shell elements. The parameters of the effective wing skin model (39) were developed by calibrating this model against the simplified wing section model that included the main spars, wing ribs, leading edge ribs, nose beams, leading edge slats, and outboard flaps. Refer to Chapter 4 of NIST NCSTAR 1-2B for further details. 


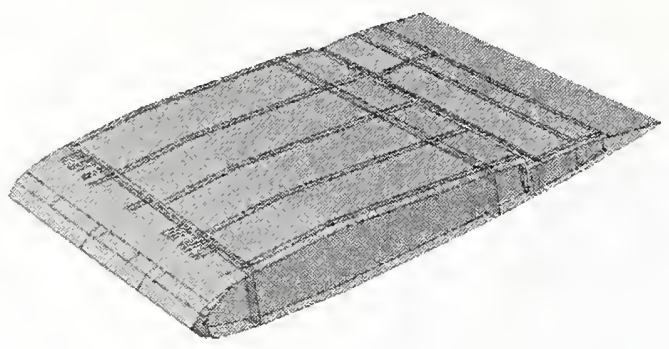

(a) Small wing section model

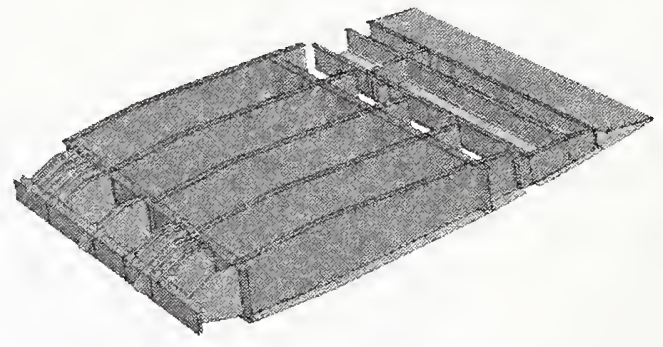

(b) Internal structure (skin removed)

Figure 5-39. Wing section model for component level and subassembly analyses.

\subsubsection{Engine Model Development}

Initial sources indicated that the Pratt \& Whitney PW4000 engine and the General Electric CF6-80 engine were on the aircraft that impacted the WTC towers (FEMA 2002). For this reason, the Engine Reference Manuals were obtaincd from Pratt \& Whitney for the PW4000 turbofan engine. A detailed finite element model of the PW4000 engine was developed from these manuals.

After the engine model was developed, the engine types on each aircraft were clarified by the Aviation Safety Network (http://aviation-safety.net/). AA 11 was powered by two General Electric CF6-80A2 engines. UAL 175 was powered by two Pratt \& Whitney JT9D-7R4D engines. However, careful review of these engines indicated that the PW4000 turbofan engine was very similar to the General Electric CF6-80A2 and the PW JT9D-7R4D engines. Comparisons of specific physical characteristics of the engines are given in Table 5-4. The JT9D-7R4D and PW4000-94 are almost identical as they are in the same family of Pratt \& Whitney aircraft engines. The PW4000 was labeled the "new technology JT9D" when it began replacing the latter engine on $767 \mathrm{~s}$ built after 1987 . The PW4000-94 is 5.8 percent heavier than the JT9D-7R4 but produces up to 10 percent more thrust. Aside from an additional set of long stator blades and elongated exit nozzle, the CF6-80C2 is also of similar weight and dimensions to the PW4000. Due to these similarities, the PW4000 engine model was used for all impact simulations. Differences in the weights of aircraft components were accounted for in the uncertainty analyses.

Table 5-4. Boeing 767 Engine Comparison.

\begin{tabular}{|c|c|c|c|}
\hline Engine & $\begin{array}{c}\text { Pratt \& Whitney } \\
\text { PW4000-94 }\end{array}$ & $\begin{array}{c}\text { Pratt \& Whitney } \\
\text { JT9D-7R4 }^{\mathbf{a}, \mathbf{b}}\end{array}$ & $\begin{array}{c}\text { General Electric } \\
\text { CF6-80C2 }^{\mathbf{c}, \mathbf{d}}\end{array}$ \\
\hline Fan Blade Diameter & 94 (in.) & 94 (in.) & 93 (in.) \\
\hline Length & 153 (in.) & 153 (in.) & $161-168$ (in.) \\
\hline Dry Weight & 9,400 (lb) & 8,885 (lb) & $9135-9860$ (lb) \\
\hline
\end{tabular}

a. The JT9D-7R4 and PW4000-94 are almost identical: (1) They are in the same family of Pratt \& Whitney aircraft engines, and (2) the PW4000 was labeled the "new technology JT9D" when it began replacing the latter engine on 767s built after 1987.

b. The PW4000-94 is 5.8 percent heavier than the JT9D-7R4 but produces up to 10 percent more thrust.

c. The CF6-80C2 has an additional set of long stator blades for the excess fan air that is not present in the PW4000.

d. The second stage compressor blades in the CF6-80C2 are closer to the central shaft than the PW4000 and do not appear to have counter weights.

e. Reference value of 106 in. also found - may include cowling.

f. The "tail" of the CF6-80C2 is much longer than the PW4000. This potentially accounts for the additional 15 in. in length. 
Figure 5-40. The engine is an important component of the aircraft with the potential to produce significant damage to the WTC tower structures. As a result, special emphasis was given to the development of the engine model to include all the details of the engine construction.

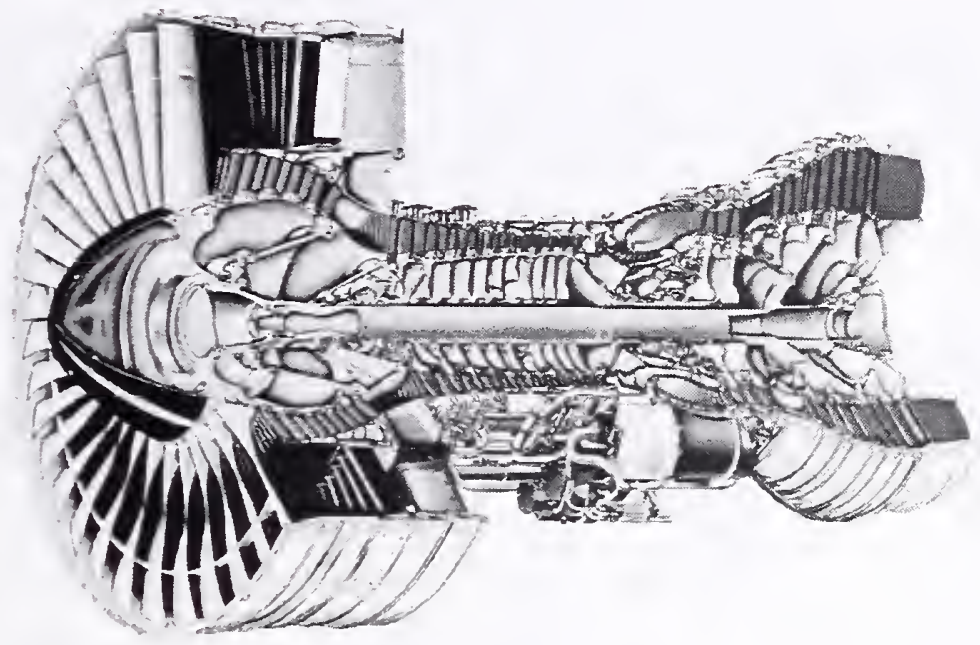

Used with Permission.

Figure 5-40. Pratt \& Whitney PW4000 turbofan engine.

The approach used to capture the geometry of the engine was to start with a cross-sectional drawing provided by Pratt \& Whitney that clearly showed many of the engine geometric details. In addition, the drawing had sufficient detail that the component thicknesses could be estimated. The primary structural components were identified and approximated with simplified geometry as illustrated in Figure 5-41. Known engine dimensions were used to determine the scale factor for the drawing. The simplified geometry of the engine structures could then be captured using a common digitization procedure. 


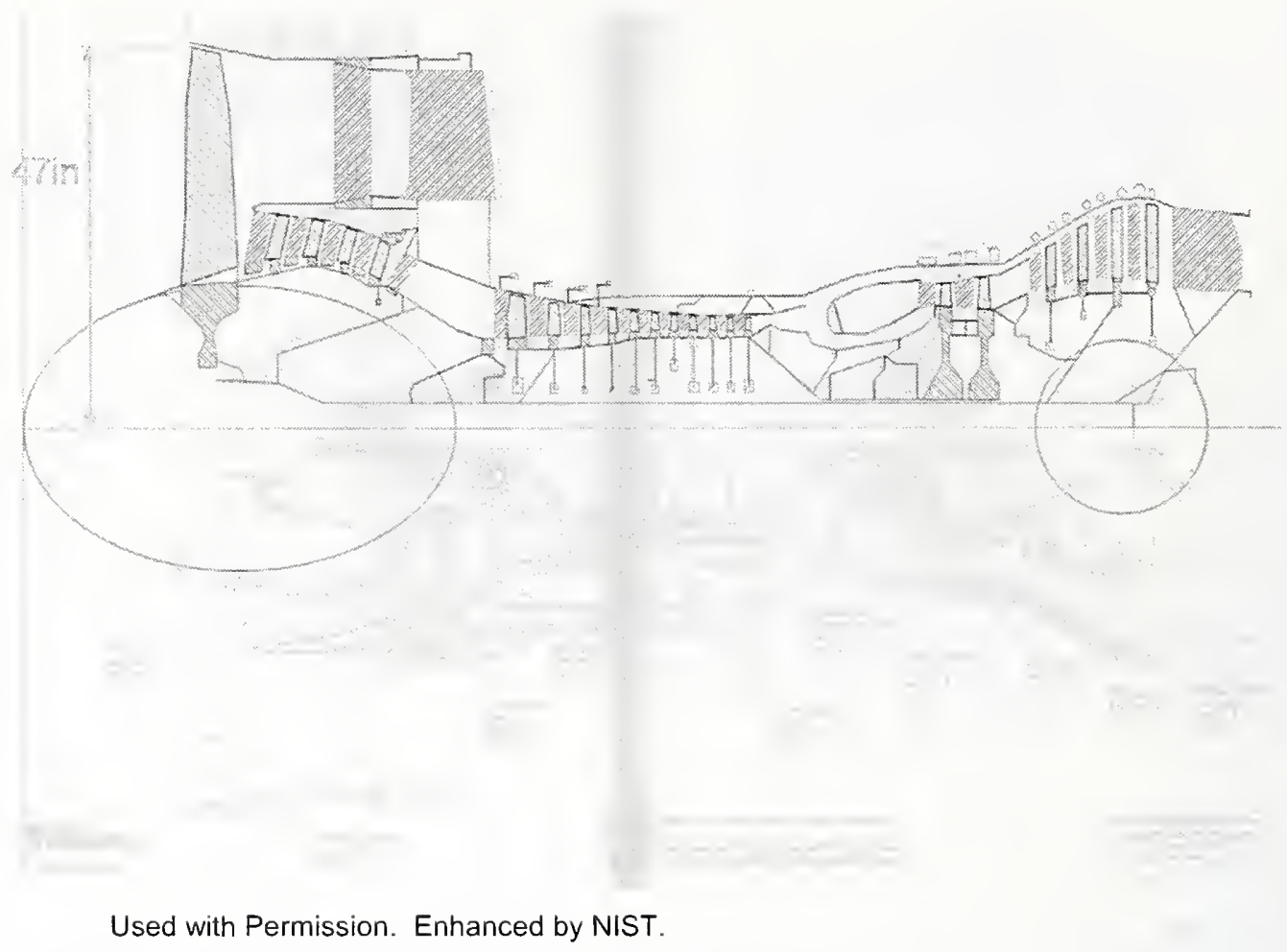

Figure 5-41. PW4000 engine cross-sectional geometry and simplification.

Once the engine internal geometry was captured, the digitized geometry was imported into TrueGrid and used to generate surface definitions and part geometries for the engine model. The engine model was developed using primarily shell elements with typical element dimensions between 1 in. and 2 in. Smaller element dimensions were required at many locations to capture details of the engine geometry. Brick elements were used for some of the thicker hubs and the roots of the compressor blades. The various components of the resulting engine model are shown in Figure 5-42. A summary of the elements used in the engine model is given in Table 5-5. 

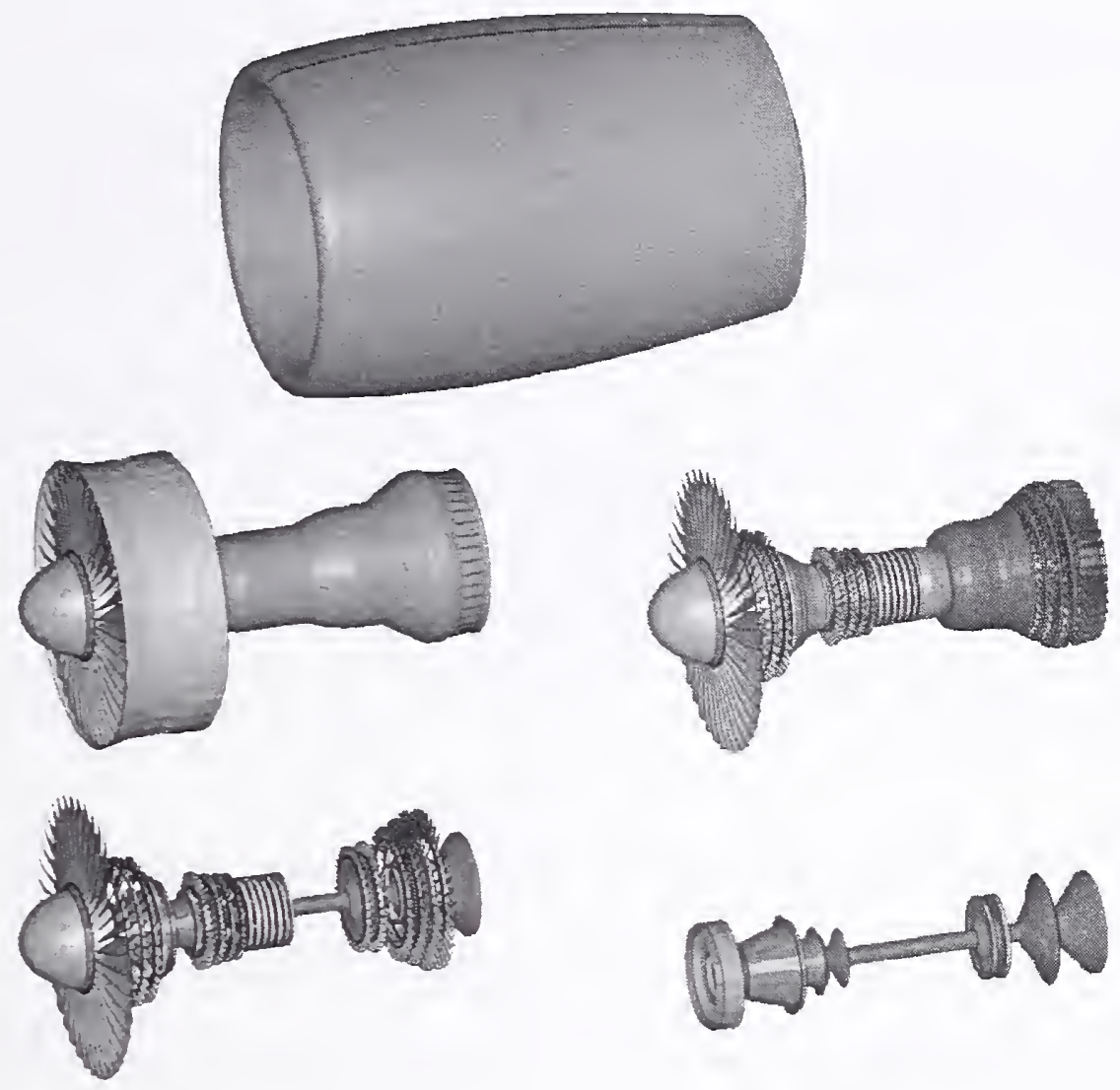

Figure 5-42. Pratt \& Whitney PW4000 turbofan engine model.

Table 5-5. Engine model parameters.

\begin{tabular}{|c|c|}
\hline & PW4000 Engine Model \\
\hline No. Brick Elements & 9,560 \\
\hline No. Shell Elements & 54,788 \\
\hline Total Nodes & 101,822 \\
\hline Preliminary Engine Model Weight & $7,873 \mathrm{lb}$ \\
\hline Adjusted Engine Model Weight & $9,447 \mathrm{lb}$ \\
\hline
\end{tabular}

After the known primary structural components of the engine were included in the engine model, the weight of the model was calculated to be $7,873 \mathrm{lb}$. The dry weight of the PW4000 engine was listed at $9,400 \mathrm{lb}$ and the JT9D-7R4 and CF6-80C2 engines weigh between 8,885 and 9,860 lb. These engine weights were approximately 20 percent larger than the initial model weight. The difference in weight potentially resulted from the nonstructural components (tubing, pumps, seals, bearings, etc.) that were not included in the model. To account for the difference, the density of all of the material models used for engine components was increased by 20 percent. This effectively smeared the missing mass in proportion to the original mass distribution in the model. The resulting adjusted engine model weight was 9,447 lb. 


\subsubsection{Aircraft Material Constitutive Models}

The constitutive and failure properties for the aircraft materials were developed from data available in the open literature. The principal sources of data for the airframe materials were the Military Handbook (MIL-HDBK-5F), 1987 and the Aerospace Structural Metals Handbook [Brown, et al. 1991]. Additional sources of data were used to verify and supplement the information obtained from these primary data sources.

Complete engineering stress-strain curves were provided in the MIL-HDBK-5F for various 2024 and 7075 aluminum alloys that are commonly used in the construction of the Boeing 767 airframe. These curves were digitized for the various 2024 and 7075 alloys. Representative stress-strain curves were then converted into true stress and true strain and used to develop tabular curves for constitutive models. The calculated true stress-strain curves and tabular constitutive model fits are shown in Figure 5-43 and Figure 5-44, respectively. Appropriate failure criteria for the aircraft materials were developed using the fine and coarse wing component models, see NIST NCSTAR 1-2B. No rate sensitivity of the aircraft materials was considered.

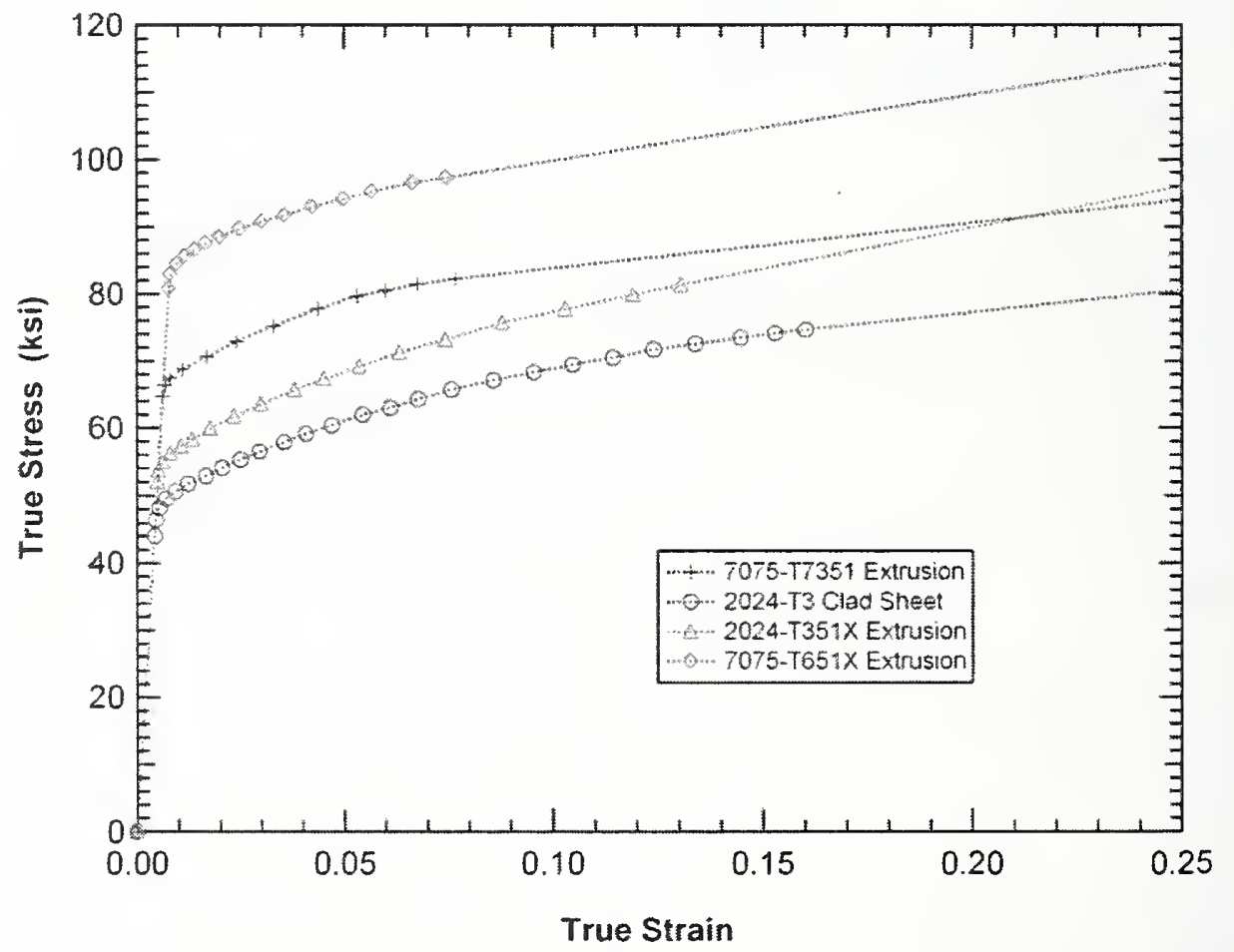

Figure 5-43. True stress-strain curves developed for various aircraft aluminum alloys. 


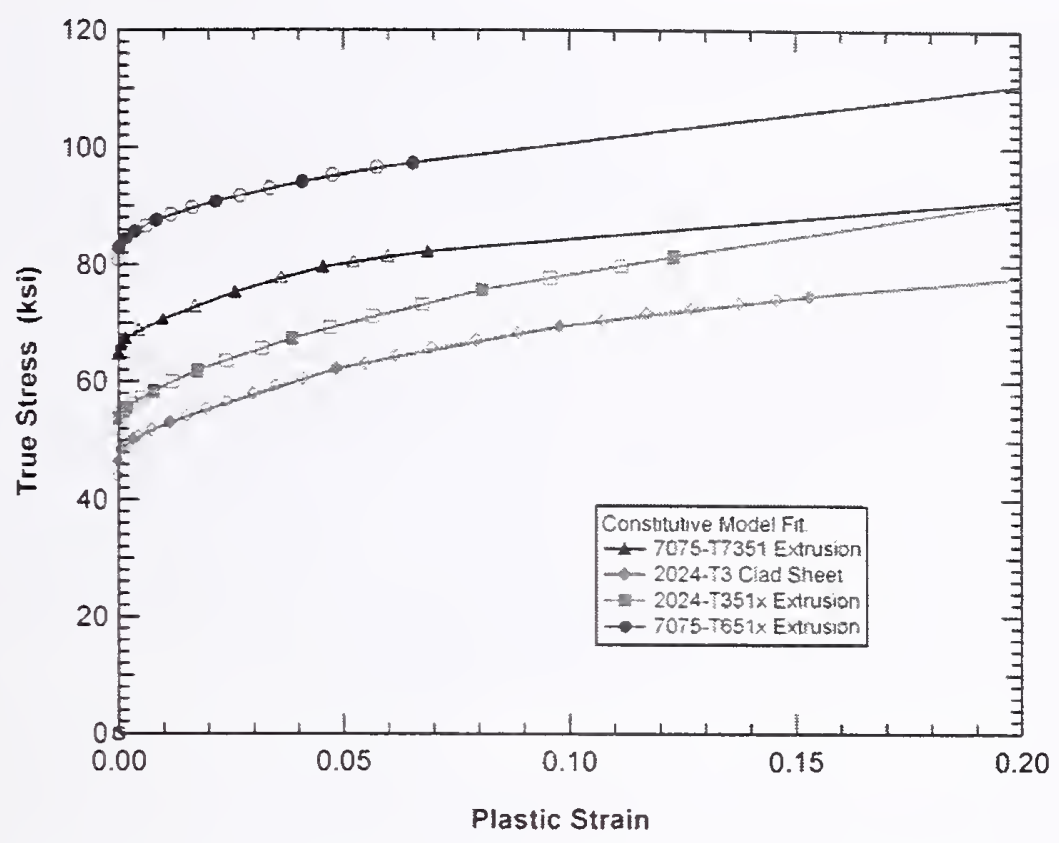

Figure 5-44. Tabular stress-strain curves developed for various aircraft aluminum alloys.

\subsection{COMPONENT AND SUBASSEMBLY LEVEL ANALYSES}

The primary objectives of the component modeling were to (1) develop understanding of the interactive failure phenomenon of the aircraft and tower components, and (2) develop the simulation techniques required for the global analysis of the aircraft impacts into the WTC towers. The approach taken for component modeling was to start with finely meshed, brick and shell element models of key components of the tower structure and progress to relatively coarsely meshed beam and shell element representations that were used for the global models. This was done to support the development of the reduced finite element global models appropriate for high fidelity global impact analyses, as modeling each component with fine details in the global models would be too demanding from a computational standpoint as was explained in Section 5.1. In addition to determining the optimal element size and type for global modeling, other key technical areas were addressed in the component modeling, including material constitutive modeling, treatment of connections, and modeling of aircraft fuel. The component analyses were also used in the uncertainty analyses to assess the effects of uncertainties associated with the aircraft and WTC towers on the level of damage to the towers after impact and to determine the most influential modeling parameters that affect the damage estimates (see Chapter 8 of NIST NCSTAR 1-2B).

The subassembly analyses were considered as a transition between the component analyses and the global impact analyses. The subassembly analyses were primarily used to investigate different modeling techniques and associated model size, run times, numerical stability, and impact response. The subassembly model was also used to investigate the sensitivity of the impact response to model parameters as well as for the uncertainty analyses (Chapter 8 of NIST NCSTAR 1-2B).

A large array of component and subassembly models were developed and used in the impact simulations. Examples of such analyses are included in this section. The reader is referred to Chapters 5 and 6 of NIST NCSTAR 1-2B for further details of the component and subassembly analyses, respectively. 


\subsubsection{Exterior Column Impacted with an Empty Wing}

The objective of this analysis was to develop a model with a coarse mesh that could be applied to the global impact analyses and still capture the impact damage properly. The analysis used an empty wing section impacting an exterior wall column. The empty wing section model was selected to produce significant column damage at an impact speed of $470 \mathrm{mph}$ without completely failing the column.

These calculations used a preliminary failure criterion. The exterior column modeled was constructed entirely with $55 \mathrm{ksi}$ steel and the spandrel plates with $42 \mathrm{ksi}$ steel. Both a model with a fine mesh of brick elements and a model with a coarser mesh of shell elements were developed. These models included a specific description of the weld geometry, with different properties. In the fine brick element model, the failure strain for the base metal, weld metal, and heat affected zone (HAZ) were all set at a uniform plastic strain of 64 percent, corresponding to the base metal ductility. Failure strains in the coarse shell element models were then adjusted until a similar impact damage and failure mechanism were obtained. A comparison of parameters for the two models is given in Table 5-6.

The calculated impact response is shown in Figure 5-45. The column model on the left has the fine mesh of brick elements, and the column model on the right has the coarse mesh of shell elements. Contours of resultant displacements are shown on the column components. The figure indicates that the overall response was similar in both magnitude and damage mode. The reduction in model refinement resulted in a significant reduction in run time from over $600 \mathrm{~min}$ to $9 \mathrm{~min}$. This comparison demonstrated the significance of the mesh refinement on capturing local stress and strain concentrations and the resulting effect on the impact response.

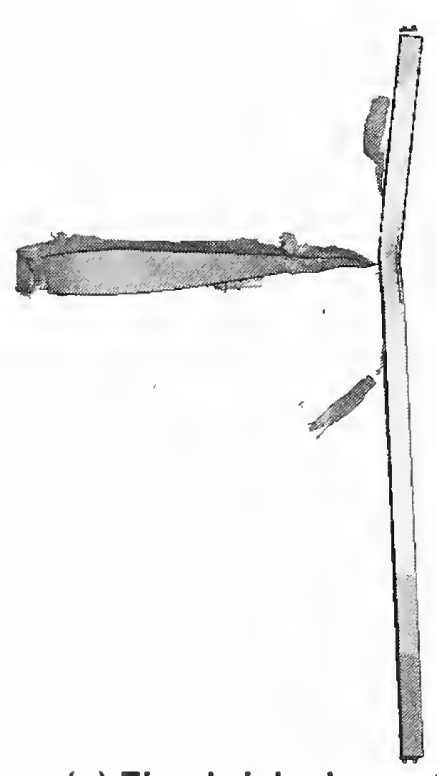

(a) Fine brick element column

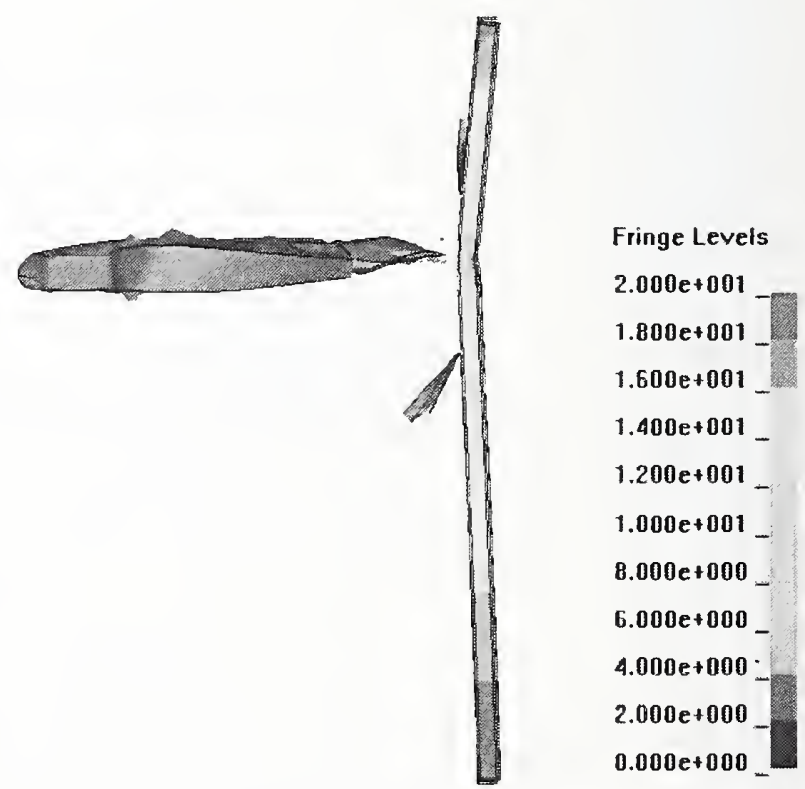

(b) Coarse shell element column

Figure 5-45. Exterior column response comparison, showing contours of the displacement magnitude (in.). 
Table 5-6. Exterior column component analyses comparison.

\begin{tabular}{|c|c|c|}
\hline Column Model Type & Fine Brick Model & $\begin{array}{c}\text { Coarse Shell } \\
\text { Model } 1\end{array}$ \\
\hline Number of Brick Elements & 473,208 & 352 \\
\hline Number of Shell Elements & 0 & 9,192 \\
\hline Number of Beam Elements & 0 & 8 \\
\hline Minimum Element Dimension & $0.0625 \mathrm{in}$ & $1.0 \mathrm{in}$. \\
\hline Bulk Material Failure Strain & $64 \%$ & $12 \%$ \\
\hline Weld Zone Failure Strain & $64 \%$ & $2 \%$ \\
\hline Calculation Time (CPU) ${ }^{\mathrm{a}}$ & $444 \mathrm{~min}$ & $3 \mathrm{~min}$ \\
\hline Elapsed Time & $624 \min$ & $9 \mathrm{~min}$ \\
\hline
\end{tabular}

a. Simulation of 0.035 second duration impact response performed on 11 CPUs.

\subsubsection{Bolted Connection Modeling}

The objective of this analysis was to develop connection models for the global impact analyses that accurately captured the capacity and failure modes of the bolted connection between exterior columns. Component models of the exterior column butt plate connections are shown in Figure 5-46. The detailed model (a) included individual bolts and butt plates modeled with solid brick elements. The simplified model (b) used coarse brick element butt plates joined by beam elements representing the bolts. A dynamic analysis was carried out to calibrate the beam element bolt model. The loading condition was a dynamic separation of the two butt plates. The velocity profile used to separate the butt plates was a linearly increasing separation velocity between the butt plates with an initial velocity of zero and a velocity of $43 \mathrm{fps}$ at a time of $5.0 \mathrm{~ms}$, obtained from a preliminary engine impact analysis against the exterior wall

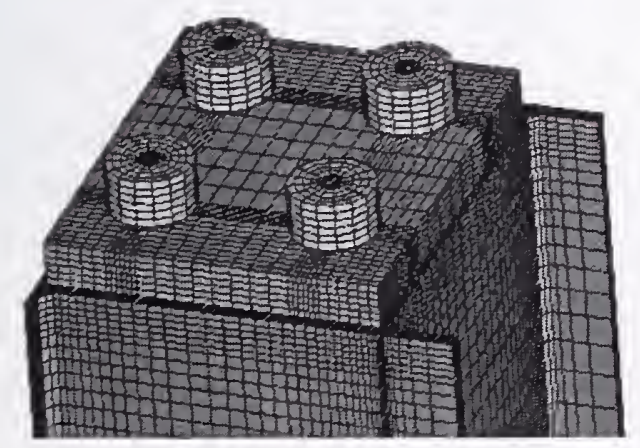

(a) Brick element bolts

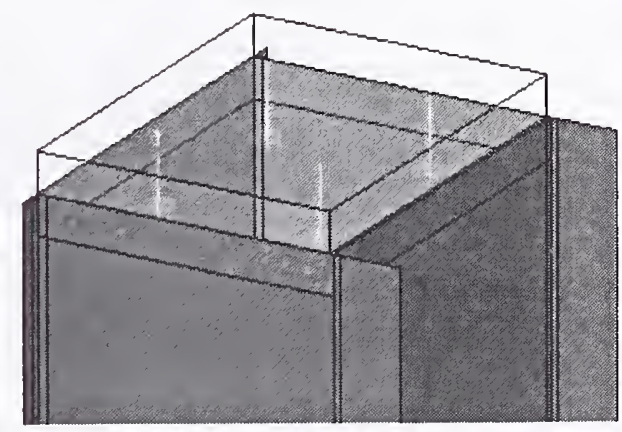

(b) Beam element bolts (butt plates shown as transparent)

Figure 5-46. Modeling of exterior column bolted connection.

Failure strain in the beam models was calibrated such that the beam bolts failed at the same time as the brick element bolts. Failure of the bolts occurred at a time of approximately $3.0 \mathrm{~ms}$. These connection models were used in the corresponding brick and shell models of the exterior column component impact 
analyses shown previously in Figure 5-45. Connection failure at the column ends was quite similar in both cases as shown in Figure 5-47. Failure of the connection is illustrated for both connection models at the same time, $35 \mathrm{~ms}$, after impact with the empty wing segment. The primary failure modc for both models was a tensile failure of the bolts and subsequent separation of the column end butt plates.

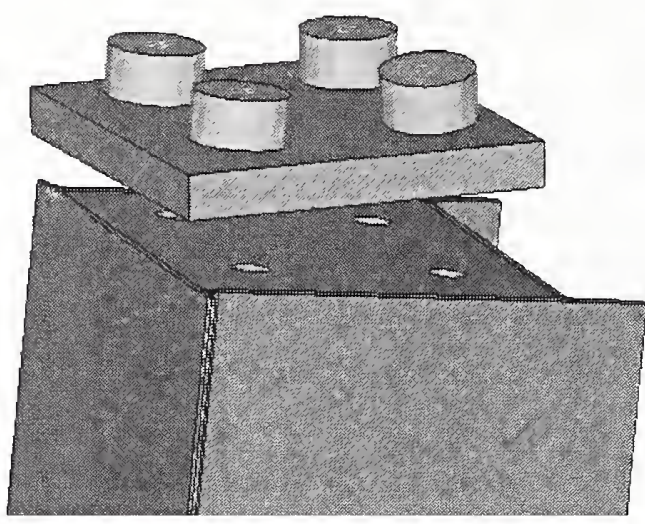

(a) Brick element bolts

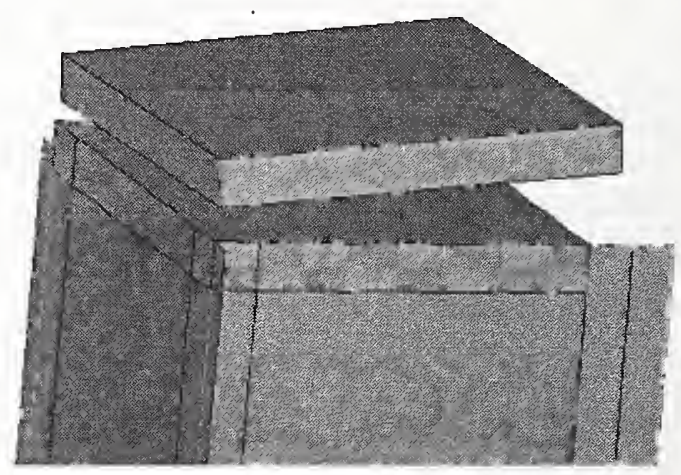

(b) Beam element bolts

Figure 5-47. Failure comparison of exterior column bolted connection treatments.

\subsubsection{Floor Assembly Component Analysis}

Floor truss impact analyses were carried out to develop a coarse representation of the truss floor, for use in the global impact simulations, that properly captured the impact response characteristics of the fine model of the floor system. For that purpose, detailed floor component models used a combination of brick elcments for the concrete slab, beam elements for the truss round bar diagonals, and shell elements for the remainder of the structures, including the truss upper and lower chords and metal decking. This model is shown in Figure 5-48. A less-refined model, similar to that used in the global impact models, was then developed with coarser shell and beam elements as shown in Figure 5-49. This model reduced the size of the floor model by an order of magnitude and the run times by more than 80 percent (see the comparison in Table 5-7).

Table 5-7. Truss floor assembly component analyses comparison.

\begin{tabular}{|c|c|c|}
\hline Model Type & Fine Brick Model & Coarse Shell Model \\
\hline No. Beam Elements & 6,928 & 3,440 \\
\hline No. Brick Elements & 230,778 & 0 \\
\hline No. Shell Elements & 148,256 & 39,000 \\
\hline Total Nodes & 372,084 & 48,971 \\
\hline CPU Time & $16,796 \mathrm{~s}(4.7 \mathrm{~h})$ & $2,482 \mathrm{~s}(0.7 \mathrm{~h})$ \\
\hline Elapsed Time & $26,553 \mathrm{~s}(7.3 \mathrm{~h})$ & $4,454 \mathrm{~s}(1.2 \mathrm{~h})$ \\
\hline
\end{tabular}

The concrete constitutive model used in the brick elements of the dctailed floor model was the pseudotensor model described in Section 5.2.6. The coarse floor model used an effective material model for the 
concrete and metal decking so that these parts would not need to be meshed separately. As the pseudotensor model is developed for brick elements, and does not work for shell elements, a piecewise plasticity model was used for the effective slab-decking behavior. A tabular stress-strain curve was developed based on the rule of mixtures of the elastic-plastic metal decking with the unconfined compressive behavior for the concrete. The combined slab and decking stress-strain curve was compared to the concrete unconfined compressive behavior in Figure 5-50. The strength of the combined floor slab was dominated by the concrete strength at low strain levels (below 1 percent strain). However, as the concrete was fragmented and removed as debris, the residual strength was equivalent to that of the metal deck alone and remained ductile until a strain of 30 percent was reached. The strain rate effects used for the combined concrete slab and metal decking were those used for concrete as shown in Figure 5-29.

The impactor used in the component modeling was a simplified plow type impactor, which produced repeatable damage, not complicated by all the debris and randomness associated with an engine-floor impact. The weight of the plow impactor was comparable to an engine, and the impact speed was $500 \mathrm{mph}$, applied horizontally. An example analysis with a plow impactor and the fine mesh floor model is shown in Figure 5-51. The calculated impact damage with the coarser shell element floor system model is shown in Figure 5-52. This component impact configuration was useful for comparing the differences in response with changes in the modeling methods or refinement.

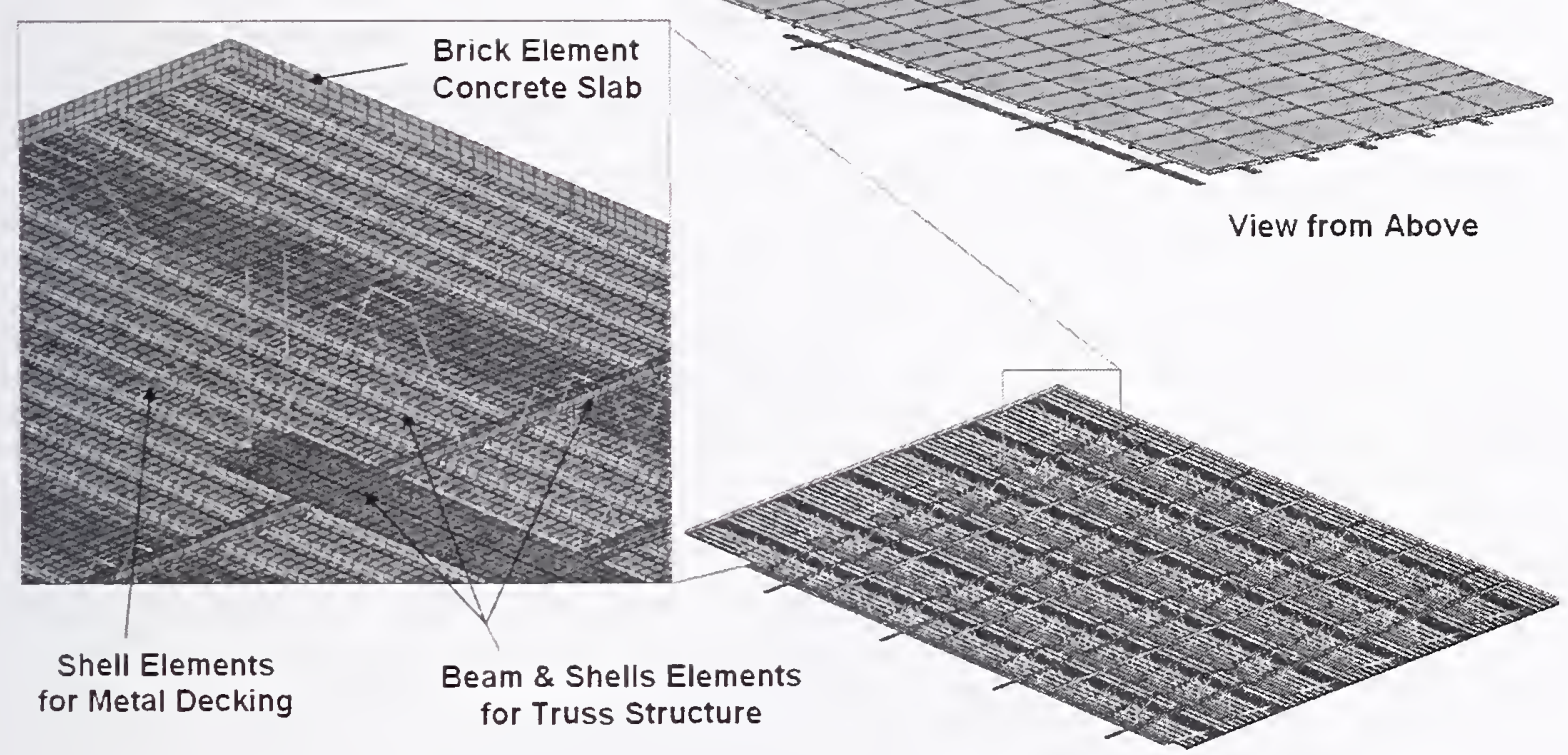

View from Below

Figure 5-48. Detailed model of the truss floor system. 
Shell Elements for Combined Concrete and Metal Decking

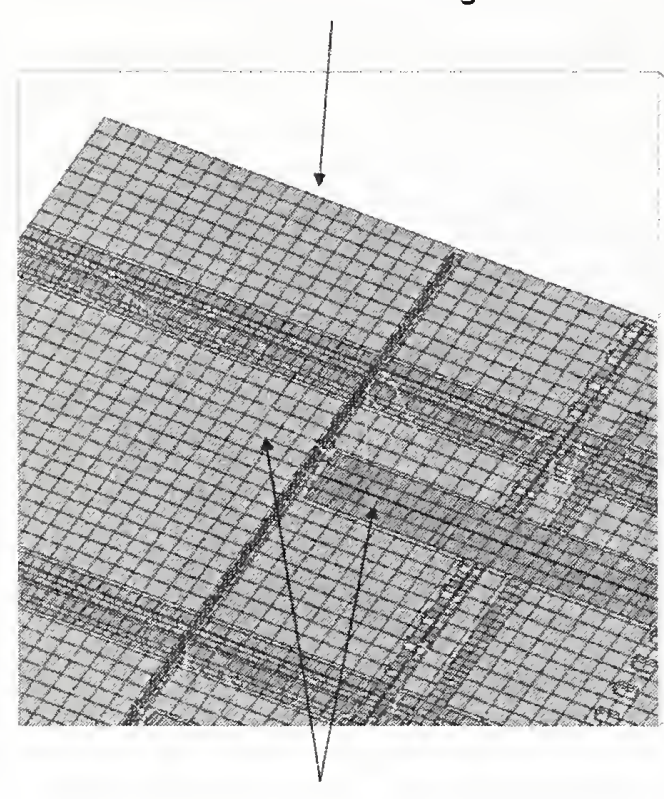

Beam \& Shell Elements for Truss Structures

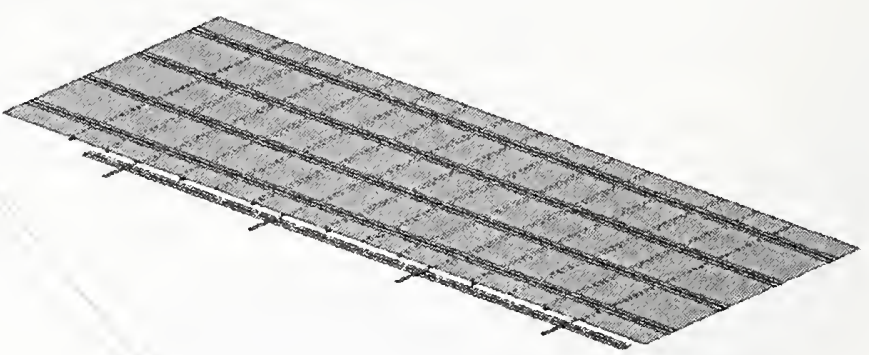

View from Above

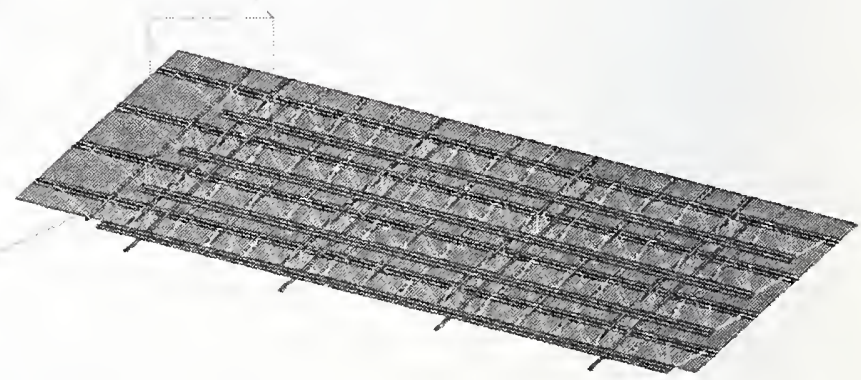

View from Below

Figure 5-49. Simplified model of the truss floor system.

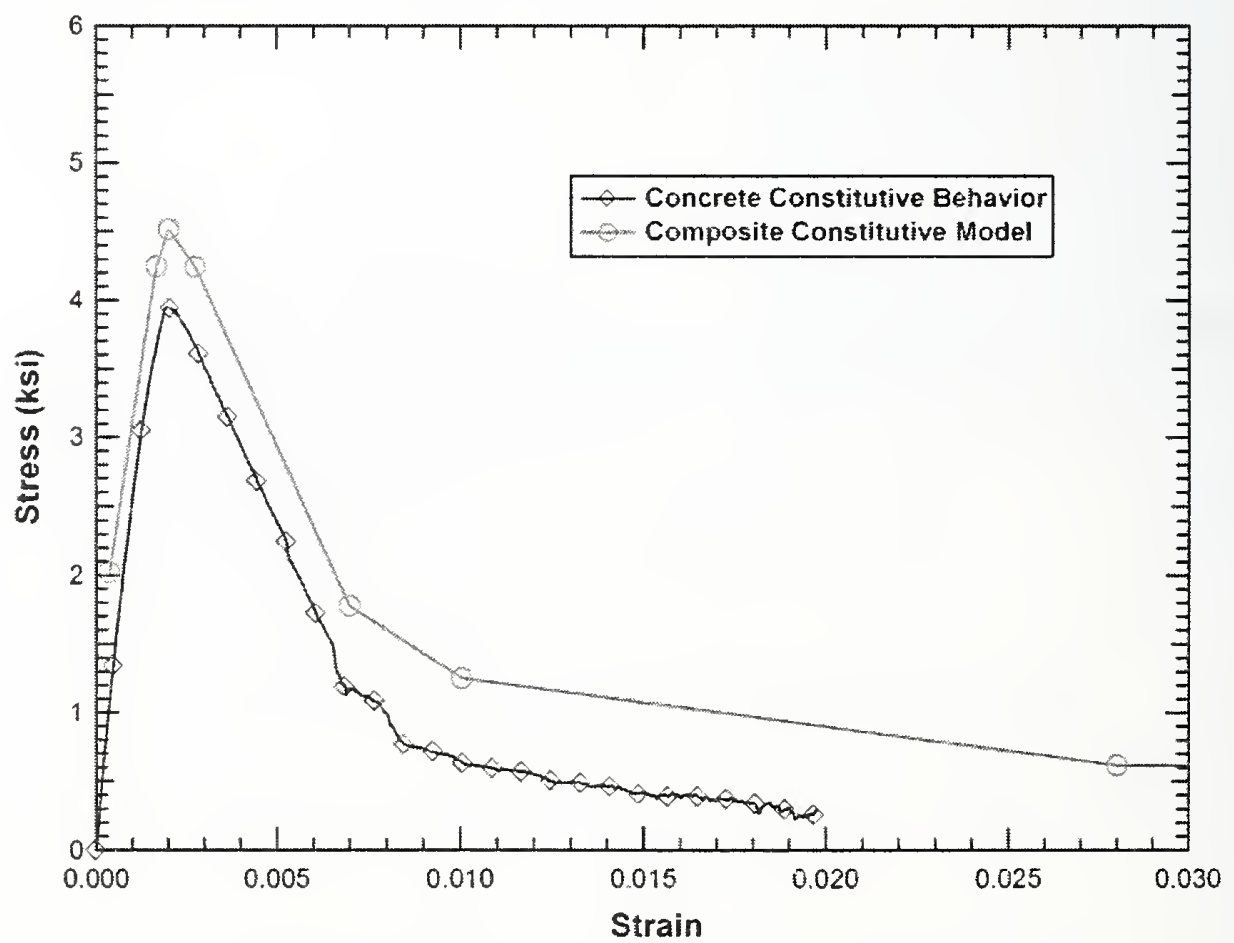

Figure 5-50. Constitutive behavior for the combined concrete and metal decking. 


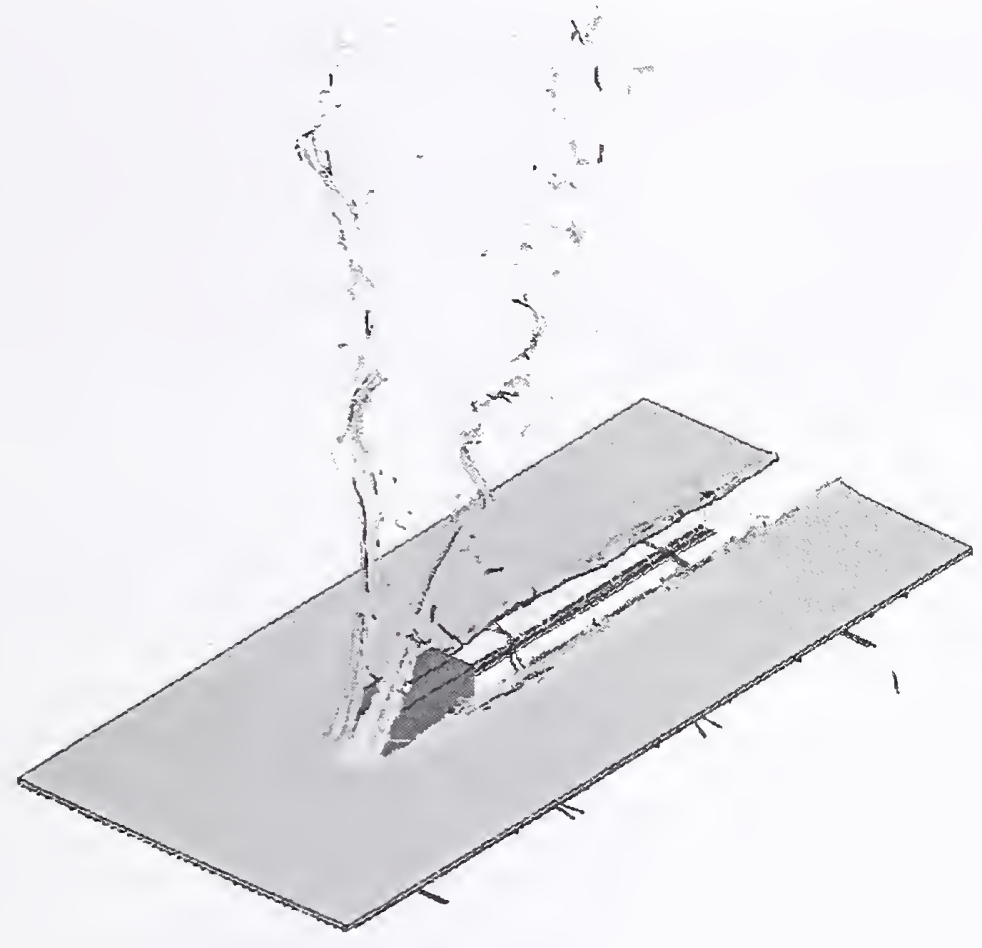

Impact response at $0.10 \mathrm{~s}$

Figure 5-51. Floor assembly impact response with brick element concrete slab.

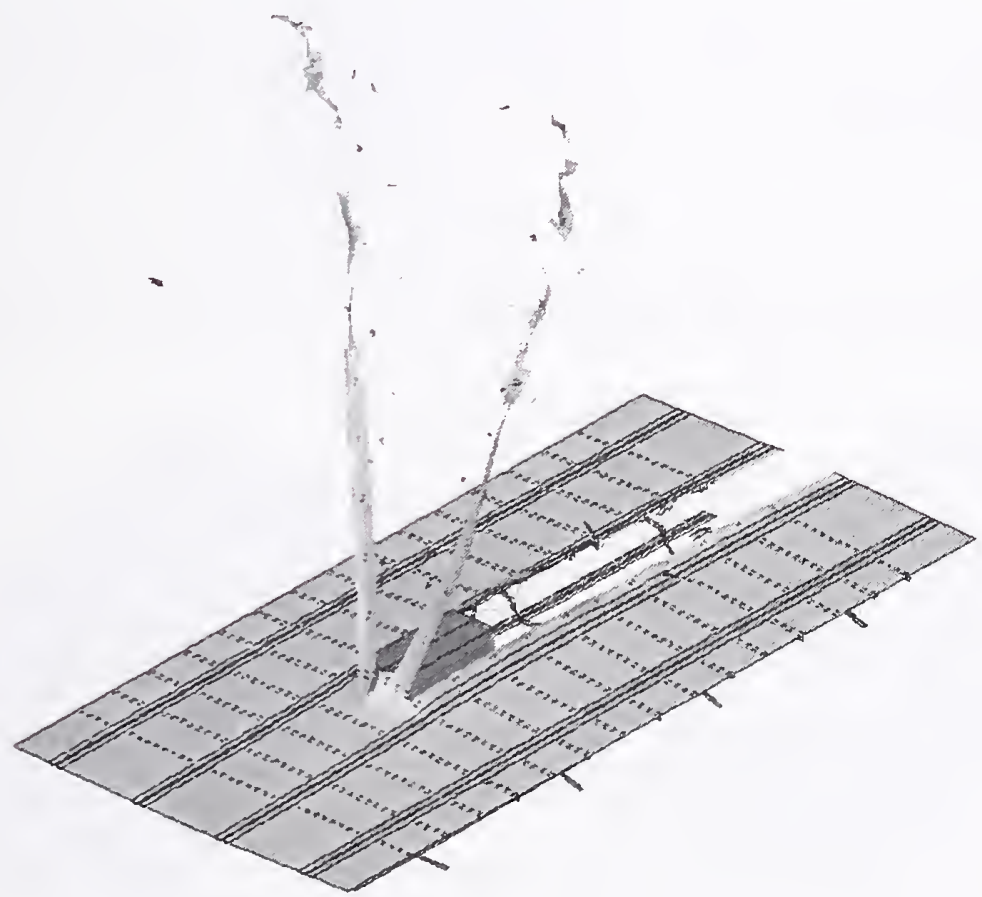

Impact response at $0.10 \mathrm{~s}$

Figure 5-52. Floor assembly impact response with shell element concrete slab. 


\subsubsection{Modeling of Aircraft Wing Section Impact with Fuel}

A significant portion of the weight of a Boeing 767 wing is from the fuel in its integral fuel tanks. At the time of impact, it is estimated that each aircraft had approximately 10,000 gal of fuel onboard. Upon impact, this fuel was responsible for large distributed loads on the exterior columns of the WTC towers and subsequently on interior structures, as it flowed into the building, potentially having a significant effect on the damage inflicted on the building structure. Modeling of the fluid-structure interaction was necessary to predict the extent of this damage and the fuel dispersion within the building to help establish the initial conditions for the fire dynamics modeling.

A number of approaches to solving fluid-structure interaction problems are available in LS-DYNA. One approach is the standard Lagrangian finite element analysis with erosion, where the fuel is modeled using a deformable mesh. This approach accounts for the inertial effects of the fuel, but does not simulate well the fuel flow during impact due to limitations on mesh distortion. The Arbitrary-Lagrangian-Eulerian (ALE) method was developed as a good approach to solve fluid and solid material interaction. With this methodology, fluids are modeled with an Eulerian mesh, which allows for materials to flow between mesh elements. Solid materials are modeled with a moving Lagrangian mesh. With ALE, both mesh types can interact. An alternative approach is to use mesh-free methods such as Smoothed Particle Hydrodynamics (SPH). SPH modeling for fuel effects has the advantage of a smaller mesh size and potentially much faster run times than ALE analyses. Both ALE and SPH methods were applied to the analysis of fuel impact and dispersion and are compared in this study.

A small wing segment was used for performing component level analyses of the wing with fuel. The segment was considered to be completely filled with fuel (approximately 850 gal). Figure 5-53 shows the wing section model with an SPH and ALE mesh for the fuel, shown in blue. The fuel was modeled with 6,720 SPH fuel particles and 110,825 ALE elements for the fuel and surrounding air region, shown in Figure 5-54. The impacted structures were two exterior wall panels as shown in Figure 5-54.

An ALE mesh, surrounding the wing segment and the panels, was needed for the fuel to flow into. In ALE analyses, material is advected from one element to the next so that a mesh is needed for initially "empty" regions. In this case, this mesh was filled with stationary air to interact with the fuel.

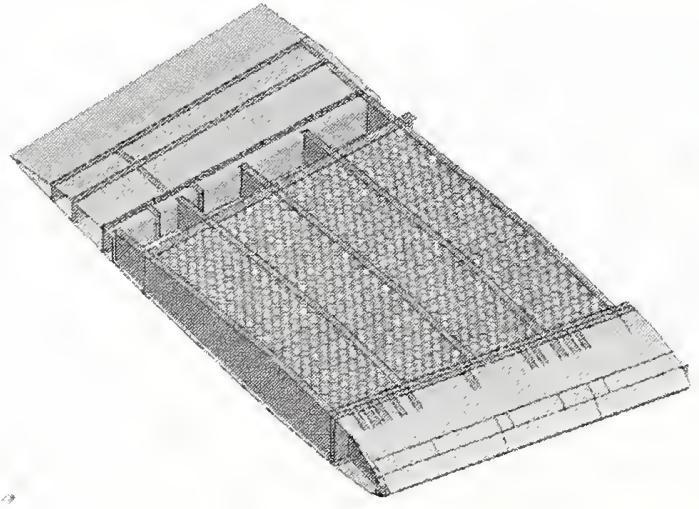

(a) SPH mesh

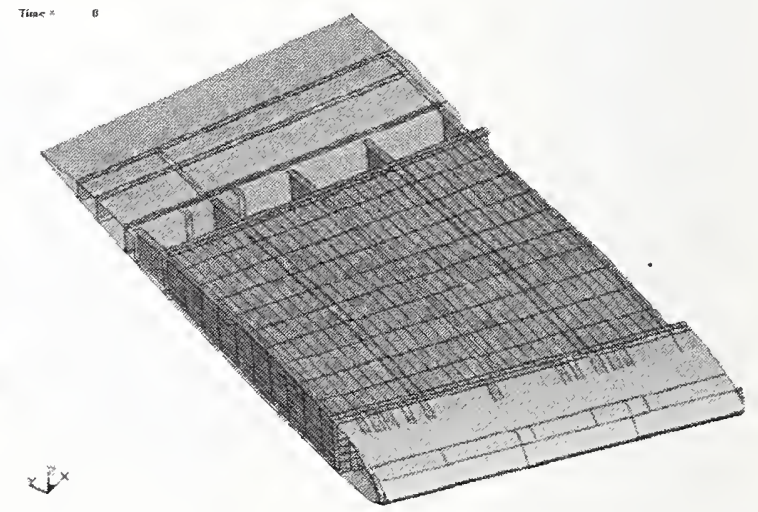

(b) ALE mesh

Figure 5-53. SPH and ALE fuel models in the small wing segment. 
The wing segment trajectory was that of a normal impact at $500 \mathrm{mph}$ at mid-height between spandrels. The wing was oriented with no pitch, yaw, or roll. Therefore, the leading edge impacted the panels with the sweep angle of the wing relative to the fuselage. The two exterior panels were constrained rigidly at the butt plates and at the floor slab locations. Refer to Chapter 5 of NIST NCSTAR 1-2B for the fuel modeling parameters used in the ALE and SPH analyses.

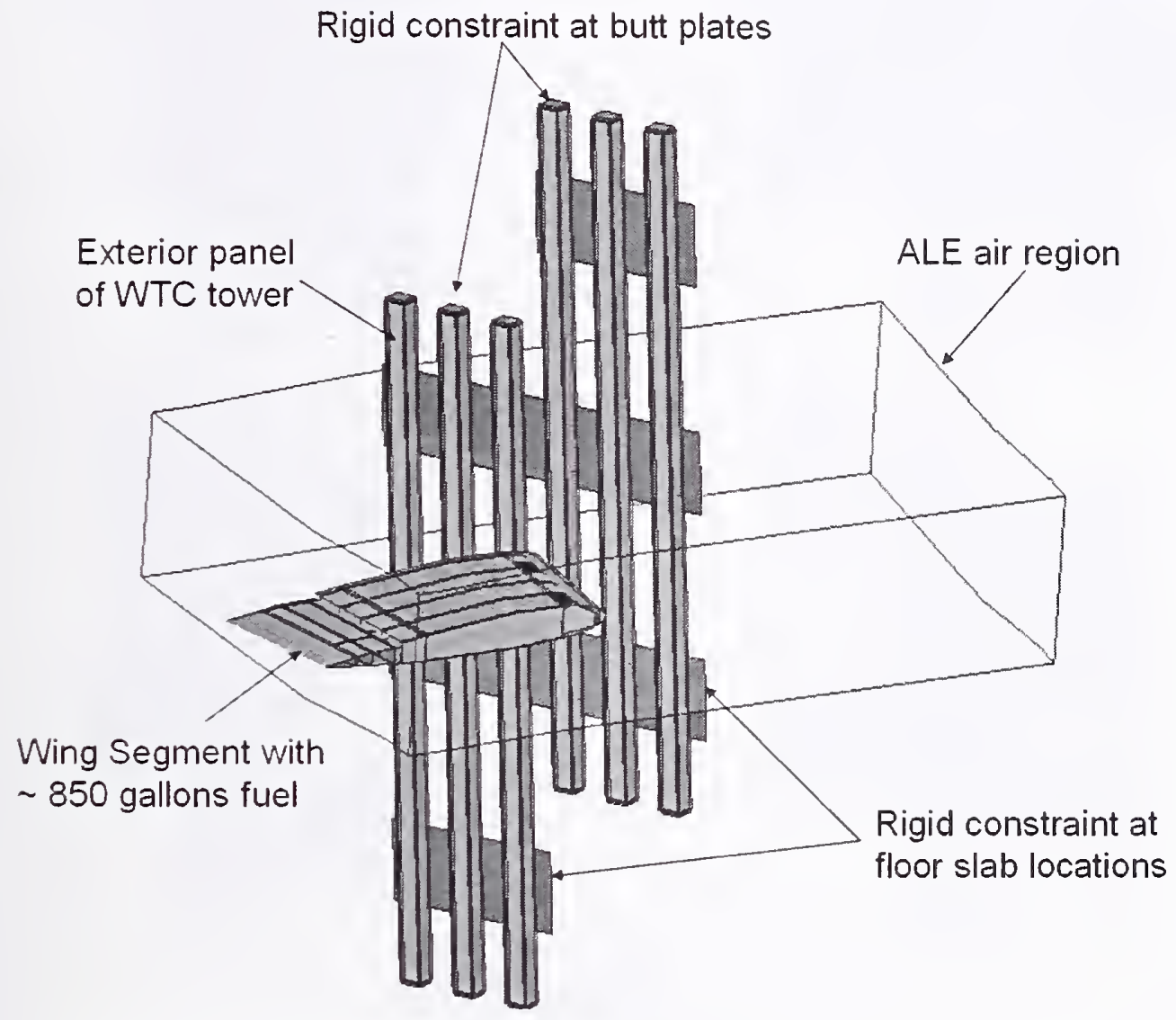

Figure 5-54. Wing segment, fuel, and exterior panel configuration.

Results of the impact analysis of the wing section using the ALE and SPH approaches are shown in Figure 5-55 and Figure 5-56, respectively. In both cases, the columns of the exterior panels were completely destroyed due to impact. Close-ups of the damage to the exterior panels are shown in Figure 5-57. Figure 5-58 and Figure 5-59 show close-up comparisons of the fuel dispersion and wing break up predicted by the two fuel modeling approaches. While both modeling approaches gave comparable results for the damage to the exterior wall panels, the SPH modeling method predicted greater fuel dispersion and wing break up than when using ALE, as can be shown clearly in the side views (Figure 5-59). Without experimental data, it is difficult to evaluate which method provides a more accurate solution.

Run-times from these component analyses clearly indicated that the SPH method was more practical for the global impact analyses. The SPH model ran about 10 times faster than the ALE method, as it required a smaller mesh and did not need to rezone after each time step, as was done in the ALE method. In 
addition, the ALE method required a mesh for both the fuel region and the air zone into which the fuel could flow. Therefore, the SPH method was selected as the modeling technique for the global analyses.
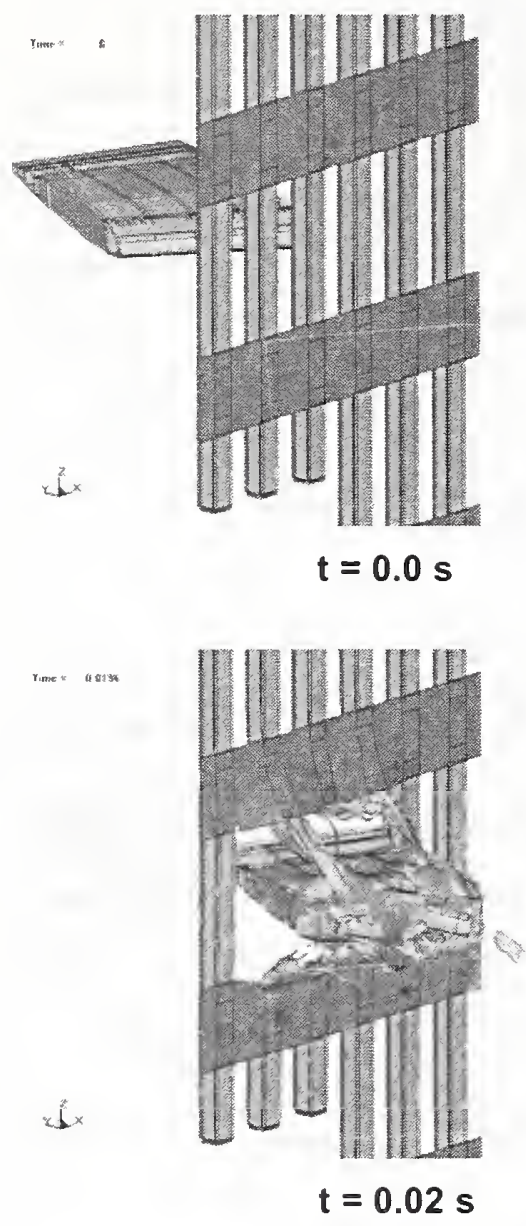
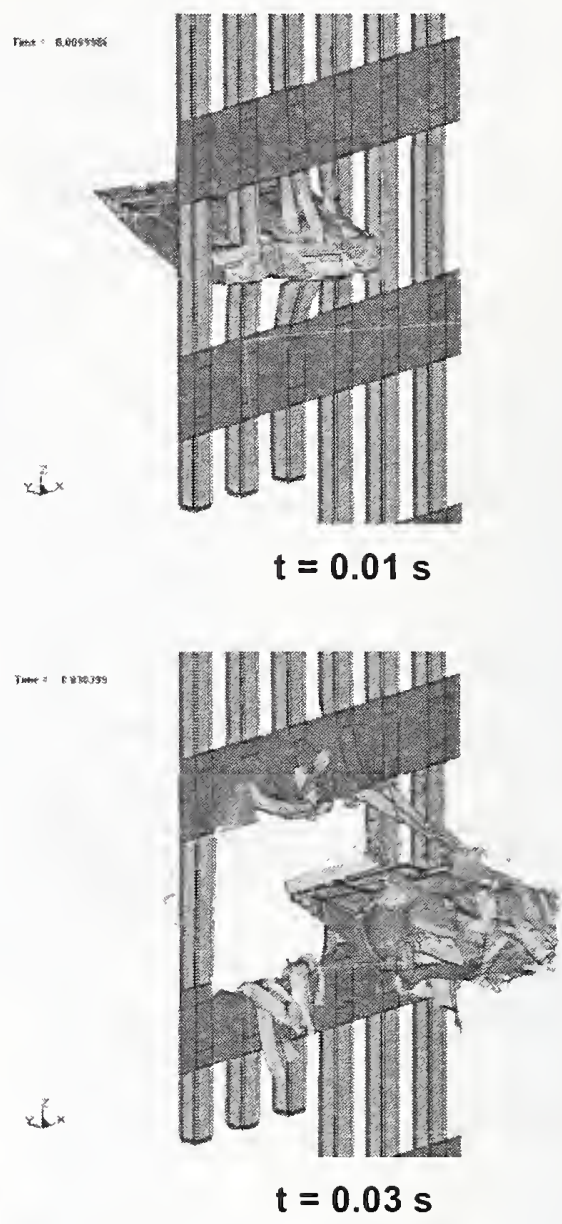

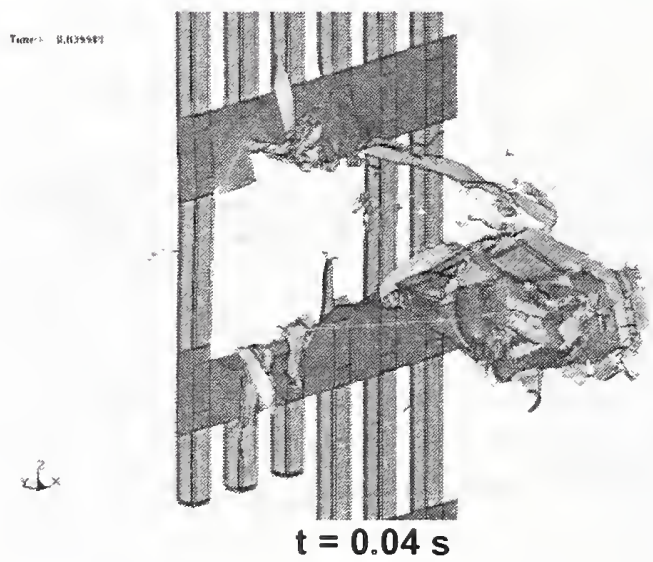

Figure 5-55. Impact response of a wing section laden with fuel modeled using ALE approach. 

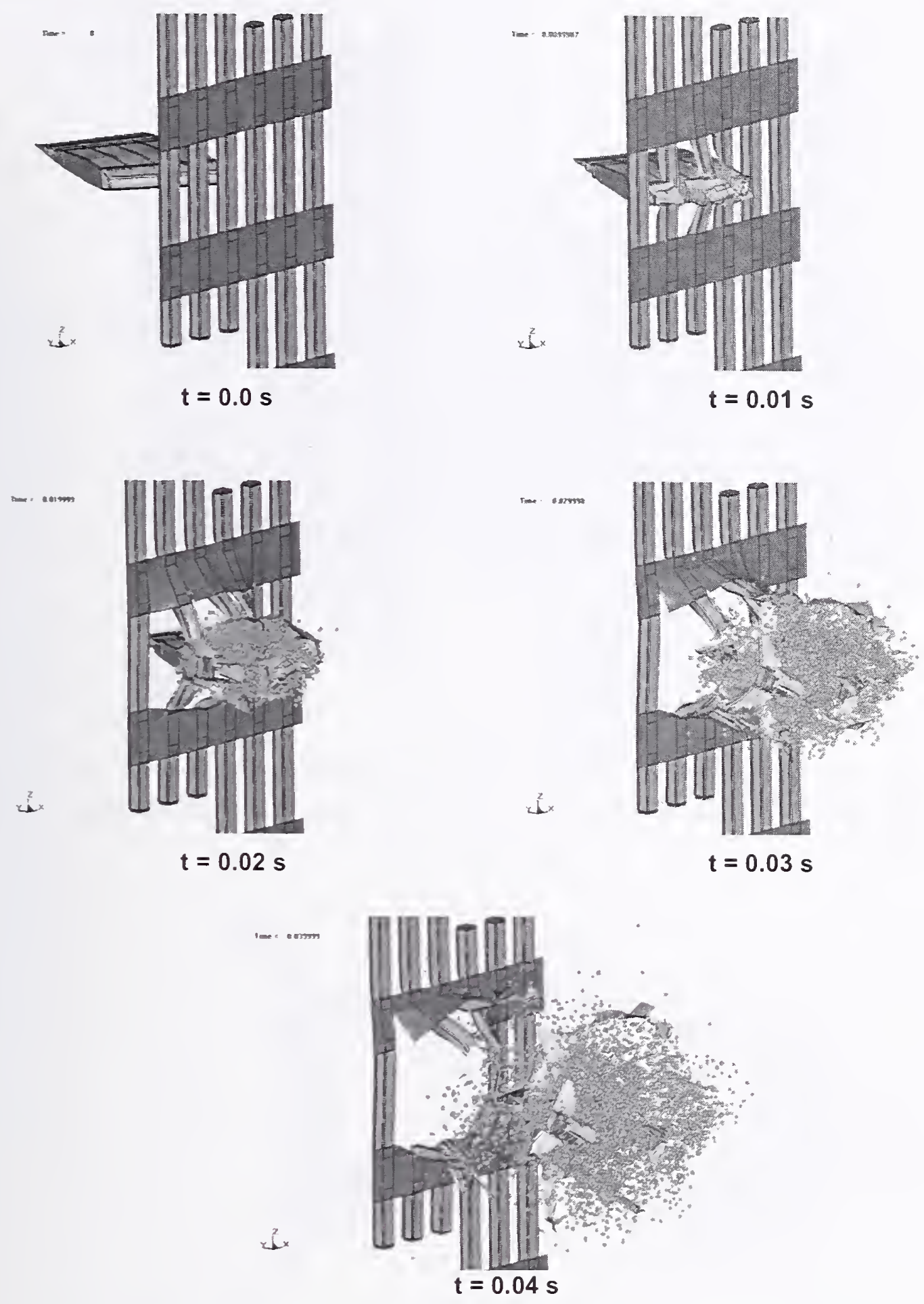

Figure 5-56. Impact response of a wing section laden with fuel modeled using SPH approach. 


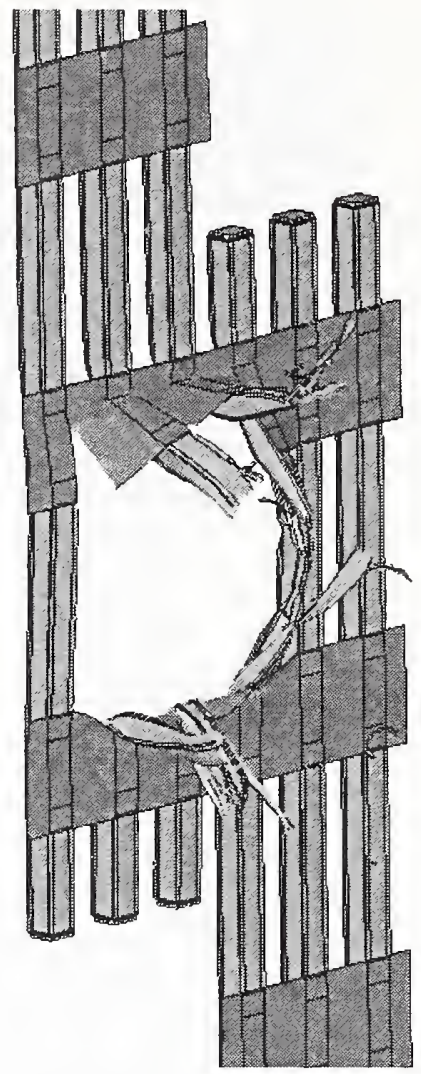

(a) With SPH approach

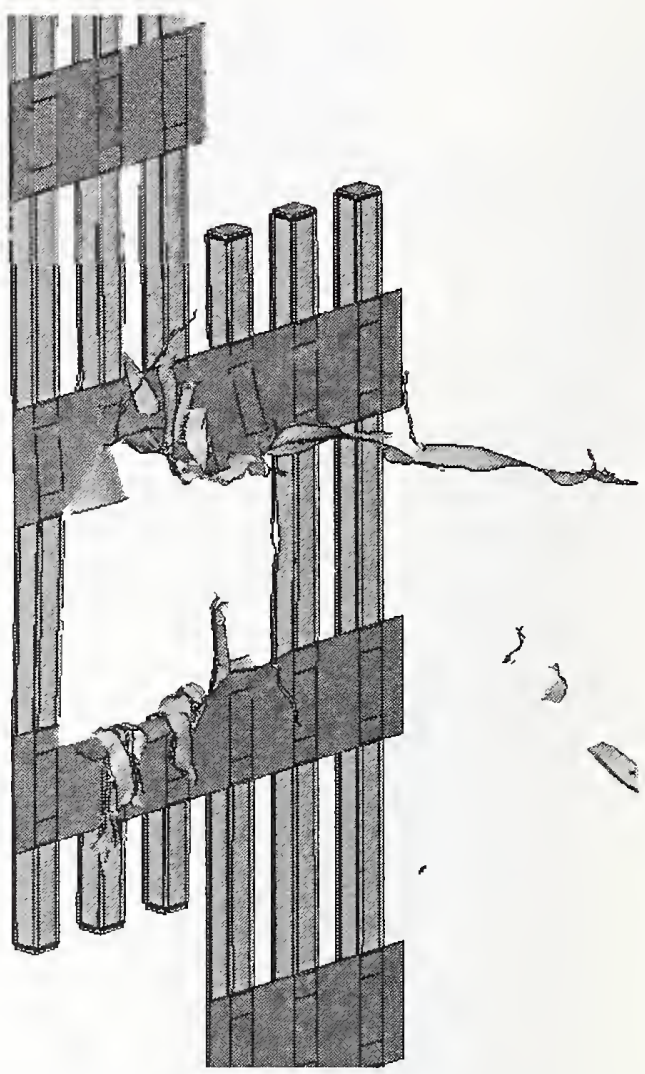

(b) With ALE appraoch

Figure 5-57. Exterior panels after impact with a wing segment with fuel. 


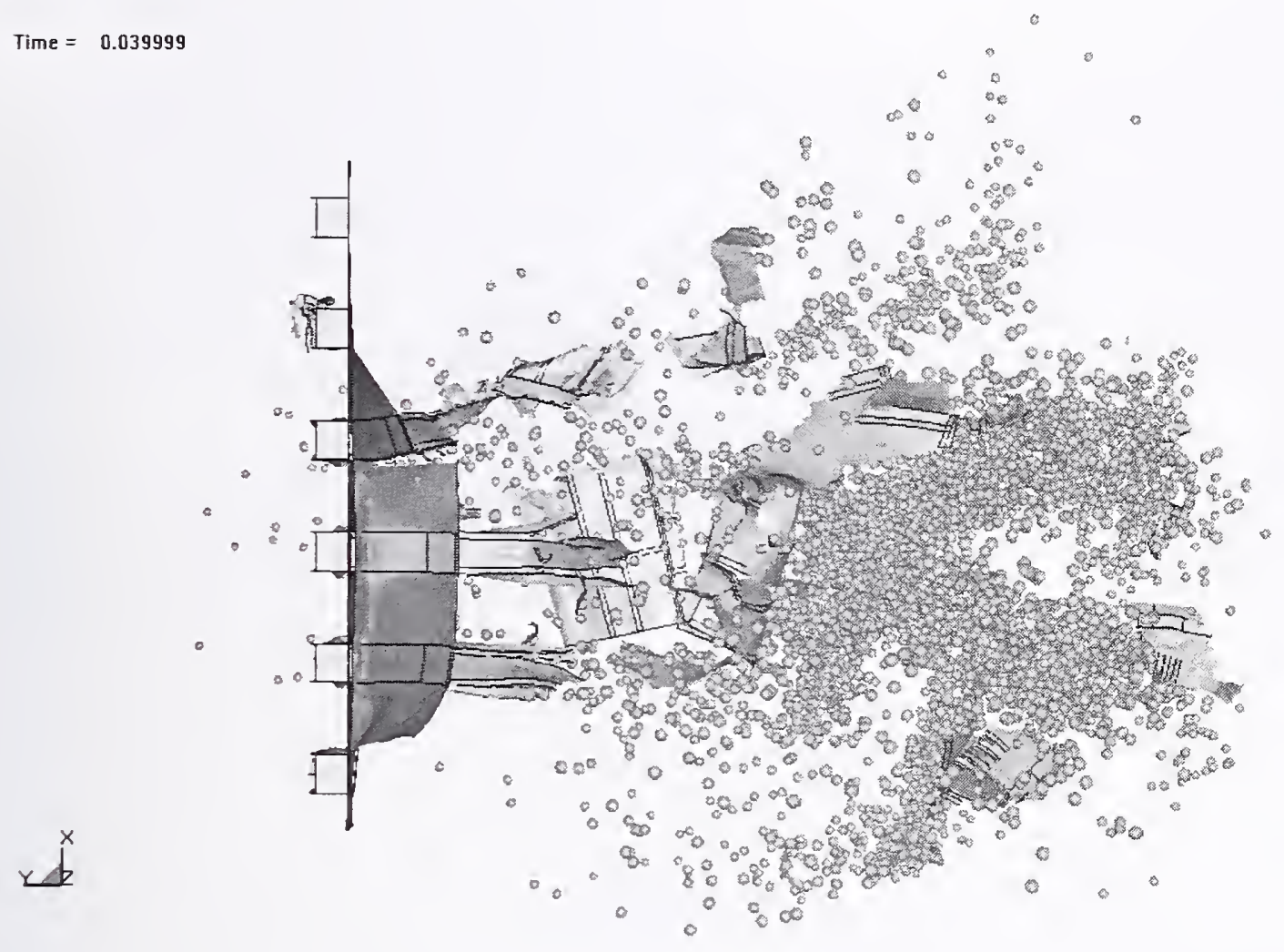

(a) $\mathrm{SPH}$ analysis

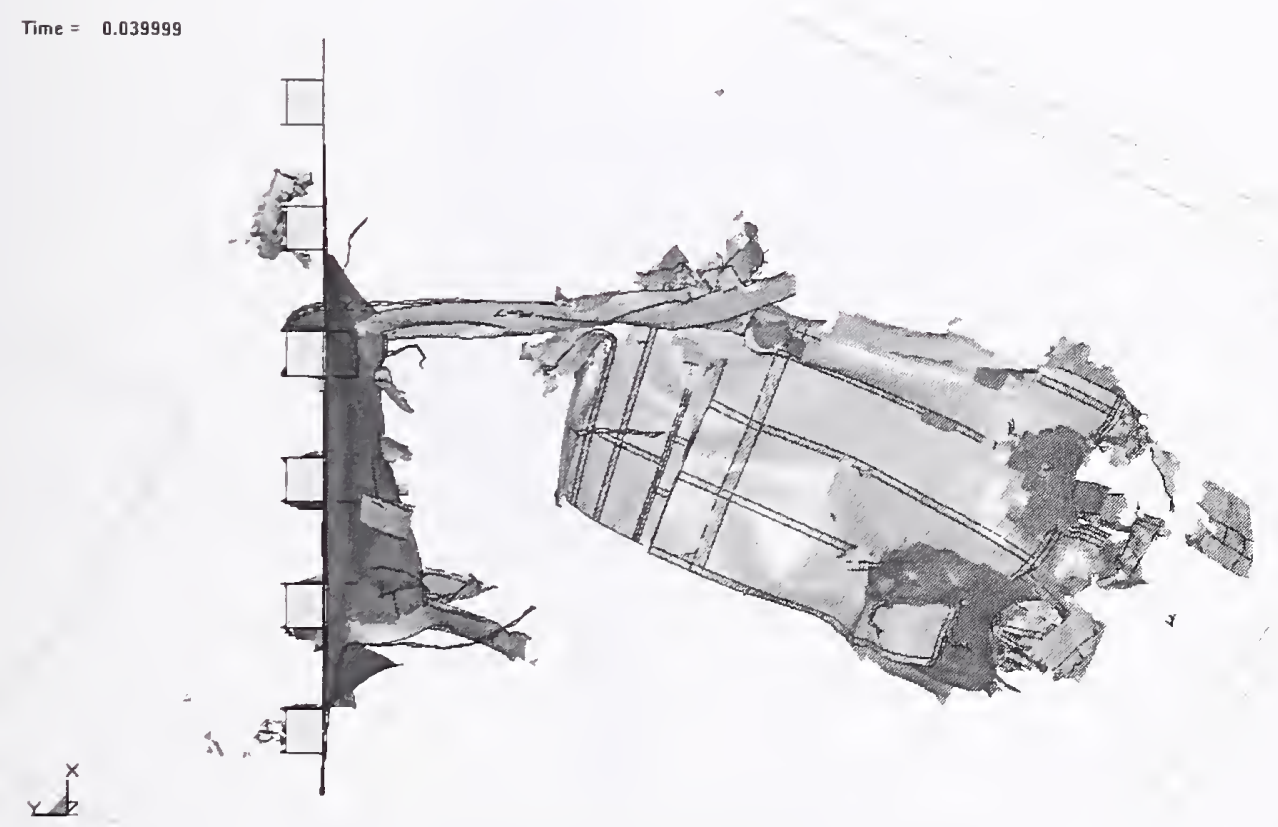

(b) ALE analysis

Figure 5-58. Top view of structural damage and fuel dispersion at $0.04 \mathrm{~s}$. 
rime $=\mathbf{0 . 0 3 9 9 9 9}$

$r x_{x}^{2}$

Time $=\mathbf{0 . 0 3 9 9 9 9}$

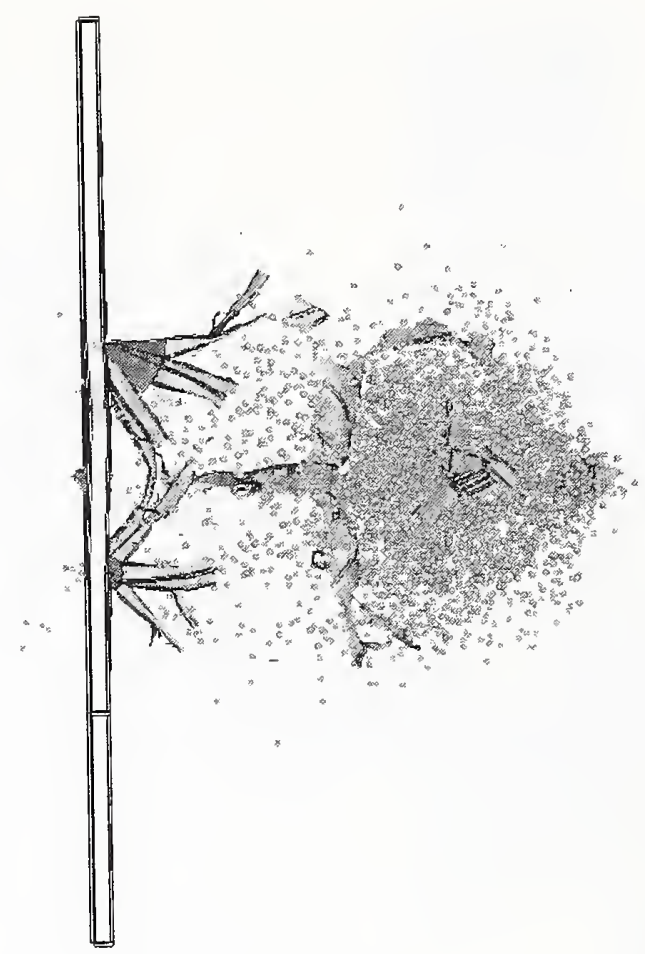

(a) $\mathrm{SPH}$ analysis

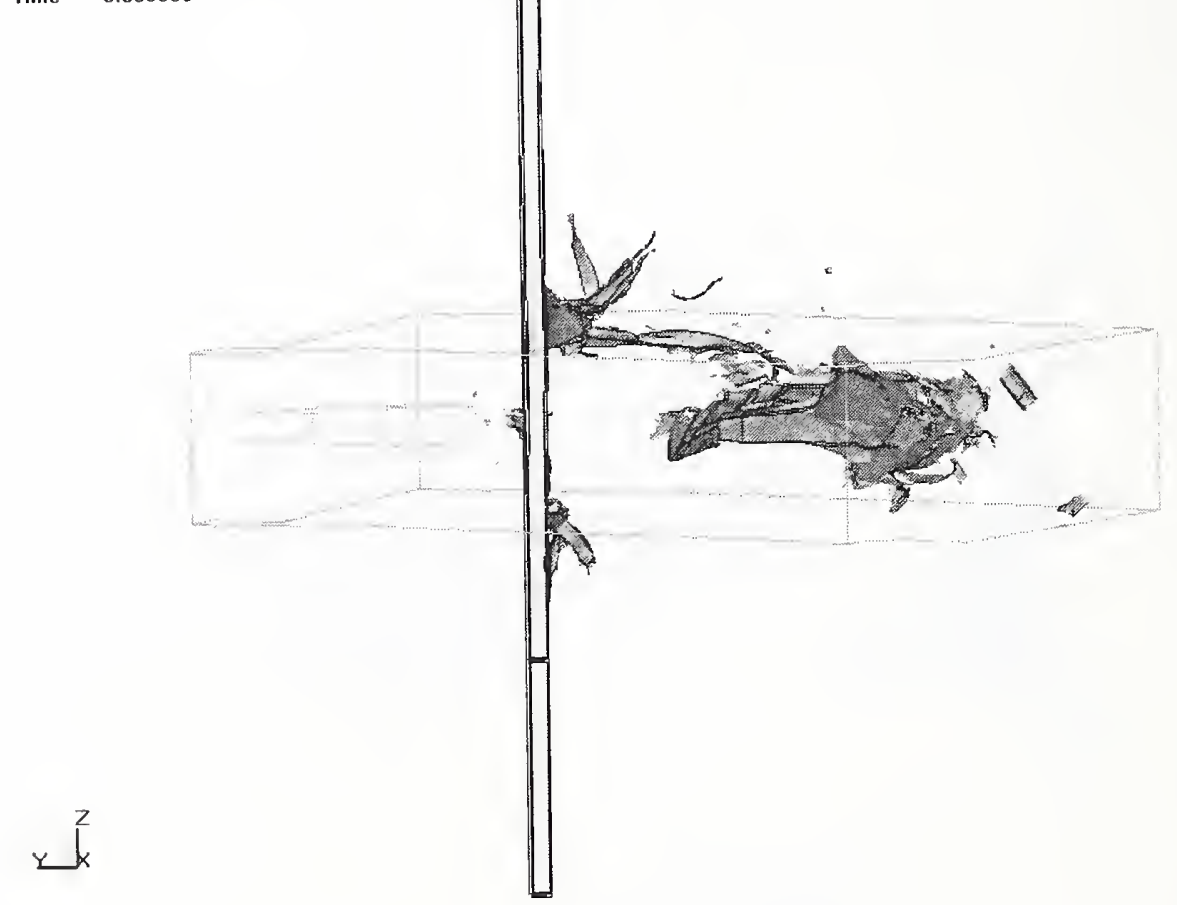

(b) ALE analysis

Figure 5-59. Side view of structural damage and fuel dispersion at $0.04 \mathrm{~s}$. 


\subsubsection{Engine Impacts Subassembly Analyses}

This subassembly model was developed using structural components from the impact zone on the north face of WTC 1. The model, shown in Figure 5-60, was used to evaluate the response of structural connections, material and failure models, and other issues affecting the global impact analyses. The model was three floors tall, spanning floors 95-97, three exterior panels wide, and extended from the exterior wall through to the first two rows of core columns. The exterior wall in the subassembly model included the exterior panels that extend into floors 95-97, as well as two panels above and below the panel. spanning all three floors. The structural components in the final subassembly model included the exterior panels, core framing, truss floor structures, and interior contents (workstations).

The vertical displacements were constrained at the top and bottom of the free ends of the core columns. For the exterior columns, a bolted connection was added to an adjacent butt plate for which the vertical motions were constrained. The lateral displacements were constrained at the free spandrel edges and at the sides of the truss floor structures.

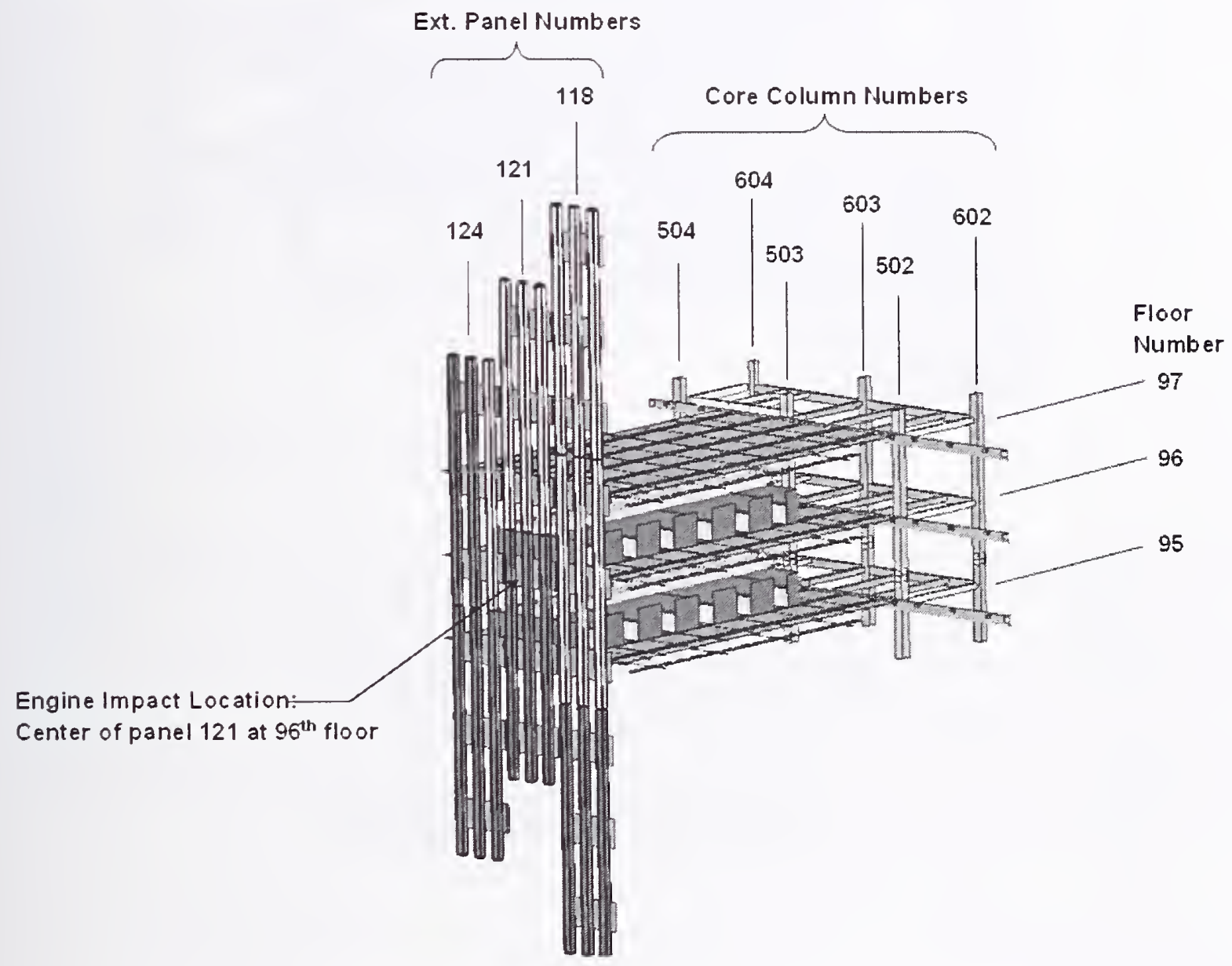

Figure 5-60. Tower subassembly model.

In this impact simulation, the engine had an initial speed of $413 \mathrm{mph}$ and a trajectory with a lateral approach angle of 4 degrees from the exterior panel normal and vertical approach angle of 7.6 degrees 
below the horizontal. The impact point was centered approximately $6 \mathrm{ft}$ below the 97 th floor so that the initial impact did engage a significant portion of the truss floor structures. The calculated impact response of the subassembly is shown in Figure 5-61. The engine penetrated the exterior wall and continued into the interior of the building along the initial downward trajectory. As the engine continued into the subassembly model, it plowed through the interior building contents (workstations) and eventually skipped off of the truss floor slab at floor 96.

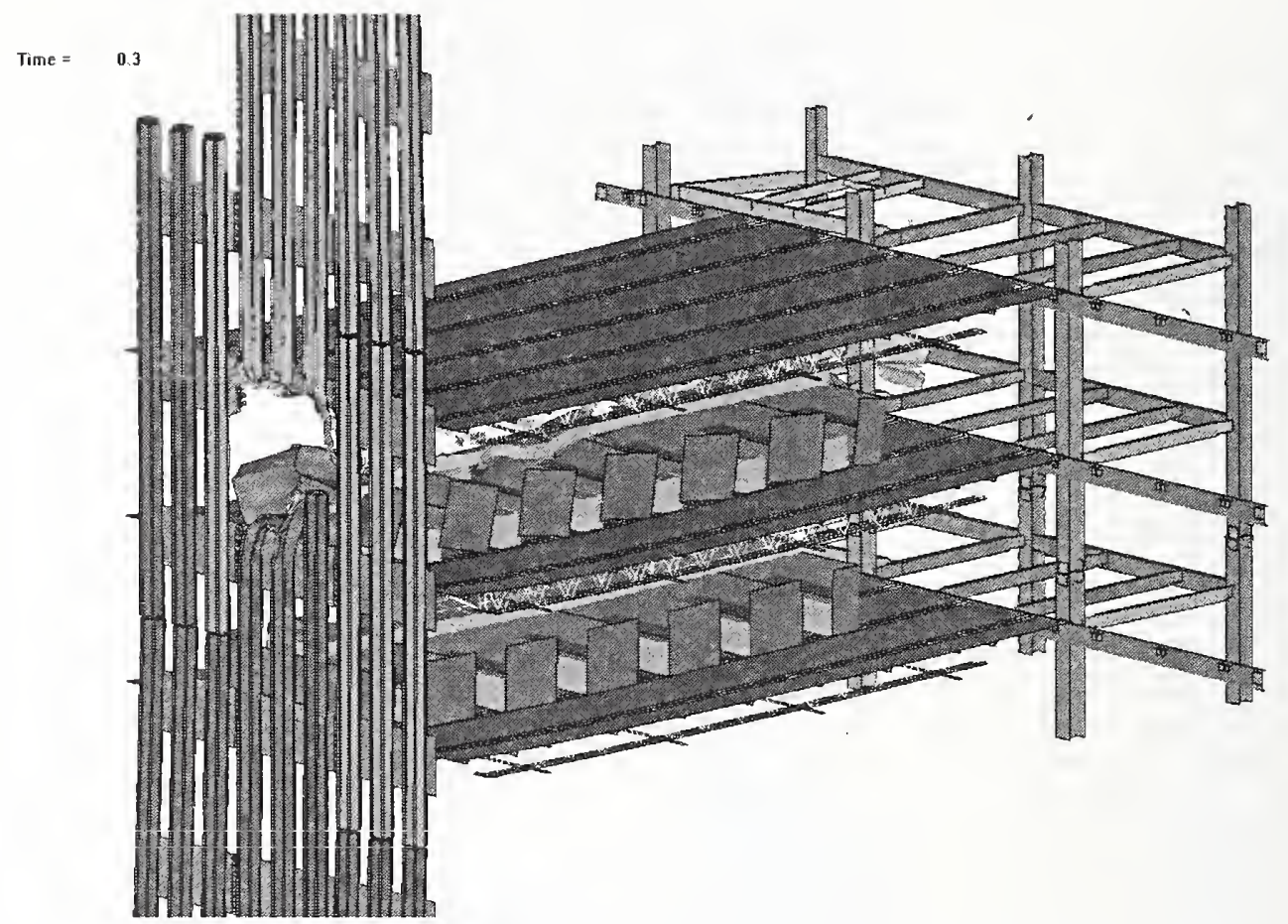

Figure 5-61. Response of the subassembly model to engine impact.

A side view of the impact behavior at different time instants during the response is shown in Figure 5-62. The engine penetrated the exterior wall following the initial downward trajectory. As the engine continued downward, it impacted the workstations and the truss floor structures of floor 96 . The engine motion was redirected by the impact with the truss floor and continued its motion toward the core penetrating additional workstations. At a time of $0.25 \mathrm{~s}$, the engine entered the core as shown in Figure 5-62(c). The impact conditions of this analysis resulted in a collision of the engine with core column 503. The speed-time history of the engine core in this impact analysis is shown in Figure 5-63. The deceleration that occurred in the first $5 \mathrm{~ms}$ was primarily from the penetration of the exterior wall and the floor slab and truss of floor 97. 


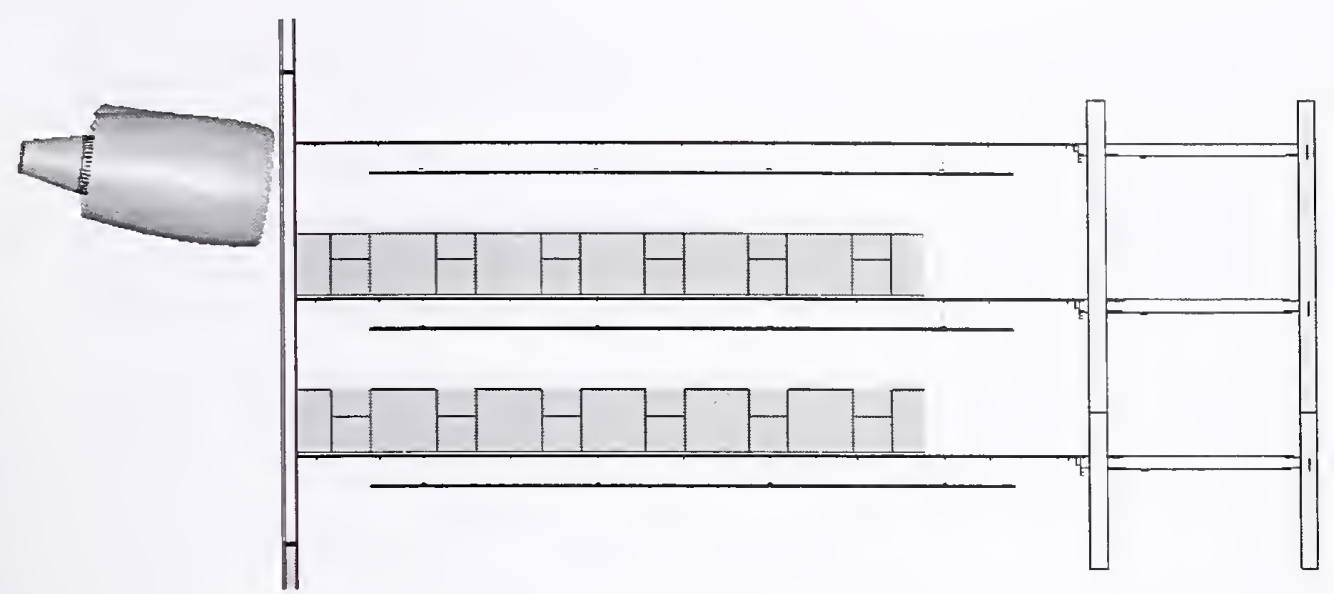

(a) Time $=0.00 \mathrm{~s}$

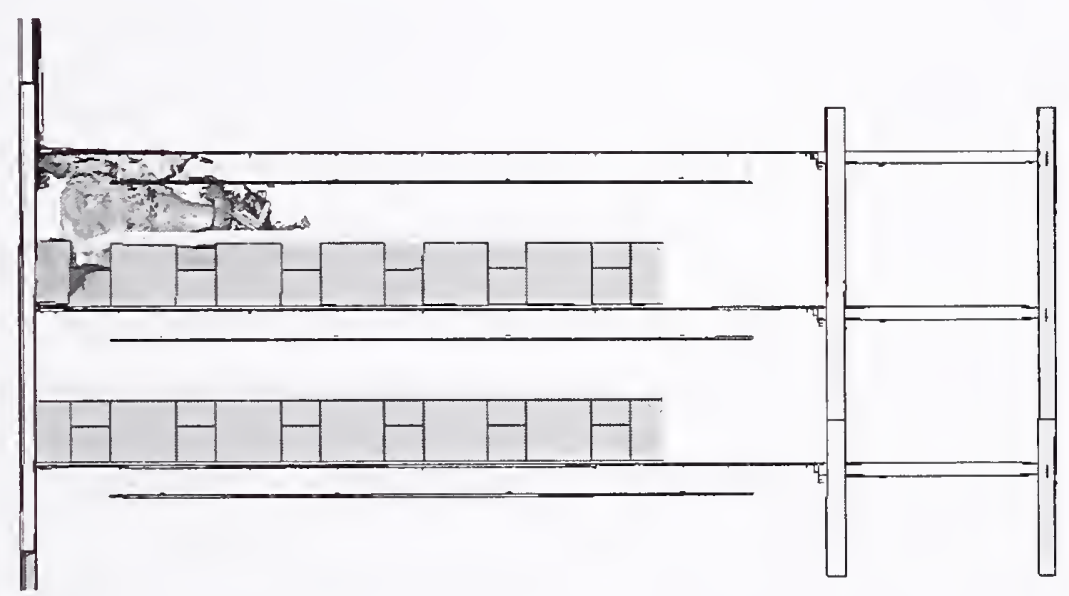

(b) Time $=0.05 \mathrm{~s}$

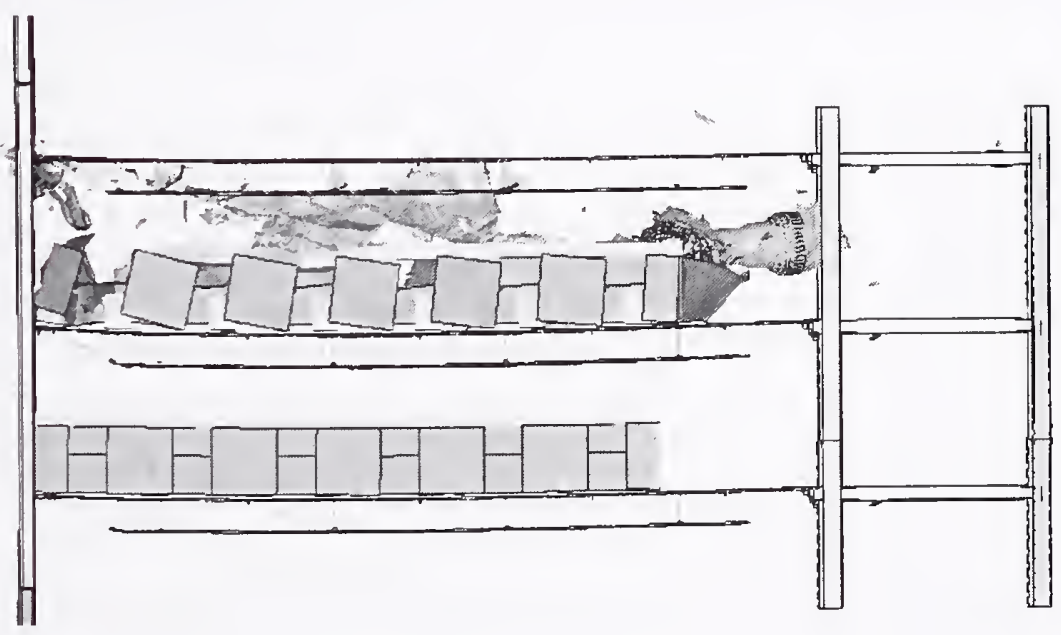

(c) Time $=0.25 \mathrm{~s}$

Figure 5-62. Subassembly-engine impact and breakup response (side view). 


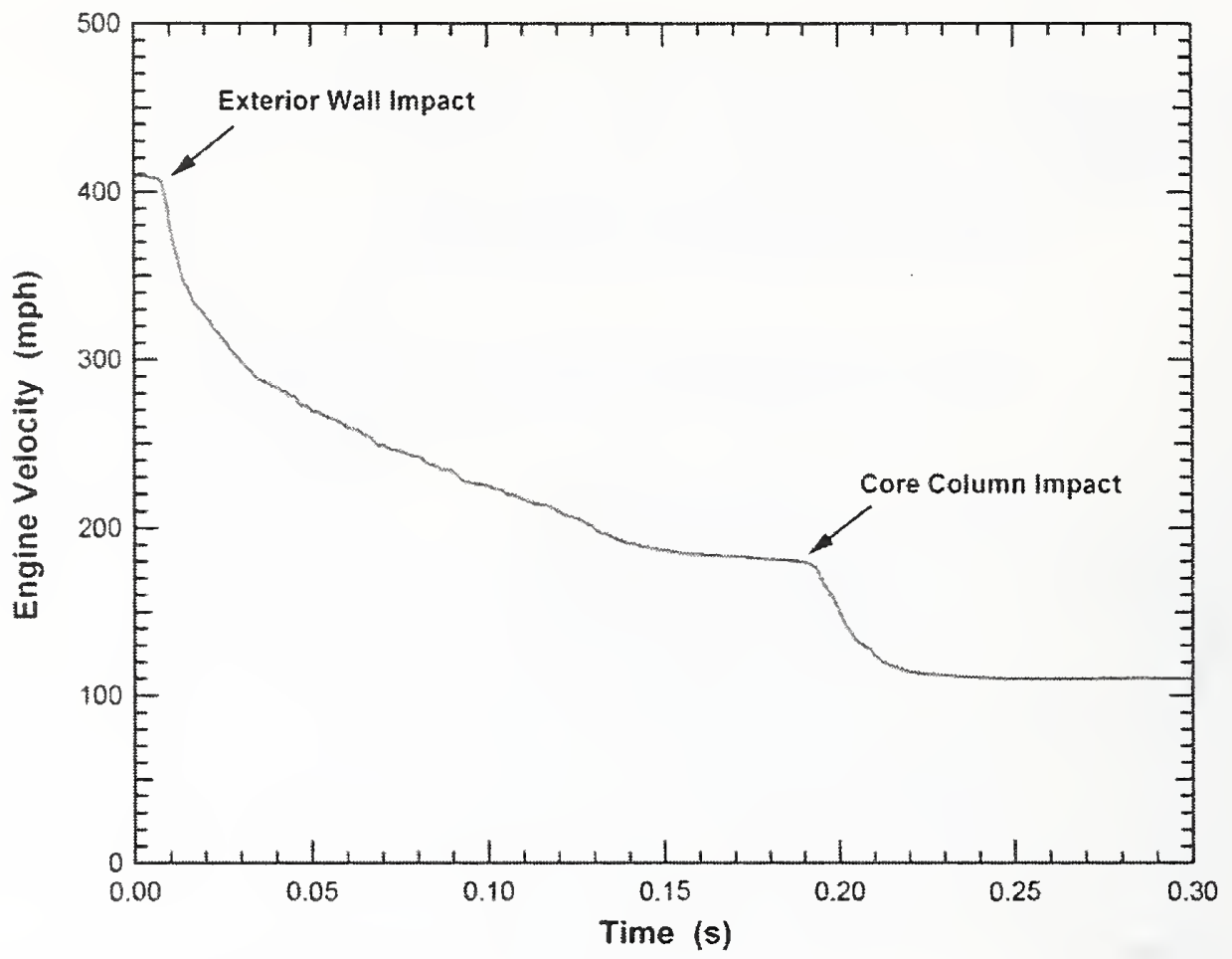

Figure 5-63. Speed history for the engine subassembly impact analysis.

This subassembly model was used to investigate the effect of a number of modeling parameters on the response and damage estimates. These parameters included the strength of the building nonstructural contents and the concrete slab strength. The reader is referred to Chapter 6 of NIST NCSTAR 1-2B for further details. The same configuration was also used to study the sensitivity of the response to 11 parameters as part of the uncertainty analysis, see Chapter 8 of NIST NCSTAR 1-2B.

\subsection{SUMMARY}

The towers were modeled primarily with shell elements with the exception of the exterior wall bolted connections (beam and brick elements) and the floor truss diagonals (beam elements). The WTC 1 model extended between floors 92 and 100, while the WTC 2 model extended between floors 77 and 85 . The global impact models of the WTC towers included the following components:

- Exterior walls: The exterior columns and spandrels were modeled using shell elements with two mesh densities, a refined density in the immediate impact zone and a coarser far field density elsewhere. For the bolted connections between exterior panels in the refined mesh areas, brick elements were used to model the butt plates, and beam elements were used for the bolts.

- Core columns and floors: Core columns were modeled using shell elements with two mesh densities, a refined density in the direct impact area and a coarser far field density elsewhere. The spliced column connections were included in the model with proper failure criteria. The 
floors within the core were modeled using shell elements representing the floor slabs and beams.

- Truss floor: In the direct impact area, the floor model included shell elements for the combined floor slab and metal decking, and for the upper and lower chords of the trusses. Beam elements were used for the truss diagonals. In the far field floor segments, simplified shell element representations were used for the floor slab and trusses.

- Interior building contents: The interior nonstructural contents of the towers were modeled explicitly. These included the partitions and workstations, which were modeled with shell elements in the path of the aircraft debris. The live load mass was distributed between the partitions and cubicle workstations.

The Boeing 767-200ER aircraft model was developed based on (1) documentary aircraft structural information, and (2) data from measurements on Boeing 767 aircraft. The airframe model contained most of the significant structural components in the aircraft. The models of the fuselage, empennage, and wing structures were developed completely using shell elements. Models for the landing gear and engines were primarily developed using shell elements, but contained some brick elements as well. The typical element dimensions were between 1 in. and 2 in. for small components, such as spar or rib flanges, and 3 in. to 4 in. for large parts such as the wing or fuselage skin.

Special emphasis was placed on modeling the aircraft engines due to their potential to produce significant damage to the tower components. The engine model was developed primarily with shell elements. The objective was to develop a mesh with typical element dimensions between $1 \mathrm{in}$. and $2 \mathrm{in}$. However, smaller element dimensions were required at many locations to capture details of the engine geometry. Brick elements were used for some of the thicker hubs and the roots of the compressor blades.

In support of the development of the global models of the towers and aircraft, a large array of component and subassembly models were developed and used in the impact simulations. Examples of such analyses included:

- Impact of a segment of an empty aircraft wing with an exterior column.

- Detailed and simplified modeling of exterior panel bolted connection under impact loading.

- Impact of a simplified plow type impactor with truss floor assembly.

- Impact of fuel-filled wing segment with exterior wall panels.

- Impact of an aircraft engine with a subassembly from the exterior wall though the core of the towers.

These component and subassembly analyses provided guidance on the optimal element size and type for global modeling, material constitutive modeling, treatment of connections, and modeling of aircraft fuel. They were also used for the sensitivity analyses conducted to assess the effects of uncertainties associated with various parameters on the level of damage to the towers and to determine the most influential modeling parameters that affect the damage estimates. 


\subsection{REFERENCES}

“TrueGrid Manual, Version 2.1.0,” XYZ Scientific Applications, Inc., September 2001.

“LS-DYNA Keyword User's Manual," Livermore Software Technology Corporation, Version 970, April 2003.

“LS-DYNA Theoretical Manual," Livermore Software Technology Corporation, May 1998.

ASTM Designation A 370 - 03a, "Standard Test Methods and Definitions for Mechanical Testing of Steel Products," Approved June 10, 2003.

Bischoff, P.H., Perry, S.H., "Compressive Behavior of Concrete at High Strain Rates," Materials and Structures, vol. 24, 1991, pp. 425-450.

Boeing Company, Aircraft Description of Boeing 767, Section 2, Document number D6-58328, www.boeing.com, 1989.

Brown, W. F. Jr., Mindlin, H., and Ho, C.Y., (Eds.), 1991, Aerospace Structural Metals Handbook, CINDAS/Purdue University Publishers, Volumes 3 \& 4.

Culver, C.G., 1976, Survey Results for Fire Loads and Live Loads in Office Buildings, NBS Building Science Series, No. 85, National Bureau of Standards, Washington, DC.

FEMA 304, May 2002, World Trade Center Building Performance Study: Data Collection, Preliminary Observations, and Recommendations, Federal Emergency Management Agency.

Military Handbook, 1987, Metallic Materials and Elements for Aerospace Vehicle Structures, U.S. Dept. of Defense, MIL-HDBK-5F.

Ross, C.A., Kuennen, S.T., Tedesco, J.W., "Effects of Strain Rate on Concrete Strength," Session on Concrete Research in the Federal Government, ACI Spring Convention, Washington, D.C., March 1992.

Wischers, G., "Application of Effects of Compressive Loads on Concrete," Betontech, Berlin, Nos. 2 and 3, 1978. 


\section{Chapter 6 \\ AIRCRAFT IMPACT INITIAL CONDITIONS}

\section{$6.1 \quad$ INTRODUCTION}

In order to determine the impact loading on the World Trade Center (WTC) towers, the aircraft impact initial conditions needed to be estimated. These initial conditions included the aircraft speed, aircraft orientation and trajectory, and location of aircraft nose at impact. The estimates also included the uncertainties associated with these parameters. This chapter describes the estimation of the initial impact conditions of the aircraft which impacted the WTC towers from available records. These records included the videos that captured the two impact events and photographs of the damage to the exterior of both towers.

Two videos captured the approach and impact of the American Airlines Flight 11 (AA 11) aircraft that impacted the WTC 1 tower, and several videos captured the United Airlines Flight 175 (UAL 175) aircraft that impacted the WTC 2 tower. In addition, a large body of photographic evidence was available that could be used to determine the impact location and orientation relative to the towers. These videos and photographs were analyzed to estimate, with the best accuracy possible, the impact speed, horizontal and vertical angles of incidence, and roll angle of each aircraft during impact with each tower, as well as the location of impact.

The analysis of the initial aircraft impact conditions was performed in two steps. The first step was to perform an analysis of the video footage of the two impact events. This analysis compared the various videos and used visual references and known dimensions and positions of towers to determine the flight conditions prior to impact (Section 6.2). The second step was to use photographs of the impact damage to refine the details of the impact position, orientation, and trajectory (Section 6.3).

The impact orientation and trajectory parameters are defined in Figure 6-1. In this figure, two vectors were defined, one for the velocity vector of the aircraft (the trajectory) and one for the orientation of the aircraft. These two vectors may not be coincident. Both vectors were described in terms of a vertical angle around structure east, as shown in the figure, and a lateral angle, which was measured clockwise around the tower axis from structure north. The orientation was also described in terms of a wing-tip roll angle, as shown in the figure.

The resolution of the video footage was not sufficient to measure the wing deflections or impact points more accurately than within $\pm 6 \mathrm{ft}$. In the two videos that captured the WTC 1 impact, there also was not enough resolution to obtain an accurate orientation of the aircraft. Consequently, the impact point and roll angle of AA 11 were determined using only the still-frame photographs of the impact damage to the north wall of WTC 1. Since the UAL 175 impact was captured by several videos, the trajectory and orientation measurements could be made from the available video footage. Similar to WTC 1, the impact location was primarily determined from the still frame photography of the damaged WTC 2 south wall. The following sections describe the analysis methodologies used to determine the motion parameters and impact conditions. 


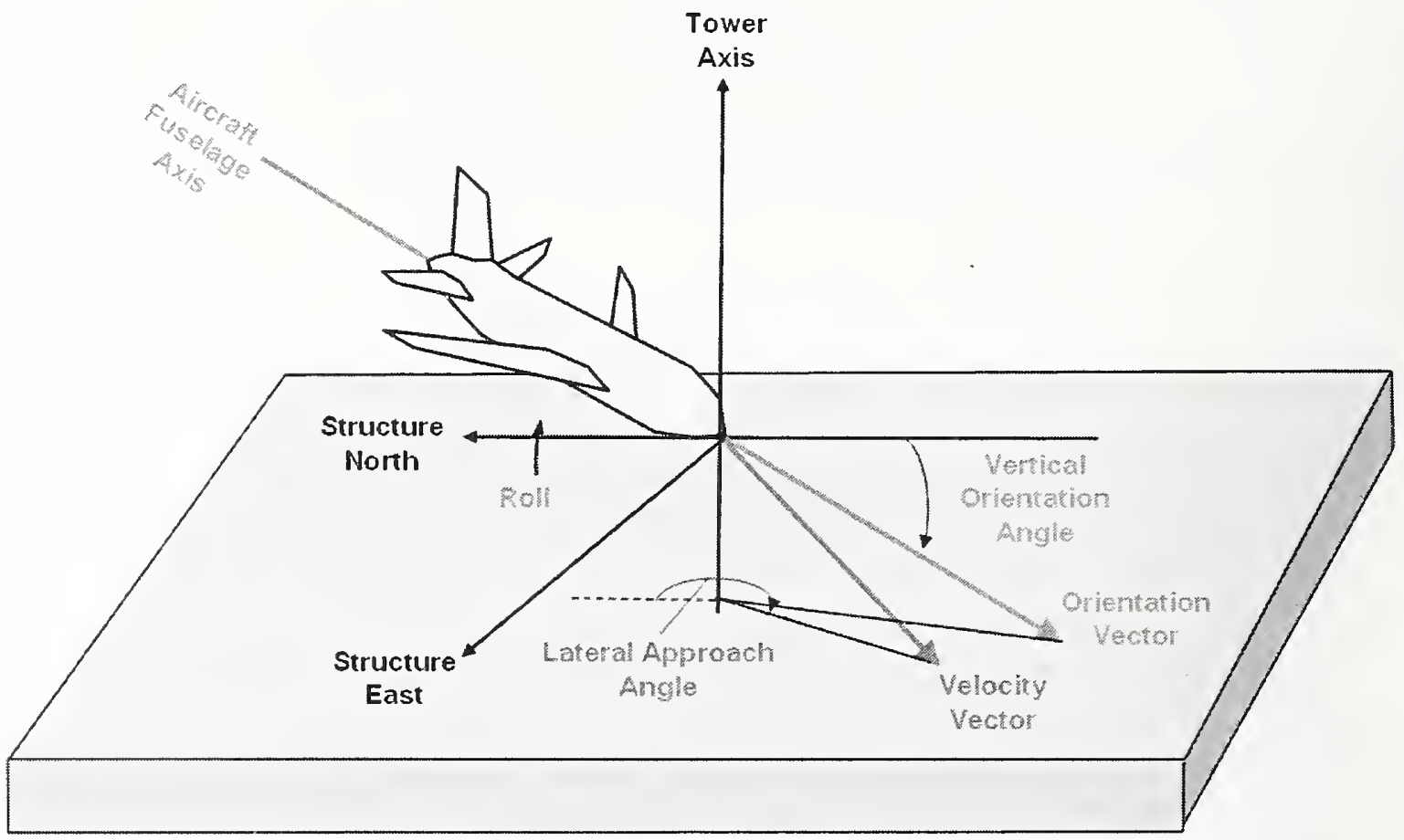

Figure 6-1. Definition of the aircraft impact parameters.

Section 6.2 of this chapter provides the details of the motion analysis methodology based on video footage of the two impact events. This included a complex and a simplified motion analysis. Section 6.3 presents the procedure used to refine the initial impact conditions obtained from the motion analysis based on the damage to exterior walls documented in photographs. Section 6.4 is a comparison between the impact conditions estimated from this study with those reported or estimated previously. Section 6.5 is a summary of the chapter.

\subsection{MOTION ANALYSIS METHODOLOGY}

\subsubsection{Videos Used in the Analysis}

The first task in the analysis of the aircraft impact conditions was to review and select appropriate videos and photographs that could be used for the estimation of the impact initial conditions. An extensive library of video and photographic evidence of the WTC tower impacts was collected by National Institute of Standards and Technology (NIST) (see NIST NCSTAR 1-5A). The available videos were reviewed to select the best video footage of the aircraft's approach and impact with each tower. The videos were digitized and stored in AVI files. The WTC 1 aircraft impact was captured in two videos, and both were used in the analysis. Several videos captured the aircraft impact into WTC 2 tower, and seven of them were selected for the analysis. The image coordinates of the aircraft nose, tail, wing tips, aileron, and several locations on the towers were measured in each frame of the videos. Adobe Photoshop was used to determine the image coordinates. Table 6-1 provides a summary of the videos used to analyze the impact initial conditions. Still images from each of these video records are provided in Appendix E. 
Table 6-1. Videos used for the analysis of aircraft impact initial conditions.

\begin{tabular}{|l|c|c|l|}
\hline Digitized Video File & $\begin{array}{c}\text { Original } \\
\text { Video } \\
\text { Format }\end{array}$ & $\begin{array}{c}\text { Tower } \\
\text { Impact }\end{array}$ & \multicolumn{1}{|c|}{ Description } \\
\hline V1 & NTSC & WTC 1 & $\begin{array}{l}\text { Footage taken at ground level at the corner of Church and } \\
\text { Lispenard streets. Taken north and east of the towers. }\end{array}$ \\
\hline V2 & PAL & WTC 1 & $\begin{array}{l}\text { Footage taken from the entrance of the Brooklyn Battery } \\
\text { Tunnel, heading west. Taken south and east of the towers. }\end{array}$ \\
\hline V3 & NTSC & WTC 2 & Footage taken from a helicopter north and west of the towers. \\
\hline V4 & NTSC & WTC 2 & $\begin{array}{l}\text { Footage taken at ground level near the Castle Clinton National } \\
\text { Monument. Footage taken south and east of the towers. }\end{array}$ \\
\hline V5 & NTSC & WTC 2 & Footage taken from Brooklyn, south and east of the towers. \\
\hline V6 & NTSC & WTC 2 & $\begin{array}{l}\text { Footage taken from the 13th floor of a building in John Street, } \\
\text { east of the towers. }\end{array}$ \\
\hline V7 & NTSC & WTC 2 & $\begin{array}{l}\text { Footage taken at ground level from the corner of Church and } \\
\text { Liberty. Taken south and east of the towers. }\end{array}$ \\
\hline V8 & NTSC & WTC 2 & Footage taken from a helicopter north of the towers. \\
\hline V9 & NTSC & WTC 2 & $\begin{array}{l}\text { Footage taken from a moving vehicle on FDR drive, heading } \\
\text { west just before the Brooklyn Bridge. Footage taken north } \\
\text { and east of the towers. }\end{array}$ \\
\hline
\end{tabular}

The second column in Table 6-1 lists the original format of the various videos that were analyzed. All the videos with the exception of one used the National Television System Committee (NTSC) video format, which is the standard television format in the United States. The V2 video used the Phase Alternating Line (PAL) video format, which is common in Europe and parts of Asia. Any image data from the interlaced field of the videos were neglected. It was also assumed that the digitized NTSC videos had a rate of 29.97 images per second, while the PAL videos had a rate of 25 images per second. The digitized images had sizes of $720 \times 480$ pixels (NTSC) and 720x576 pixels (PAL). The original video footage was assumed to have an aspect ratio of $1.33 / 1$, so the $\mathrm{X}$-values of the measured image coordinates were adjusted to account for the actual aspect ratio. The image coordinates were also shifted relative to the locations of fixed points in the field of view (corners of a tower) to eliminate the effects of movement and shaking of the camera.

\subsubsection{Complex Motion Analysis}

A complex motion analysis was the method originally used in this study to calculate the speed and the orientation and trajectory vectors of the aircraft. However, subsequent analysis methodologies, as discussed in the following sections, provided more accurate estimates of speed and orientation. The quality and limited video footage available produced larger uncertainty using the complex motion analysis methodology. Therefore, this analysis methodology was only used to define the aircraft trajectory. Following is a discussion on the complex motion analysis and an assessment of its accuracy.

The methodology used in this analysis to determine the aircraft impact conditions was previously developed for other applications (Cilke 1995). Figure 6-2 describes the analysis procedure. The image coordinates of the moving object (the aircraft) and two stationary positions on the structures within the field-of-view were triangulated with the known real-world positions of the structures and camera. The 
camera was assumed to be a pin-hole type camera, i.e., all the light rays pass through a single focal point and project onto a flat surface that records the image. The result was the definition of the vector extending from the camera to the aircraft. However, the position of the aircraft along the vector was still unknown. The vector was then intersected with a surface defined by a set of vectors extending from a second camera to the measured object in multiple frames. The result was the real-world position of the aircraft at one instance in time. The global positions of other points on the aircraft and positions of the aircraft in multiple frames were then used to define the orientation and trajectory of the aircraft. Note that in ideal test conditions, where the video cameras and reference positions are precisely surveyed and the camera field-of-views are designed, the uncertainties in the measured object velocities range from 1 percent to 1.5 percent.

\section{Step 1:}

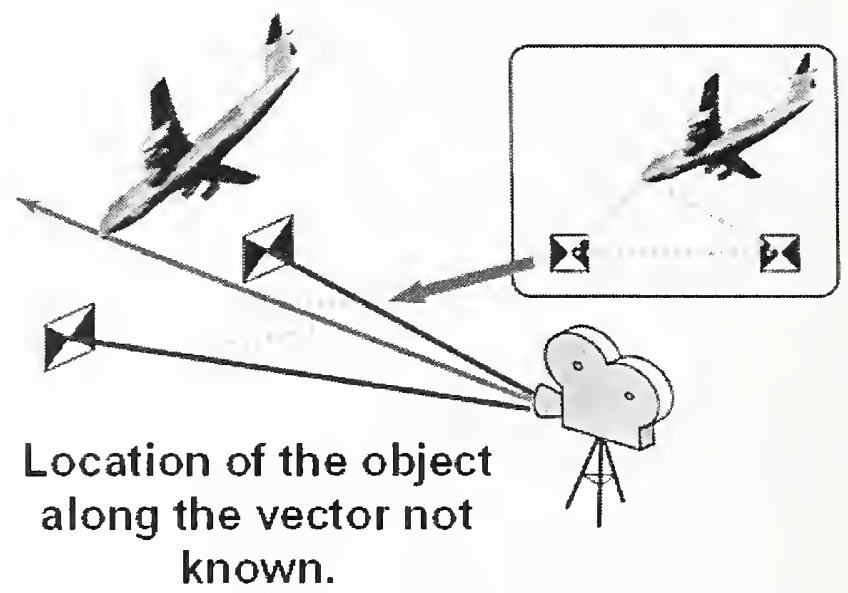

\section{Step 2:}

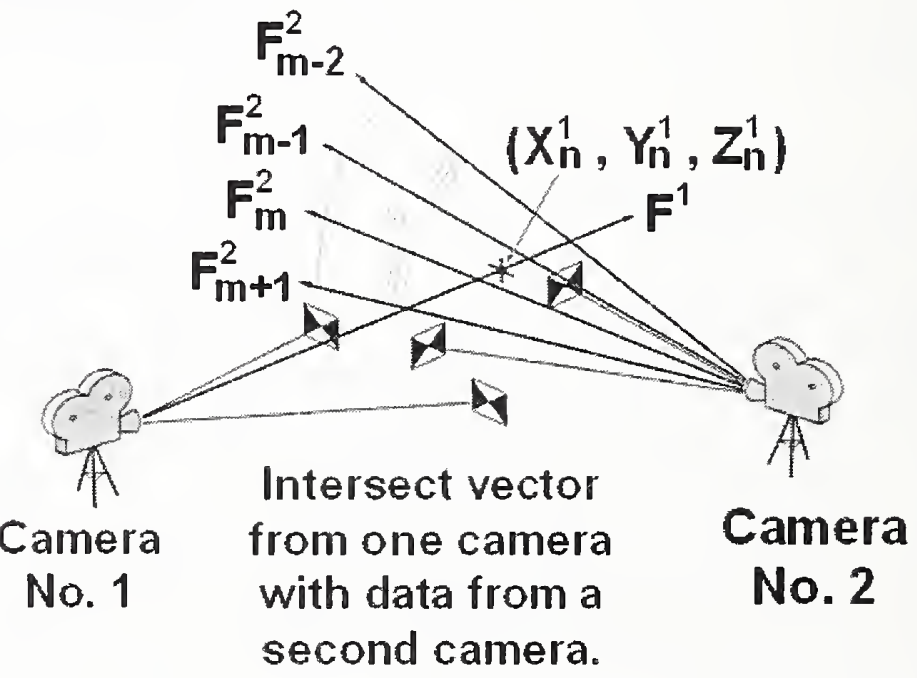

Figure 6-2. Complex motion analysis to measure object motions using multiple cameras. 
For the WTC aircraft motion analysis, various locations on the two towers were used as fixed reference locations. The four corners of the towers at three floor levels were used, as they could be easily identified in the video footage. These three levels included the top floor and two mechanical floors. Additional points on the WTC 1 antenna were also used as reference locations. The tower reference positions were at the center of each beveled corner. The coordinates of the reference locations were determined by using the original construction drawings of the towers. While the locations on the structure could be determined with high fidelity, the coordinates of the cameras had to be estimated through an iterative process.

With the camera locations estimated. motion analyses were performed using the complex motion analysis technique. For the WTC 1 aircraft impact, image data from the V1 video were correlated with the data from the V2 video. The analysis produced a speed of $435 \mathrm{mph} \pm 30 \mathrm{mph}$ for the WTC 1 aircraft at time of impact.

For the WTC 2 aircraft impact, data from each of the V4, V5, and V9 videos were correlated with the other two cameras to determine the motion of the aircraft prior to impact. The other cameras were less effective with this analysis technique (see Chapter 7 of NIST NCSTAR 1-2B for further details). Image data from the three videos converged to a tight set of trajectory angles and aircraft orientations (see Table 6-3). The uncertainties in the measured angles were derived from three components. First, there was a significant amount of scatter in the measured image coordinates. The perceived motion and orientation of the aircraft varied between frames, due to the relatively low resolution of the images and the motion of the camera fields-of-view. The scatter in the image data contributed to approximately \pm 2 degrees to \pm 4 degrees of the image uncertainty. The tips of the aircraft wings were more difficult to define accurately; the scatter in the wing measurements led to an estimated uncertainty of \pm 4 degrees in the roll angle. Second, the uncertainties in the camera locations contributed to the uncertainties in measured angles. Since there was more uncertainty in the cameras' horizontal positions than the vertical positions, the measured horizontal azimuths had larger uncertainties ( \pm 2 degrees). Third, the potential distortion in the field of view would distort the measured angles. The uncertainty of the measured angles due to image distortion was estimated to be \pm 1 degree.

The initial analyses using the complex motion methodology indicated the UAL 175 aircraft impact speed to be about $497 \mathrm{mph}$. which was heavily based on the V4 footage. However, subsequent analyses showed that the cameras did not provide an accurate aircraft impact speed due to three possible causes. First, the range of the camera could only be estimated. If the camera was close to the object motion, the range of the camera would have a significant effect on the perceived scale of the object in motion. Second, the scale of the image was determined from the dimensions of the towers in the field-of-view, which took up a relatively small portion of the field of view. As a result, the uncertainties in the measured image distances increased. Third, and most important, there were measurable distortions in the camera fields of view. For example, in the V5 video, the camera pans from left to right, tracking the aircraft as it approaches the south tower. The tower initially appears from the right edge of the image and moves to the center. The length of the aircraft (which remained in the center of the field-of view) appeared to decrease by 1.5 percent. However, the width of the south tower's east edge appeared to decrease by 7 percent, indicating a significant distortion in the field of view. As a result, a simplified motion analysis procedure was used to determine the speed of the WTC 2 aircraft as described in the next section. The complex motion analysis was used only to define the aircraft orientation and trajectory vectors. 


\subsubsection{Simplified Motion Analysis}

This procedure determined the impact speed by scaling the displacement of the aircraft within the field of view with the apparent fuselage length of the aircraft. Figure 6-3 depicts the simplified procedure to determine the aircraft speed. For several videos of the WTC tower impacts, linear regressions were performed for the image coordinates as functions of time. The displacements of the nose, tail, and wing tips were measured. The apparent length of the fuselage within each image was determined from the nose and tail regression lines, and the apparent displacement of the aircraft between images was normalized to the apparent length of the fuselage. Multiplying the result by the length of the aircraft determined the aircraft speed (there are constant time steps between frames). Finally, a geometric correction was made if the fuselage orientation and trajectory were not aligned.

The length of the fuselage of the Boeing 767-200ER aircraft is $155 \mathrm{ft}$ (see Chapter 7 of NIST NCSTAR 1-2B). However, for the simplified motion analysis, the fuselage was assumed to have an apparent length of $153 \pm 2 \mathrm{ft}$. The adjustment in apparent fuselage length was a result of the relatively low resolution of the video footage. As a sharp object entered a region captured by a single pixel, the background dominated the pixel color value until the object entered by a significant fraction. The low resolution could not accurately capture the shape of the aircraft nose and tail, and the aircraft nose in the videos appeared to be blunter than the actual nose of the Boeing 767-200ER. The average length of the fuselage in the videos analyzed was approximately 75 pixels (but varied depending on the footage). It was assumed that the resolution effect resulted in an apparent loss of approximately a half pixel at each end of the fuselage (one $\mathrm{ft}$ at each end of the fuselage). As a result, the apparent length of the fuselage in the video footage was approximately $2 \mathrm{ft}$ less than the actual length.

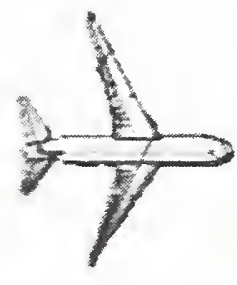

Image 1

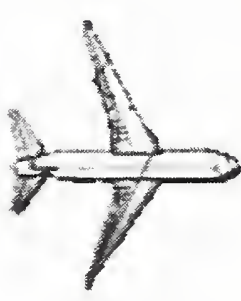

Image 2

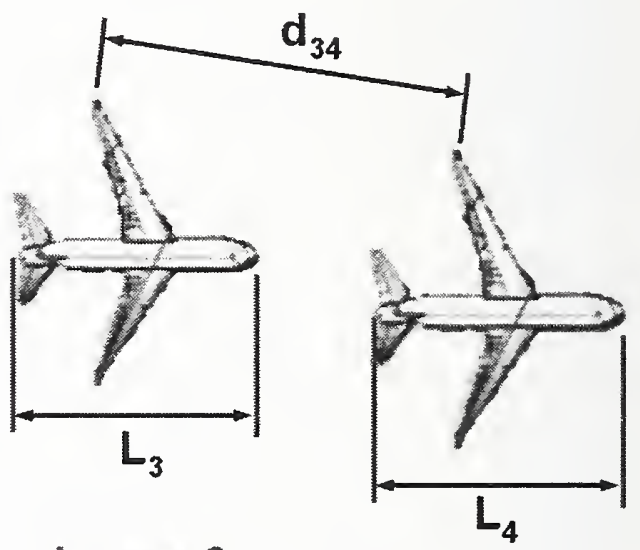

Image 3

Image 4

$$
\text { Speed }=\frac{\left(d_{34}\right)}{\left(L_{3}+L_{4}\right) / 2}(\text { Actual plane length })(\text { Image Rate })
$$

\section{Figure 6-3. Simplified motion analysis procedure to determine aircraft speed.}

The simplified motion analysis technique was used for the analysis of aircraft speed for both tower impacts. For the WTC 1 impact, only the V1 video could be used to determine the aircraft speed with this technique. The second video, V2, could not be used to obtain an accurate measure of speed as the aircraft 
was traveling away from the camera. The simplified analysis produced a speed of $451 \pm 30 \mathrm{mph}$, which was $16 \mathrm{mph}$ higher than the value obtained from the complex motion analysis technique. Both of these values for the WTC 1 impact speed were within the uncertainties in the corresponding analyses. As a result, the WTC 1 aircraft impact speed provided in Table 6-3 was selected as the average of the two speeds obtained using the complex and simplified motion analysis methodologies.

Five videos with a viewing angle approximately perpendicular to the UAL 175 flight direction were used to estimate the aircraft speed at the time of impact. The results of the simplified motion analyses from each camera for UAL 175 are provided in Table 6-2. The uncertainties in the table were based on the scatter in the measured displacements, the aircraft length within the image, and uncertainty in the actual aircraft length as seen in the images due to unknown orientation. A systematic error in calculating the aircraft speed was introduced due to the lateral fuselage orientation relative to trajectory. The uncertainty in this value was due to the aircraft maneuvers during its approach. In calculating the uncertainty in the speed, an uncertainty of \pm 3 degrees in orientation was assumed.

A speed estimate was then calculated from the individual videos. A mean value was calculated using the weighted average of the mean values. The measurement precision (the reciprocal of the variance) was used as a weight factor on the mean values. If measuremerts were independent, the uncertainty in the mean could be calculated by summing the individual measurement precisions, giving $443 \pm 21 \mathrm{mph}$ for AA 11 and $542 \pm 14 \mathrm{mph}$ for UAL 175. However, some uncertainties were systematic and the actual bound on the uncertainty was larger as a result. Therefore, the uncertainty range was increased to \pm 30 mph and $\pm 24 \mathrm{mph}$ for AA 11 and UAL 175, respectively. A summary of the impact conditions derived from video analysis (both complex and simplified motion analyses) is presented in Table 6-3.

Table 6-2. Measured UAL 175 impact speeds using the simplified analysis methodology.

\begin{tabular}{|c|c|}
\hline Video Reference & Calculated Aircraft Speed \\
\hline V4 & $573 \pm 55 \mathrm{mph}$ \\
\hline V5 & $556 \pm 27 \mathrm{mph}$ \\
\hline V6 & $535 \pm 23 \mathrm{mph}$ \\
\hline V7 & $523 \pm 31 \mathrm{mph}$ \\
\hline V9 & $557 \pm 53 \mathrm{mph}$ \\
\hline Best Estimate Speed & $542 \pm 24 \mathrm{mph}$ \\
\hline
\end{tabular}


Table 6-3. Summary of measured aircraft impact conditions from video analysis.

\begin{tabular}{|l|c|c|}
\hline & AA 11 (WTC 1) & UAL 175 (WTC 2) \\
\hline Impact Speed (mph) & $443 \pm 30$ & $542 \pm 24$ \\
\hline $\begin{array}{l}\text { Vertical Approach Angle } \\
\text { (Velocity vector) }\end{array}$ & $\begin{array}{c}10.6^{\circ} \pm 3^{\circ} \text { below horizontal } \\
\text { (heading downward) }\end{array}$ & $\begin{array}{c}8^{\circ} \pm 4^{\circ} \text { below horizontal } \\
\text { (heading downward) }\end{array}$ \\
\hline $\begin{array}{l}\text { Lateral Approach Angle } \\
\text { (Velocity vector) }\end{array}$ & $\begin{array}{c}180.3^{\circ} \pm 4^{\circ} \text { clockwise from } \\
\text { Structure North }\end{array}$ & $\begin{array}{c}19^{\circ} \pm 6^{\circ} \text { clockwise from } \\
\text { Structure North }\end{array}$ \\
\hline $\begin{array}{l}\text { Vertical Fuselage Orientation } \\
\text { from horizontal }\end{array}$ & - & $\begin{array}{c}3^{\circ} \pm 4^{\circ} \text { below horizontal } \\
\text { (heading downward) }\end{array}$ \\
\hline $\begin{array}{l}\text { Lateral Fuselage Orientation } \\
\text { from Structure North }\end{array}$ & - & $\begin{array}{c}8^{\circ} \pm 6^{\circ} \text { clockwise from } \\
\text { Structure North }\end{array}$ \\
\hline Roll Angle (left wing downward) & $25^{\circ} \pm 4^{\circ}$ & $38^{\circ} \pm 4^{\circ}$ \\
\hline
\end{tabular}

a. Structure North is approximately 29 degrees clockwise from True North.

Initial results from the simplified motion analysis produced a mean speed for UAL 175 of $546 \mathrm{mph}$. This speed was therefore used in the global impact analysis, discussed in Chapter 7. Subsequent refinement of the analysis and associated uncertainties produced the slightly lower mean value of $542 \mathrm{mph}$ as discussed above. Since this difference in speed was less than 1 percent and well within the uncertainty range, the speed used for the impact analysis was not modified.

\subsection{REFINEMENT OF AIRCRAFT IMPACT CONDITIONS}

Estimates of the aircraft impact locations, orientations, and trajectories were further refined based on the damage patterns documented on the exterior walls of the WTC towers. The general approach was to visualize the aircraft within the range of flight conditions estimated from the video analysis (Section 6.2) and project the impact points of the wings, fuselage, engines, and vertical stabilizer onto the exterior wall of each tower. A damage pattern was then estimated and compared to that obtained previously from analysis of the film and photographic evidence.

The estimated damage to the north face of WTC 1 is shown in Figure 6-4 along with approximate impact locations for various aircraft components of AA 11, including the wind tips, vertical stabilizer tip, and engines. For AA 11, it was found that the fuselage orientation needed to be 2 degrees above the vertical approach angle ( 2 degrees nose-up). The difference in the lateral approach angle and the fuselage orientation from structure north was $0^{\circ}$.

An example impact condition is shown in Figure 6-5, where the vertical approach angle was 10.6 degrees (fuselage orientation from horizontal $=8.6$ degrees) and the lateral approach angle was $180^{\circ}$ (fuselage orientation from structure north $=180$ degrees). The position of the vertical stabilizer tip was the most critical factor in determining this relationship. The impact points of the wing tips were known to within approximately $\pm 2 \mathrm{ft}$. This corresponded to an uncertainty in the roll angle of approximately \pm 2 degrees. Since no accurate orientation information could be derived from the video analysis, analysis of the damage pattern was critical in estimating the aircraft orientation at the time of impact. 

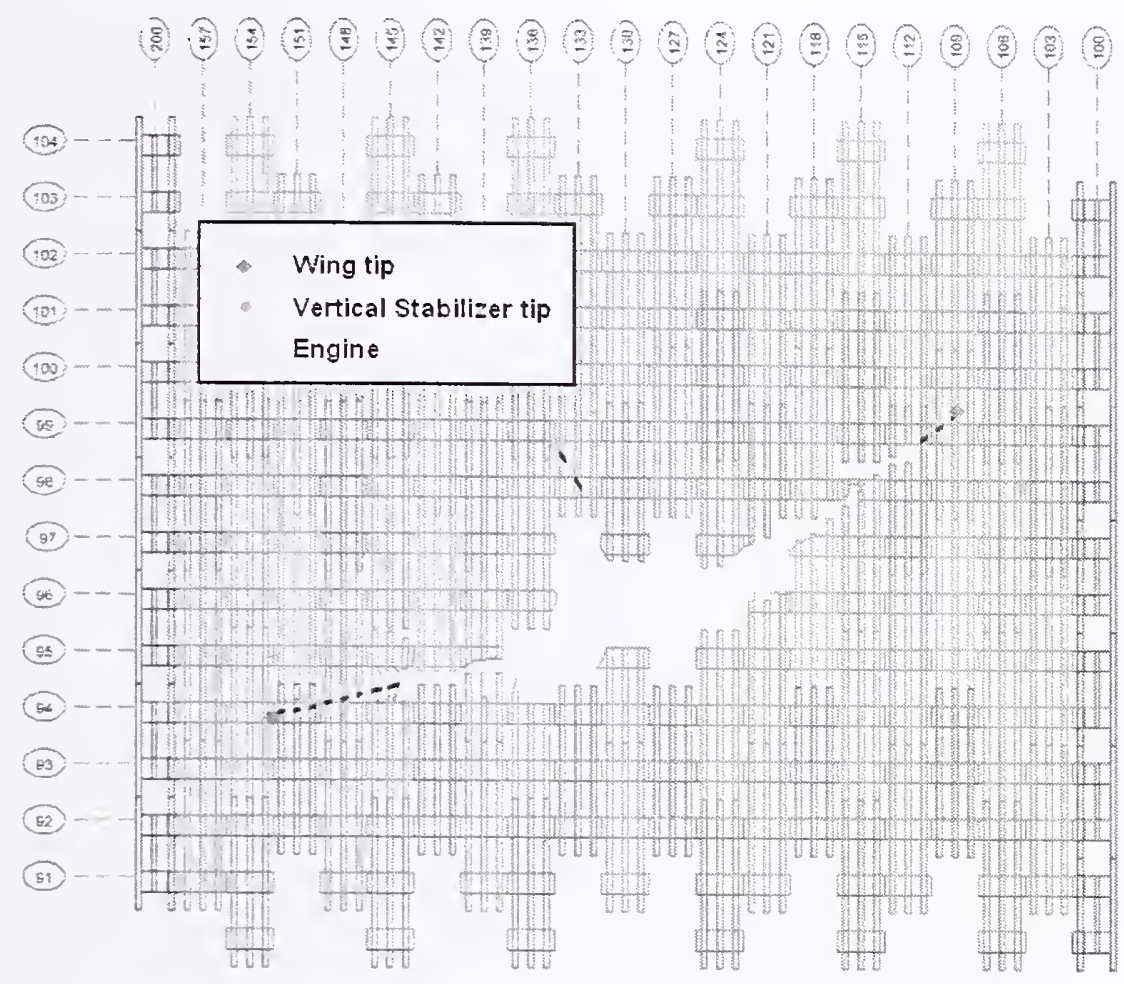

Figure 6-4. Estimated impact locations of aircraft components superimposed on the damaged face of WTC 1.

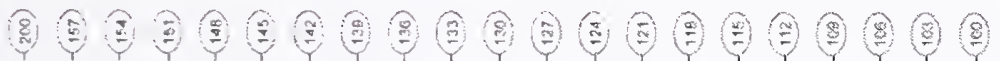

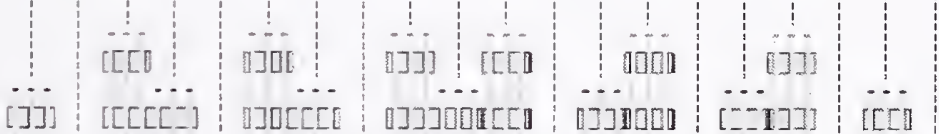

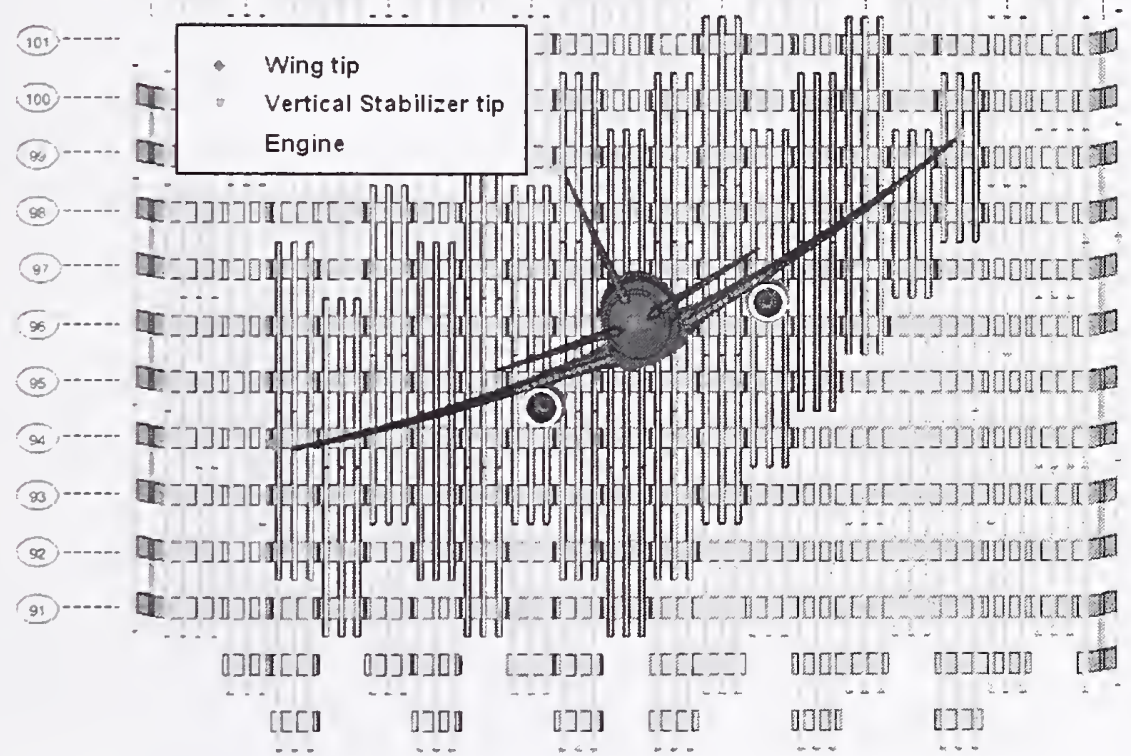

Figure 6-5. Orientation and trajectory of AA 11 that matched the impact pattern (vertical approach angle $=10.6^{\circ}$, lateral approach angle $=0^{\circ}$ ). 
The estimated damage to the face of WTC 2 is shown in Figure 6-6, along with approximate impact locations for various aircraft components of UAL 175. From these impact locations, the combinations of flight conditions that were consistent with the observed impact damage could be estimated.

Figure 6-7 shows the south face of WTC 2 with the aircraft model positioned in the impact orientation and location estimated from the video analysis (Table 6-3). The viewpoint of the figure was along the trajectory axis so that the projection of each aircraft component onto the tower face represented its approximate impact location, assuming no significant structural deformation prior to impact with the building exterior. During the impact simulation, little structural deformation was observed in parts of the aircraft that had not yet impacted the towers. The vertical stabilizer, the last part of the aircraft to enter the building and the part that had the longest time to experience structural deformation, impacted close to this projected impact location.

The impact conditions shown in Figure 6-7, which were based on video analysis alone, would cause the starboard wing tip to miss the building and were, therefore, not physically possible. Also shown in the figure are the estimated impact locations for the wing tips, vertical stabilizer, and engines. These also did not align well with the observed impact damage. Translation of the aircraft alone did not account for the discrepancy in the impact point shown in the figure. Both a translation of $3.3 \mathrm{ft}$ higher and $9.8 \mathrm{ft}$ further west were needed, along with a specific relationship between the trajectory and orientation in order for the impact pattern to match. The final impact points, defined as the location where the nose of each aircraft initially contacted the towers, are provided in Table 6-5.

It was found that a strict relationship between the aircraft trajectory and orientation needed to be established in order to achieve an impact pattern consistent with the damage observed on the south wall of WTC 2. The fuselage orientation needed to be 1 degree above the vertical approach angle (i.e., 1 degrees nose-up). The difference in the lateral approach angle and the fuselage orientation from structure north was 3 degrees as listed in Table 6-3. An example impact condition for UAL 175 is shown in Figure 6-8, where the vertical approach angle was 6 degrees (fuselage orientation from horizontal $=5$ degrees) and the lateral approach angle was 13 degrees (fuselage orientation from structure north= 10 degrees). Larger or smaller angles resulted in projected impact points with the engines spaced too far horizontally or vertically or with the tip of the vertical stabilizer in the wrong location. Also, note that the impact point of the nose had been moved from original estimates, as previously discussed, and that the roll angle was maintained. A second example of an acceptable impact condition, this time with a lateral approach angle of 17 degrees, is shown in Figure 6-9.

The relationship between aircraft trajectory and orientation was then used to reduce the uncertainty of these parameters. The uncertainty in the vertical approach angle from the video analysis varied from 4 degrees to 12 degrees, as shown in Table 6-3, and the fuselage orientation from horizontal varied from -1 degrees to 7 degrees. As a 1 degree difference needed to be maintained in order for the impact pattern to match the observed damage, uncertainty in the vertical approach angle was reduced to 6 degrees \pm 2 degrees and the fuselage orientation from horizontal to 4 degrees \pm 1 degrees. Uncertainty in the lateral approach angle and the fuselage orientation from structure north was similarly reduced, as shown in Table 6-4. The impact points of the wing tips were known to within approximately $\pm 2 \mathrm{ft}$. This corresponded to an uncertainty in the roll angle of approximately \pm 2 degrees. 

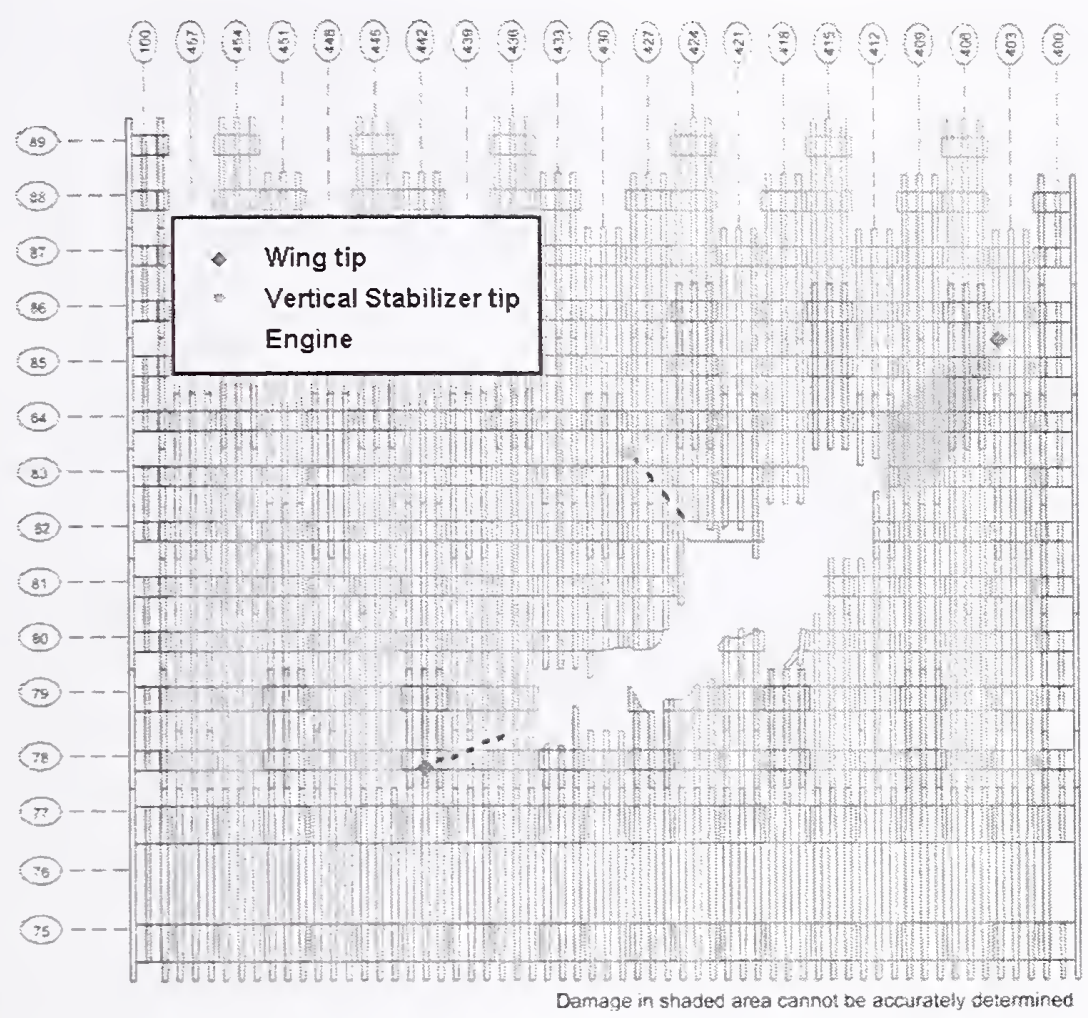

Figure 6-6. Estimated impact locations of aircraft components superimposed on the damaged face of WTC 2.

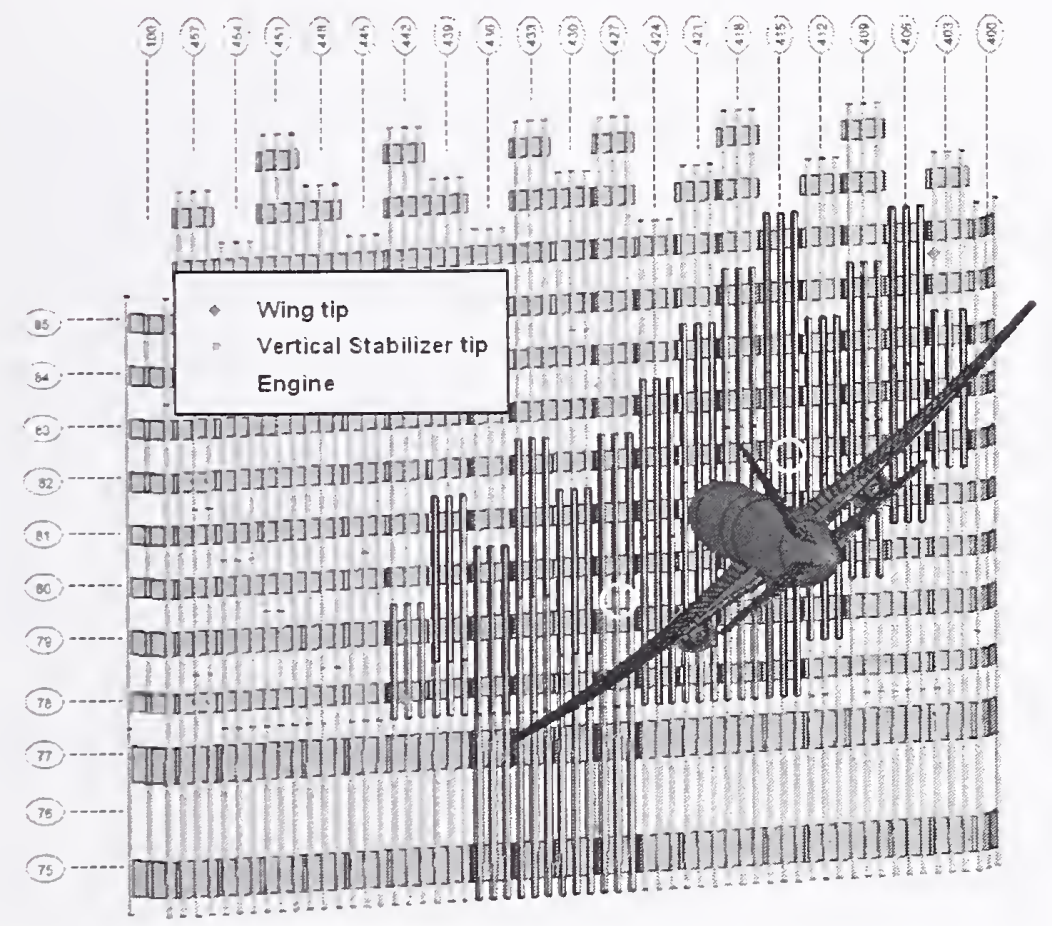

Figure 6-7. Orientation and Trajectory of UAL 175 from Video Analysis. 
Table 6-4. Aircraft impact locations on the WTC towers.

\begin{tabular}{|l|l|l|}
\hline & \multicolumn{1}{|c|}{$\begin{array}{c}\text { Horizontal } \\
\text { Location }\end{array}$} & \multicolumn{1}{|c|}{$\begin{array}{c}\text { Vertical } \\
\text { Location }\end{array}$} \\
\hline AA 11 (WTC 1) & $\begin{array}{l}2.0 \pm 3 \mathrm{ft} \text { west of } \\
\text { tower centerline }\end{array}$ & $\begin{array}{l}1.6 . \pm 4 \mathrm{ft} \text { above } \\
\text { floor } 96\end{array}$ \\
\hline UAL 175 (WTC 2) & $\begin{array}{l}23.1 \pm 3 \mathrm{ft} \text { east of } \\
\text { tower centerline }\end{array}$ & $\begin{array}{l}0.6 . \pm 4 \mathrm{ft} \text { above } \\
\text { floor } 81\end{array}$ \\
\hline
\end{tabular}

Table 6-5. Summary of refined aircraft impact conditions.

\begin{tabular}{|l|c|c|}
\hline & AA 11 (WTC 1) & UAL 175 (WTC 2) \\
\hline $\begin{array}{l}\text { Impact Speed (mph) } \\
\text { (Velocity vector) }\end{array}$ & $443 \pm 30$ & $542 \pm 24$ \\
\hline $\begin{array}{l}\text { Lateral Approach Angle } \\
\text { (Velocity vector) }\end{array}$ & $\begin{array}{c}10.6^{\circ} \pm 3^{\circ} \text { below horizontal } \\
\text { (heading downward) }\end{array}$ & $\begin{array}{c}6^{\circ} \pm 2^{\circ} \text { below horizontal } \\
\text { (heading downward) }\end{array}$ \\
\hline $\begin{array}{l}\text { Vertical Fuselage Orientation } \\
\text { Relative to Trajectory }\end{array}$ & $\begin{array}{c}180.3^{\circ} \pm 4^{\circ} \text { clockwise from } \\
\text { Structure North }\end{array}$ & $\begin{array}{c}1^{\circ} \pm 2^{\circ} \text { clockwise from } \\
\text { nose-up from the vertical } \\
\text { approach angle }\end{array}$ \\
\hline $\begin{array}{l}\text { Lateral Fuselage Orientation } \\
\text { Relative to Trajectory }\end{array}$ & $\begin{array}{c}1^{\circ} \text { nose-up from the vertical } \\
\text { approach angle }\end{array}$ \\
\hline Roll Angle (left wing downward) & $\begin{array}{c}0^{\circ} \text { clockwise from lateral } \\
\text { approach angle }\end{array}$ & $\begin{array}{c}-3^{\circ} \text { clockwise from lateral } \\
\text { approach angle }\end{array}$ \\
\hline
\end{tabular}

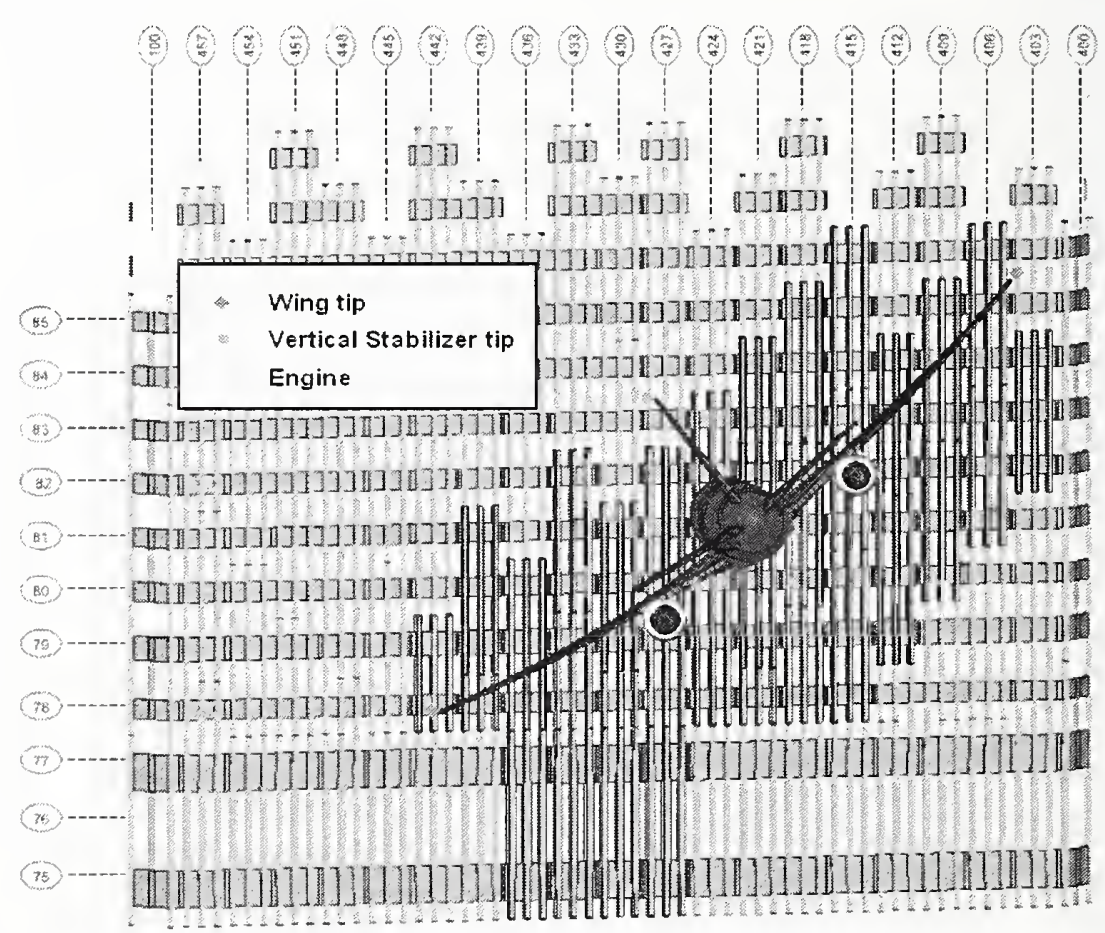

Figure 6-8. Orientation and trajectory of UAL 175 that matches the impact pattern (vertical approach angle $=6^{\circ}$, lateral approach angle $\left.=13^{\circ}\right)$. 


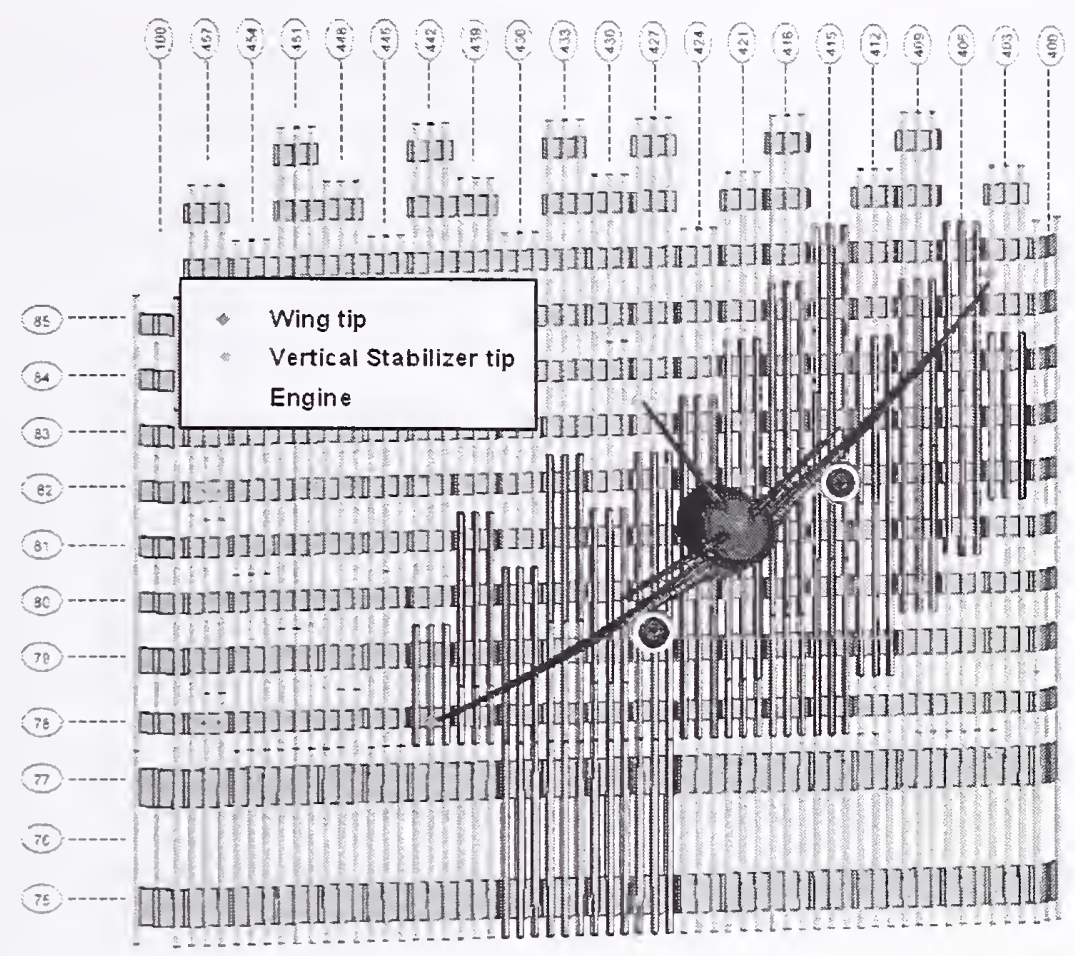

Figure 6-9. Orientation and trajectory of UAL 175 that matches the impact pattern (vertical approach angle $=6^{\circ}$, lateral approach angle $=17^{\circ}$ ).

Although the lateral approach angle of UAL 175 had a nominal value of 15 degrees, additional observable information was used to define the most probable flight condition. Figure 6-10 shows the top view of WTC 2 with the engines and landing gears in their pre-impact location. Also shown is the projected trajectory of the starboard engine of UAL 175, with an initial lateral approach trajectory of 13 degrees instead of 15 degrees, assuming the engine was not significantly deflected as it passed through the building. With this lateral trajectory, the starboard engine would exit the tower at the north east corner, consistent with the observables from video and photographic evidence. As a result, a lateral approach trajectory of 13 degrees was used for all WTC 2 impact simulations.

It is possible that the tower structure and/or contents could have deflected the engine from its initial lateral trajectory. The global simulations used a standard configuration for building contents similar to WTC 1. This configuration did not cause substantial deviation in the trajectory of the starboard engine. This lateral trajectory was, therefore, the most likely and was adopted for the global analyses. 


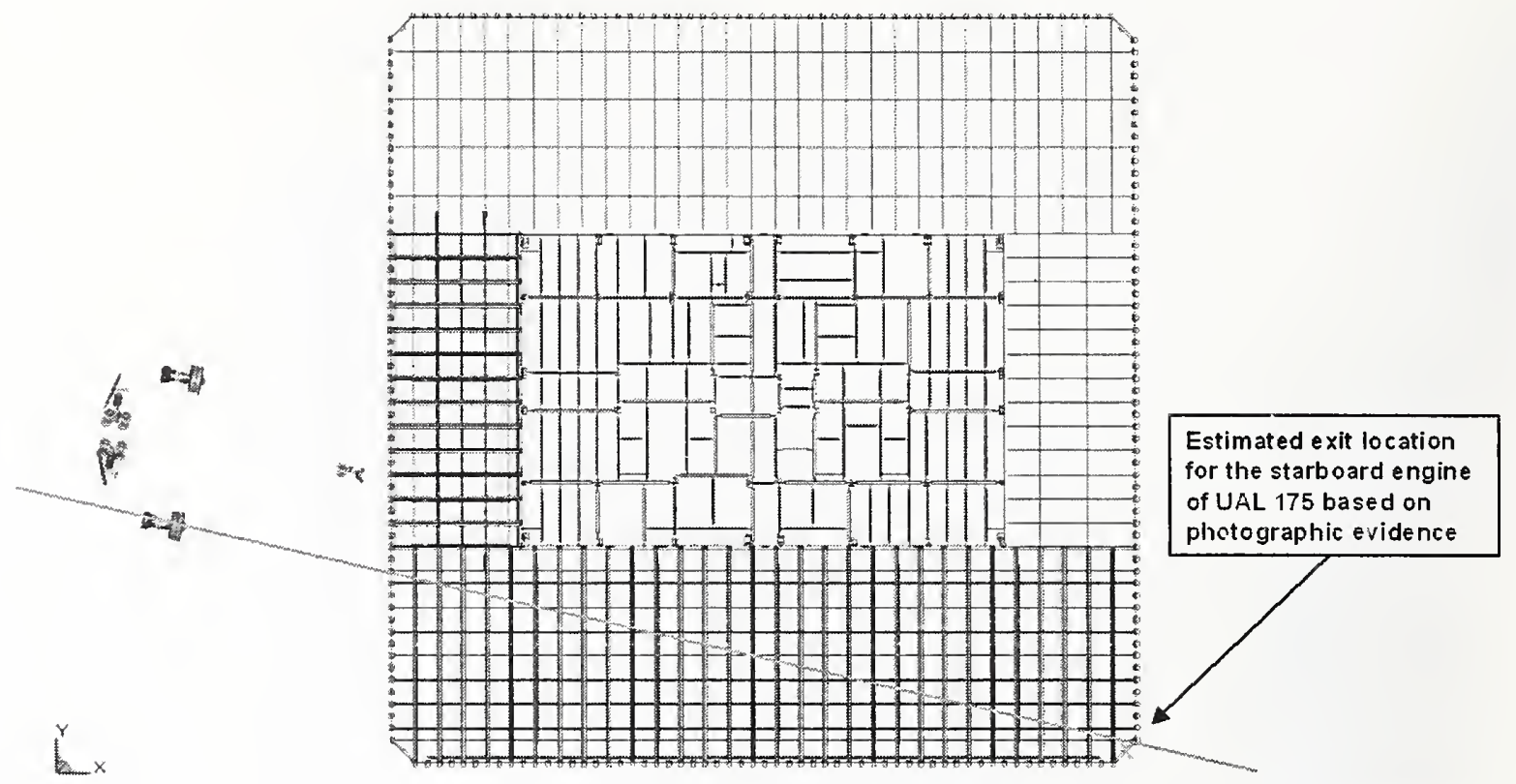

Figure 6-10. Projected trajectory of the starboard engine of UAL 175 with an initial lateral approach angle of $13^{\circ}$.

\subsection{COMPARISON WITH PREVIOUS ESTIMATES OF AIRCRAFT IMPACT INITIAL CONDITIONS}

Alternate analyses and values of the aircraft impact initial conditions were performed and reported by other studies. The objective of this chapter was to provide an independent assessment using the full database of video and photographic evidence collected and maintained by NIST. Many of these data sources may not have been available in the previous analyses. In this section, a comparison is presented between the aircraft impact conditions estimated in this study and those reported earlier. This comparison provides an opportunity to review the methodologies applied, as well as assists in the determination of the uncertainties in the impact conditions. The comparison includes estimates or analyses performed by the Federal Emergency Management Agency (FEMA), Federal Bureau of Investigation (FBI) (reported in the New York Times), Hart-Weidlinger, and MIT, and the analyses presented in this chapter (NIST). The analysis methodologies and data sources used for the FEMA and FBI estimates of the impact speeds werc not available. As a result, an evaluation of those estimates of impact conditions and determination of their uncertainties could not be made. In addition, preliminary estimates of the speed based on a simplified analysis of a single video footage for each tower (V1 video for WTC 1 and V6 video for WTC 2) were conducted by Project 5 (NIST NCSTAR 1-5A) and are included in this comparison.

Table 6-6 compares the results of the motion analyses for the AA 11 impact. Both the Hart-Weidlinger and Massachusetts Institute of Technology (MIT) analyses utilized the Doppler shift of the engine noise to determine the aircraft speed. The Hart-Weidlinger velocity analysis was based on AA 11 approaching the north tower at an angle 4 degrees shallower than the analyses presented here (NIST analysis in Table 6-6). If the Hart-Weidlinger analysis had the aircraft approaching at a steeper angle, it would have reported a speed much closer to the MIT and NIST analyses. The difference between the speed estimated from this study and that from the simplified analysis (NIST NCSTAR 1-5A) was about 5 percent. However, both speeds were well within the uncertainty range. One significant difference in the analyses 
of the AA 11 impact conditions was that none of the previous analyses had the opportunity to utilize the V2 video. This second video from a different location was very helpful to determine the motion parameters of the AA 11.

Table 6-6. AA 11 (WTC 1) aircraft impact analysis comparison.

\begin{tabular}{|l|c|c|c|c|c|c|}
\hline & FEMA $^{\mathrm{a}}$ & $\mathrm{FBI}^{\mathrm{b}}$ & $\begin{array}{c}\text { Hart- } \\
\text { Weidlinger }\end{array}$ & MIT $^{\mathrm{d}}$ & $\begin{array}{c}\text { NIST } \\
\text { Simplified } \\
\text { Analysis }^{\mathrm{e}}\end{array}$ & NIST \\
\hline Best Estimate Speed (mph) & 470 & 494 & 500 & 429 & 466 & 443 \\
\hline Speed Error Estimate (mph) & & & $+30 /-50$ & \pm 51 & \pm 34 & \pm 30 \\
\hline $\begin{array}{l}\text { Lateral Approach Angle } \\
\text { (clockwise) }\end{array}$ & & & $4.3^{\circ}$ & & & $0.3^{\circ} \pm 4^{\circ}$ \\
\hline $\begin{array}{l}\text { Vertical Approach Angle } \\
\text { (downward) }\end{array}$ & & $6.2^{\circ}$ & & & $10.6^{\circ} \pm 3^{\circ}$ \\
\hline $\begin{array}{l}\text { Aircraft Roll (left wing } \\
\text { down) }\end{array}$ & & & $20.7^{\circ}$ & & & $25^{\circ} \pm 2^{\circ}$ \\
\hline
\end{tabular}

a. FEMA World Trade Center Building Performance Study, May 2002. Analysis methodology or data source not available.

b. Lipton. E. and J. Glanz, 2002, "First Tower to Fall Was Hit at Higher Speed, Study Finds," The New York Times, February 23

c. Lery, M. and Abboud N.. 2002, "World Trade Center - Structural Engineering Investigation," Hart-Weidlinger.

d. The Towers Lost and Beyond, Massachusetts Institute of Technology, Eduardo Kausel.

e. NIST NCSTAR 1-5A.

Table 6-7 compares the results of the various motion analyses for the UAL 175 impact. The HartWeidlinger and the analyses presented here were consistent with the exception of the lateral approach angle. The MIT estimates of impact speed were low compared to the other analyses. However, assuming a lateral approach angle of 20 degrees would have increased the MIT estimate of the UAL 175 impact speed to about $524 \mathrm{mph}$. The simplified analysis (NIST NCSTAR 1-5A) yielded a speed that was very close to that obtained in this study.

Table 6-7. UAL 175 (WTC 2) aircraft impact analysis comparison.

\begin{tabular}{|l|c|c|c|c|c|c|}
\hline & FEMA $^{\mathrm{a}}$ & $\mathrm{FBI}^{\mathrm{b}}$ & $\begin{array}{c}\text { Hart- } \\
\text { Weidlinger }^{\mathrm{c}}\end{array}$ & MIT $^{\mathrm{d}}$ & $\begin{array}{c}\text { NIST } \\
\text { Simplified } \\
\text { Analysis }^{\mathrm{e}}\end{array}$ & NIST \\
\hline Best Estimate Speed (mph) & 590 & 586 & 550 & 503 & 545 & 542 \\
\hline Speed Error Estimate (mph) & & & & \pm 38 & \pm 18 & \pm 24 \\
\hline $\begin{array}{l}\text { Lateral Approach Angle } \\
\text { (clockwise) }\end{array}$ & & & $11.7^{\circ}$ & $15^{\circ}$ & & $15^{\circ} \pm 2^{\circ}$ \\
\hline $\begin{array}{l}\text { Vertical Approach Angle } \\
\text { (downward) }\end{array}$ & & $2.7^{\circ}$ & $0^{\circ}$ & & $6^{\circ} \pm 2^{\circ}$ \\
\hline $\begin{array}{l}\text { Aircraft Roll (left wing } \\
\text { down) }\end{array}$ & & & $30.1^{\circ}$ & & & $38^{\circ} \pm 2^{\circ}$ \\
\hline
\end{tabular}

a. FEMA World Trade Center Building Performance Study, May 2002. Analysis methodology or data source not available.

b. Lipton, E. and J. Glanz, 2002, "First Tower to Fall Was Hit at Higher Speed, Study Finds," The New York Times,

February 23

c. Levy, M. and Abboud N., 2002, "World Trade Center - Structural Engineering Investigation," Hart-Weidlinger.

d. The Towers Lost and Beyond, Massachusetts Institute of Technology, Eduardo Kausel.

e. NIST NCSTAR 1-5A. 


\subsection{SUMMARY}

Three methods were used to estimate the impact conditions for the two aircraft that impacted the WTC towers. The initial impact conditions included aircraft speed, horizontal and vertical angles of incidence, roll angle of each aircraft, and the location of nose impact with each tower. The estimates also included the uncertainties associated with these parameters. The first method used a comparison of videos from different positions to calculate the three-dimensional trajectory of the aircraft. The second method used the relative frame-by-frame motion in a single video, scaled to the length of the aircraft in the video to calculate the impact speed. Finally, analysis of the impact damage on the face of each tower was used to refine the relative impact orientation and trajectory. This was done by matching the projected impact points of the wings, fuselage, engines, and vertical stabilizer onto the exterior wall of each tower to the observed damage pattern.

\subsection{REFERENCES}

Cilke, R.W., (1995), "Motion Picture Analysis Procedures for Impact Parameters of Air-Delivered Weapons," FCT-LR-95-6, prepared by Applied Research Associates, Inc., Letter Report to the Defense Nuclear Agency, June.

FEMA, May 2002, "World Trade Center Building Performance Study: Data Collection, Preliminary Observations and Recommendations," FEMA 403.

Kausel, E., "The Towers Lost and Beyond," Massachusetts Institute of Technology, May, 2002, http://web.mit.edu/civenv/wtc/index.html.

Levy, M. and Abboud N., August 1, 2002, "World Trade Center - Structural Engineering Investigation," Hart-Weidlinger Technical Report, Prepared for Wachtell, Lipton, Rosen, and Katz.

Lipton, E. and J. Glanz, 2002, "First Tower to Fall Was Hit at Higher Speed, Study Finds," The New York Times, February 23. 


\section{Chapter 7 \\ AIRCRAFT IMPACT DAMAGE RESULTS}

\section{$7.1 \quad$ INTRODUCTION}

This chapter presents the results of the analyses of the aircraft impacts into the two World Trade Center (WTC) towers. The analysis results include the estimation of the structural damage and the condition and position of nonstructural contents such as partitions, workstations, aircraft fuel, and other debris that influenced the behavior of the subsequent fires in the towers. These results were uscd to provide the initial conditions for the subsequent structural analyses (level of damage to columns and floor systems) and damage to fireproofing due to debris impact. The global impact simulations provided, for each towcr, a range of damage estimates. These included the base case, based on reasonable initial estimates of all input parameters, along with a less severe and a more severe damage scenario. The less severe damage case did not meet two key observables: (1) no aircraft debris was calculated to exit the side opposite to impact and most of the debris was stopped prior to reaching that side, in contradiction to what was observed in photographs and videos of the impact event (see Section 7.10), and (2) the fire-structural and collapse initiation analyses of the damaged towers (NIST NCSTAR 1-6) indicated that the towers would not have collapsed had the less severe damage results been used. As a result, this chapter provides detailed description of the results of the analyses pertaining to the base casc and the more severe case, which were used as the initial conditions for the fire dynamics simulations (NIST NCSTAR 1-5F), thermal analyses (NIST NCSTAR 1-5G), and fire-structural response and collapse initiation analyses (NIST NCSTAR 1-6). Only a brief description is provided for the less severe damage results for comparison purposes. The details of the less severe damage estimates can be found in National Institute of Standards and Technology (NIST) NCSTAR 1-2B.

Section 7.2 provides a description of the analysis methodology, including assumptions and limitations. Sections 7.3 and 7.4 provide detailed description of the impact analysis results for the base case and the more severe case, respectively for WTC 1. Sections 7.6 and 7.7 provide similar results for WTC 2 . Sections 7.5 and 7.8 provide a brief description of the less severe case results for WTC 1 and WTC 2, respectively. The last three sections present different comparisons. Scction 7.9 presents a comparison of the impact response between WTC 1 and WTC 2. Section 7.10 compares the simulation results with observables based on video and photographic evidence as well as eyewitness intcrviews. Section 7.11 presents a comparison between the damage estimates from this study with those from previous studies. A summary is provided in Section 7.12.

\subsection{ANALYSIS METHODOLOGY, ASSUMPTIONS, AND LIMITATIONS}

The impact analyses were performed using the LS-DYNA finite element code (LS-DYNA Version 971). LS-DYNA is a commercially available nonlinear explicit finite element code for the dynamic analysis of structures (LSTC 2003) and has been used for a wide variety of crash, blast, and impact applications. The impact analyses used a variety of capabilities and algorithms in LS-DYNA. A brief description of these capabilities is described in this section. A significantly detailed description of the analysis methods is provided in the LS-DYNA Theoretical Manual (1998). 
The impact simulations used a nonlinear transient analysis with an explicit dynamics solver. This solver allows for simulating softening and failure of components in the analysis. The analysis solved the dynamic system of equations with a very small time increment $(\Delta \mathrm{T} \approx 0.8 \mu \mathrm{s})$, and with external loading defined as the initial conditions of the aircraft (velocity vector and location of the aircraft, see Chapter 6). Such analysis utilizes a number of capabilities that might not be customarily used in structural engineering applications. These include the following:

- Element erosion: Damage and failure of components were included in the models through the constitutive algorithms. Damage criteria (such as maximum plastic strain) were tracked for each element within the constitutive model evaluation, and elements were eroded when the failure criteria were exceeded. This allowed for a direct evaluation of damage and failure within the impact simulations. The eroded elements allow for the initiation and extension of fracture in the model. Eroded elements no longer supported any stress, and the strains in the eroded elements were no longer calculated. The associated mass of the elements remained with the nodes in the calculation. If adjacent elements did not reach the failure surface, the nodes remained attached to the structure. If all of the elements connected to a specific node failed, the node became a free particle. Free nodes can either be eliminated from the calculation or remain in the calculation with associated inertial properties and potential for impacts against other structural components (free nodes remain in contact algorithms).

- Contact behavior: A contact algorithm was used to detect contact between two bodies and to estimate the forces generated by this contact. Overall contact in the impact analyses was modeled using the automatic single surface contact algorithms in LS-DYNA. Interacting components were defined by a material list, and contact segments were automatically generated by LS-DYNA. This greatly simplified the specification of contact between various components in the aircraft and tower structures. The type 1 soft constraint option was used in the contact algorithm that determined the contact stiffness based on stability considerations, time step size, and nodal mass. This soft constraint option was found to be more robust than the default penalty formulation for modeling the complex contact behaviors in large impact and crash simulations.

- Complex failure modes: In specific applications, unique algorithms were required to introduce failure modes in the analysis. These were primarily used in modeling the response and failure of connections (see Chapter 5 for description of some of these connections). An example is the splice between core columns, where the connection between the splice plate and column flange was modeled with a surface-to-surface tied interface without failure. This resulted in a perfect bond between the nodes of the splice plate and the flange of the adjacent column. When columns were pulled apart, the elements at the splice plate spanning the gap between column ends would be stretched. Failure of the splice plate in the model resulted from ductile failure of the splice plate in the elements spanning the connection.

- Fluid-structure interaction: This was needed to model the fuel impact on the exterior wall and the subsequent dispersion inside the towers. The Smooth Particle Hydrodynamics (SPH), which utilizes a mesh free approach, was used to model the fuel in the impacting aircraft. In this approach, fuel was modeled as particles that were allowed to interact with the structure of the aircraft and tower. 
The finite element meshes used in the impact analyses typically used elements with single point integration. The biggest disadvantage of the single point integration is the potential for hourglassing or zero energy modes. There are several methodologies for controlling hourglass modes in LS-DYNA. The typical approach used in the impact analyses was to apply a viscous hourglass control where a viscous damping was introduced that suppressed the formation of hourglass modes, but did not significantly influence the global modes.

As mentioned in Chapter 5, the global impact simulations were limited by the maximum finite element model size that could be executed on the available 32-bit computer clusters. The primary assumptions and limitations of the global impact analyses were the result of reducing the model size to meet this limitation, as well as to achieve a run time that allowed the global impact analyses to be completed within the duration of the investigation.

Although the analyses were performed on a 32 bit computer cluster, the precision used in the analyses can be controlled by the analysis software. Both single precision and double precision versions of LS-DYNA were available for the impact analyses. In general, single precision analyses are more efficient and the precision is sufficient for the type of impact simulation being performed. However, when the dimensions of the structure being analyzed are sufficiently large, the single precision analyses can introduce rounding errors in the analyses. The rounding errors occur since the analysis is resolving deformations or analyzing element penetrations on a local scale that is several orders of magnitude smaller than the controlling dimension.

In preliminary simulations, the coordinate system for the models of the tower structures was located near the base of the tower. As a result, the largest dimensions were the vertical position of the structures in the impact zone. This large vertical dimension controlled the size scale in the impact analyses and introduced rounding errors that were manifested as unstable element behaviors. To eliminate this precision problem, the tower model coordinate system was moved to be centered on the impact zone of the tower. The largest controlling dimension was therefore the distance across tower (significantly smaller than the height of the tower). After adjusting the coordinate location, the unstable element behaviors were no longer observed.

To confirm the adequacy of the single precision analysis, subassembly impact analyses (Section 5.4.5) were performed on the same model in both single and double precision. The comparison of the two analyses showed no substantial difference in the impact response and damage.

Specific assumptions and limitations introduced in the analyses to meet the computational and time constraints included:

- Tower structures away from the impact zone had a coarse mesh resolution, and as a result, damage in these regions may not have been accurately captured. An example is the potential damage to the exterior wall on the far side of the tower (opposite to impact). As debris passed through the building and struck a panel on the far side, the coarse mesh and merged boundary conditions at column ends (as opposed to bolted connections in the impact zone) underestimated the secondary impact damage.

- Tower contents (workstations and nonstructural walls) were only included in the expected path of the aircraft impact and subsequent debris cloud. Therefore, debris and fuel that 
passed beyond this region could move more freely through the structure, only interacting with primary structural components. Also, the workstation layout from WTC 1 was used for WTC 2. That added an additional uncertainty to the nonstructural building contents for WTC 2 .

- The analysis of the impact response of the aircraft fuel cloud had several limitations. Smooth Particle Hydrodynamics (SPH) was used to model the fuel in the impacting aircraft. The air in and around the towers was not modeled, so the deceleration of the fuel particles in the cloud by aerodynamic resistance was not included. The contact algorithm for the fuel particles and tower did not include a sticking or "wetting" behavior so the fuel particles would bounce off of components in the tower. The results of these limitations would spread the fuel cloud over a larger region in the simulation. Finally, the deflagration of the fuel was not modeled, and the resulting dynamic over-pressures in the tower from the combustion process were not included in the analysis.

- Windows were not modeled on the exterior of the tower. The open space between the exterior columns allowed fuel particles and small debris fragments from the aircraft and tower to escape that may have been contained if the windows were included. Note, however, that the weight of the windows was added to the columns as part of the superimposed dead loads.

- The rotational velocity of the spinning aircraft engine components was not modeled. The effects of the rotational kinetic energy, spin stabilization of the engine trajectory, or potential for engine thrust during impact were, therefore, not included in the analysis. An analysis was performed to estimate the magnitude of the effects of this assumption (see Chapter 10 of NIST NCSTAR 1-2B). The analysis indicated that the rotational kinetic energy of each engine was approximately one percent of the aircraft initial kinetic energy. In addition, much of this rotational energy was probably dissipated by internal deformations of the engine components following impact with the tower exterior. Therefore, this approximation should have had a small influence on the global impact damage.

- Aeroelastic forces were not applied to the aircraft wings since the resulting stresses were not expected to affect the impact response. A wing tip deflection of 52 in. was applied to the aircraft model based on photographic evidence.

- Gravitational acceleration was modeled during the impact analyses to include the gravity effects on debris movement and potential contributions to the collapse of the damaged truss floor regions. However, initial service loads (stresses) in the tower and aircraft were not included. The material internal energy associated with the elastic service loads were small compared to the material internal energy capacity. Therefore, their execution was not expected to have a significant influence on the dynamic impact response and deformation. Simplified analyses were performed to evaluate the magnitude of the effects of this assumption for the impact response of a core column (see Chapter 10 of NIST NCSTAR 1-2B). These analyses indicated that ignoring the static preload in the column had little influence on either the dynamic column deformations or the reserve capacity of the column. 
- The impact analyses were subject to uncertainties in the input parameters, such as initial impact conditions, material properties and failure criteria, aircraft mass and stiffness properties, mass distribution inside the towers, the jet fuel distribution and dispersion, connections behavior, the presence of nonstructural building contents, etc. Sensitivity analyses were conducted as described in Chapter 8 of NIST NCSTAR 1-2B to assess the effects of these parameters on the damage estimates. The global analyses not only provided a "base case" based on reasonable initial estimates of all input parameters, but also provided a range of damage estimates based on variations of the most influential parameters, identified in the sensitivity analyses.

\section{3}

\section{WTC 1 BASE CASE IMPACT ANALYSIS - CASE A}

This case is referred to as Case A in the remainder of the WTC Investigation reports. This analysis provided an estimate of the impact damage based on reasonable initial estimates of all the variables obtained from photographic evidence, material testing, and data in the open literature. The combined aircraft and tower model used for the base case global impact conditions of WTC 1 is shown in Figure $7-1$. 


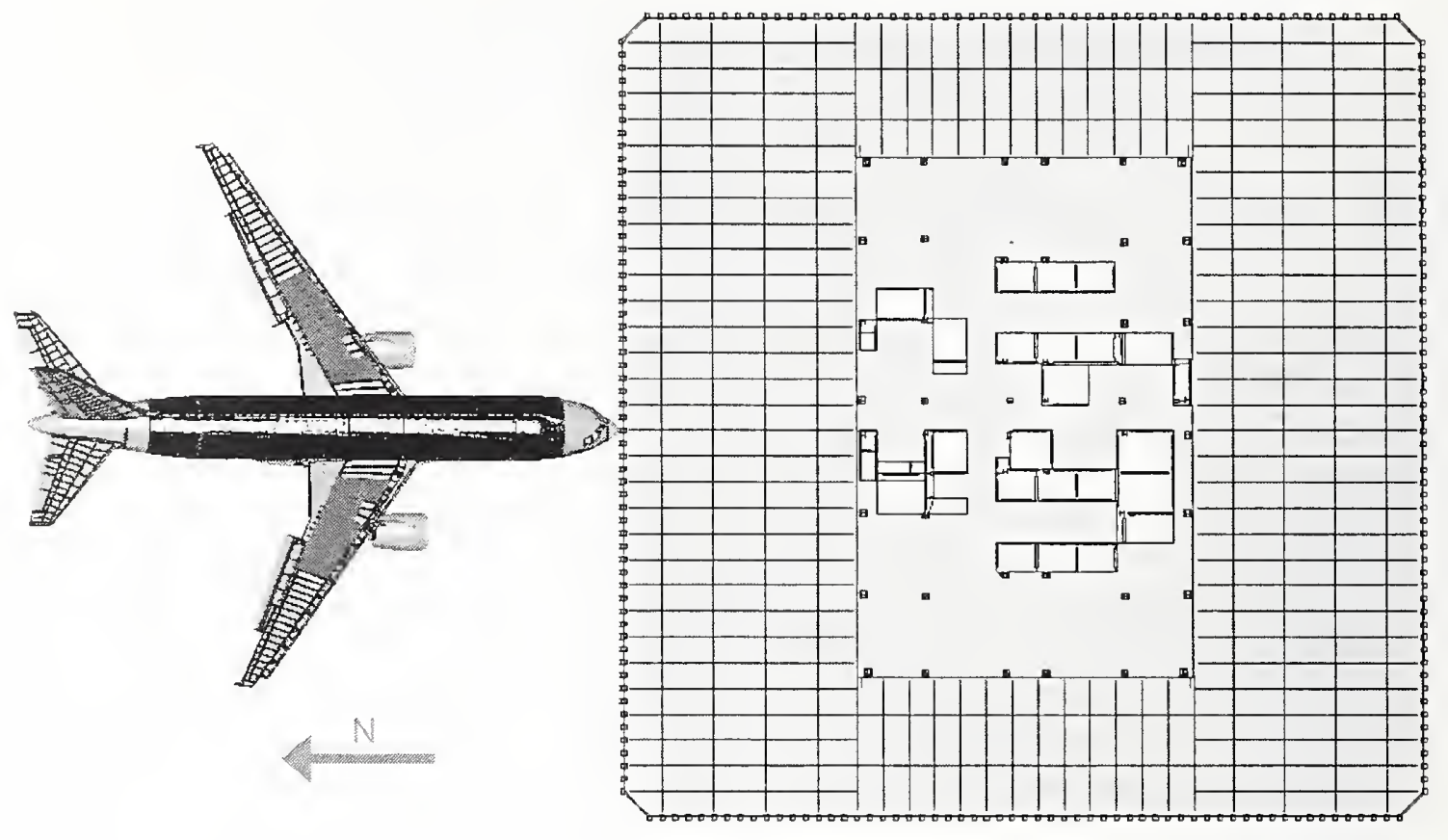

(a) Plan view

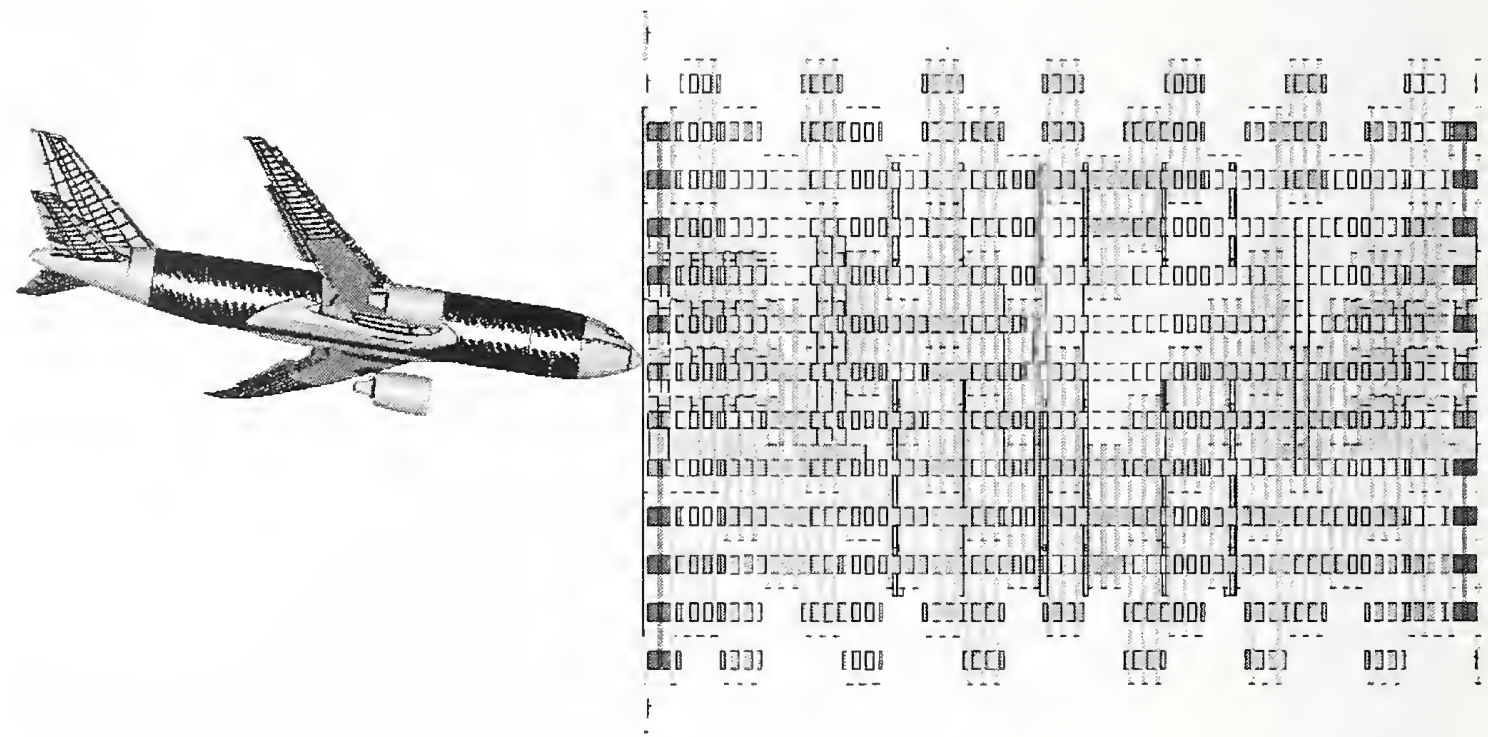

\section{(b) Side view}

Figure 7-1. WTC 1 global impact model.

The WTC 1 base case analysis was performed for a $0.715 \mathrm{~s}$ duration following initial impact of the aircraft nose with the north exterior wall. The analysis was performed on a computer cluster using twelve $2.8 \mathrm{GHz}$ Intel Xeon processors, each on a separate node of the cluster. The run time for this analysis was approximately two weeks. The progress of the global impact simulations was monitored on average every two days. The calculations were terminated when the damage to the towers reached a steady state 
and the motion of the debris was reduced to a level that was not expected to produce significant impact damage. The residual kinetic energy in the airframe components at the termination of the global impact simulation was less than one percent of the initial kinetic energy at impact.

\subsubsection{Impact Response}

The impact response of WTC 1 is shown in side and plan views in Figure 7-2 and Figure 7-3, respectively. The response is shown at intervals of $0.1 \mathrm{~s}$ from impact through the initial $0.5 \mathrm{~s}$ of the response. The initial $0.1 \mathrm{~s}$ of the response, shown in Figure 7-2(b) and Figure 7-3(b), was dominated by the impact, penetration, and fragmentation of the forward fuselage structures. The engines and wing sections were just starting to impact the exterior wall. The forward fuselage structures were severely damaged both from the penetration through the exterior columns and the interaction with the $96^{\text {th }}$ floor slab that sliced the fuselage structures in half. The downward trajectory of the aircraft structures caused the airframe to collapse against the floor, and the subsequent debris motion was redirected inward along a more horizontal trajectory parallel to the floor.

By $0.2 \mathrm{~s}$ after impact, the wings completely penetrated the exterior wall, and only the tail structures were still outside the tower. as shown in Figure 7-2(c) and Figure 7-3(c). The wing structures were completely fragmented by the penetration through the exterior wall. The aircraft fuel cloud was starting to spread out but was still relatively dense. and the leading edge of the fuel was just reaching the tower core. The downward trajectory of the aircraft structures transferred sufficient vertical load that the truss floor structures on floors 95 and 96 were starting to collapse in the impact zone.

At $0.3 \mathrm{~s}$ after impact, the aircraft was completely inside of the tower (full penetration completed at approximately $0.25 \mathrm{~s}$ ), as shown in Figure 7-2(d) and Figure 7-3(d). The airframe was mostly broken up, but some large sections of the aft fuselage and tail were still intact, having penetrated through the opening in the north wall created by the forward fuselage structures. The aircraft fuel cloud penetrated approximately half the distance through the core and was spreading out. However, the subsequent motion of the aircraft fragments and fuel debris cloud began to be noticeably slowed beyond this time. The fuel and debris did continue to spread through the tower, but at a much slower rate, as seen in the remaining images in Figure 7-2 and Figure 7-3. 


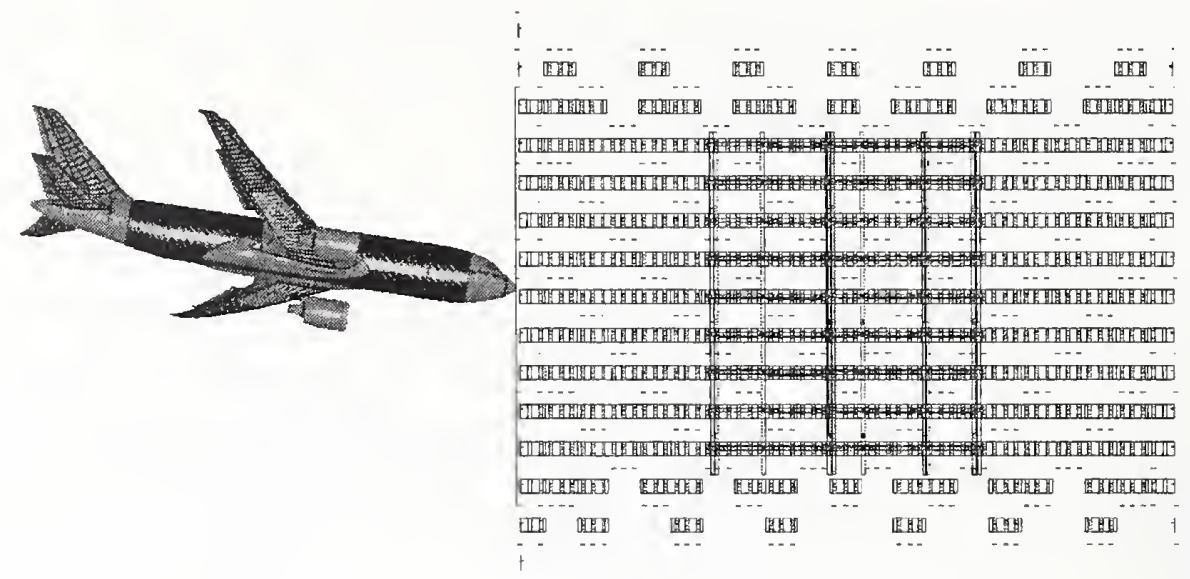

\section{(a) Time $=0.00 \mathrm{~s}$}

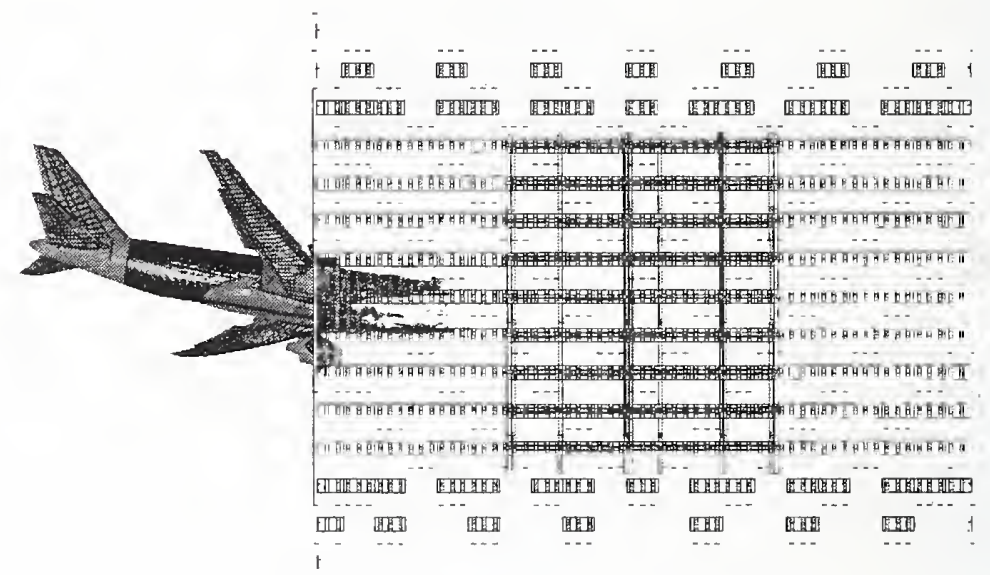

\section{(b) Time $=0.10 \mathrm{~s}$}

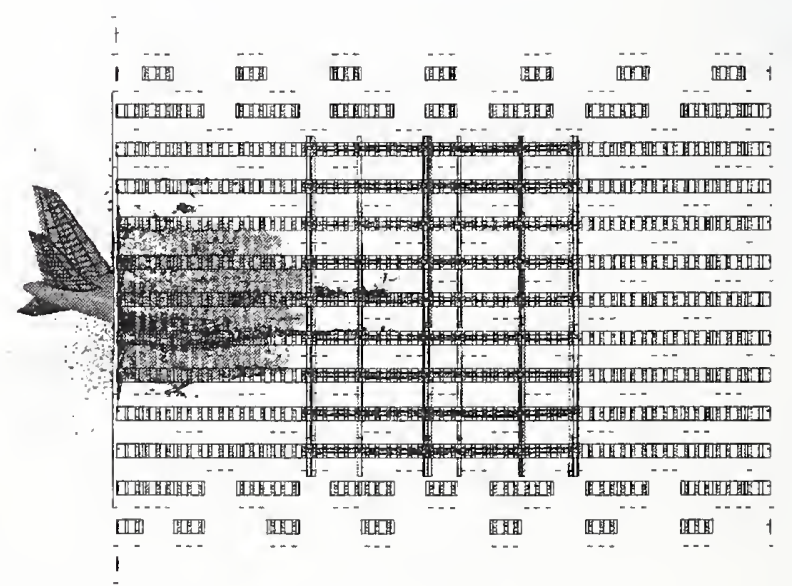

(c) Time $=0.20 \mathrm{~s}$

Figure 7-2. WTC 1 base case global impact analysis (side view). 


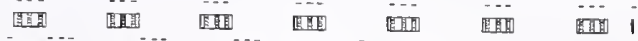
(10 Th TH: (5) 7 . 3 (36) Kry 7.

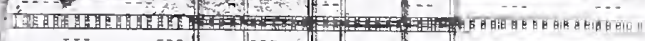

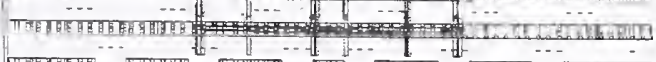
THसE

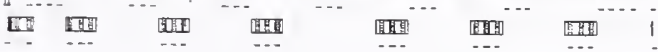

\section{(d) Time $=0.30 \mathrm{~s}$}

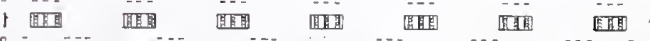
एँ

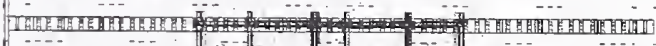
PLER

2.

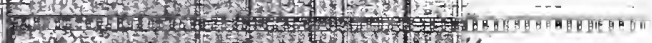

Now

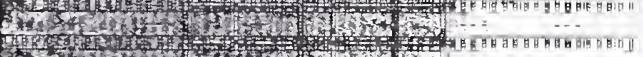

2. 4 -

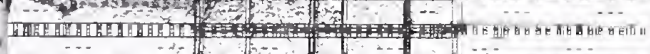

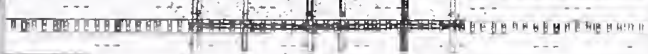

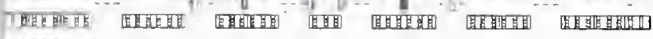

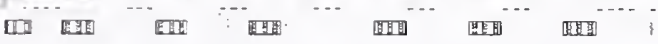
i

(e) Time $=0.40 \mathrm{~s}$

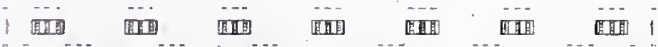

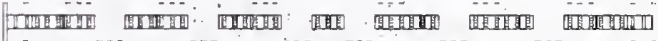
This:

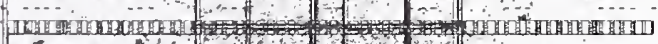
4

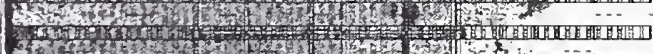
7.

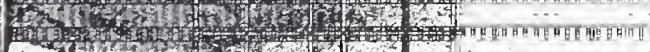

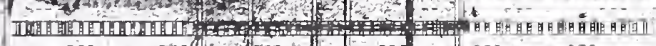

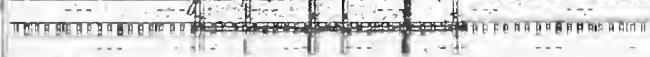

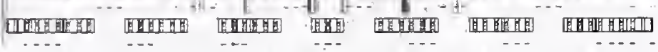

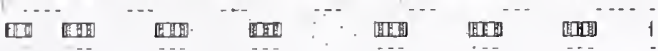

(f) Time $=0.50 \mathrm{~s}$

Figure 7-2. WTC 1 base case global impact analysis (side view) (continued). 


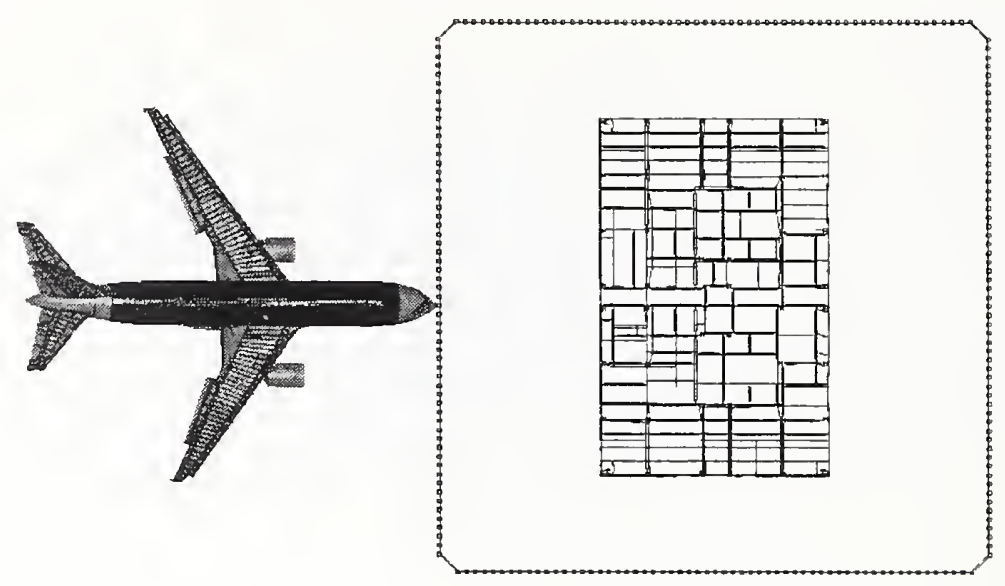

(a) Time $=0.00 \mathrm{~s}$

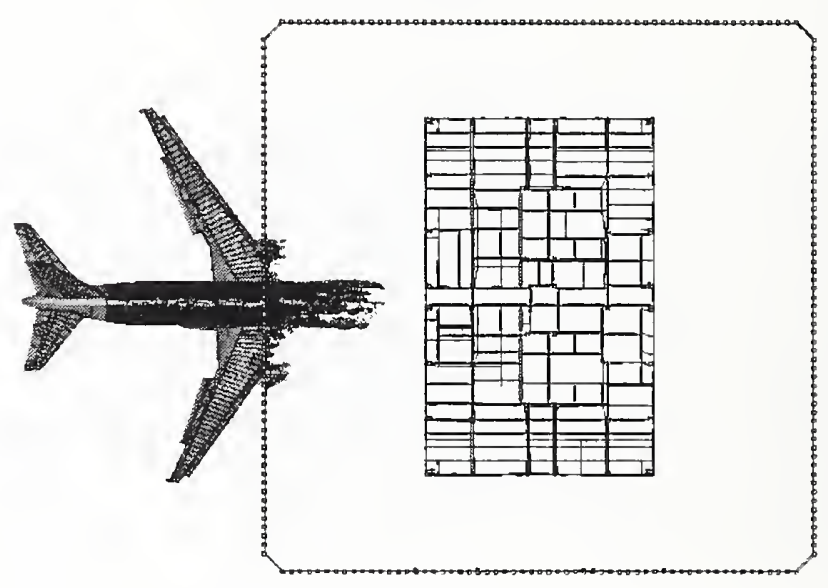

(b) Time $=0.10 \mathrm{~s}$

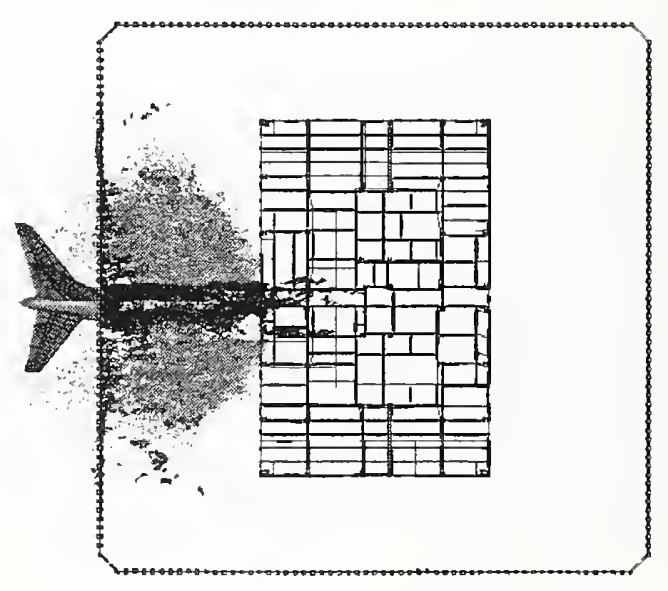

(c) Time $=0.20 \mathrm{~s}$

Figure 7-3. WTC 1 base case global impact analysis (plan view). 


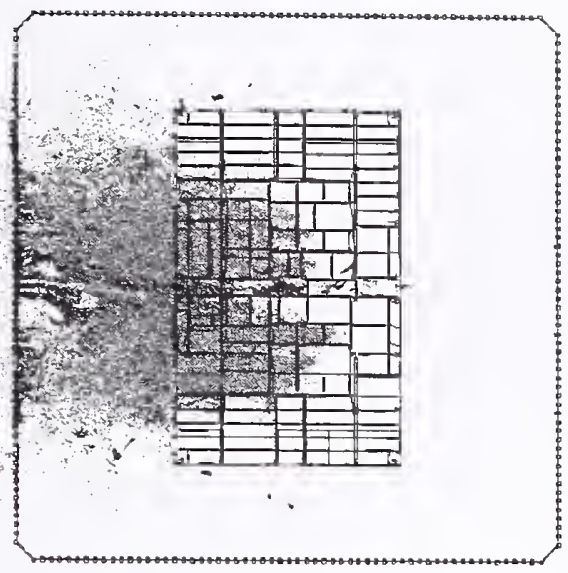

(d) Time $=0.30 \mathrm{~s}$

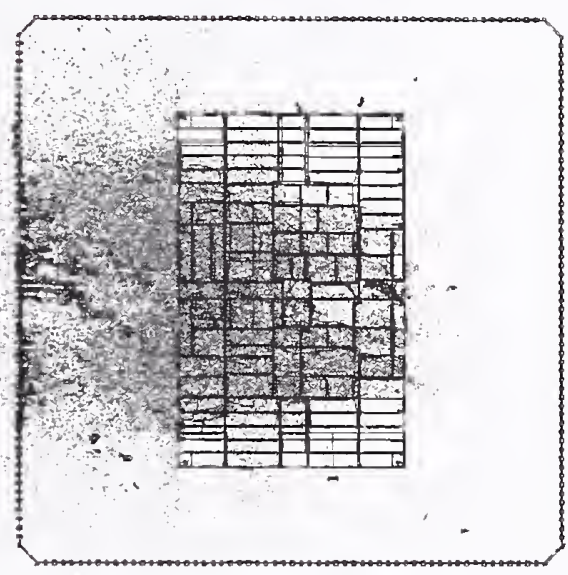

(e) Time $=0.40 \mathrm{~s}$

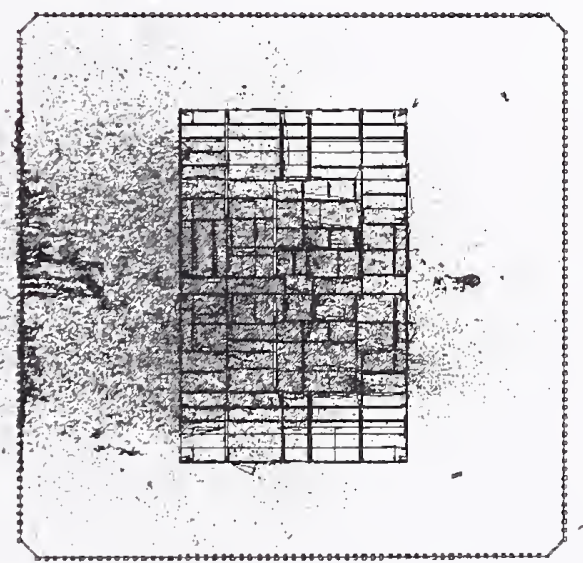

(f) Time $=0.50 \mathrm{~s}$

Figure 7-3. WTC 1 base case global impact analysis (plan view) (continued). 
The load transfer of the aircraft impact can be described by the time-history of the aircraft momentum as shown in Figure 7-4. The momentum plotted was for all of the aircraft structures and contents (including fuel), normalized by the initial momentum magnitude. The curve illustrates an initial ratc of load transfer during the first $0.1 \mathrm{~s}$ of impact as the forward fuselage penetrated the exterior wall and impacted the interior structures. Between $0.1 \mathrm{~s}$ and $0.25 \mathrm{~s}$, a more rapid load transfer rate was obscrved as the area of the impact became larger (extending outward in the wing impact regions) and a higher percentage of the aircraft mass was impacting the interior structures. At $0.25 \mathrm{~s}$, the aircraft completely penetrated the building and retained approximately 30 percent of its initial momentum. Beyond this time, the rate of load transfer was steadily decreasing with very little load transfer after approximately $0.5 \mathrm{~s}$.

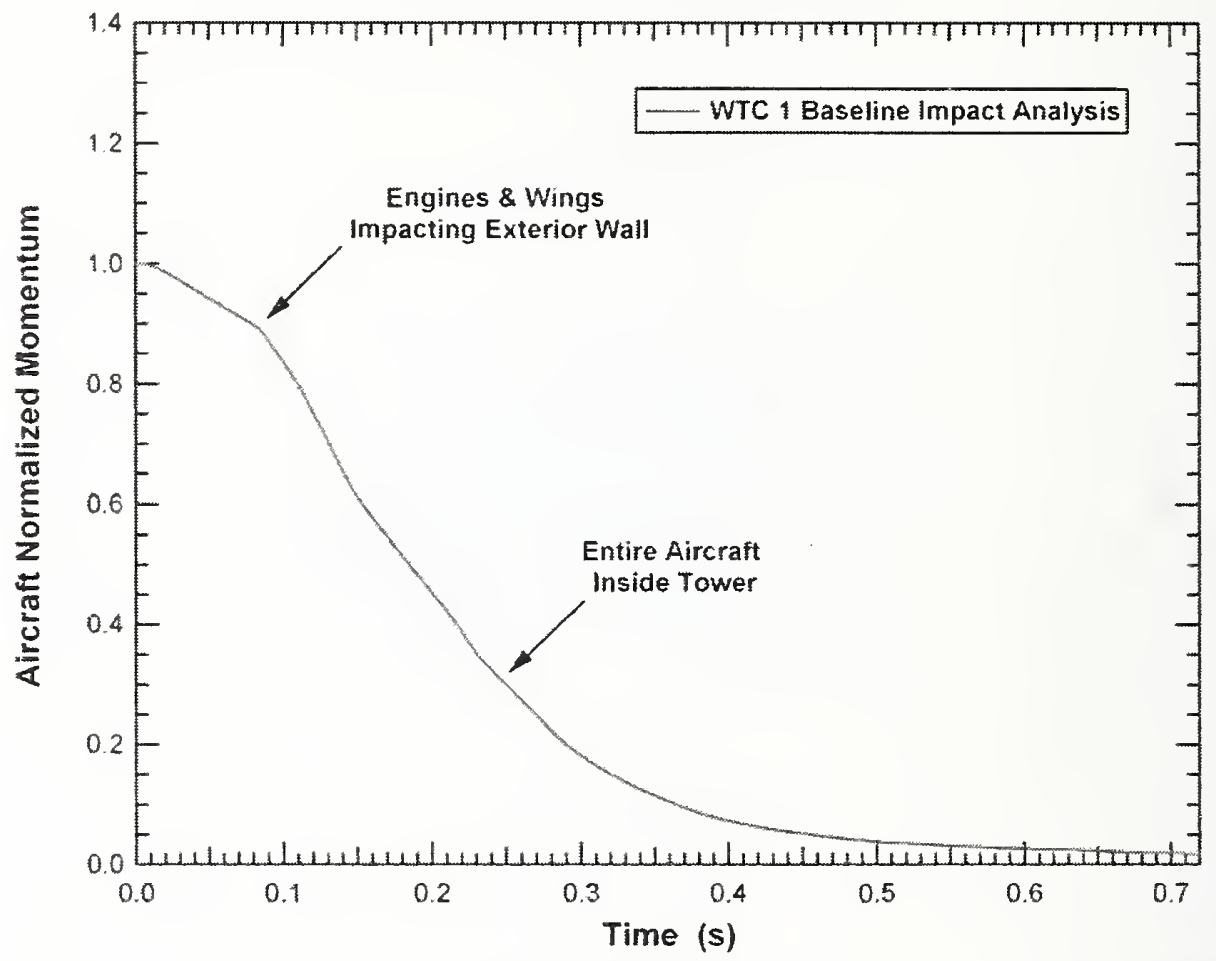

Figure 7-4. Normalized aircraft momentum for the WTC 1 base case impact.

The aircraft was severely broken into thousands of debris fragments of various sizes and mass as a result of the impact with the tower. Larger fragments occurred for specific components such as the engines. At the end of the simulation, the port engine was still inside the core, and the starboard engine was roughly one third of the distance from the core to the south exterior wall. Each engine had a speed of less than $50 \mathrm{mph}$.

\subsubsection{Tower Structural Damage}

The structural damage to the WTC 1 tower by the base case impact conditions is described in this section. The primary structural components of interest were the exterior wall, core columns and core framing components, and the floor structures and concrete floor slab. Only limited results are presented in this chapter. Refer to Chapter 9 of NIST NCSTAR 1-2B for further details. 


\section{Exterior Wall Damage}

The exterior wall was the one structural system for which direct visual evidence of the impact damage was available. Therefore, the comparison of the calculated and observed exterior wall damage can provide a partial validation of the analysis methodologies used in the global impact analyses. A comparison of the north exterior wall observed and calculated damage from the base case WTC 1 global impact analysis is shown in Figure 7-5. The calculated impact damage to the exterior wall is shown with color fringes representing plastic strain magnitude, with undamaged sections in blue and strains at or above 5 percent shown in red. The schematic of observed damage was developed from inspections of the film and photographic data collected on the tower after impact. Both the observed and calculated damage wall regions illustrate a region of the exterior wall from column 108 to column 152, extending from floor 91 to floor 100 (spandrels at floors 92 through 100).

The comparison of the calculated and observed damage indicated that the geometry and location of the impact damage zone were in good agreement. This agreement in the position and shape of the impact damage served to validate the geometry of the aircraft model, including the aircraft orientation, trajectory, and flight distortions of the wings.

The comparison also indicated good agreement in the magnitude and mode of impact damage on the exterior wall. The exterior wall completely failed in the regions of the fuselage, engine, and fuel-filled wing section impacts. Damage to the exterior wall was observed all the way out to the wing tips, but the exterior columns were not completely failed in the outer wing and vertical stabilizer impact regions. Failure of the exterior columns occurred both at the bolted connections between column ends and at various locations in the column depending on the local severity of the impact load and the proximity of the bolted connection to the impact. The agreement of both the mode and magnitude of the impact damage served to partially validate the constitutive and damage modeling of the aircraft and exterior wall of the tower. Section 7.10.1 provides a detailed comparison of the calculated and observed damage mode and magnitude.

\section{Core Structural Damage}

The estimation of the damage to the core columns and core beams was important in determining the residual strength for the subsequent analyses of structural stability and collapse. The core had significant damage in the region close to the impact point. The columns in line with the aircraft fuselage failed on the impact side, and several of the core beams were also severely damaged or failed in the impact zone.

The calculated damage to the core columns by row is shown in Figure 7-6. The columns are shown with color fringes representing plastic strain magnitude, with undamaged sections in blue and strains at or above 5 percent shown in red. A summary of the column damage is listed in Table 7-1. The qualitative classification of the column damage levels is shown in Figure 7-7. This classification levels were light damage, moderate damage, heavy damage, and failed (severed). The light damage level was defined as having evidence of impact (low level plastic strains), but without significant structural deformations. The moderate damage level had visible local distortions of the column cross section (e.g. bending in a flange) but no lateral displacements of the column centerline. The heavy damage classification was for impacts that produced significant global deformation, resulting in a permanent deflection of the column centerline. 
The severed columns were completely failed and could carry no residual load. The damage to the core floor framing for floors 95 and 96 is shown in Figure 7-8.

$\mathrm{P}-\Delta$ effects generated due to the sway of the towers after impact, as observed in video evidence, were not expected to affect or impose additional damage to the core columns. The core columns were designed as axially loaded members without continuity of framing, and thus would not develop significant $\mathrm{P}-\Delta$ moments (see Chapter 5 of NIST NCSTAR 1-2A). 


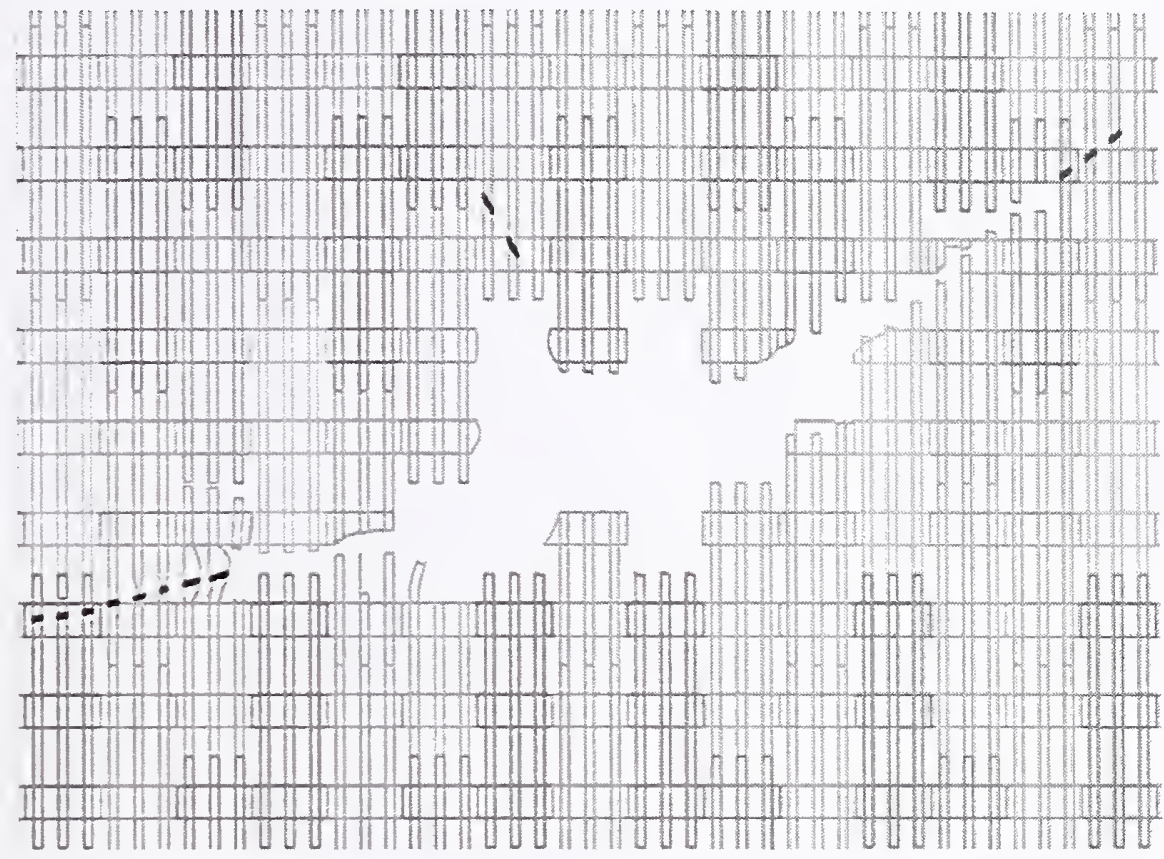

(a) Schematic of observed damage

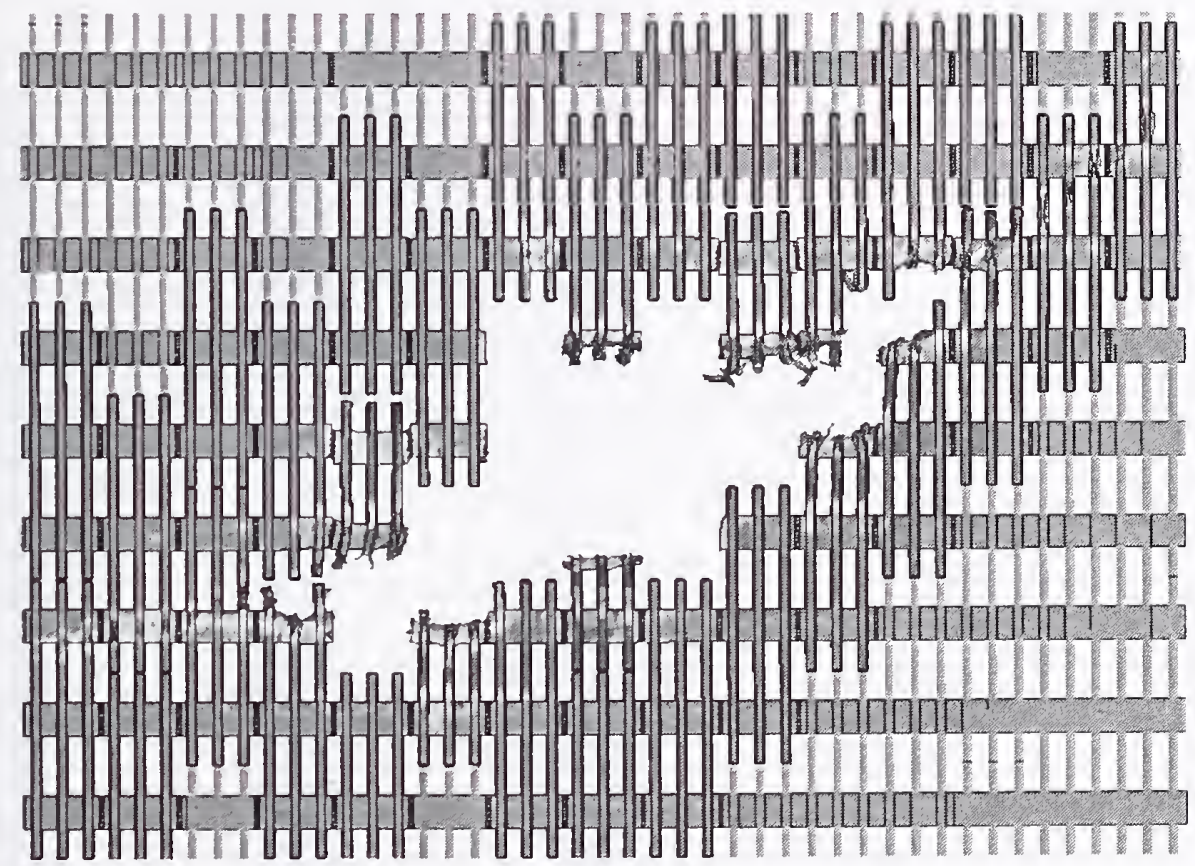

(b) Calculated damage

Figure 7-5. Base case impact damage to the WTC 1 exterior wall. 


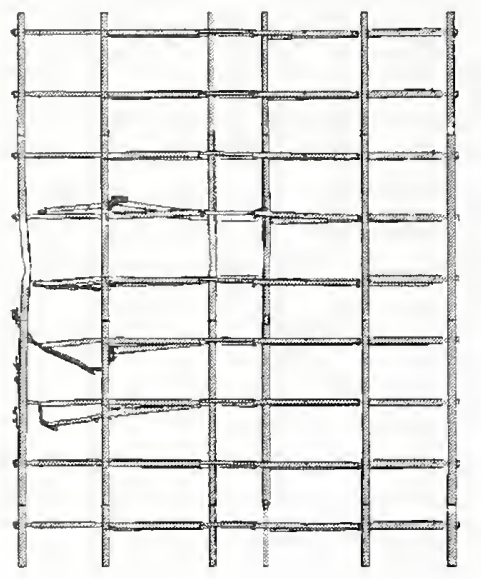

(a) Columns 503-1003

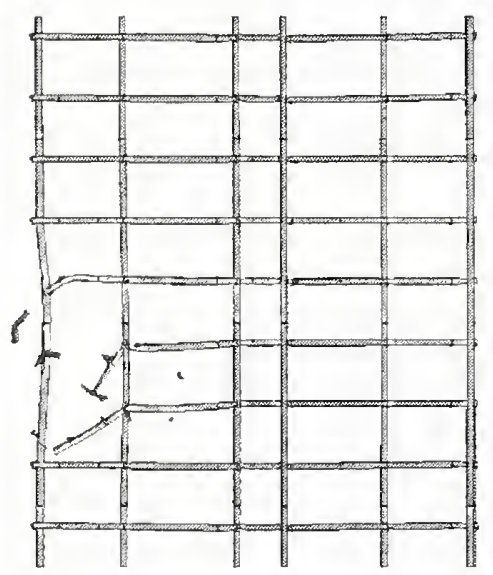

(c) Columns 505-1005

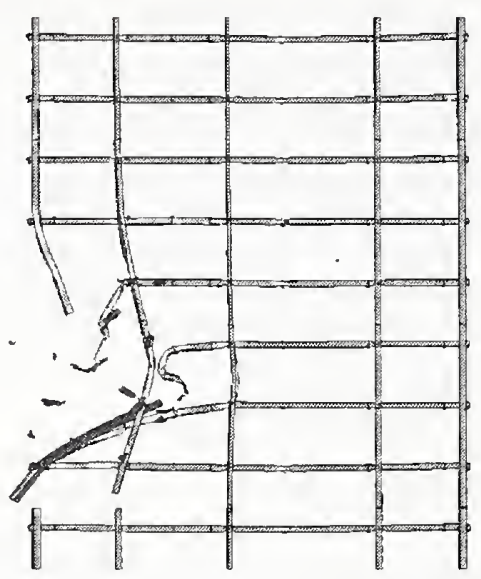

(b) Columns 504-1004

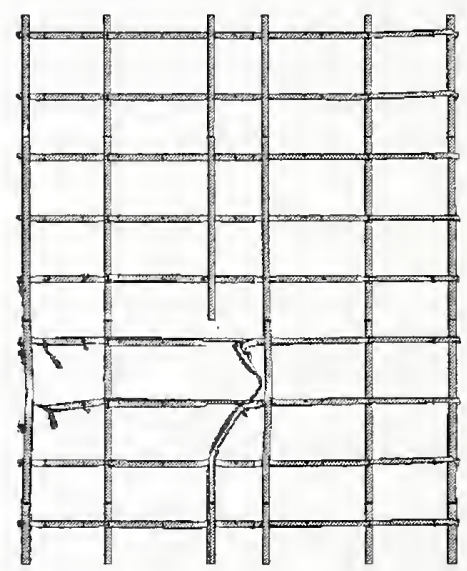

(d) Columns 506-1006
Fringe Levels

5.000e-02 $4.500 \mathrm{e}-02$ $4.000 \mathrm{e}-02$ $3.500 \mathrm{e}-02$ 3.000e-02 2.500e-02 2.000e-02 $1.500 \mathrm{e}-02$ 1.000e-02 5.000e-03 $0.000 \mathrm{e}+100$

Figure 7-6. Base case impact damage to the WTC 1 core columns. 
Table 7-1. Summary of core column damage for the base case WTC 1 impact.

\begin{tabular}{|c|c|c|c|}
\hline Column & Location & Damage Level & $\begin{array}{c}\text { Lateral Deflection of } \\
\text { Column Centerline (in.) }\end{array}$ \\
\hline Column 503 & Floor 96 & Heavy & 18 \\
\hline Column 504 & Floors 92-96 & Severed & \\
\hline Column 505 & Floors 93-96 & Heary & 20 \\
\hline Column 506 & Floors 93-94 & Heavy & 10 \\
\hline Column 604 & Floors 92-96 & Severed & \\
\hline Column 605 & Floors 94-95 & Moderate & \\
\hline Column 702 & Floor 96 & Moderate & \\
\hline Column 703 & Floor 96 & Moderate & \\
\hline Column 704 & Floor 94 & Heavy & 18 \\
\hline Column 705 & Floor 95 & Moderate & \\
\hline Column 706 & Floors 93-95 & Severed & \\
\hline Column 802 & Floor 96 & Moderate & \\
\hline Column 805 & Floor 94 & Moderate & \\
\hline
\end{tabular}

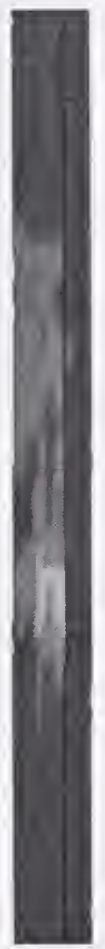

(a) Light

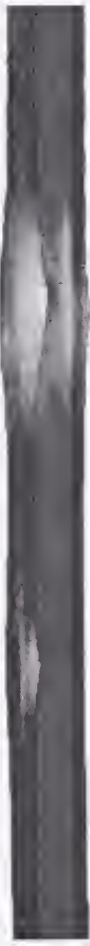

(b) Moderate
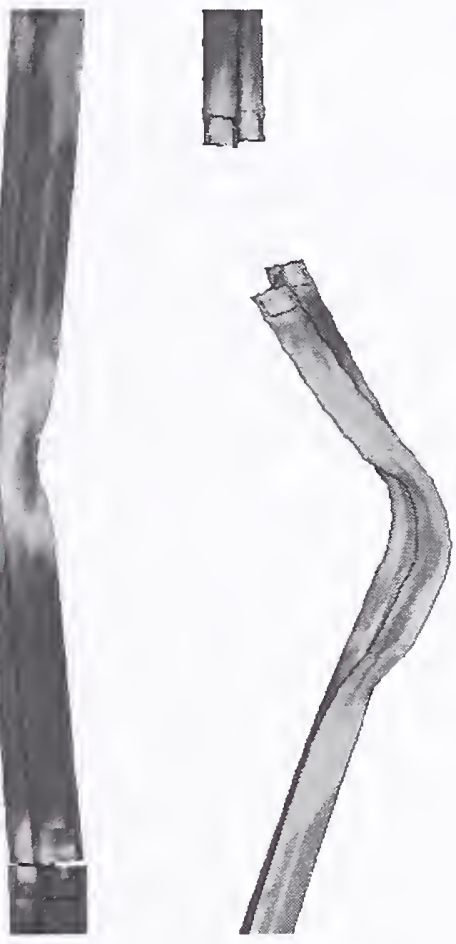

(c) Heavy
Fringe Levels

$1.000 \mathrm{e}-01$

$9.000 \mathrm{e}-02$

$8.000 \mathrm{e}-02$

$7.000 \mathrm{e}-02$

$6.000 \mathrm{e}-02$

$5.000 \mathrm{e}-02$

$4.000 \mathrm{e}^{-02}$

$3.000 \mathrm{e}-02$

$2.000 \mathrm{e}-02$

$1.000 \mathrm{e}-02$

$0.000 e+00$

Figure 7-7. Classification of damage levels in core columns. 


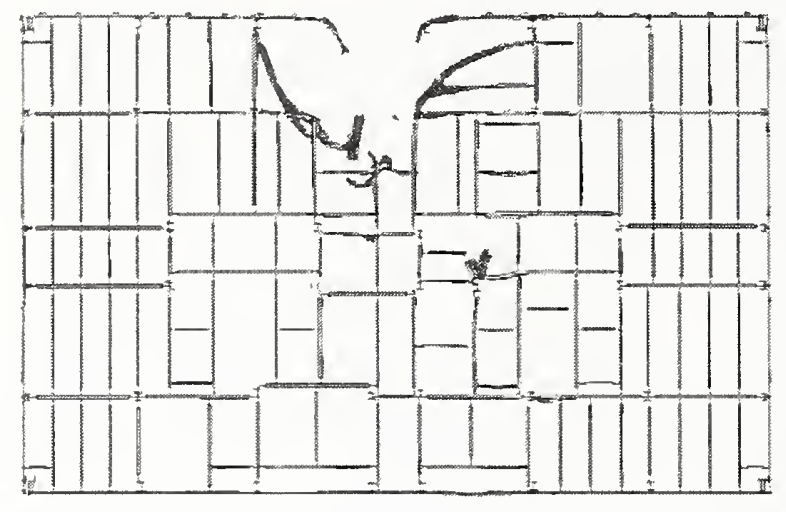

(a) Floor 95 Core Framing Damage

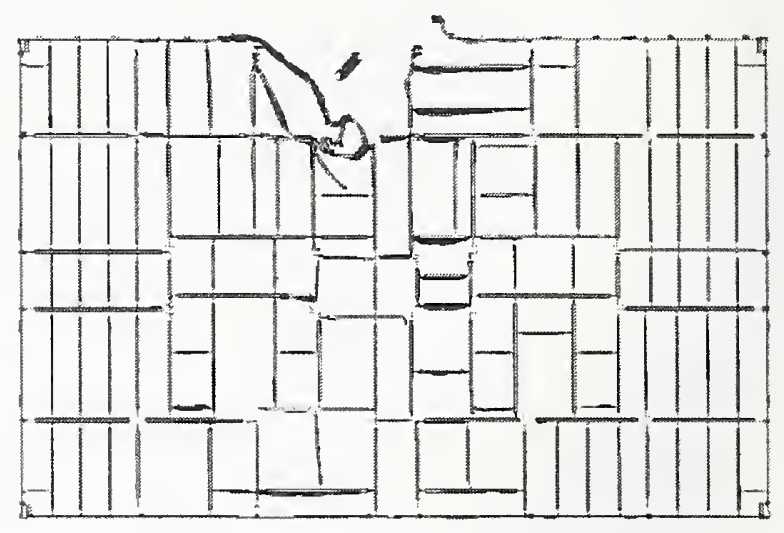

(b) Floor 96 Core Framing Damage

Figure 7-8. Base case impact damage to the core beams of floors 95 and 96 of WTC 1.

\section{Floor Truss and Slab Damage}

An overall frontal view of the floor trusses in the impact zone along with the calculated impact damage to the floor trusses is shown in Figure 7-9. The figure shows that the trusses experienced significant damage and sagging in the impact zone. A plan view of the calculated damage to the trusses on floors 95 and 96 is shown in Figure 7-10. The calculated impact response produced severe damage to the truss structures in the primary impact path of the fuselage from the exterior wall to the core. The truss floor system on floors 94 through 96 were damaged and sagged downward as a result of the impact loading.

The calculated damage to the WTC 1 floor slab for floors 95 and 96 are shown in Figure 7-11. The fringes of damage were set such that the concrete slab failed in the regions colored red ( 2 percent plastic strain was used, corresponding to the zero strength strain limit for the concrete in unconfined compression). At these strain levels, the concrete slab was severely damaged and probably removed, exposing the supporting metal decking. Beyond 2 percent plastic strain, the strength of the floor slab was severely reduced in the analyses to model the residual strength of the metal deck after the concrete failure, breakup, and removal. At a plastic strain of 30 percent, corresponding to failure levels for the metal decking material, the elements were eroded (seen as holes ruptured in the floor slabs shown). 


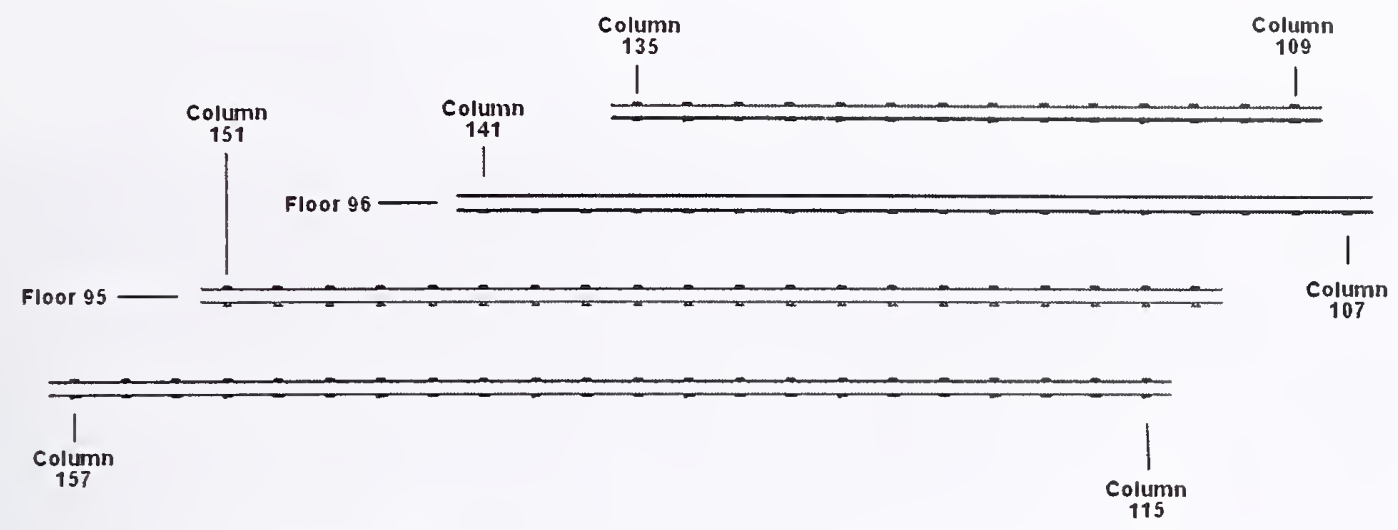

(a) Initial detailed truss structures

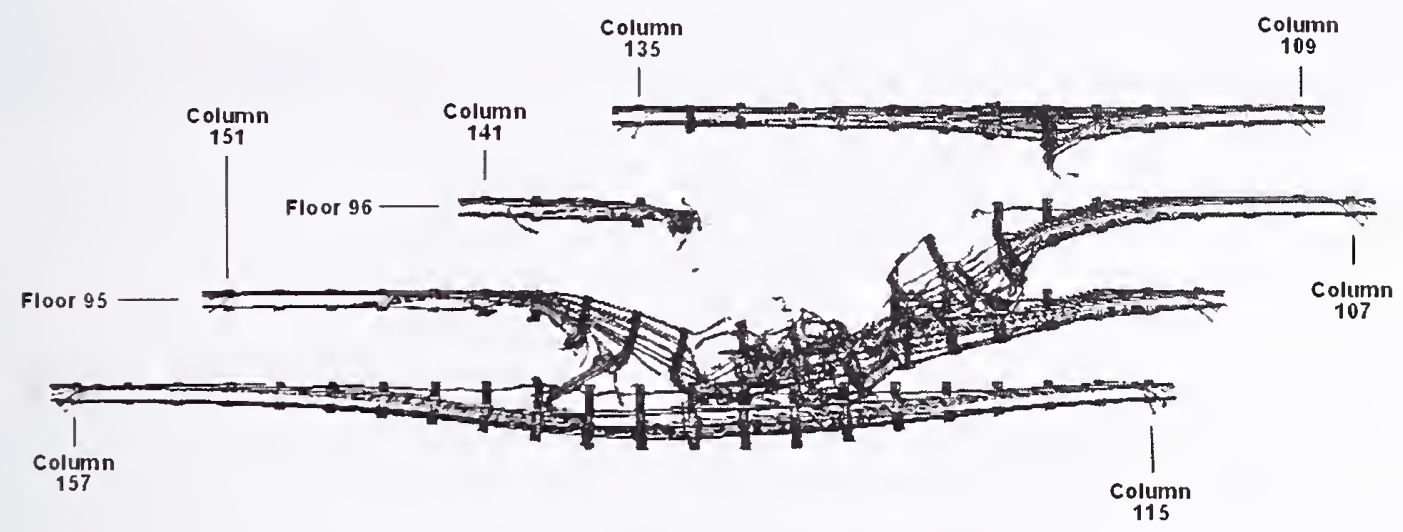

(b) Calculated damage

Figure 7-9. Base case impact damage to the WTC 1 floor trusses (front view). 


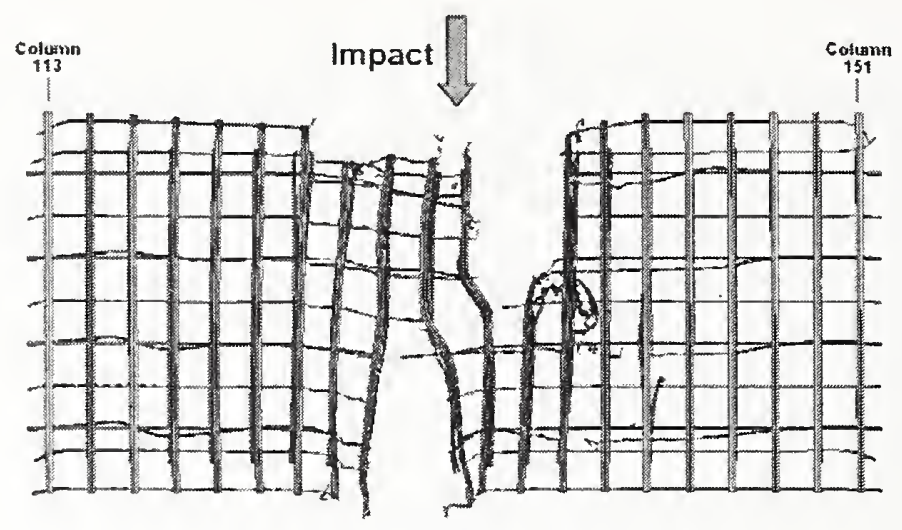

(a) Floor 95 truss damage

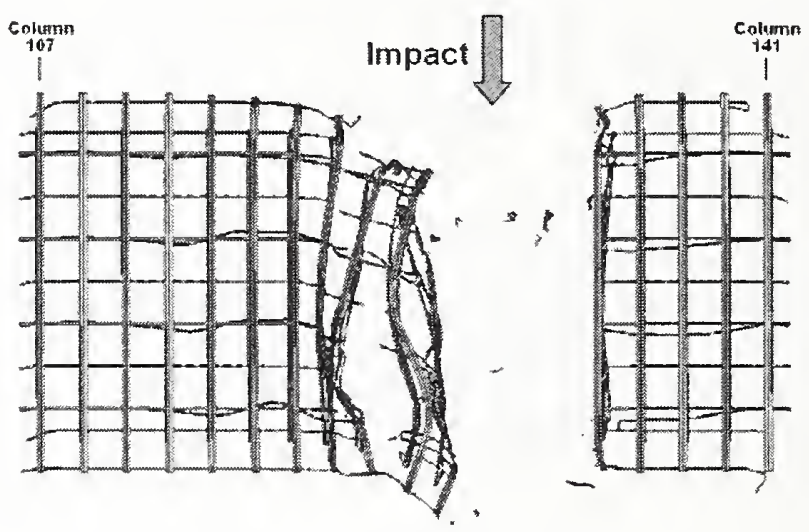

(b) Floor 96 truss damage

Figure 7-10. Base case impact damage to the trusses on floors 95 and 96 of WTC 1 (plan view). 


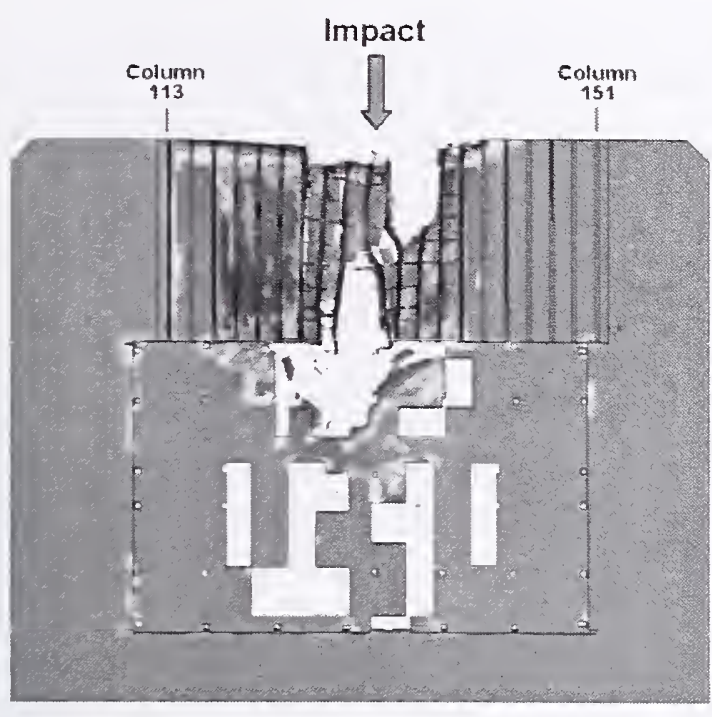

(a) Floor 95 slab damage

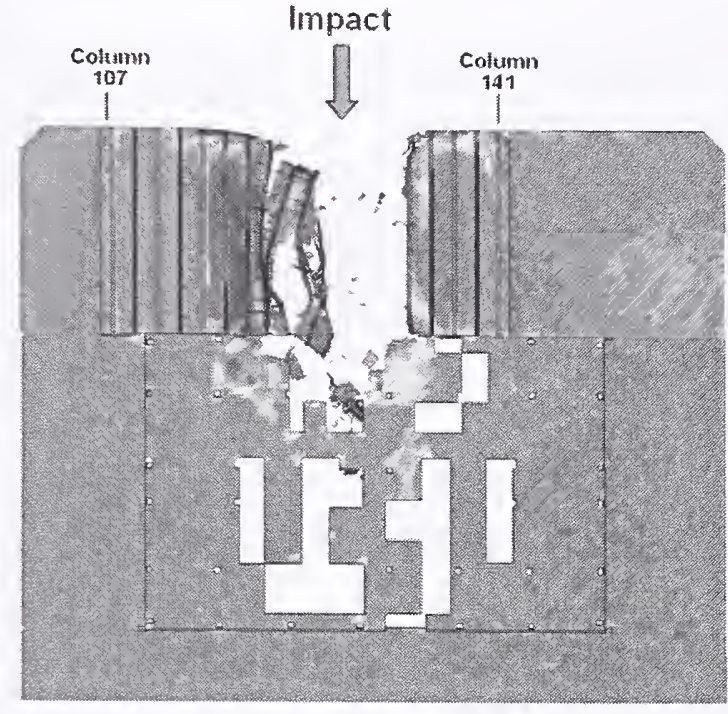

(b) Floor 96 slab damage

\section{Figure 7-11. Base Case impact damage to the slabs on floors 95 and 96 of WTC 1} (plan view).

\section{Summary of Structural Damage}

The impact-induced structural damage described above was used as the initial conditions for the postimpact fire-structural analyses. Figure 7-12 shows a summary of the structural damage to the core columns and floor systems at floors 93 through 97 of WTC 1 for the base case (Case A). The damage to the columns at the various levels is identified by the color of the circles, where red, blue, green, and yellow signify severed, heavily damaged, moderately damaged, and lightly damaged columns, respectively. The dotted boxes on the figures indicate areas where the impact created an opening in the floor. These were used to identify slab openings in the fire dynamics simulations (NIST NCSTAR 1-5F). The solid boxes indicate areas in the floor system that had severe structural damage. These areas were removed from the subsequent structural analyses (NIST NCSTAR 1-6).

Figure 7-13 presents the cumulative damage to WTC 1 on all affected floors and columns. The figure shows the damage to the exterior walls due to impact based on the photographs of the north wall. Note the panel that was severed in the south wall of the tower. While the analysis did not capture the failure of the connections at the ends of this panel due to the coarse mesh of the south wall, photographic evidence showed that this panel was knocked down by the impact (see Section 7.10.1). As a result, this panel was removed from the subsequent structural analyses (NIST NCSTAR 1-6). 


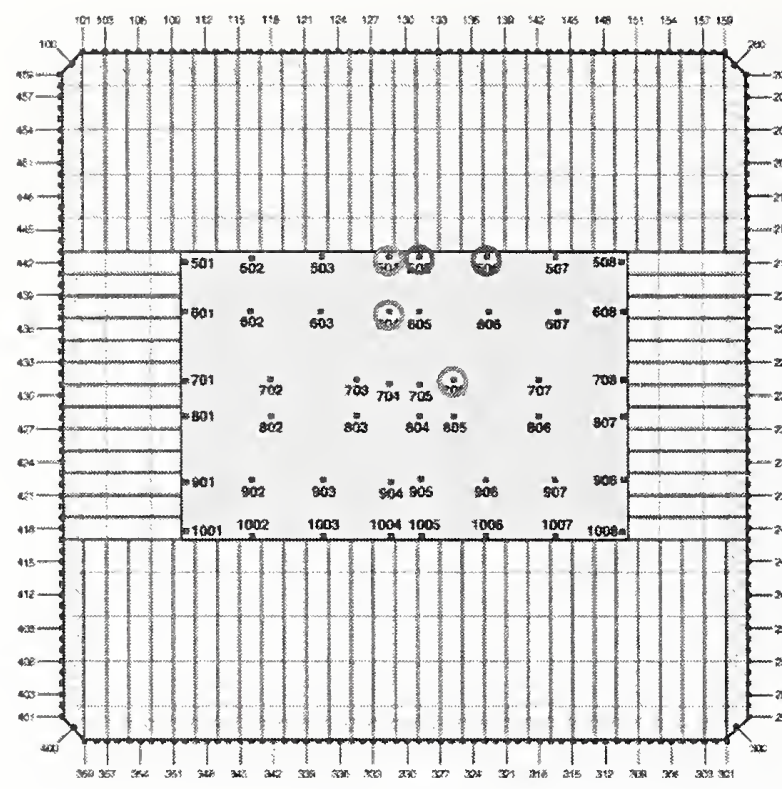

(a) Floor 93

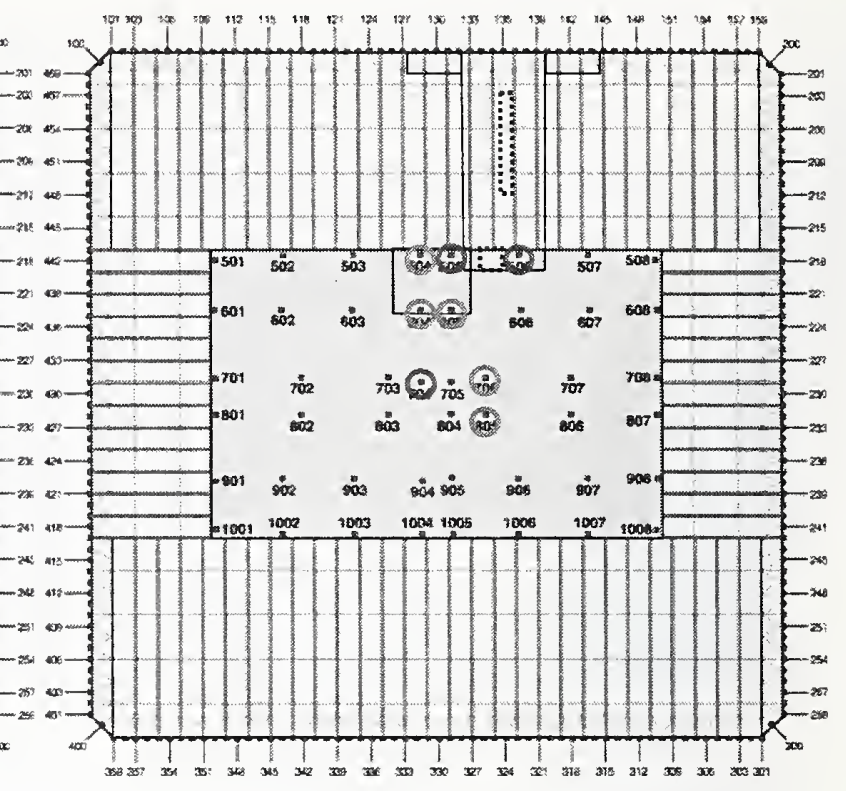

(b) Floor 94

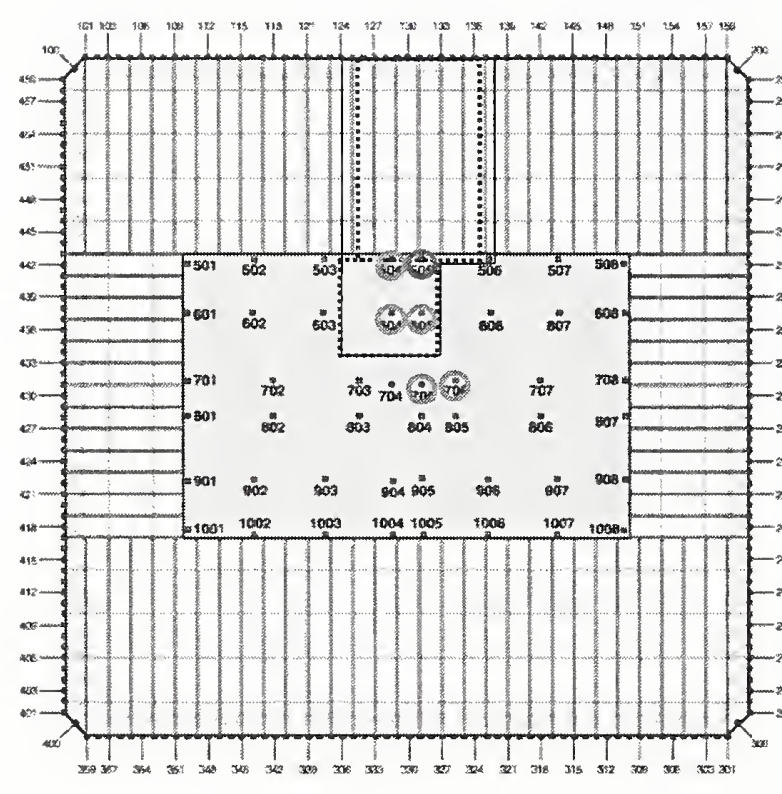

(c) Floor 95

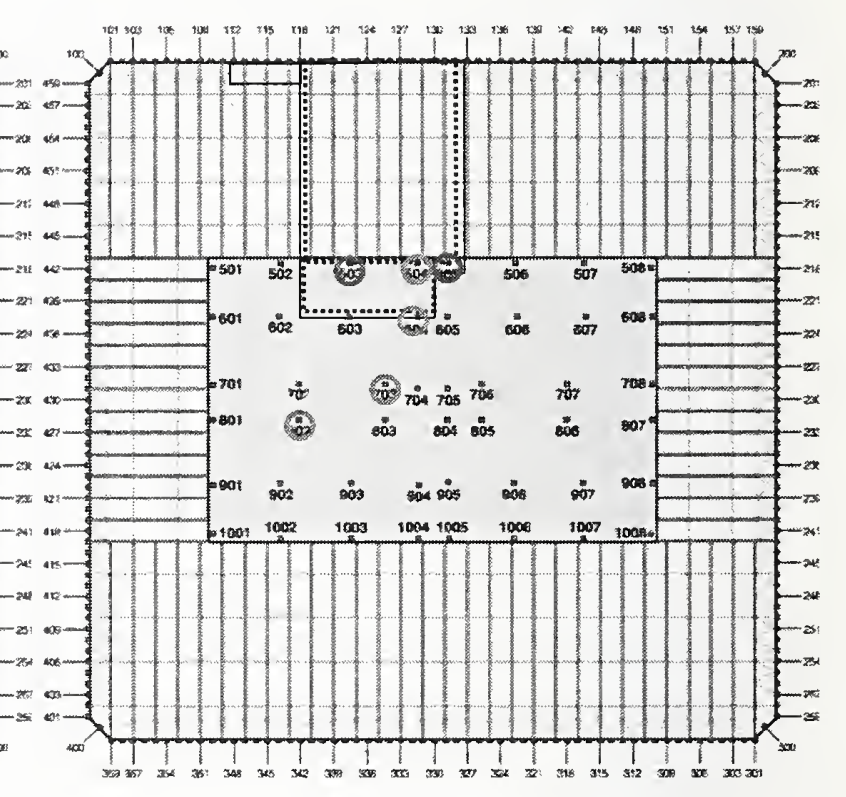

(d) Floor 96

Figure 7-12. Summary of the floor-by-floor structural damage to the floors and columns of WTC 1 (base case). 


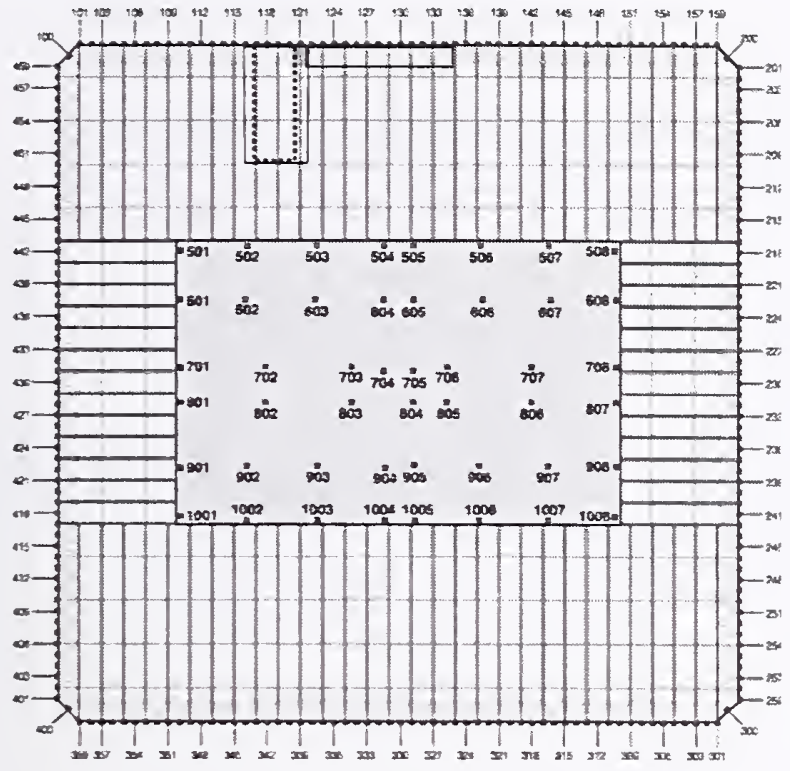

\section{Severe Floor Damage \\ Floor system structural damage $\square$ \\ Floor system removed}

\section{Column Damage}

Severed

Heavy Damage

Moderate Damage

Light Damage

(e) Floor 97

Figure 7-12. Summary of the floor-by-floor structural damage to the floors and columns of WTC 1 (base case) (continued).

\section{Severe Floor Damage}

Floor system structural damage

Floor system removed

\section{Column Damage}

Severed

Heavy Damage

Moderate Damage

Light Damage

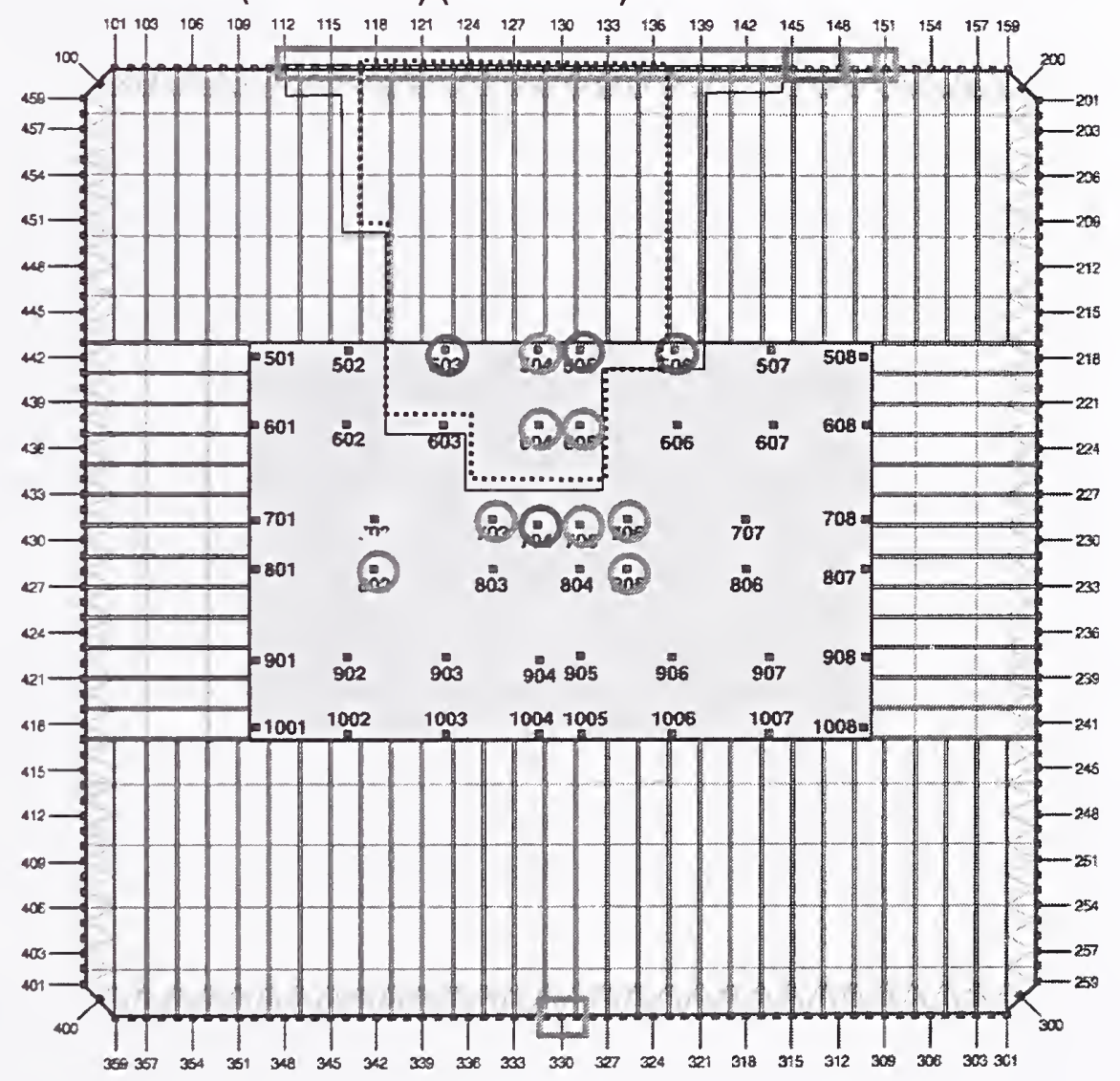

Figure 7-13. Cumulative structural damage to the floors and columns of WTC 1

(base case). 


\subsubsection{Fuel and Debris Distributions}

The global impact results presented in this section include the distribution of the jet fuel inside the tower, the damage to the building contents (partition walls and workstations), and the aircraft debris distribution in the towers. For the base case WTC 1 global impact analysis, the calculated distribution of the fuel in the tower in a plan view and side view is shown in Figure 7-14. At the termination of the global impact analysis, the residual momentum of the jet fuel in the impact direction was less than one percent of the initial momentum, indicating that the fuel cloud was nearly at rest at about $0.715 \mathrm{~s}$.

To more clearly present the calculated response of the structures that influenced the fire propagation, the structural components were removed from the visualization, with the exception that the core columns were maintained in the visualizations for reference positions. A plan view of the response of the remaining building contents and aircraft debris is shown in Figure 7-15. Similar plan views of floors 95 and 96 response of the building contents and debris field are provided in Figure 7-16 and Figure 7-17, respectively. The bulk of the aircraft debris and fuel were arrested prior to exiting the far side of the tower core. A small amount of aircraft debris was calculated to exit the south wall of the tower.

Plots of debris distribution and damage to tower contents at the end of the impact simulation similar to those in Figure 7-16(c) and Figure 7-17(c) were used to estimate the damage to fireproofing. The extent of disiodged fireproofing was estimated by considering fireproofing damage only to structural components in the direct path of debris. For details of the methodology and the extent of fireproofing damage, see NIST NCSTAR 1-6.

A quantitative characterization of the fuel and aircraft debris distribution was obtained by slicing the model at vertical floor locations and calculating the mass at each floor level. A summary of the floor-byfloor fuel and debris distributions is given in Table 7-2. The bulk of the fuel and aircraft debris was deposited in floors 93 through 97, with the greatest concentration on floor 94 . Approximately $18,000 \mathrm{lb}$, or 7 percent, of aircraft mass was eliminated from the debris cloud at the final state as a result of the erosion in the aircraft structures due to impact and breakup. This mass was not accounted for in the fuel and debris distributions provided in Table 7-2. A first approximation would be to increase the airframe debris distribution proportionately to account for the eroded mass. This eroded mass was maintained in the calculation but was no longer included in the contact algorithm. As a result, any residual momentum at the time of erosion could not be subsequently transferred to the tower.

The calculated debris cloud included 17,400 lbs of debris and 6,700 lbs of aircraft fuel outside of the tower at the end of the impact analysis, either rebounding from the impact face (north wall) or passing through the tower (south wall). This amount might have been larger in the calculation, since the exterior walls were not modeled with windows that could contain the fuel cloud and small debris inside the towers. In addition, the impact behavior of the aircraft fuel cloud did not include the ability to stick to, or wet, interior components. Rather, the aircraft fuel SPH particles tended to bounce off of internal structures.

The physics of fuel impact and dispersion in this type of impact event is complex and no appropriate validation data could be found. The fuel starts as a continuous fluid within the tanks and ends up distributed both on the tower structures and as small droplets that interact with the atmosphere surrounding the impact zone. No single analysis technique is currently available that can analyze this full range of fuel dispersion without significant uncertainties. 
Both the SPH and ALE analysis techniques (see Section 5.4.4) available for the analysis of the fuel impact and dispersion had limitations. Details of the fuel behavior such as the wetting of the fuel against tower structures and interior contents or the physics of the fuel breakup into droplets are not accurately reproduced in either analysis technique. However, the momentum transfer from the fuel to the tower structures and subsequent impact damage produced by the fuel can be modeled by both analysis techniques.

The detailed predictions of the fuel dispersion and distribution using SPH in the global impact analyses had significant uncertainties in the absence of improved validation testing. However, some aspects of the distribution had a higher confidence. The floors confined the vertical motion of the fuel, and the floor-byfloor distribution of fuel was controlled more by the geometry of the tower and impact conditions. As a result, this distribution by floor has a higher level of confidence. Similarly, the interior contents and partition walls, and the damage to these structures, controlled the spread of fuel. 
Time $=0.715$

$x$

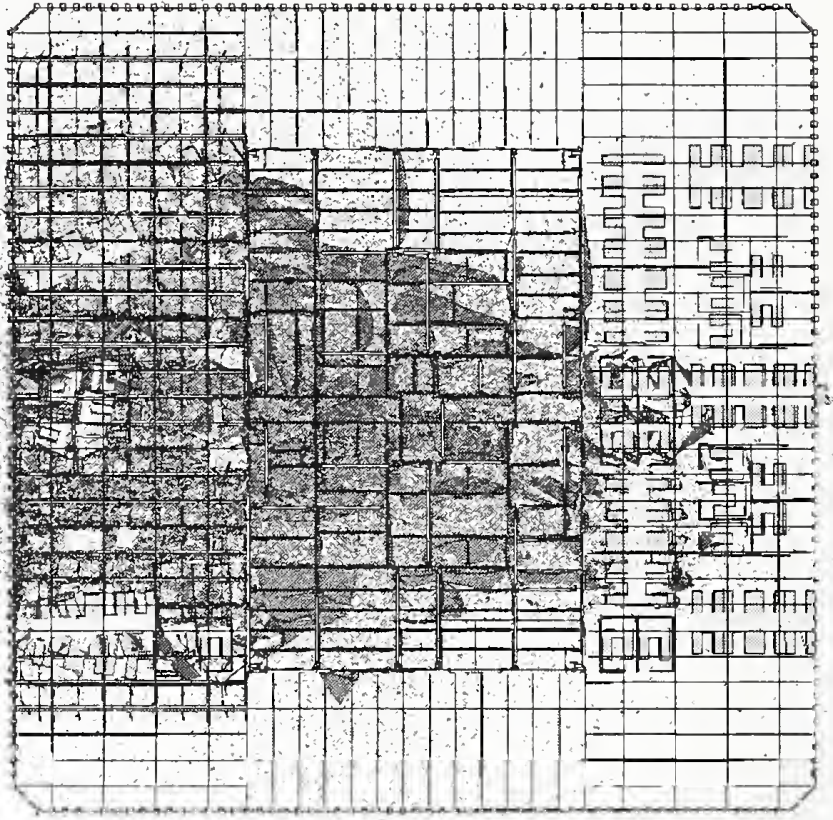

(a) Plan view (floor slab removed)

Time $=.0 .715$

\section{(b) Side view}

Figure 7-14. Calculated fuel distribution in the base case WTC 1 analysis. 


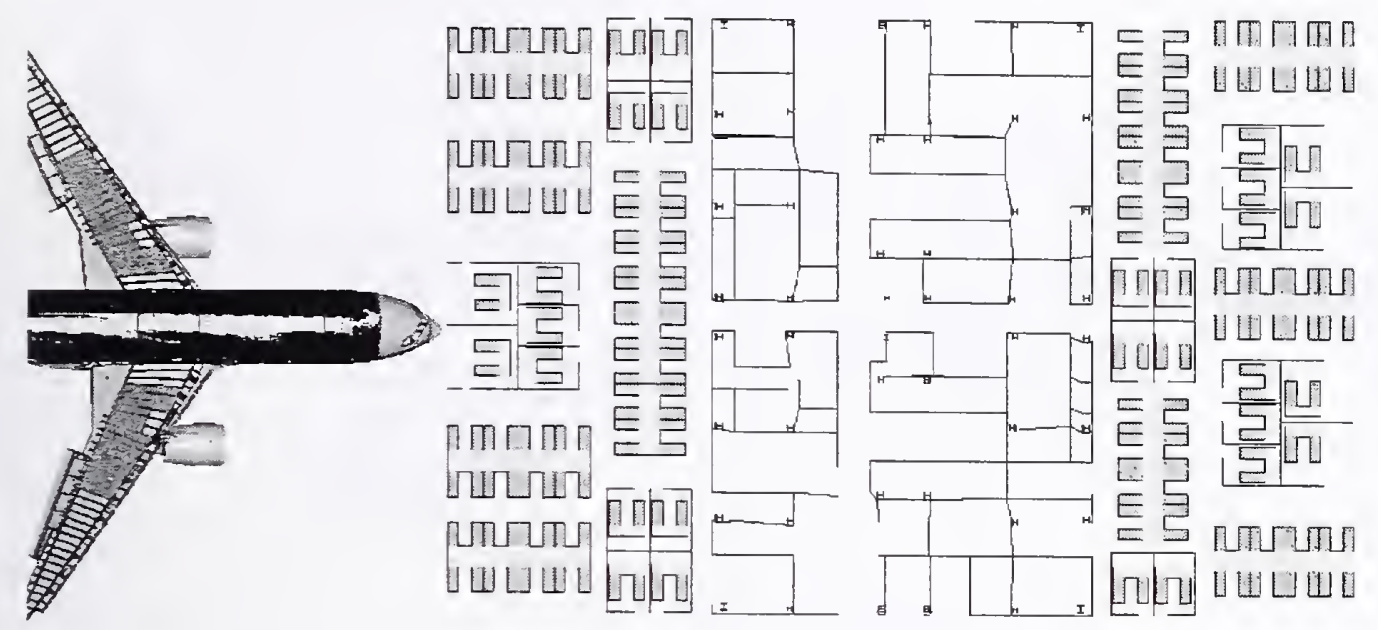

(a) Pre-impact configuration

Time $=-0.715$
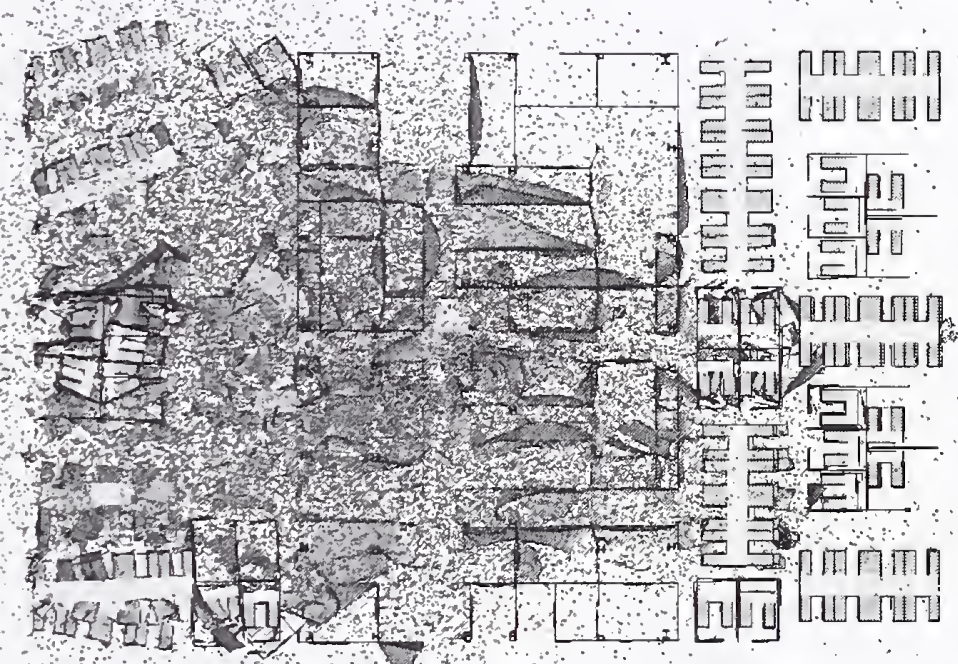

$\times \int^{x}$

(b) Calculated impact response

Figure 7-15. Plan view of calculated WTC 1 building, fuel, and aircraft debris distribution for the base case. 


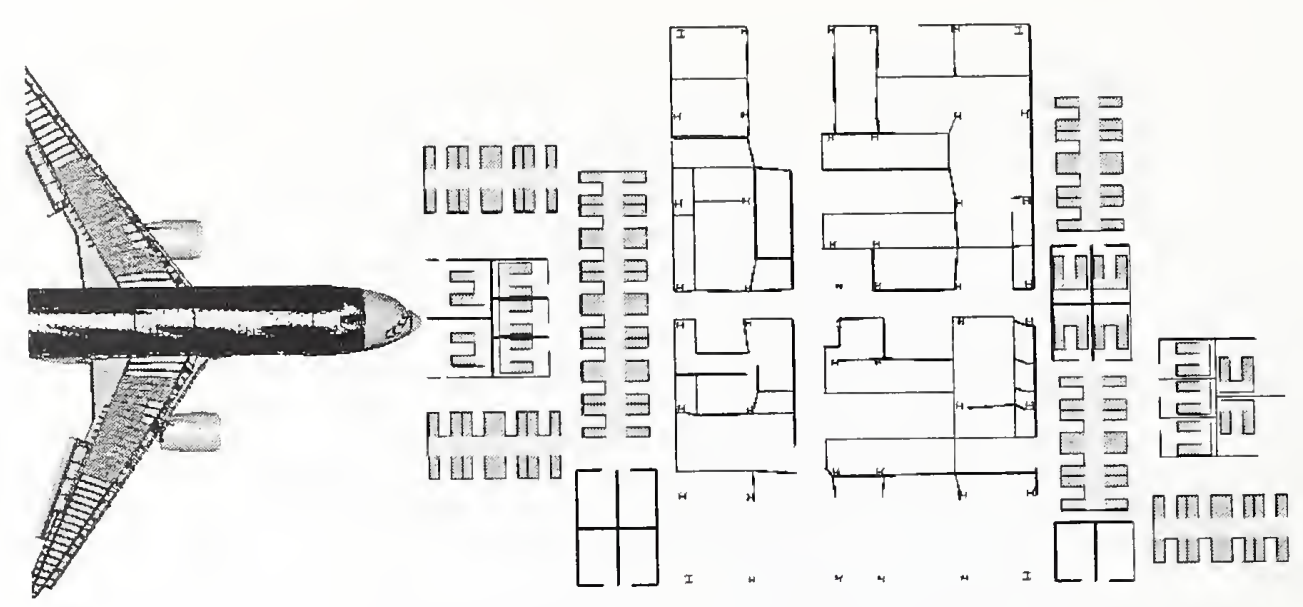

(a) Pre-impact configuration

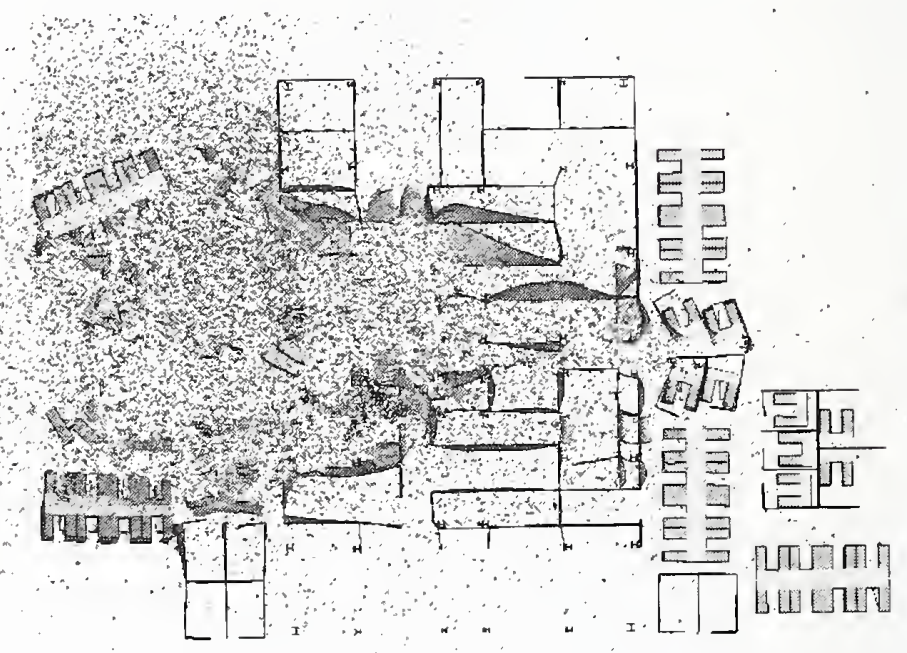

(b) Calculated impact response

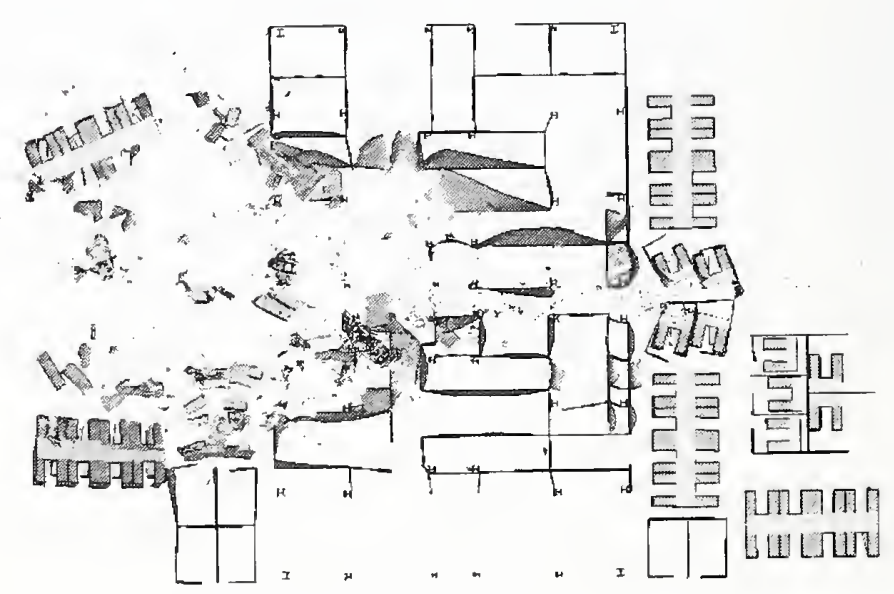

(c) Calculated impact response (fuel removed)

Figure 7-16. Calculated floor 95 contents and fuel distribution (base case). 


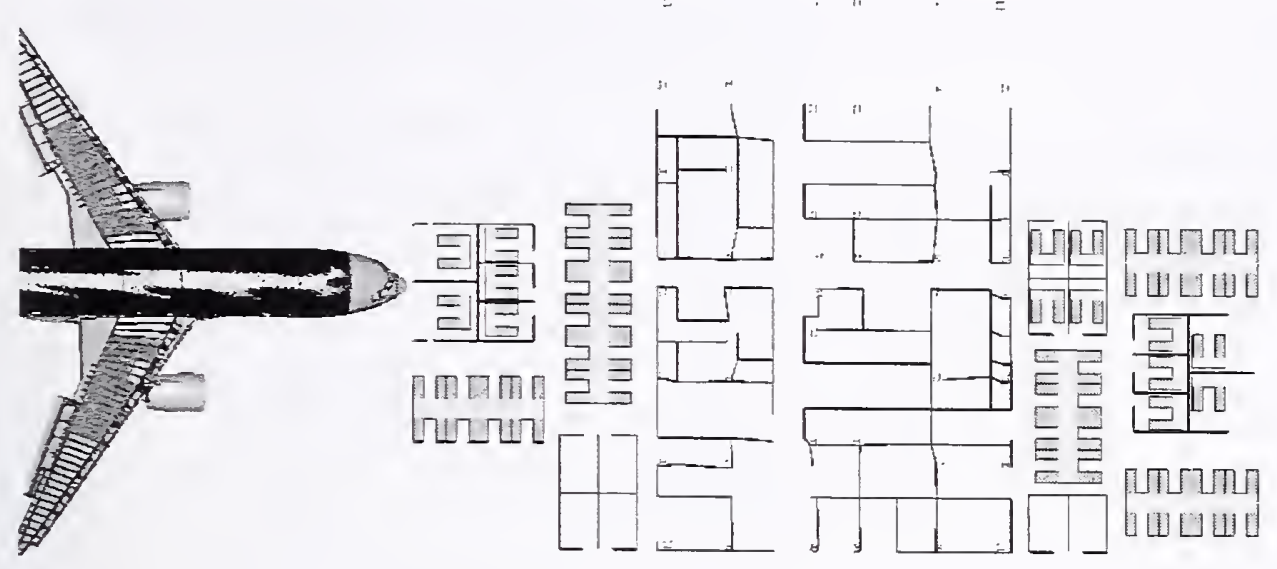

(a) Pre-impact configuration

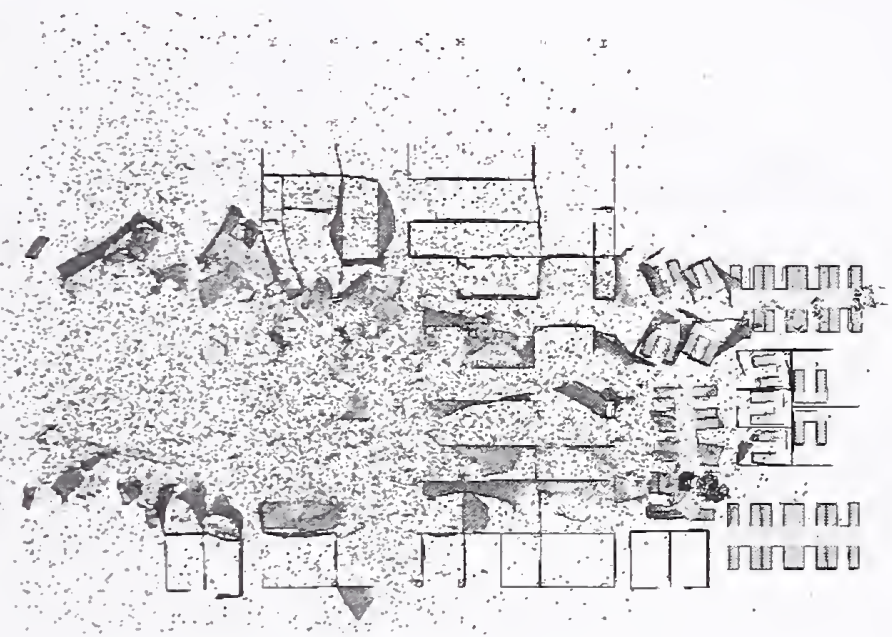

(b) Calculated impact response

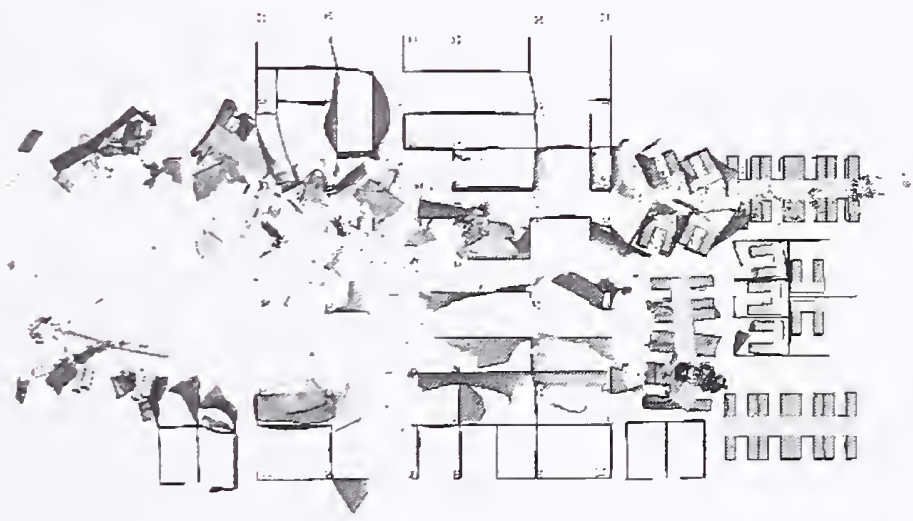

(c) Calculated impact response (fuel removed)

Figure 7-17. Calculated floor 96 contents and fuel distribution (base case). 
Table 7-2. Fuel and aircraft debris distribution for the base case WTC 1 impact.

\begin{tabular}{|l|c|c|}
\hline \multicolumn{1}{|c|}{ Tower Location } & Aircraft Fuel & Aircraft Debris \\
\hline Total Outside Tower & $6,700 \mathrm{lb}$ & $17,400 \mathrm{lb}$ \\
\hline WTC 1 Floor 92 & $810 \mathrm{lb}$ & $260 \mathrm{lb}$ \\
\hline WTC 1 Floor 93 & $6,100 \mathrm{lb}$ & $22,600 \mathrm{lb}$ \\
\hline WTC 1 Floor 94 & $16,100 \mathrm{lb}$ & $96,000 \mathrm{lb}$ \\
\hline WTC 1 Floor 95 & $12,200 \mathrm{lb}$ & $28,000 \mathrm{lb}$ \\
\hline WTC 1 Floor 96 & $11,700 \mathrm{lb}$ & $19,400 \mathrm{lb}$ \\
\hline WTC 1 Floor 97 & $9,500 \mathrm{lb}$ & $6,000 \mathrm{lb}$ \\
\hline WTC 1 Floor 98 & $2,200 \mathrm{lb}$ & $6,000 \mathrm{lb}$ \\
\hline WTC 1 Floor 99 & $770 \mathrm{lb}$ & $90 \mathrm{lb}$ \\
\hline Total Weight & $66,100 \mathrm{lb}$ & $196,000 \mathrm{lb}$ \\
\hline
\end{tabular}

\subsection{WTC 1 MORE SEVERE IMPACT ANALYSIS - CASE B}

This case is referred to as Case B for the remainder of the WTC Investigation reports.

In addition to the base case impact analysis described in Section 7:3, two more impact analyses were performed for each tower to provide a range of calculated impact-induced damage. The variations in impact analysis parameters were developed based on the results of the sensitivity analyses and additional evaluations of the parameter uncertainties (see Chapter 8 of NIST NCSTAR 1-2B). These analyses included a more severe and a less severe case. Presented in this section is the more severe case.

The parameters for the more severe WTC 1 impact scenario are compared to the corresponding parameters in the base case analysis in Table 7-3. For the flight parameters, the impact speed was $472 \mathrm{mph}$ in the more severe impact scenarios, which was the upper bound obtained from the analysis of aircraft impact conditions described in Chapter 6 . The aircraft vertical trajectory angle was varied from 10.6 degrees in the base case to 7.6 degrees for the more severe impact case, which resulted in more impact energy directed inward toward the core. The lateral trajectory was not varied since the impact was close to being centered on the tower and normal to the north face of WTC 1. A small variation in the lateral approach angle would have had little effect on the energy of the aircraft debris entering the tower and core.

The parameters varied for the aircraft model were the weight of the aircraft and the ductility of the aircraft materials. A 5 percent increase in the total aircraft weight was considered for the more severe case. The failure strain was varied to be 125 percent of the baseline value. This relatively large variation in aircraft material ductility was used for multiple reasons. First, no material characterization testing of specimens cut from a 767 were performed as part of this Investigation. All of the material properties used for the aircraft was obtained from sources available in the open literature. Secondly, the variation in ductility was used as the single parameter in this analysis to evaluate the uncertainties in the energy absorption capacity of aircraft materials. An increase in aircraft material strength would have had a similar effect to an increase in material ductility for producing increased impact damage to the towers. Finally, the 
material failure parameters were influenced by the resolution of the models in the impact analysis. The mesh refinement effects introduced an increased uncertainty on the failure strains in these analyses.

Table 7-3. Input parameters for the more and less severe WTC 1 impact analysis.

\begin{tabular}{|c|l|c|c|c|}
\hline \multicolumn{2}{|c|}{ Analysis Parameters } & Base Case & More Severe & Less Severe \\
\hline \multirow{4}{*}{$\begin{array}{c}\text { Flight } \\
\text { Parameters }\end{array}$} & Impact speed & $443 \mathrm{mph}$ & $472 \mathrm{mph}$ & $414 \mathrm{mph}$ \\
\cline { 2 - 5 } & Trajectory - pitch & $10.6^{\circ}$ & $7.6^{\circ}$ & $13.6^{\circ}$ \\
\cline { 2 - 5 } & Trajectory - yaw & $0.0^{\circ}$ & $0.0^{\circ}$ & $0.0^{\circ}$ \\
\cline { 2 - 5 } & Orientation - pitch & $8.6^{\circ}$ & $5.6^{\circ}$ & $11.6^{\circ}$ \\
\cline { 2 - 5 } & Orientation - yaw & $0.0^{\circ}$ & $0.0^{\circ}$ & $0.0^{\circ}$ \\
\hline \multirow{2}{*}{$\begin{array}{c}\text { Aircraft } \\
\text { Parameters }\end{array}$} & Weight & 100 percent & 105 percent & 95 percent \\
\cline { 2 - 5 } & Failure Strain & 100 percent & 125 percent & 75 percent \\
\hline \multirow{2}{*}{$\begin{array}{c}\text { Tower } \\
\text { Parameters }\end{array}$} & Failure Strain & 100 percent & 80 percent & 120 percent \\
\cline { 2 - 5 } & Live Load Weight & 25 percent & 20 percent & 25 percent \\
\hline
\end{tabular}

Finally, the parameters varied for the tower model were the ductility of the steel used in the tower construction and the weight of the contents inside the tower. A variation of 20 percent was used to account for the uncertainty in failure strain for the tower materials. The combination of increasing the aircraft material ductilities by 25 percent and reducing the tower material ductilites by 20 percent covered a wide range in relative aircraft and tower strength assumptions. The variations in internal tower contents (live load weight in Table 7-3) are specified as a percentage of the design live load.

Table 7-3 provides also the parameters used in the less severe damage case. As can be secn from the table, the parameters are selected to provide for a stronger tower and a weaker aircraft to yield less damage to the tower structure.

\subsubsection{Impact Response}

The impact response of WTC 1 for the more severe case is shown in side and plan views in Figure 7-18 and Figure $7-19$, respectively. The response is shown at intervals of $0.1 \mathrm{~s}$ from impact through the initial $0.5 \mathrm{~s}$ of the response. Comparing the more severe impact response in Figure 7-18 and Figure 7-19 with the base case response in Figure 7-2 and Figure 7-3, it can be seen that the two responses were very similar with two exceptions. These were the slightly compressed time scale and the larger amount of debris exiting the south wall in the more severe case. These differences were due to the larger impact speed, the increased weight and material toughness of the aircraft, and the reduced contents mass and material toughness of the towers for the more severe case. 


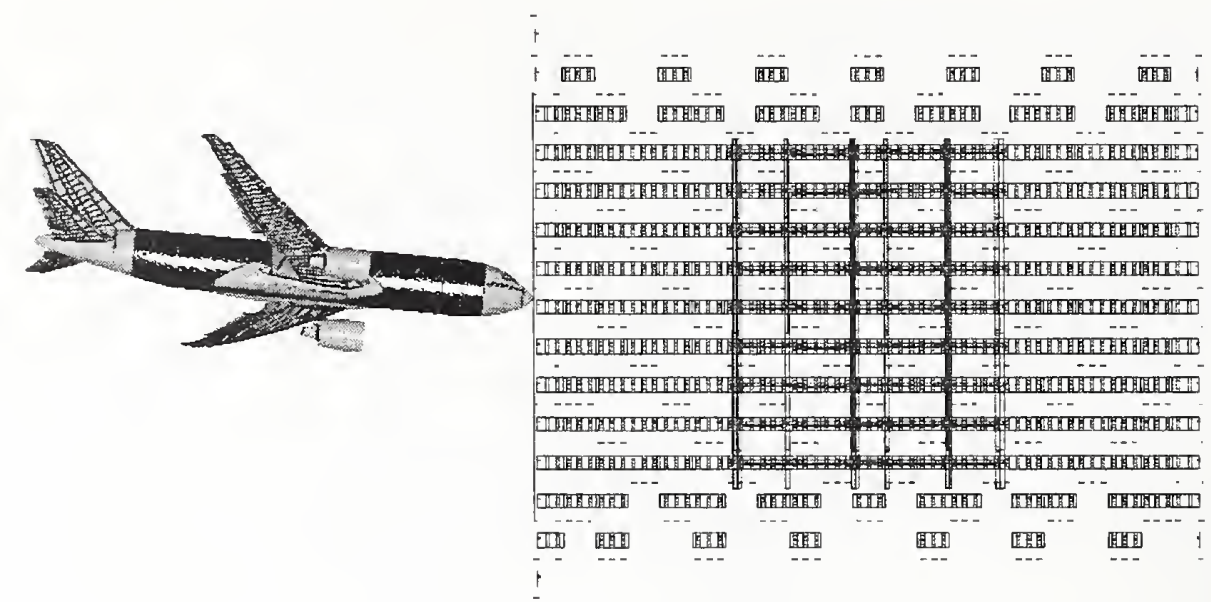

(a) Time $=0.00 \mathrm{~s}$

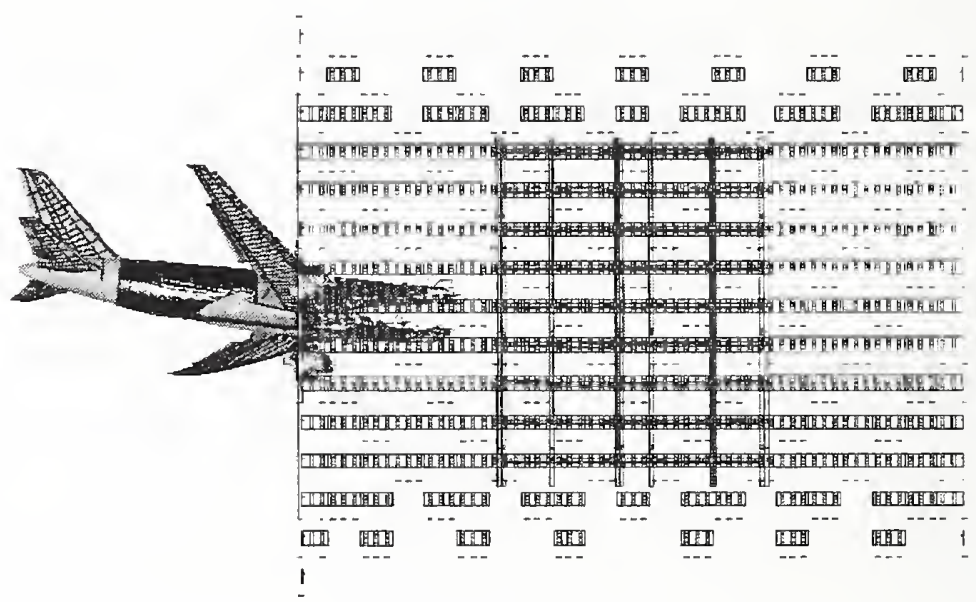

\section{(b) Time $=0.10 \mathrm{~s}$}

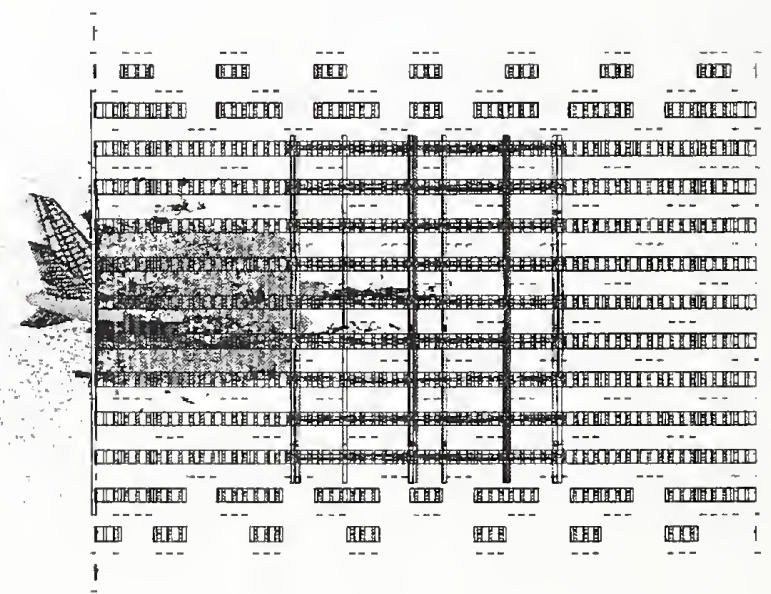

(c) Time $=0.20 \mathrm{~s}$

Figure 7-18. WTC 1 more severe global impact analysis (side view). 


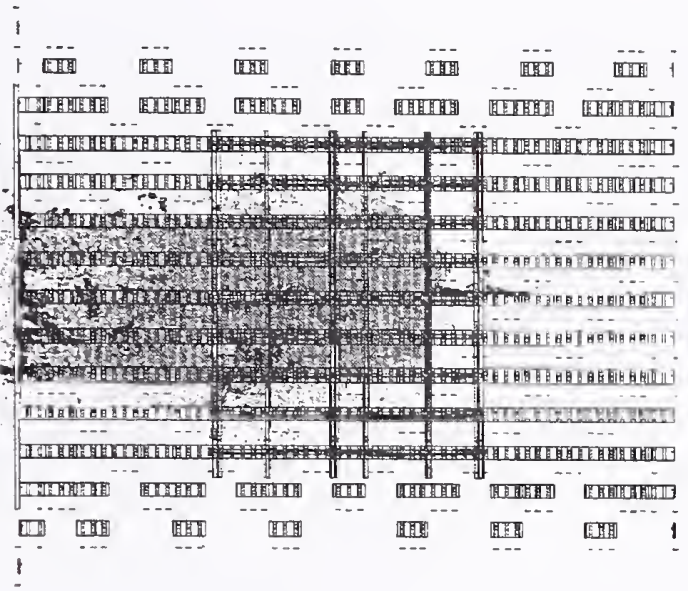

(d) Time $=0.30 \mathrm{~s}$

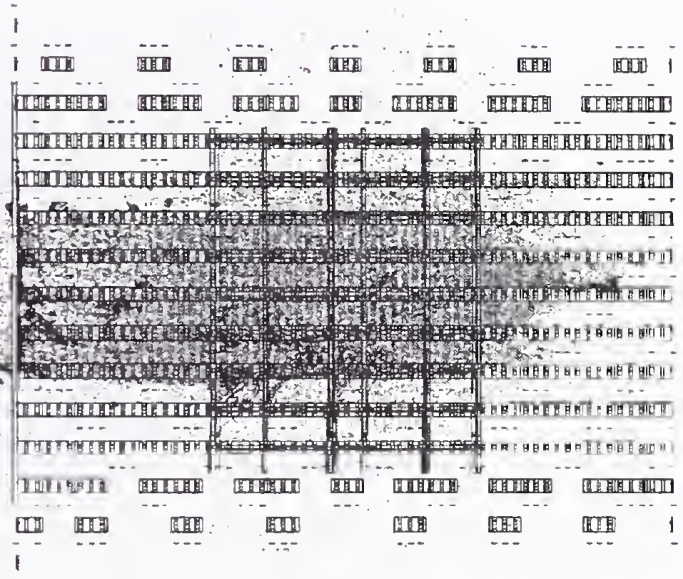

(e) Time $=0.40 \mathrm{~s}$

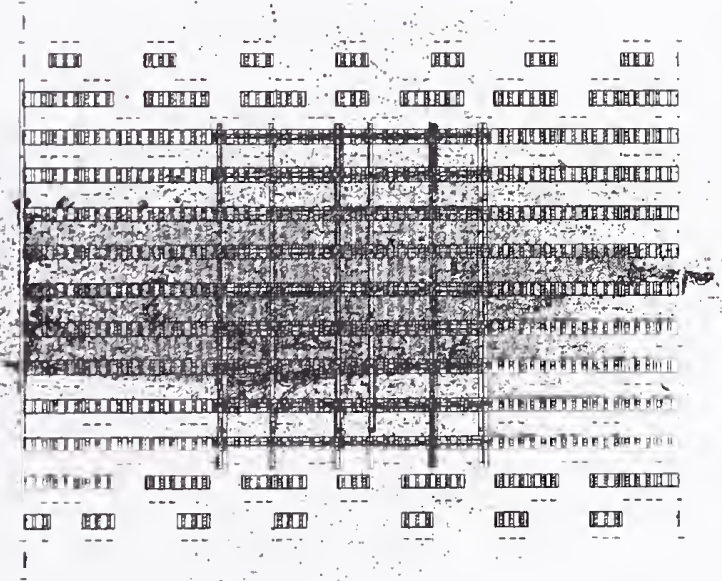

(f) Time $=0.50 \mathrm{~s}$

Figure 7-18. WTC 1 more severe global impact analysis (side view) (continued). 


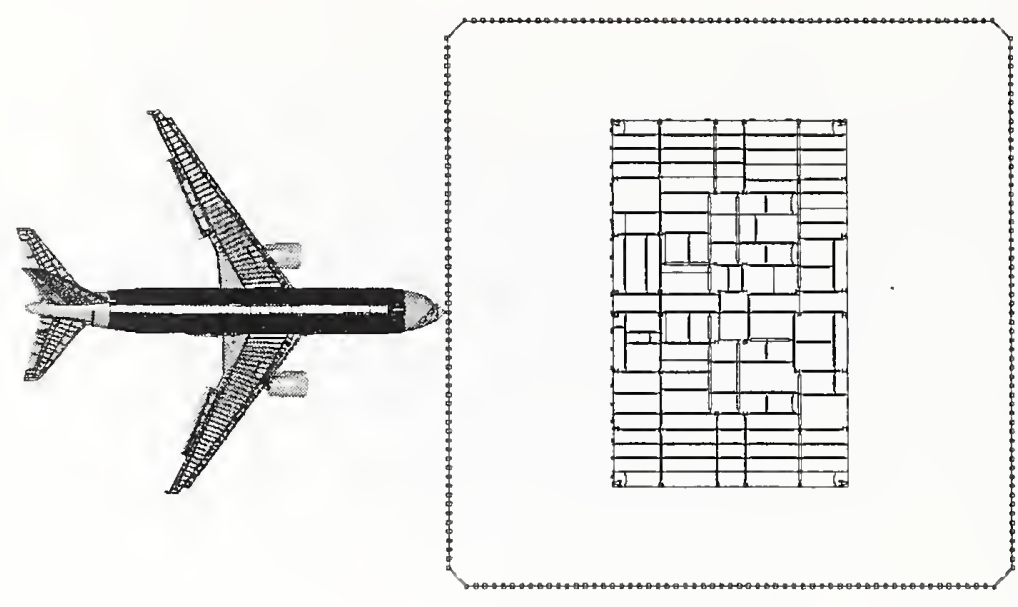

(a) Time $=0.00 \mathrm{~s}$

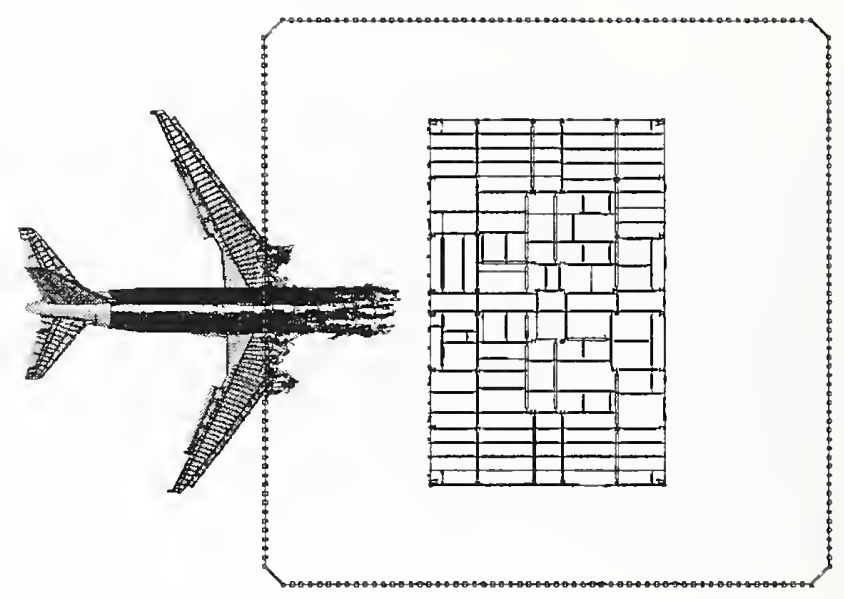

(b) Time $=0.10 \mathrm{~s}$

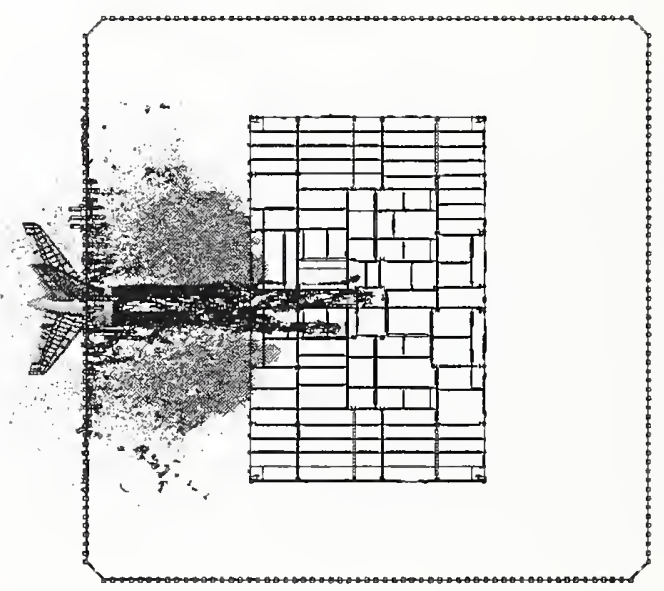

(c) Time $=0.20 \mathrm{~s}$

Figure 7-19. WTC 1 more severe global impact analysis (plan view). 


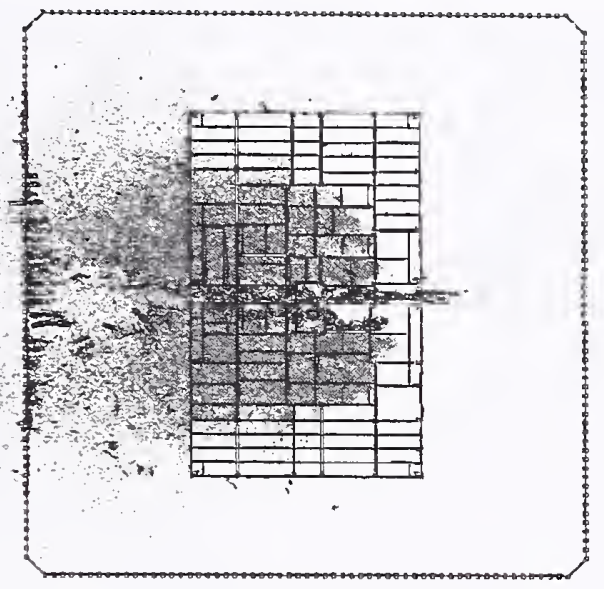

(d) Time $=0.30 \mathrm{~s}$

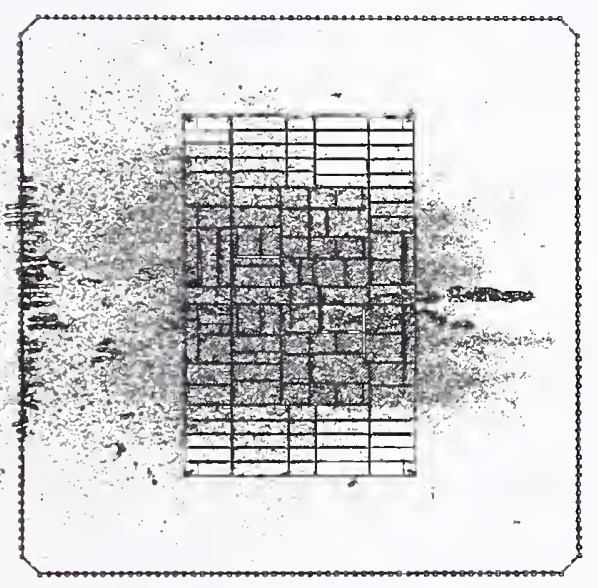

(e) Time $=0.40 \mathrm{~s}$

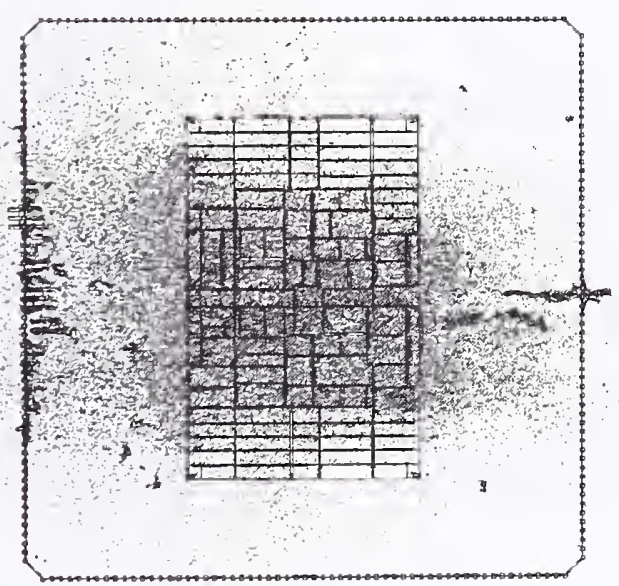

(f) Time $=0.50 \mathrm{~s}$

Figure 7-19. WTC 1 more severe global impact analysis (plan view) (continued). 


\subsubsection{Tower Structural Damage}

\section{Exterior Wall Damage}

A comparison of the north exterior wall observed and calculated damage from the more severe WTC 1 global impact analysis is shown in Figure 7-20. The calculated and observed magnitude and mode of impact damage on the exterior wall were still in good agreement for the more severe impact analysis.

Comparing Figure 7-5 and Figure 7-20, it can be concluded that the overall agreement with the observed damage to the north wall was good for the base case and the more severe case, with the base case analysis providing the better match to the observed damage. The differences in apparent damage were largely due to panels that may have sevcred columns in one case and were removed at the connections in another. Toward the wing tips, where the columns and spandrels were not completely severed, the more severe impact damage analysis calculated higher damage to the exterior wall panels. These columns had the largest amount of material with plastic strains above 5 percent (shown in red in the figure). As would be expected, the base case analysis calculated less damage to the exterior wall than the more severe case near the wing tips. 


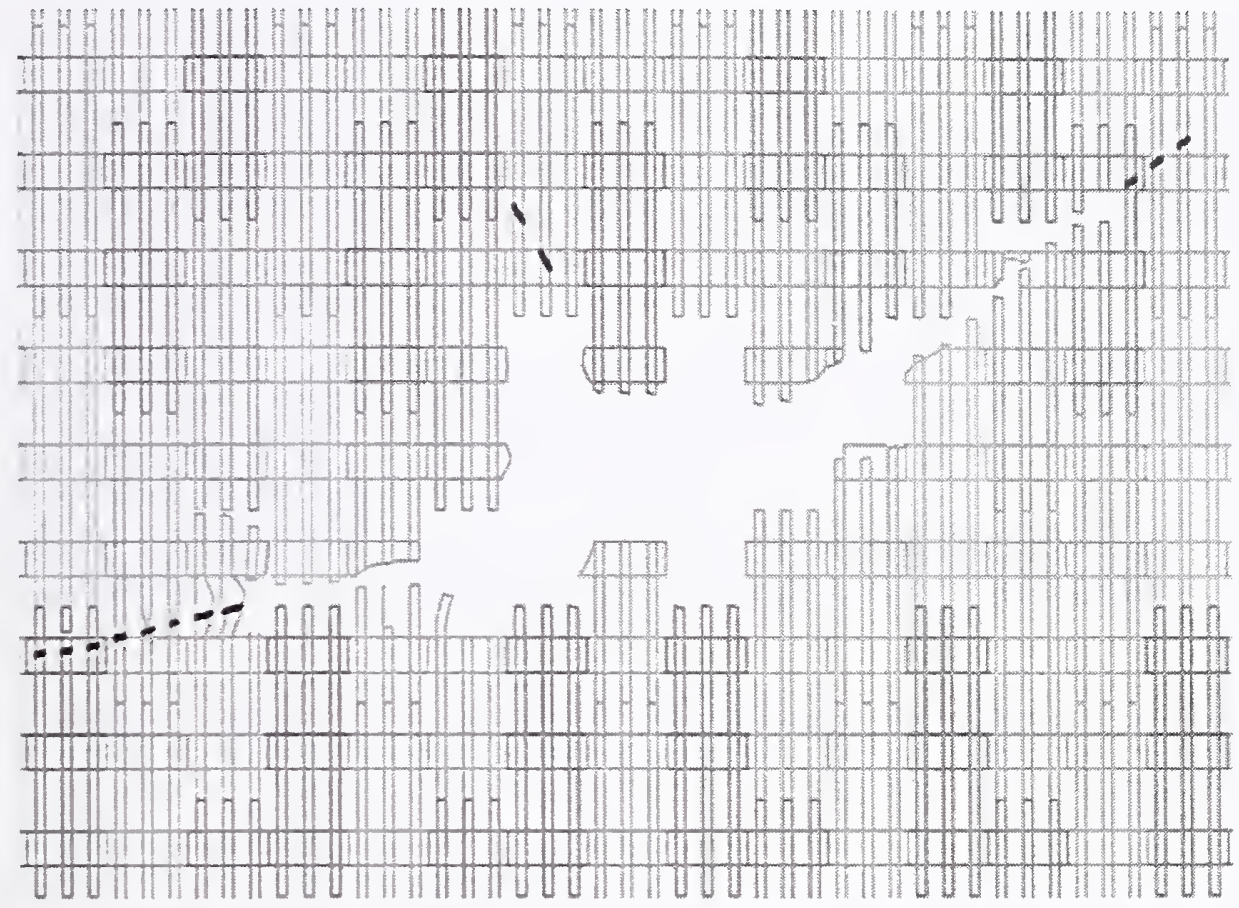

(a) Schematic of observed damage

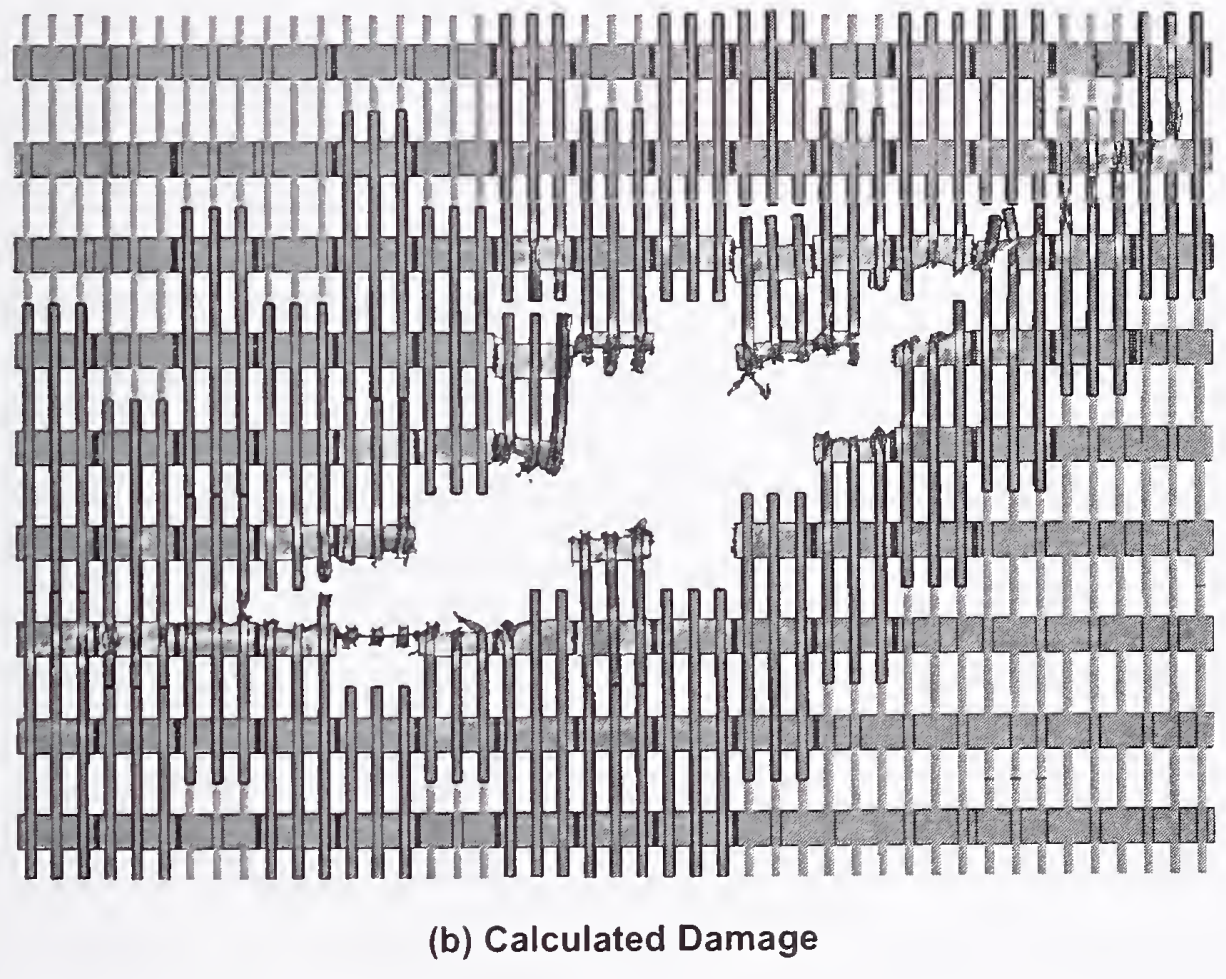

Figure 7-20. More severe impact damage to the WTC 1 exterior wall. 


\section{Core Structural Damage}

The core had extensive damage in the region close to the impact point. The columns in line with the aircraft fuselage failed on the impact side, and several of the core beams were also severely damaged or failed in the impact zone. In some cases, failure of the column splices located on floors 92, 95, and 98 contributed significantly to the failure of the core columns.

The calculated damage to the core columns by row is shown in Figure 7-21, and the damage to the core framing for floors 95 and 96 is shown in Figure 7-22. A summary of the core column damage is provided in Table 7-4, with the qualitative classification of the column damage levels provided previously in Figure 7-7. A total of six columns were severed, and three columns were heavily damaged in the more severe case, compared to three columns severed and four columns heavily damaged in the base case WTC 1 impact analysis. This shows a clear correlation between damage magnitude and impact severity.

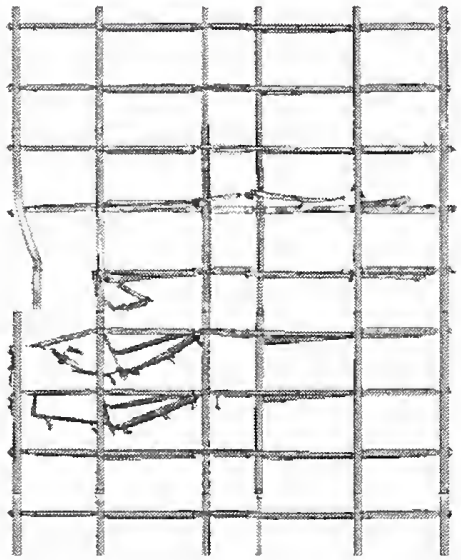

(a) Columns 503-1003

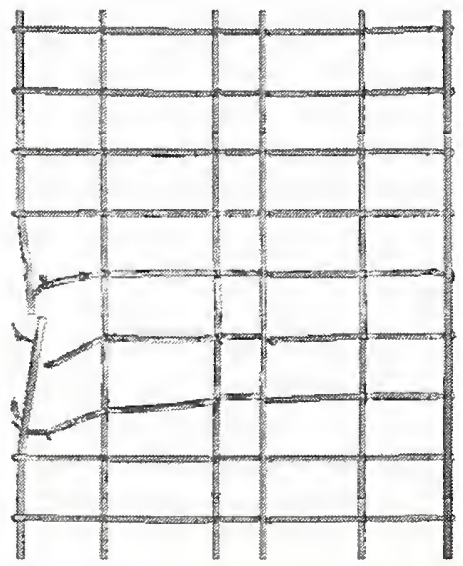

(c) Columns 505-1005

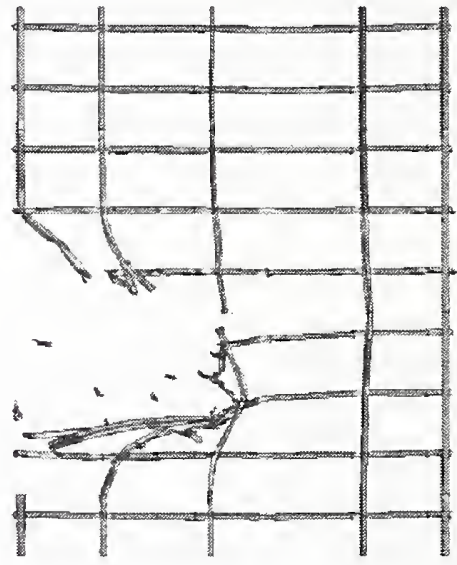

(b) Columns 504-1004

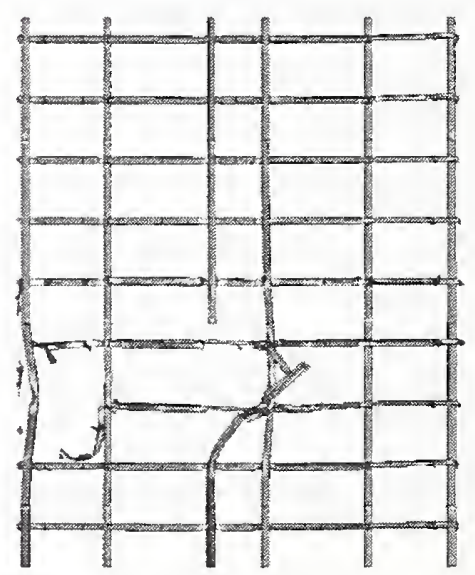

(d) Columns 506-1006

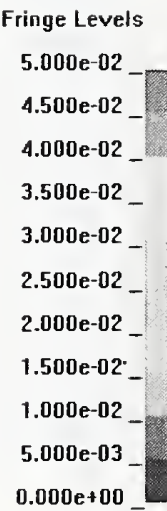

(e) Reference scale

Figure 7-21. More severe impact response of the WTC 1 core columns. 


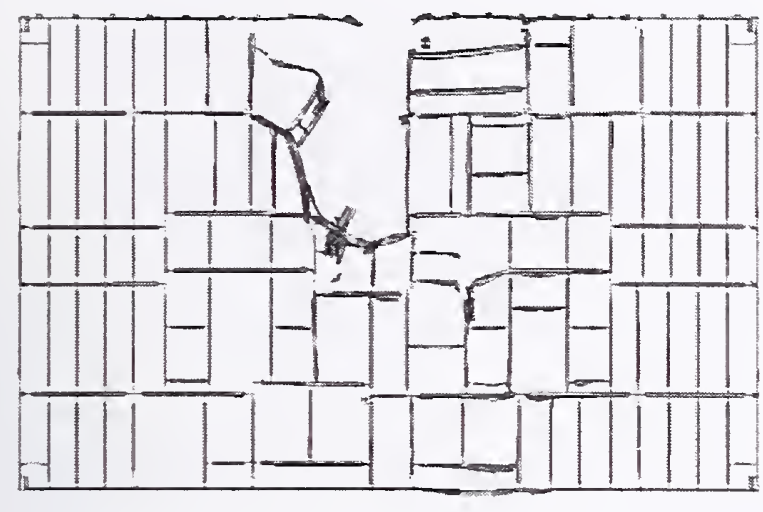

(a) Floor 95 core framing damage

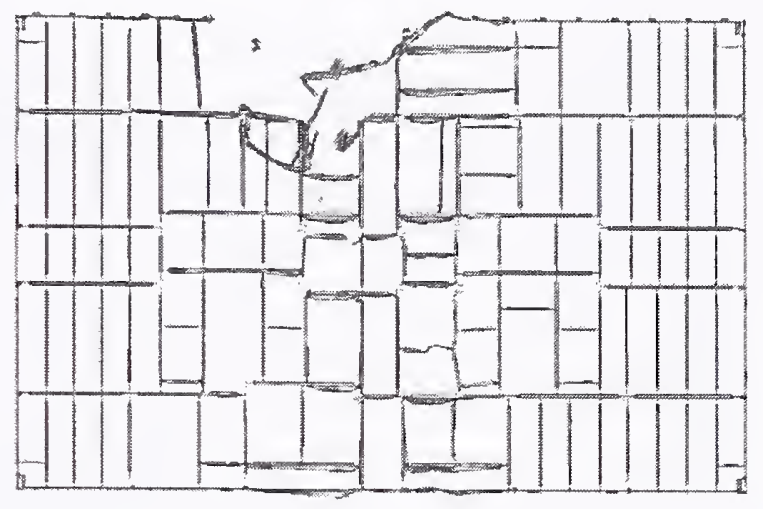

(b) Floor 96 core framing damage

Figure 7-22. More severe impact damage to the core beams of floors 95 and 96 of WTC 1.

Table 7-4. Summary of core column damage for the more severe WTC 1 impact.

\begin{tabular}{|c|c|c|c|}
\hline Column & Location & Damage Level & $\begin{array}{c}\text { Lateral Deflection of } \\
\text { Column Centerline (in.) }\end{array}$ \\
\hline Column 503 & Floor 95-96 & Severed & \\
\hline Column 504 & Floors 92-96 & Severed & \\
\hline Column 505 & Floors 93-96 & Severed & \\
\hline Column 506 & Floors 93-95 & Heavy & 24 \\
\hline Column 603 & Floors 96-97 & Moderate & \\
\hline Column 604 & Floors 92-96 & Severed & \\
\hline Column 605 & Floors 94-95 & Moderate & \\
\hline Column 606 & Floors 94 & Light & \\
\hline Column 702 & Floor 97 & Light & \\
\hline Column 703 & Floor 96 & Moderate & \\
\hline Column 704 & Floors 92-96 & Severed & \\
\hline Column 705 & Floor 95 & Moderate & \\
\hline Column 706 & Floors 93-95 & Severed & \\
\hline Column 802 & Floor 96 & Light & \\
\hline Column 803 & Floors 96-97 & Moderate & \\
\hline Column 804 & Floor 94-96 & Moderate & \\
\hline Column 805 & Floors 93-95 & Heavy & \\
\hline Column 903 & Floor 96 & Light & \\
\hline Column 904 & Floors 95-96 & Floor 95 & \\
\hline Column 905 & & & \\
\hline
\end{tabular}


The strong correlation between the core damage and impact severity was expected. All of the parameter variations were expected to produce an increase in core damage. The flight parameters had an increasing impact speed and a shallower impact angle, directing more energy toward the core. The aircraft had an increasing weight and higher material toughness. The tower had reduced mass in the contents and a reduced material toughness. All of these variations contributcd toward the increased core damage with impact severity.

\section{Floor Truss and Slab Damage}

An overall frontal view of the floor truss structure in the impact zone along with the calculated more severe impact damage to the floor trusses is shown in Figure 7-23. The figure shows that the trusses experienced significant damage in the impact zone. A plan view of the calculated damage to the truss on floors 95 and 96 is shown in Figure 7-24. The calculated impact response produced severe damage to the truss structures in the primary impact path of the fuselage from the exterior wall to the core. The truss floor system on floors 94 through 96 was damaged and sagged downward as a result of the impact loading.

When the floor-by-floor damage was compared for the base case and more severe impact analyses, the damage appeared to be slightly less for the more severe impact analysis. The parameters used in the more severe global impact analysis would primarily contribute to an increased damage magnitude for the tower structurcs. However, the downward impact trajectory angle was reduced from the 10.6 degree angle in the base case analysis to a 7.6 degree angle in the more severe impact analysis. This would have the effect of directing more of the impact energy inward toward the tower core but reducing the normal downward force on the floor structures in the impact zone. As a rcsult, the combined effects of the analysis parameter variations produced slightly less damage to the truss structure in the more severe impact analysis scenario. 

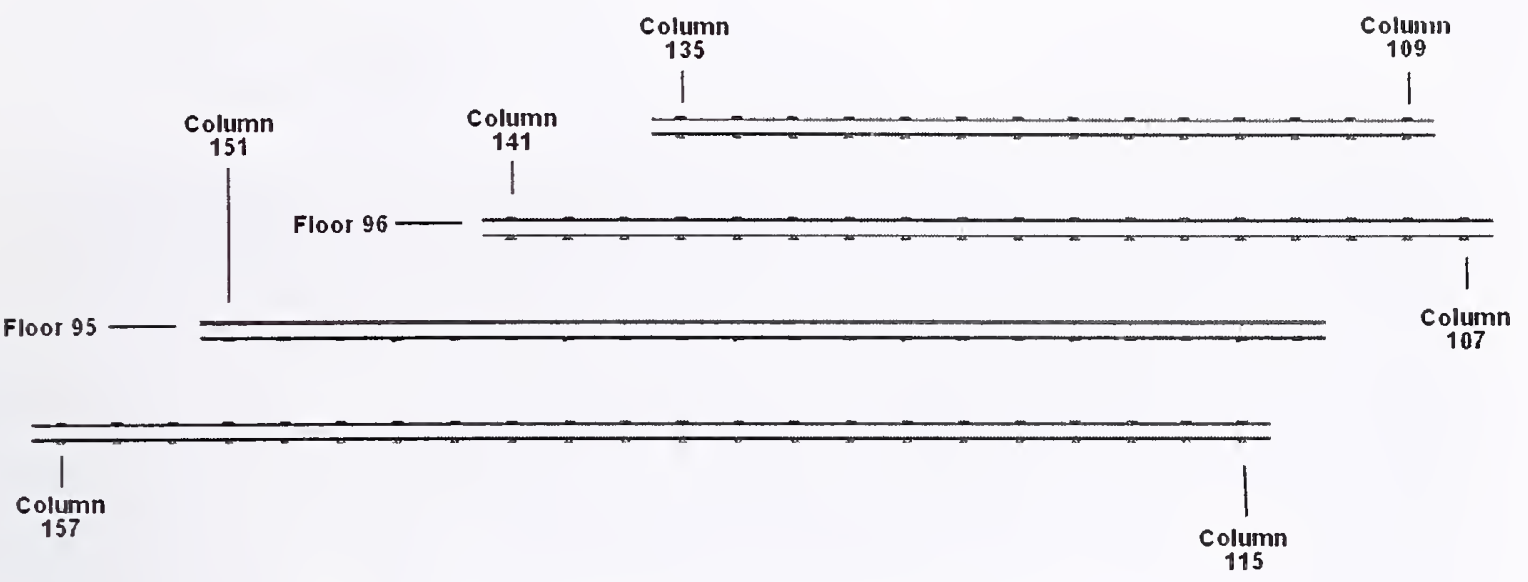

(a) Initial detailed truss structures

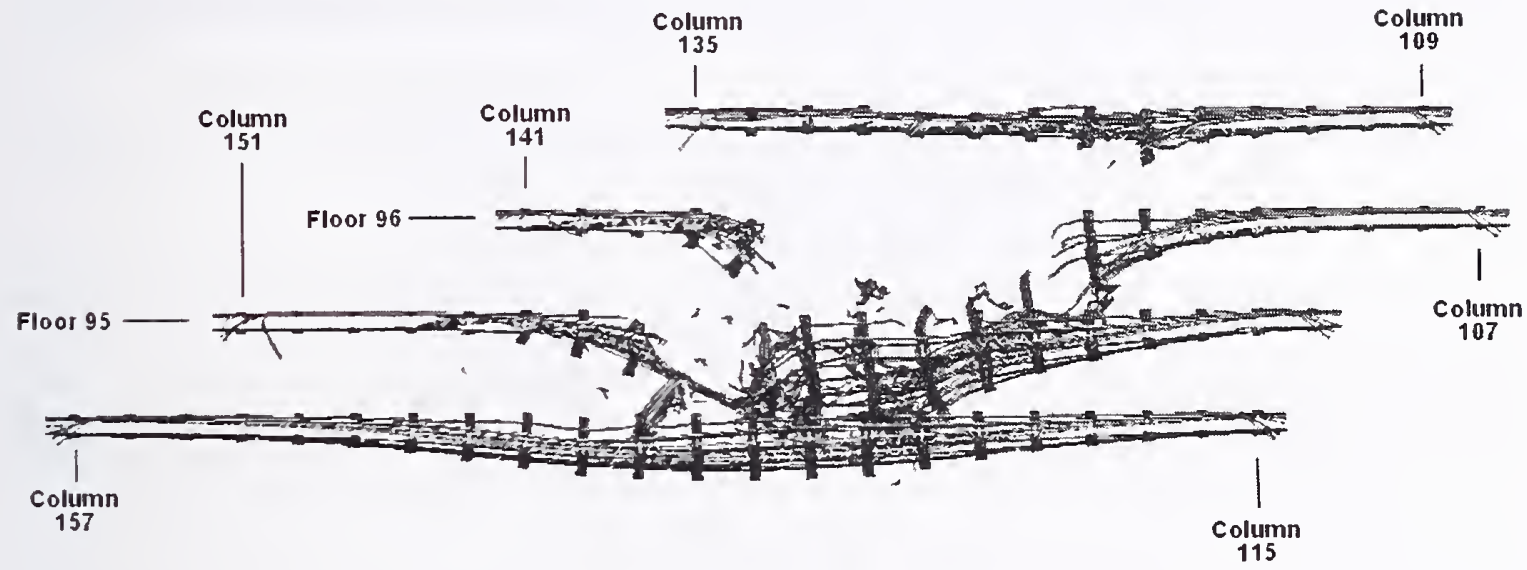

(b) Calculated damage

Figure 7-23. More severe impact damage to the WTC 1 floor trusses (front view). 


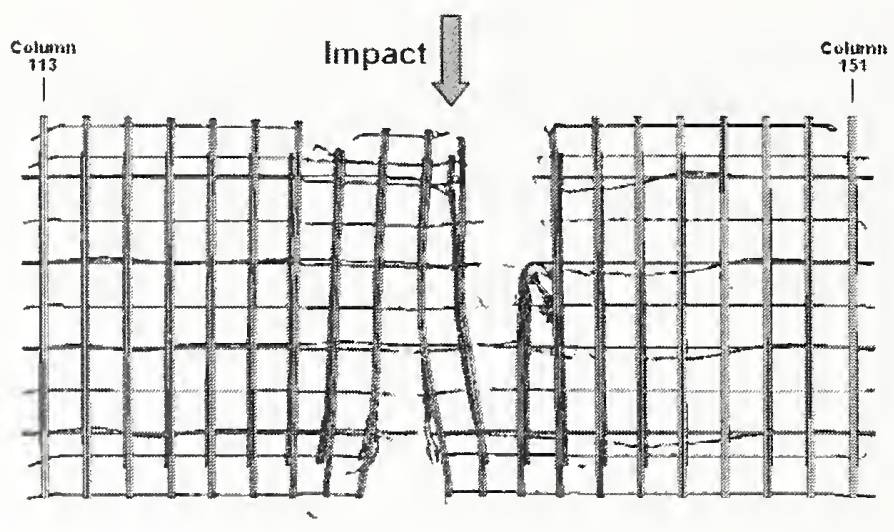

(a) Floor 95 truss damage

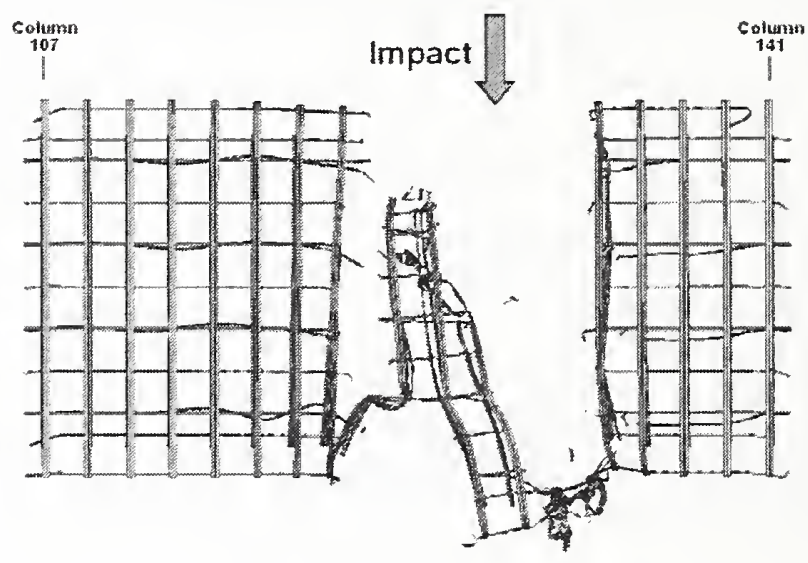

(b) Floor 96 truss damage

Figure 7-24. More severe impact damage to the trusses on floors 95 and 96 of WTC 1 (plan view).

The calculated more severe impact damage to the WTC 1 floor slab for floors 95 and 96 is shown in Figure 7-25. The magnitude of floor slab damage was, in general, very similar for the base case and more severe global impact analyses. When the floor-by-floor damage was compared for the two analyses, the damage appeared to be slightly less for the more severe impact analysis. Similar to the truss damage, the reduced damage in the floor slab is believed to be the result of the reduction in the downward impact trajectory angle from 10.6 to 7.6 degrees in the more severe impact analysis, reducing the normal downward force on the floor structures. 


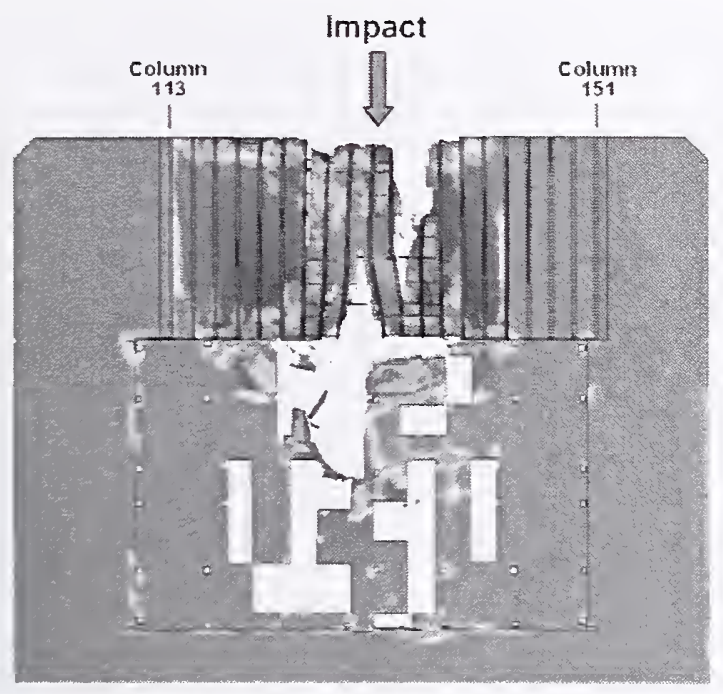

(a) Floor 95 slab damage

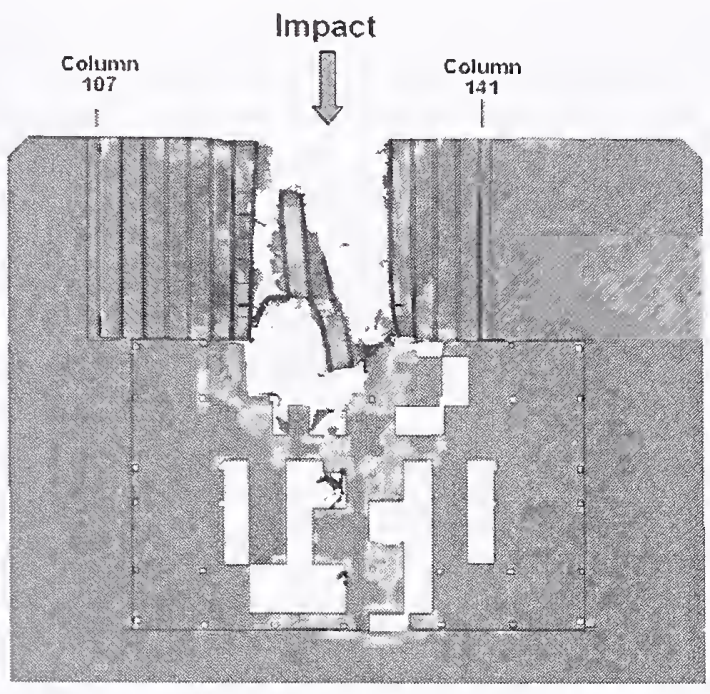

(b) Floor 96 slab damage

Figure 7-25. More severe impact damage to the slabs on floors 95 and 96 of WTC 1 (plan view).

\section{Summary of Structural Damage}

Figure 7-26 shows a summary of the structural damage to the core columns and floor systems at floors 93 through 97 of WTC 1 for the more severe case (Case B). Figure 7-27 presents the cumulative damage to WTC 1 on all affected floors and columns. 


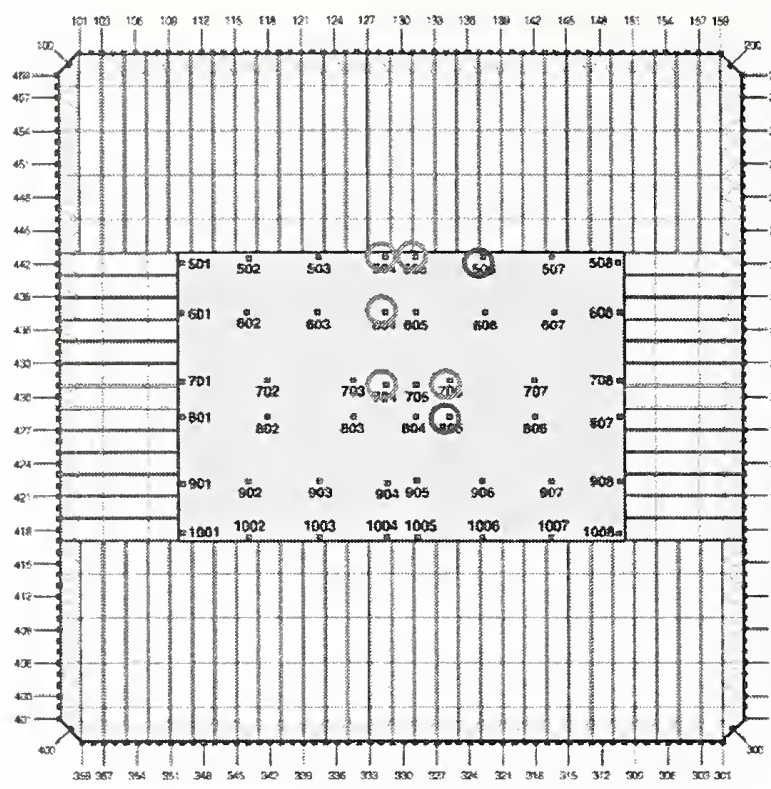

(a) Floor 93

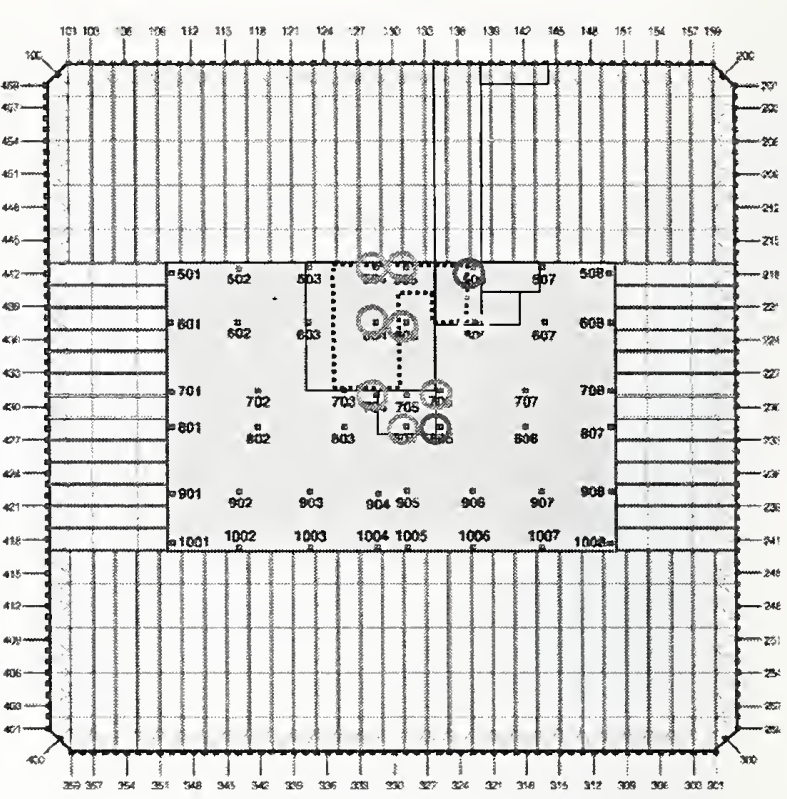

(b) Floor 94

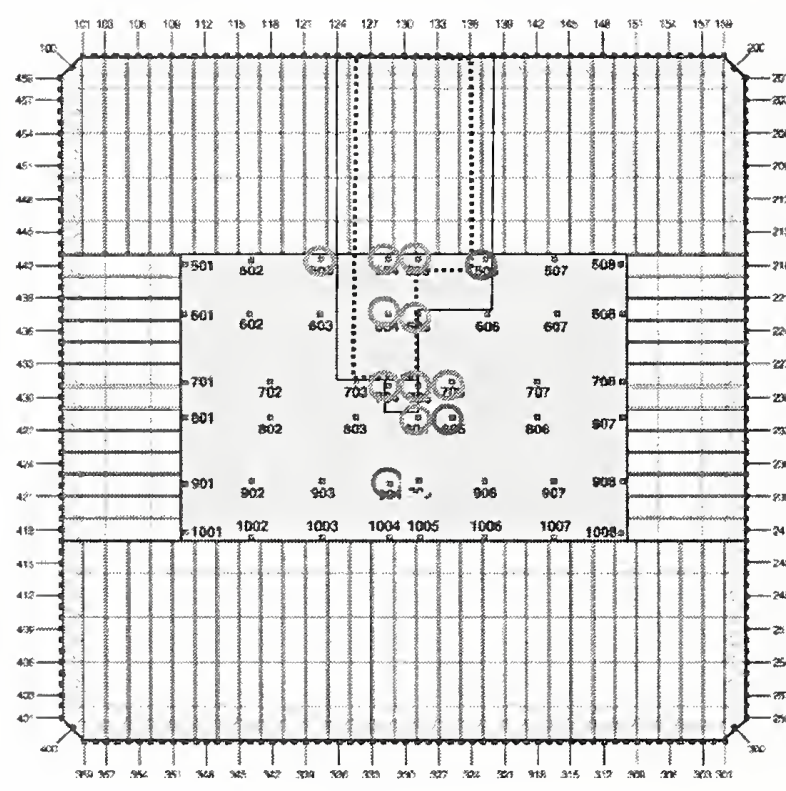

(c) Floor 95

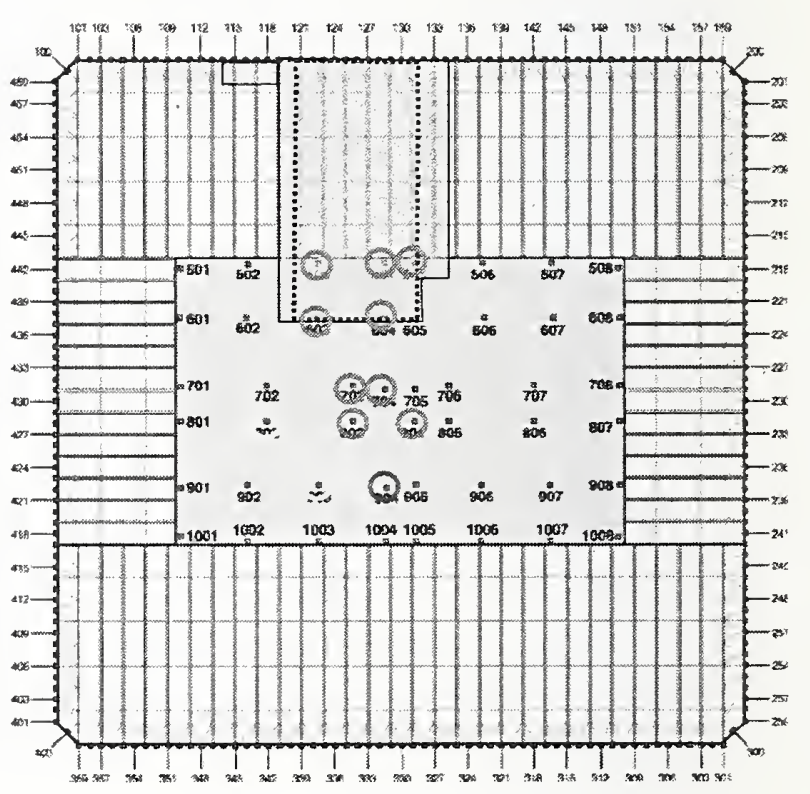

(d) Floor 96

Figure 7-26. Summary of the floor-by-floor structural damage to the floors and columns of WTC 1 (more severe case). 


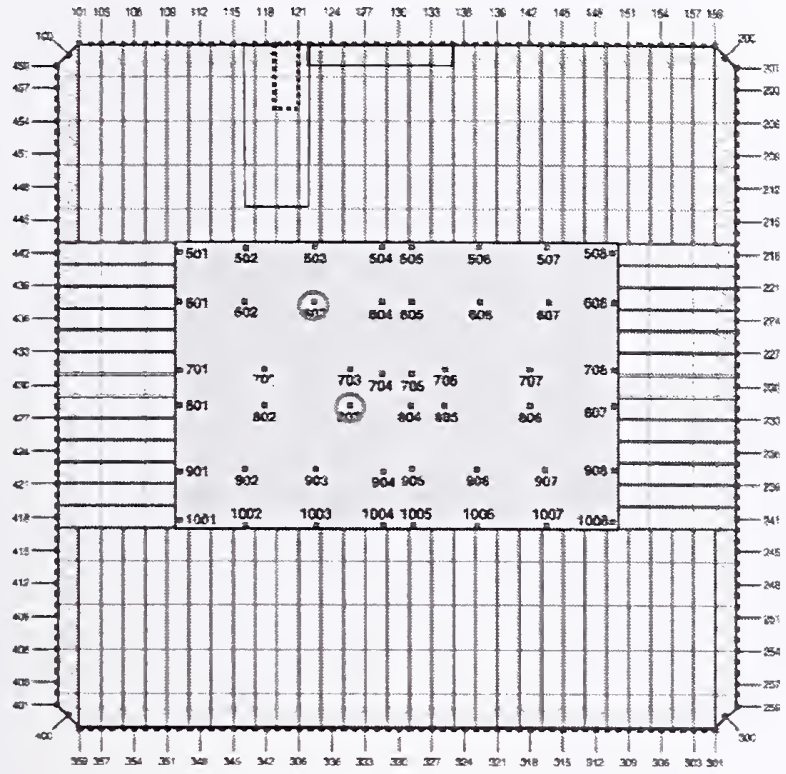

\section{Severe Floor Damage \\ Floor system structural damage $\square$}

Floor system removed

a......

(e) Floor 97

Figure 7-26. WTC 1 more severe global impact analysis (plan view) (continued).

Severe Floor Damage

Floor system structural damage $\square$

Floor system removed

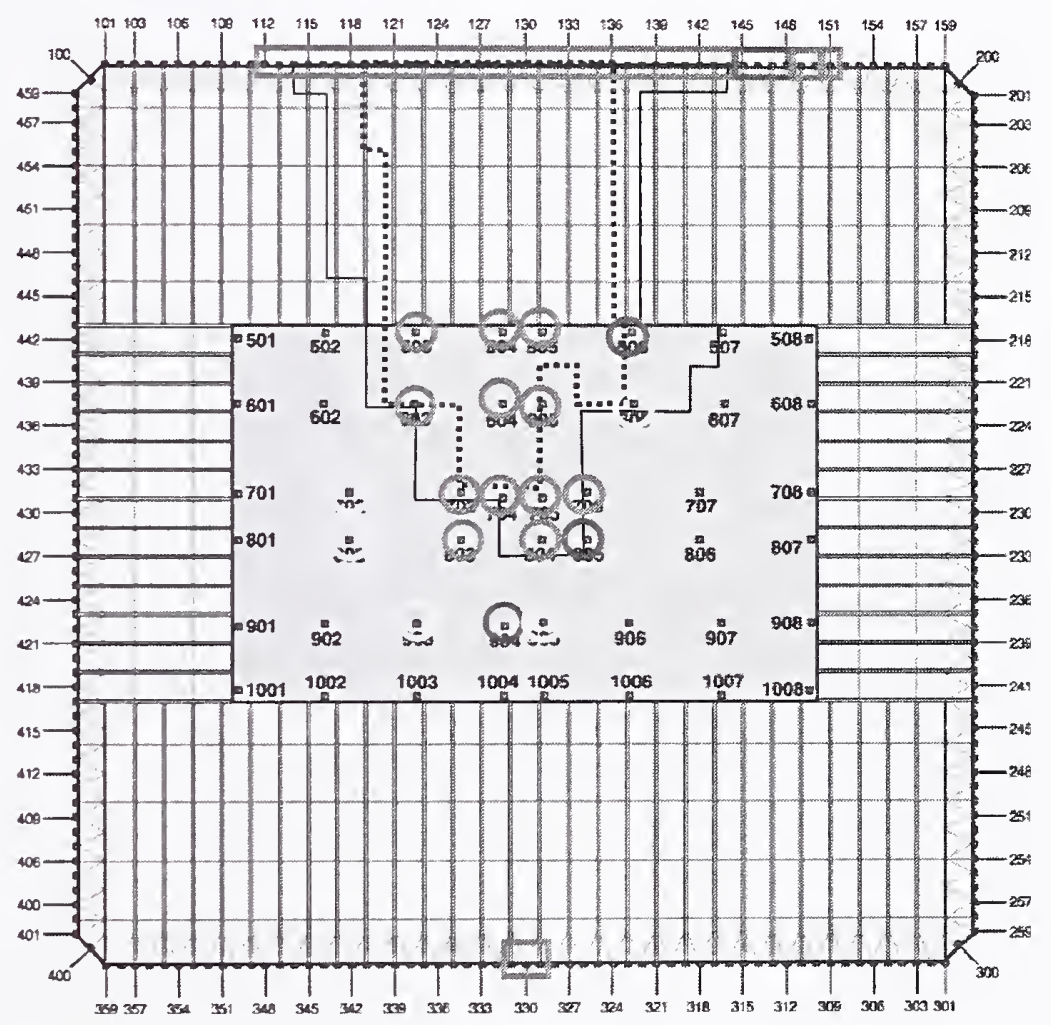

Figure 7-27. Cumulative structural damage to the floors and columns of WTC 1 (more severe case). 


\subsubsection{Fuel and Debris Distribution}

The distribution of the fuel in the tower, calculated from the more severe case, in a plan view and side view is shown in Figure 7-28. At the termination of the global impact analysis, the residual momentum of the jet fuel was less than one percent of the initial momentum, indicating that the fuel cloud was nearly at rest. To more clearly present the calculated response of the structures that influenced the fire propagation, the structural components were removed from the visualization, with the exception that the core columns were maintained in the visualizations for reference positions. A plan view of the response of the remaining building contents and aircraft debris is shown in Figure 7-29.

The calculated damage to the WTC 1 contents for the more severe impact case is shown in plan views for floors 95 and 96 in Figure 7-30 and Figure 7-31, respectively. A comparison to the calculated damage for the base case WTC 1 impact analysis indicated that the content damage zone was very similar in width, but extended further south through the tower in the more severe impact. The more severe impact produced significantly greater content damage on the far side of the core and extended more fully through the tower.

A summary of the floor-by-floor fuel and debris distributions is given in Table 7-5. The bulk of the fuel and aircraft debris was deposited in floors 93 through 97, with the greatest concentration on floor 94 . The calculated debris cloud included 46,800 lbs of debris and 7,500 lbs of aircraft fuel outside of the tower at the end of the impact analysis, either rebounding from the impact face (north wall) or passing through the tower (south wall). This amount might have been larger in the calculation due to the reasons mentioned previously for the base case impact (see Scction 7.3.3). Comparing Figure 7-29 and Tablc 7-5 with Figure 7-15 and Table 7-2, it can be seen that the amount of debris exiting the south wall of the tower in the more severe case was much larger than that from the base case.

Table 7-5. Fuel and aircraft debris distribution for the more severe WTC 1 impact.

\begin{tabular}{|l|c|c|}
\hline \multicolumn{1}{|c|}{ Tower Location } & Aircraft Fuel & Aircraft Debris \\
\hline Total Outside Tower & $7,500 \mathrm{lb}$ & $46,800 \mathrm{lb}$ \\
\hline WTC 1 Floor 92 & $1.200 \mathrm{lb}$ & $15 \mathrm{lb}$ \\
\hline WTC 1 Floor 93 & $5,800 \mathrm{lb}$ & $39,100 \mathrm{lb}$ \\
\hline WTC 1 Floor 94 & $14,100 \mathrm{lb}$ & $59,900 \mathrm{lb}$ \\
\hline WTC 1 Floor 95 & $13,600 \mathrm{lb}$ & $22,500 \mathrm{lb}$ \\
\hline WTC 1 Floor 96 & $13,300 \mathrm{lb}$ & $21,500 \mathrm{lb}$ \\
\hline WTC 1 Floor 97 & $9,600 \mathrm{lb}$ & $5,200 \mathrm{lb}$ \\
\hline WTC 1 Floor 98 & $3,100 \mathrm{lb}$ & $7,300 \mathrm{lb}$ \\
\hline WTC 1 Floor 99 & $1,100 \mathrm{lb}$ & $400 \mathrm{lb}$ \\
\hline Total Weight & $69,300 \mathrm{lb}$ & $202,700 \mathrm{lb}$ \\
\hline
\end{tabular}




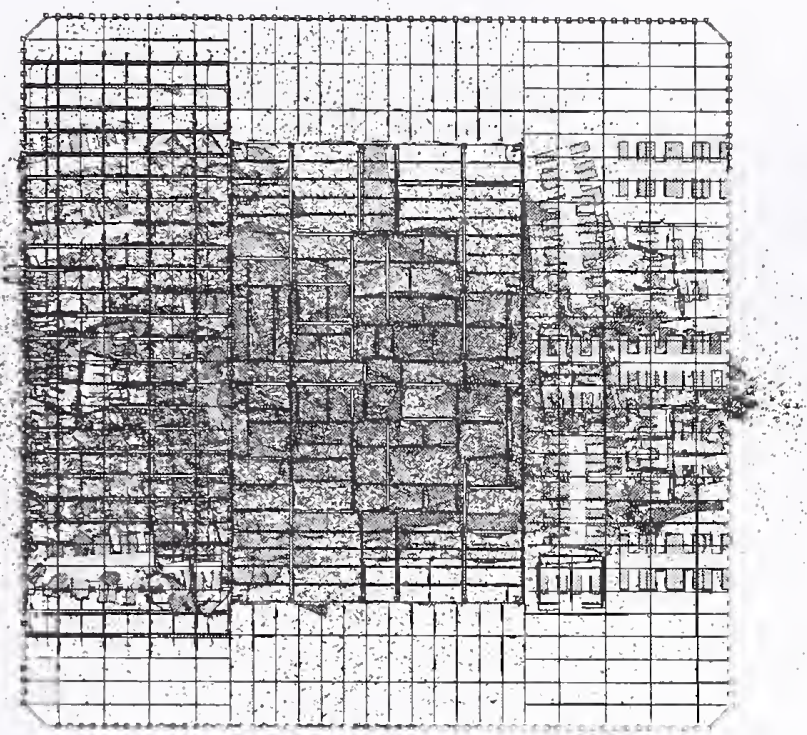

(a) Plan view (floor slab removed)

Time $=0.685$

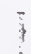

1 忬

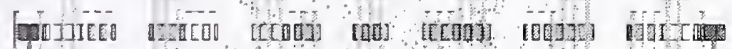

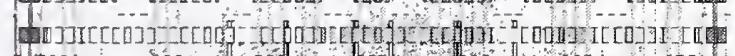

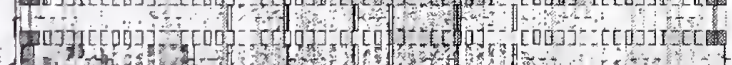
(1) 2.

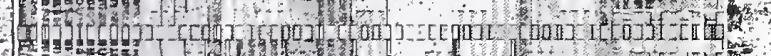
Gor anozir.

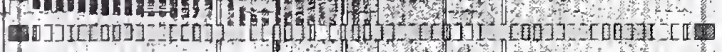

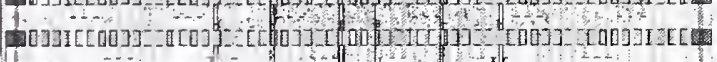

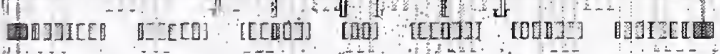

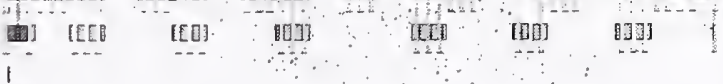

(b) Side view

Figure 7-28. Calculated fuel distribution in the more severe WTC 1 analysis. 


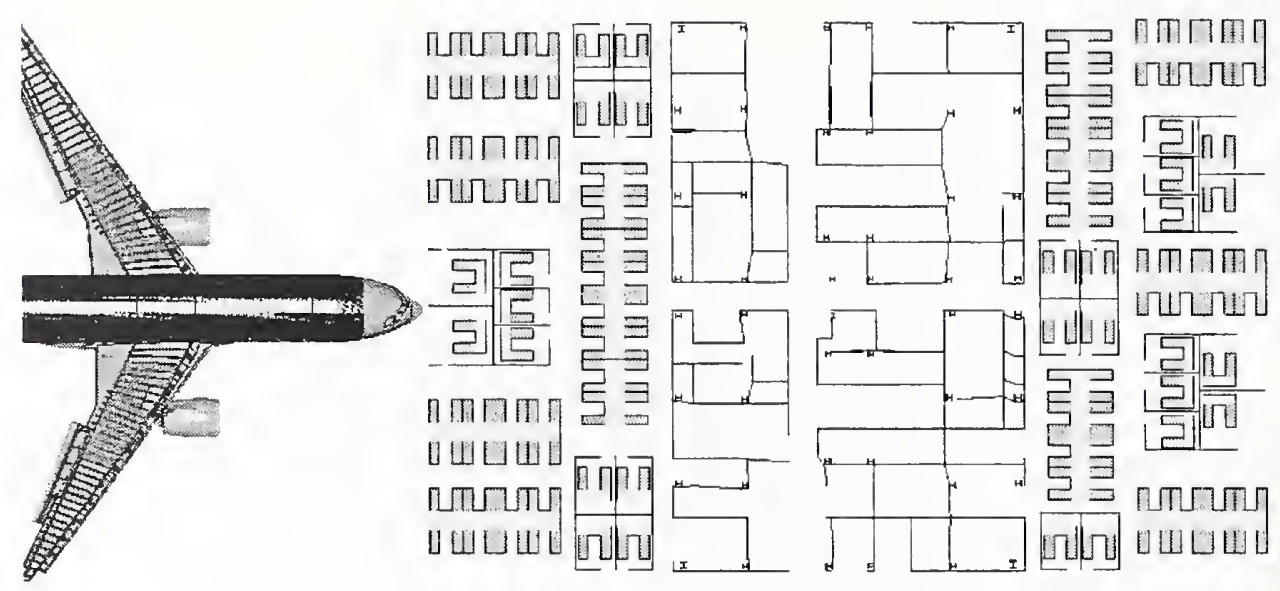

(a) Pre-impact configuration

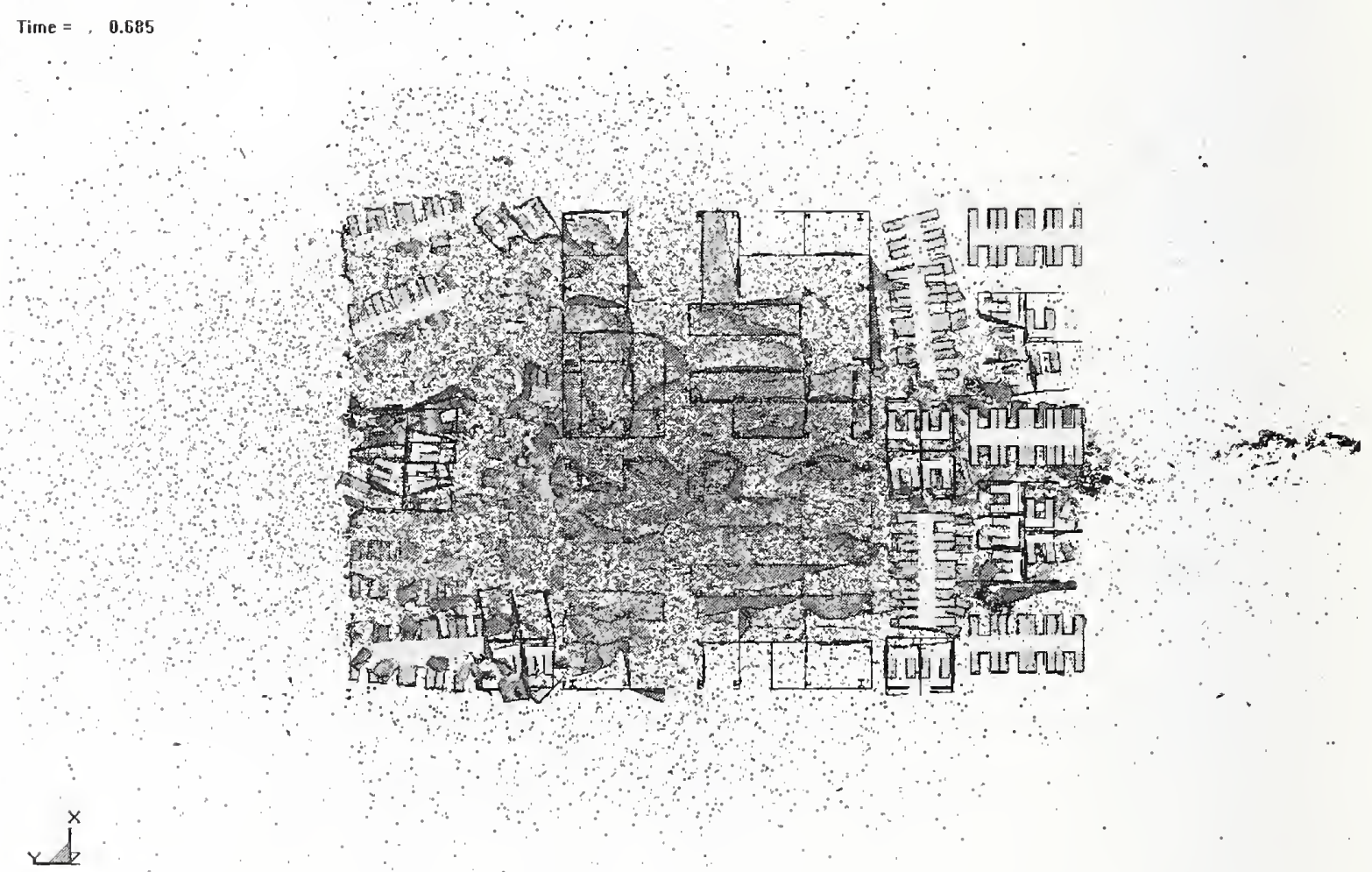

(b) Calculated impact response

Figure 7-29. Plan view of calculated WTC 1 building, fuel, and aircraft debris distribution for the more severe case. 


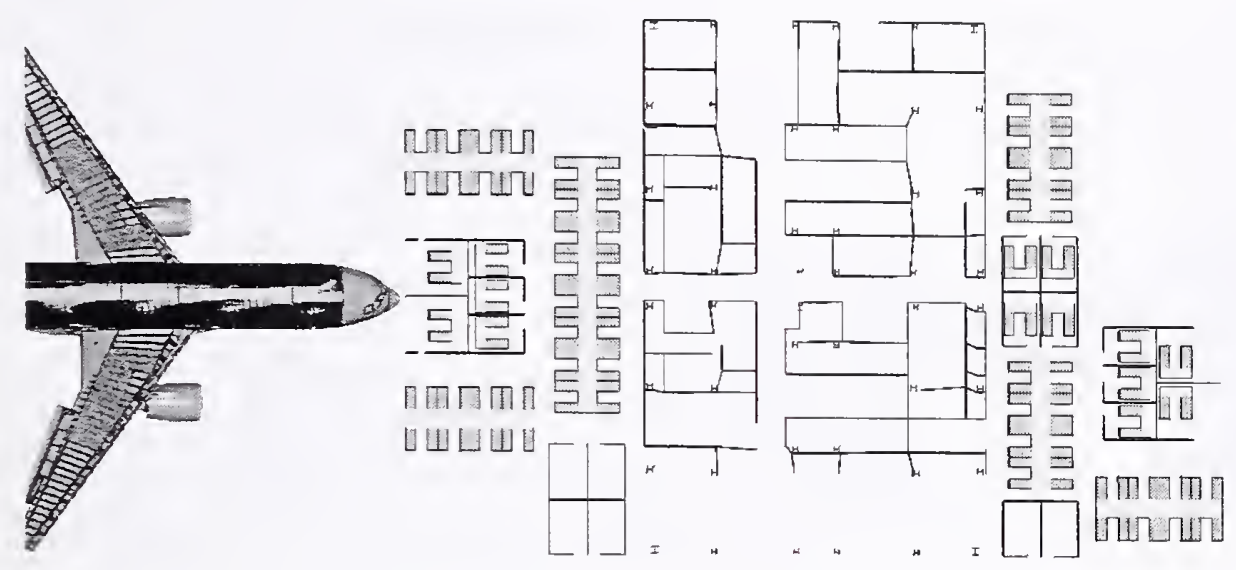

(a) Pre-impact configuration

rear $=0.005$

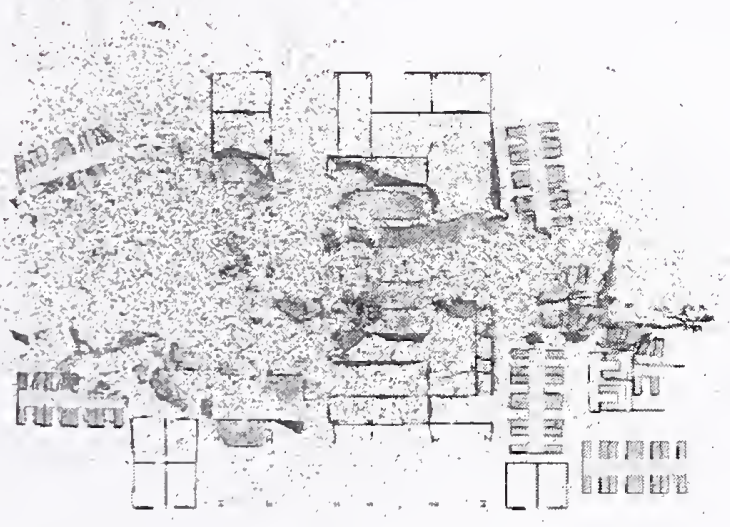

(b) Calculated impact response

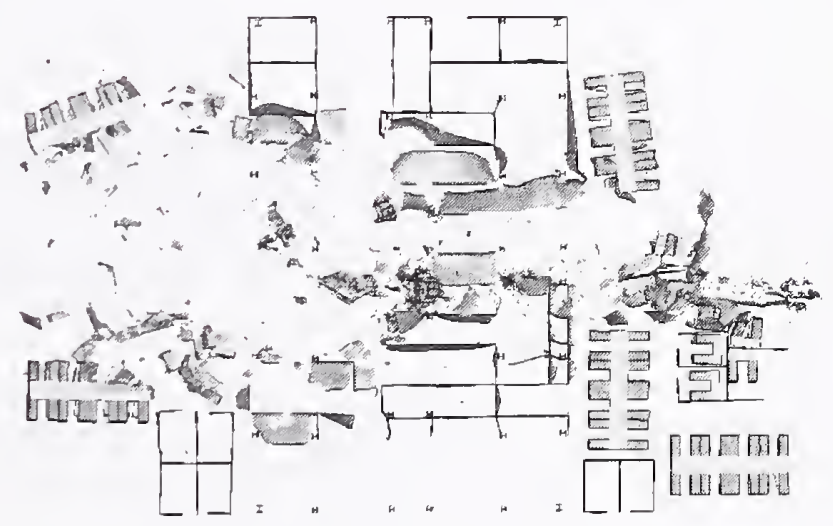

(c) Calculated impact response (fuel removed)

Figure 7-30. Calculated more severe WTC 1 impact response of floor 95 contents. 


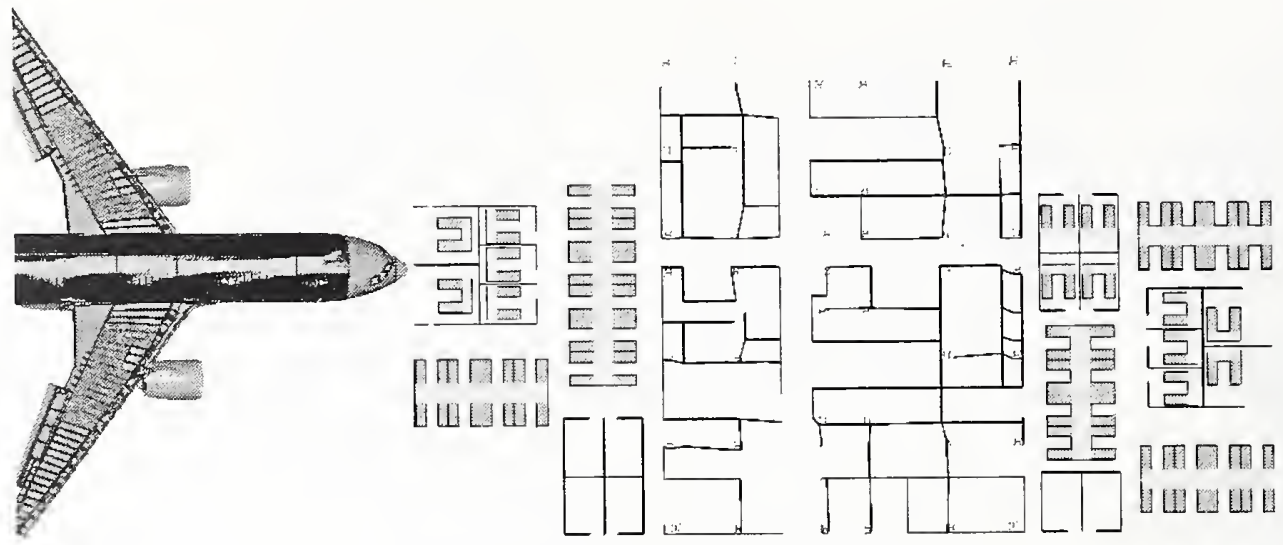

(a) Pre-impact configuration

0.695

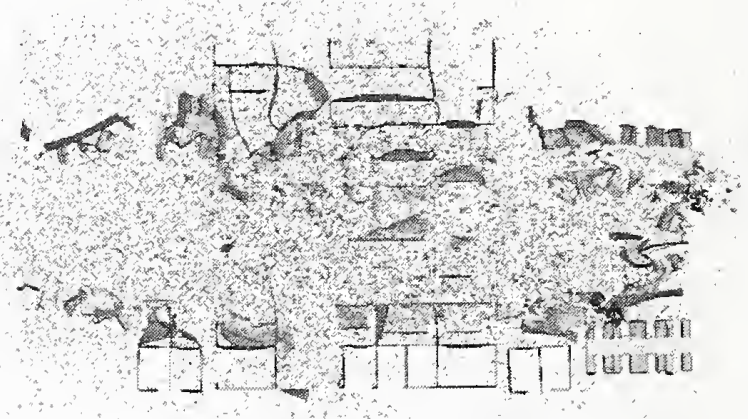

(b) Calculated impact response

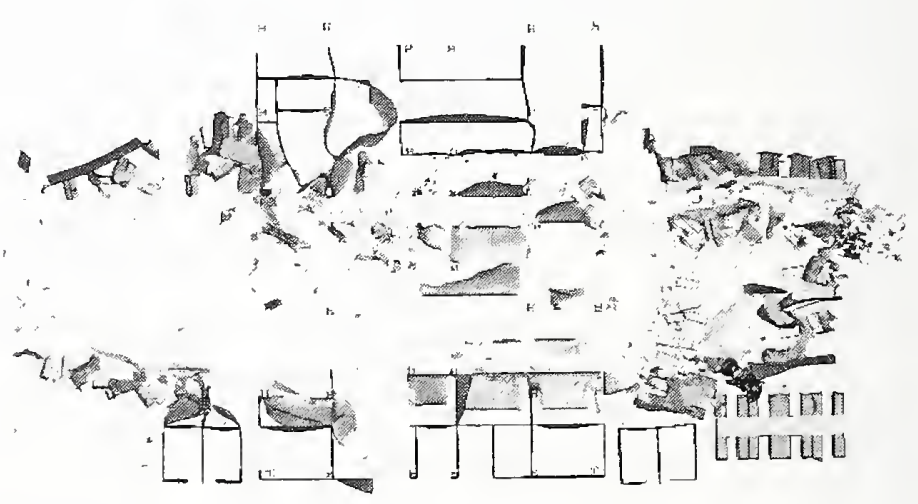

(c) Calculated impact response (fuel removed)

Figure 7-31. Calculated more severe WTC 1 impact response of floor 96 contents. 


\subsection{WTC 1 LESS SEVERE IMPACT ANALYSIS - BRIEF DESCRIPTION}

This section presents a brief description of the results from the less severe damage case. The rcader is referred to NIST NCSTAR 1-2B for further details.

For the north exterior wall of WTC 1, the magnitude and mode of impact damage were still in good agreement with the observed damage for the less severe impact scenario.

The core had a limited damage confined to the region nearest to the impact point. Only one column was severed, and two columns were heavily damaged for the less severe case, compared to three severed columns and four heavily damaged columns in the base case WTC 1 impact analysis. The failure of the column splices located on floors 92 and 95 contributed to the failure of the core column.

The floor trusses experienced significant damage in the impact zone. The calculated impact response produced severe damage to the truss structures in the primary impact path of the fuselage. The truss structures were severely damaged from the exterior wall to the core. The truss floor system on floors 94 through 96 were damaged and sagged downward as a result of the impact loading.

When compared with the base case, the magnitude of damage to the floor trusses and floor slabs was slightly increased for the less severe impact analysis. The parameters used in the less severe global impact analysis would primarily contribute to a reduced damage magnitude for the tower structures. However, the downward impact trajectory angle was increased from the 10.6 degree angle in the base case analysis to a 13.6 degree angle in the more severe impact analysis. This would have the effect of directing more of the impact energy downward, increasing the normal force on the floor structures in the impact zone. As a result, the combined effects of the analysis parameter variations produccd a small increase in the damage to the truss structure in the less severe impact analysis scenario.

A comparison to the base case and less severe case indicated that the building contents damage zone was very similar in width but did not extend as far through the tower in the less severe impact. The less severe impact produced little content damage on the far side of the core and did not extend fully through the tower. Little or no debris penetration of the south wall of the tower was expected for the less severe impact condition.

\subsection{WTC 2 BASE CASE IMPACT ANALYSIS - CASE C}

This case is referred to as Case C for the remainder of the WTC Investigation reports. The combined aircraft and tower model used for the base case global impact conditions of WTC 2 is shown in Figure 7-32. The WTC 2 base case impact analysis was performed for a $0.62 \mathrm{~s}$ duration following initial impact of the aircraft nose with the south exterior wall. 


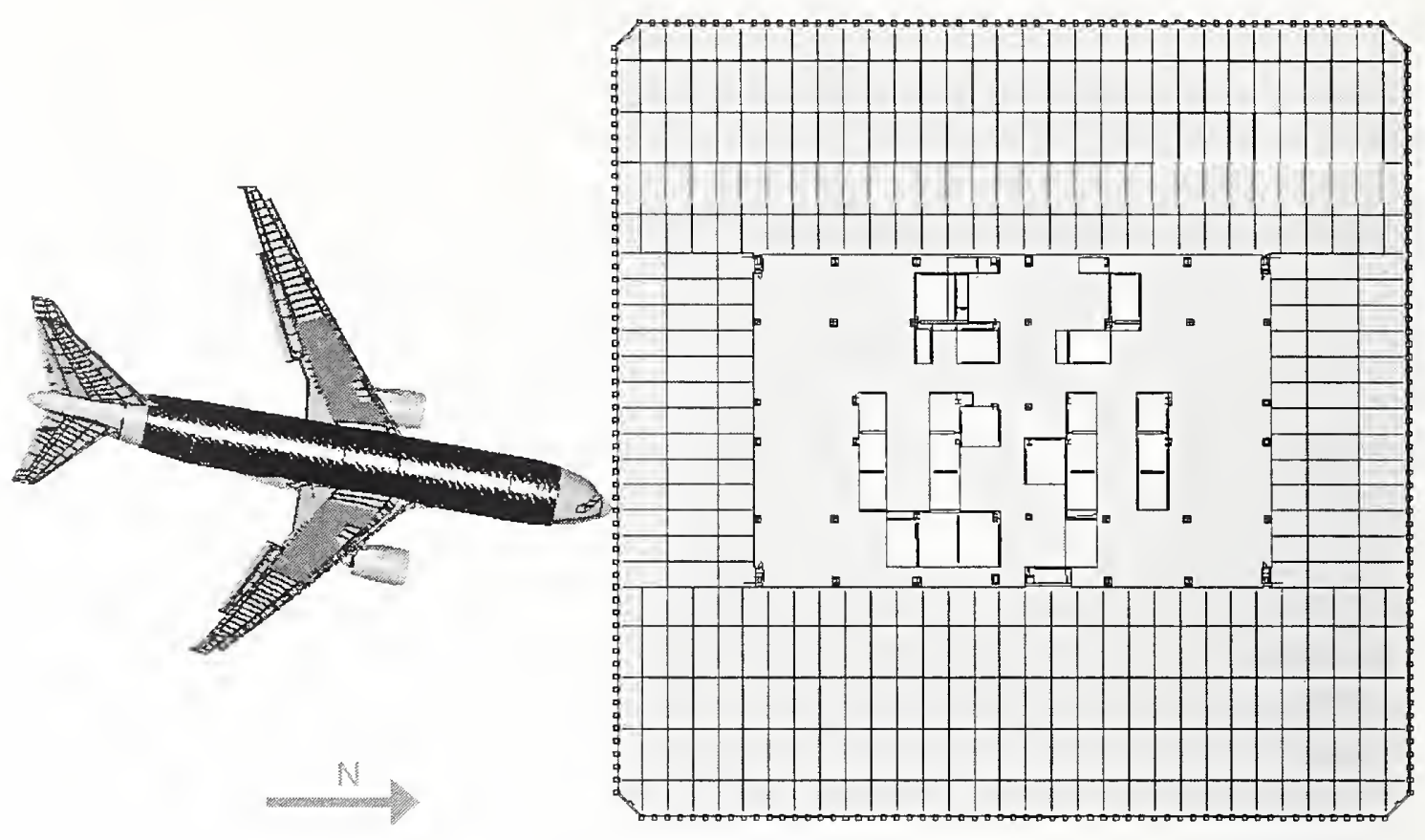

(a) Plan view

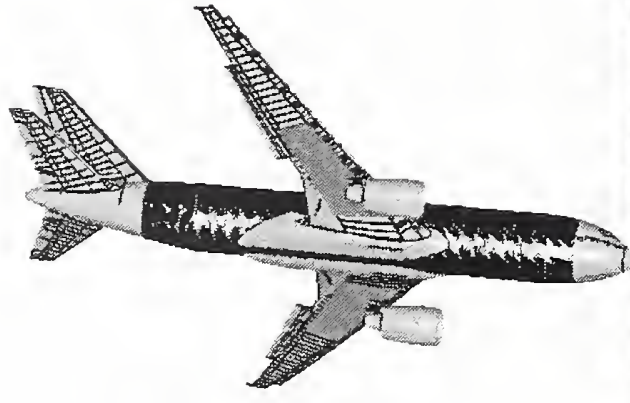

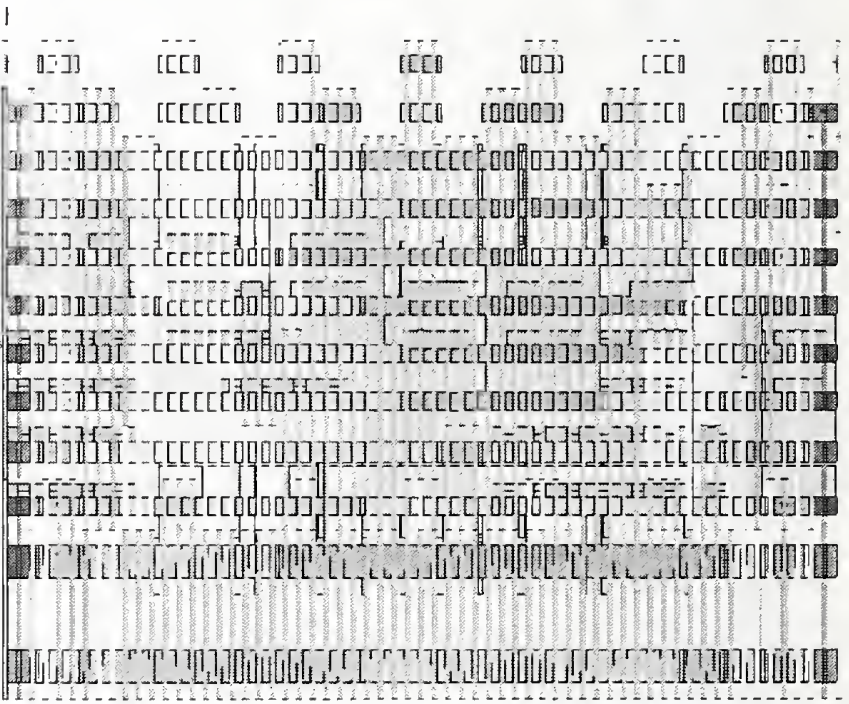

(b) Side view

Figure 7-32. WTC 2 global impact model.

\subsubsection{Impact Response}

The base case global aircraft impact response of WTC 2 is shown in side views and plan views in Figure 7-33 and Figure 7-34, respectively. The response is shown at intervals of $0.1 \mathrm{~s}$ from impact through the initial $0.5 \mathrm{~s}$ of the response. The initial $0.1 \mathrm{~s}$ of the base case global aircraft impact response, shown in Figure 7-33(b) and Figure 7-34(b), was dominated by the impact, penetration, and 
fragmentation of the forward fuselage structures. The engines and leading portions of the wings penetrated the exterior wall. The forward fuselage structures were severely damaged both from the penetration through the exterior columns and the interaction with the 81 st floor slab that sliced the fuselage structures in half. The downward trajectory of the aircraft structures caused the airframe to collapse against the floor, and the subsequent debris motion was redirected inward along a more horizontal trajectory parallel to the floor. The higher impact speed and short truss floor span in this impact orientation had the forward fuselage structures well into the tower core by this time.

By $0.2 \mathrm{~s}$ after impact, the full penetration of the aircraft into the tower was just completed, as shown in Figure 7-33(c) and Figure 7-34(c). The airframe was mostly broken up, but some large sections of the aft fuselage and tail were still intact, having penetrated through the opening in the south wall produced by the forward fuselage structures. The aircraft fuel cloud was starting to spread out, but was still relatively dense, and the leading edge of the fuel was approximately one-third through the tower core. By $0.2 \mathrm{~s}$, the downward trajectory of the aircraft structures transferred sufficient vertical load that the truss floor structures on floors 80 and 81 were starting to collapse in the impact zone.

At $0.3 \mathrm{~s}$ after impact, the aircraft fuel cloud had penetrated approximately two-thirds the distance through the core and was spreading out, as shown in Figure 7-33(d) and Figure 7-34(d). However, the subsequent motion of the aircraft fragments and fuel debris cloud began to be noticeably slowed beyond this time. The fuel and debris continued to spread through the tower, but at a much slower rate, as seen in the remaining images in Figure 7-33 and Figure 7-34. The spread of the fuel and debris cloud was more rapid and extensive in the open truss floor regions than through the core as a result of the open volume above the workstations in the truss floor zone.

The load transfer of the base case WTC 2 aircraft impact can be described by the time-history of the aircraft momentum as shown in Figure 7-35. The curve illustrates an initial rate of load transfer during the first $0.1 \mathrm{~s}$ of impact as the forward fuselage penetrated the exterior wall and impacted the interior structures. Between $0.1 \mathrm{~s}$ and $0.2 \mathrm{~s}$, a more rapid load transfer rate was observed as the area of the impact became larger (extending outward in the wing impact regions) and a higher percentage of the aircraft mass was impacting the interior structures. At $0.2 \mathrm{~s}$, the aircraft completely penetrated the building and retained approximately 30 percent of its initial momentum. Beyond this time, the rate of load transfer was steadily decreasing, with very little load transfer after approximately $0.4 \mathrm{~s}$. The behavior was very similar to that of the base case WTC 1 impact, shown in Figure 7-4, but with a slightly compressed time scale resulting from the higher impact speed on WTC 2. 


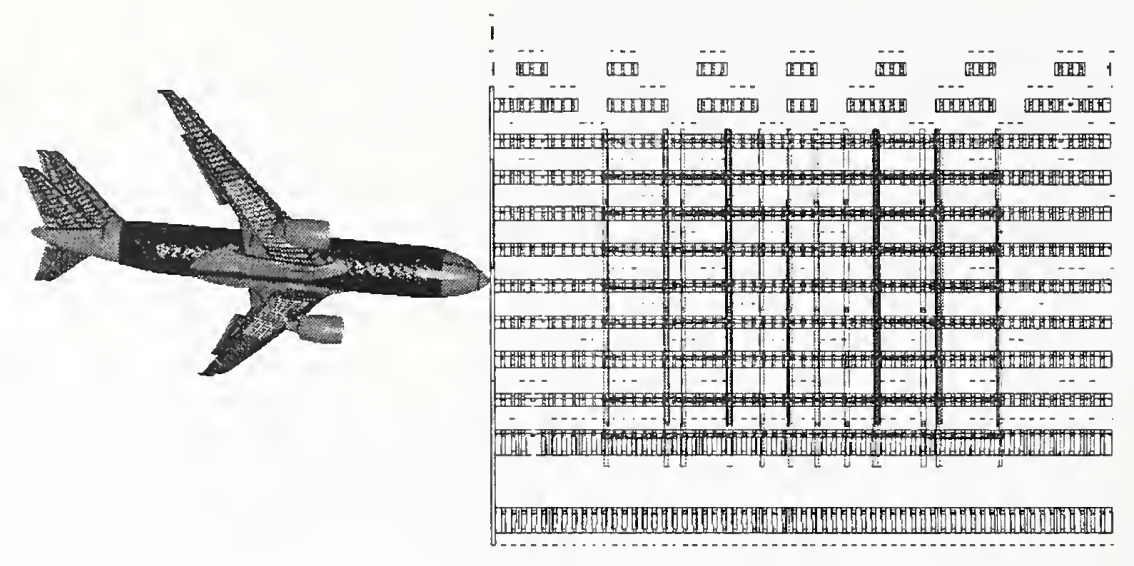

(a) Time $=0.00 \mathrm{~s}$

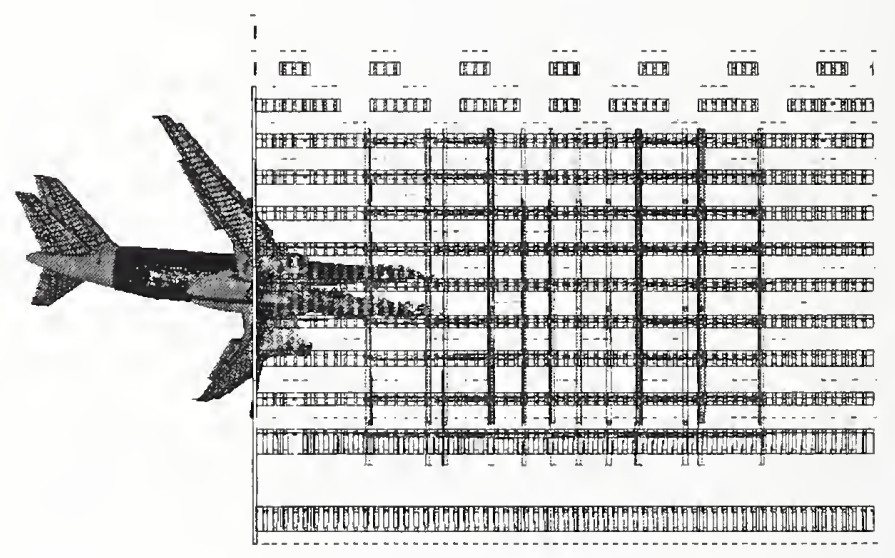

(b) Time $=0.10 \mathrm{~s}$

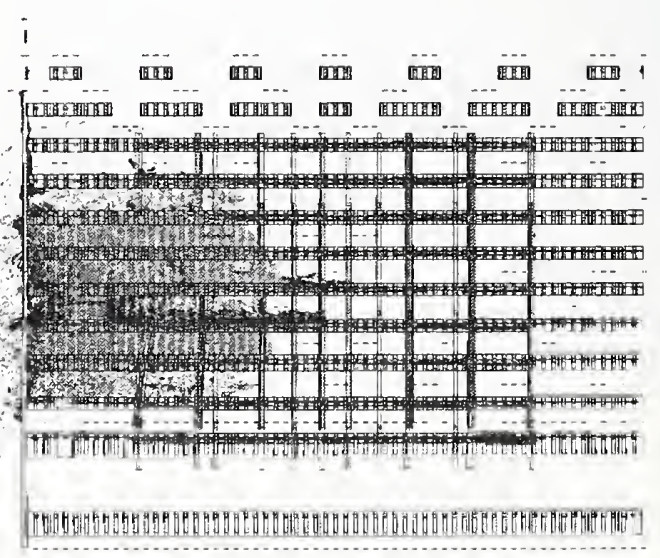

(c) Time $=0.20 \mathrm{~s}$

Figure 7-33. WTC 2 base case global impact analysis (side view). 


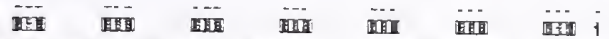
Иัง tritHol Gin

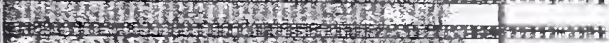

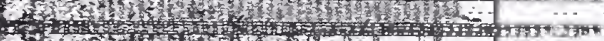

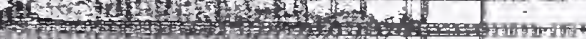

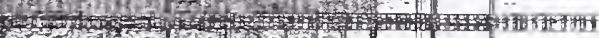

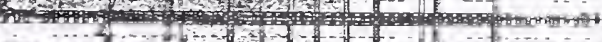
1 10 min J

(d) Time $=0.30 \mathrm{~s}$

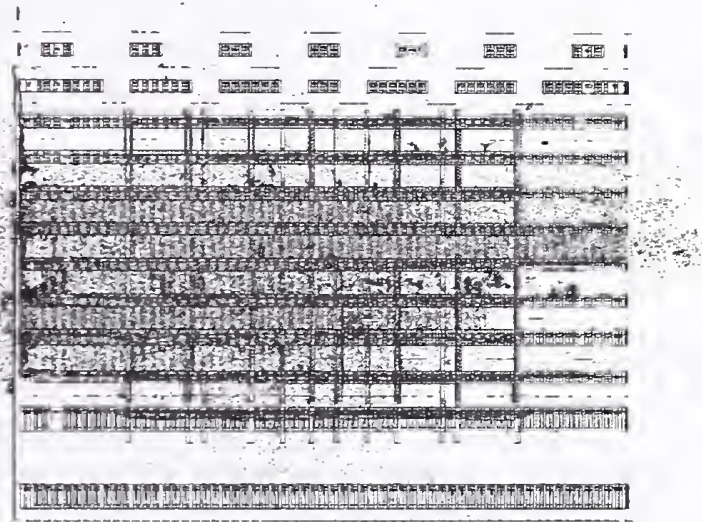

(e) Time $=0.40 \mathrm{~s}$

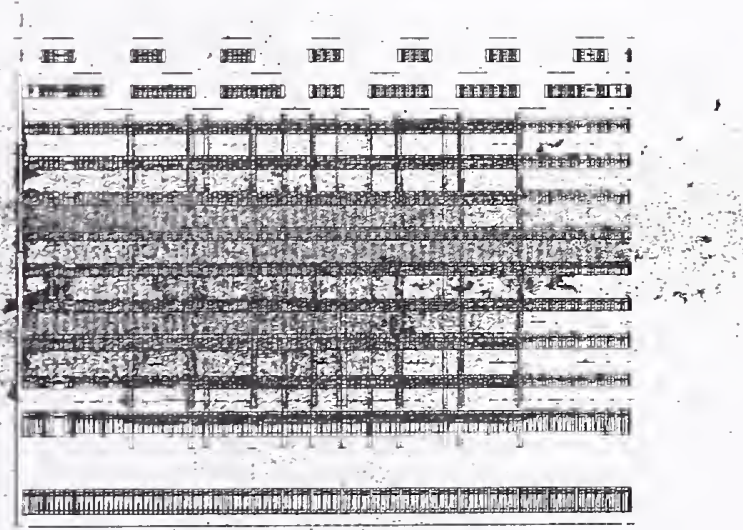

\section{(f) Time $=0.50 \mathrm{~s}$}

Figure 7-33. WTC 2 base case global impact analysis (side view) (continued). 


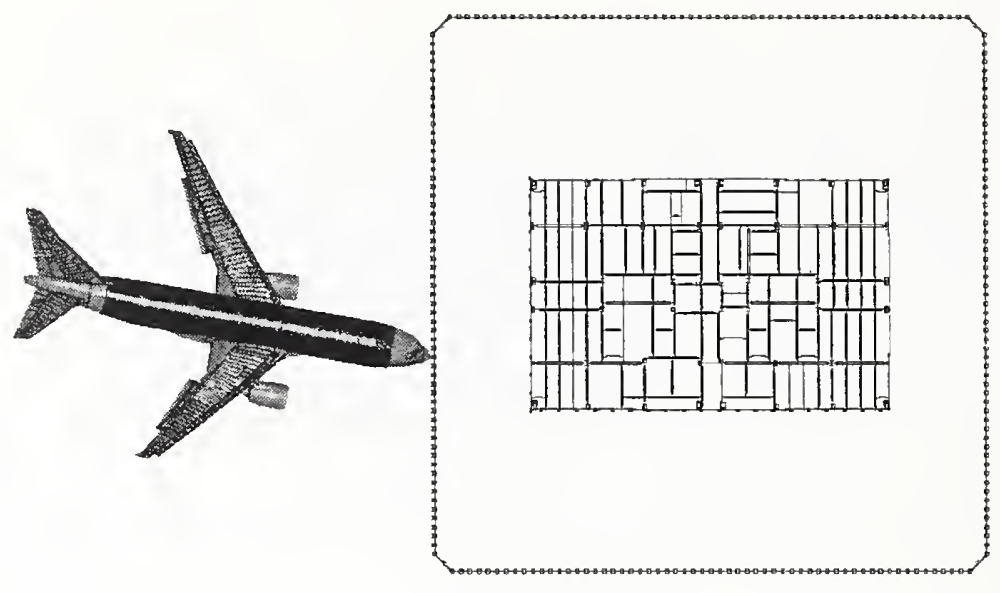

(a) Time $=0.00 \mathrm{~s}$

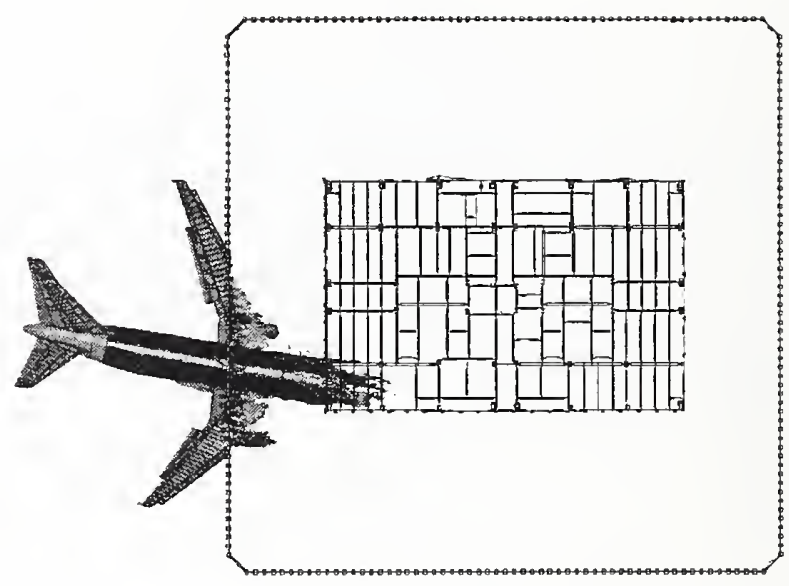

(b) Time $=0.10 \mathrm{~s}$

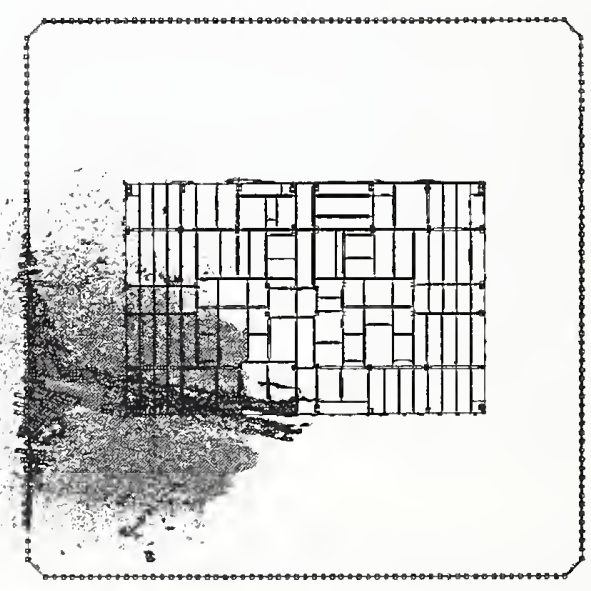

(c) Time $=0.20 \mathrm{~s}$

Figure 7-34. WTC 2 base case global impact analysis (plan view). 


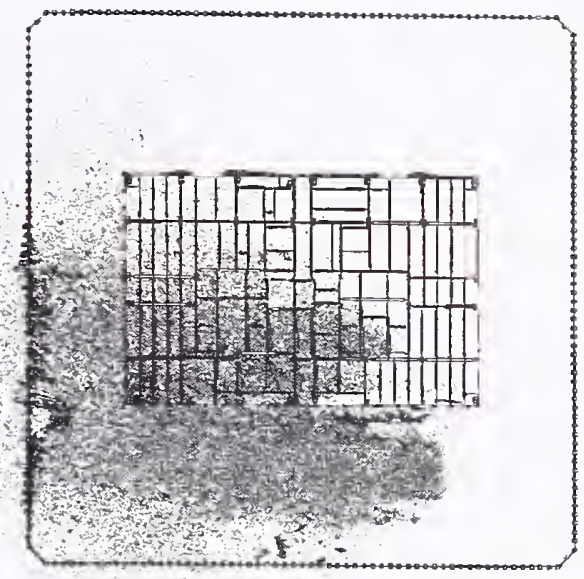

(d) Time $=0.30 \mathrm{~s}$

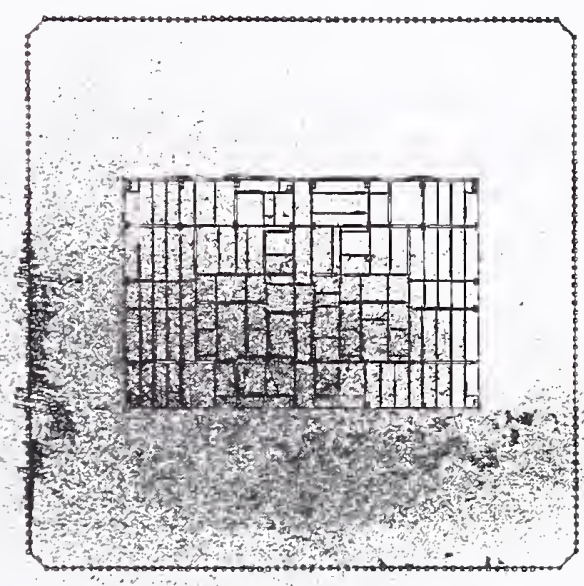

(e) Time $=0.40 \mathrm{~s}$

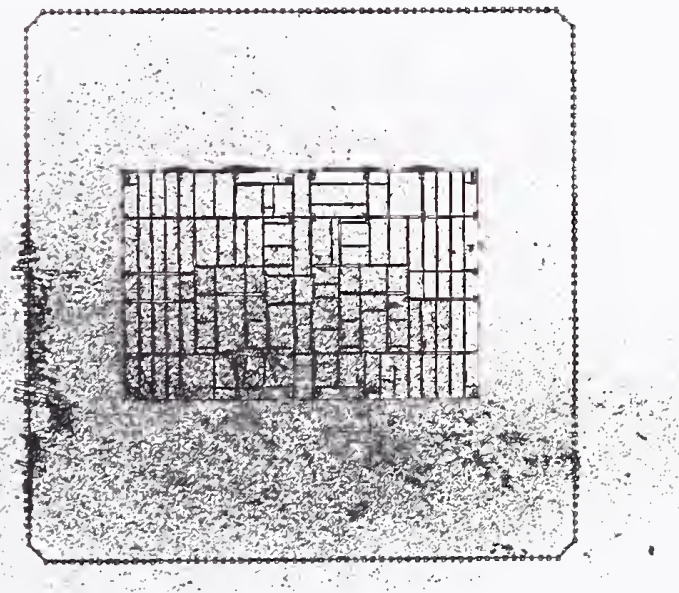

(f) Time $=0.50 \mathrm{~s}$

Figure 7-34. WTC 2 base case global impact analysis (plan view) (continued). 


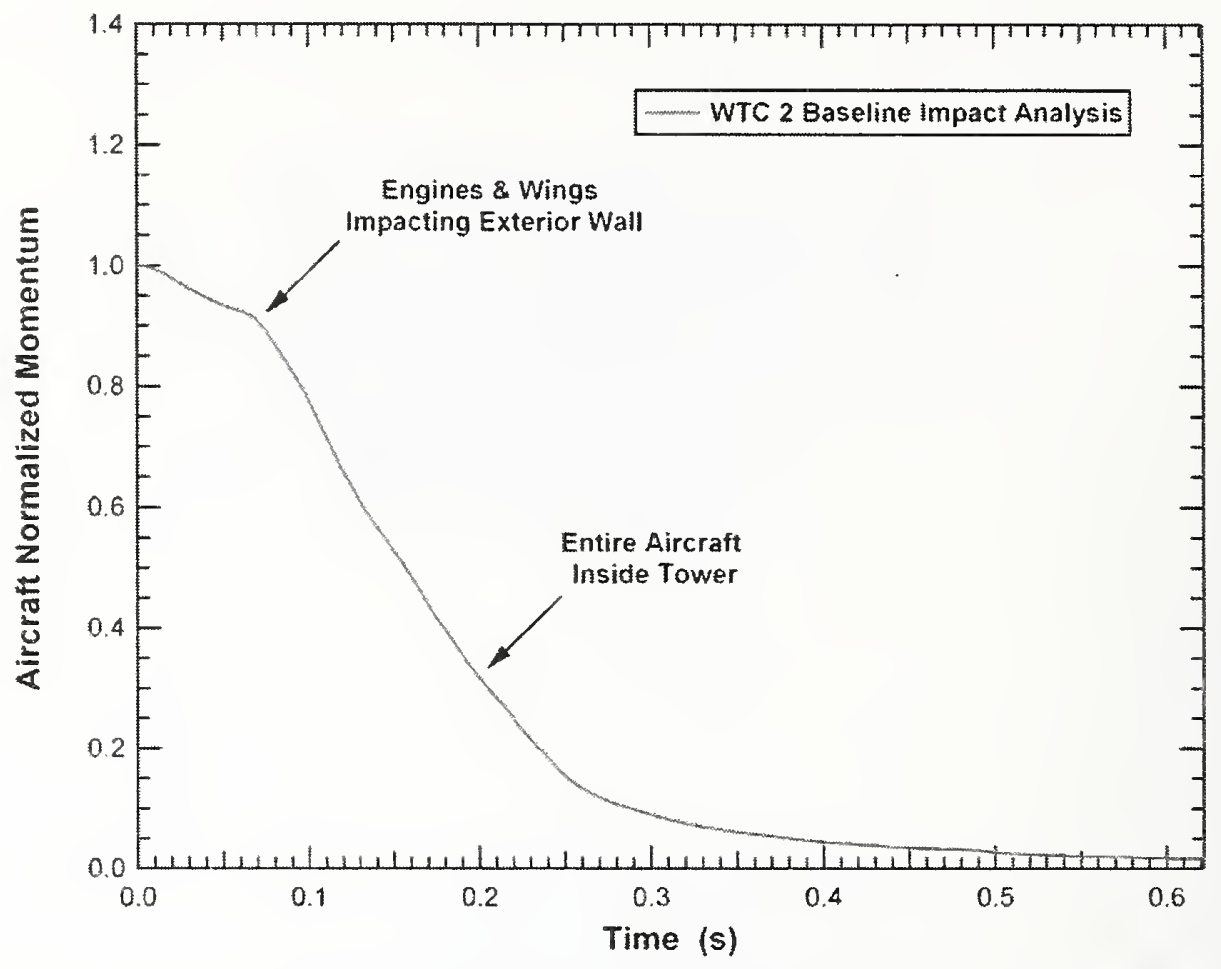

Figure 7-35. Normalized aircraft momentum for the WTC 2 base case impact.

The aircraft was severely broken into thousands of debris fragments of various sizes and mass as a result of the impact with WTC 2. Larger fragments occurred for specific components, such as the engines and landing gear components. This behavior was very similar to the WTC 1 aircraft breakup. A discussion of the location of the engines at the end of the simulation is presented in Section 7.10.2.

\subsubsection{Tower Structural Damage}

The structural damage to the WTC 2 tower by the base case impact conditions is described in this section. The primary structural components of interest were the exterior wall, core columns and core framing components, and the floor structures and concrete floor slab. Only limited results are presented herein. Refer to Chapter 9 of NIST NCSTAR 1-2B for further details.

\section{Exterior Wall Damage}

A comparison of the south exterior wall observed and calculated damage from the base case WTC 2 global impact analysis is shown in Figure 7-36. The calculated impact damage to the exterior wall is shown with color fringes representing plastic strain magnitude, with undamaged sections in blue and strains at or above 5 percent shown in red. The schematic of observed damage was developed from inspections of the film and photographic data collected on the tower after impact. Both the observed and calculated damage regions shown in Figure 7-36 illustrate a region of the exterior wall from column 402 to column 446, extending from floor 76 to floor 86 (spandrels at floors 77 through 86 ). 
The exterior wall completely failed in the regions of the fuselage, engine, and fuel-filled wing section impacts. Damage to the exterior wall extended to the wing tips, but the exterior columns were not completely failed in the outer wing and vertical stabilizer impact regions. Failure of the exterior columns occurred both at the bolted connections between column ends and at various locations in the column, depending on the local severity of the impact load and the proximity of the bolted connection to the impact.

The initial observation from the comparison of the calculated and observed damage was that the geometry and location of the impact damage zone were in good agreement. This agreement in the position and shape of the impact damage served to validate the geometry of the aircraft model, including the aircraft orientation, trajectory, and flight distortions of the wings. The agreement of both the mode and magnitude of the impact damage served to partially validate the constitutive and damage modeling of the aircraft and exterior wall of the tower. Section 7.10.2 provides a detailed comparison of the calculated and observed damage mode and magnitude.

\section{Core Structural Damage}

The core had significant damage in the region close to the impact point, in particular the southeast corner of the core. The columns in line with the aircraft fuselage failed on the impact side, and several of the core beams were also severely damaged or failed in the impact zone. In some cases, failure of the column splices located on floors 77,80 , and 83 contributed significantly to the failure of the core columns. This was particularly true for the heavy column number 1001 at the southeast corner of the core that failed at the three splice locations.

The calculated damage to the core columns by row is shown in Figure 7-37. The columns are shown with color fringes representing plastic strain magnitude, with undamaged sections in blue and strains at or above 5 percent shown in red. A summary of the column damage is listed in Table 7-6. The qualitative classification of the column damage levels were provided previously in Figure 7-7. The damage to the core beams for floors 80 and 81 is shown in Figure 7-38. 


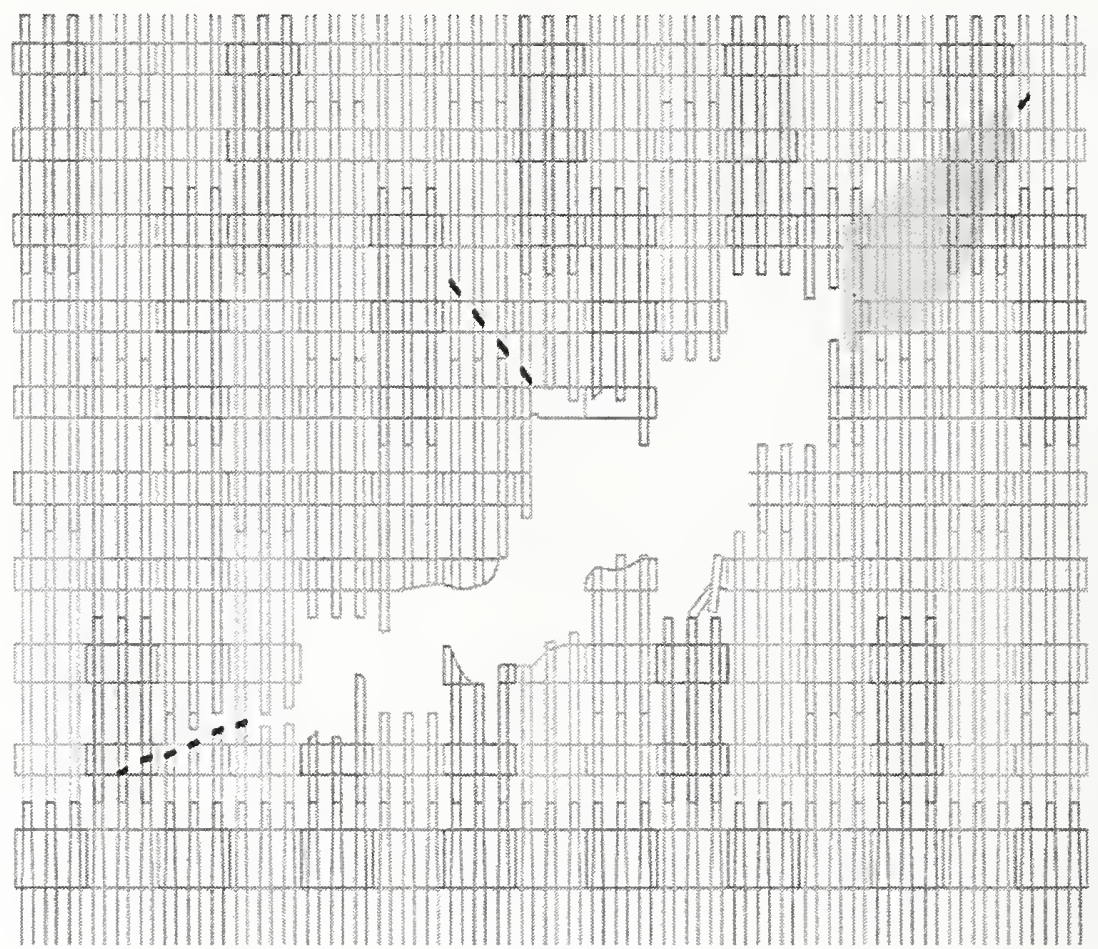

(a) Schematic of observed damage

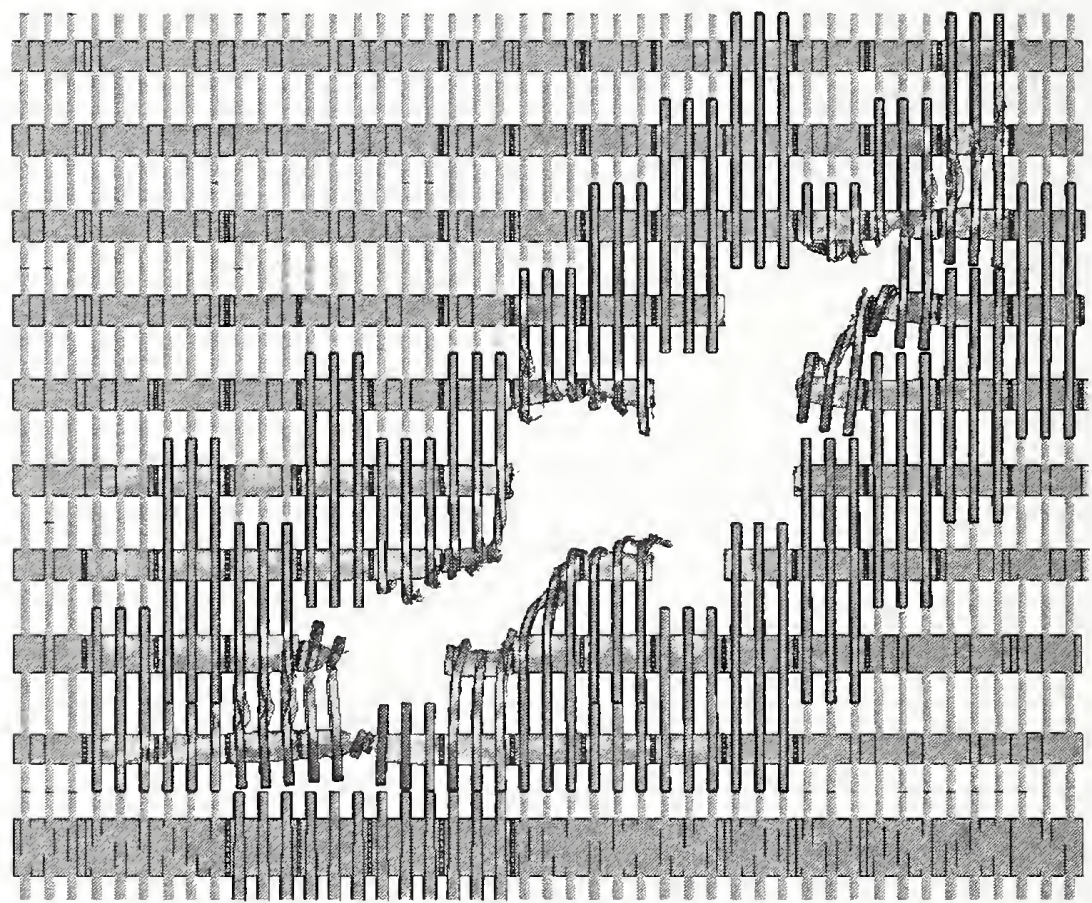

(b) Calculated damage

Figure 7-36. Base case impact damage to the WTC 2 exterior wall. 


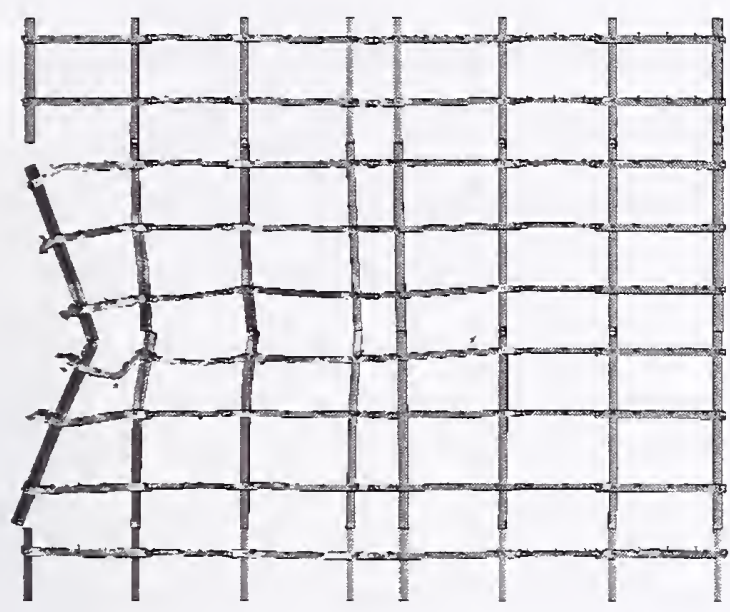

(a) Columns 1001-1008

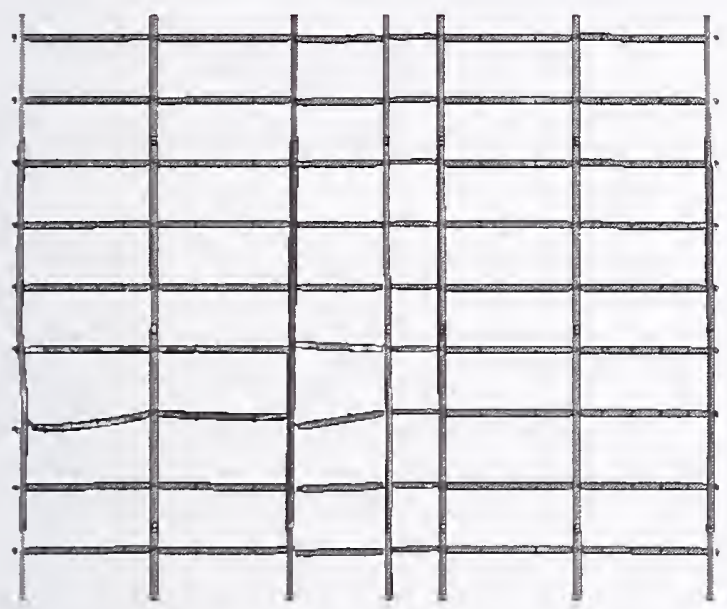

(c) Columns $801-807$

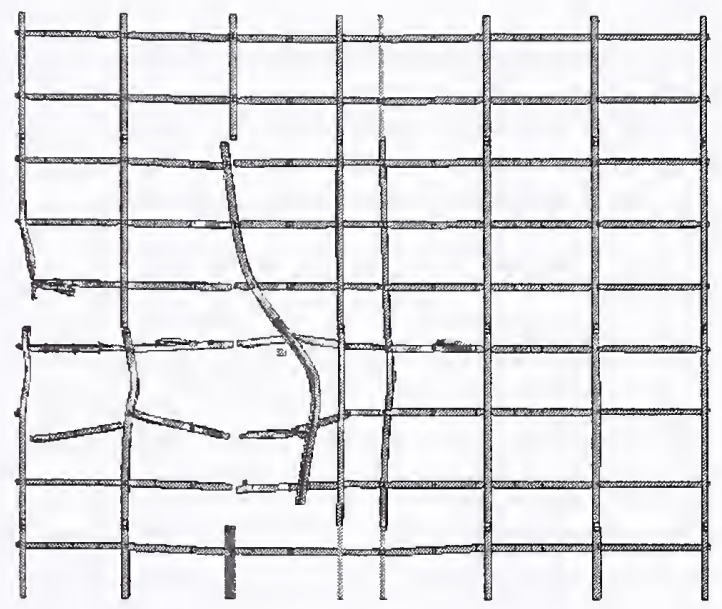

(b) Columns 901-908

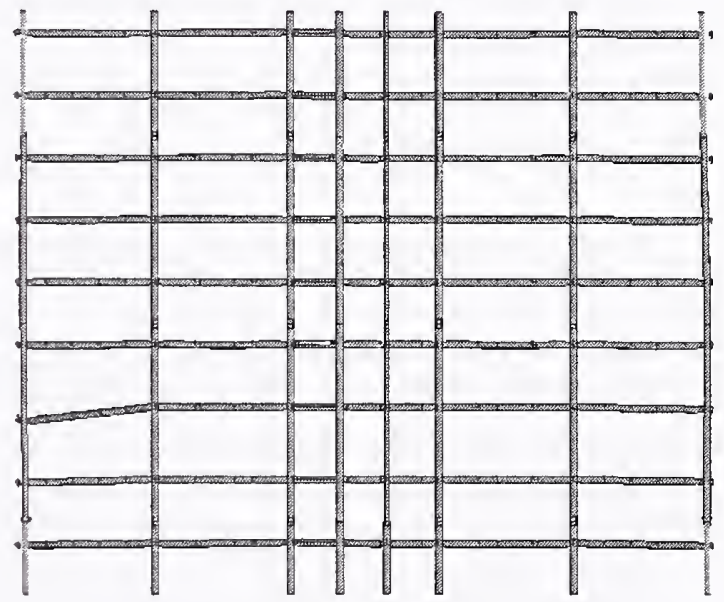

(d) Columns 701-708

Figure 7-37. Base case impact damage to the WTC 2 core columns.

\section{Floor Truss and Slab Damage}

An overall frontal view for the floor truss structure in the WTC 2 impact zone, along with the calculated base case impact damage to the trusses, is shown in Figure 7-39. The figure shows that the trusses experienced significant damage in the impact zone, with the largest amount of damage on floor 81 . A plan view of the calculated damage to the trusses on floors 80 and 81 is shown in Figure 7-40. The calculated impact response produced severe damage to the truss structures in the primary impact path of the fuselage. The truss structures were severely damaged from the exterior wall to the core. The truss floor system on floors 79 and 81 had sufficient damage from the impact that truss floor sections sagged downward as a result of the impact. 
Table 7-6. Summary of core column damage for the base case WTC 2 impact.

\begin{tabular}{|c|c|c|c|}
\hline Column & Location & Damage Level & $\begin{array}{c}\text { Lateral Deflection of } \\
\text { Column Cen terline } \\
\text { (in.) }\end{array}$ \\
\hline Column $\mathbf{8 0 1}$ & Floor 79 & Heavy & 10 \\
\hline Column 901 & Floors 79-82 & Severed & \\
\hline Column 902 & Floor 79 & Heavy & 32 \\
\hline Column 903 & Floors 77-83 & Severed & \\
\hline Column 904 & Floor 79 & Moderate & 18 \\
\hline Column 905 & Floor 79 & Heavy & \\
\hline Column $\mathbf{1 0 0 1}$ & Floors 77-83 & Severed & \\
\hline Column $\mathbf{1 0 0 2}$ & Floors 79-81 & Severed & \\
\hline Column $\mathbf{1 0 0 3}$ & Floor 80 & Severed & \\
\hline Column $\mathbf{1 0 0 4}$ & Floor 80 & Heavy & \\
\hline
\end{tabular}

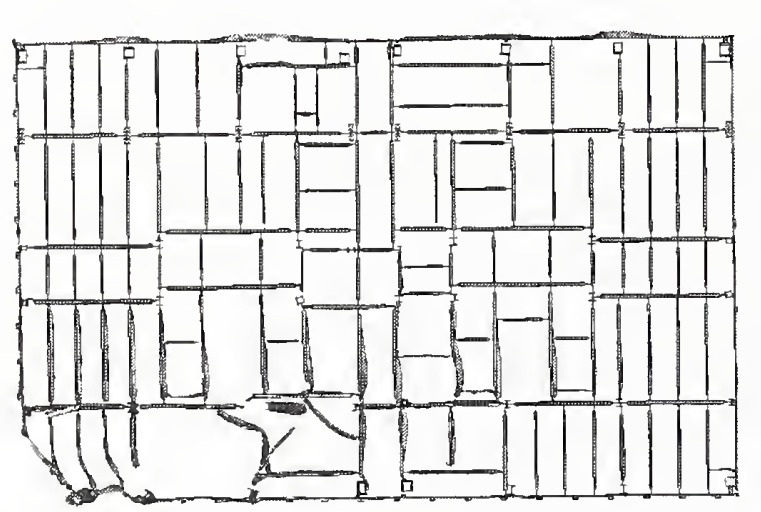

(a) Floor 80 core framing damage

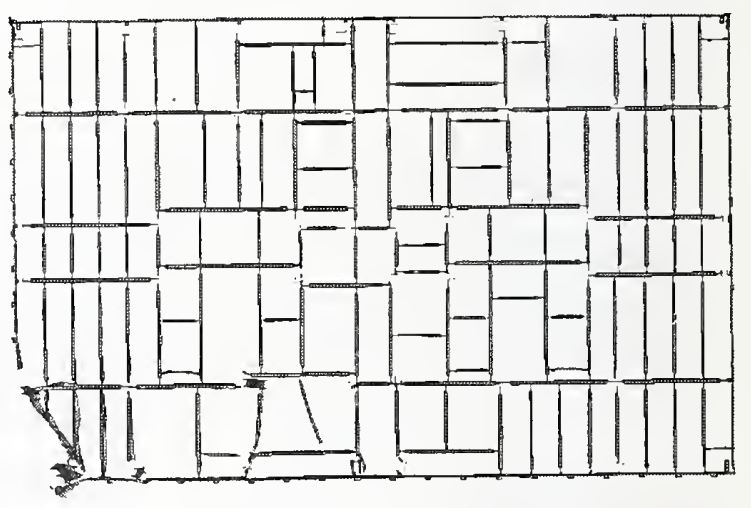

(b) Floor 81 core framing damage

Figure 7-38. Base case impact damage to the core beams of floors 80 and 81 of WTC 2. 
Floor 82

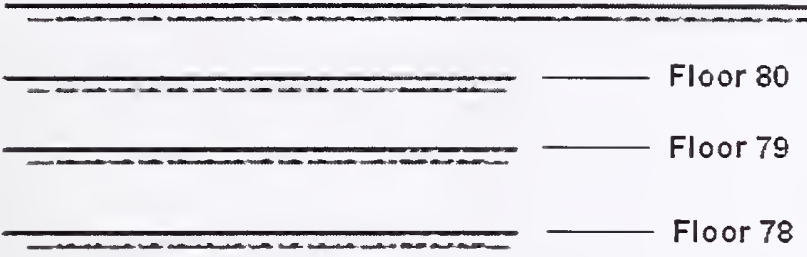

(a) Initial detailed truss structures

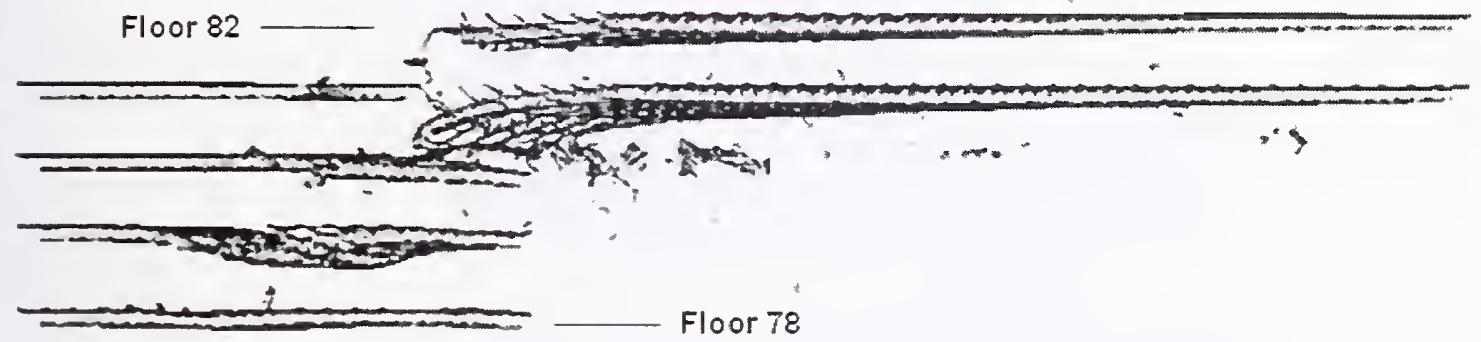

(b) Calculated damage

Figure 7-39. Base case impact damage to the WTC 2 floor trusses (front view).

The calculated damage to the WTC 2 floor slabs for floors 80 and 81 is shown in Figure $7-41$. The fringes of damage were set such that the concrete failed in the regions colored red ( 2 percent plastic strain). In these regions, it is expected that the concrete had been severely damaged and potentially removed, exposing the supporting metal decking. The strength of the floor slab was severely reduced in the analysis beyond this strain to model the residual strength of the metal deck after the concrete failure, breakup, and removal. At a plastic strain of 30 percent, corresponding to failure levels for the metal decking material, the elements were eroded (seen as holes ruptured in the floor slab shown). 


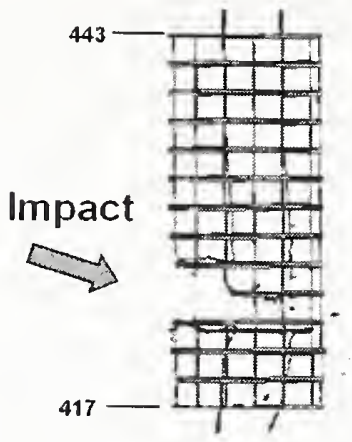

(a) Floor 80 truss damage
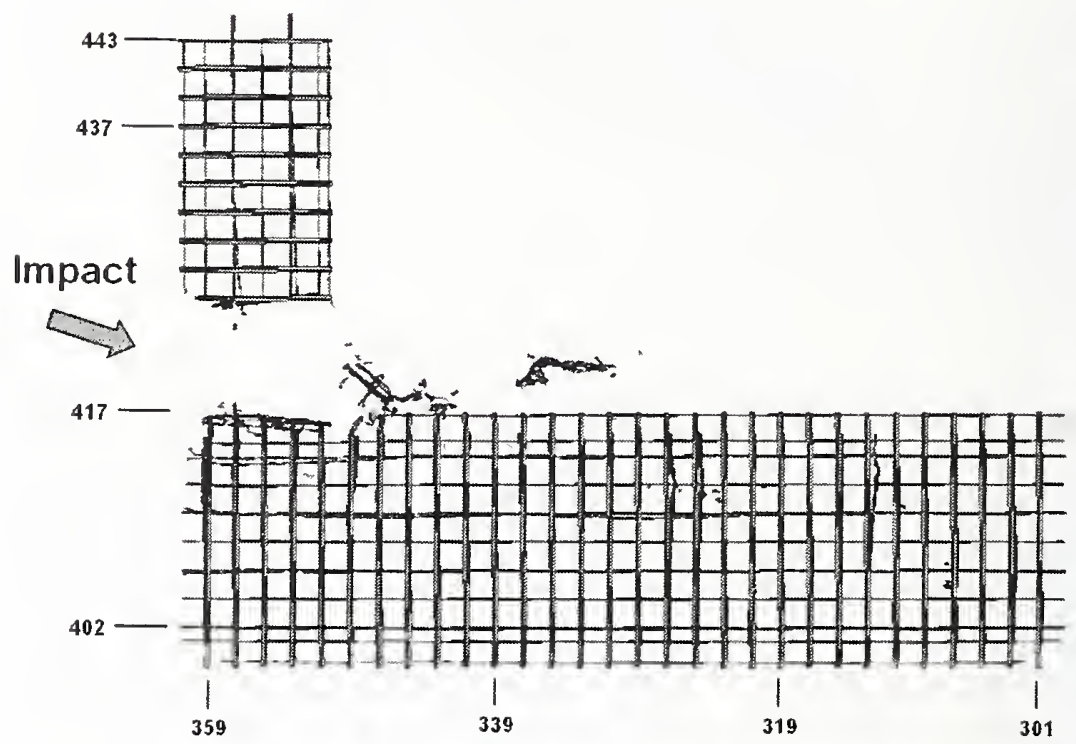

(b) Floor 81 truss damage

Figure 7-40. Base case impact damage to the trusses on floors 80 and 81 of WTC 2 (plan view). 


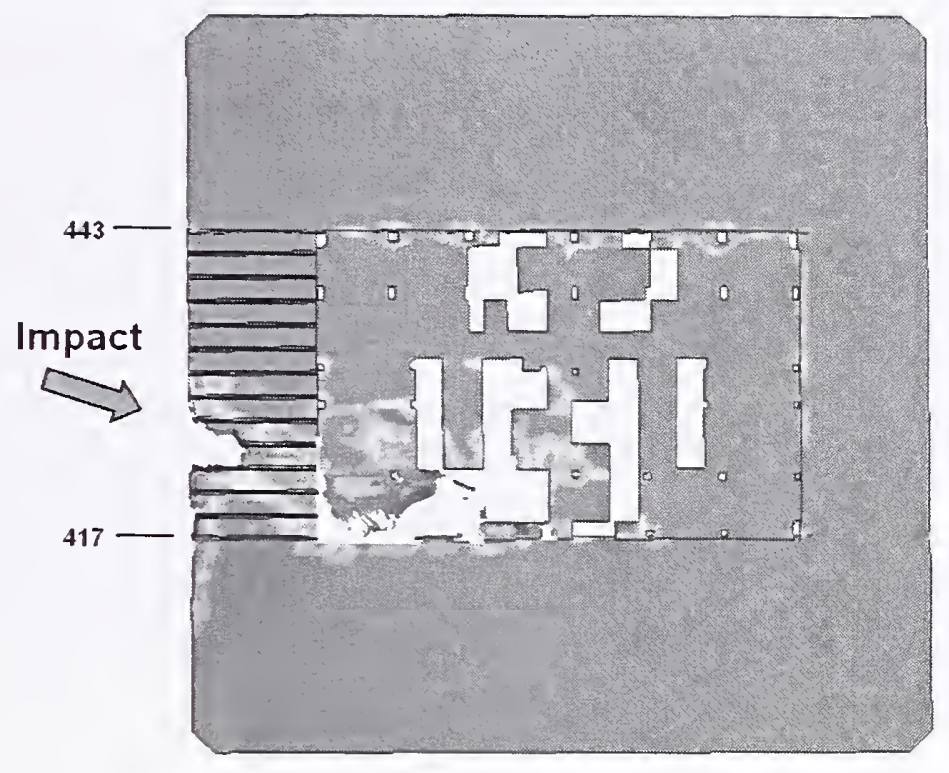

(a) Floor 80 slab damage

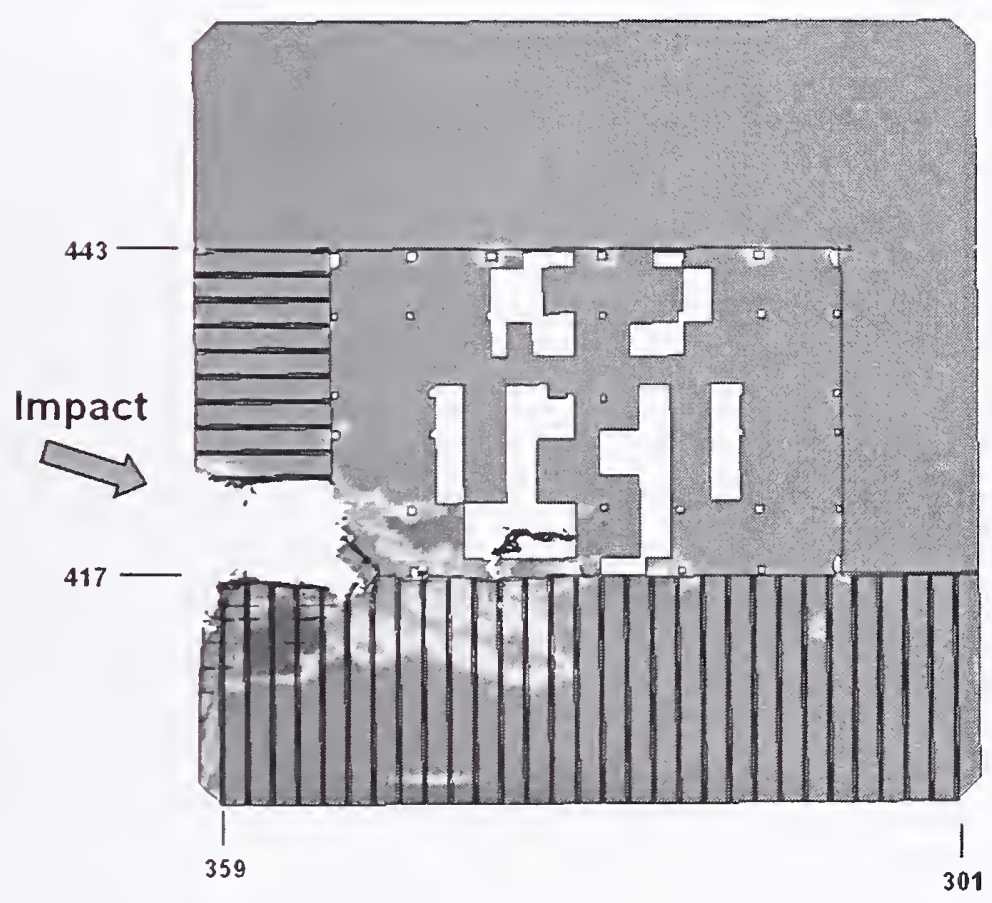

(b) Floor 81 slab damage

Figure 7-41. Base case impact damage to the slabs on floors 80 and 81 of WTC 2 (plan view).

\section{Summary of Structural Damage}

The impact-induced structural damage described above was used as the initial conditions for the postimpact fire-structural analyses. Figure $7-42$ shows a summary of the structural damage to the core 
columns and floor systems at floors 77 through 83 of WTC 2 for the base case (Case C). The damage to the columns at the various levels is identified by the color of the circles, where red, blue, green, and yellow signify severed, heavily damaged, moderately damaged, and lightly damaged columns, respectively. The dotted boxes on the figures indicate areas where the impact created an opening in the floor. These were used to identify openings in the floor slab in the fire dynamics simulations (NIST NCSTAR 1-5F). The solid boxes indicate areas in the floor system that had severe structural damage. These areas were removed from the subsequent structural analyses (NIST NCSTAR 1-6).

Figure 7-43 presents the cumulative damage to WTC 2 on all affected floors and columns. The figure shows the damage to the south exterior wall due to impact, based on photographs of the south walls. Note that damage to columns 407 through 409 was based on the analysis results, since this area was obscured by smoke in the photographs. Figure 7-43 also shows the damage to columns on the north perimeter wall, which the analysis did not capture due to the coarse mesh on the north wall. This damage was observed in photographs (see Section 7.10.2). As a result, this damage was accounted for in the subsequent structural analyses (NIST NCSTAR 1-6). 


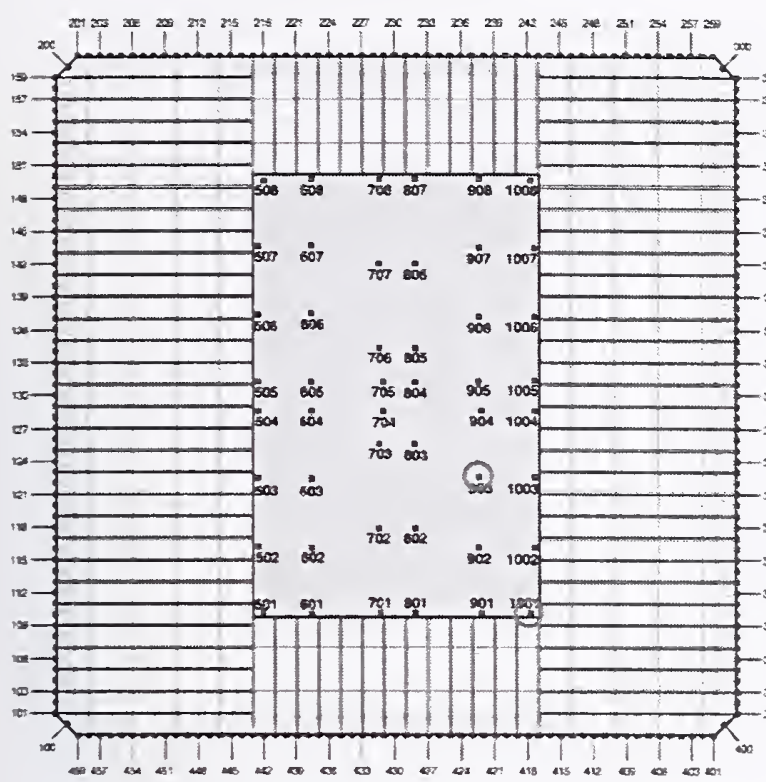

(a) Floors 77 and 78

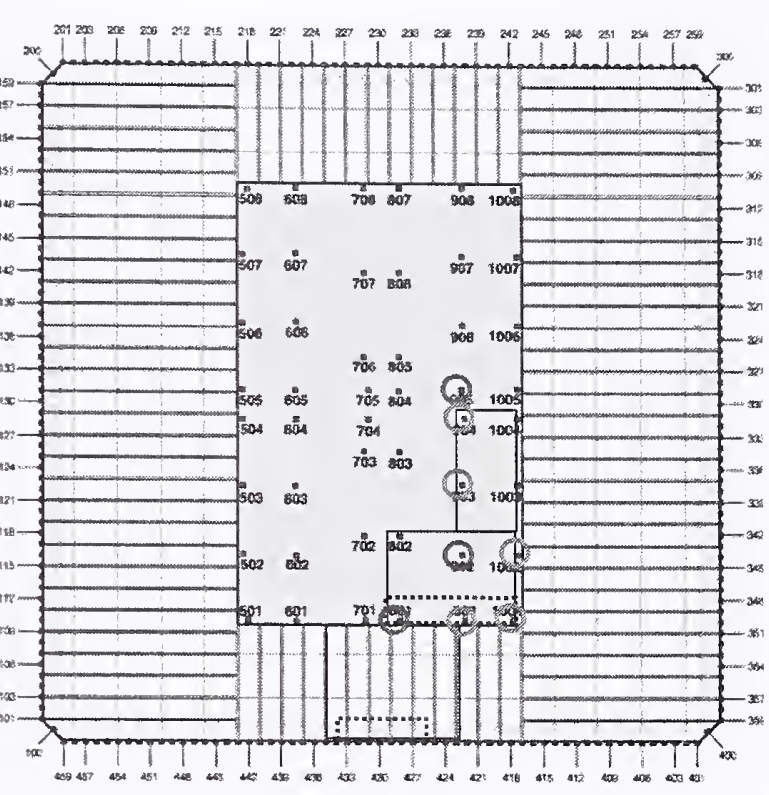

(b) Floor 79

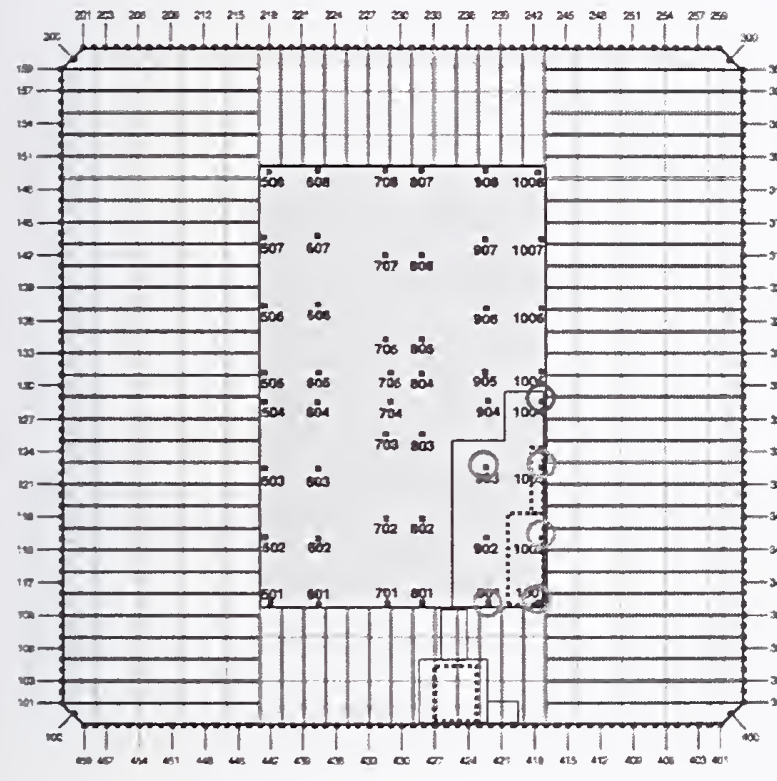

(c) Floor 80

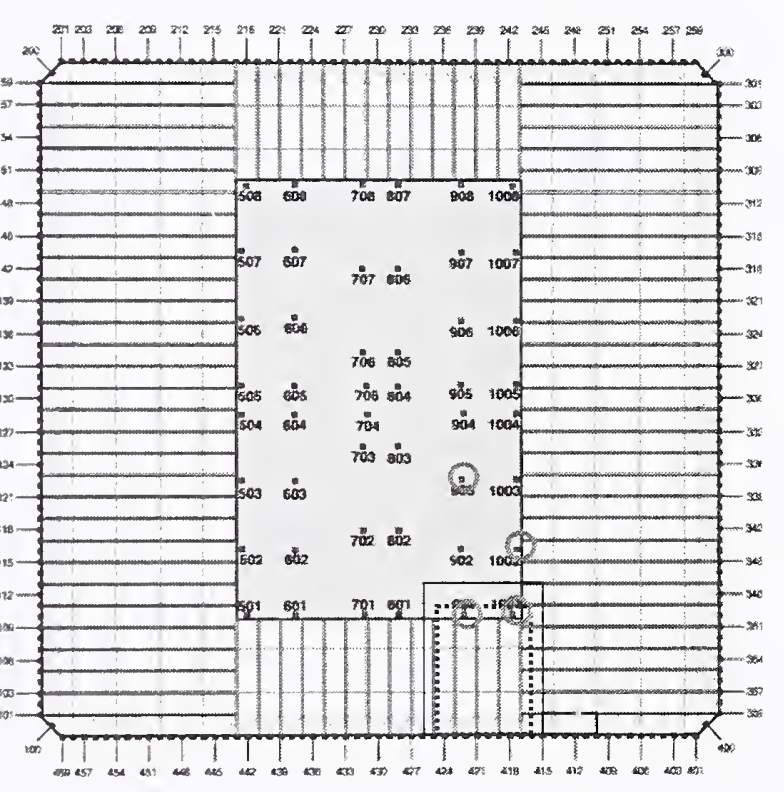

(d) Floor 81

Figure 7-42. Summary of the floor-by-floor structural damage to the floors and columns of WTC 2 (base case). 


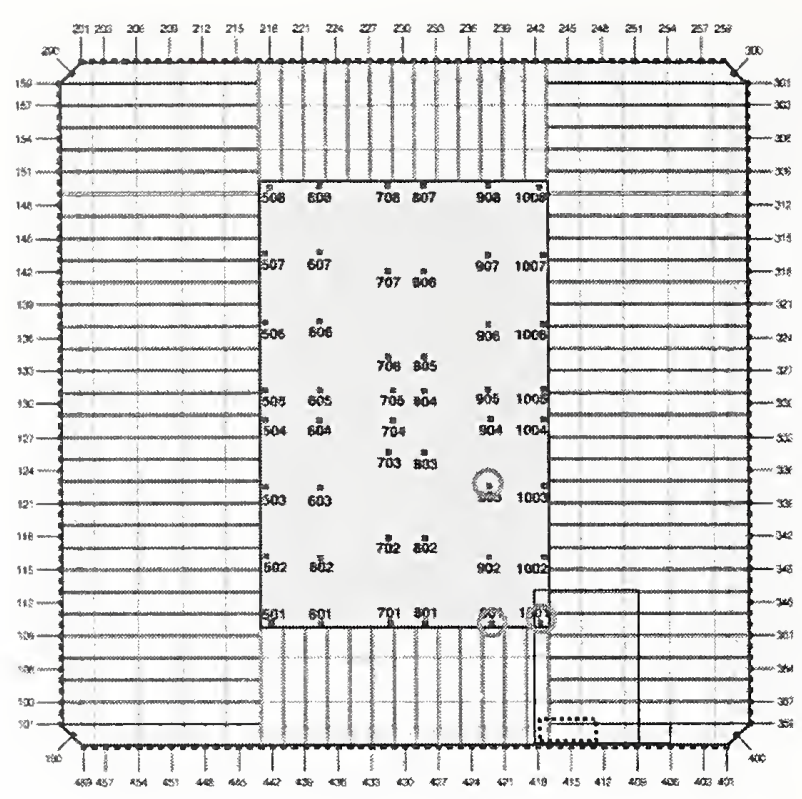

(c) Floor 82

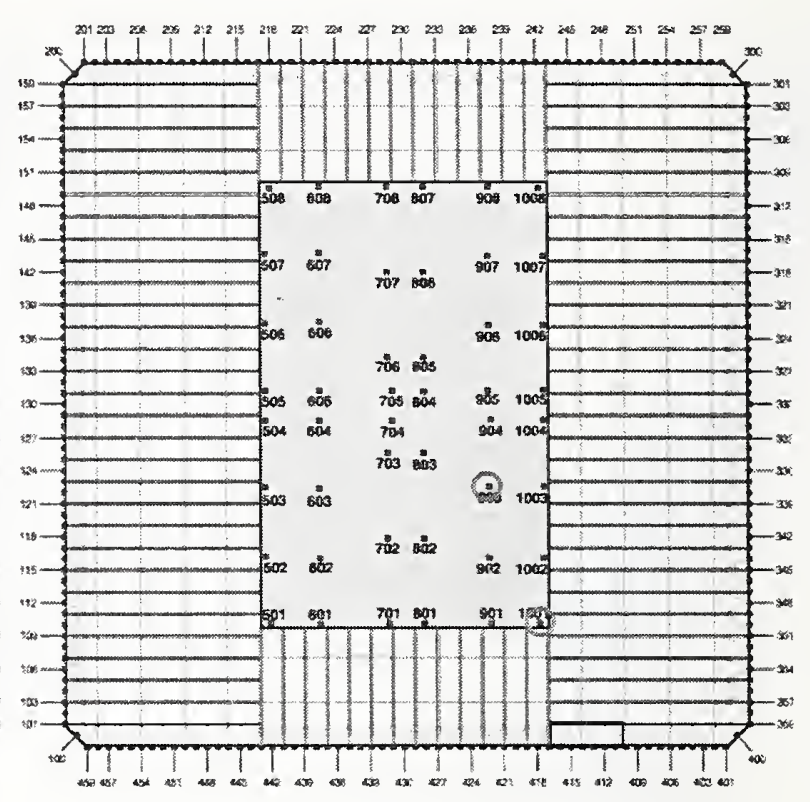

(d) Floor 83

Severe Floor Damage

Floor system

structural damage $\square$

Floor system

removed

:a......

\section{Column Damage}

Severed

Heavy Damage

Moderate Damage

Light Damage

Figure 7-42. Summary of the floor-by-floor structural damage to the floors and columns of WTC 2 (base case) (continued). 


\section{Severe Floor Damage \\ Floor system structural damage $\square$ \\ Floor system removed}

\section{Column Damage}

Severed

Heavy Damage

Moderate Damage

Light Damage

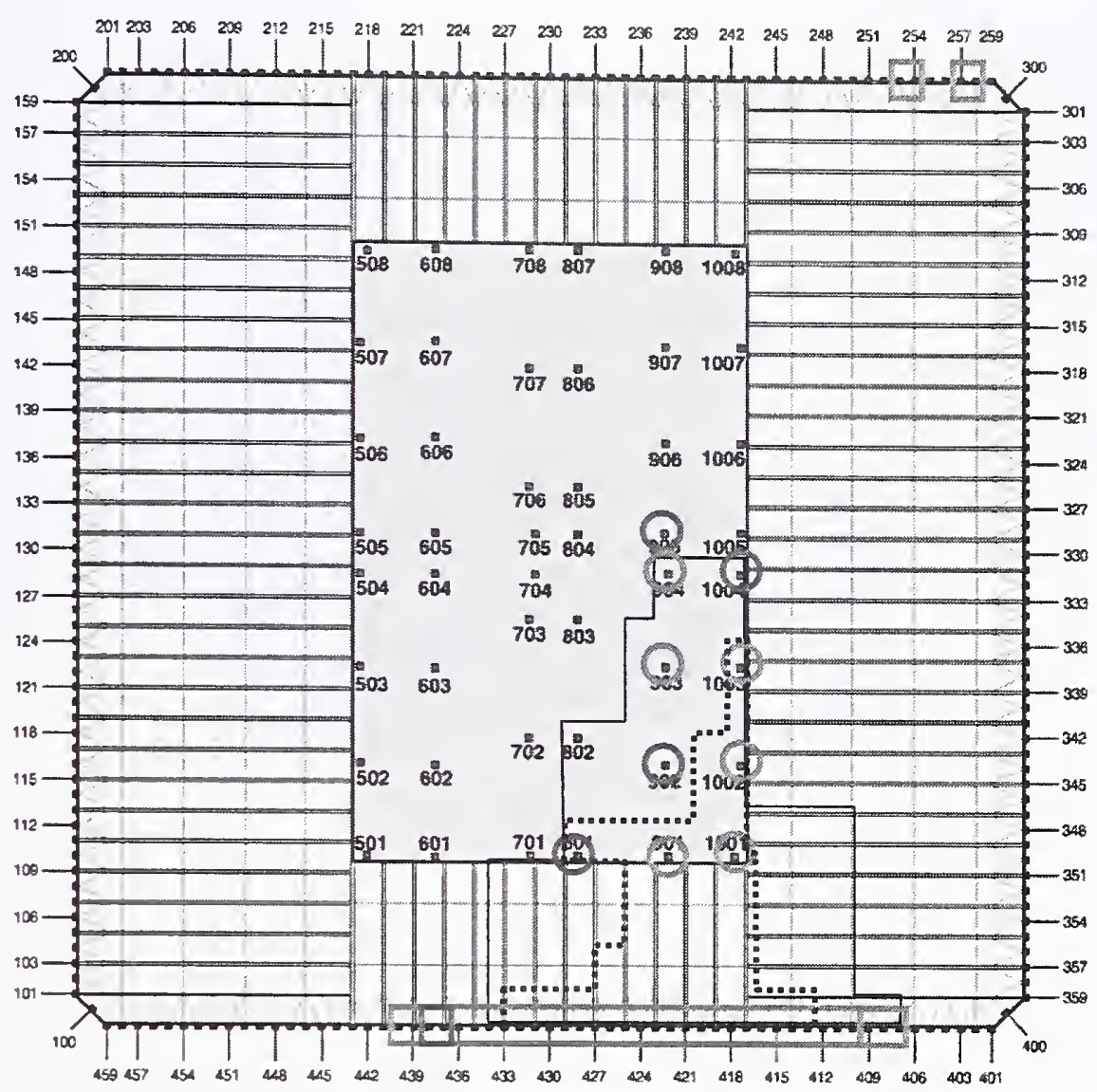

Figure 7-43. Cumulative structural damage to the floors and columns of WTC 2 (base case).

\subsubsection{Fuel and Debris Distributions}

The global impact results presented in this section include the distribution of the jet fuel and aircraft debris in the WTC 2 towcr, and the damage to the building contents (partition walls and workstations). For the base case WTC 2 global impact analysis, the calculated distribution of the fuel in the tower and shape of the fuel cloud in a plan view and side view are shown in Figure 7-44. At the end of the analysis, the residual momentum of the jet fuel in the impact direction was less than one percent of the initial momentum, indicating that the fuel cloud was nearly at rest at about $0.62 \mathrm{~s}$.

To more clearly present the calculated response of the structures that influenced the fire propagation, the structural components were removed from the visualization, with the exception that the core columns were maintained in the visualizations for reference positions. A plan view of the response of the remaining building contents and aircraft debris are shown in a plan view in Figure 7-45. Similar plan views of floor 80 and 81 slices through the building contents and debris field are provided in Figure 7-46 and Figure 7-47, respectively. The bulk of the aircraft debris and fuel was arrested prior to exiting the tower structures. However, a significant amount of aircraft debris was calculated to exit the north and east sides of the tower (Sides 300 and 200 of WTC 2). 
Plots of debris distribution and damage to tower contents at the end of the impact simulation similar to those in Figure 7-46(c) and Figure 7-47(c), were used to estimate the damage to fireproofing. The extent of dislodgcd fireproofing was estimated by considering fireproofing damage only to structural components in the direct path of debris. For details of the methodology and the extent of fireproofing damage, see NIST NCSTAR 1-6.

A quantitative characterization of the fuel and aircraft debris distribution was obtained by slicing the model at vertical floor locations and calculating the mass at each floor level. A summary of the floor-byfloor fuel and debris distributions is given in Table 7-7. The bulk of the fuel and aircraft debris was deposited in floors 78 through 80 , with the greatest concentration of aircraft debris on floor 80 , and the largest concentration of aircraft fuel on floors 79, 81, and 82. Approximately 14,000 lb, or 5 percent, of the total aircraft mass was eliminated from the debris cloud in the final state as a result of the erosion in the aircraft structures due to impact and breakup. This eroded mass was maintained in the calculation but eliminated from consideration in the contact algorithm. As a result, any residual momentum at the time of erosion could not be subsequently transferred to the tower.

The calculated debris distribution included 55,800 lbs of debris and 10,600 lbs of aircraft fuel outside of the tower at the end of the impact analysis, either rebounding from the impact face or passing through the tower. These estimates of mass outside the tower were expected to be overestimated in the calculation since the exterior walls were not modeled with windows that could contain the fuel cloud and small debris inside the towers. In addition, the impact behavior of the aircraft fuel cloud did not include the ability to stick to, or wet, interior components. Rather the aircraft fuel SPH particles tended to bounce off of internal structures (see Section 7.3.3). 
Time $=0.6219$

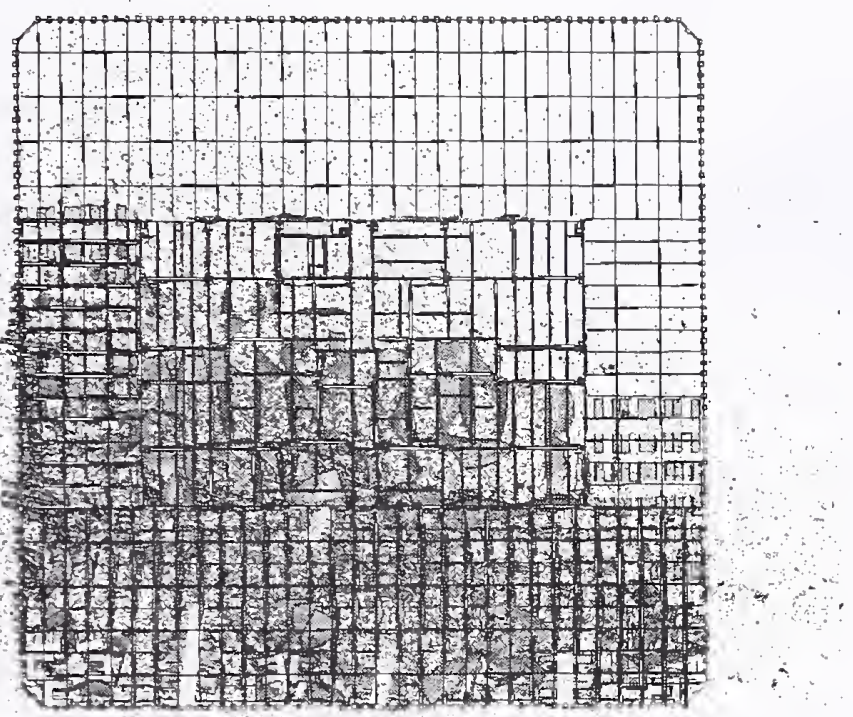

(a) Plan view (floor slab removed)

Time $=0.6219$

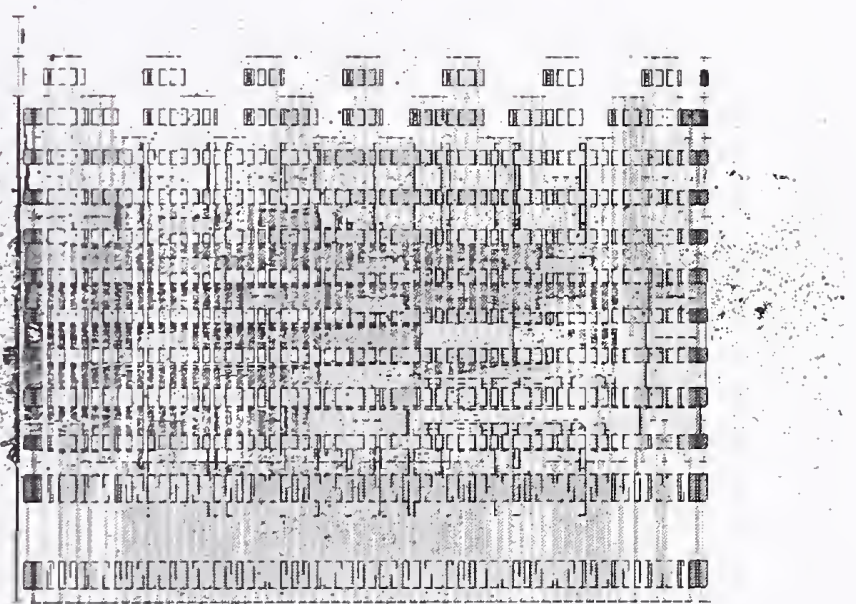

(b) Side view

Figure 7-44. Calculated fuel distribution in the base case WTC 2 analysis. 


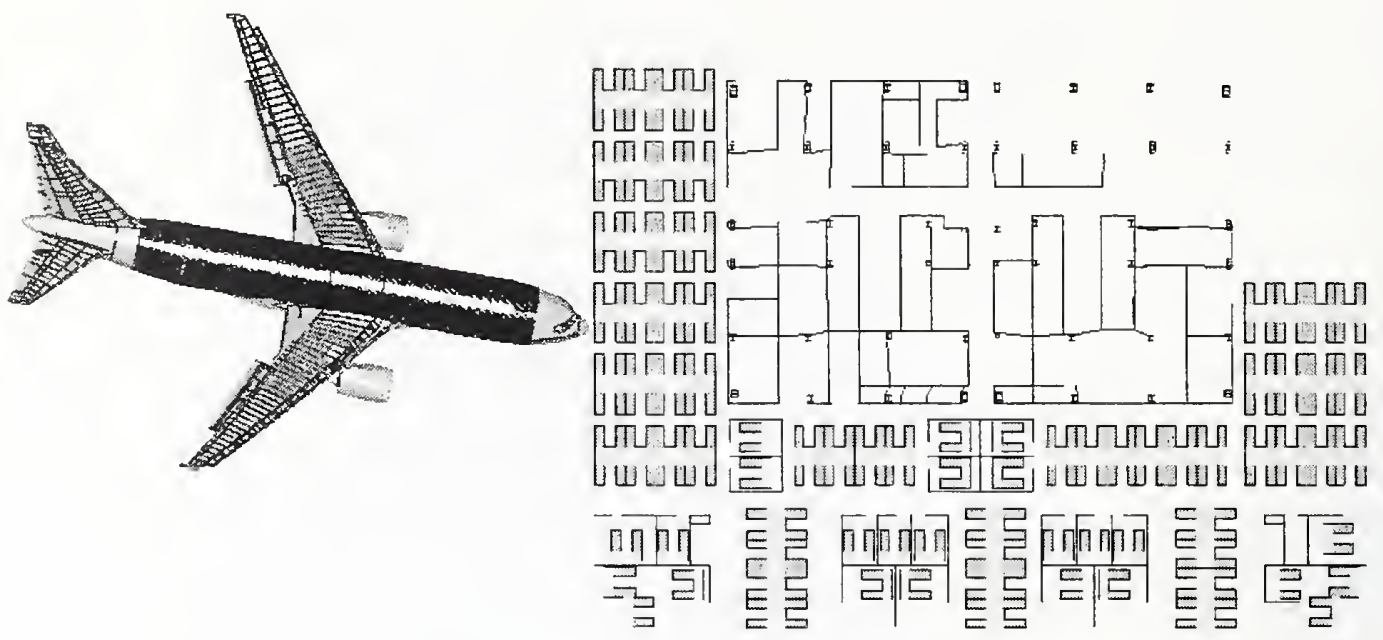

(a) Pre-impact configuration

Time $=\quad 0.6219$
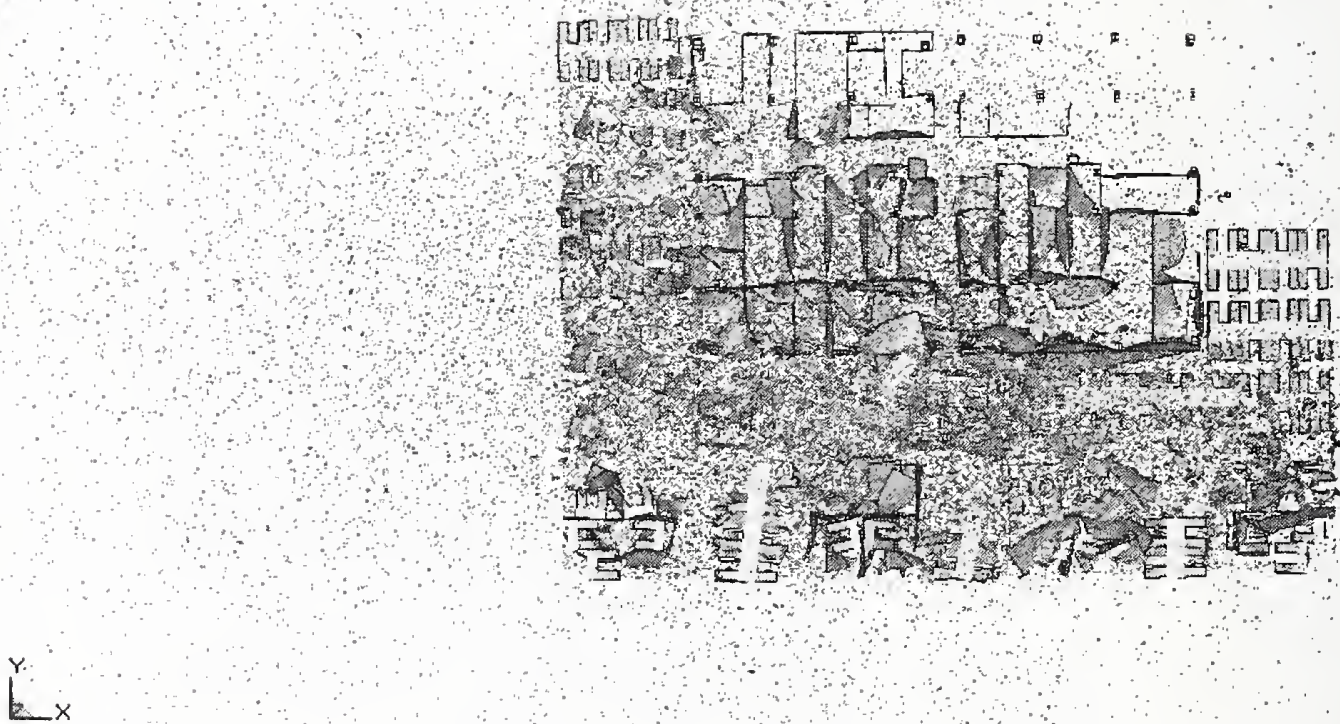

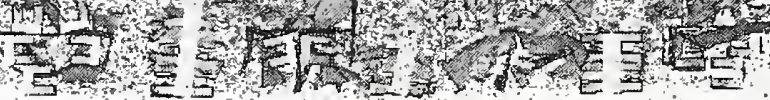

(b) Calculated impact response

Figure 7-45. Plan view of calculated WTC 2 building, fuel, and aircraft debris distribution for the base case. 


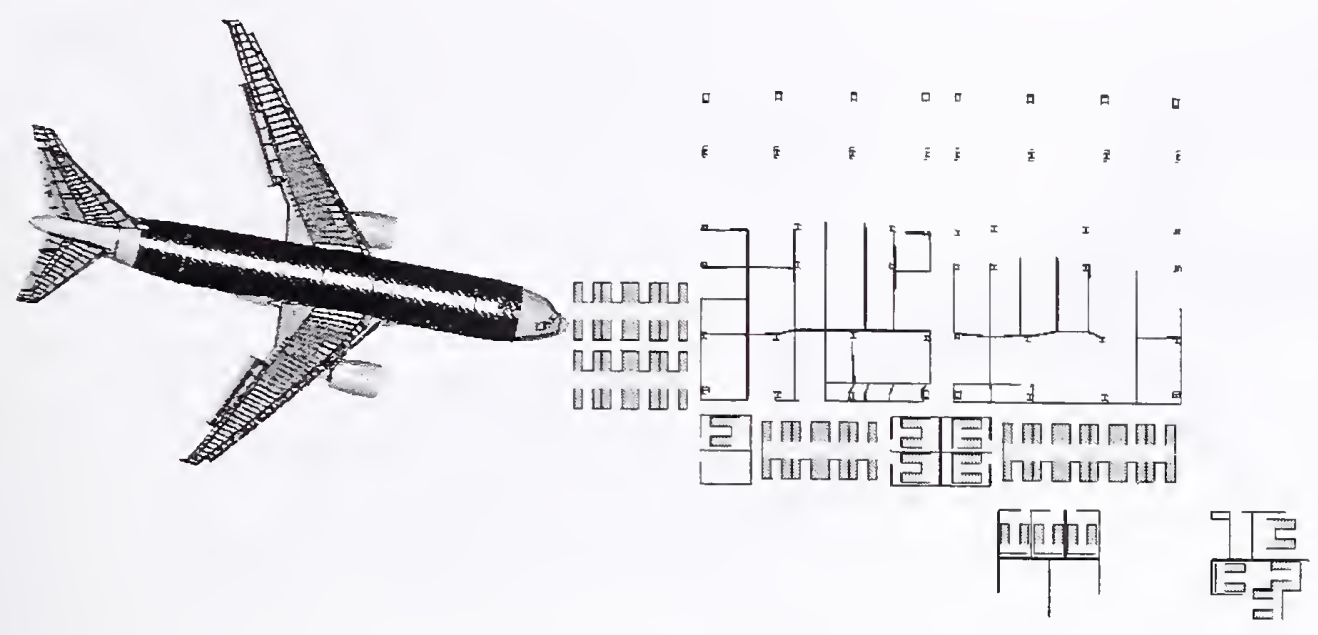

(a) Pre-impact configuration

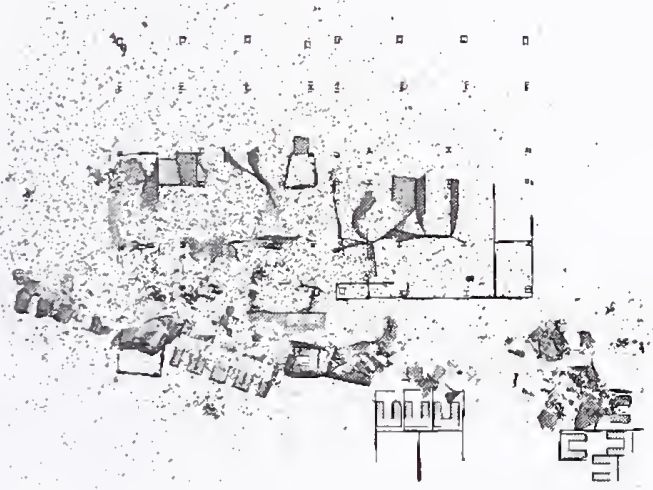

(b) Calculated impact response

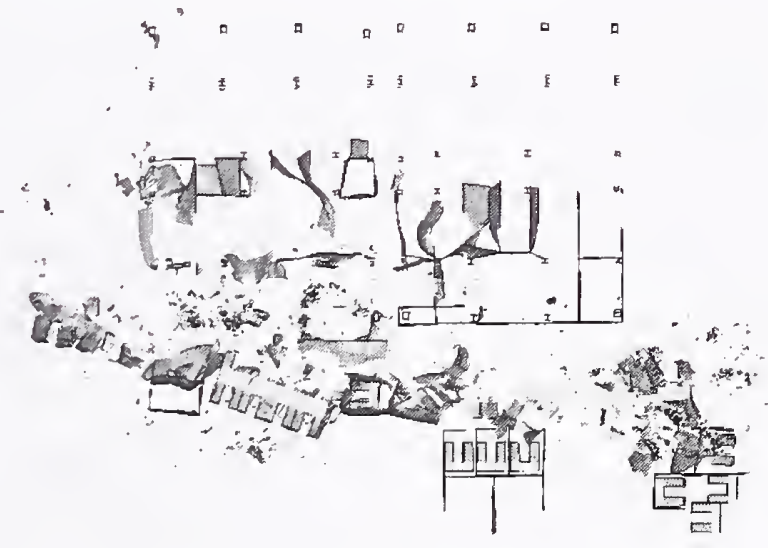

(c) Calculated impact response (fuel removed)

Figure 7-46. Calculated floor 80 contents, and fuel distribution (base case). 


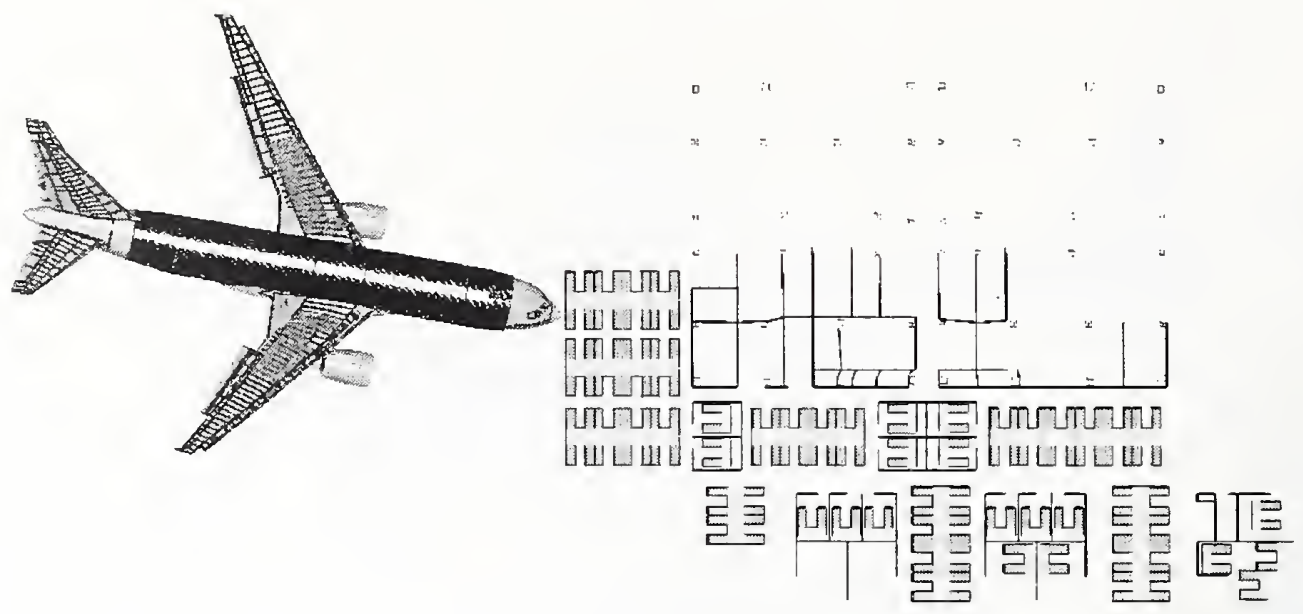

(a) Pre-impact configuration

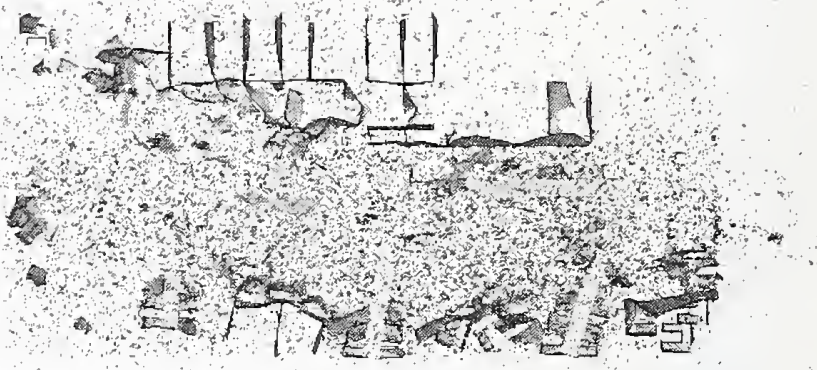

(b) Calculated impact response

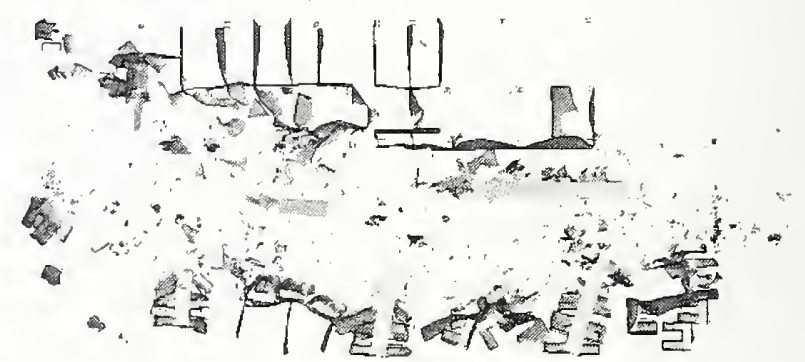

(c) Calculated impact response (fuel removed)

Figure 7-47. Calculated floor 81 contents and fuel distribution (base case). 
Table 7-7. Fuel and aircraft debris distribution for the base case WTC 2 impact.

\begin{tabular}{|l|c|c|}
\hline \multicolumn{1}{|c|}{ Tower Location } & Aircraft Fuel & Aircraft Debris \\
\hline Total Outside Tower & $10,600 \mathrm{lb}$ & $55,800 \mathrm{lb}$ \\
\hline WTC 2 Floor 77 & $1,300 \mathrm{lb}$ & $400 \mathrm{lb}$ \\
\hline WTC 2 Floor 78 & $6,200 \mathrm{lb}$ & $4,800 \mathrm{lb}$ \\
\hline WTC 2 Floor 79 & $11,400 \mathrm{lb}$ & $16,200 \mathrm{lb}$ \\
\hline WTC 2 Floor 80 & $6,000 \mathrm{lb}$ & $83,800 \mathrm{lb}$ \\
\hline WTC 2 Floor 81 & $14,400 \mathrm{lb}$ & $27,300 \mathrm{lb}$ \\
\hline WTC 2 Floor 82 & $10,600 \mathrm{lb}$ & $3,600 \mathrm{lb}$ \\
\hline WTC 2 Floor 83 & $1,500 \mathrm{lb}$ & $4,300 \mathrm{lb}$ \\
\hline WTC 2 Floor 84 & $200 \mathrm{lb}$ & $500 \mathrm{lb}$ \\
\hline Total Weight & $62,000 \mathrm{lb}$ & $197,600 \mathrm{lb}$ \\
\hline
\end{tabular}

\section{7} WTC 2 MORE SEVERE IMPACT ANALYSIS - CASE D

This case is referred to as Case D for the remainder of the WTC Investigation reports.

In addition to the base case impact analysis described in Section 7.6, two more impact analyses were performed for WTC 2 to provide a range of calculated impact-induced damage. The variations in impact analysis parameters were developed based on the results of the sensitivity analyses and additional evaluations of the parameter uncertainties (see Chapter 8 of NIST NCSTAR 1-2B). These analyses included a more severe and a less severe case. Presented herein is the more severe case only.

The parameters for the more severe impact scenario are compared to the corresponding parameters in the base case analysis in Table 7-8. For the flight parameters, the impact speed was $570 \mathrm{mph}$ in the more severe impact scenario, which was the upper bound obtained from the analysis of aircraft impact conditions described in Chapter 6. The aircraft vertical trajectory angle was also varied from 6 degrees in the base case to 5 degrees for the more severe impact scenario, which resulted in more impact energy directed inward toward the core. The lateral trajectory was not varied in this analysis so that the starboard engine trajectory was aligned with exiting the northeast corner of the tower, as was observed from photographic evidence (see Section 7.10.2). 
Table 7-8. Input parameters for the more severe WTC 2 impact analysis.

\begin{tabular}{|c|c|c|c|c|}
\hline \multicolumn{2}{|c|}{ Analysis Parameters } & Base Case & More Severe & Less Severe \\
\hline \multirow{5}{*}{$\begin{array}{c}\text { Flight } \\
\text { Parameters }\end{array}$} & Impact Velocity & $546 \mathrm{mph}$ & $570 \mathrm{mph}$ & $521 \mathrm{mph}$ \\
\hline & Trajectory - pitch & $6.0^{\circ}$ & $5.0^{\circ}$ & $8.0^{\circ}$ \\
\hline & Trajectory - yaw & $13.0^{\circ}$ & $13.0^{\circ}$ & $13.0^{\circ}$ \\
\hline & Orientation - pitch & $5.0^{\circ}$ & $4.0^{\circ}$ & $7.0^{\circ}$ \\
\hline & Orientation - yaw & $10.0^{\circ}$ & $10.0^{\circ}$ & $10.0^{\circ}$ \\
\hline \multirow{2}{*}{$\begin{array}{c}\text { Aircraft } \\
\text { Parameters }\end{array}$} & Weight & 100 percent & 105 percent & 95 percent \\
\hline & Failure Strain & 100 percent & 115 percent & 75 percent \\
\hline \multirow{3}{*}{$\begin{array}{c}\text { Tower } \\
\text { Parameters }\end{array}$} & Contents Strength & 100 percent & 80 percent & 100 percent \\
\hline & Failure Strain & 100 percent & 90 percent & 120 percent \\
\hline & Live Load Weight & 25 percent & 20 percent & 25 percent \\
\hline
\end{tabular}

For WTC 2, the variations in the parameters from the base case were similar to those for WTC 1 (see Table 7-3), with two exceptions. The first exception was the introduction of the strength of the building contents as a parameter. There was less information available about the layout of building contents in the WTC 2 impact zone and therefore a larger uncertainty associated with the contents was assumed (the workstation layout from WTC 1 was used for WTC 2). Thus, in the more severe case, the contents strength was reduced to 80 percent of the baseline value.

The second exception was the failure strains for the aircraft and tower materials. For the more severe WTC 1 analysis, 125 percent and 80 percent of the baseline values were used for the aircraft and tower failure strains, respectively. For the more severe WTC 2 analysis, 115 percent and 90 percent of the baseline values were used. The more severe WTC 2 analysis was the final global impact analysis performed. Based on the previous analyses, the variation in damage levels indicated that the WTC 2 more severe impact analysis would produce impact damage state that was not viable (e.g., the amount of debris exiting the north wall). To ensure that a viable damage state was obtained, the aircraft and tower materials were adjusted to the values presented in Table 7-8.

Table 7-8 provides also the parameters used in the less severe damage case. As can be seen from the table, the parameters are selected to provide for a stronger tower and a weaker aircraft to yield less damage to the tower structure.

\subsubsection{Impact Response}

The impact response of WTC 2 for the more severe case is shown in side and plan views in Figure 7-48 and Figure $7-49$, respectively. The response is shown at intervals of $0.1 \mathrm{~s}$ from impact through the initial $0.5 \mathrm{~s}$ of the response. Comparing the more severe impact response in Figure 7-48 and Figure 7-49 with the base case response in Figure 7-33 and Figure 7-34, it can be seen that the two responses were very similar with two exceptions. These were the slightly compressed time scale and the larger amount of debris exiting the north wall in the more severe case. These differences were due primarily to the larger impact speed, the increased weight and material toughness of the aircraft, and the reduced contents mass and material toughness of the towers for the more severe case. 


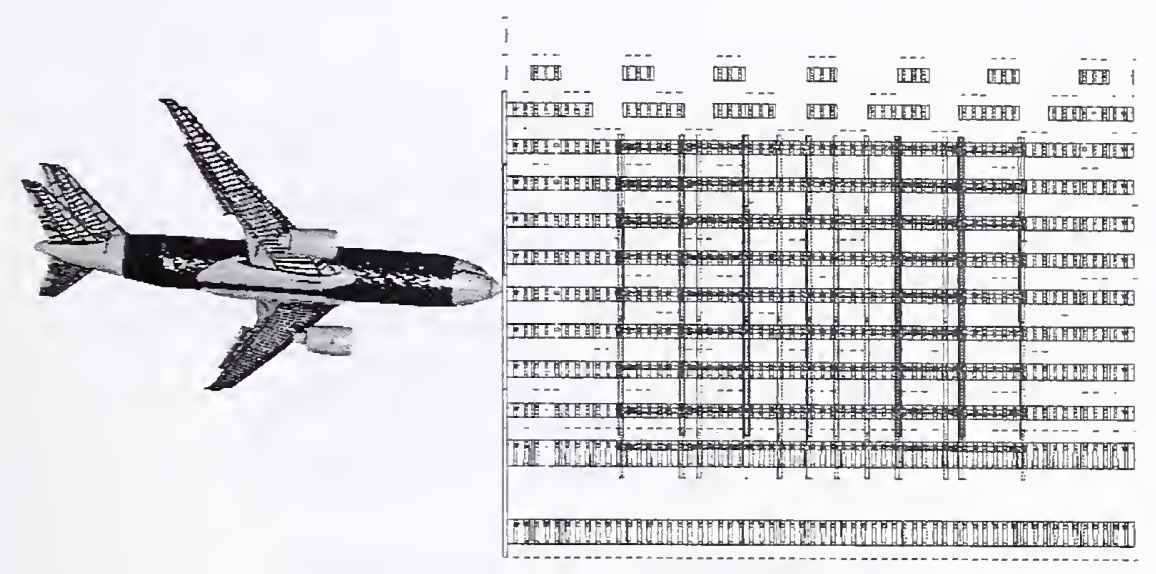

(a) Time $=0.00 \mathrm{~s}$

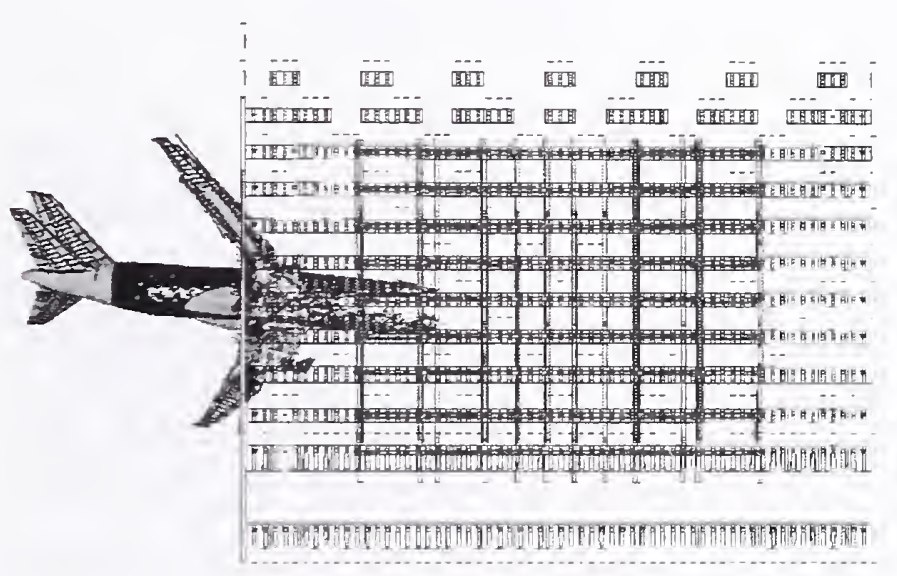

(b) Time $=0.10 \mathrm{~s}$

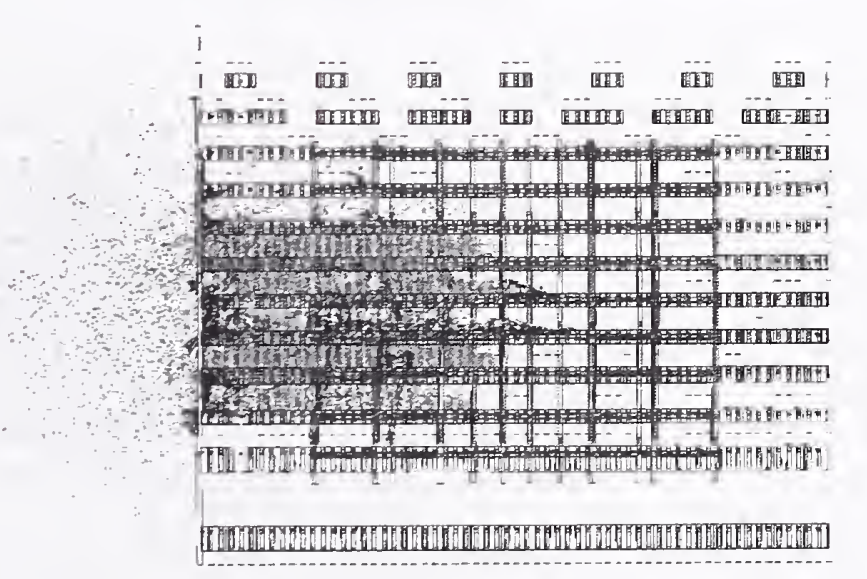

(c) Time $=0.20 \mathrm{~s}$

Figure 7-48. WTC 2 more severe global impact analysis (side view). 


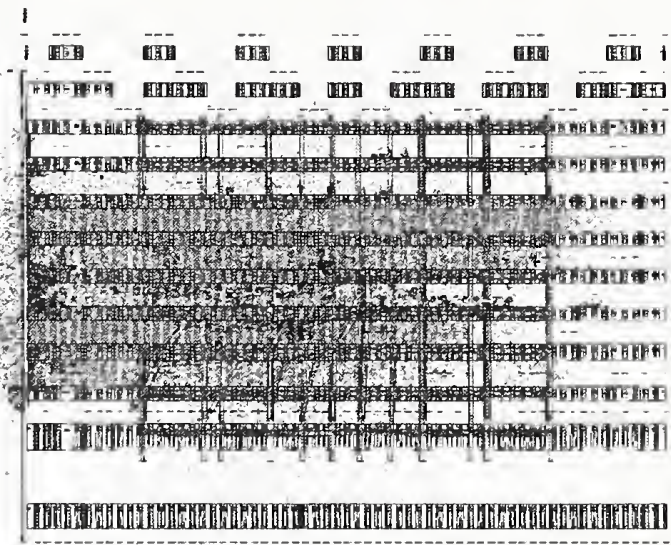

(d) Time $=0.30 \mathrm{~s}$

$i$

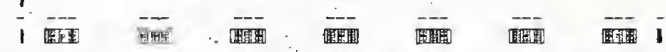

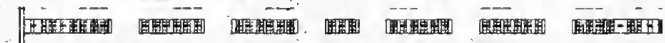

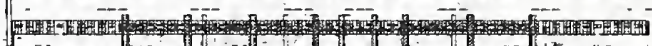

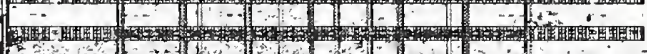
F. 1

Hom W 1

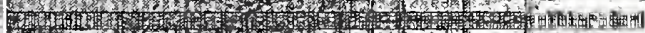
(1) imfle 10 ind

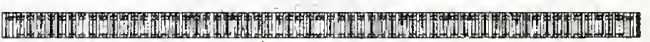

(e) Time $=0.40 \mathrm{~s}$

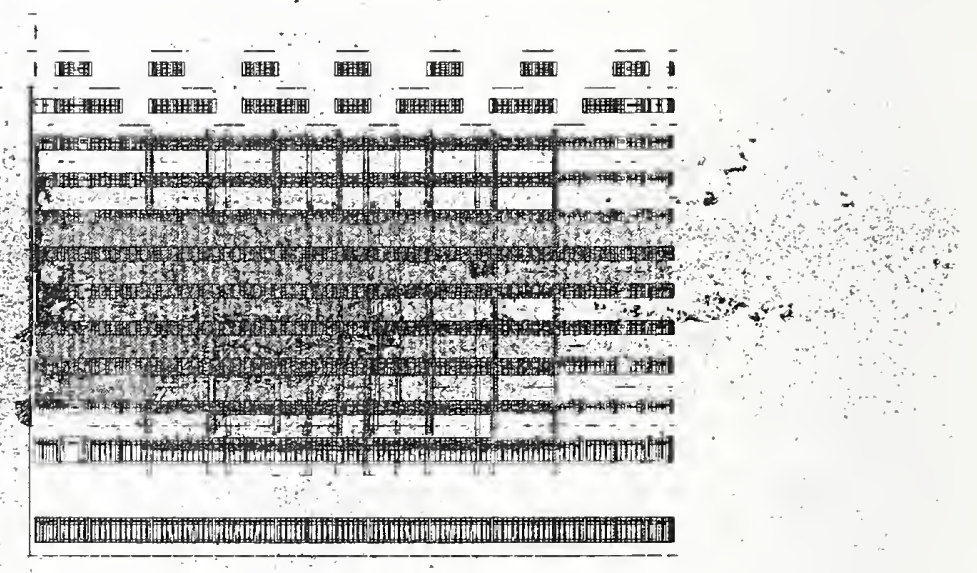

(f) Time $=0.50 \mathrm{~s}$

Figure 7-48. WTC 2 more severe global impact analysis (side view) (continued). 


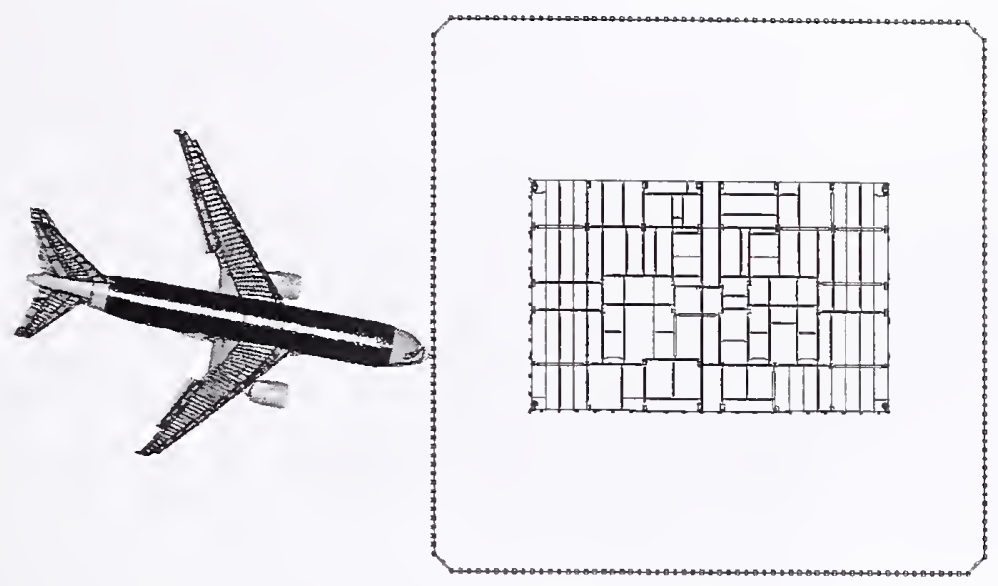

(a) Time $=0.00 \mathrm{~s}$

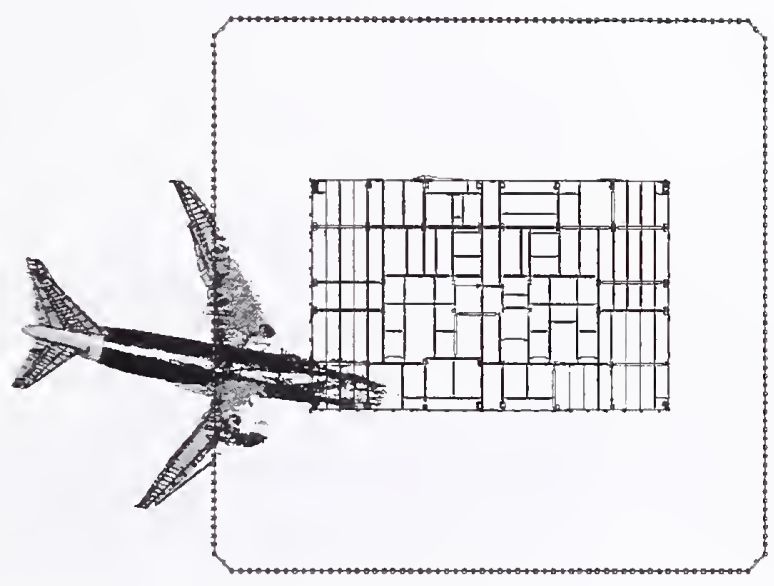

(b) Time $=0.10 \mathrm{~s}$

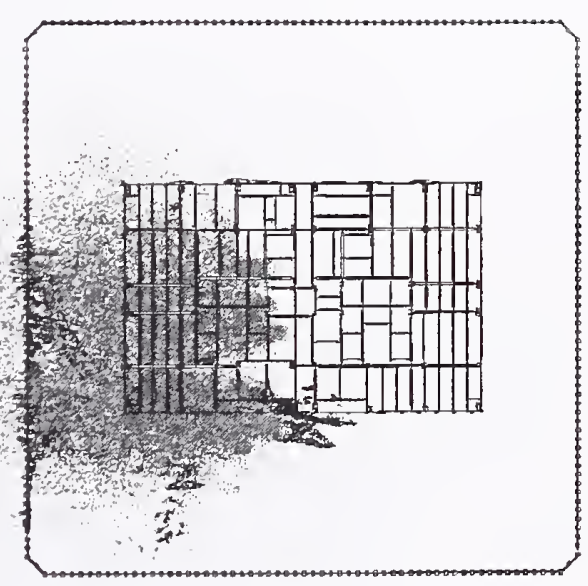

(c) Time $=0.20 \mathrm{~s}$

Figure 7-49. WTC 2 more severe global impact analysis (plan view). 


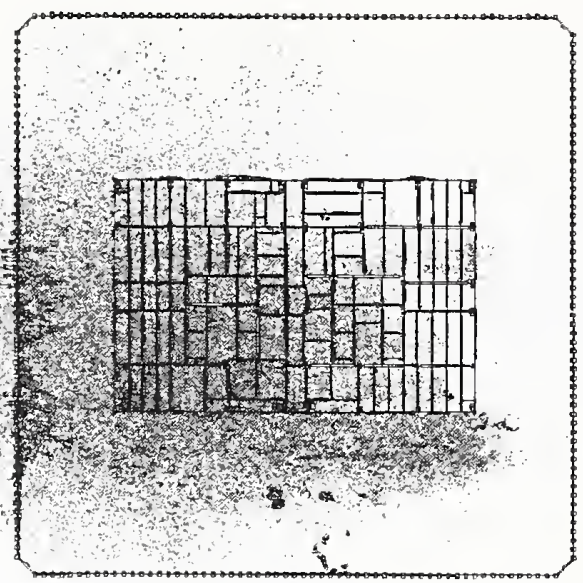

(d) Time $=0.30 \mathrm{~s}$

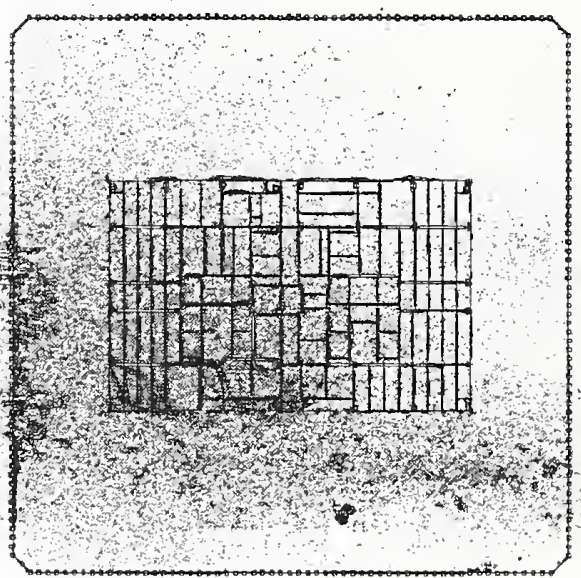

(e) Time $=0.40 \mathrm{~s}$

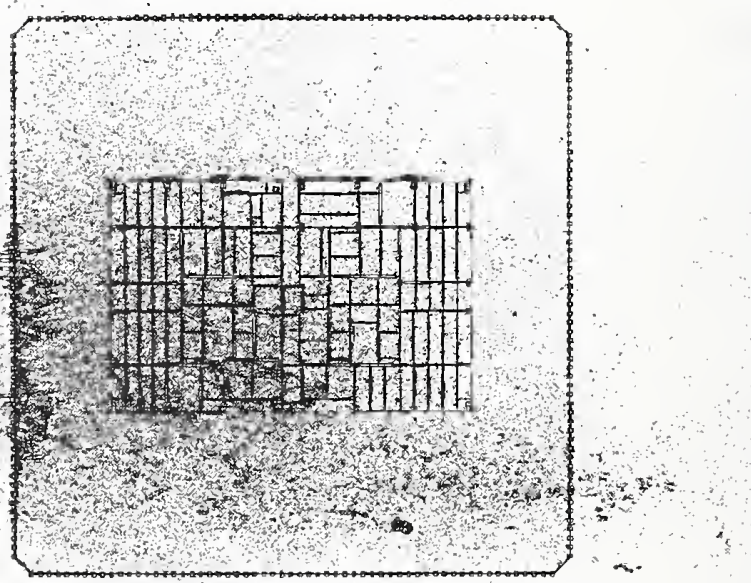

(f) Time $=0.50 \mathrm{~s}$

Figure 7-49. WTC 2 more severe global impact analysis (plan view) (continued). 


\subsubsection{Tower Structural Damage}

\section{Exterior Wall Damage}

A comparison of the south exterior wall observed and calculated damage from the more severe WTC 2 global impact analysis is shown in Figure 7-50. The calculated impact damage to the exterior wall is shown with color fringes representing plastic strain magnitude, with undamaged sections in blue and strains at or above 5 percent shown in red. The mode and magnitude of the calculated and observed impact damage on the exterior wall were still in good agreement in this more severe impact analysis.

As was the case for WTC 1, there were small differences in the damage estimates for the south wall of IVTC 2 from the base case and the more severe case scenarios (compare Figure 7-36 and Figure 7-50). Overall, the agreement with the observed damage from photographs was very good for both cases. The most obvious differences were largely due to portions of panels that may have severed columns in one case or have been removed at the connections in another. 


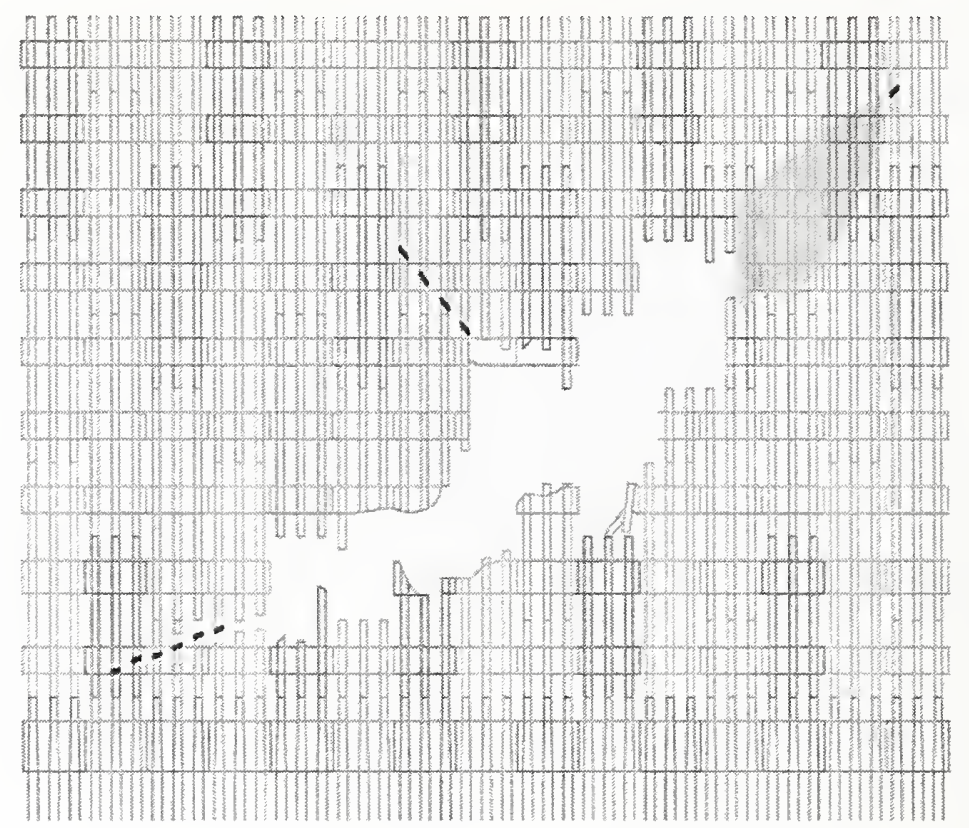

(a) Schematic of observed damage

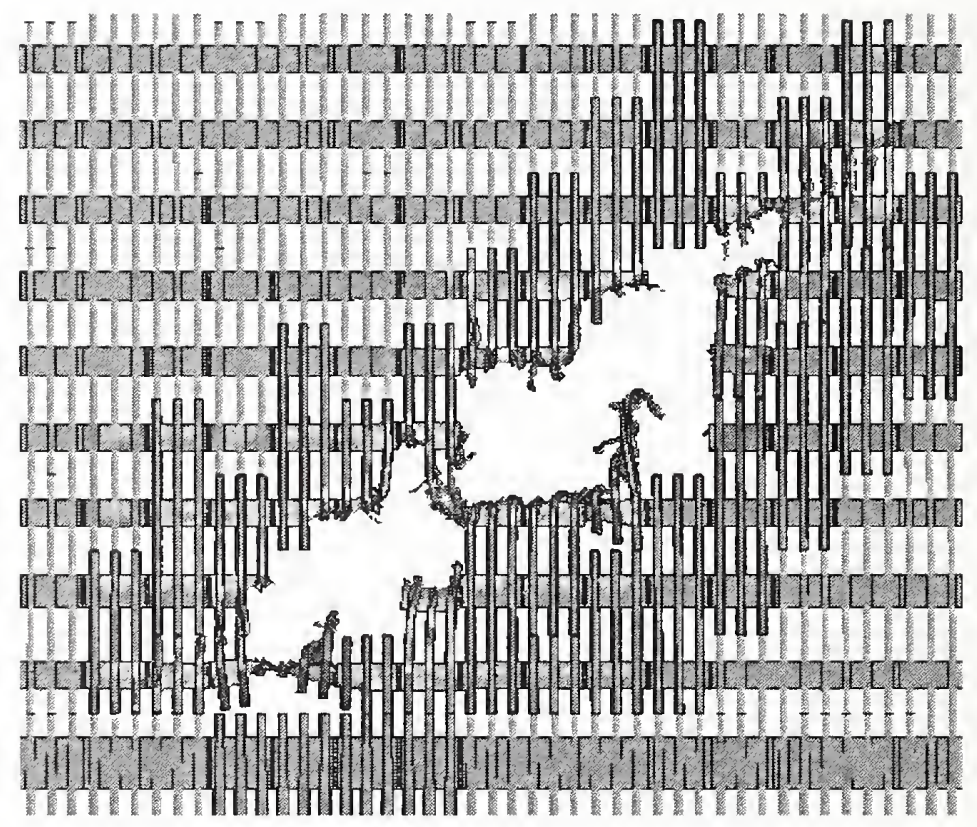

(b) Calculated damage

Figure 7-50. More severe impact damage to the WTC 2 exterior wall.

\section{Core Structural Damage}

The core had extensive damage in the region close to the impact point. The columns in line with the aircraft fuselage failed on the impact side, and several of the core beams were also severely damaged or failed in the impact zone. In some cases, failure of the column splices located on floors 77,80 , and 83 contributed significantly to the failure of the core columns. 
The calculated damage to the core columns by row is shown in Figure 7-51, and the damage to the core framing at floors 80 and 81 is shown in Figure 7-52. A summary of the column damage is provided in Table 7-9, with the qualitative classification of the column damage levels provided previously in Figure 7-7. A total of ten columns were severed, and one column was heavily damaged in this WTC 2 more severe case, compared to five columns severed and four columns heavily damaged in the base case WTC 2 impact analysis.

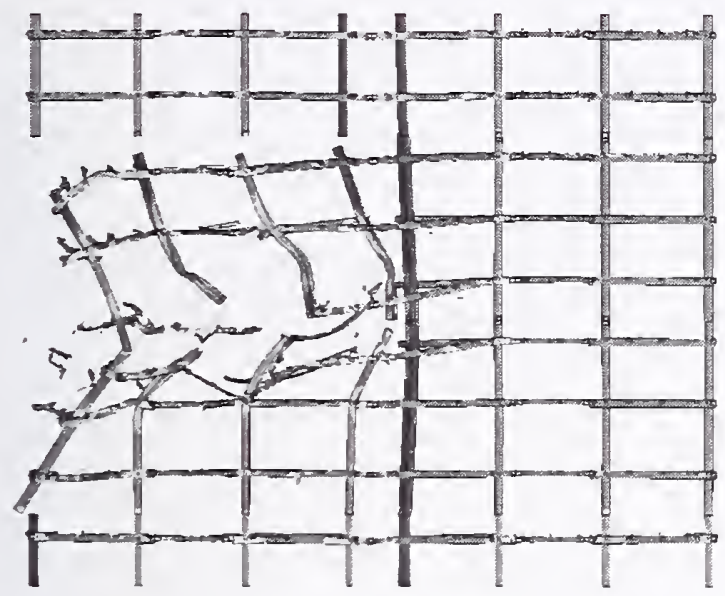

(a) Columns 1001-1008

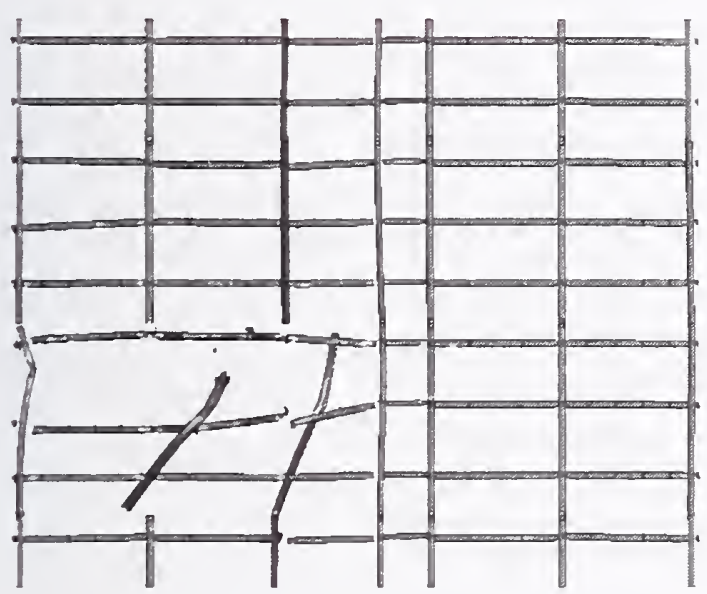

(c) Columns 801-807

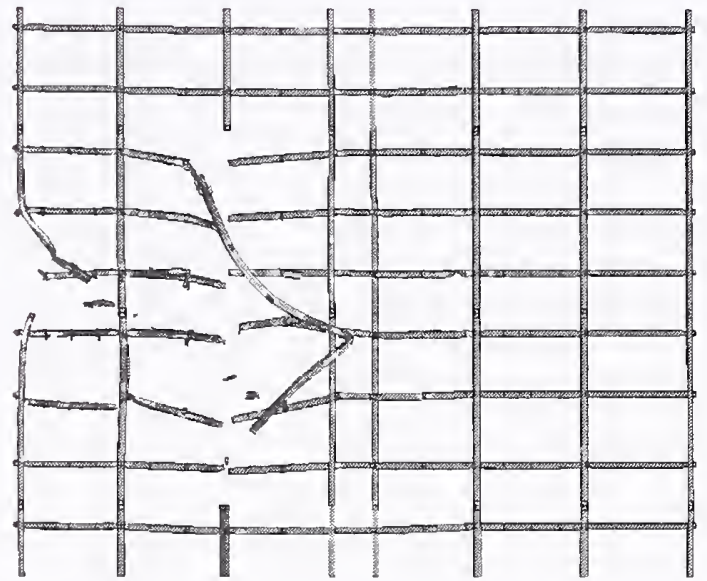

(b) Columns 901-908

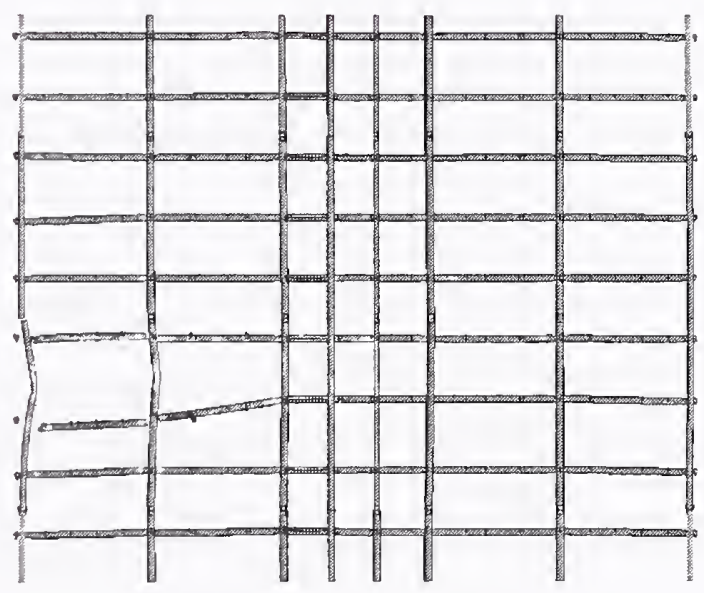

(d) Columns 701-708

Figure 7-51. More severe impact damage to the WTC 2 core columns.

The strong correlation between the core damage and impact severity was expected. All of the parameter variations would be expected to produce an increase in core damage. The flight parameters had an increasing impact speed and a shallower impact angle, directing more energy toward the core. The aircraft had an increasing weight and higher material toughness. The tower had reduced mass in the contents and a reduced material toughness. All of these variations contributed toward the increased core damage with impact severity. 


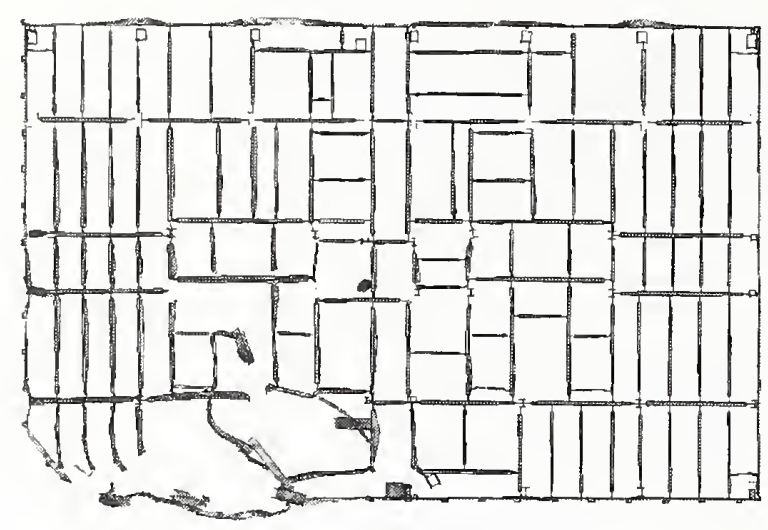

(a) Floor $\mathbf{8 0}$ core framing damage

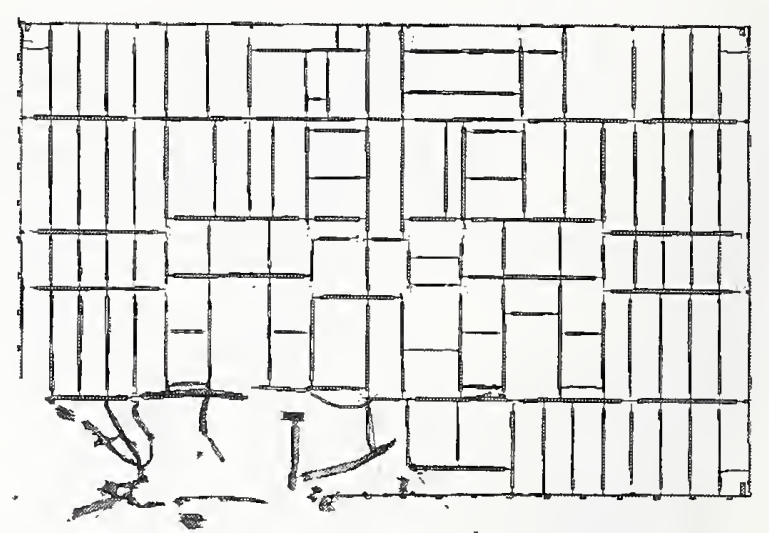

(b) Floor 81 core framing damage Figure 7-52. More severe impact damage to the core beams of floors 80 and 81 of WTC 2. 
Table 7-9. Summary of core column damage for the more severe WTC 2 impact.

\begin{tabular}{|c|c|c|c|}
\hline Column & Location & Damage Level & $\begin{array}{l}\text { Lateral Deflection of } \\
\text { Column Centerline (in.) }\end{array}$ \\
\hline Column 602 & Floor 79 & Moderate & \\
\hline Column 605 & Floor 79 & Moderate & \\
\hline Column 701 & Floors $79-80$ & Severed & \\
\hline Column 702 & Floor 79 & Heavy & 16 \\
\hline Column 703 & Floor 79 & Moderate & \\
\hline Column 704 & Floor 79 & Light & \\
\hline Column 705 & Floors 78-79 & Light & \\
\hline Column 705 & Floor 78 & Light & \\
\hline Column 801 & Floors 79-80 & Severed & \\
\hline Column 802 & Floors $77-80$ & Severed & \\
\hline Column 803 & Floors 77-80 & Severed & \\
\hline Column 804 & Floor 79 & Light & \\
\hline Column 901 & Floors $80-81$ & Severed & \\
\hline Column 902 & Floor 79 & Moderate & \\
\hline Column 903 & Floors $77-83$ & Severed & \\
\hline Column 904 & Floors 79-81 & Moderate & \\
\hline Column 905 & Floors $79 \& 81$ & Light & \\
\hline Column 907 & Floor 81 & Light & \\
\hline Column 1001 & Floors $77-83$ & Severed & \\
\hline Column 1002 & Floors 79-83 & Severed & \\
\hline Column 1003 & Floors 79-83 & Severed & \\
\hline Column 1004 & Floors $79-83$ & Severed & \\
\hline Column 1005 & Floors 79-81 & Moderate & \\
\hline
\end{tabular}

\section{Floor Truss and Slab Damage}

An overall frontal view for the floor truss structure in the WTC 2 impact zone, along with the calculated more severe impact damage to the trusses, is shown in Figure 7-53. The figure shows that the trusses experienced significant damage in the impact zone, with the heaviest damage on floor 81. A plan view of the calculated damage to the trusses on floors 80 and 81 is shown in Figure 7-54. The calculated impact response produced severe damage to the truss structures in the primary impact path of the fuselage. The truss structures were severely damaged from the exterior wall to the core. The truss floor system on floors 79 through 82 had sufficient damage from the impact that portions of the truss floor sections sagged downward as a result of the impact. 
Floor 82

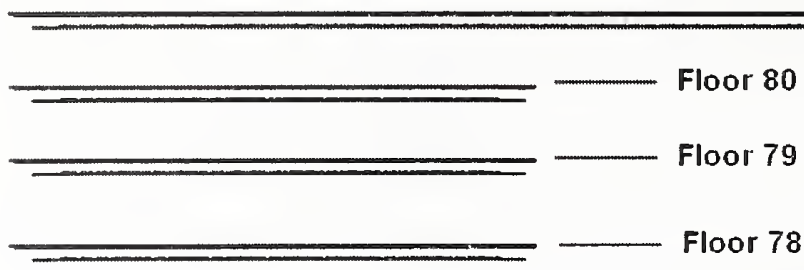

(a) Initial detailed truss structures

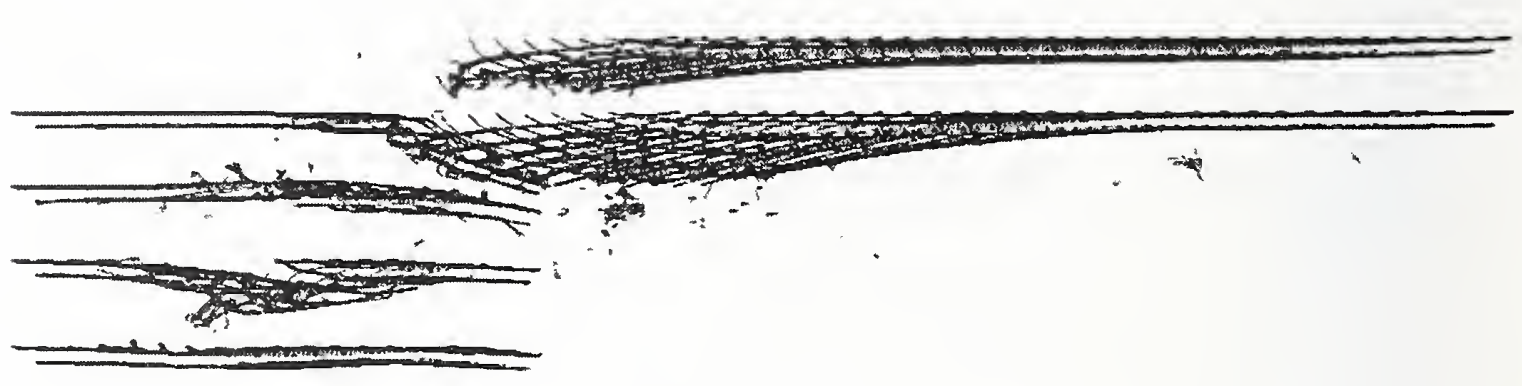

(b) Calculated damage

Figure 7-53. More severe impact damage to the WTC 2 floor trusses (front view).

The magnitude of truss floor damage was very similar for the base case and more severe global impact analyses. The parameters used in the more severe global impact analysis would primarily contribute to an increased damage for the tower structures. However, the downward impact trajectory angle was reduced from the 6 degree angle in the base case analysis to a 5 degree angle in the more severe impact analysis. This resulted in directing more of the impact energy inward toward the tower core, but reducing the normal downward force on the floor structures in the impact zone. As a result, the combined effects of the analysis parameter variations produced very similar damage to the truss structure.

The calculated damage to the WTC 2 floor slabs for floors 80 and 81 for the more severe impact is shown in Figure 7-55. The magnitude of floor slab damage was very similar for the base case and more severe global impact analyses due to the reasons explained above for the floor trusses. 


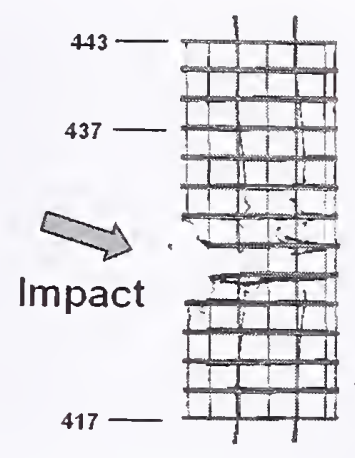

(a) Floor 80 truss damage

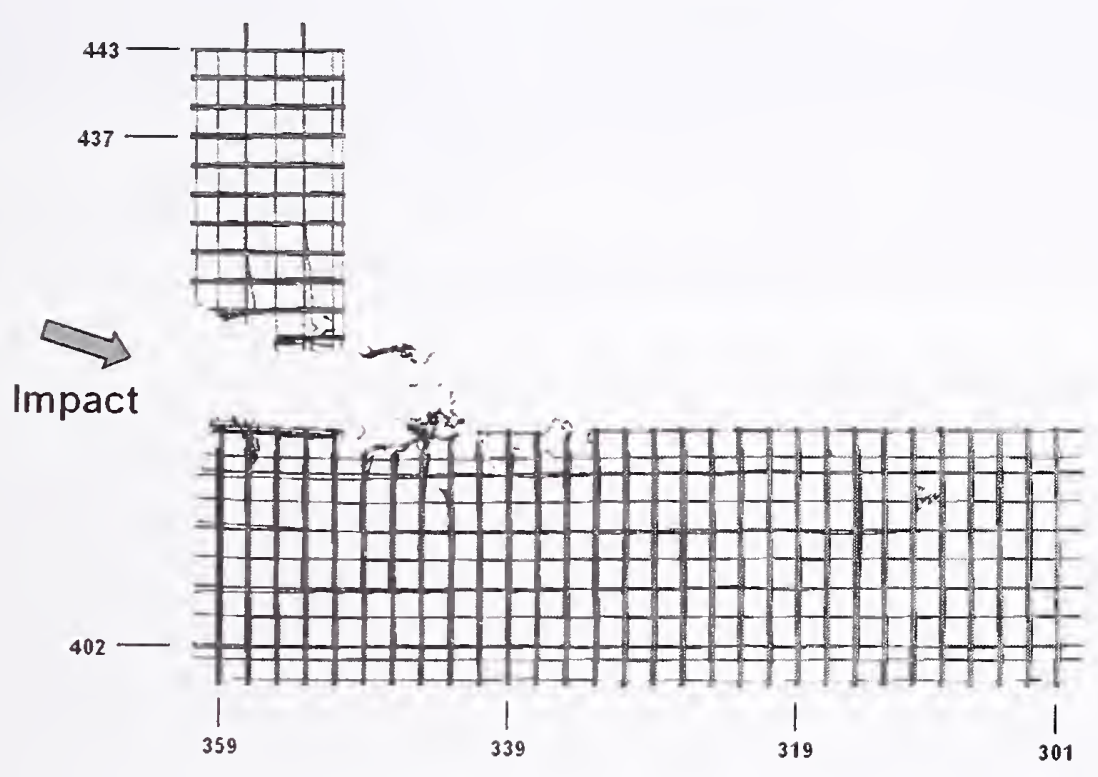

(b) Floor 81 truss damage

Figure 7-54. More severe impact damage to the trusses on floors 80 and 81 of WTC 2 (plan view). 


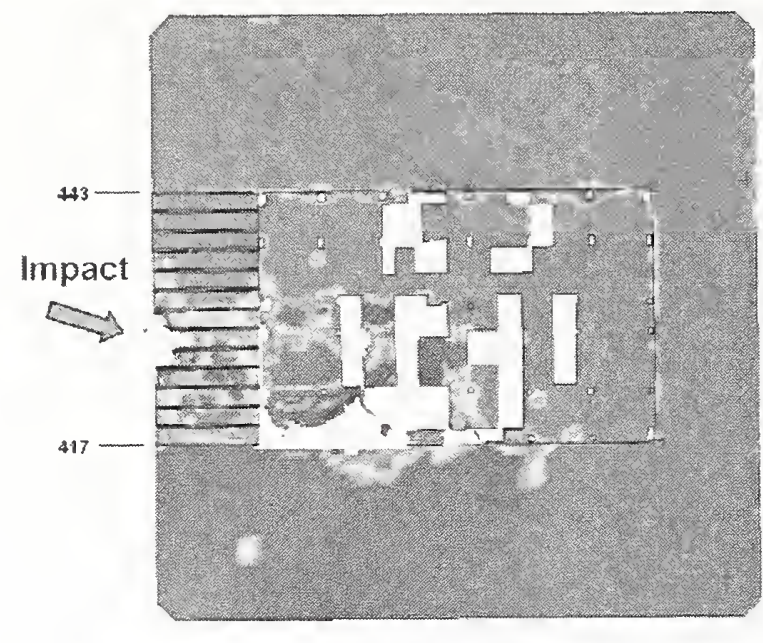

(a) Floor 80 slab damage

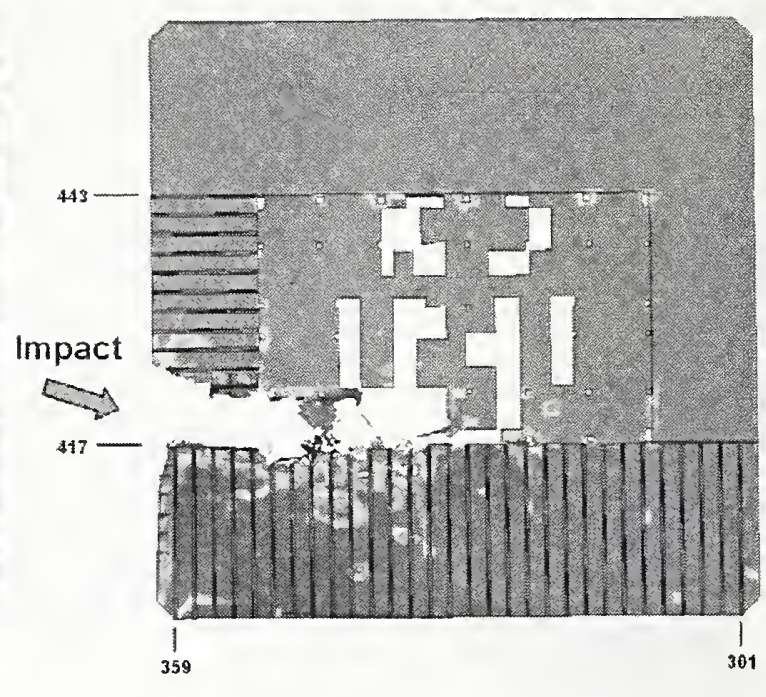

(b) Floor 81 slab damage

Figure 7-55. More severe impact damage to the WTC 2 floor slab (plan view).

\section{Summary of Structural Damage}

Figure 7-56 shows a summary of the structural damage to the core columns and floor systems at floors 77 through 83 of WTC 2 for the more severe case (Case D). Figure 7-57 presents the cumulative damage to WTC 2 on all affected floors and columns. 


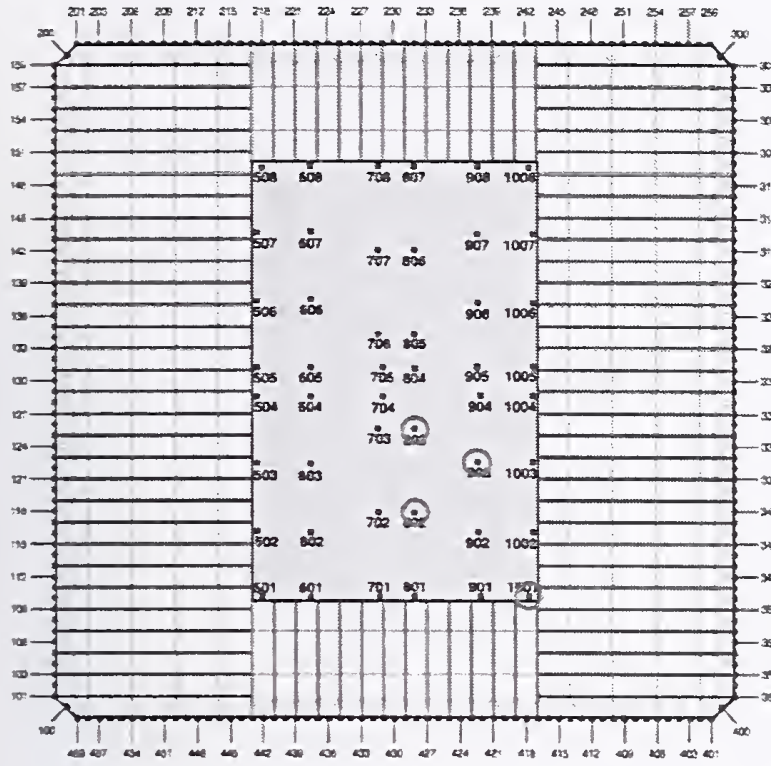

(a) Floors 77

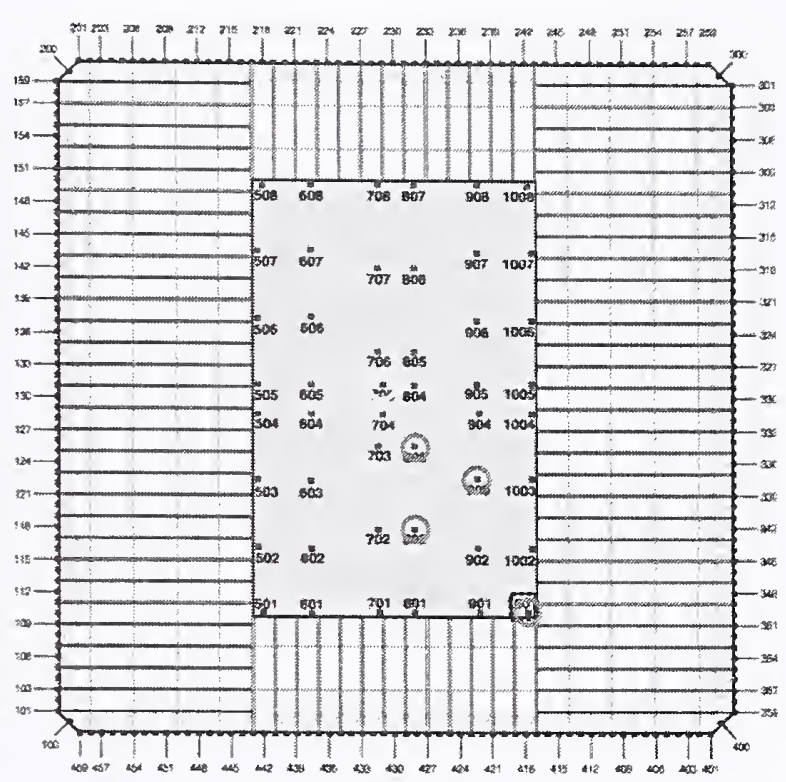

(b) Floor 78

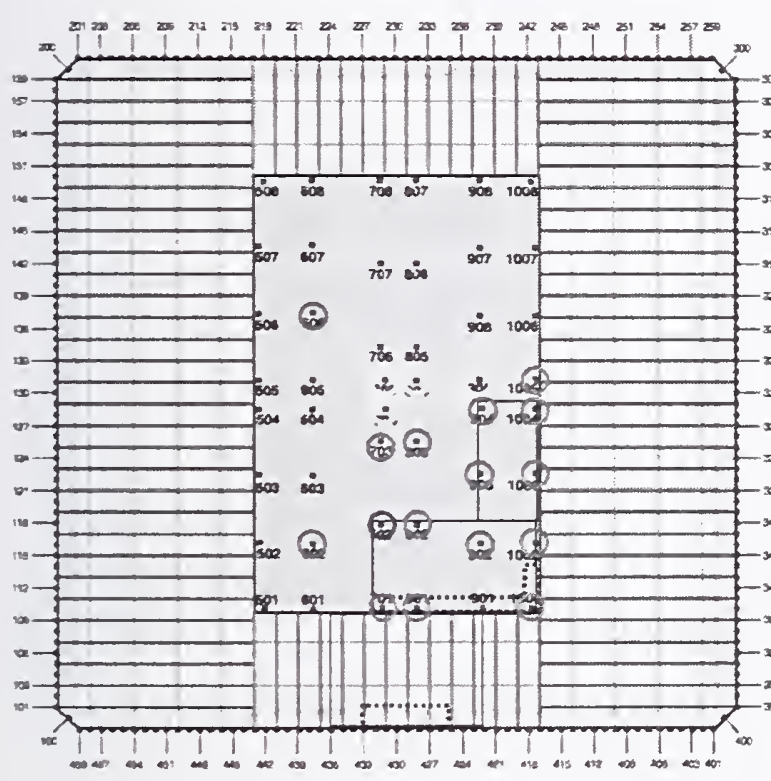

(c) Floor 79

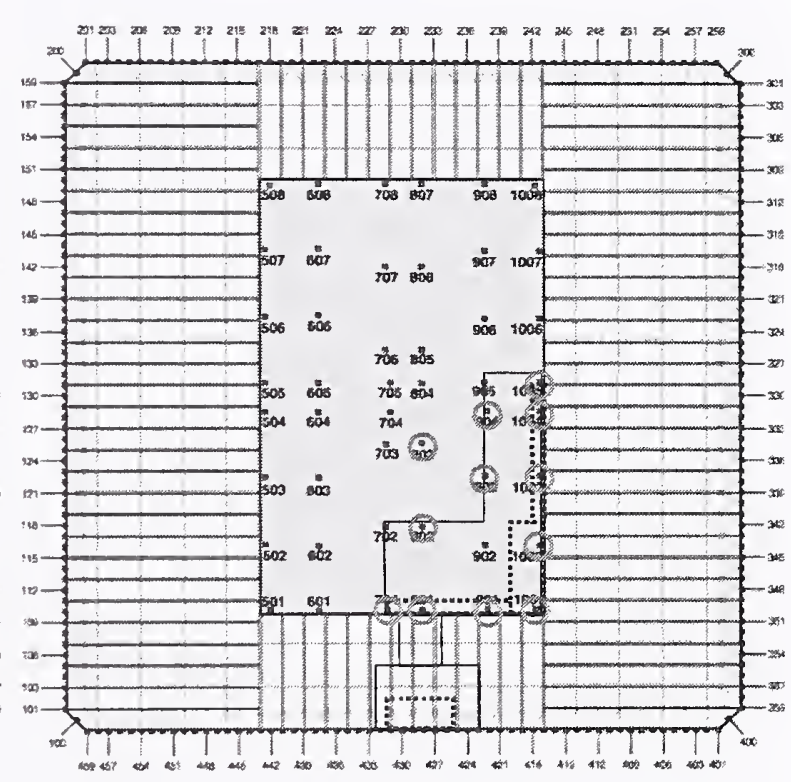

(d) Floor 80

Figure 7-56. Summary of the floor-by-floor structural damage to the floors and columns of WTC 2 (more severe case). 


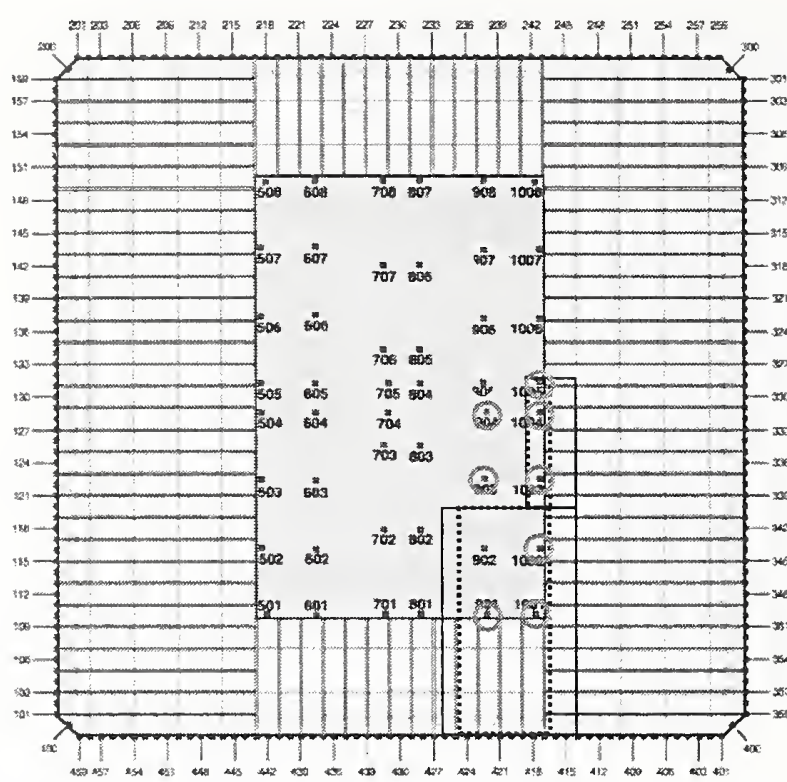

(e) Floor 81

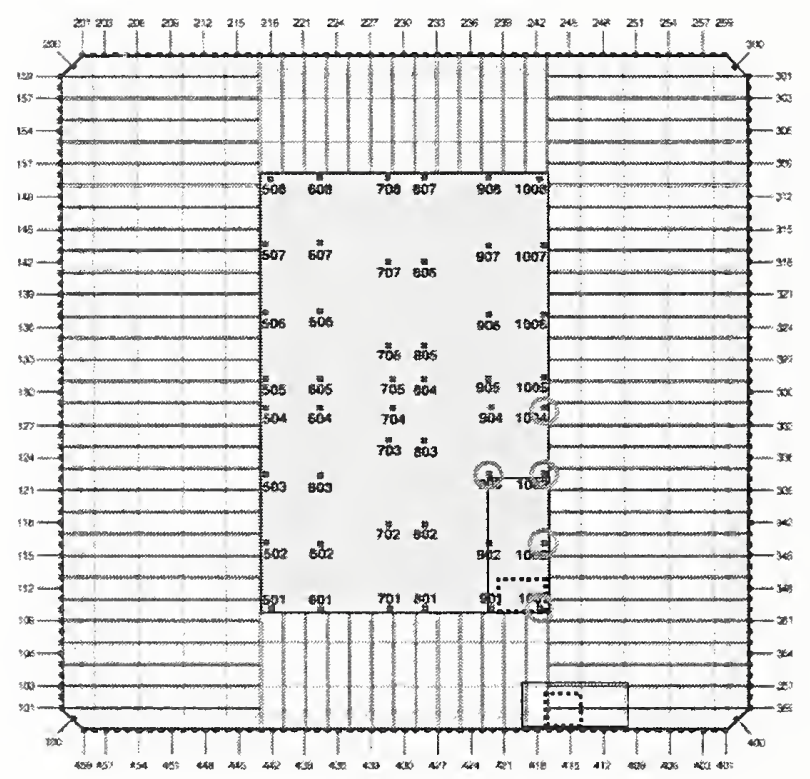

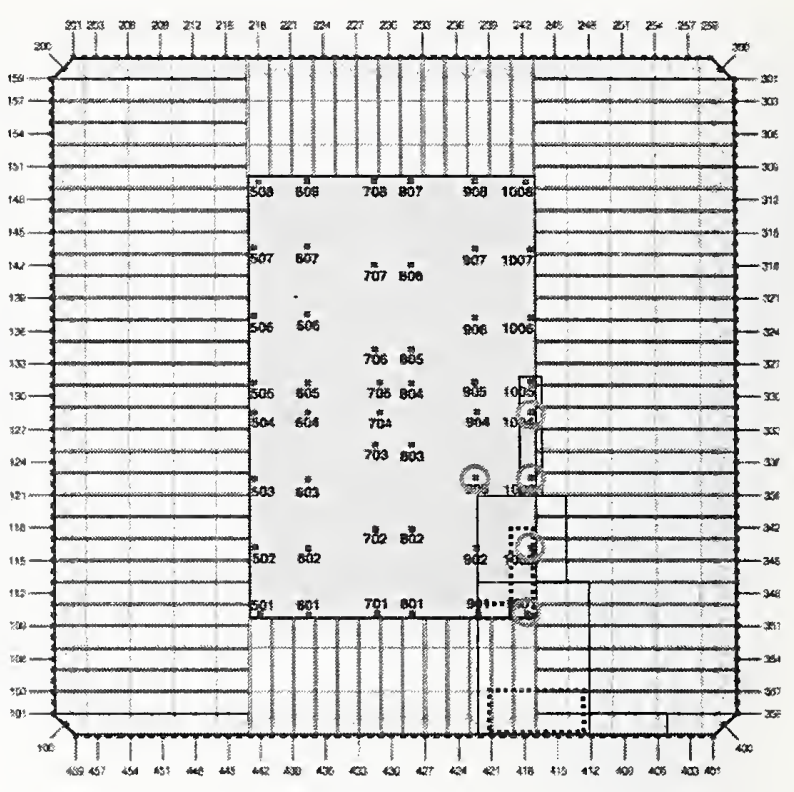

(f) Floor 82

\section{Severe Floor Damage \\ Floor system \\ structural damage $\square$}

Floor system
removed

\section{Column Damage}

Severed

Heavy Damage

Moderate Damage

Light Damage

(g) Floor 83

Figure 7-56. Summary of the floor-by-floor structural damage to the floors and columns of WTC 2 (more severe case) (continued). 


\section{Severe Floor Damage Floor system structural damage}

\section{Floor system removed}

\section{Column Damage}

Severed

Heavy Damage

Moderate Damage

Light Damage

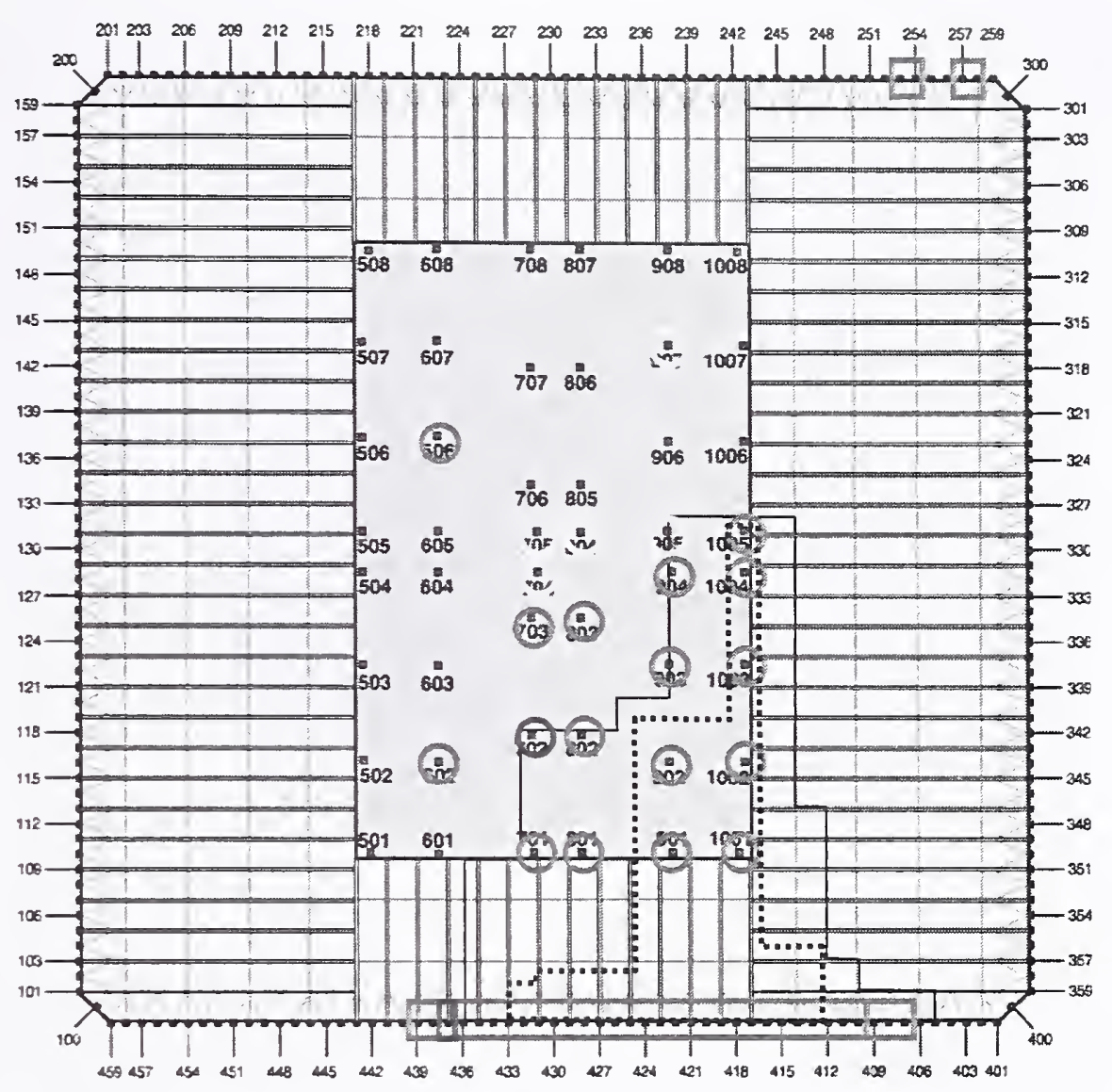

Figure 7-57. Cumulative structural damage to the floors and columns of WTC 2 (more severe case).

\subsubsection{Fuel and Debris Distributions}

The distribution of the fuel in the tower calculated from the more severe case in a plan view and side view is shown in Figure 7-58. At the termination of the global impact analysis, the residual momentum of the jet fuel was less than one percent of the initial momentum, indicating that the fuel cloud was nearly at rest. To more clearly present the calculated response of the structures that influenced the fire propagation, the structural components were removed from the visualization, with the exception that the core columns were maintained in the visualizations for reference positions. A plan view of the response of the remaining building contents and aircraft debris is shown in Figure 7-59.

The calculated damage to the WTC 2 contents for the more severe impact case is shown in plan views for floors 80 and 81 in Figure 7-60 and Figure 7-61, respectively. A comparison to the calculated damage for the base case WTC 2 impact analysis indicated that the tower contents damage zone was similar, with a slight increase in damage for the more severe impact.

A summary of the floor-by-floor fuel and debris distributions is given in Table 7-10. The bulk of the fuel and aircraft debris was deposited in floors 78 through 80 , with the greatest concentration on floor 80 . The calculated debris cloud included 121,000 lbs of debris and 14,800 lbs of aircraft fuel outside of the tower at the end of the impact analysis, either rebounding from the impact face (north wall) or passing through 
the tower (south wall). This amount might have been larger in the calculation due to the reasons mentioned previously for the base case impact (see Section 7.3.3). Comparing Figure 7-59 and Table 7-10 with Figure 7-45 and Table 7-7, it can be seen that the amount of debris exiting the north wall of the tower in the more severe case was much larger than that from the base case.

Table 7-10. Fuel and aircraft debris distribution for the more severe WTC 2 impact.

\begin{tabular}{|l|c|c|}
\hline \multicolumn{1}{|c|}{ Tower Location } & Aircraft Fuel & Aircraft Debris \\
\hline Total Outside Tower & $14,800 \mathrm{lb}$ & $121,000 \mathrm{lb}$ \\
\hline WTC 2 Floor 77 & $1,300 \mathrm{lb}$ & $300 \mathrm{lb}$ \\
\hline WTC 2 Floor 78 & $7,400 \mathrm{lb}$ & $2,500 \mathrm{lb}$ \\
\hline WTC 2 Floor 79 & $12,500 \mathrm{lb}$ & $16,400 \mathrm{lb}$ \\
\hline WTC 2 Floor 80 & $7,200 \mathrm{lb}$ & $40,700 \mathrm{lb}$ \\
\hline WTC 2 Floor 81 & $10,000 \mathrm{lb}$ & $21,400 \mathrm{lb}$ \\
\hline WTC 2 Floor 82 & $10,200 \mathrm{lb}$ & $1,400 \mathrm{lb}$ \\
\hline WTC 2 Floor 83 & $1,400 \mathrm{lb}$ & $1,100 \mathrm{lb}$ \\
\hline WTC 2 Floor 84 & $300 \mathrm{lb}$ & $400 \mathrm{lb}$ \\
\hline Total Weight & $65,100 \mathrm{lb}$ & $205,200 \mathrm{lb}$ \\
\hline
\end{tabular}




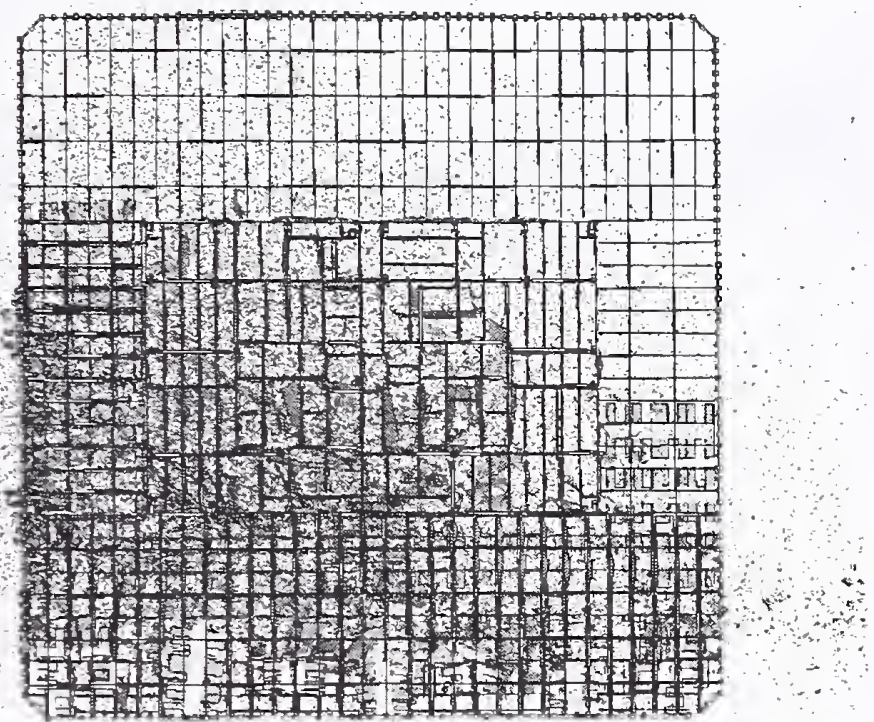

(a) Plan view (floor slab removed)

Time $=\quad 0.58$

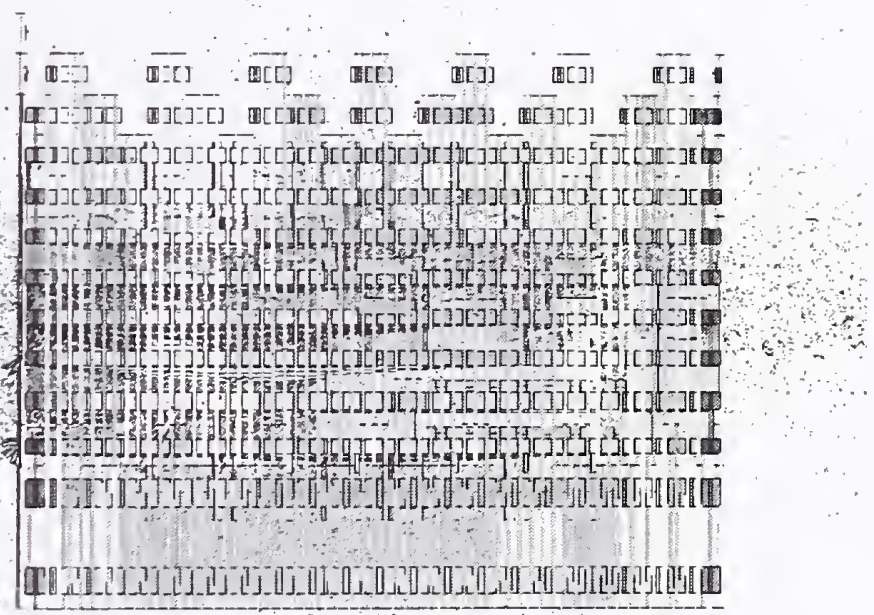

(b) Side view

Figure 7-58. Calculated fuel distribution in the more severe WTC 2 analysis. 


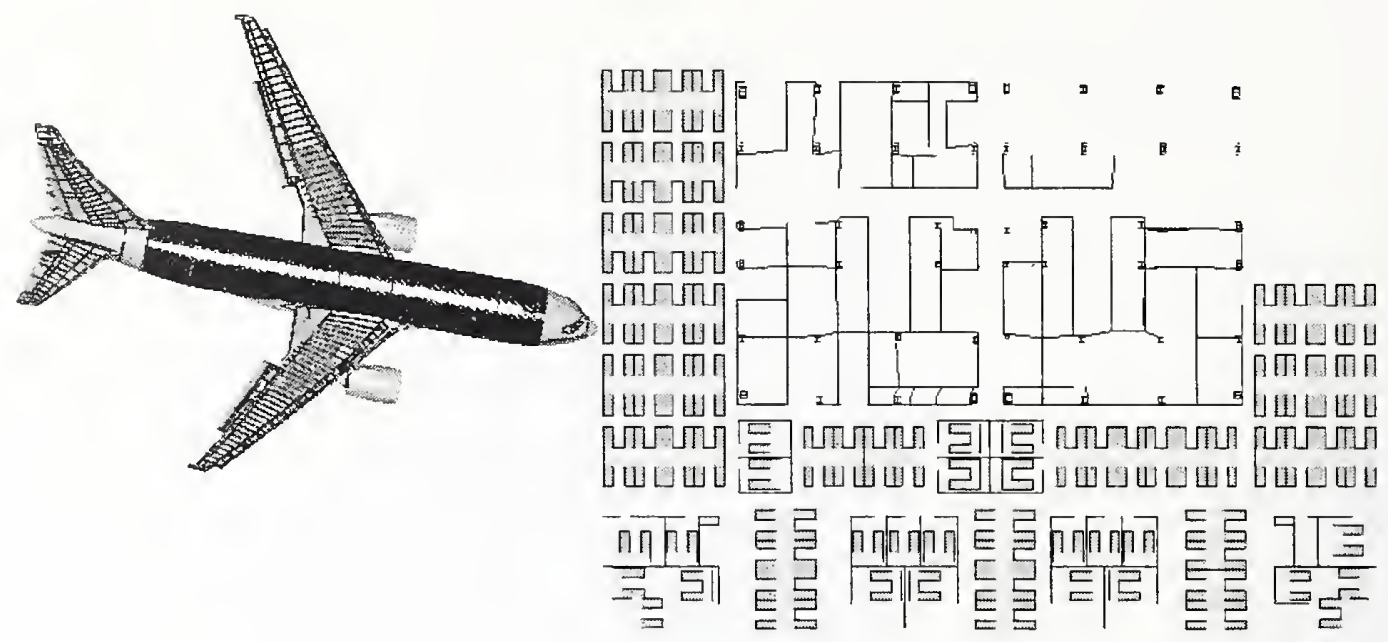

(a) Pre-impact configuration

Time $=0.6219$

(b) Calculated impact response

Figure 7-59. Plan view of calculated more WTC 2 building, fuel, and aircraft debris distribution for the more severe case. 


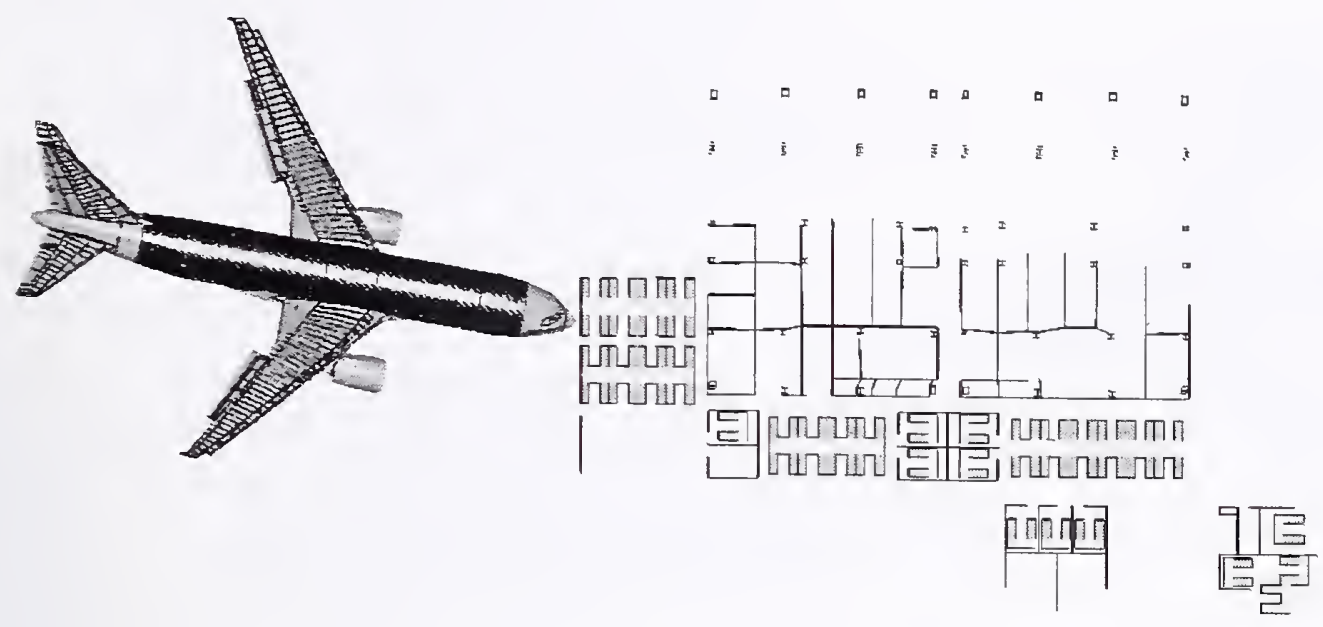

(a) Pre-impact configuration

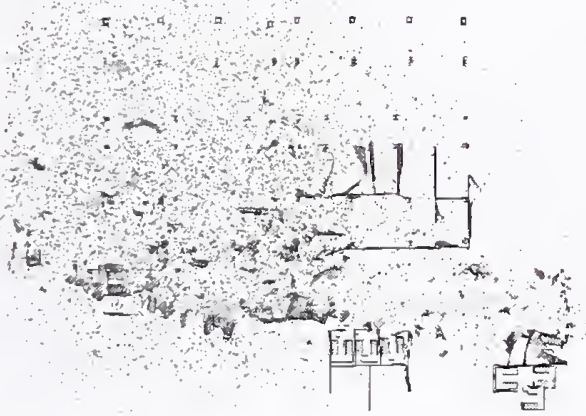

(b) Calculated impact response

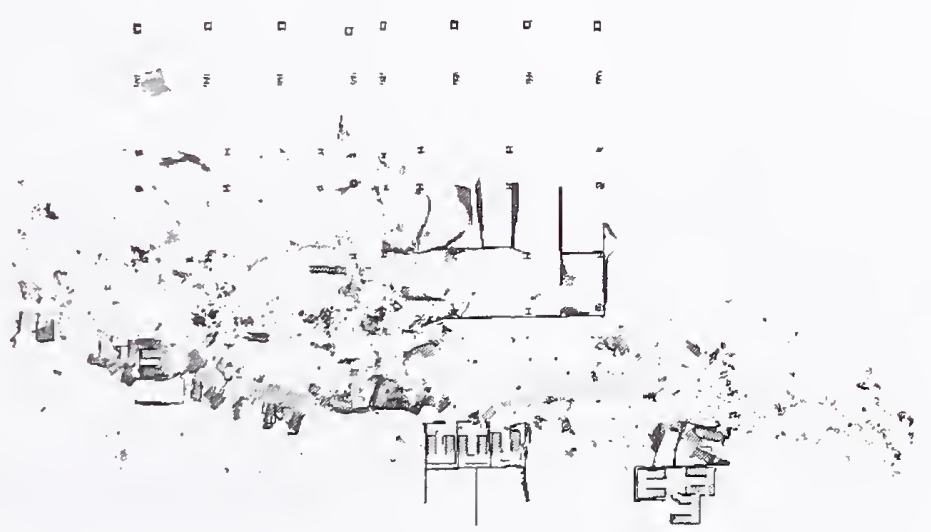

(c) Calculated impact response (fuel removed)

Figure 7-60. Calculated floor 80 contents and fuel distribution (more severe case). 


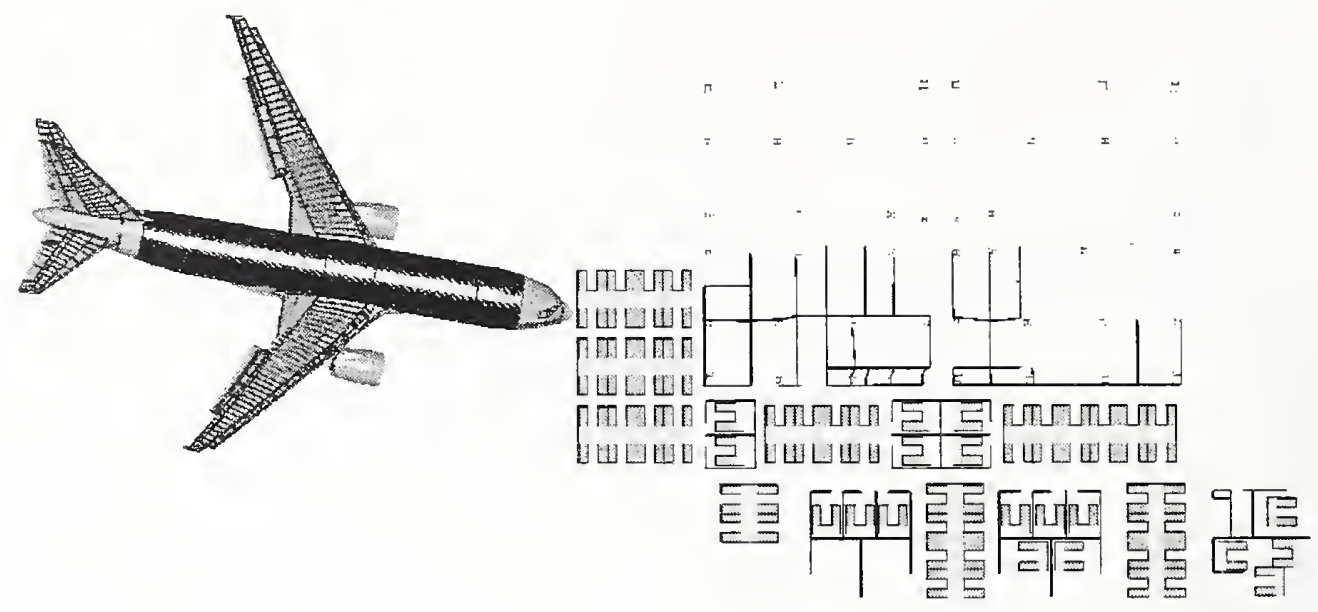

(a) Pre-impact configuration

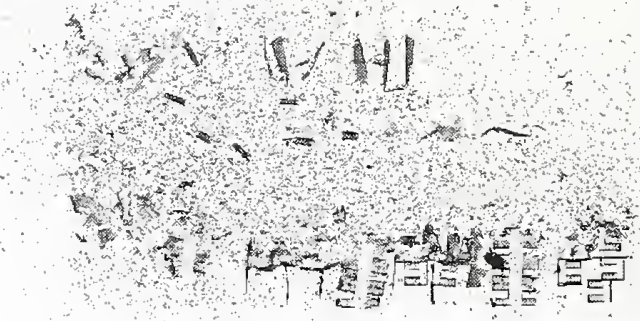

(b) Calculated impact response

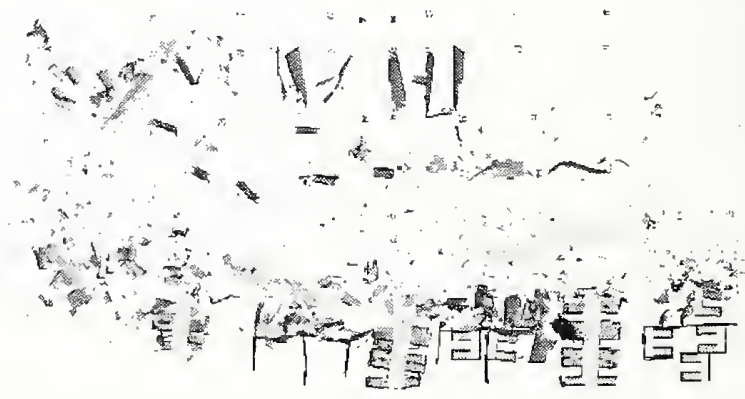

(c) Calculated impact response (fuel removed)

Figure 7-61. Calculated floor 81 contents and fuel distribution (more severe case). 


\subsection{WTC 2 LESS SEVERE IMPACT ANALYSIS - BRIEF DESCRIPTION}

This section presents a brief description of the results from the less severe damage case. The reader is referred to NIST NCSTAR 1-2B for further details.

For the south exterior wall of WTC 2, the magnitude and mode of impact damage were still in good agreement with the observed damage for the less severe impact scenario.

The core had significant damage in the region close to the impact point. The columns in line with the aircraft fuselage failed on the impact side, and several of the core beams were also severely damaged or failed in the impact zone. In some cases, failure of the column splices located on floors 77, 80, and 83 contributed significantly to the failure of the core columns. A total of three columns were severed, and two columns heavily damaged, compared to five severed columns and four heavily damaged columns in the base case WTC 2 impact analysis.

The truss floor system on floors 79 through 82 had sufficient damage from the impact that portions of the truss floor sections sagged downward as a result of the impact. The trusses experienced significant damage in the impact zone, with the heaviest damage on floor 81 . The calculated impact response produced severe damage to the truss structures in the primary path of the fuselage. The truss structures were completely destroyed along the impact path on floor 81 from the exterior wall to the core.

When compared with the base case, the magnitude of damage to the floor trusses and floor slabs was slightly increased for the less severe impact analysis. The parameters used in the less severe global impact analysis would primarily contribute to a reduced damage magnitude for the tower structures. However, the downward impact trajectory angle was increased from the 6 degree angle in the base case analysis to an 8 degree angle in the less severe impact analysis. This would have the effect of directing more of the impact energy downward, increasing the normal force on the floor structures in the impact zone. As a result, the combined effects of the analysis parameter variations produced very similar damage to the truss structure.

A comparison to the base case and less severe case indicated that the building contents damage zone was similar, with a slight reduction in damage for the less severe impact.

\subsection{COMPARISON BETWEEN WTC 1 AND WTC 2}

The comparison of the aircraft impact response and resulting tower damage for WTC 1 and WTC 2 was complicated by the differences in the two impact scenarios. The base case WTC 1 impact was close to centered and perpendicular on the face of the tower, with the long-span trusses between the impact point and the core. The WTC 1 impact scenario resulted in a debris trajectory where almost all of the aircraft debris would pass through the core. The baseline impact conditions for WTC 1 were a 443 mph collision with a downward impact trajectory angle of 10.6 degrees. In contrast, the baseline WTC 2 impact was off center and angled away from the core, resulting in a significant fraction of the aircraft debris cloud outside (east) of the core. The WTC 2 impact had short-span trusses between the impact point and the core. Finally, the baseline impact conditions for WTC 2 were a $542 \mathrm{mph}$ collision with a downward impact trajectory angle of 6 degrees. 


\subsubsection{Exterior Wall Damage}

The calculated exterior wall damage for the base case WTC 1 and WTC 2 impacts are compared in Figure 7-62. Despite the differences in impact conditions, the mode and magnitude of damage to the exterior walls were quite similar in both towers. This was because the impact loads distributed over the majority of the aircraft structures were much larger than the exterior column rupture strength. The details of the failure mode (column deformation and rupture or failure and separation of bolted column end connections) were determined by the proximity of the floor slab and column joints to the impact point. For both impacts, the wing tip structures imparted damage, but did not completely fail the columns.

\subsubsection{Core Column Damage}

The calculated core column damage for the base case WTC 1 and WTC 2 impacts are compared in Figure 7-63. In the WTC 1 impact, there were three columns severed and four columns heavily damaged. The calculated region of significant core column damage appeared to extend three column rows deep into the core. In contrast, the calculated damage for the WTC 2 impact included five columns severed and four columns heavily damaged, and the region of significant core column damage appeared to extend four column rows deep. This increase in core damage was even more significant since the impact zone was 15 floors lower in WTC 2 (and therefore designed to carry more gravity loads), and as a result the core columns were heavier and more resistant to impact damage in the WTC 2 impact zone.

The differences in the core column damage between WTC 1 and WTC 2 can be explained by two primary factors. The first was that the WTC 2 impact speed was 23 percent higher (approximately 50 percent larger impact energy), and the shallower impact angle directed more impact energy inward toward the core. The second factor was that the orientation of the core relative to the impact was different in the two towers, as the core was closer to the impact point in WTC 2. As a result, WTC 2 had reduced energy absorbing capacity due to the shorter floor structures and less building contents between the impact point and the core. 


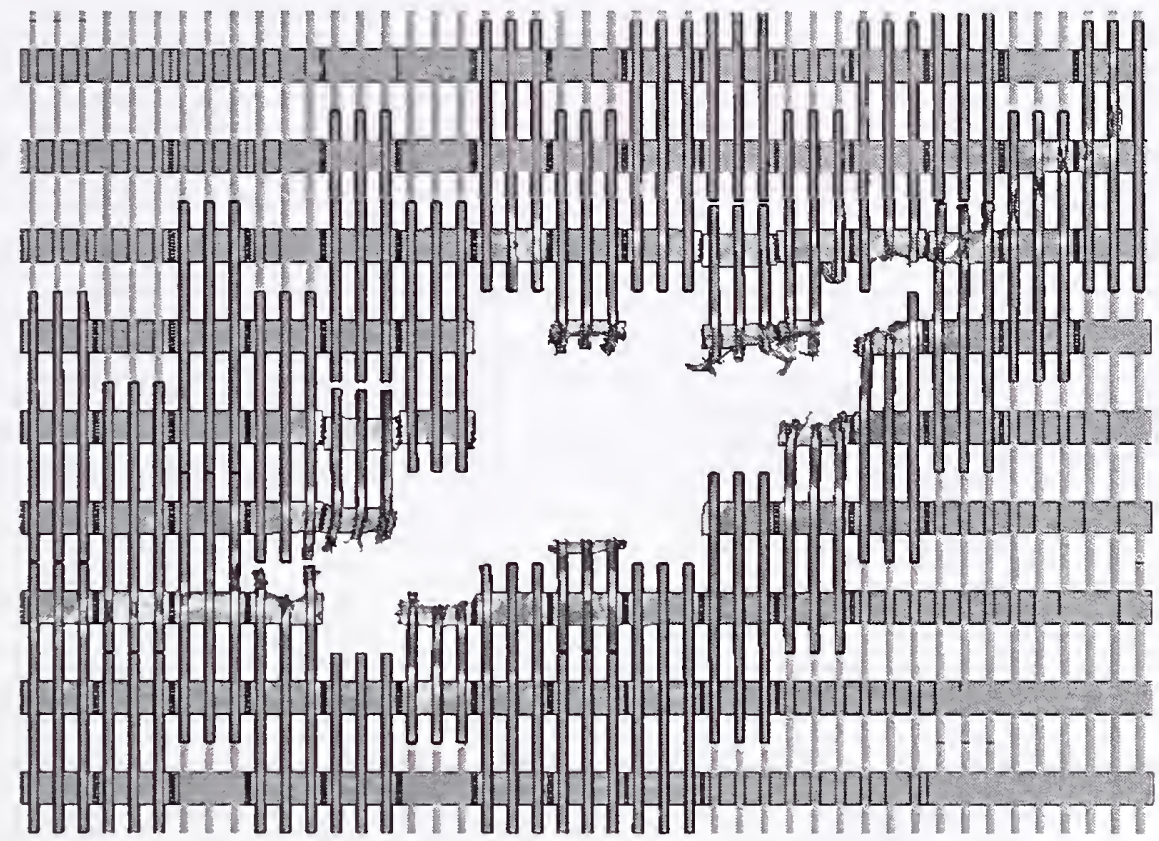

(a) WTC 1 calculated damage to the north wall

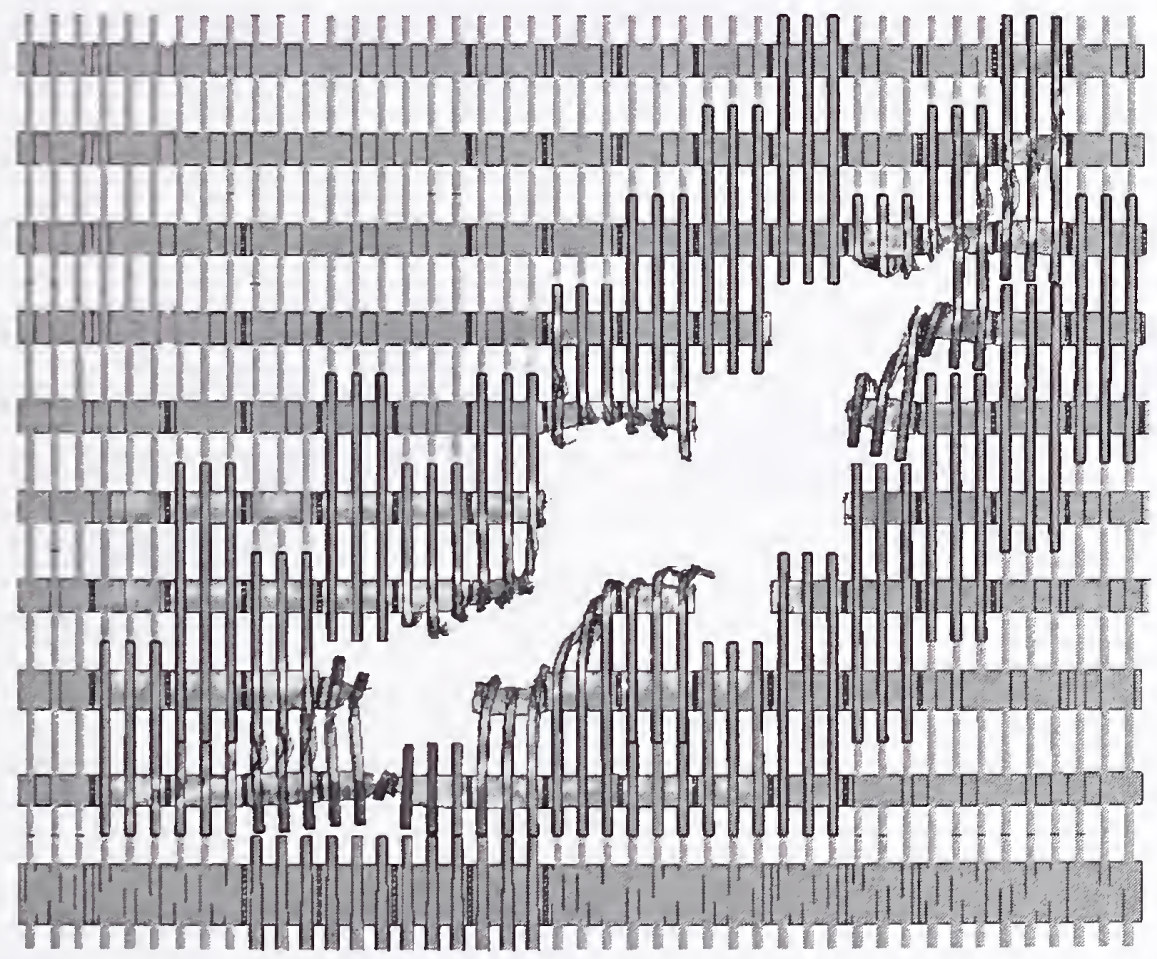

(b) WTC 2 calculated damage to the south wall

Figure 7-62. Comparison of base case impact damage to the exterior walls of WTC 1 and WTC 2. 

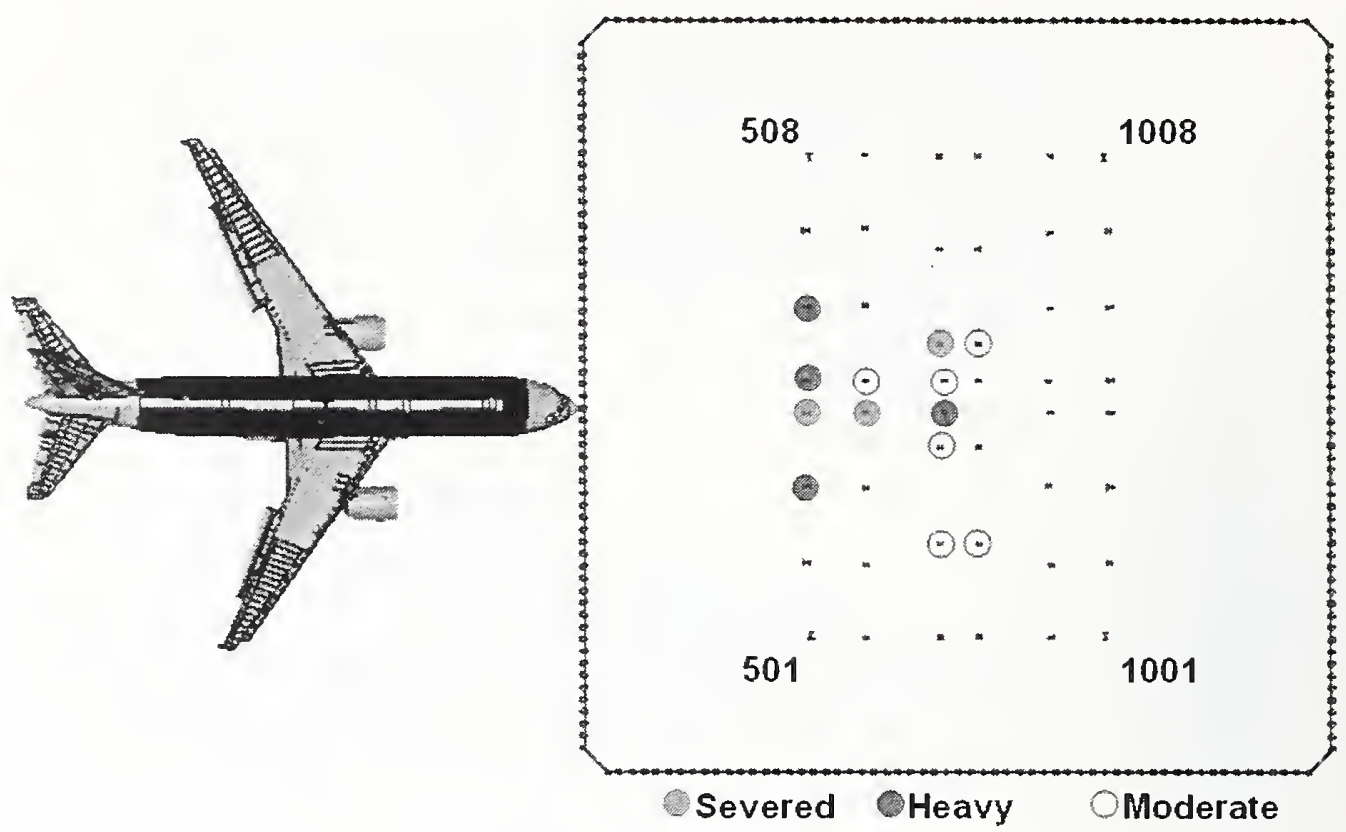

(a) WTC 1 calculated damage

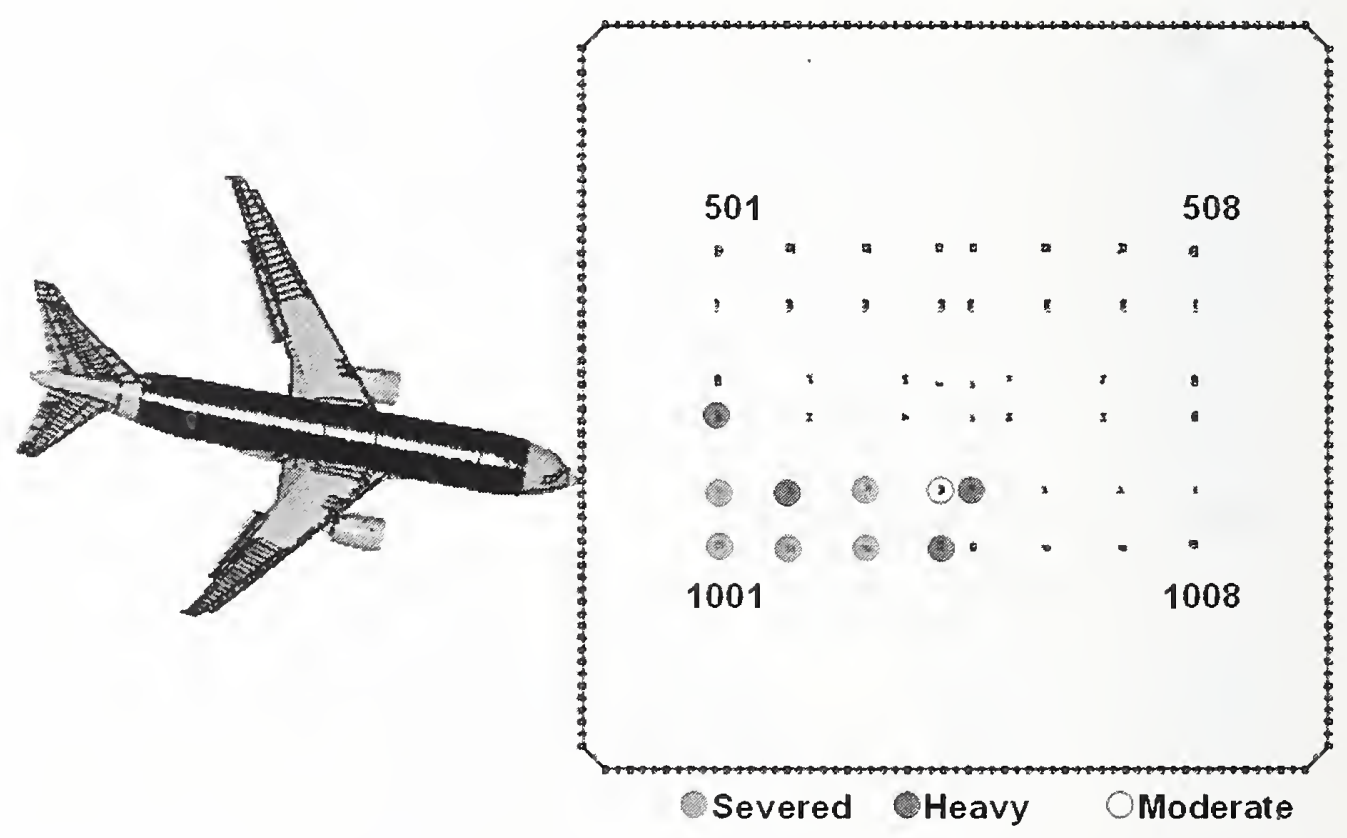

(b) WTC 2 calculated damage

Figure 7-63. Comparison of base case impact damage to the core columns of WTC 1 and WTC 2. 


\subsubsection{Floor Truss Damage}

The calculated floor truss damage for the base case WTC 1 and WTC 2 impacts are compared in Figure 7-64. The comparison shows that the WTC 1 floor truss had greater damage and collapse of the truss floor despite the lower aircraft impact energy. The greater truss floor damage and deflection in WTC 1 can be explained by two factors. The primary factor was that the WTC 1 downward impact trajectory was nearly twice as steep as that of the WTC 2 impact. As a result, the steeper impact angle directed more impact energy normal to the floor slab. The vertical component of the impact load in WTC 1 was approximately 40 percent higher than in WTC 2 . The secondary factor was that the damage to the long-span truss floors in the WTC 1 impact zone produced larger displacements than the corresponding damage level to the short-span truss region in WTC 2.

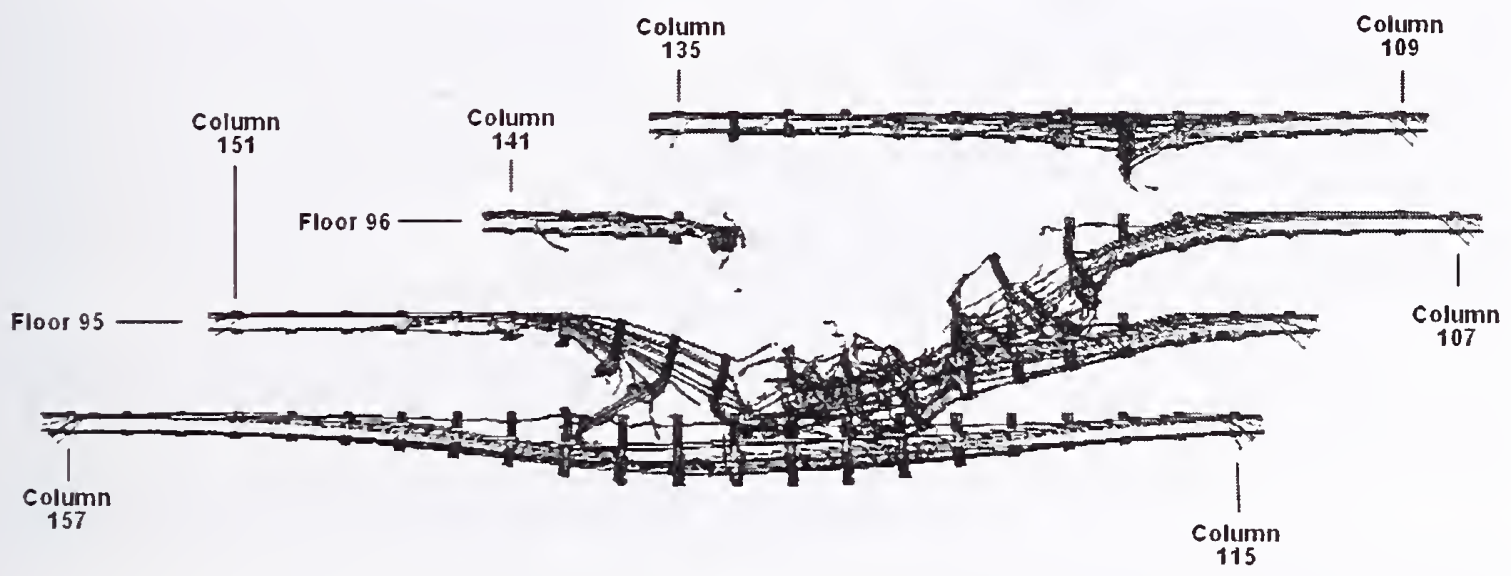

(a) WTC 1 calculated damage

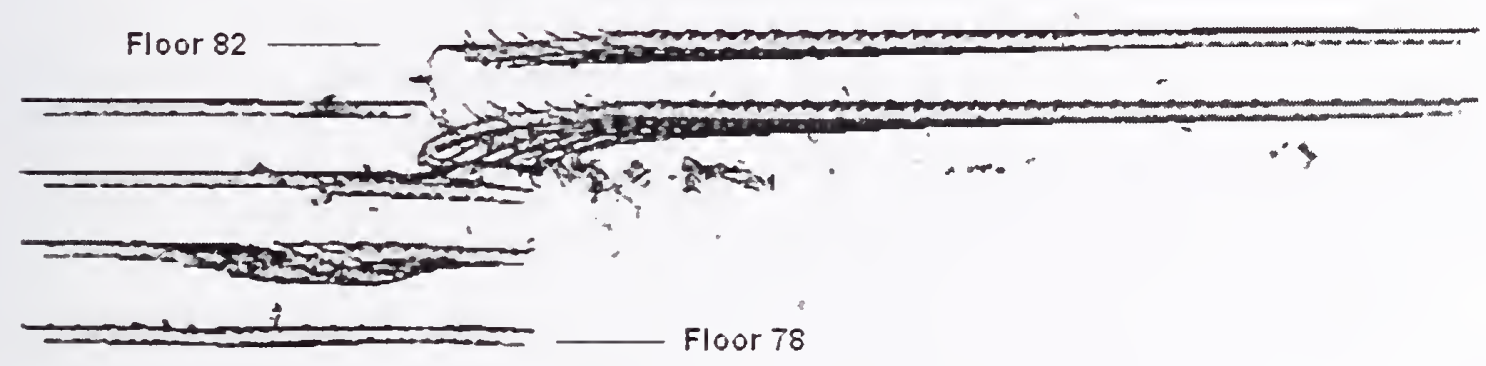

(b) WTC 2 calculated damage

Figure 7-64. Comparison of base case impact damage to floor trusses of WTC 1 and WTC 2.

\subsection{0} COMPARISON WITH OBSERVABLES

The observable evidence available to help validate the global impact analyses included the following:

- Damage to the building exterior documented by photographic evidence.

- Floor damage visible from the building exterior documented by photographic evidence. 
- Aircraft debris external to the towers as documented by photographic evidence.

- Eyewitness accounts from survivors who were inside portions of the buildings.

Another observable was that each tower remained standing after sustaining the impact-induced structural damage. Analyses of the structural response of the damaged towers immediately after impact, presented in NIST NCSTAR 1-6, showed that this observable was met for both towers. Sections 7.10.1 and 7.10.2 compare, for WTC 1 and WTC 2, respectively, these observables with the results of the simulations.

\subsubsection{Comparison with Observables on WTC 1}

\section{Damage Comparison on the North Exterior Wall of WTC 1}

The most valuable observable from a modeling standpoint was the damage to the impacted exterior wall of each tower. The impact damage to the exterior walls was well documented, and the impact response did not depend much on unknown parameters, such as the detailed office layout on each floor. Good agreement of the calculated and observed damage profile indicated that the geometric modeling of the aircraft and the initial trajectory and orientation of the aircraft were accurate. The agreement of both the mode and magnitude of the structural damage on the impact wall served to partially validate the constitutive and damage modeling of the aircraft and exterior wall structures of the tower. The agreement in exterior wall damage, based on the modeling methodologies described in this report, contributed to the confidence that the damage predictions for the interior of the towers were reasonably estimated.

Figure 7-65 provides the results of a detailed comparison between the observed and calculated damage (from the base case analysis) on the north wall of WTC 1. The comparison includes the mode, magnitude, and location of failure around the hole created by the aircraft impact. The color code included the following: (1) green circles indicating a proper match of the failure mode and magnitude between the observed and calculated damage; (2) yellow circles indicating a proper match in the failure mode, but not the magnitude; (3) red circles indicating that the failure mode and magnitude predicted by the calculation did not match that was observed; and (4) black circles indicating that the observed damage was obscured by smoke, fire, or other factors. The comparison shown in Figure 7-65 indicates that the overall agreement with the observed damage was very good. 


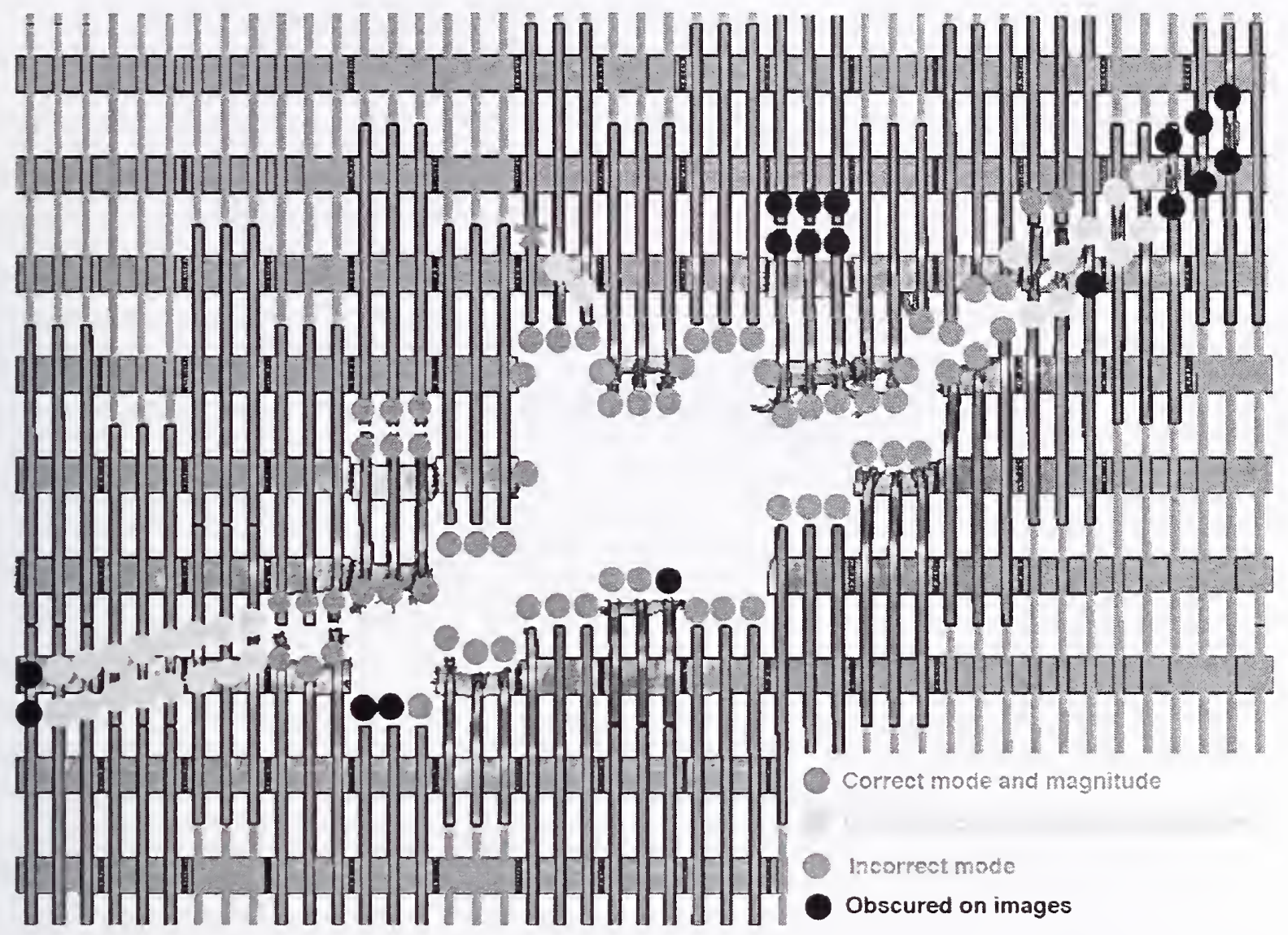

Figure 7-65. Comparison of observable and calculated base case impact damage to the north wall of WTC 1.

\section{Damage Comparison on the South Exterior Wall of WTC 1}

The exterior panel from column 329 to 33 I between floors 94 through 96 on the south face of WTC 1 was knocked free by landing gear and possibly other debris (see NIST NCSTAR 1-5A). These columns were located in the center of the south wall of the WTC 1. In both the base case and more severe damage global analyses, aircraft debris impacted the south face of the tower, as shown in Figure 7-66 and Figure 7-67, and exited the building. The figures also show the calculated landing gear debris for both simulations. None of the debris impacting the south wall happened to contain landing gear fragments. In the base case analysis, the debris impacted columns 328 to 330 at floor 96 . In the more severe impact analysis, debris impacted columns 328 to 333 on both floors 95 and 96 . In the base case analysis, very little damage was done to the exterior panels on the south wall. However, damage was heavy in the more severe damage analysis, as shown in Figure 7-68. 


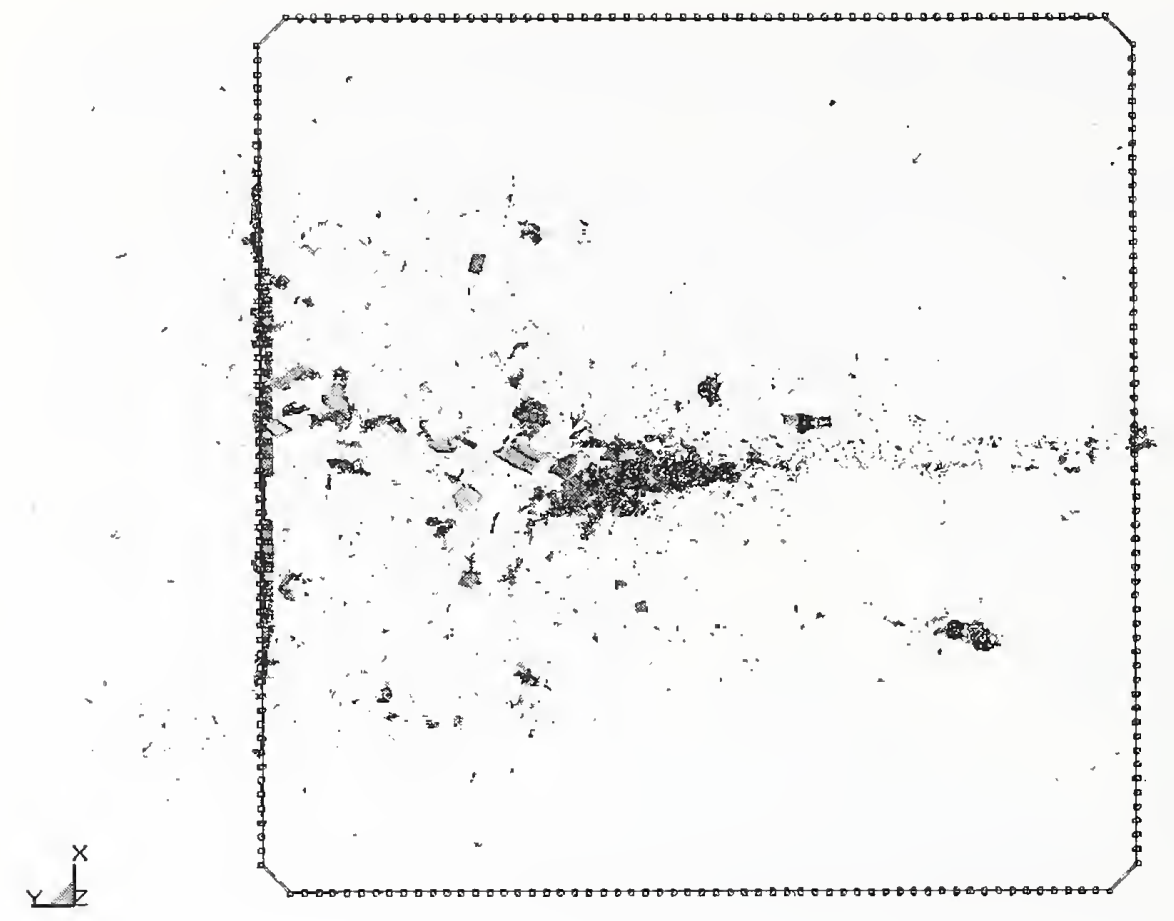

(a) Calculated aircraft debris $(t=0.71 \mathrm{~s})$

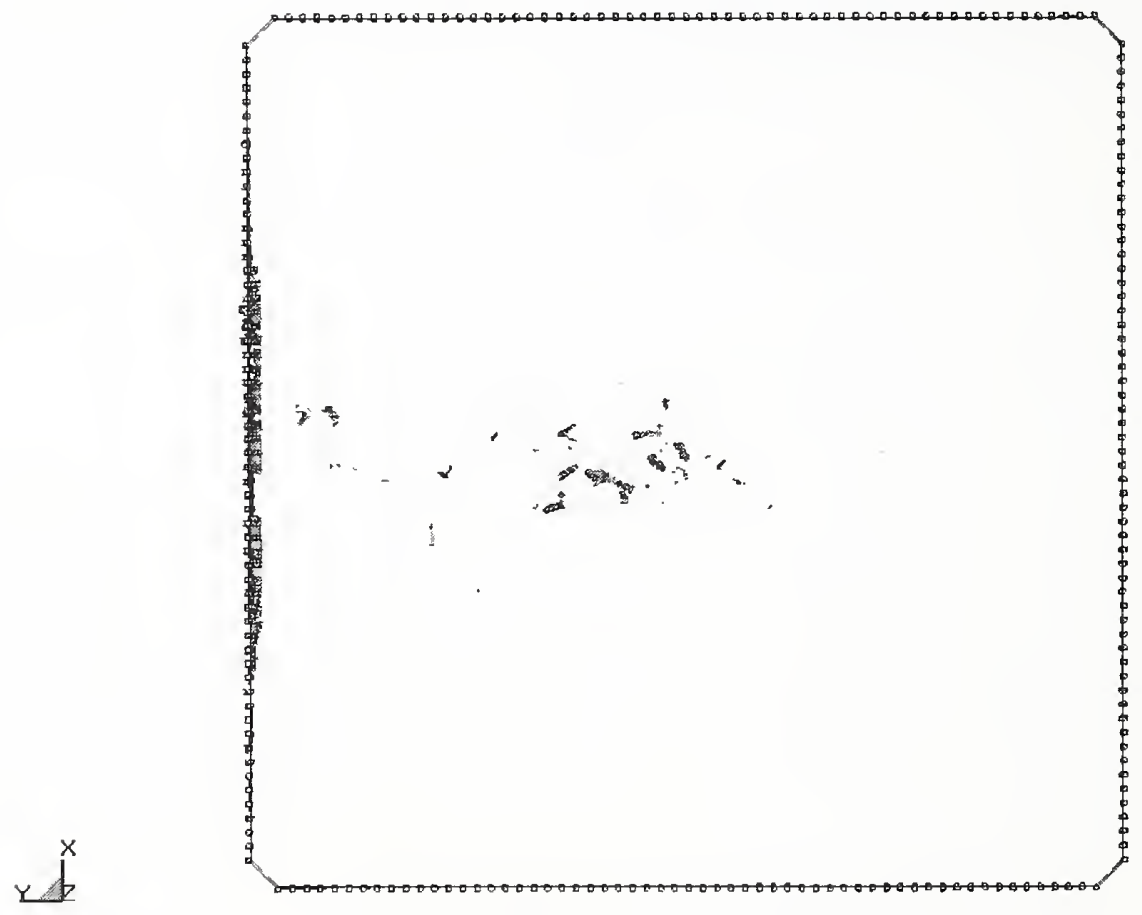

(b) Calculated landing gear debris $(\mathrm{t}=\mathbf{0 . 7 1 \mathrm { s } )}$

Figure 7-66. Base case aircraft debris distribution in WTC 1. 


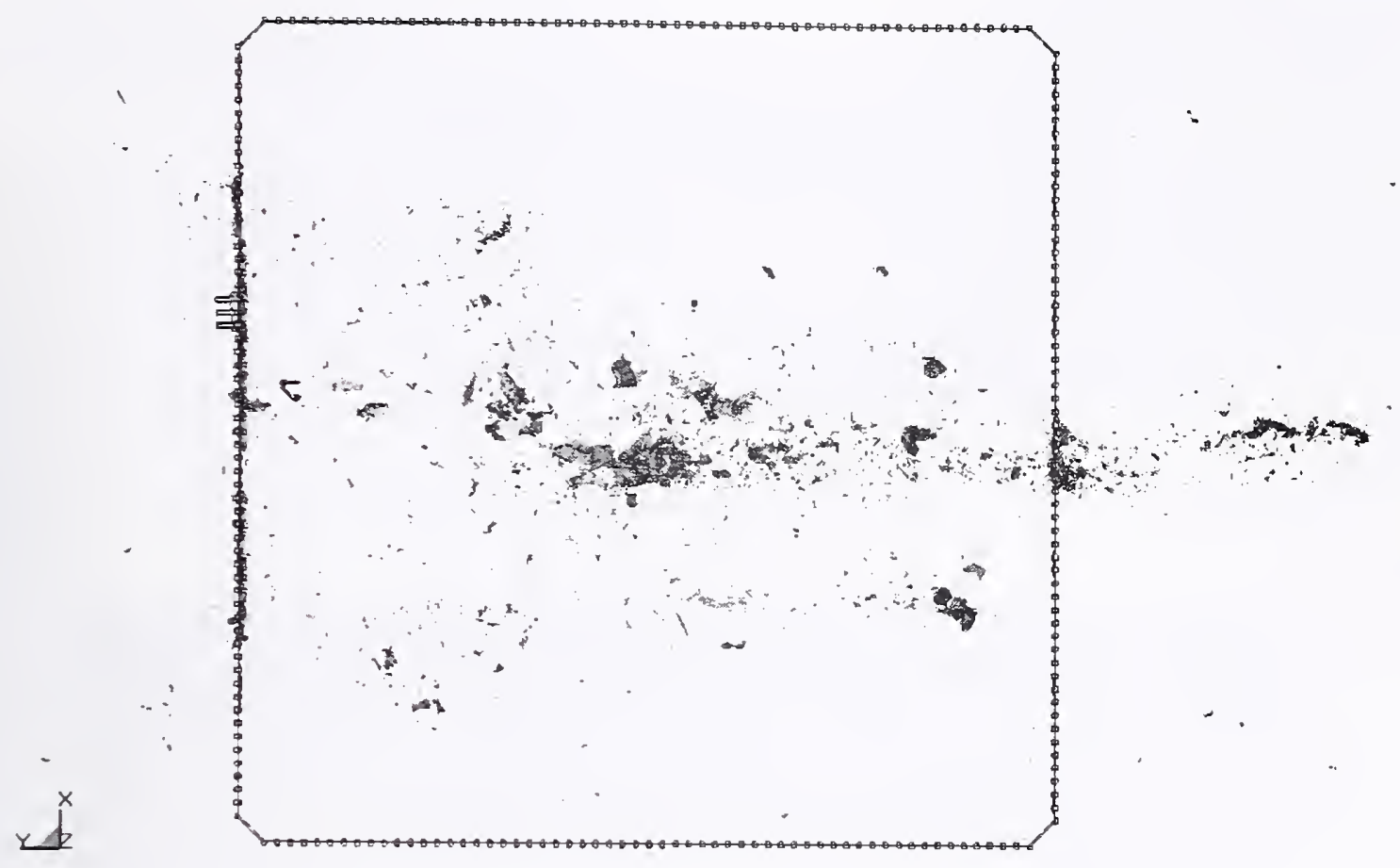

(a) Calculated aircraft debris $(t=0.685 \mathrm{~s})$

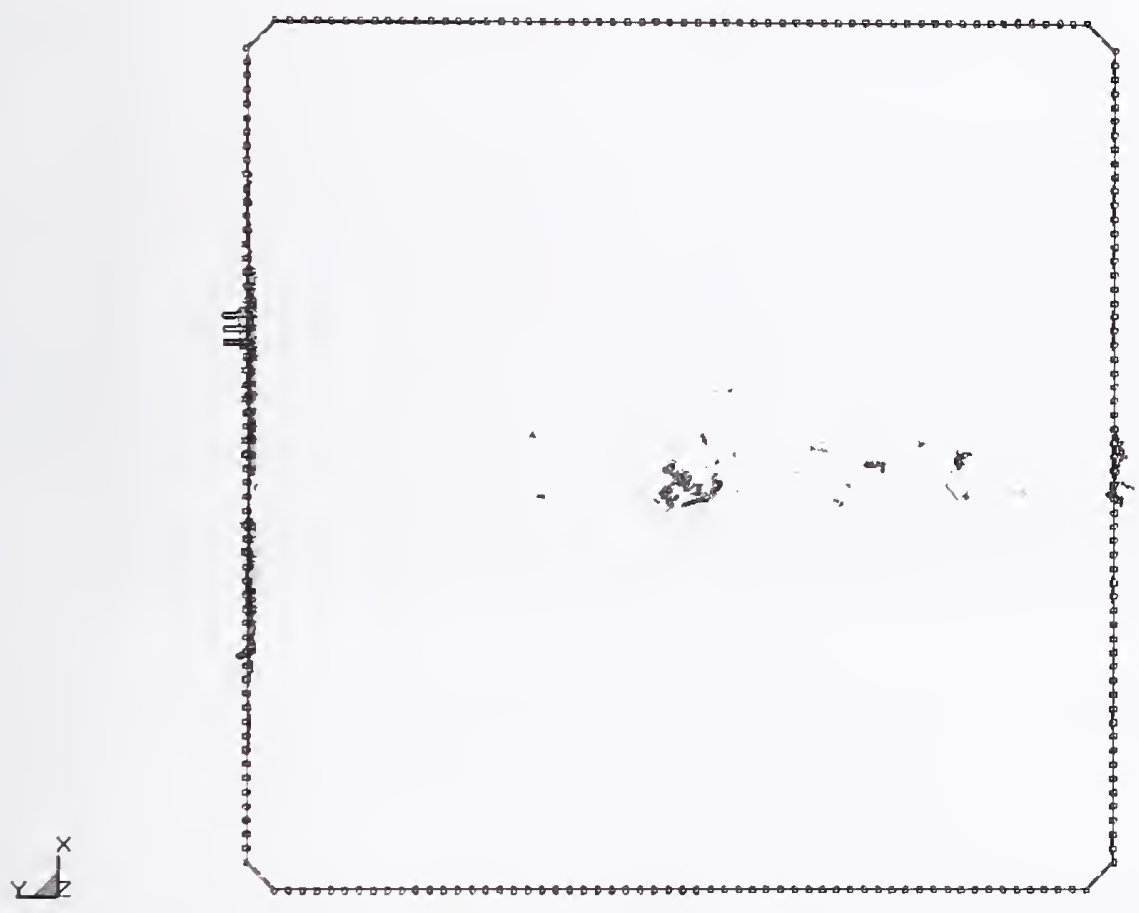

(b) Calculated landing gear debris ( $\mathrm{t}=0.685 \mathrm{~s}$ )

Figure 7-67. More severe damage aircraft debris distribution in WTC 1. 


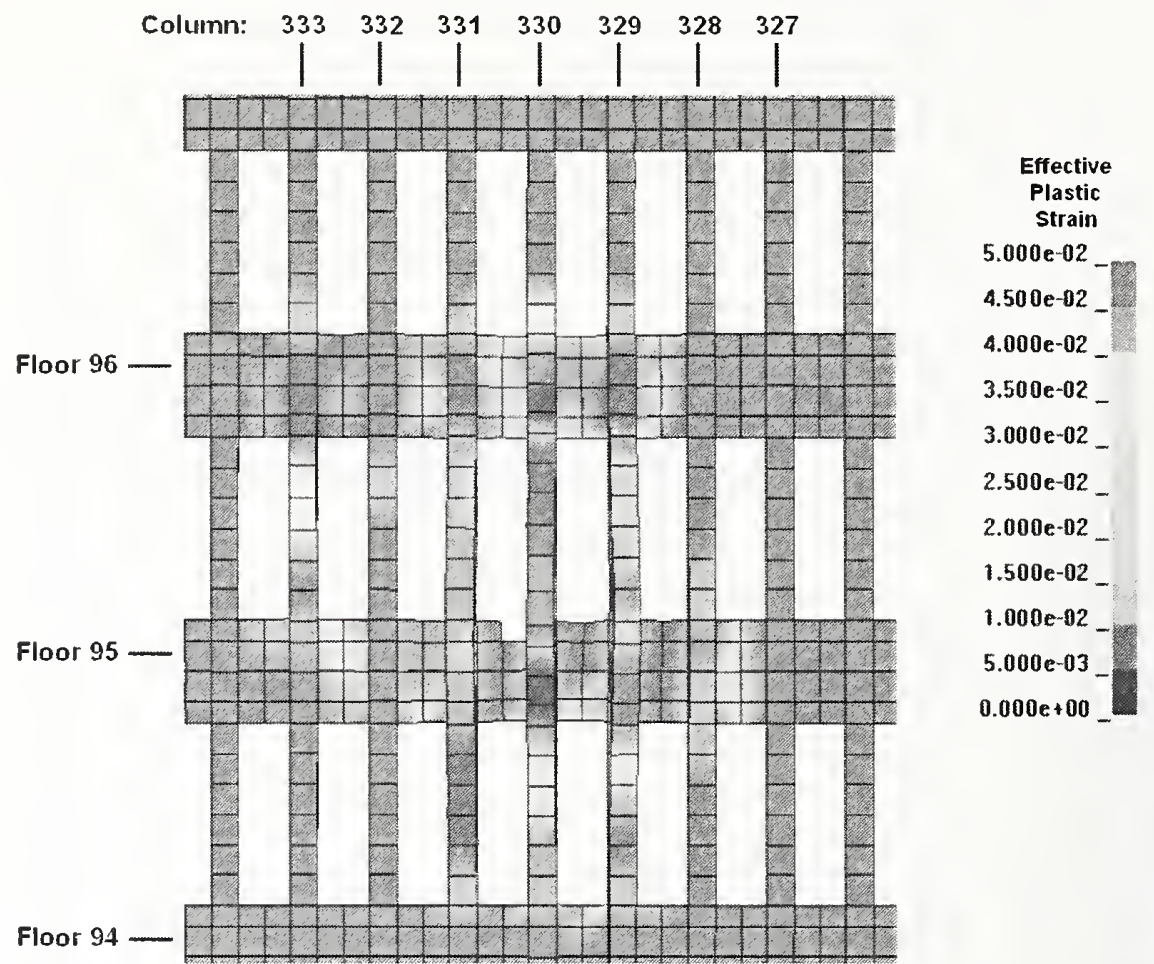

Figure 7-68. Damage to the south face of WTC 1 from the more severe damage global analysis.

Because of model size constraints, the panels on the south face of WTC 1 were modeled with a very coarse resolution. Neither the spandrel splice joints nor exterior column butt joints were modeled. Column ends and spandrel edges were merged together. The model therefore underestimated the damage to the tower on this face. The calculated damage produced by the more severe impact, shown in Figure 7-68, indicated that columns 329-331 on floors 94 through 96 sustained substantial damage. Had a fine mesh been used on these columns, it is likely that they would have failed on floor 95, and possibly on 94 and 96. Based on the failure modes observed on the north face and on the speed and mass of the debris, the panel would potentially be knocked free by failing at the connections.

\section{Landing Gear Trajectory Comparison}

A portion of the main landing gear of AA 11 exited WTC 1 at the 94th or 95th floor and landed at the corner of Rector St. and West St. The debris consisted of a tire, wheel, brake assembly and hub of a main landing gear, as shown in Figure 7-69. Based on the final position of the landing gear and assuming the landing gear to be a projectile with a horizontal initial velocity, the exit speed of the landing gear from the south wall of WTC 1 can be estimated to be about $105 \mathrm{mph}$. Note that there is a significant uncertainty in this estimate associated with the exit trajectory, aerodynamic effects, landing position rather than final resting position of debris, etc. Another piece of landing gear debris, shown in Figure 7-70, was found embedded in what is postulated to be the panel containing columns 329, 330,331, running from the 93rd to the 96th floors. This panel was dislodged from the building and found at Cedar Street near its intersection with West Street. As little other damage had been documented on the south face of WTC 1, 
it is postulated that the landing gear debris that landed at the corner of Rector St. and West St. also exited through this panel location.

The amount of aircraft debris found to exit WTC 1 in the global impact analyses varied, as shown in Figure 7-67 and Figure 7-68. However, no portion of the landing gear was observed to exit the towcr in the simulations, but rather was stopped inside, or just outside, of the core. In ordcr to simulate the trajectory of specific pieces of aircraft debris, a fairly precise knowledge of the internal configuration of the building was needed. This is especially true with components passing through the corc of the building, where some of the most massive building contents and partition walls were present.

Uncertainties regarding the internal layout of each floor, such as the location of hallways or walls, could make the difference between debris from a specific component passing through or being stopped inside the tower. In addition, modeling uncertainties and assumptions might play a role in not matching the observable.

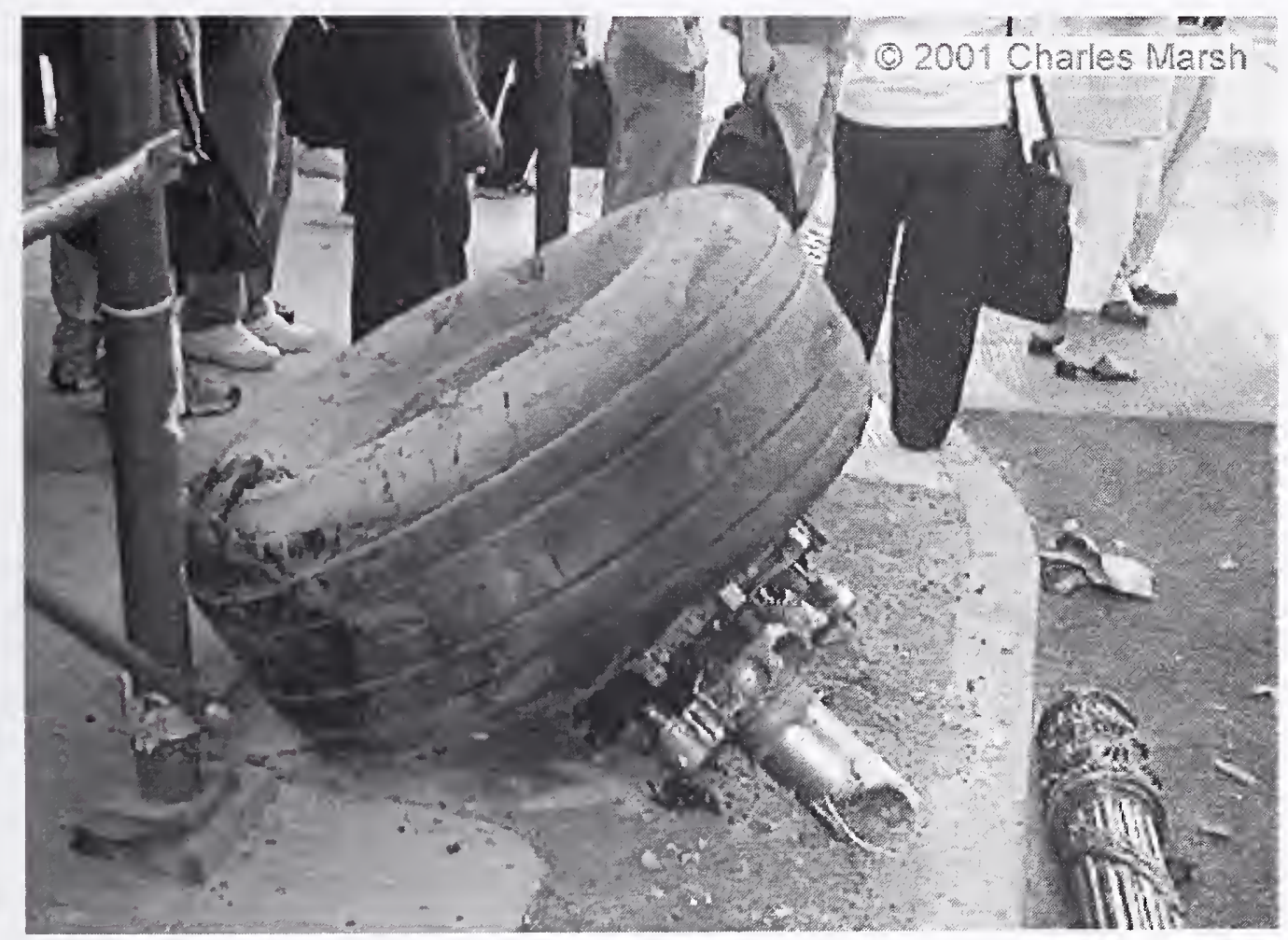

Figure 7-69. Landing gear found at the corner of West and Rector Streets. 


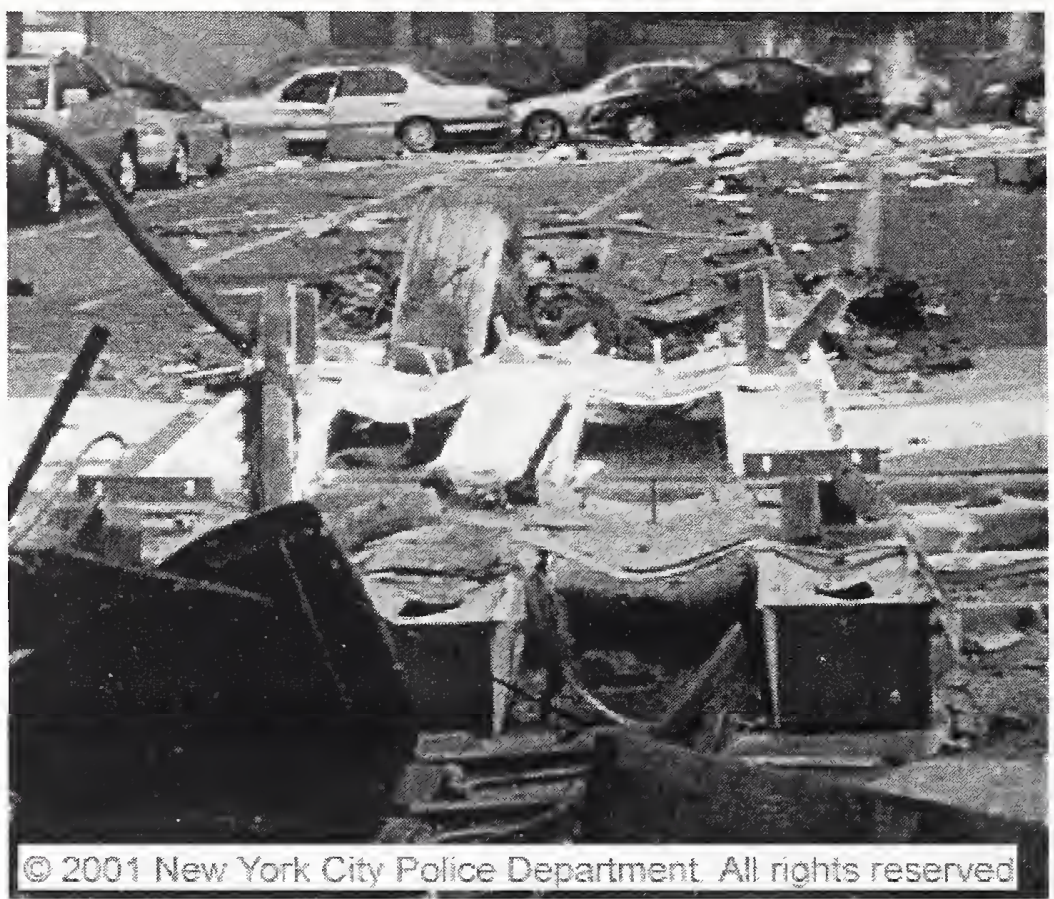

Figure 7-70. Landing gear found embedded in exterior panel knocked free from WTC 1.

\section{Stairwell Disruption Comparison}

According to eyewitness interviews, stairwells 1 (referred to also as stairwell A), 2 (stairwell C), and 3 (stairwell B) inside the core were impassable at floor 92 and possibly above after the impact of AA 11 (see NIST NCSTAR 1-7). The calculated base case stairwell disruption is shown in Figure 7-71 for floors 93 through 97. Stairwell positions are outlined with red boxes in the figure. No debris or disruption was observed to the core on floor 92 in the calculation, therefore, it is not shown in the figure. Recall that the global model for WTC 1 only contained partition walls in the core on floors 94 through 97. Therefore, the ability to ascertain damage and/or debris in the stairwell on floors 92 and 93 was limited. The floor slab was removed from the view on floors 94 through 97 so that debris is more visible.

Based on the calculated damage to, or debris in, the stairwells on floors 94 to 96 , all three stairwells appear impassable. Given that falling debris in these areas would cause further subsequent damage to the floors below, as well as block passage on these floors, this result was reasonably consistent with the eyewitness accounts. 


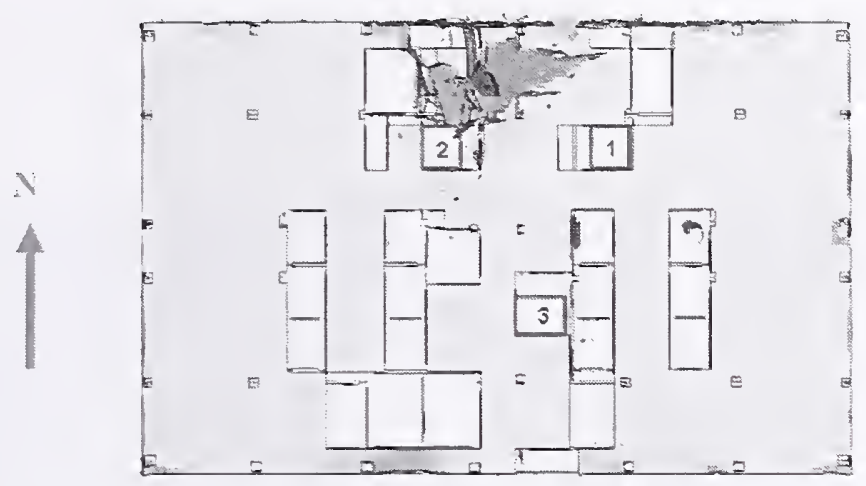

(a) Floor 93

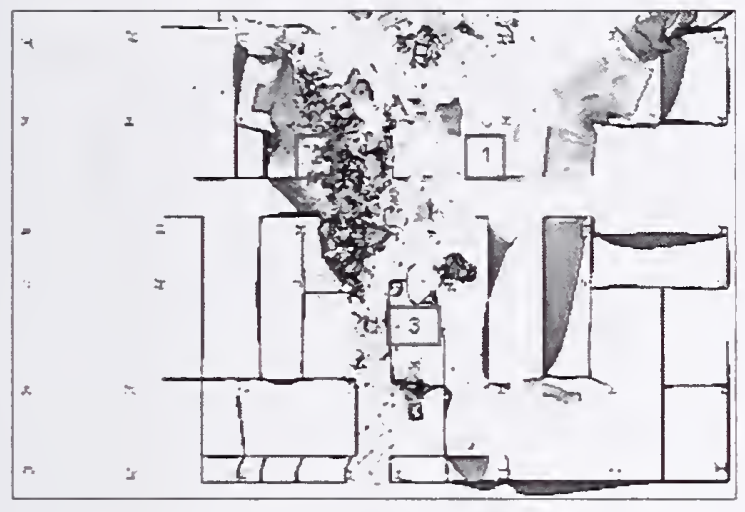

(b) Floor 94

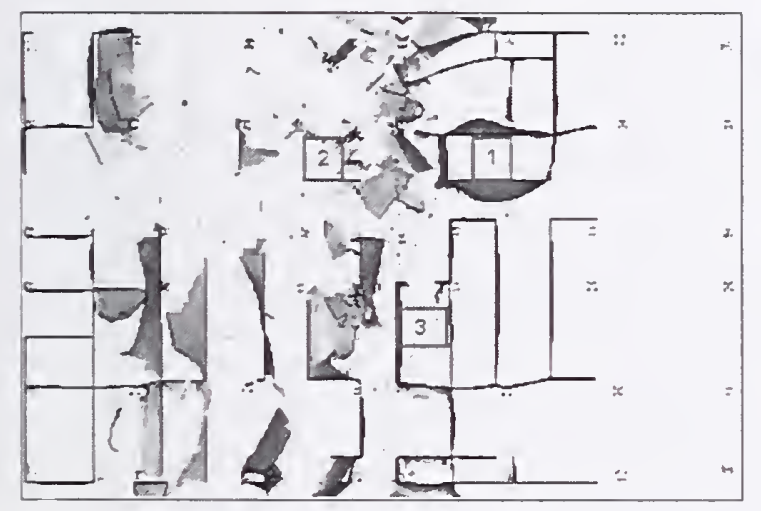

(d) Floor 96

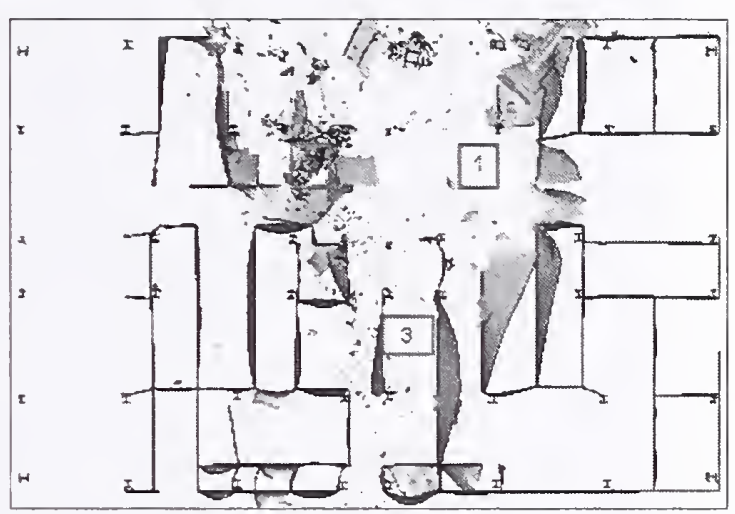

(c) Floor 95

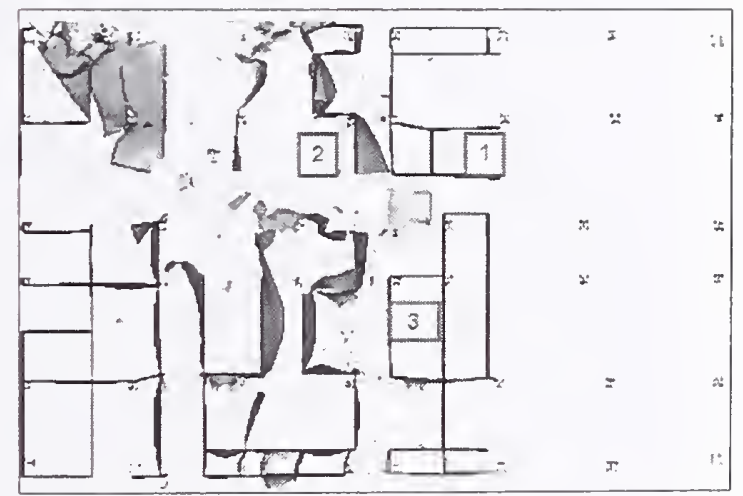

(e) Floor 97

Figure 7-71. Base case stairwell disruption in WTC 1.

\section{Floor Damage Visible on the North Face of WTC 1}

One location where the damage to the WTC 1 truss floors could be observed was through the opening in the tower exterior produced by the aircraft impact. A photograph of the impact damage on the north face of WTC 1 is shown in Figure 7-72(a). The magnitude of damage was difficult to quantify as a result of 
the strong contrast in lighting between the tower interior and exterior and the smoke inside the building. However, the photograph shows that the truss floor was heavily damaged and/or removed in the primary impact zone. The depth of the floor damage extending into the tower could not be determined.

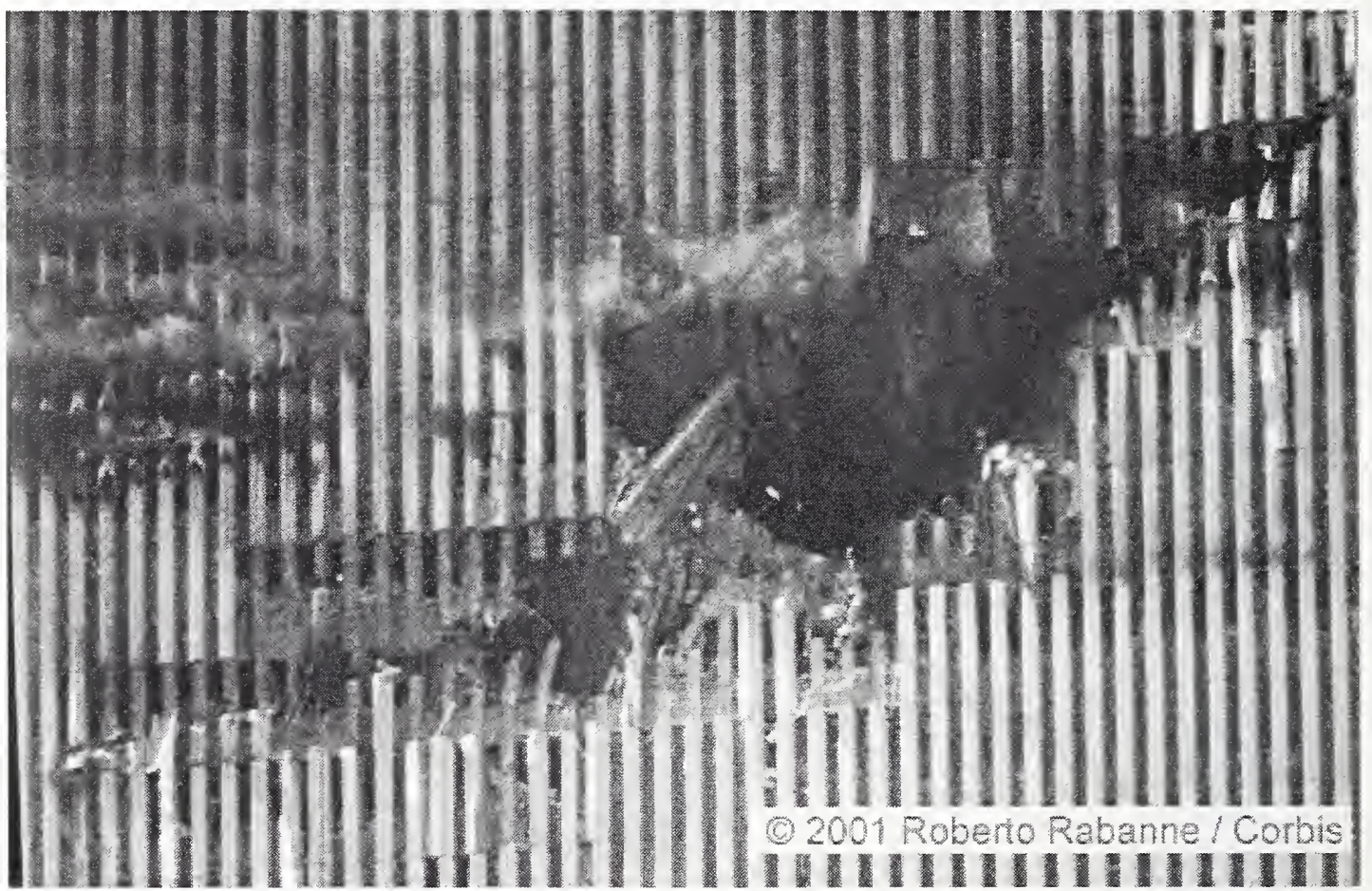

(a) Observed Damage

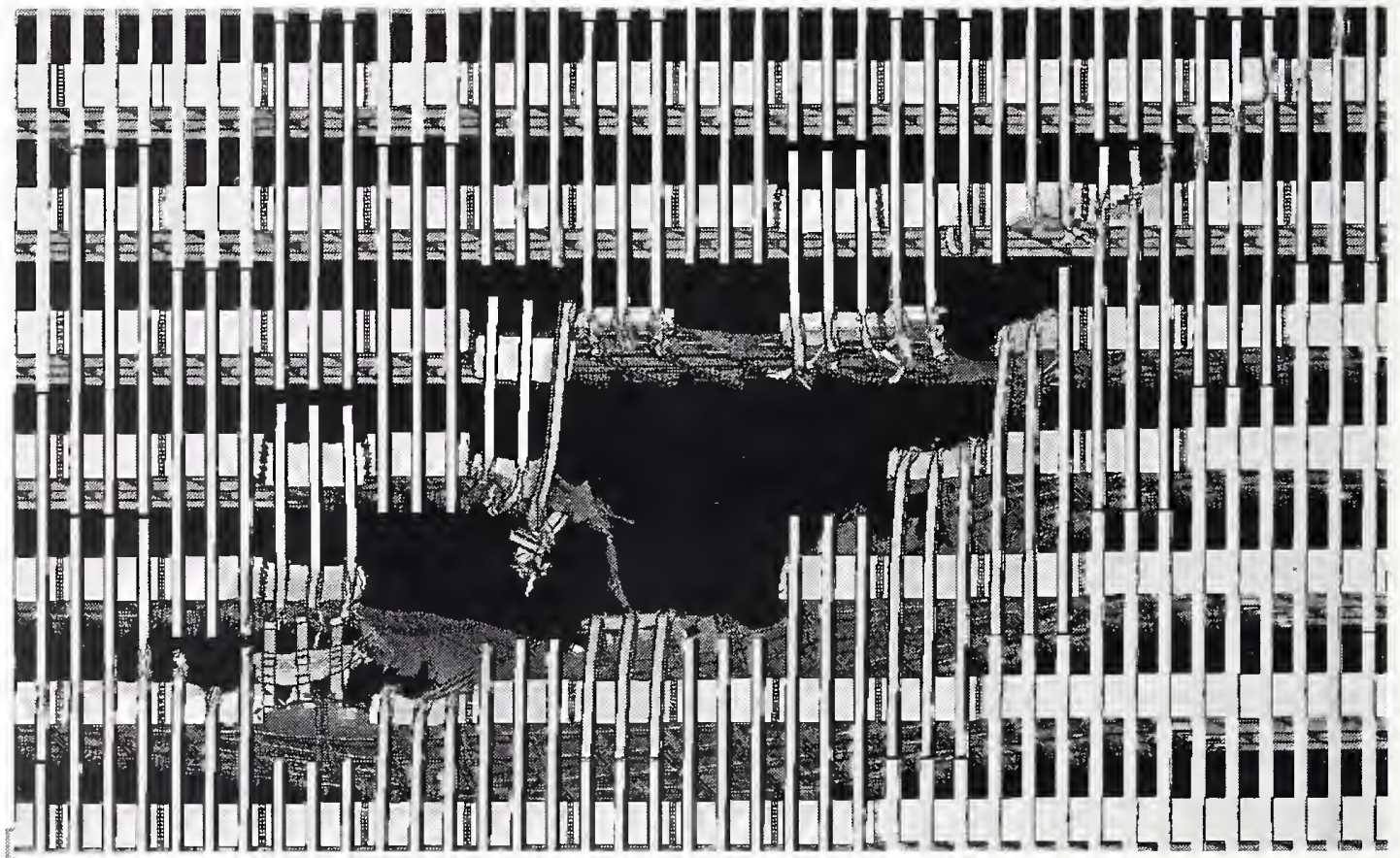

(b) Calculated damage

Figure 7-72. Observed and calculated WTC 1 damage (front view). 
A corresponding image of the calculated damage to the tower structures is shown in Figure 7-65(b). The structures beyond the start of the core were removed and replaced with a black background for comparison with the photograph. Although a quantitative comparison of the calculated and observed damage could not be made from the available damage photographs, the truss floor damage appeared to be consistent.

\subsubsection{Comparison with Observables on WTC 2}

\section{Damage Comparison on the South Wall of WTC 2}

Figure 7-73 provides the results of a careful comparison between the observed and calculated damage (from the base case analysis) on the south wall of WTC 2. The comparison includes the mode, magnitude, and location of failure around the hole created by the aircraft impact. The comparison indicates that the overall agreement with the observed damage was very good.

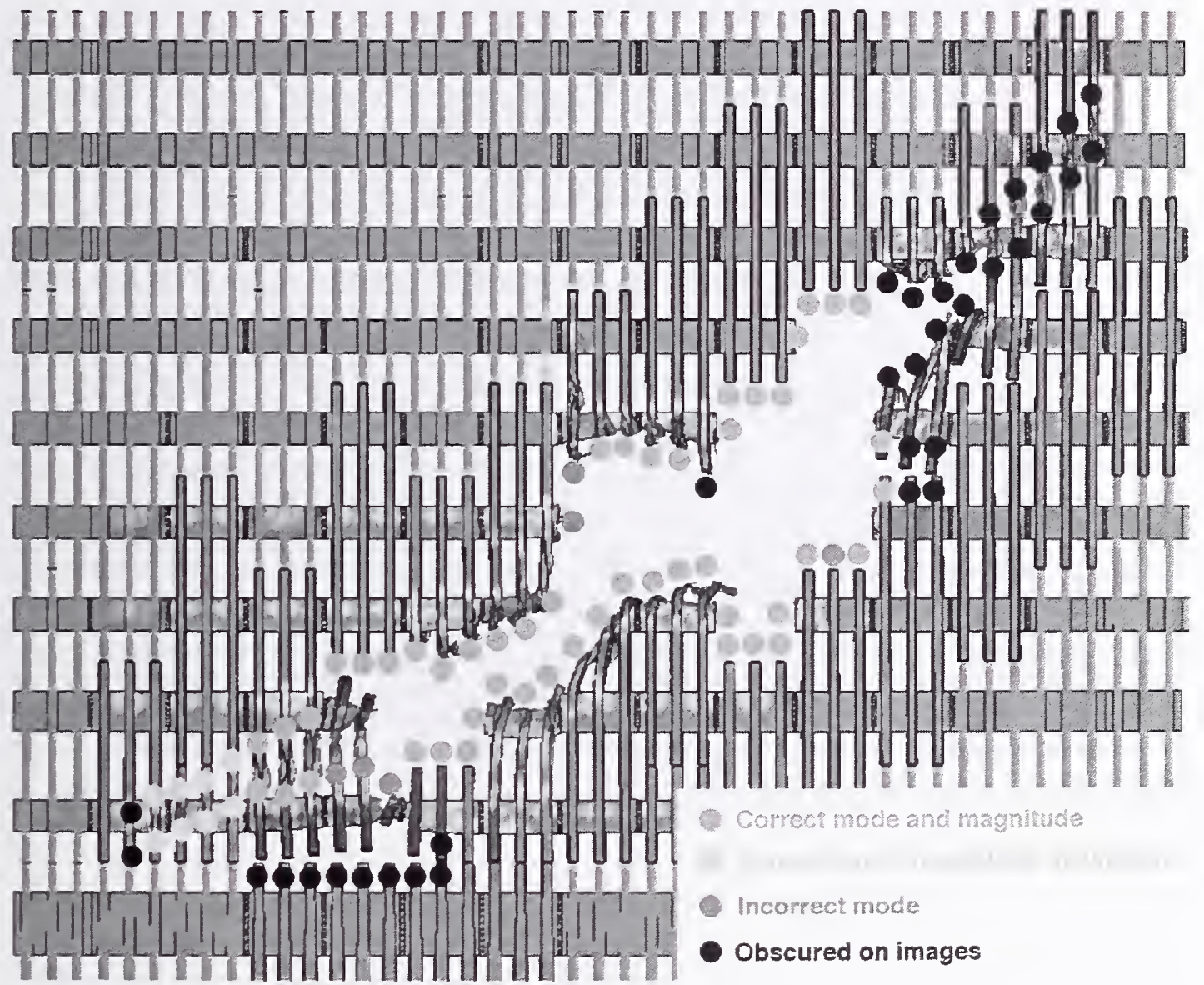

Figure 7-73. Comparison of observable and calculated base case impact damage to the south wall of WTC 2. 


\section{Damage Comparison on the North Wall of WTC 2}

From photographic evidence, such as that shown in Figure 7-74, damage on the north wall at the northeast corner of WTC 2 was documented and is shown in Figure 7-75. As mentioned earlier, there was significant uncertainty as to the actual layout of the workstations and other building contents on the impacted floors of the towers. Recall that generic workstation configurations were used to model these building contents, as shown in the northeast corner of WTC 2 in Figure 7-76(a). Uncertainties regarding this layout, such as missing partition walls and workstations, could make the difference between debris from a specific component passing through or being stopped inside the structure. The base case impact response of the northeast corner of WTC 2 on the 81st floor is shown in Figure 7-76(b).

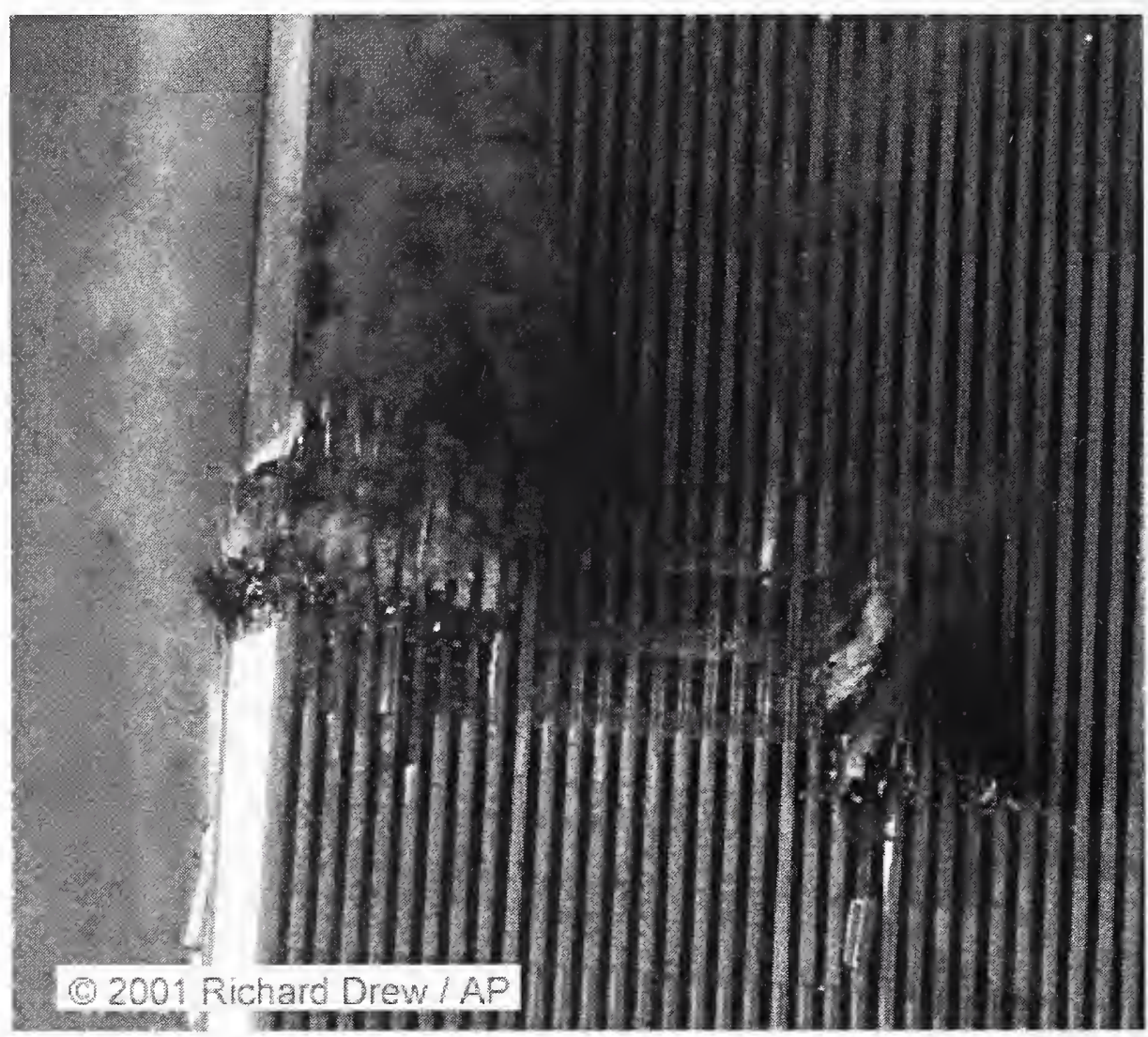

Figure 7-74. Impact damage to the northeast corner of the exterior wall of WTC 2. 


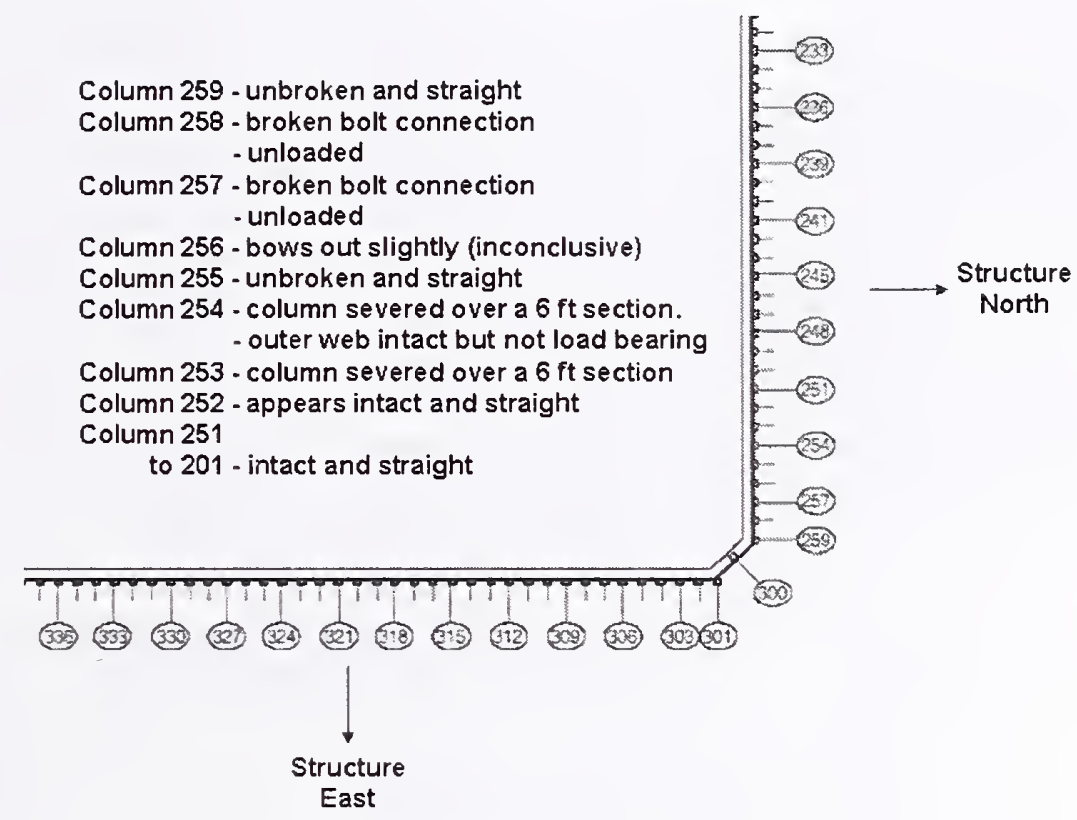
Figure 7-75. Documented damage to the northeast corner of
floor 81 of WTC 2.

Aircraft debris on floor 81 of WTC 2 is shown in Figure 7-76(c), with the coloring depicting the residual speed of the debris field. Notice that some of the debris in this figure, weighing approximately $3,800 \mathrm{lb}$, was traveling at 110-150 mph and was projected to impact between columns 252 and 256 . The leading debris was portions of the starboard main landing gear main strut and main landing gear beam. That significant debris was projected to impact in the region of significant damage shows positive agreement with damage evidence available for the north wall of WTC 2. 

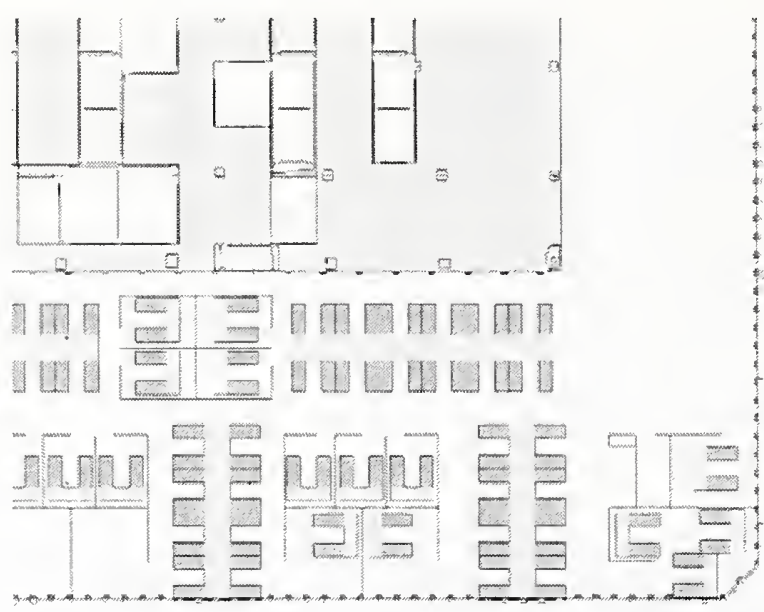

(a) Initial workstation configuration

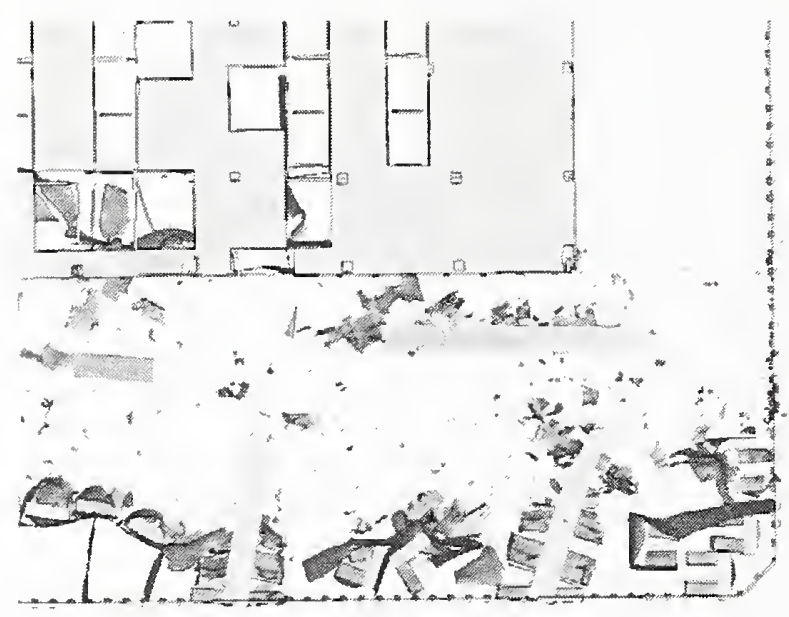

(b) Debris field at $\mathrm{t}=0.62 \mathrm{~s}$

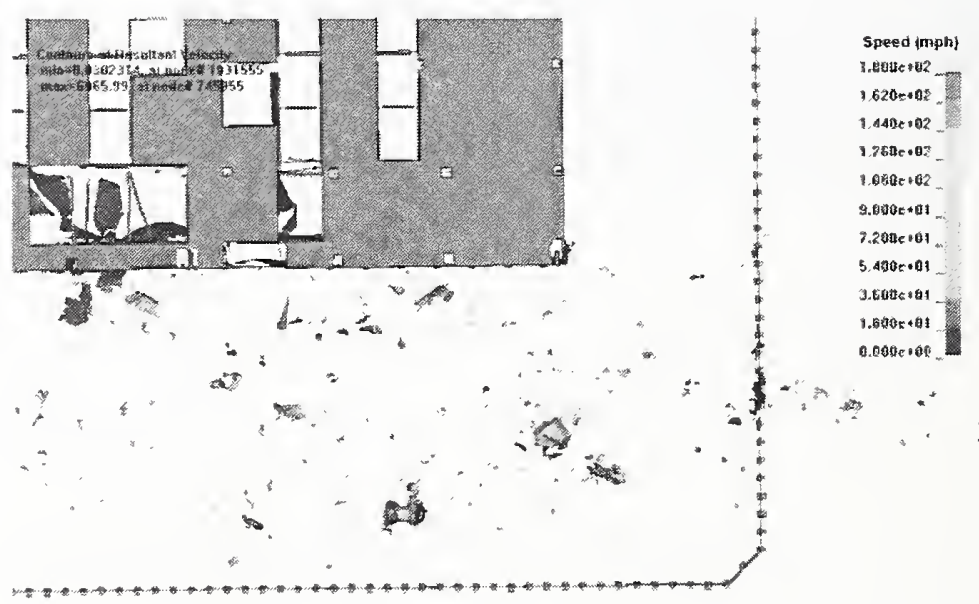

(c) Residual speed of aircraft debris (contours in $\mathrm{mph}$ )

Figure 7-76. Base case response on the northeast corner of floor 81 of WTC 2. 


\section{Stairwell Disruption Comparison}

According to eyewitness interviews, stairwells 2 and 3 on floor 78 of WTC 2 were impassable (see NIST NCSTAR 1-7). Stairwell 1 (referred to also as stairwell A), which was located in the northwest corner of the core, was passable. The calculated base case stairwell disruption is shown in Figure 7-77.

Stairwells 1 and 2 (stairwell C) on floor 78 of WTC 2 were outside of the core column region as is shown in the figure. These stairwells were not included in the WTC 2 model. Therefore, a good assessment could not be made for stairwell 2. However, disruption to stairwell 3 (stairwell B) is shown in Figure 7-77. By the damage shown in the figure, the stairwell appears to be impassable. As no damage or debris was seen in the northwest corner of the tower, the top right in the figure, stairwell 1 in this area of the core was likely unaffected. Both of these assessments were consistent with the eyewitness accounts.

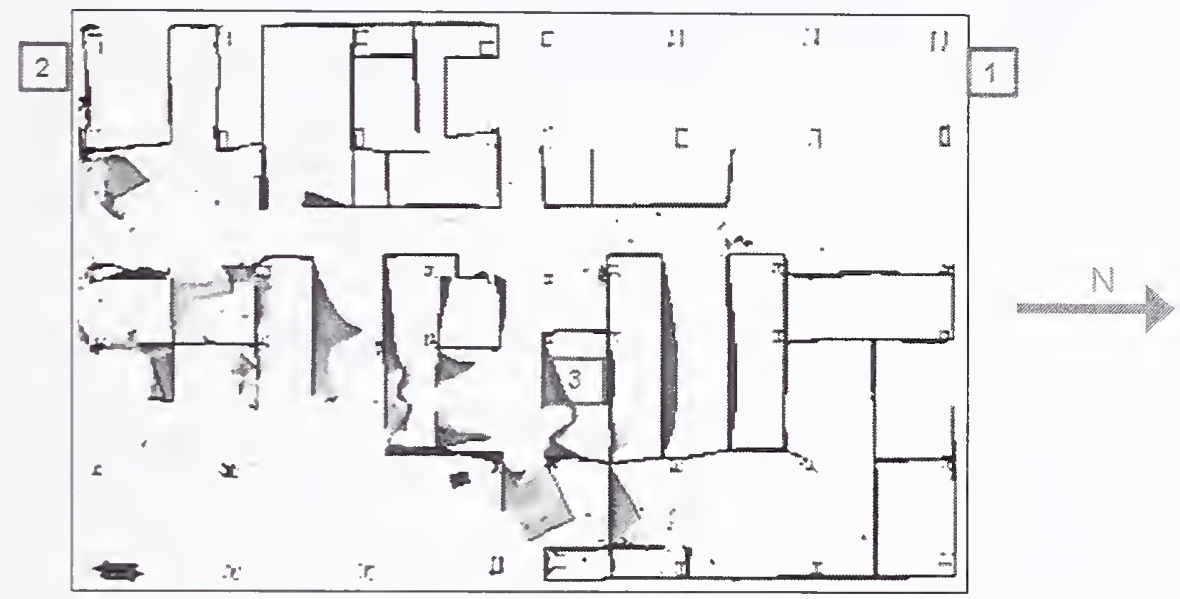

Figure 7-77. Base case stairwell disruption on floor 78 in WTC 2.

\section{Landing Gear Trajectory Comparison}

A portion of the landing gear of UAL 175 exited WTC 2 and landed on the roof of 45 Park Place (see FEMA 2002). No photographic evidence was available to document the size of the fragment and whether this was a nose or main landing gear. From the damage to the building, the landing gear fragment might have exited somewhere along the north wall between column 251 and the northeast corner on floor 81 . Based on the final position of the landing gear and assuming the landing gear to be a projectile with a horizontal initial velocity, the exit speed of the landing gear from the north wall of WTC 2 can be estimated to be about $102 \mathrm{mph}$. Note that there is a significant uncertainty in this estimate associated with the exit trajectory, aerodynamic effects, landing position rather than final resting position of debris, etc.

The calculated aircraft debris distribution and landing gear and engine debris distributions for UAL 175 are shown in Figure 7-78 and Figure 7-79 for the base case and more severe case, respectively. A portion of the port main landing gear was seen to exit the building at approximately $230 \mathrm{mph}$ in the more severe impact analysis, as shown in Figure 7-79(b). No landing gear debris exited the building in the base case. At the conclusion of the simulation, the base case analysis had a substantial piece of the starboard main landing gear still moving at approximately $130 \mathrm{mph}$ that was expected to impact the northeast corner. 


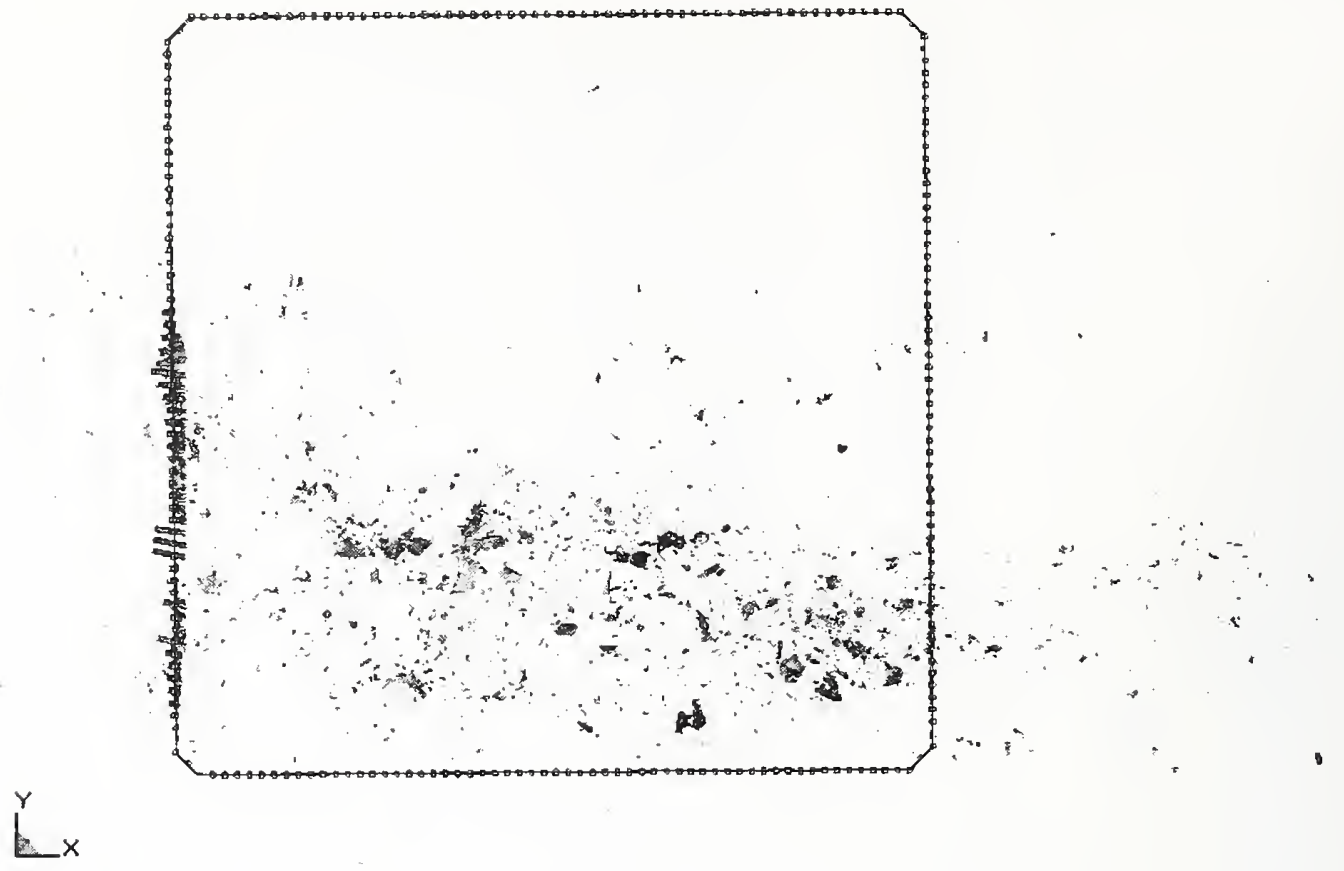

(a) Calculated aircraft debris $(\mathrm{t}=0.62 \mathrm{~s})$

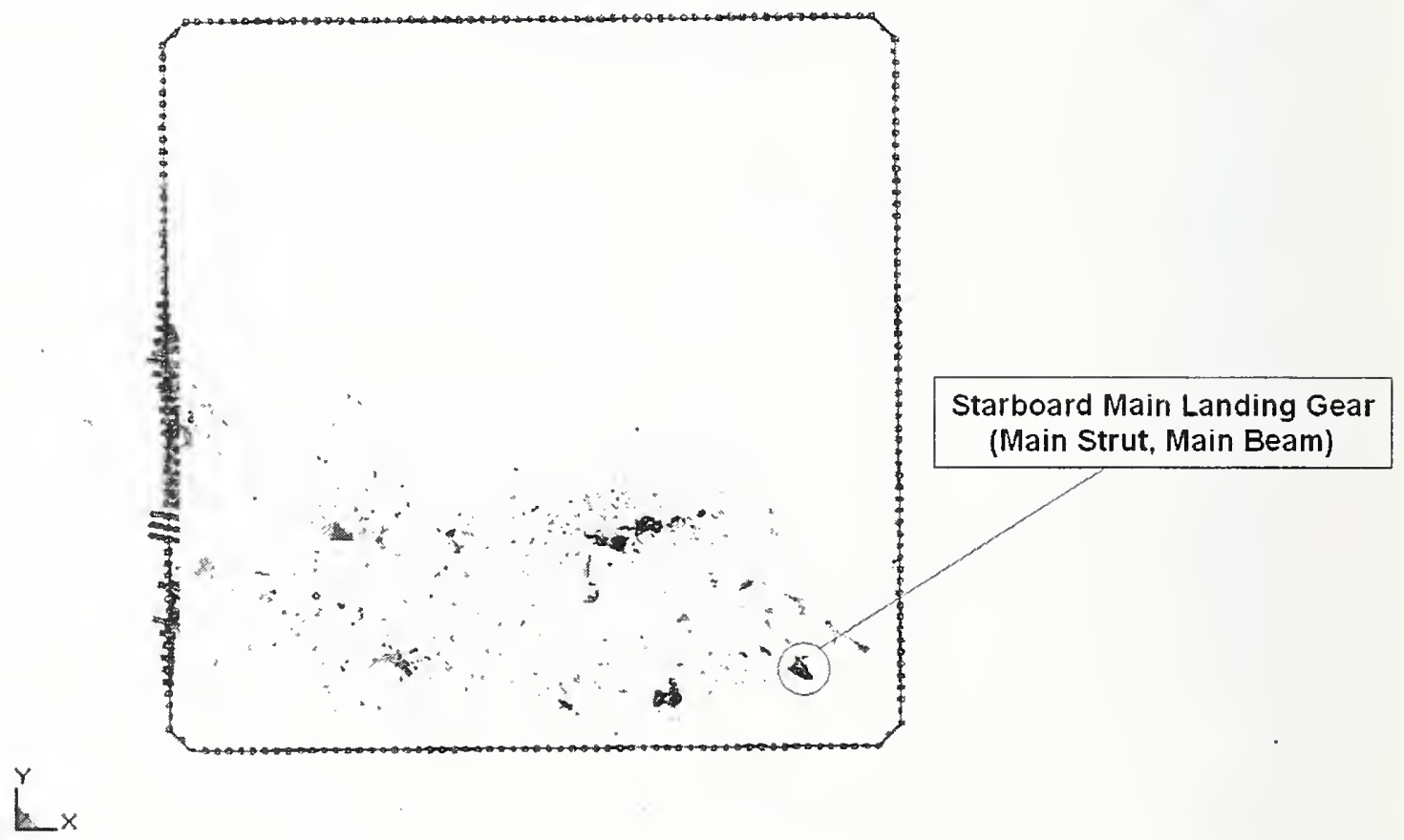

(b) Calculated engine and landing gear debris $(t=0.62 \mathrm{~s})$

Figure 7-78. Base case damage aircraft debris distribution in WTC 2. 


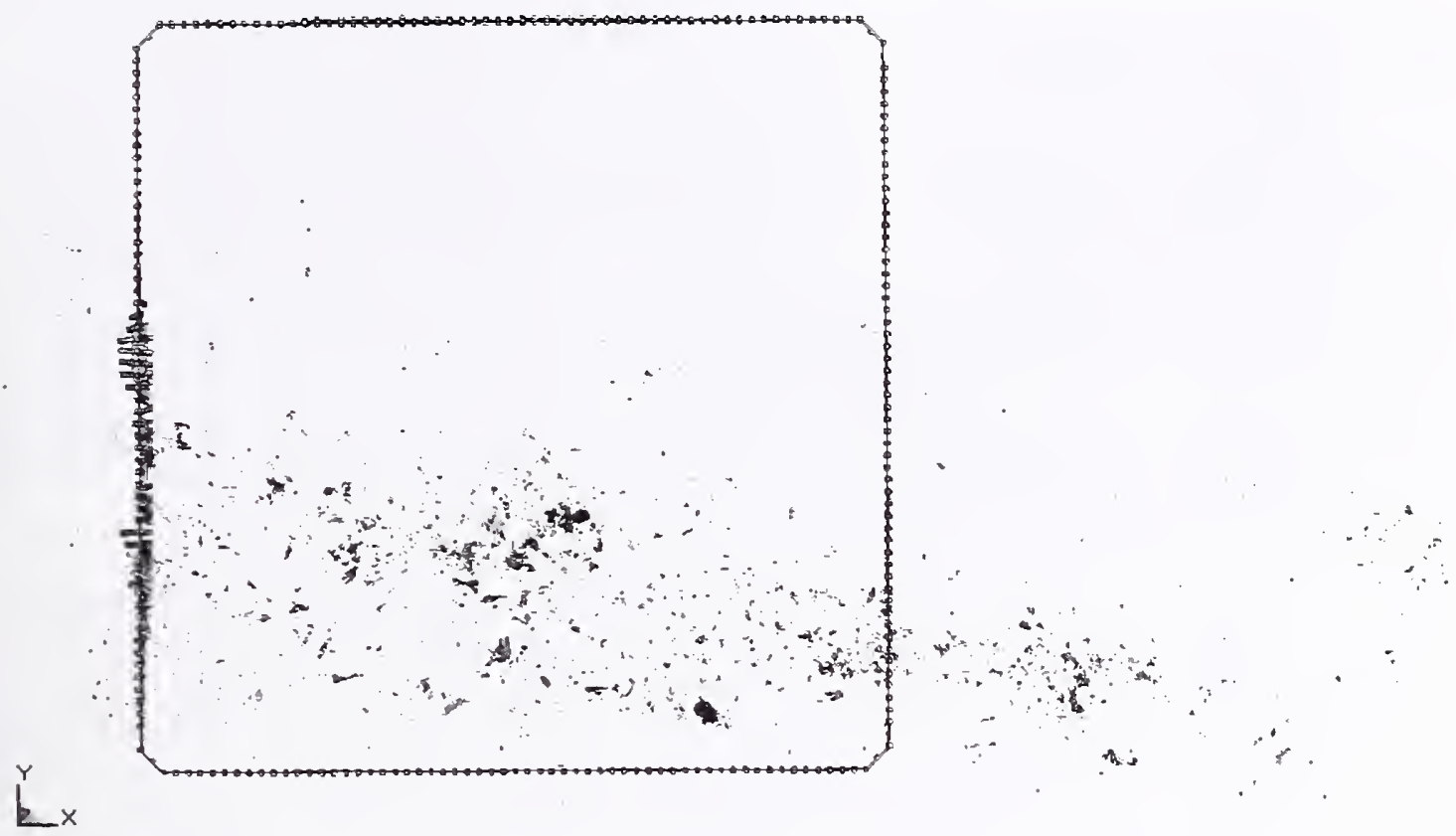

(a) Calculated aircraft debris ( $\mathrm{t}=0.58 \mathrm{~s})$

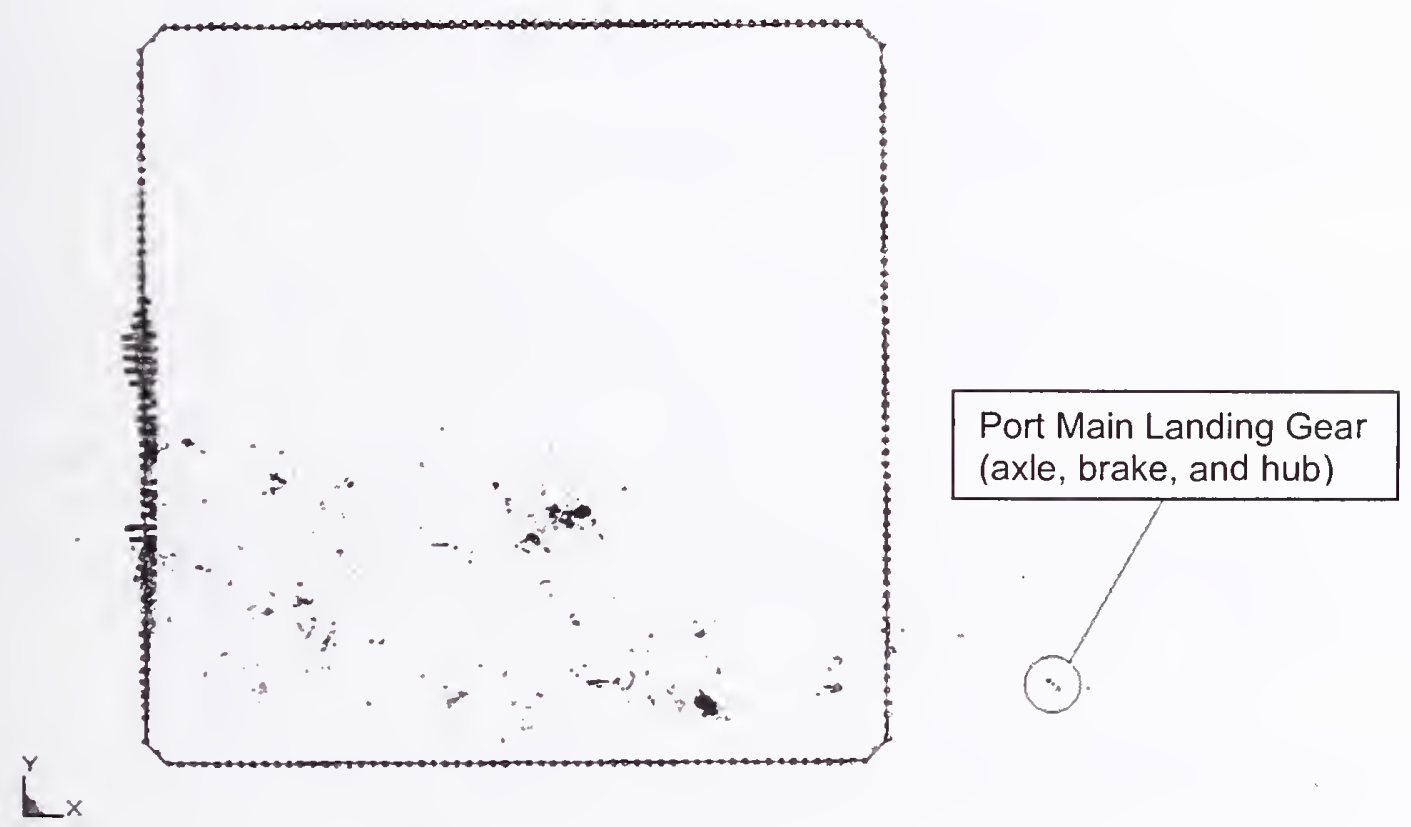

(b) Calculated engine and landing gear debris ( $t=0.58 \mathrm{~s}$ )

Figure 7-79. Aircraft debris distribution in the more severe WTC 2 impact. 


\section{Engine Trajectory Comparison}

A portion of an engine also exited the tower at the northeast corner of the building and was found at the intersection of Murray and Church Streets. From the damage to the building, it was believed that the engine exited the building in this corner of WTC 2. Based on this trajectory, it was estimated that the engine exited the building at approximately $120 \mathrm{mph}$. The engine trajectories predicted from the base case global analysis are shown in Figure 7-80, which indicates that the engine that exited from the northeast corner of the tower is likely the starboard engine. The dotted line indicates the extrapolated engine flight path based in the initial trajectory of the starboard engine. Notice that this trajectory would result in engine fragments exiting at the northeast corner. In the simulations, the engines were projected to stop short of this position, although they follow the extrapolated trajectory reasonably well.

Speed time-histories for the aft portion of the starboard engine are shown in Figure 7-81. The engine would typically breakup into smaller fragments from the forward section of the engine and a larger section from the aft end, as shown in Figure 7-82. In all simulations, the speed was seen to drop by approximately $200 \mathrm{mph}$ due to impact with the exterior panel, floor slab, and floor truss. Interaction with these portions of the structure ended by approximately $0.12 \mathrm{~s}$. This initial impact from the base case is shown in Figure 7-83. The engine debris then continued through the tenant space of the 81st floor, plowing through the workstations and contents. Whether or not the fragment passed over these contents, or if other debris and fuel removed the contents from the engine's path, affected the deceleration of the fragment. At the end of the simulation, the speed of the aft portion of the engine was below $80 \mathrm{mph}$, and it was more than $60 \mathrm{ft}$ from the northeast corner of the building. For these calculations, it was estimated that the building contents would likely stop the engine fragment prior to impacting the northeast corner of the exterior wall.

None of the three WTC 2 global impact simulations resulted in a large engine fragment exiting the tower. However, the impact behavior suggests that only minor modifications would be required to achieve this response. For example, if the starboard engine impact location was lowered by 1 to $2 \mathrm{ft}$, which is within the aircraft impact geometry uncertainty range, the engine would likely have had a greater residual speed inside the tower, over $100 \mathrm{mph}$. In the global analyses performed, the engine impacted the underside of the 82 nd floor, as shown in Figure 7-76. This resulted in a large reduction in speed of approximately $200 \mathrm{mph}$. In the component analyses, the engine speed decreased by roughly $60 \mathrm{mph}$ when impacting an exterior panel alone. This additional speed would likely result in a large engine fragment exiting the northeast corner of the tower.

Other minor modifications to the model could also result in a large engine fragment exiting the building. As mentioned previously, there was significant uncertainty in the distribution of building contents on the floors of the impact area. If any portion of the east side of WTC 2 was relatively free of office materials, the engine fragment would have been free to move relatively unrestricted and would have experienced little loss of speed. After the engine entered the structure, and without office materials, the engine fragment would only slow due to friction with the floor slab and occasional interaction with floor trusses above. After initially entering the building, the engine did not further penetrate the floor slab. Removing much of the building contents from the east side would result in the starboard engine fragment impacting the northeast corner of the tower with sufficient speed to exit the building. Little or no difference in core damage would result, as debris in this area had no chance of impacting the core. 

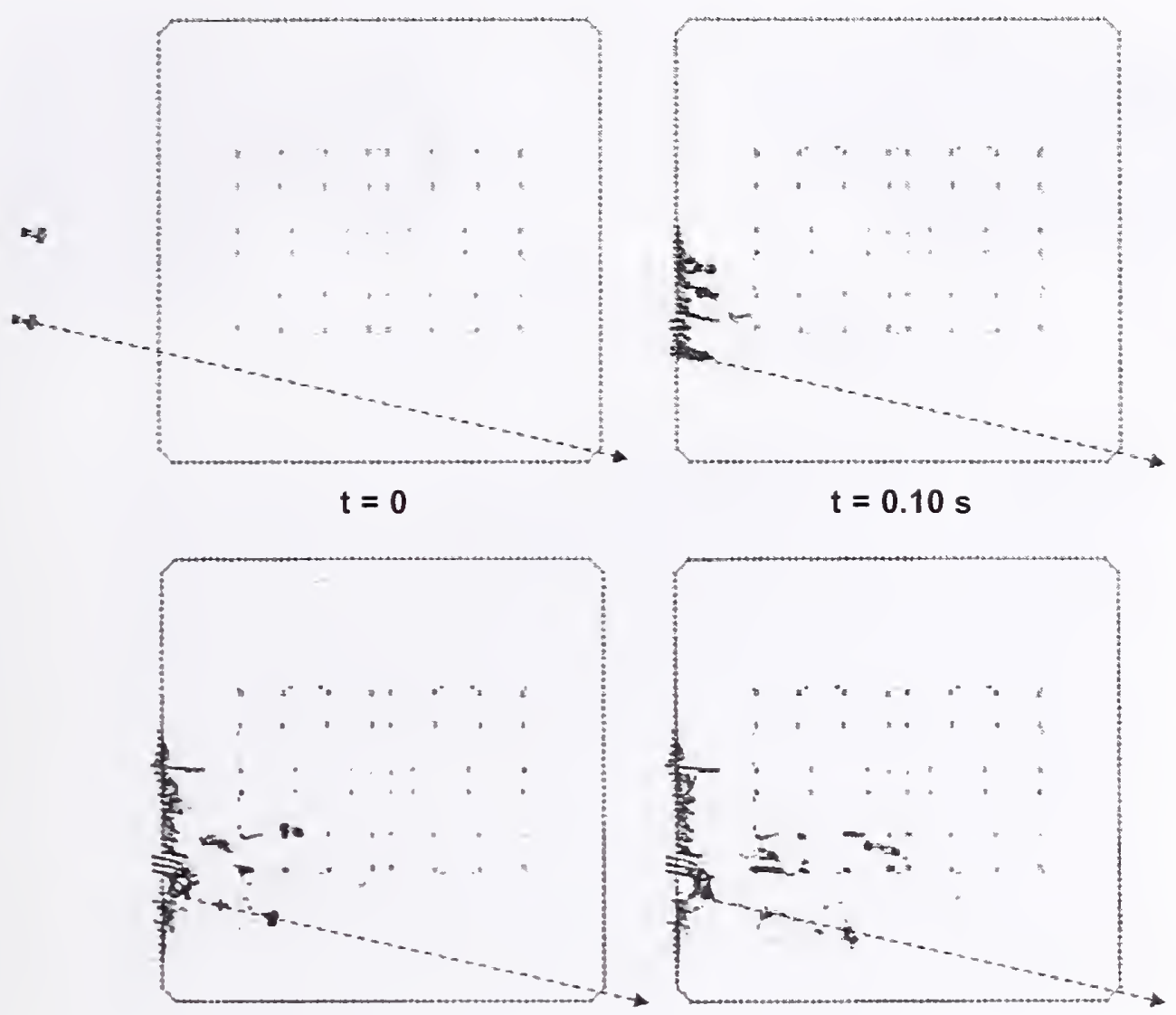

$\mathrm{t}=0.20 \mathrm{~s}$

$t=0.30 s$
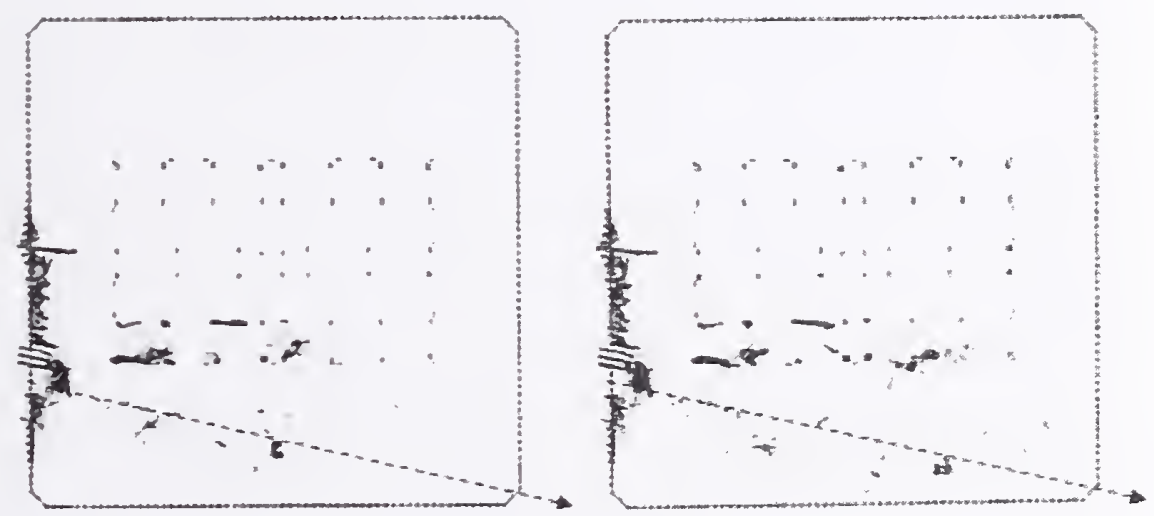

$\mathrm{t}=0.40 \mathrm{~s}$

$t=0.62 s$

Figure 7-80. Starboard engine fragment trajectory in the base case global analysis of WTC 2. 


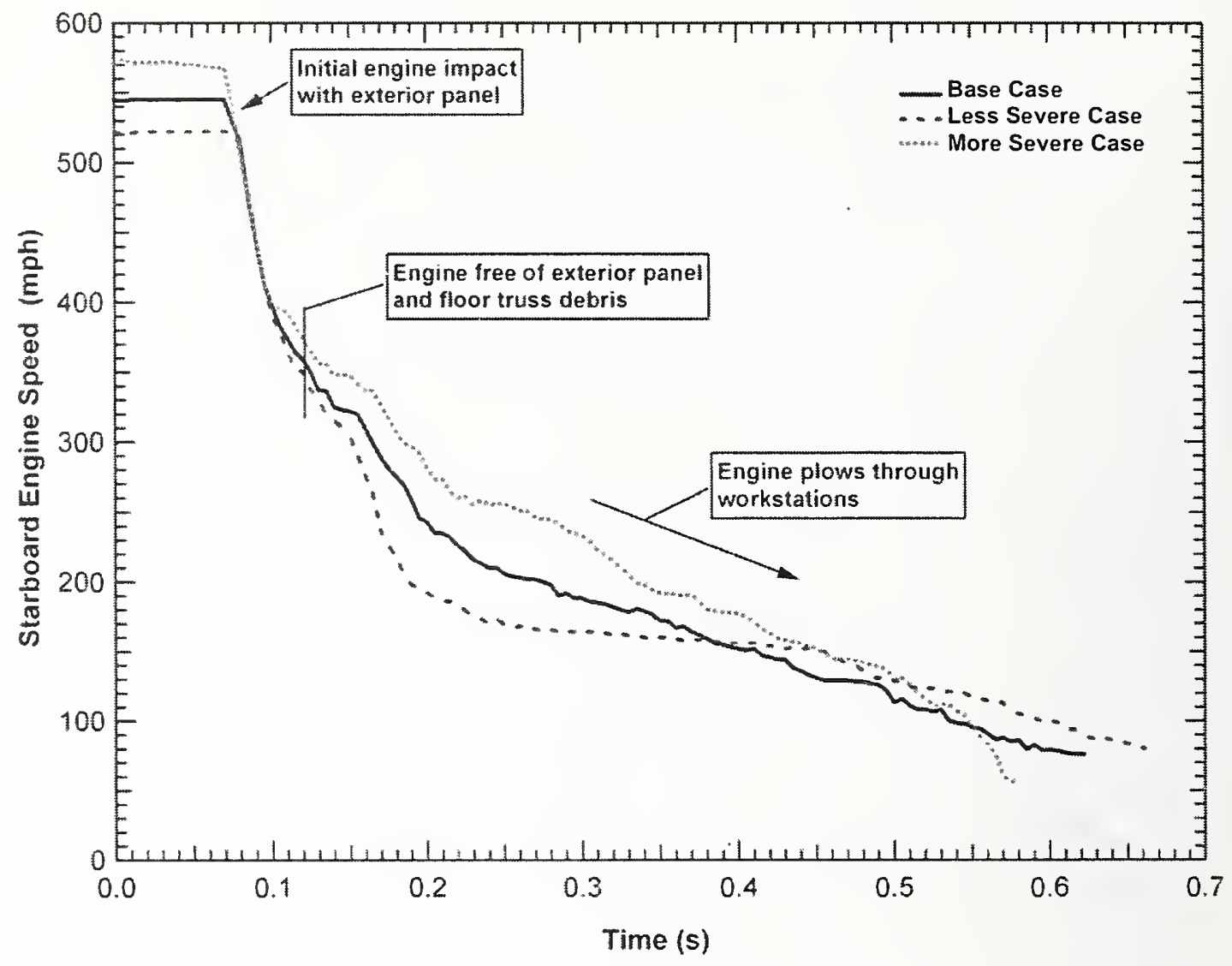

Figure 7-81. Speed of the aft portion of the starboard engine. 


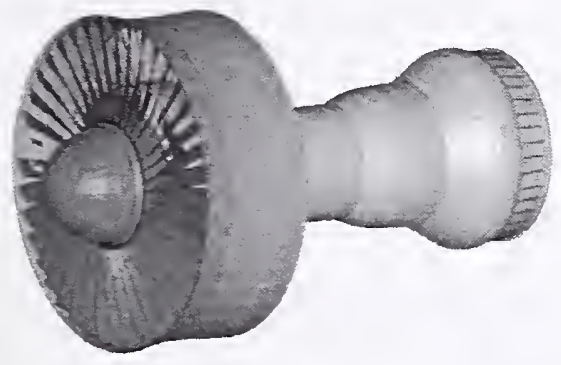

(a) Undamaged engine

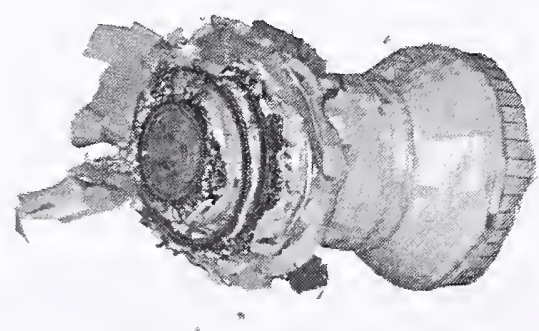

(b) Large engine fragment

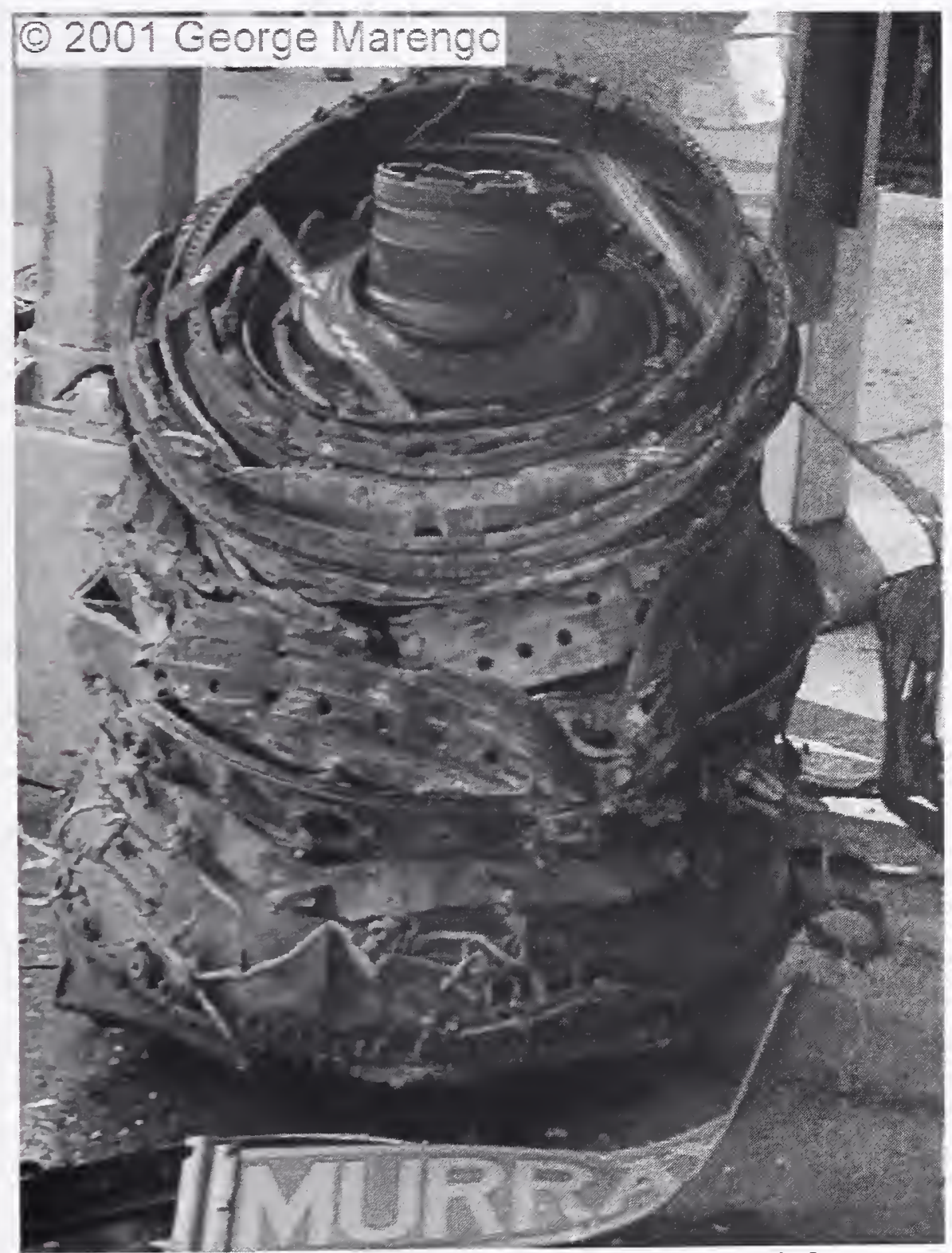

(c) Engine fragment found at Murray and Church St.

Figure 7-82. Calculated and observed engine damage. 

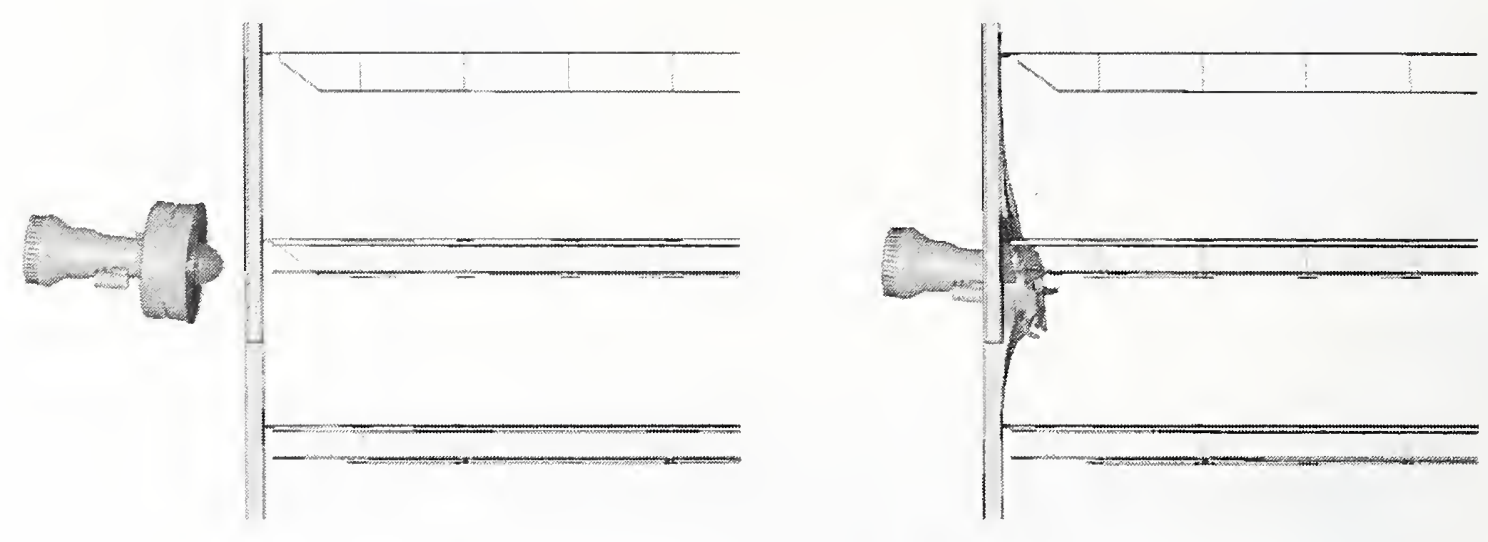

$t=0.07 \mathrm{~s}$

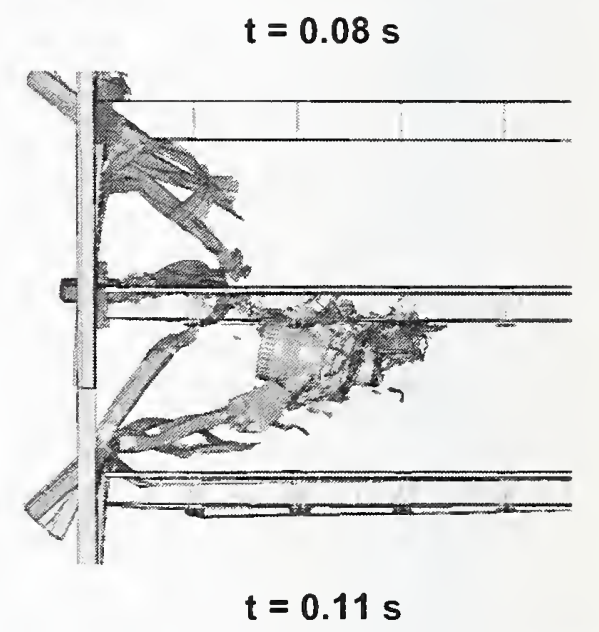

Figure 7-83. Starboard engine impact with the south face of WTC 2 in the base case global analysis.

\section{Floor Damage Visible on the South Face of WTC 2}

One location where the damage to the WTC 2 truss floor could be observed was through the opening in the tower exterior produced by the aircraft impact. A similar comparison for the WTC 1 truss floor damage was shown in Figure 7-72. The magnitude of damage was difficult to quantify as a result of the strong contrast in lighting between the tower interior and exterior and the smoke inside the building. This was worse for WTC 2, where the prevailing wind and fire conditions resulted in larger quantities of smoke exiting through the opening on the impact face. The partial photographic evidence did suggest that a similar level of truss floor damage in the impact zone occurred for WTC 2. The severity and the depth of the floor damage extending into the tower could not be determined. Although a quantitative comparison of the calculated and observed damage could not be made from the available damage photographs, the truss floor damage appeared to be consistent. 


\section{The 'Cold Spot' on the North Face of WTC 2}

A 'cold spot' was observed on the north face of the tower between columns 238 and 250 on floors 80,81 , and 82 . The cold spot was a region of the tower where no debris could be seen from the exterior of the tower and no significant fires were observed prior to tower collapse.

Much of the explanation for the cold spot was obtained from an analysis of the debris trajectory aligned with the cold spot. The debris path, obtained by projecting the width of the cold spot along the initial lateral impact trajectory of the aircraft, is shown in Figure 7-84 (13 degrees relative to the tower face normal). This region was aligned laterally with the left side of the fuselage and the port wing structures. Considering the baseline impact orientation and trajectory, shown in Figure 7-85, it can be seen that much of the wing debris impacted on floors lower than the observed cold spot. Only debris from very close to the fuselage would be expected on floor 80 or above. The debris from the port wing, including the majority of the aircraft fuel in the left side tanks, entered at floors 78 and 79.

The base case WTC 2 global analysis calculated a small amount of aircraft debris passing through the cold zone on floors 80 and 81 . However, the building contents were not completely modeled over the entire path in this section. After clearing the core region, the debris in the calculation had primarily an open path to the cold spot on the north wall of WTC 2. If all of the internal contents had been included, it is likely that all of this debris would have been stopped before reaching the cold spot.

The comparison of the calculated and observed impact response cold spot is inconclusive. Much of the absence of damage and aircraft debris in this region is explained by the impact orientation and trajectory. Much of this region was not directly in the path of significant aircraft fuel and debris. In addition, the debris aligned with the cold spot would be required to pass through a significant portion of the core. A more accurate analysis of the impact mechanics leading to the formation of a cold spot would require a specific survey of the tenant layout, including both contents that acted as a barrier to the debris and walls that provided a barrier to subsequent fire propagation. 


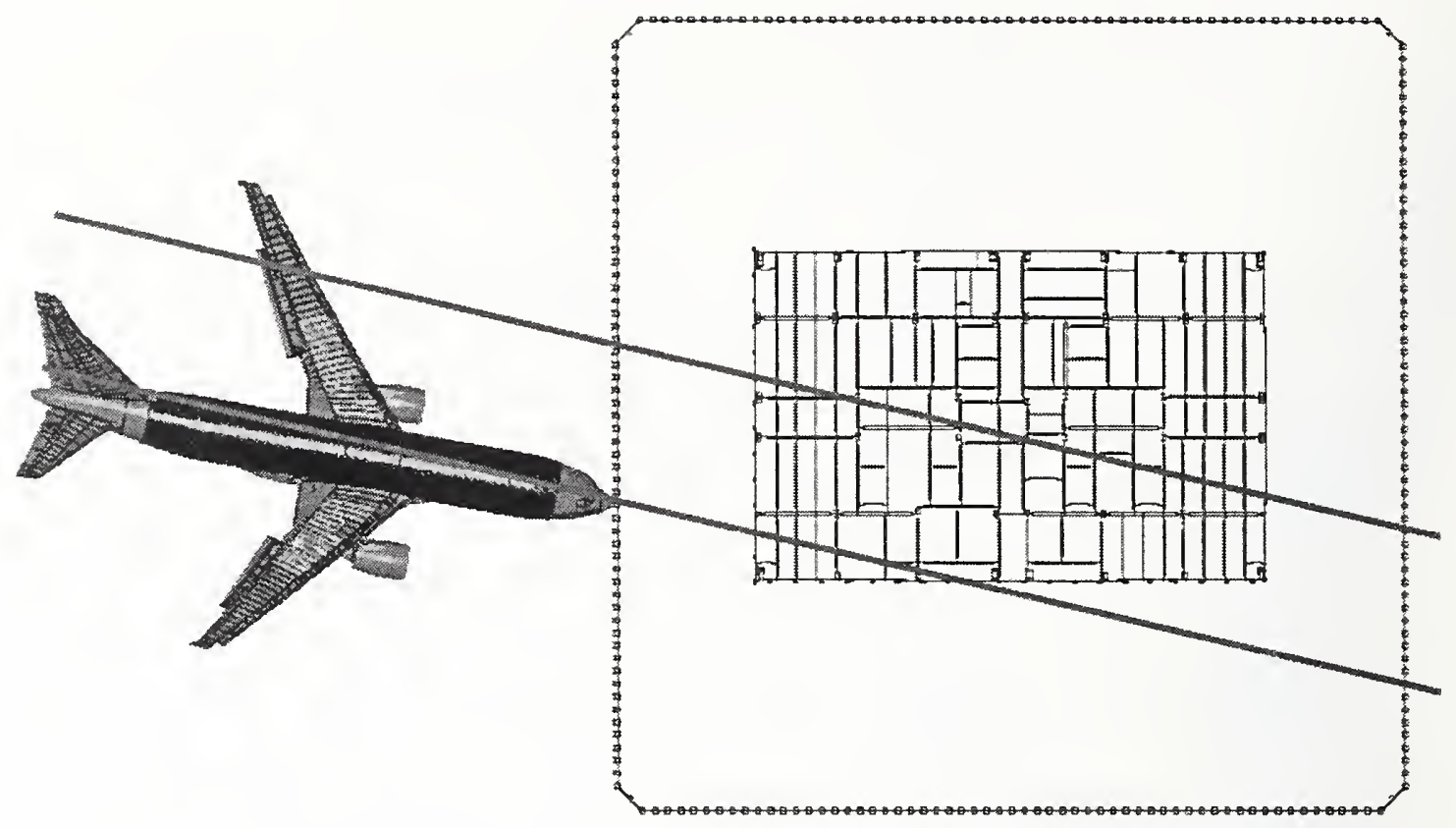

Figure 7-84. Projected debris path for the WTC 2 north face cold spot.

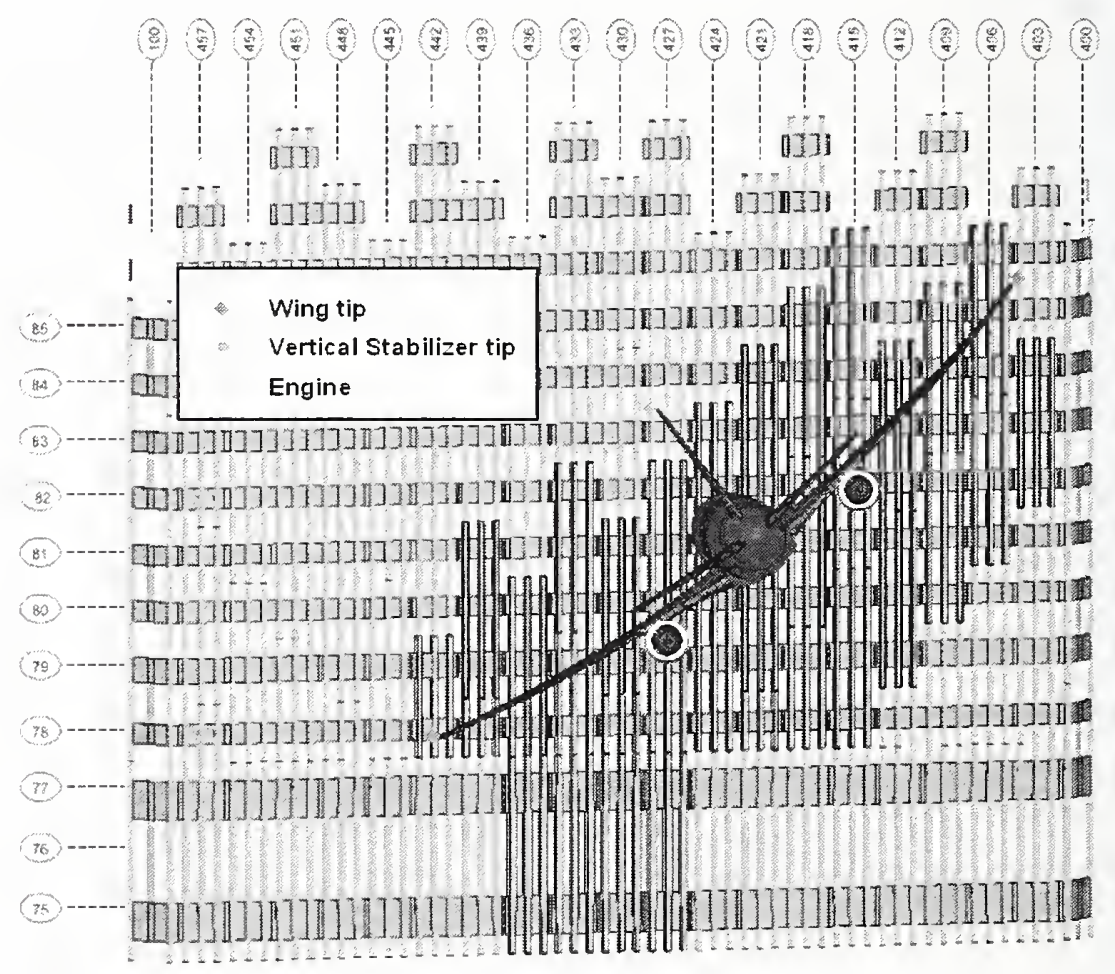

Figure 7-85. Base case WTC 2 impact orientation and trajectory (vertical approach angle $=6^{\circ}$. lateral approach angle $=13^{\circ}$ ). 


\subsubsection{Summary}

In general, not all of these observables were perfectly matched by the impact simulations due to the uncertainties in exact impact conditions, the imperfect knowledge of the interior tower contents, the chaotic behavior of the aircraft breakup and subsequent debris motion, and the limitations of the models. In general, however, the results of the simulations matched these observables reasonably well. Examples where the simulations matched the observables included: (1) the damage to the exterior walls of both towers, (2) the disruption to the stairwells in both towers, (3) the landing gear trajectory and the cold spot on WTC 2.

\subsection{COMPARISON WITH PREVIOUS STUDIES}

Two previous studies were conducted to estimate the impact damage to the WTC towers. These studies were performed by Massachusetts Institute of Technology (MIT) (Wierzbicki, Xue, and HendryBrogan, 2002) and Weidlinger Associates, Inc. (WAI) (Levy and Abboud 2002). The MIT study used an energy balance approach to estimate damage to the core columns. Estimates were made for the initial kinetic energy of the impacting aircraft, and the internal energy absorbed in fragmentation of the aircraft and damage to the tower exterior columns, floor slab, and core columns. The energy absorbed by the core was used to estimate the number of failed core columns.

The WAI study used the FLEX finite element code to calculate the aircraft impact damage to both towers. The FLEX family of finite element modeling software (Vaughan 1997) was developed and maintained by WAI. FLEX is an explicit, nonlinear, large deformation transient analysis finite element code for the analysis of structures subjected to blast, impact, and shock loadings. The overall code architecture is similar to that of LS-DYNA, used to calculate the aircraft impact damage in this investigation.

In the WAI calculations, the aircraft and WTC towers models were composed of beam and shell elements. The aircraft model consisted of 27.000 shell elements and 23,000 beam elements. The aircraft fuel was included in the model by increasing the mass of the structures in the wing box. The tower models included the exterior wall on the impact face and the floor structures and the core frame for floors 91-101 and floors 76-86 for WTC 1 and WTC 2, respectively. The tower models had fixed boundary conditions at the top and bottom floors.

\subsubsection{Comparison of Exterior Wall Damage}

The calculated base case impact damage to the exterior north wall of WTC 1 from this study is compared to the impact damage calculated by WAI in Figure 7-86. The figure also shows a schematic of the damage observed in photographic evidence. Figure 7-87 shows a similar comparison for the south wall of WTC 2. In both towers, the base case impact damage estimated in this study closely matched the observed damage. The damage profiles in the WAI impact simulations had some noticeable differences. The first was that the damage profile included complete failure of the exterior columns over the entire length of the wings and to the top of the vertical stabilizer. The second difference was that the failure mode of the exterior walls was dominated more by local rupture of the columns adjacent to the impact point with less influence of the bolted connections on panel failure and removal. 
The differences in the damage profiles in the two calculations most likely resulted from a variety of differences in the models. One major difference between the two studies was in the fidelity of the aircraft models. The WAI Boeing 767 model was based on their model of a Lockheed C-141B military transport. In the WAI model, the external geometry of the C-141B was modified to fit the dimensions of the 767 , but the internal components, such as stiffener configuration, as well as material thicknesses and properties remained the same. The differences in the internal structure and materials could affect the way the aircraft responded to the impact. The aircraft model used in this study also contained an order of magnitude more elements (70,000 bricks, 562,000 shells, and 61,000 SPH particles) than the WAI model (27,000 shell elements and 23,000 beam elements). The higher resolution of the NIST model could also account for significant differences in the determination of the impact load distribution and resulting exterior damage. Additionally, the NIST model explicitly modeled the fuel. If the fuel mass in the WAI model was spread out further toward the wing tips as part of the wing structure, it would be expected that the calculated column damage would extend over a wider portion of the wings.

Secondary differences in the WAI and NIST impact analyses included, but were not limited to, variations in impact conditions (impact speed, orientation and trajectory, location, etc.), aircraft model differences (airframe geometry, component thicknesses, mass distribution, material properties, etc.) and tower model differences (material properties, geometry, joint modeling, number of elements, etc.). 


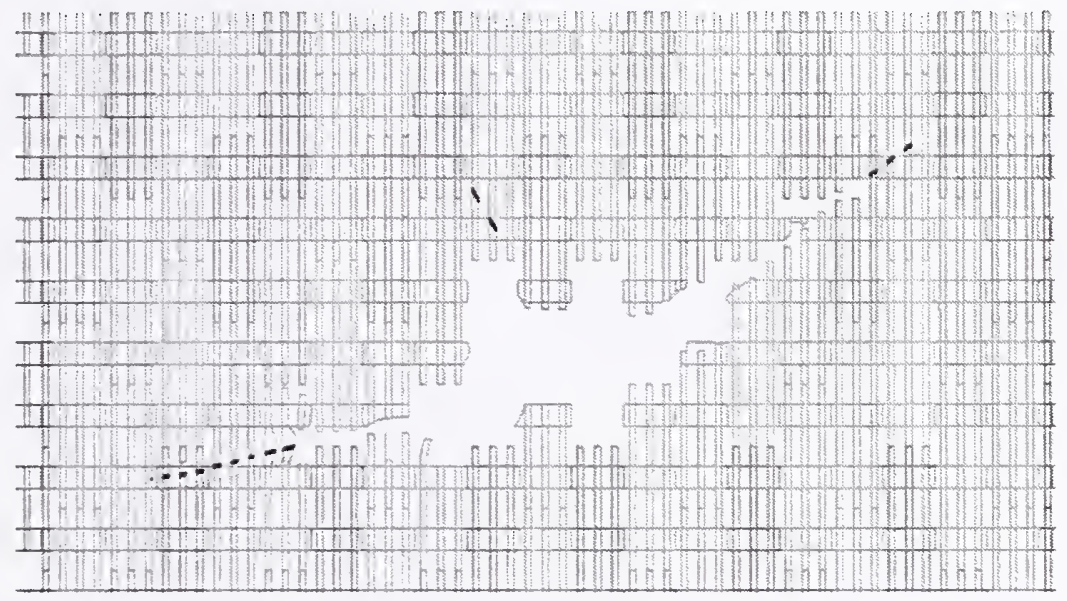

(a) Schematic of observed damage

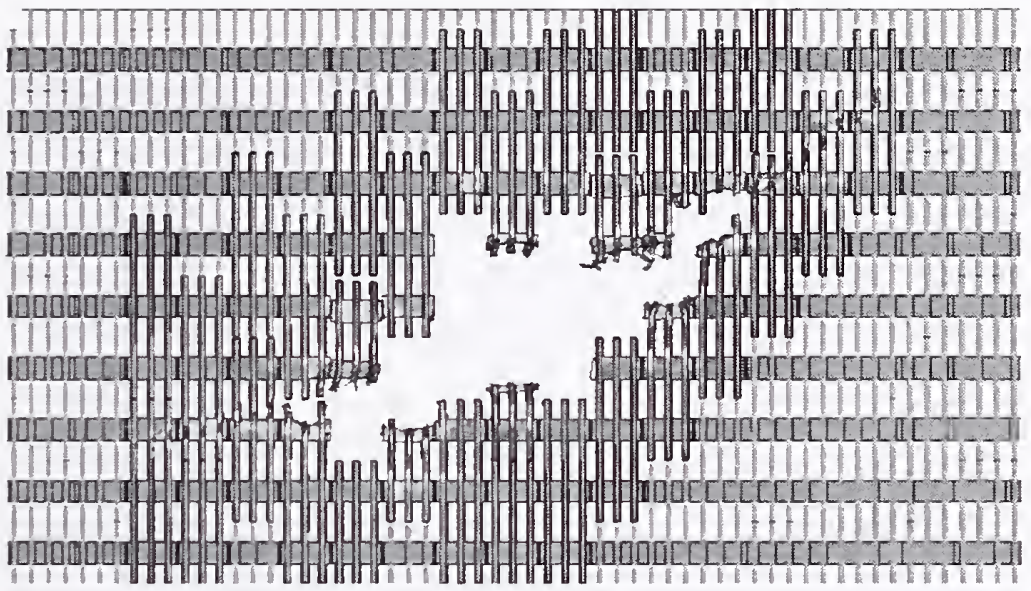

(b) NIST base case impact damage

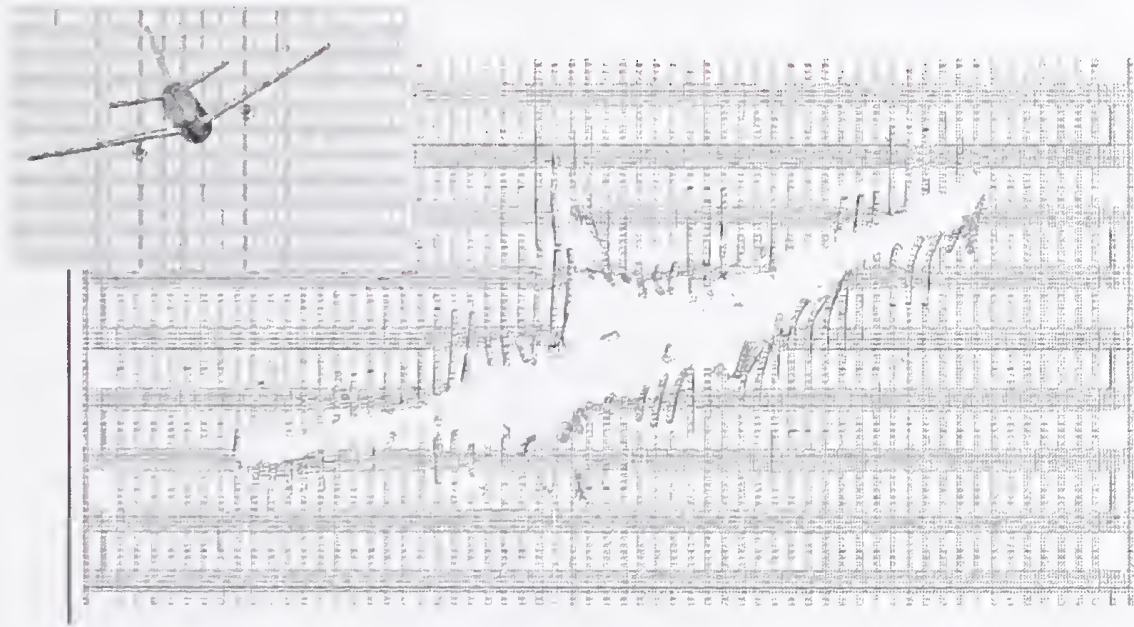

(c) WAl calculated damage (from Levy and Abboud, 2002)

Figure 7-86. Comparison of impact damage to the north wall of WTC 1. 


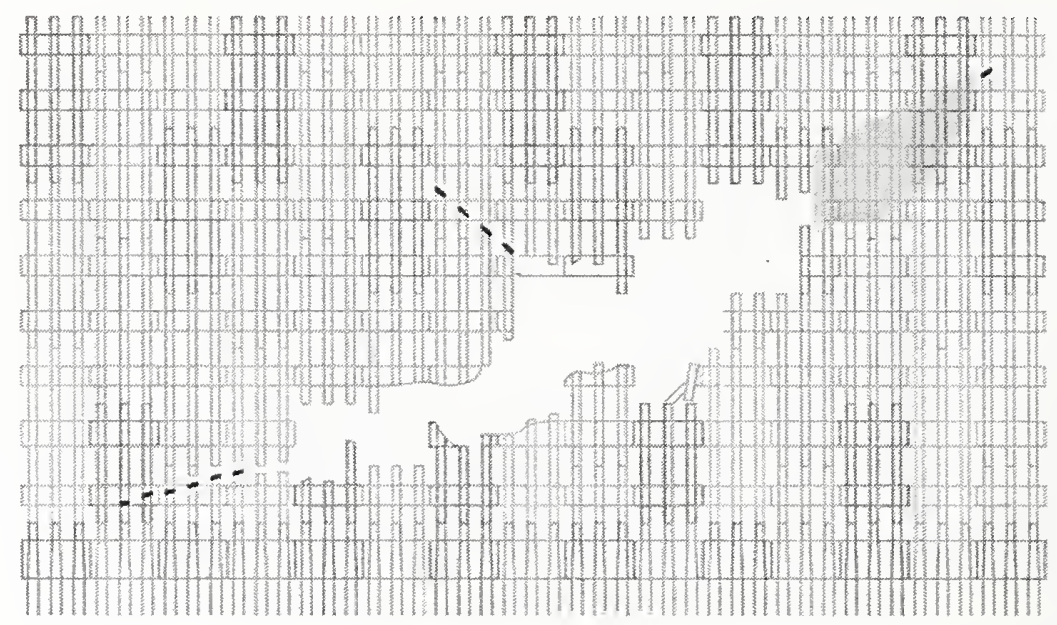

(a) Schematic of observed damage

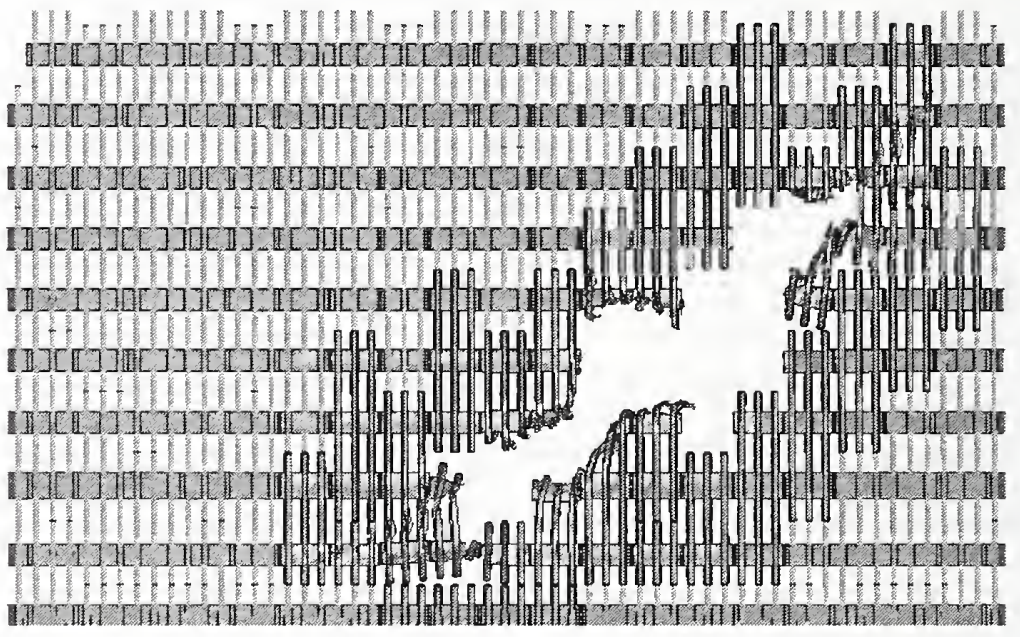

(b) NIST base case impact damage

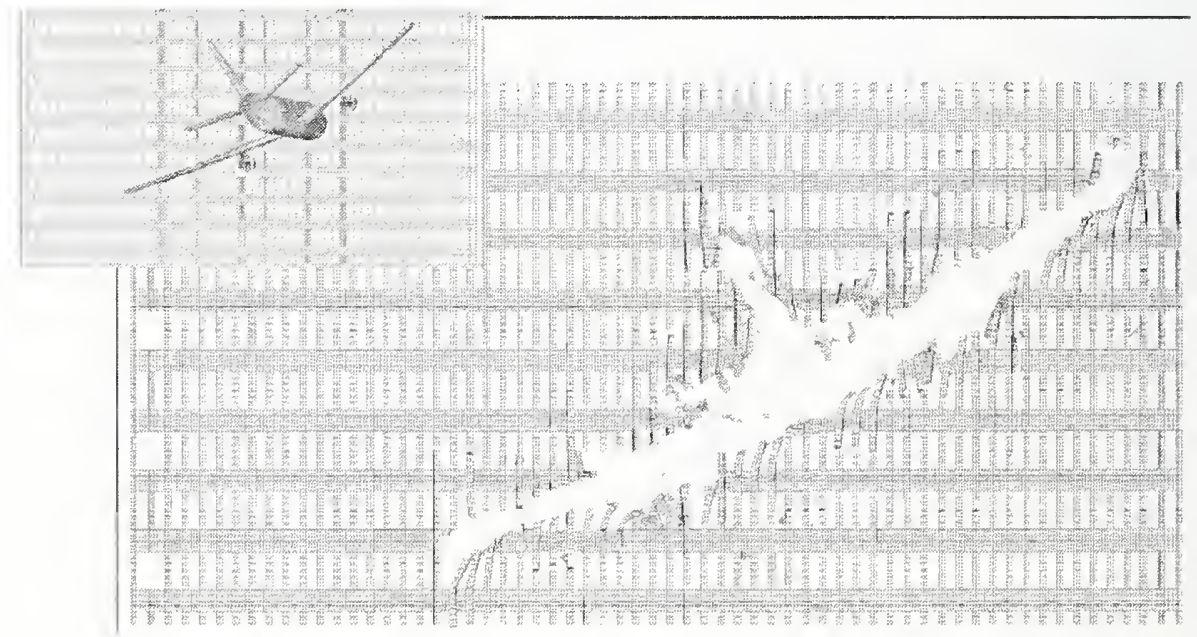

(c) WAI calculated damage (from Levy and Abboud, 2002)

Figure 7-87. Comparison of impact damage to the south wall of WTC 2. 


\subsubsection{Comparison of Core Column Damage}

Table 7-11 compares the estimated core column damage from the various studies. For WTC 1, MIT (Wierzbicki. Xue, and Hendry-Brogan 2002) estimated that 4 to 12 core columns were failed. This MIT estimate of core columns was based on energy balance calculations and corresponded to a damage distribution ranging from four columns failed over a three-story length to 12 columns failed over a single floor length. The expected distribution of damage would fall between these bounds, with some columns damaged on a single floor and others with damage distributed on multiple floors. WAI gave two estimates for core column failure. The first estimate of 23 core columns failed and five damaged was obtained from the FLEX impact analysis. The second estimate of 20 failed columns was the number used in their collapse analysis. The NIST base case impact damage of three severed and four heavily damaged and less severe estimate of one severed and two heavily damaged fall below both the MIT and WAI estimates. The more severe estimate of six severed and three heavily damaged falls in the middle of the MIT range, but still well below the WAI estimates.

A similar trend in the predicted damage to the core columns was found in the WTC 2 analysis. MIT estimated seven to 20 columns failed (from seven columns failed over a three-story length to 20 columns failed over a single floor length). WAI calculated 14 core columns failed and another 10 damaged in their FLEX analysis, but reduced the number of failed columns to five for their collapse analysis. The NIST base case impact damage of five severed and four heavily damaged, as well as the more severe estimate of 10 severed and one heavily damaged fall in the middle of the range predicted by MIT. The less severe impact scenario predicted fewer columns sevcred and heavily damaged than the MIT and WAI studies.

The MIT prediction of the number of failed core columns agreed remarkably well with the NIST estimates using their simplified analysis. Differences may be a result of the estimates of material properties and structural geometry used (MIT did not have access to the detailed structural drawing of the WTC towers for their study), approximations in the estimates of damagc mode and resulting energy absorption, as well as the fact that the MIT study did not include the energy absorbed by internal tower contents.

The WAI impact analysis predicted much greater core column failure and damage than the NIST estimates. One reason for the greater damage prediction may be the lack of internal tower contents in the WAI model, such as workstations and other live loads. This study found that the internal tower material absorbed a significant amount of the impact energy and, therefore, reduced the loads applied to the core columns. Another reason for the greater damage prediction in the WAl study could result from the aircraft model. As noted above, the WAI aircraft impact simulation overpredicted the extent of column damage and failure on the exterior wall. It is possible to assume that the aircraft model would also overpredict the damage to the core columns, especially that this damage configuration resulted in an unstable tower (Levy and Abboud, 2002).

In conducting a collapse analysis, WAl used engineering estimates to reduce the number of failed columns from that predicted by their FLEX model to stabilize the tower immediately after impact. Despite this adjustment, the WAI study still estimated significantly greater damage for WTC 1 than the MIT and NIST studies. For WTC 2 their adjusted estimate falls in line with the MIT and NIST studies.

In general, the MIT and WAI studies appear to over-predict the damage to the core columns compared to the NIST estimates. 
Table 7-11. Comparison of damage to core columns from various studies

\begin{tabular}{|c|c|c|}
\hline WTC Impact Study & WTC 1 Core Column Damage & WTC 2 Core Column Damage \\
\hline $\begin{array}{c}\text { MIT } \\
\text { Impact Analysis }\end{array}$ & $4-12$ Severed & $7-20$ Severed \\
\hline $\begin{array}{c}\text { WAI } \\
\text { Impact Analysis }\end{array}$ & $\begin{array}{c}23 \text { failed \& significantly damaged } \\
\text { Plus 5 damaged }\end{array}$ & $\begin{array}{c}\text { 14 failed and significantly damaged } \\
\text { Plus 10 damaged }\end{array}$ \\
\hline $\begin{array}{c}\text { WAI } \\
\text { Collapse Analysis }\end{array}$ & 20 Failed & 5 Failed \\
\hline $\begin{array}{c}\text { NIST Base Case } \\
\text { Impact Analysis }\end{array}$ & Plus 4 Heavily Damaged & Plus 4 Heavily Damaged \\
\hline $\begin{array}{c}\text { NIST More Severe } \\
\text { Impact Analysis }\end{array}$ & $\begin{array}{c}\text { 6 Severed } \\
\text { Plus 3 Heavily Damaged }\end{array}$ & $\begin{array}{c}\text { 10 Severed } \\
\text { Plus 1 Heavily Damaged }\end{array}$ \\
\hline $\begin{array}{c}\text { Imp Less Severe } \\
\text { Impact Analysis }\end{array}$ & 1 Severed \\
\hline
\end{tabular}

\subsection{SUMMARY}

Presented in this chapter were estimates of damage to the WTC towers due to aircraft impact, calculated from the global impact simulations. The results indicated significant structural damage to the exterior walls, core columns, and floor systems in the affected floors. This structural damage contributed to the weakening of the tower structures, but did not, by itself, initiate building collapse. The aircraft impact damage, however, contributed greatly to the subsequent fires and the thermal response of the tower structures that led ultimately to the collapse of the towers by:

- Dispersing jet fuel and igniting building contents over large areas

- Creating large accumulations of combustible materials containing aircraft and building contents

- Increasing the air supply into the damaged buildings that permitted significantly higher energy release rates than would normally be seen in ventilation building fires, allowing the fires to spread rapidly on multiple floors (see NIST NCSTAR 1-5F)

Other effects of the impact on the towers were investigated in other projects of the Investigation based on the results reported herein. These included: (1) damage and dislodging of fireproofing from structural components in the direct path of the debris (see NIST NCSTAR 1-6), (2) damage to the sprinkler and water supply systems in the path of the aircraft debris (see NIST NCSTAR 1-4), and (3) damage to ceilings that enabled unabated heat transport over the floor-to-ceiling partition walls and to structural components (see NIST NCSTAR 1-5D). 


\subsection{REFERENCES}

“LS-DYNA Keyword User`s Manual," Livermore Software Technology Corporation, Version 970, April 2003.

FEMA, May 2002, "World Trade Center Building Performance Study: Data Collection, Preliminary Observations and Recommendations," FEMA 403.

Kausel, E., "The Towers Lost and Beyond," Massachusetts Institute of Technology, May, 2002, http://web.mit.edu/civenv/wtc/index.html.

Levy, M. and Abboud N., August 1, 2002, "World Trade Center - Structural Engineering Investigation," Hart-Weidlinger Technical Report, Prepared for Wachtel, Lipton, Rosen, and Katz.

Vaughan, D. K., FLEX User's Guide, Report UG8298, Weidlinger Associates, Los Altos, CA, May 1983 plus updates through 1997.

Wierzbicki, T., Xue. L., and Hendry-Brogan, M. (2002). "Aircraft impact damage of the World Trade Center towers." Tech. Rep. No. 74. Impact and Crashworthiness Lab, Massachusetts Institute of Technology, Cambridge, MA. 
This page intentionally left blank 


\section{Chapter 8 \\ FINDINGS}

\subsection{BASELINE PERFORMANCE ANALYSIS}

\subsubsection{Wind Loads on the World Trade Center Towers}

Various wind load estimates for the World Trade Center (WTC) towers were considered in this study. These included: (1) wind loads used in the original WTC design, (2) wind loads based on two recent wind tunnel studies conducted in 2002 by Cermak Peterka Peterson, Inc. (CPP) and Rowan Williams Davis and Irwin, Inc. (RWDI) for insurance litigation concerning the towers, and (3) refined wind loads estimated by National lnstitute of Standards and Technology (NIST) by critically assessing information obtained from the CPP and RWDI reports and by bringing to bear state-of-the-art considerations. The following summarizes the study findings.

Finding 1: The original design wind loads on the towers exceeded those established in the prescriptive provisions of the New York City Building Code (NYCBC) prior to 1968, when the WTC towers were designed, and up to and including 2001. The original design load estimates were also higher than those required by other selected building codes of the time (Chicago and New York State), including the relevant national model building code, Building Officials and Code Administrators (BOCA). The prescriptive approach in these codes is oversimplified, and as a result, these codes are not necessarily appropriate for super-tall building design. This finding is supported by the fact that wind effects obtained from three separate wind-tunnel-based studies (the original WTC design, the CPP, and the RWDI studies) were in all cases higher than wind effects based on the prescriptive codes.

Finding 2: In the majority of the cases, each of the two orthogonal shear components and of the two orthogonal overturning moment components at the base of the towers used in the original wind design were smaller, than the CPP, RWDI, and refined NIST estimates. However, the most unfavorable combined peaks (resultant) from the original design were larger, or smaller by at most 15 percent, than estimates based on the CPP, RWDI, and NIST estimates. This is due to the conservative approach used to combine the loads in the original design. For example, the refined NIST estimates were higher by as much as 15 percent than the most unfavorable original design wind loads for WTC 1 , and lower by about 5 percent than the most unfavorable original design loads for WTC 2.

Finding 3: The estimated wind-induced loads on the towers varicd by as much as 40 percent between the wind tunnel/climatological studies conducted in 2002 by CPP and RWDI. The primary rcason for these differences was the different approaches used in those studies to (1) estimate extreme wind speeds; (2) estimate wind profiles; (3) integrate aerodynamic, dynamic, and extreme wind climatological information; and (4) combine wind effects in two orthogonal directions and in torsion. Such disparity is indicative of the limitations and inconsistencies associated with the current state of practice in wind engineering for tall buildings. Among the issues that need to be considered are:

- Estimation methods for combining directional wind loads, integrating climatological (wind) and aerodynamic (wind tunnel) data. 
- Evaluation of the wind speed specifications and the development of improved design wind speeds, as well as protocols for selection of site-specific wind speeds and directionality.

- Protocols for conducting the wind tunnel tests.

- Profiles of hurricane and non-hurricane winds.

- Load combinations, and material-specific responses to peak loads.

Finding 4: A comparison of wind speeds indicated significant differences among various specified design wind speeds. The basic wind speed spccified in American Society of Civil Engineers

(ASCE 7-02) for New York City is equivalent to an $88 \mathrm{mph}$ fastest-mile wind speed at $33 \mathrm{ft}$ above ground for open terrain exposure. The wind speed specified in the New York City Building Code (2001) is $80 \mathrm{mph}$ and is interpreted to be a fastest-mile wind speed at $33 \mathrm{ft}$ above ground. For the original WTC design, a design wind speed of $98 \mathrm{mph}$ averaged over 20 minutes at a height of $1,500 \mathrm{ft}$ above ground was used. This speed is equivalent to a fastest-mile wind speed at $33 \mathrm{ft}$ above ground in open terrain of between $67 \mathrm{mph}$ and $75 \mathrm{mph}$. The wind speed estimated by NIST for three airports (La Guardia, Newark International Airport, and John F. Kennedy International Airport), regardless of direction, was equivalent to $96 \mathrm{mph}$ fastest-mile wind speed. An evaluation of the wind speed specifications and the development of improved design wind speeds, as well as protocols for selection of site-specific wind speeds and directionality, are, therefore, in order.

\subsubsection{Baseline Performance of the Global Tower Models}

The global models of the towers were analyzed under the following gravity and wind loading cases: (1) the original WTC design load case, (2) the lower-estimate state-of-the-practice case (NYCBC 2001 gravity loads plus wind loads from the RWDI study, scaled in accordance with NYCBC 2001 wind speed), and (3) the refined NIST estimate case (gravity loads from ASCE 7-02 plus refined wind loads developed by NIST). The following summarizes the findings from the analyses.

Finding 5: Under the original WTC design loads, the cumulative drifts at the top of the WTC towers ranged from $\mathrm{H} / 263$ to $\mathrm{H} / 335$, where $\mathrm{H}$ is the building height. For the lower-estimate state-of-the-practice case, those drifts ranged from $\mathrm{H} / 253$ to $\mathrm{H} / 306$. Under design loading conditions, the maximum interstory drift was as high as $\mathrm{h} / 230$ and $\mathrm{h} / 200$ for WTC 1 and WTC 2 , respectively, where $\mathrm{h}$ is the story height. Maximum inter-story drifts under the state-of-the practice case were about $\mathrm{h} / 184 \mathrm{and} \mathrm{h} / 200$ for WTC 1 and WTC 2, respectively. For the refined NIST estimate case, the cumulative and inter-story drifts were about 25 percent larger than those from the state-of-the practice case. Currently no building codes specify a drift limit for wind design. The commentary to Section B.1.2 of the ASCE 7 Standard indicates that drift limits in common usage for building design are on the order of $1 / 400$ to $1 / 600$ of the building (for total drift) or story height (for inter-story drift) to minimize damage to cladding and nonstructural walls and partitions. Structural engineers often use in their practice the criterion that total drift ratios should not exceed $\mathrm{H} / 400$ to $\mathrm{H} / 500$ for serviceability considerations and to enhance overall safety and stability (including second order P- $\Delta$ effects). For inter-story drifts, structural engineers often use in their practice an inter-story drift limit in the range of $h / 300$ to $h / 400$. This is primarily done for serviceability considerations. Similar to total drift, inter-story drifts of the towers were larger than what is generally used in current practicc. 
Finding 6: The demand/capacity ratios (DCRs), based on the allowable stress design procedure, estimated from the original WTC design load case were in general close to those obtained for the lowerestimate state-of-the practice case. For both cases, a fraction of the structural components had DCRs larger than 1.0. These were mainly observed in both towers at (1) the exterior walls: (a) at the columns around the corners. (b) where the hat truss connected to the exterior walls, and (c) below floor 9; and (2) the core columns on the 600 line between floors 80 and 106 and at core perimeter columns 901 and 908 for much of their height. The DCRs obtained for the refined NIST estimate case were higher than those for the original WTC design and the lower-estimate state-of-the-practice load cases, owing to the following reasons: (1) the NIST estimated wind loads were larger than those used in the state-of-thepractice case by about 25 percent, and (2) the original WTC design and the state-of-the-practice cases used NYCBC load combinations, which result in lower DCRs than the ASCE 7-02 load combinations used for the refined NIST case.

Finding 7: The safety of the WTC towers on September 11, 2001 was most likely not affected by the fraction of members for which the demand exceeded allowable capacity due to: (1) the inherent factor of safety in the allowable stress design method, (2) the load redistribution capability of ductile steel structures, and (3) on the day of the attack, the towers were subjected to in-service live loads (a fraction of the design live loads) and minimal wind loads.

Finding 8: The behavior of the lower portion of the towers at the basement floors resembled that of a braced frame, while the behavior of the super-structure resembled that of a framed tube system based on the analysis of the axial stress distribution in the columns under wind loads. Under a combination of the original WTC design dead and wind loads, tension forces developed in the exterior walls of both towers. The forces were largest at the base of the building and at the corners. These tensile column loads were transferred from one panel to another through the column splices. The DCRs for the exterior wall splice connections under these tensile forces for both towers were shown to be less than 1.0.

Finding 9: For the towers' resistance to shear sliding under wind loads, the factor of safety was between 10 and 11.5 , while the factor of safety against overturning ranged from 1.9 to 2.7 for both towers.

\subsubsection{Baseline Performance of the Typical Floor Models}

Finding 10: For the typical truss-framed floor under the original WTC design gravity loads, the DCRs for all floor trusses were less than unity for 99.4 percent of the floor truss components with a maximum of 1.14. Inside the core, the DCRs for all floor beams were less than 1.08, and more than 99 percent of floor beams had a DCR of less than 1.0. The maximum mid-span deflections of the long-span and short-span zones under the original design loads were approximately 1.79 in. $(\approx \mathrm{L} / 400)$ and 0.57 in. $(\approx \mathrm{L} / 750)$, respectively, where $\mathrm{L}$ is the floor span. For the typical beam-framed floor under the original design gravity loads, the DCRs for all floor beams were less than 1.0 except for two core beams, where the DCRs in shear were 1.125 and 1.09. The maximum mid-span deflections of the long-span and short-span zones under the original design loads were approximately 1.55 in. $(\approx L / 450)$ and 0.70 in. $(\approx L / 600)$, respectively. 


\subsection{AIRCRAFT IMPACT DAMAGE ANALYSIS}

\subsubsection{Safety of the WTC Towers in Aircraft Collision}

Finding 11: Buildings are not specifically designed to withstand the impact of fuel-laden commercial aircraft, and building codes in the United States do not require building designs to consider aircraft impact. Documents obtained from The Port Authority of New York and New Jersey indicated that the safety of the WTC towers and their occupants in an aircraft collision was a consideration in the original design. The documents indicate that a Boeing 707, the largest commercial aircraft at the time, flying at $600 \mathrm{mph}$ was considered and that the analysis indicated that such collision would result in only local damage which could not cause collapse or substantial damage to the building and would not endanger the lives and safety of occupants not in the immediate area of impact. No documentary evidence of the aircraft impact analysis was available to review the criteria and mcthods used in the analysis of the aircraft impact into the WTC towers, or to provide details on the ability of the WTC towers to withstand such impacts.

\subsubsection{Preliminary Impact Analyses (Component and Subassembly Levels)}

Component and subassembly impact analyses were conducted with the objectives of (1) developing understanding of the interactive failure phenomenon of the aircraft and tower components, (2) developing simulation techniques required for the global analysis of the aircraft impacts into the WTC towers, and (3) investigating different modeling techniques and associated model size, run times, numerical stability, and impact response. The following summarizes the analyses' findings:

Finding 12: Impact of a Boeing 767 engine at a speed of $500 \mathrm{mph}$ on an exterior wall panel resulted in a complete penetration of the engine through the exterior wall and failure of impacted exterior columns. If the enginc did not impact the floor slab, the majority of the engine core would remain intact through the exterior wall penetration, with a reduction in specd between 10 and 20 percent. The residual velocity and mass of the engine after penetration of the exterior wall was sufficient to fail a core column in a direct impact condition. Interaction with interior building contents prior to impact, or a misaligned impact against the core column, could alter this response of the core column.

Finding 13: An impact of an empty wing segment from approximately mid-span of the wing normal to the exterior wall produced significant damage to the exterior columns but not complete failure. Impact of the same wing section, but filled with fuel, resulted in extensive damage to the external panels of the tower, including complete failure of the exterior columns. The resulting debris propagating into the building maintained the majority of its initial momentum prior to impact.

Finding 14: The response of the nonstructural building contents and the floor concrete slab to an aircraft engine impact was dominated by the mass of the workstations and the concrete slab, rather than by their strength.

\subsubsection{Aircraft Impact Damage Results}

The global analyses of the aircraft impacts into the WTC towers provided the following: (1) estimates of probable damage to structural systems, (2) estimates of the aircraft fuel dispersion during the impact, and (3) estimates of debris damage to the building nonstructural contents, including partitions and 
workstations. The global analyses included, for each tower, a "base case" based on reasonable initial estimates of all input parameters. They also provided a range of damage estimates of the towers due to aircraft impact. These included a more severe and a less severe damage estimates. The initial impact conditions were estimated based on a detailed analysis of video records that captured the approach and impact of the aircraft with the towers and the photographs of the exterior tower damage. The following summarizes the analyses findings:

Finding 15: The aircraft that impacted WTC 1 had a speed of $443 \pm 30 \mathrm{mph}$ with a roll angle of $25 \pm 2$ degrees (port wing downward). The vertical approach downward angle was $10.6 \pm 3$ degrees, and the lateral approach angle was close to being normal to the north wall of the tower. For WTC 2, the impacting aircraft had a speed of $542 \pm 24 \mathrm{mph}$, with a roll angle of $38 \pm 2$ degrees (port wing downward). The vertical approach downward angle was $6 \pm 2$ degrees, and the lateral approach angle was $13 \pm 2$ degrees clockwise from the south wall of the tower.

Finding 16: The aircraft impact on WTC 1 resulted in extensive damage to the north wall of the tower, which failed in the regions of the fuselage, engine, and fuel-filled wing section impacts. Damage to the exterior wall extended to the wing tips, but the exterior columns were not completely failed in the outer wing and vertical stabilizer impact regions. According to photographs, columns 112 to 144 along with column 151 were completely severed, while columns 145 to 148 were heavily damaged, and columns 149 to 150 were moderately damaged (for reference, columns 101 and 159 are located on the west and east corner, respectively, of the north wall). The results of the impact analyses matched well with this damage pattern to the north wall. Photographic evidence also indicated that an exterior panel with columns 329 , 330 , and 331 on the south wall between floors 94 to 96 was dislodged. Failure of the exterior columns occurred both at the bolted connections between column ends and at various locations in the column, depending on the local severity of the impact load and the proximity of the bolted connection to the impact. Subject to the uncertainties inherent in the models, the global impact simulations indicated that a total of three core columns were severed, and four columns were heavily damaged in the base case, compared to six columns severed and three columns heavily damaged in the more severe case and one columns severed and two columns heavily damaged in the less severe case. In the analyses, the floor trusses, core beams, and floor slabs experienced significant impact-induced damage on floors 94 to 96 , particularly in the path of the fuselage. The analyses indicated that the wing structures were completely fragmented due to the interaction with the exterior wall and as a result, aircraft fuel was dispersed on multiple floors. In addition, aircraft debris resulted in substantial damage to the nonstructural buildings contents (partitions and workstations) and also in dislodging of fireproofing. The bulk of the fuel and aircraft debris was deposited in floors 93 through 97, with the largest concentration on floor 94.

Finding 17: The aircraft impact on WTC 2 resulted in extensive damage to the south wall of the tower, which failed in the regions of the fuselage, engine, and fuel-filled wing section impacts. Damage to the exterior wall extended to the wing tips, but the exterior columns were not completely failed in the outer wing and vertical stabilizer impact regions. According to photographs, columns 410 to 436 and columns 438 to 439 were completely severed, while column 437 was heavily damaged (for reference, columns 401 and 459 are located on the east and west corner, respectively, of the south wall). The results of the impact analyses matched this damage pattern to the south wall well. In addition, columns 407 to 409 were obscured by smoke, but the analysis results indicated that these columns were moderately damaged. Photographic evidence also indicated that columns 253, 254, 257, and 258 on the north wall were failed. Failure of the exterior columns occurred both at the bolted connections between column ends and at 
various locations in the column, depending on the local severity of the impact load and the proximity of the bolted connection to the impact. Subject to the uncertainties inherent in the models, the global impact simulations indicated that a total of five core columns were severed, and four columns were heavily damaged in the base case, compared to ten columns severed and one column heavily damaged in the more severe case and thrce columns severed and two columns heavily damaged in the less severe case. In some cases, failure of the column splices located on floors 77,80 , and 83 contributed significantly to the failure of the core columns. In the analyses, the floor trusses, core beams, and floor slabs experienced significant impact-induced damage on floors 79 to 81 , particularly in the path of the fuselage. The analyses indicated that the wing structures were completely fragmented due to the interaction with the exterior wall and as a result, aircraft fuel was dispersed on multiple floors. In addition, aircraft debris resulted in substantial damage to the nonstructural buildings contents (partitions and workstations) and also in dislodging of fireproofing. The bulk of the fuel was concentrated on floors 79,81 , and 82 , while the bulk of the aircraft debris was deposited in floors 78 through 80 , with the largest concentration on floor 80 .

Finding 18: Natural periods calculated from the reference global model of the WTC 1 tower matched well with those measured on the tower based on the analysis of data from accelerometers located atop WTC 1. The calculated period of oscillation in the N-S direction of the reference global model of WTC 2 matched well with the period estimated immediately after aircraft impact based on a detailed analysis of the building motion which was captured in a video footage of the WTC 2 impact. This indicated that the overall lateral stiffness of the tower was not affected appreciably by the impact damage. The maximum deflection at the top of the tower after impact was estimated from the footage to be more than $1 / 3$ of the drift resulting from the original design wind loads. This indicated that the tower still had reserve capacity after losing a number of columns and floor segments due to aircraft impact.

Finding 19: The towers sustained significant structural damage to the exterior walls, core columns, and floor systems due to aircraft impact. This structural damage contributed to the weakening of the tower structures, but did not, by itself, initiate building collapse. However, the aircraft impact damage contributed greatly to the subsequent fires and the thermal response of the tower structures that led ultimately to the collapse of the towers by: (1) dispersing jet fuel and igniting building contents over large areas, (2) creating large accumulations of combustible materials containing aircraft and building contents, and (3) increasing the air supply into the damaged buildings that permitted significantly higher energy release rates than would normally be seen in ventilation building fires, allowing the fires to spread rapidly on multiple floors. 

$C$ 